\title{
Functional Fiction to Collective Action: Speculative Participatory Serious Urban Design Gaming to Enhance Slum-upgrading Processes
}

BY

HAMISH BEATTIE

\begin{abstract}
A thesis
submitted to the Victoria University of Wellington in fulfilment of the requirements for the degree of Doctor of Philosophy in Architecture
\end{abstract}







\section{Motivations for the Study}

In 2013 while working in Kenya for the United Nations Human Settlement Programme (UN-Habitat), I spent weekends volunteering at Lipela Orphanage located about two hours' drive from Nairobi on the foothills of Mt. Kenya. One afternoon in September, after playing some football with the young people, I sat down under a tree to check emails on my smartphone. One of the youths, a 15-year-old boy named Edward, ambled over, squatted down beside me and asked if I had any games that he could play. As I was working with UN Habitat's Block by Block programme at the time, I had the pocket edition of Minecraft installed in my smartphone. I launched the application and handed him the device. Over the course of the next thirty minutes, Edward not only learned to navigate the interface of the game with skill but constructed a three-dimensional model of the orphanage in which he lived.

Shortly after this, I detailed the experience in a blog post I wrote for the Block by Block programme titled Mobile Minecrafting in Central Kenya (Beattie, 2013). The first observation I made concerned the prevalence of mobile phones, and more specifically mobile computing, in some of the most marginalised regions of Kenya. At the time, I pointed out that most 'slum-dwellers' had access to mobile phones with "at least the most basic of functionality" and that within the near future those same inhabitants would have access to cheap, broadband-enabled smartphones with threedimensional rendering capabilities, which could be used by architectural designers to engage people in urban design processes ((Beattie, 2013). Digital technologies are a mainstay of many marginalised, informal settlement or slum communities. They are vital for communication, navigation, entertainment and even the functionality of what Robert Neuwirth calls the "informal economy" - or the diversified set of economic activities, enterprises, jobs, and workers that are not regulated or protected by the state-which relies on the prevalence of mobile microfinancing technologies (Neuwirth, 2012).

In 2016 the United Nations declared "online freedom" a "human right" (United Nations General Assembly, 2016). We are now at a point where many of the world's slum-dwellers carry the technology in their pockets necessary to build and share Computer-Aided Design (CAD) models, and the vast majority of people, even those most marginalised, have some degree of digital literacy due to this rapid and recent proliferation of technology (Tacchi \& Chandola, 2016). This is an exciting time for 
architects, urban designers and planners looking for new ways of ensuring that those most marginalised are central to decision-making processes in architecture and urban design.

The second observation I made in the blog post related to ways in which Edward constructed the model of his environment. As one would expect, the model was proportionally inaccurate - and was little more than a rudimentary spatial abstraction of his environment, constructed within the three-dimensional grid-based Minecraft medium. When I spoke with him about his model, I found that it was inspired by and represented much more than just the spatial attributes of his physical surroundings. What he had produced was a three-dimensional semi-fictional diagram of the orphanage - one that he used to explain the emotive qualities of the environment to me in a metaphorical way. As one of the oldest children at the orphanage, Edward was responsible for much of the cleaning and cooking that took place in the noisy steel shed that had little storage space and was not connected to the main hall building by any sort of shelter-something he saw as important during the rainy season. On the one hand, the spaces in which he carried out these activities, such as the kitchen and washing areas, were represented as enclosed concrete spaces as opposed to the corrugate iron and timber lean-to structure that existed in reality. He described these to me as a representation of his feelings about the activities he performed in them. On the other hand, the dormitory, where he relaxed, was modelled as a large open space, made out of lighter timber materials, with a high ceiling and large windows as opposed to the seemingly cramped dormitory with little natural light. Edward felt this space was his "relaxing space" or a sort of sanctuary-a space where he could retreat from the chores of everyday life. These assertions aided me in understanding what value these spaces had to Edward-not just whether or not they were functional.

The digital gaming experience I had with Edward served as one of the catalysts for this dissertation and represents one of the values of digital participatory design toolsthe ability for community members to express themselves visually and to communicate emotive qualities of space. It was of course difficult to tell whether Edward's explanation was a post-rationalisation or not, or even if it evolved over the course of its construction. But being able to use the game as a speculative discursive prop to talk about intangible perceptions of space - one's feelings and one's interactions - was of great value. The model served as a mechanism to enable Edward to communicate these values to me, to contemplate the relationships between spaces from his perspective, 
and to not just do so abstractly or artistically, but to locate the conversation in space and time in a state of hyper-reality.

This experience of design-orientated digital gaming highlights the ubiquitous nature of the computer gaming medium. It speaks to how digital engagement strategies can be employed in different contexts to help people not usually engaged in design processes to find a voice and to collaboratively share their tacit knowledge, experiences and points of view. It also speaks to the ability of architectural representation to orientate that discussion towards memories, feelings, experiences and desires, which can be crucial for the identification and refinement of urban development problems and ultimately their solutions. The experience with Edward provided me with my first insights into the discursive qualities of a sort of hybridreality space that can be created between a fictional world created through representation and discussion and what Malmgren describes as the "empirical" world that is central to the aspirational outcomes of the dissertation (Malmgren, 1985). It encouraged me to explore how urban focussed gaming could prompt people to contemplate the intangible, or collaboratively draw out those tacit experiences of urban space and enable them to share those views with others who might empower them by pulling in the same direction. This goal forms the primary motivation for this research. 


\section{Table of Contents}

Motivations for the Study .......................................................

Table of Contents.....................................................................

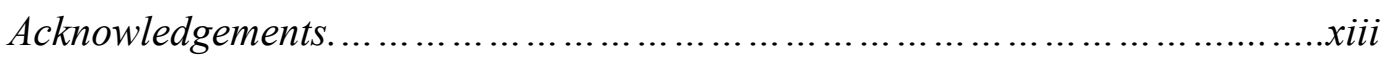

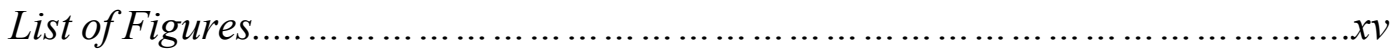

List of Tables ...............................................................

Publications Information ....................................................

Glossary of Terms ............................................................

Abstract.....................................................................xxxiii

1. INTRODUCTION

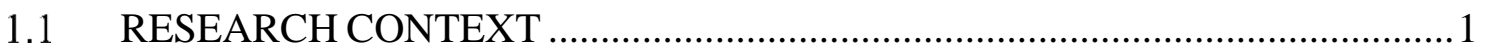

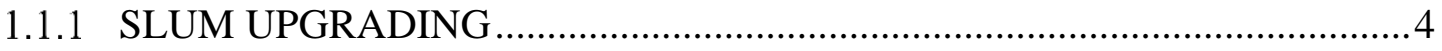

1.2 THE PARTICIPATORY SLUM-UPGRADING APPROACH ….....................5

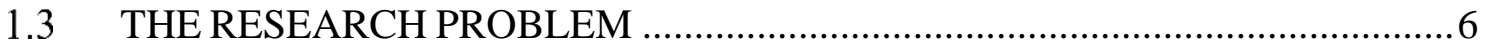

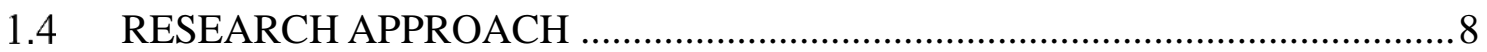

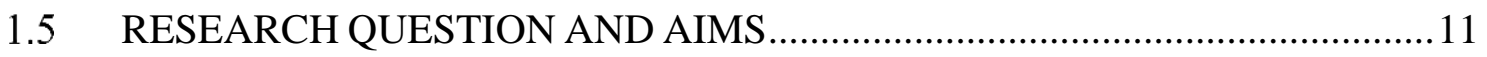

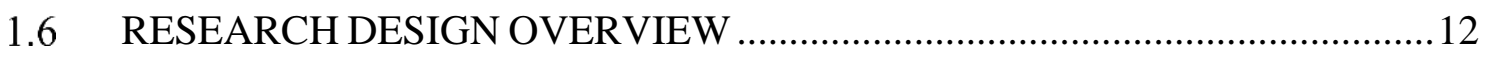

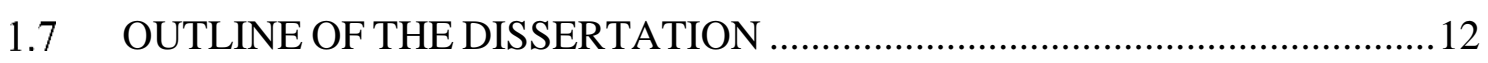

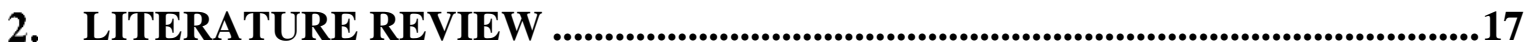

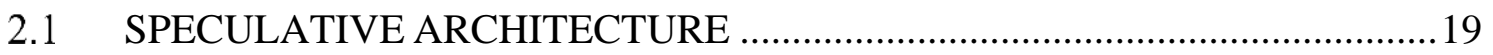

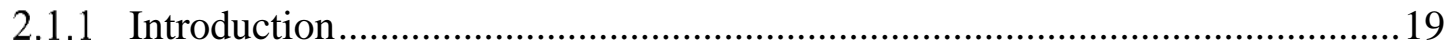

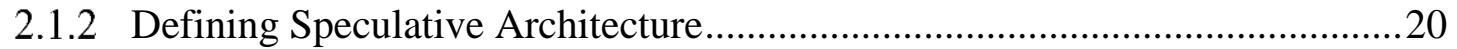

2.1.2.1 Speculative Architecture and Plurality .................................................22

2.1.2.2 Temporal Positioning of Speculative Architecture .................................23

2.1.3 Ways of Speculative Architectural Worldmaking .........................................22

2.1.3.1 Balancing Fiction and the Actual World .............................................29

2.1.3.2 How is the Speculation in Architecture Legitimised? ...............................30

2.1.3.3 Ensuring Intentional and Extensional Legitimacy in Speculative

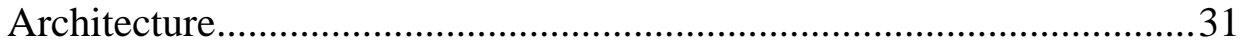

2.1.4 Speculative Architectures to Promote Design Ideation ..................................32 
2.1.4.1.1Utopias and Dystopias .32

2.1.4.1.2Urban Extrapolations .34

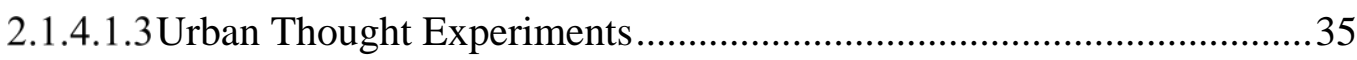

2.1.5 Enabling Social Discourse Through Speculative Architecture .........................36

2.1.5.1 Internally and Externally Oriented Speculations ....................................3

2.1.5.2 Terminal and Instrumental Operational Modality .................................39

2.1.5.3 Agonistic Speculative Architecture as Discursive Provocateur................40

2.1.5.4 Participatory Speculation ............................................................... 43

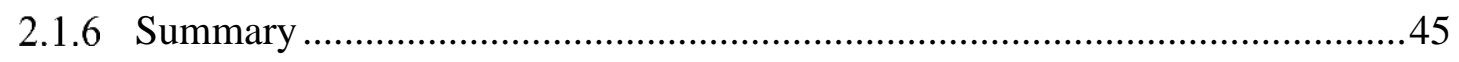

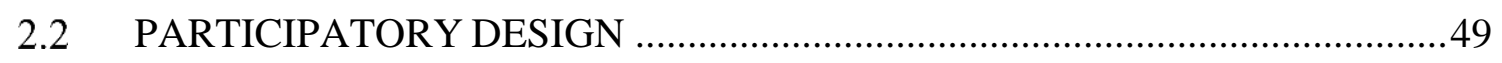

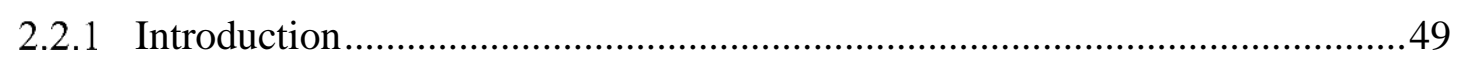

2.2.2 Positioning Participatory Design ..............................................................50

2.2.2.1 Towards Genuine Participation............................................................51

2.2.2.2 Exploring Conflicting Perspectives and Assumptions............................54

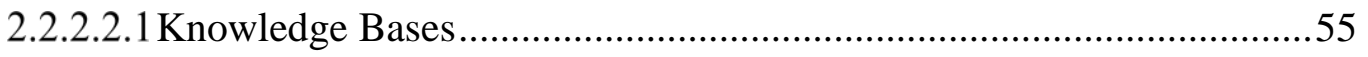

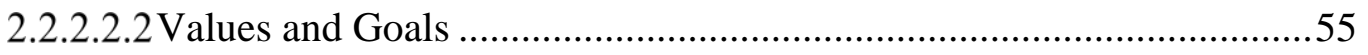

2.2.2.2.3Negotiation of Knowledge, Values and Goals in Participatory Design56

2.2.3 Revealing Participants' Knowledge, Values and Goals .................................57

2.2.3.1 Priming Participants for Participatory Design ......................................57

2.2.3.2 Participatory Tools for Revealing Knowledge, Values and Goals ...........58

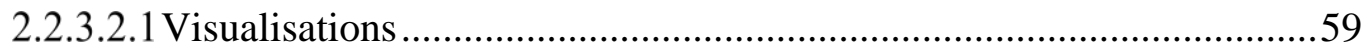

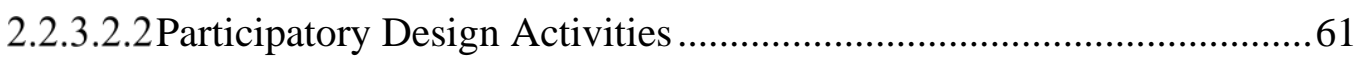

2.2.3.2.3 ICT based Approaches to Participatory Urban Design.........................62

2.2.4 Developing Knowledge, Values and Goals ................................................64

2.2.4.1 Agreement and Conflicting on Knowledge, Values and Goals ...............65

2.2.4.2 Agonistic Approaches to Participatory Design Activities ........................70

2.2.5 Grounding Knowledge, Values and Goals..................................................73

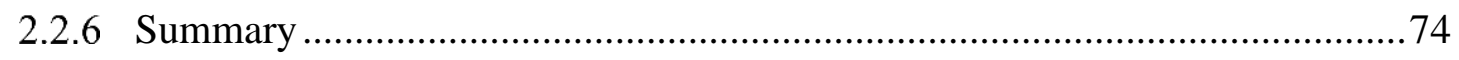

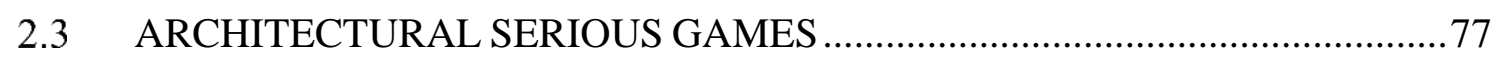

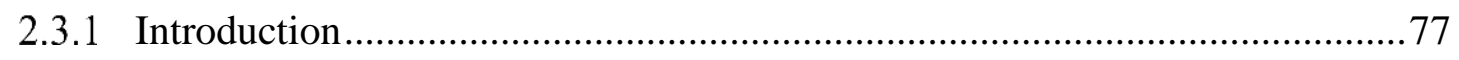

2.3.2 Defining Serious Gaming in Architecture and Planning ..............................79

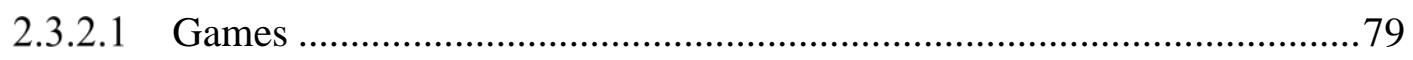

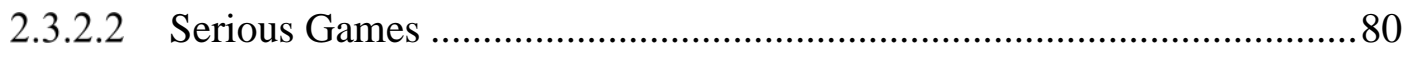

2.3.2.3 Serious Games in Architecture and Planning ....................................... 81 
2.3.2.4 Serious Games Used in Slum-upgrading Research .86

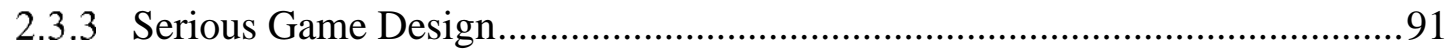

2.3.3.1 Serious Game Mechanics..................................................................... 92

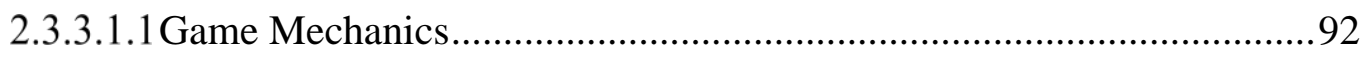

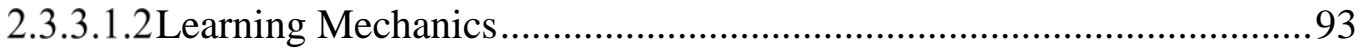

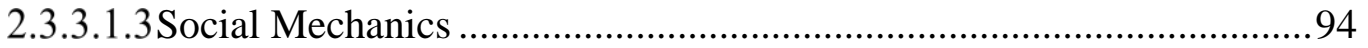

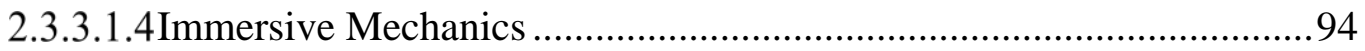

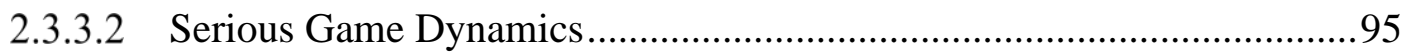

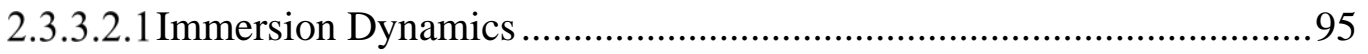

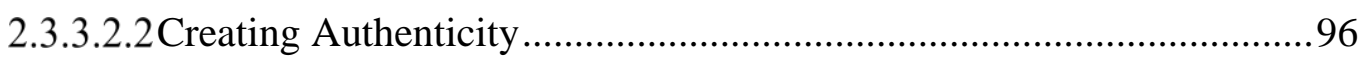

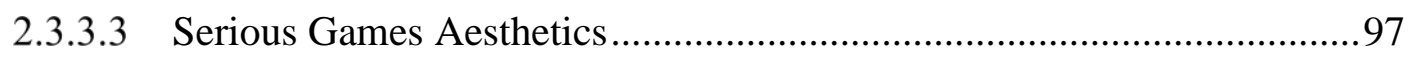

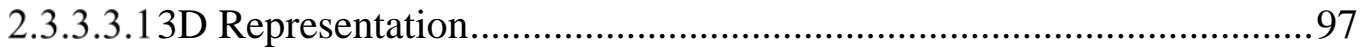

2.3.4 Facilitating Design Collaboration and Ideation in Serious Games ................ 102

2.3.5 Conflicting Stakeholder Perspectives and Social Capital in Serious Games.103

2.3.5.1 Civic Engagement and Social Capital................................................. 105

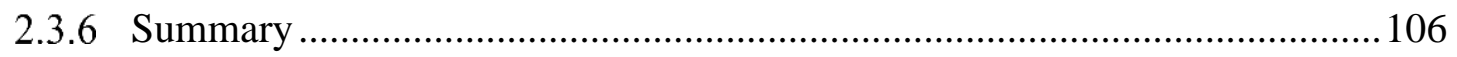

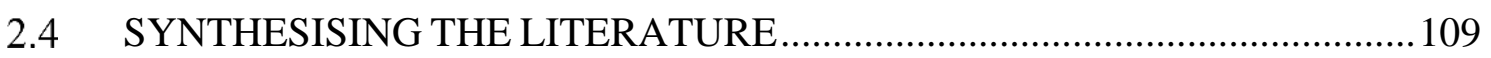

2.4.1 Speculative Participatory Serious Urban Gaming (SPS-UG) ........................ 109

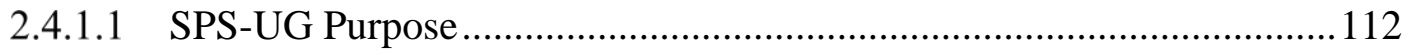

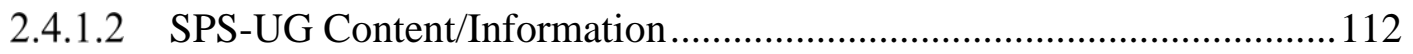

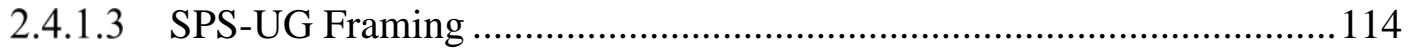

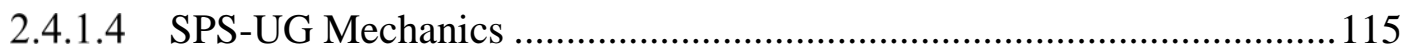

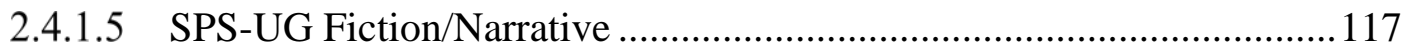

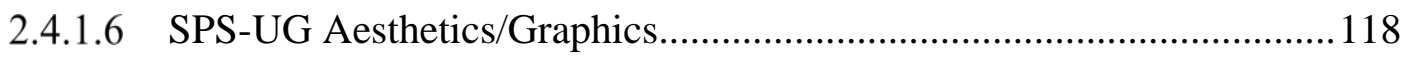

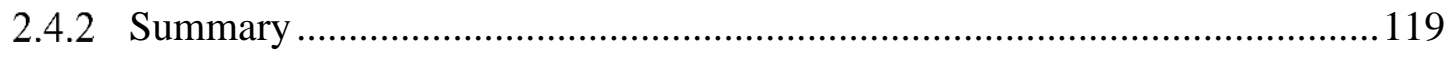

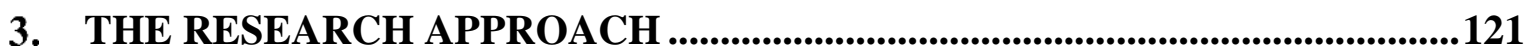

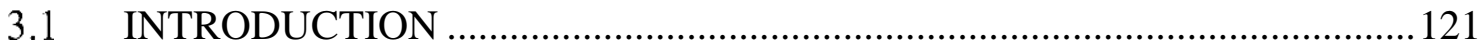

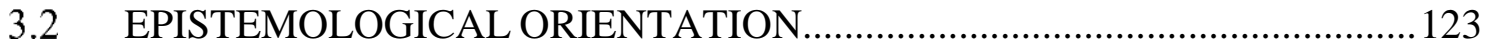

3.2.1 Design as Action Research - A Methodological Approach ..........................123

3.2.1.1 A Case Study Research Strategy Approach to Action Research ............125

3.2.1.2 Action Research Through Participatory Design Workshops ................. 126

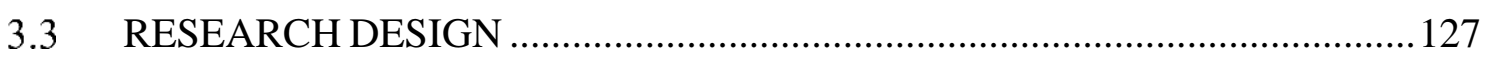

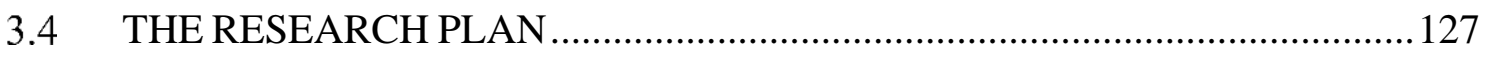




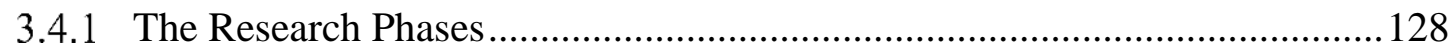

3.4.1.1 Phase One - Context Documentation Studies and Analysis ...................128

3.4.1.2 Phase Two - SPS-UG Development ........................................................131

3.4.1.3 Phase Three - SPS-UG Workshops....................................................132

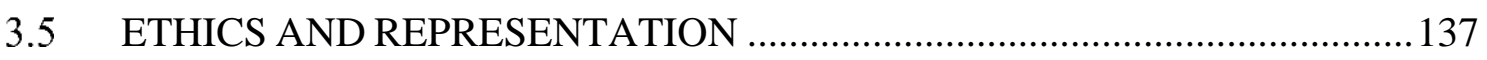

3.5.1 Reflexivity, Validity/Transferability and Relevance .....................................138

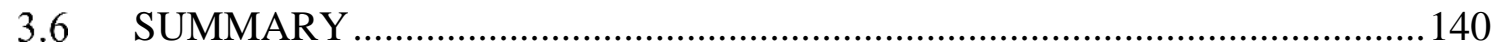

4. OPERATIONALISING THE SPS-UG APPROACH .............................................141

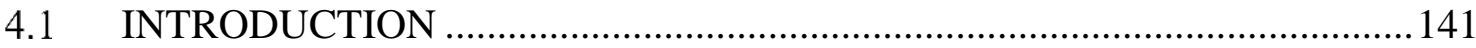

4.2 PHASE ONE: DOCUMENTATION OF THE RESEARCH CONTEXT ..........142

4.2.1.1 Ghazipur-Documentation of Context ......................................................142

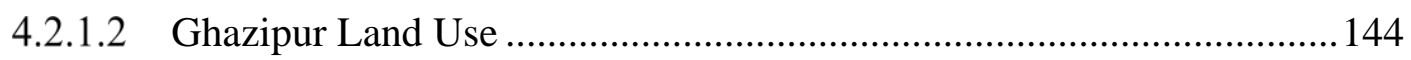

4.2.1.2.1 Ghazipur Housing ............................................................................. 145

4.2.1.3 Ghazipur Livelihood Generation ......................................................... 147

4.2.1.4 Main Slum-Upgrading Issues ..............................................................149

4.2.2 CS2 - Bhalswa - Documentation of Context …………………………….....151

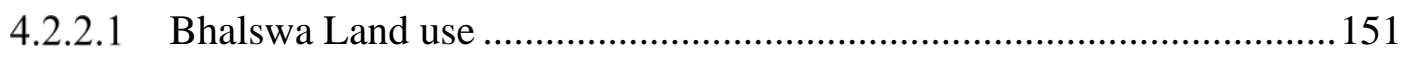

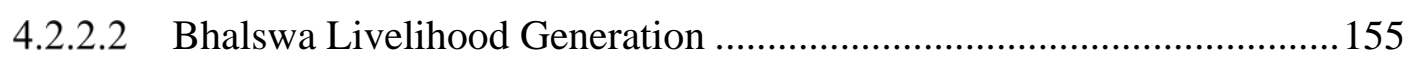

4.2.2.3 Main Slum-Upgrading Issues .............................................................155

4.2.3 CS3 - Shanti Nagar - Documentation of Context...........................................158

4.2.3.1 Shanti Nagar Land Use ....................................................................... 158

4.2.3.1.1 Shanti Nagar Housing ........................................................................ 161

4.2.3.2 Shanti Nagar Livelihood Generation ........................................................ 164

4.2.3.3 Main Slum-Upgrading Issues .............................................................. 165

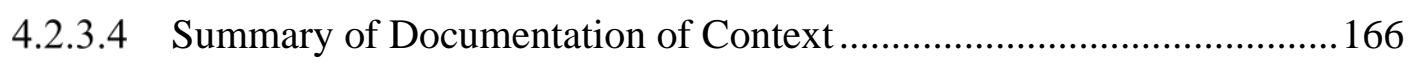

4.2.4 Data Collection for Understanding Conflicting Perspectives ..........................167

4.2.4.1 Data Collection Procedure …………………………………………...... 167

4.2.4.1.1 Ghazipur Perspectives......................................................................171

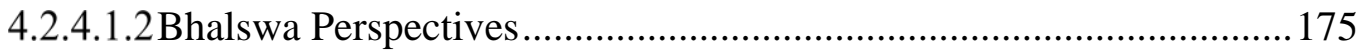

4.2.4.1.3 Shanti Nagar Perspectives .............................................................. 179

4.2.4.2 Identification of Important Contextual Issues......................................... 183

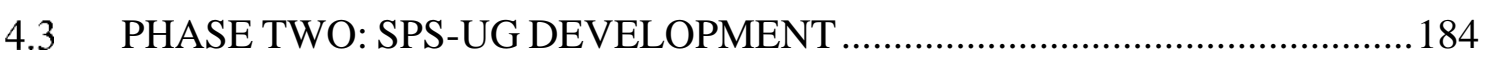

4.3.1 Stage One: Development of 3D Assets........................................................... 184 


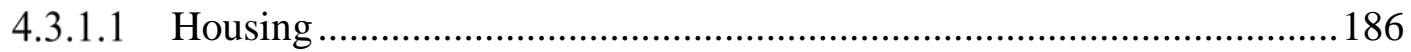

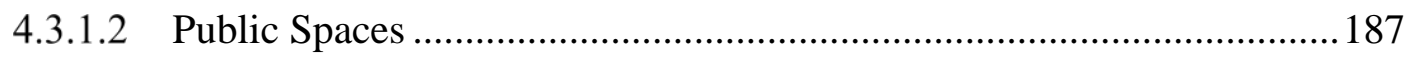

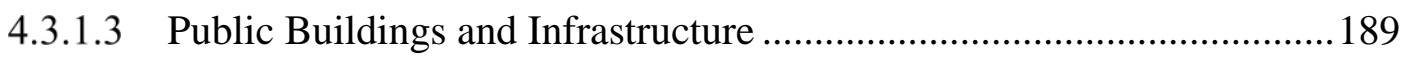

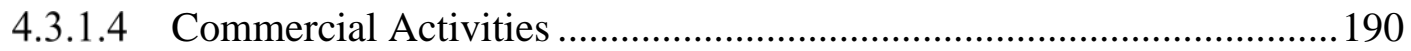

4.3.1.5 Compositing Urban Form for SPS-UG's ........................................... 191

4.3.1.5.1Compositing Urban Morphology and Contextual Issues....................192

4.3.2 Stage Two: Development of Interactive Mechanics and Dynamics SPS-UG194

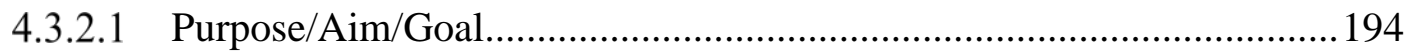

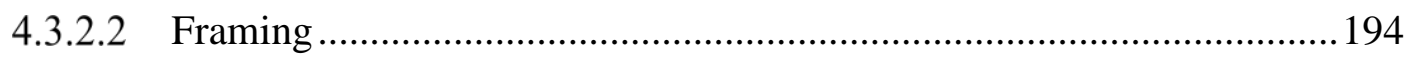

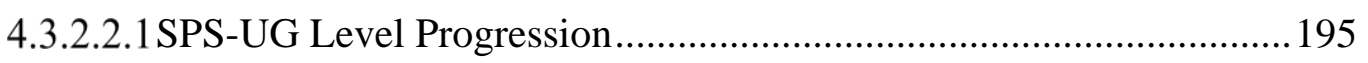

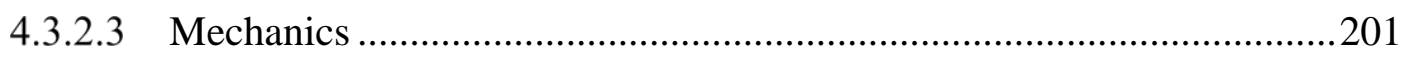

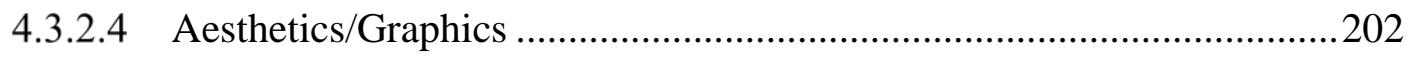

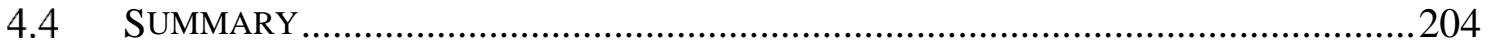

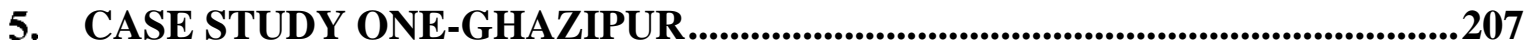

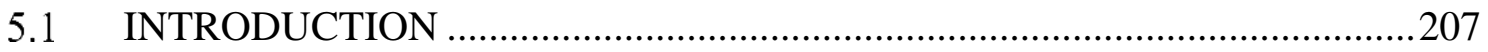

5.1.1 Summary of Case Study One - Ghazipur ...............................................207

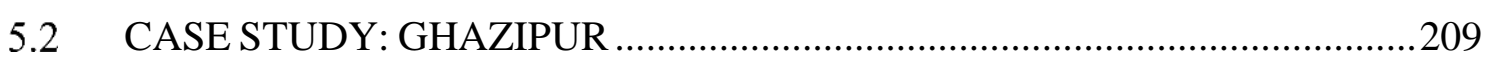

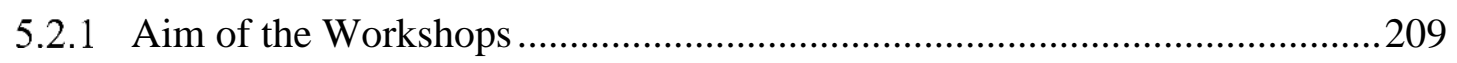

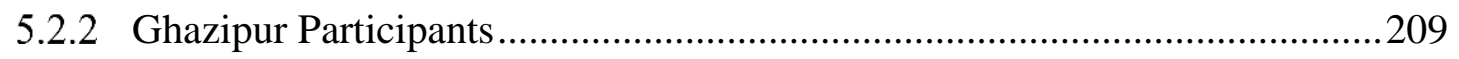

5.2.3 Workshop preparation process .................................................................210

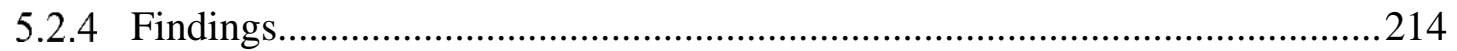

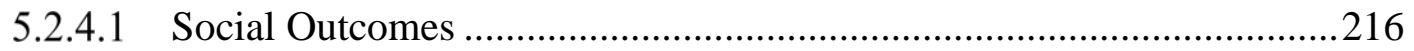

5.2.4.1.1Revealing Conflicting Perspectives ...............................................216

5.2.4.1.2Evaluation of participant cooperation and understanding .................217

5.2.4.1.3Dissemination of workshop outcomes and experiences ....................218

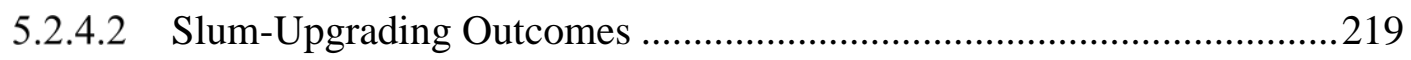

5.2.4.2.1 The importance of housing being in close proximity to the landfill...222

5.2.4.2.2The community problems associated with lack of security or tenure. 223

5.2.4.2.3 The role of the waste-to-energy plant within the community.............224

5.2.4.2.4The importance of location and use of public spaces and amenities ..225

5.2.5 The role of "speculation" in aiding the exploration of conflicting perspectives

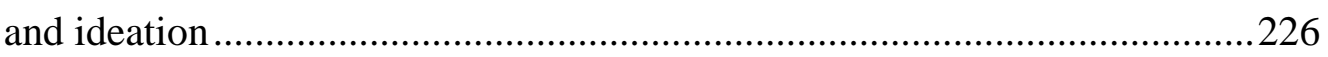

5.2.6 The relationship between the speculative and the real..............................228 


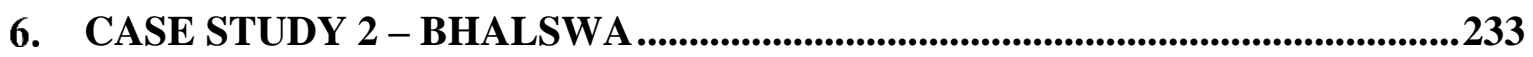

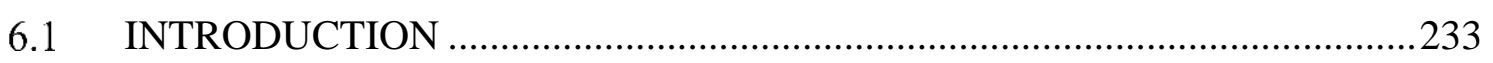

6.1.1 Summary of Case Study Two - Bhalswa ...................................................233

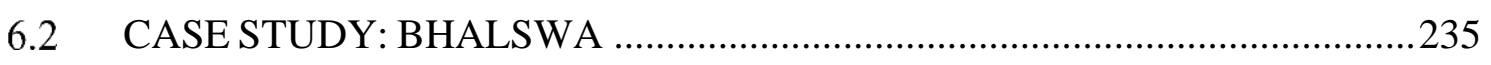

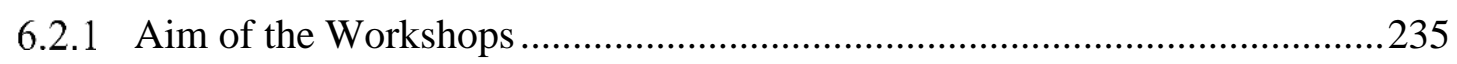

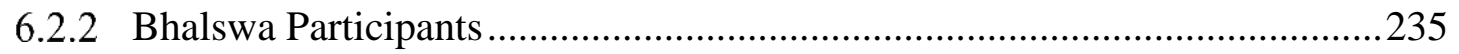

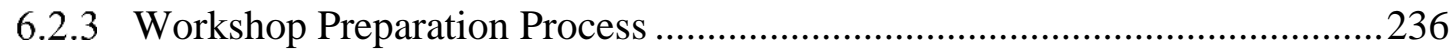

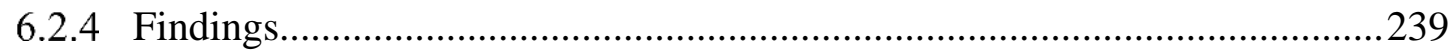

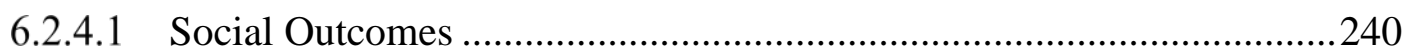

6.2.4.1.1Conflict as a generator of creative solutions to problems..................240

6.2.4.1.2Galvanising around Matters of Concern ............................................243

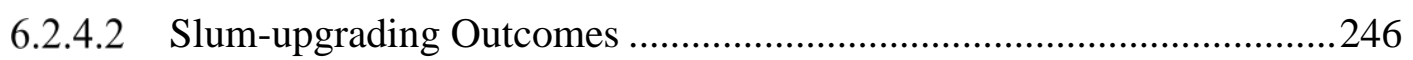

6.2.4.2.1 The construction of higher quality housing ....................................246

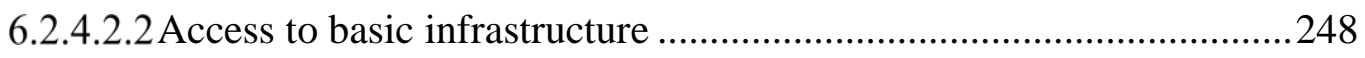

6.2.4.2.3 Adapting the digital SPS-UG context to explore ideas......................248

6.2.5 Challenges with working with the most marginalised ................................251

6.2.6 Experiential stories as a means to explore social and spatial tensions and ideas

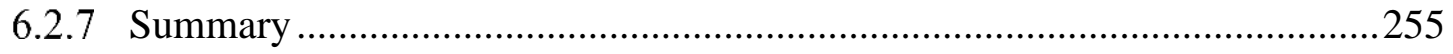

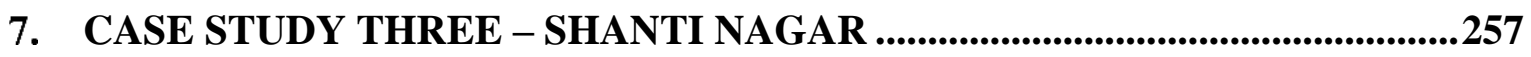

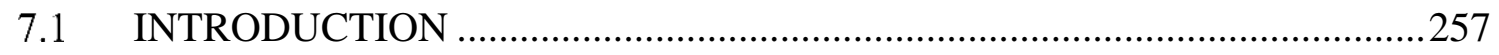

7.1.1 Summary of Case Study Three - Shanti Nagar ..........................................257

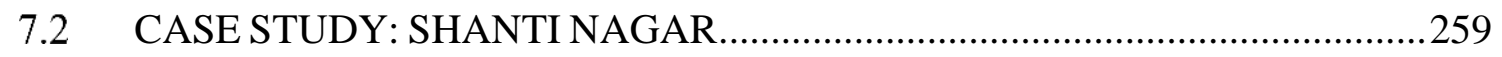

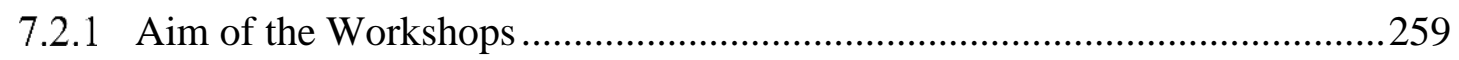

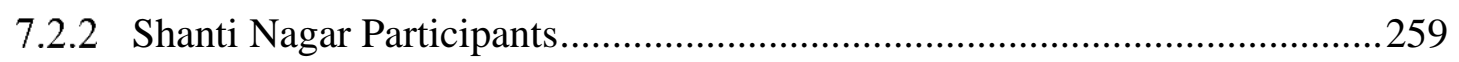

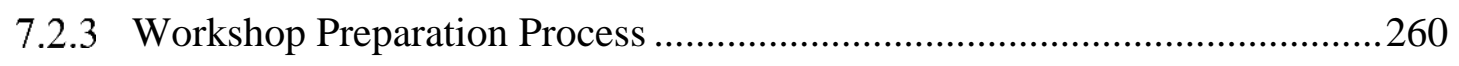

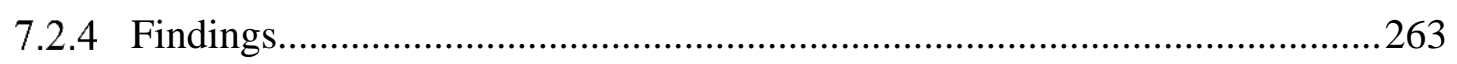

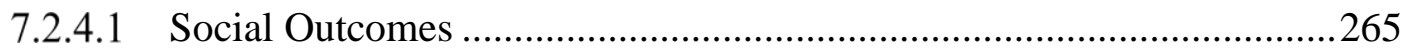

7.2.4.1.1 Aiding the discussion of sensitive topics .........................................265

7.2.4.1.2Reflecting through Recursive Engagement .....................................267

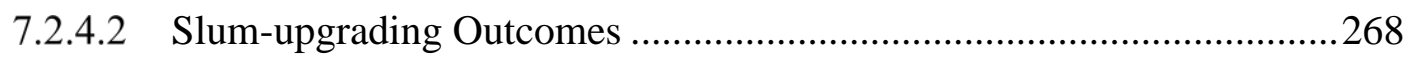


7.2.4.2.1 Access to schools

7.2.4.2.2Environmental Concerns Relating to Garbage

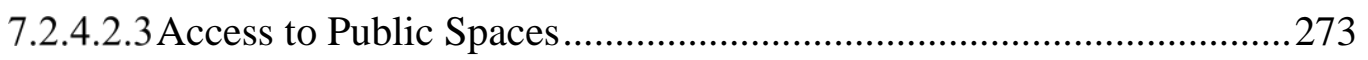

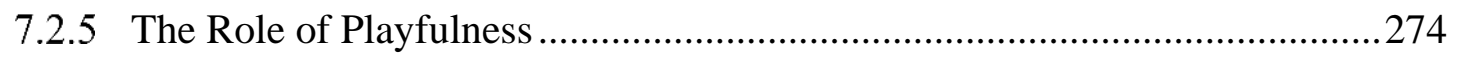

7.2.6 Increasing Social Capital through Participatory Gaming .............................277

7.2.7 Digital Participatory Workshops with Marginalised Youth ..........................278

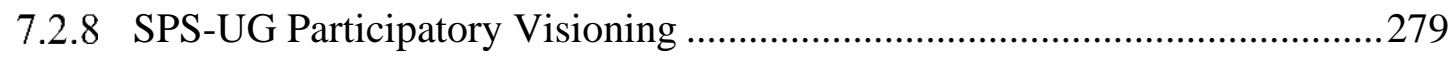

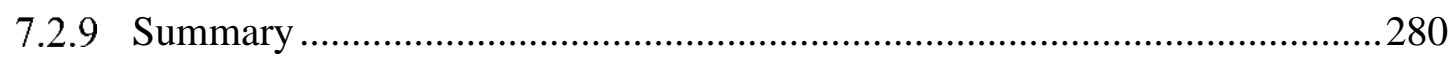

\section{DISCUSSION: SPS-UG AS AN ENABLER OF SOCIAL AND DESIGN}

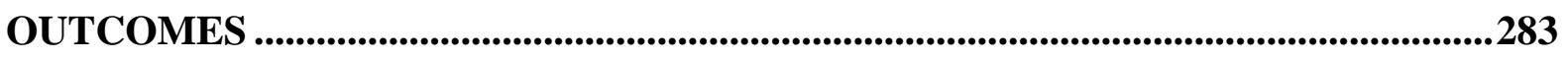

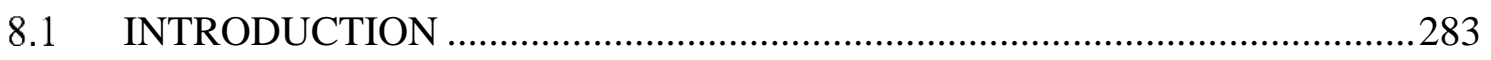

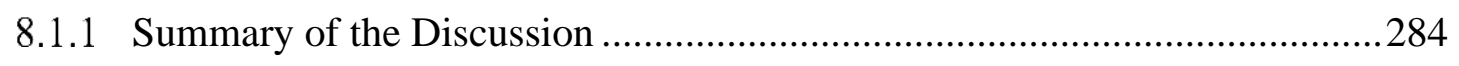

8.2 ENHANCING SOCIAL OUTCOMES VIA THE SPS-UG APPROACH.........285

8.2.1 Factor 1: Temporary Worlds and Perceptual Bridging .................................286

8.2.1.1 Social Interaction and Collaborative Learning ....................................290

8.2.2 Factor 2: Developing Participants' Knowledge, Values and Goals...............292

8.2.3 Factor 3: Grounding Participants' Knowledge, Values and Goals through

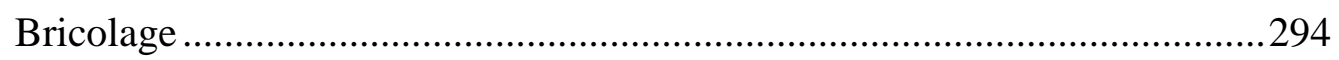

8.3 ENHANCING DESIGN (SLUM-UPGRADING) OUTCOMES VIA SPS-UGS ... .294

8.3.1 Factor 1: Hybrid-Realities as a Means to Define Design Parameters............2295

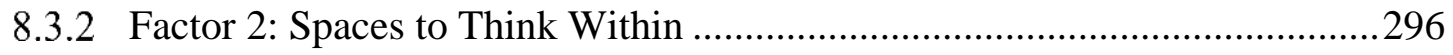

8.4 METHODOLOGICAL INSIGHTS INTO THE SPS-UG APPROACH ...........297

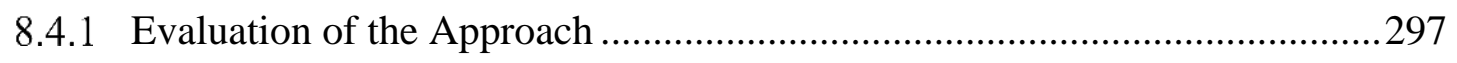

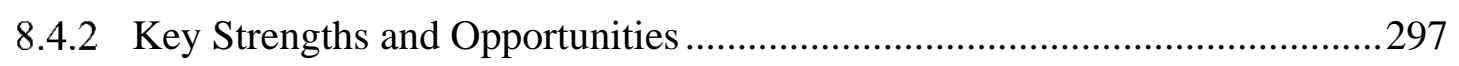

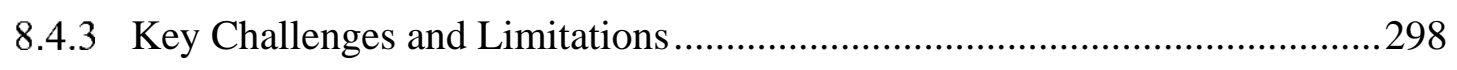

8.4.3.1 Limitations of Context and Application .............................................299

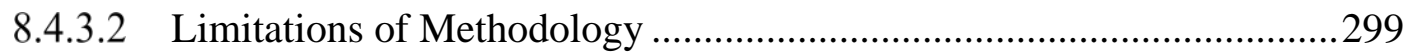

8.4.3.3 Bridging the Gap Between Priming and Generating Slum-Upgrading .301

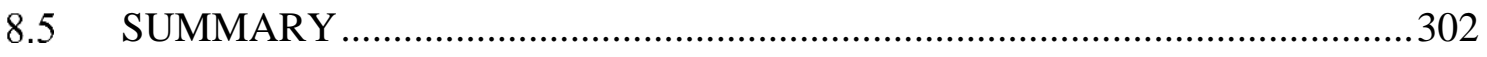

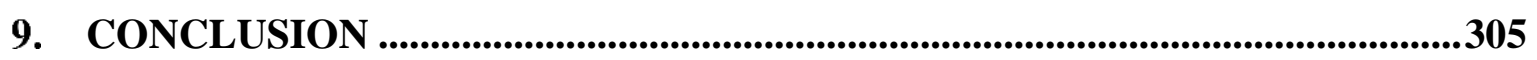

9.1 REFLECTION ON THE RESEARCH QUESTIONS ......................................306 
9.1 RECOMMENDATIONS FOR FUTURE RESEARCH …..............................308

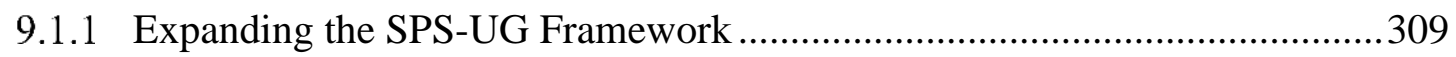

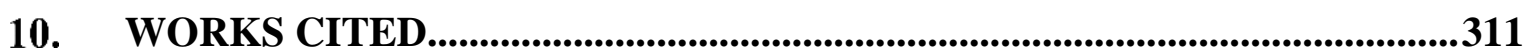

Appendix 1 - Phase One: Maslow's Palace Workshops - Interview Questions...353

Appendix 2 - Maslow's Palace In-Game Instructions .............................355

Appendix 3 - Phase Three: Maslow's Palace Workshops - Facilitation

Instructions

Appendix 4 - Phase Three: Maslow's Palace Workshops - Interview

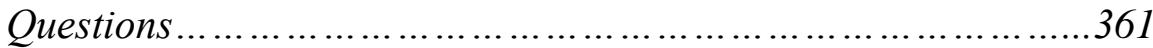

Appendix 5 - Digital Link to Maslow's Palace ..........................................365

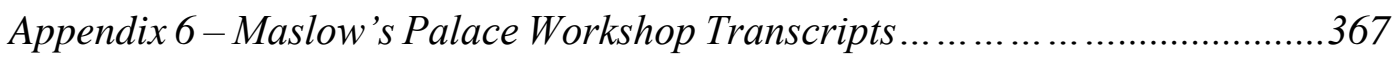




\section{Acknowledgements}

During four years of research I have met many people who have contributed both directly and indirectly to this research. Some have encouraged me, some have tested me, and some have inspired me. Some have lent an ear, some their voice. Some have helped with much needed distractions, some have sharpened my focus.

Sincere thanks to my supervisors Professor Daniel K. Brown and Dr. Sara Kindon for their support, dedication, and inspiring collaboration over the years and for going over and above in order to help this research reach fruition. Thank you also to Dr. Mark Johnson for his guidance regarding ethics matters.

Thank you to Victoria University of Wellington's Faculty of Graduate Research for their assistance in providing a scholarship to complete this research. Thank you also to Freemasons New Zealand for granting me a Freemasons New Zealand Postgraduate Scholarship which enabled me to conduct the critical international fieldwork central to the research.

Many thanks to staff and volunteers from the Chintan Environmental Research and Action Group for all of your enthusiasm, support and organisational efforts in helping conduct field workshops with the Ghazipur and Bhalaswa communities in Delhi, India. More specifically thank you to Bharati Chaturvedi (Directior of Chintan Environmental Research and Action), Anindita Chakraborty, Ganesh Kumar, Wasim Akram, Naheed Tabassum, Usha Kumari, Karan Minz, Balmukund Kumar, Salman Khan, Momin Khan and Gaurav Shanna.

Thank you also to the staff from Apnalaya in Mumbai for your gracious hospitality and organisational efforts in running the field workshops with the Shanti Nagar community in Mumbai. Specifically thank you to Anjali Chaudr, Rama Shyam, Sara Hasan, Shivani Khandelwal and Siddique Danish.

To my partner Kate, for tolerating my late nights and weekends at the office and for your emotional and culinary support in the form of baked goods and lasagne on tough weeks. Your support is invaluable and I could not have done this without you.

To my parents David and Liz for all of their support through my many years of research. To my sister Megan for putting up with my research related chat at family dinners. 
Finally, thank you to all participants of each of the workshops. I hope you gained a lot from participating. Through this research, your contribution will help others improve their own slum-upgrading situations. 


\section{List of Figures}

Figure 1. Diagram that shows the areas of interest, in particular the ones resulting in the intersection of the three main areas investigated in the literature review 1

Figure 2. Participatory functions deployed at various stages of the urban development process. Adapted from (Lucero et al., 2012; Lynch, 1984; Sanders et al., 2010).

Figure 3. "The Futures Cone”. Adapted from ( Hanckock and Bezold, 2003)......................24

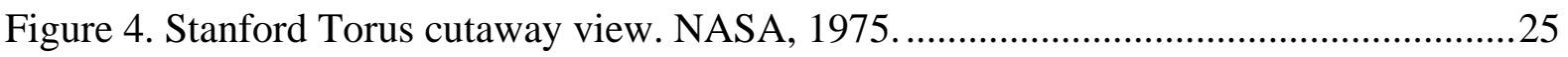

Figure 5. Buckminster Fuller, Dome Over Manhattan, 1960.............................................26

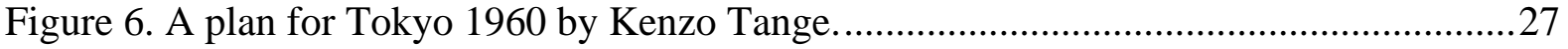

Figure 7. Architect Olalekan Jeyifous imagines what Lagos, Nigeria could look like in the future in his series Shanty Megastructures, 2016..........................................28

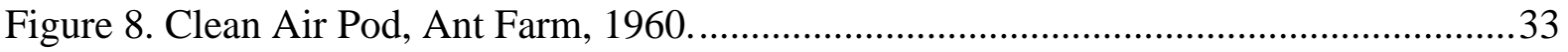

Figure 9. Rapid Re(f)use: Waste to Resource City, TerreformOne, 2009..............................34

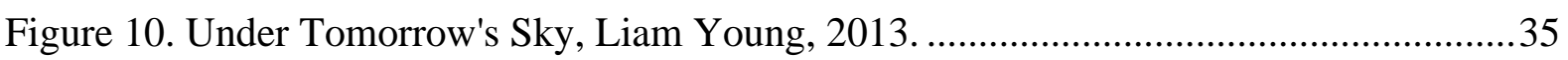

Figure 11. The film Jonah (2013, directed by Kibwe Tavares, explores the effects of tourism, globalisation, and commercialisation in Zanzibar through speculative

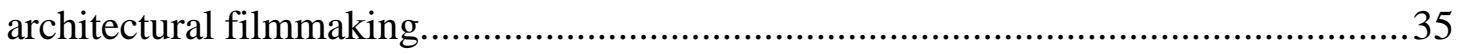

Figure 12. Weaponized Architecture, Léopold Lambert, 2010 ..........................................36

Figure 13. Positioning terminal-instrumental/ internal external Speculative Architecture. Adapted from (Tharp \& Tharp, 2019)................................................. 37

Figure 14. Million Dollar Blocks, Laura Kurgan, 2012 ..................................................42

Figure 15. Underground Berlin 3, Lebbeus Woods, 1988 .................................................43

Figure 16. Future of Hearts and Minds scene (Gerber, 2018) .............................................44

Figure 17. Driverless City: Scenario builder, mind map and visualisation to support citizen conversations for a future with driverless cars (Clarke et al., 2018). ...............45

Figure 18. Ladder of Citizen Participation. Adapted from Arnstein (1969)...........................52 
Figure 19. Future Visioning Workshops using simple props for reflecting, discussing and visualising future aspirations, fears and expectations about urban futures amongst disparate participants (Pollastri et al., 2017, p. 8).

Figure 20. Screen shot from the Smarticipate participatory urban design tool (Z. Khan et al., 2017).

Figure 21. Placing feedback on a selected urban feature in Min Stad (Tahvilzadeh, 2015) .64

Figure 22. The Product Value Game: Two players negotiate silently which values they want to attribute to their product using colourful picture cards (Iversen \& Buur, 2002).

Figure 23. Participants playing "Play Noord" a Generative City Game designed to explore masterplanning by integrating typical and atypical urban actors through a City Game interface (Tan, 2014, p. 269).... .68

Figure 24. Finding Places by the CityScienceLab at Hafencity University and the city of Hamburg in partnership with M.I.T. (Noymana, Holtz, Kröger, Noennig \& Larson, 2017).

Figure 25. A participant in Kibera, Kenya highlights the size of the football pitch in the Minecraft model as part of a UN-Habitat participatory slum-upgrading project (Westerberg \& von Heland, 2015, p. 8) . .70

Figure 26. Participants contributing to the Change By Design project in Nairobi, Kenya (Frediani et al., 2011, p. 108).

Figure 27. The World Game: Integrative Resource Utilisation Planning Tool, R.

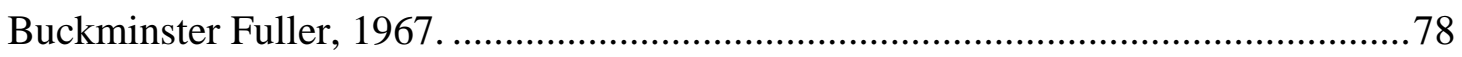

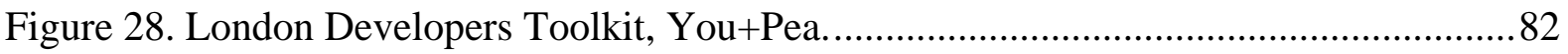

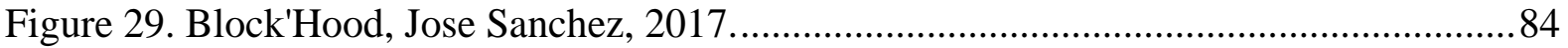

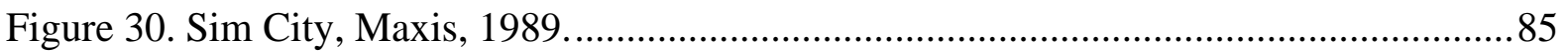

Figure 31. Cities Skylines being projected onto a wall for use in participatory design workshops in Norra Djurgårdstaden, Stockholm, Sweden, 2016. .86

Figure 32. GetH20 (Butterfly Works, 2010)

Figure 33. Block by Block participants in Nairobi Kenya collaborate in public space design (Block by Block, 2017). .88 
Figure 34. Places identified as different types of properties in YouPlaceIt (Poplin \& Vemuri, 2018, p. 78).

Figure 35. Participation event in Mumbai-residents using VR devices (Markopoulou et al., 2018, p. 229). .90

Figure 36. Participation event in Mumbai-residents using VR devices (Markopoulou et al., 2018, p. 229). .90

Figure 37. Kolb's experiential learning model. Adapted from (Kolb, 1984, p. 21). .93

Figure 38.Simplified, low-polygon graphic style of 3D City Builder. 99

Figure 39. Stylised graphic style used in Block'Hood.

Figure 40. Realistic visual style of Cities Skylines with "Slums for Cities Skylines" modification 100

Figure 41. Synthesising the "SPS-UG" approach (author, 2019). 110

Figure 42. Serious Game Design Assessment Framework Adapted from (Mitgutsch \& Alvarado, 2012)

Figure 43. Synthesising the SPS-UG approach, contributing game elements (by author).

Figure 44. The research design.

Figure 45. Visualising the central role of SPS-UG participatory design workshops with the case study communities

Figure 46. Phase Three research procedure.

Figure 47. Research Phases One and Two detailed within this chapter.

Figure 48. Ghazipur, Delhi, India. Satellite image from Google Earth., 2019.

Figure 49. Ghazipur area, Delhi. Satellite image from Google Earth., 2019 144

Figure 50. Ghazipur land use, 2019. 145

Figure 51. Ghazipur. Satellite image from Google Earth. Accessed 2019. 146

Figure 52, left. Residents cooking next to open drains, Ghazipur, 2017. Photo by Author.

Figure 53, right. Ghazipur dwellings, 2017. Photo by Author. 147 
Figure 54. Delhi Metro Station under construction with residential area in the foreground, Ghazipur 2017. Photo by Author

Figure 55, left. Ghazipur landfill, dairy farm buildings and dairy cows grazing on the landfill. Ghazipur 2017. Photo by Author.

Figure 56, right. Recycling human hair, Ghazipur, 2017. Photo by Author. 148

Figure 57, left. Outsourced garment labour, Ghazipur, 2017. Photo by Author. 149

Figure 58, right. Waste-to-energy Plant, Ghazipur 2017. Photo by Author.

Figure 59. Overlooking garment factories and indoor dairy farms with Ghazipur landfill in the background, 2017. Photo by Author.

Figure 60. Bhalswa, Delhi. Satellite image from Google Earth., 2019.

Figure 61. Bhalswa case study site. Satellite image from Google Earth., 2019.

Figure 62. Bhalswa landfill as viewed from Bhalswa Dairy, 2017. Photo by Author.

Figure 63. Wider Bhalswa area land use, 2019

Figure 64, left. Bhalswa dwellings as viewed from the landfill, 2017. Photo by Author.

Figure 65, right. Bhalswa dwellings within the slum area next to the landfill, 2017.

Photo by Author.

Figure 66. A typical dwelling within the slum area next to the landfill, Bhalswa, 2017. Photo by Author.

Figure 67, left. Waste collection at the top of Bhalswa Landfill, Bhalswa, 2017. Photo by Author. 155

Figure 68, right. Waste sorting, Bhalswa Landfill, 2017. Photo by Author. 155

Figure 69. Toilets and storage spaces are located in the cloth covered shacks at the rear of the photo, which are partially dug into the landfill behind, Bhalswa, 2017. Photo by Author. 156

Figure 70, left. A child mining the landfill for salvageable items, Bhalswa Landfill, 2017. Photo by Author.

Figure 71, right. Children collecting discarded bricks for local construction from the landfill, Bhalswa Landfill, 2017. Photo by Author.

Figure 72, Shivaji Nagar, Mumbai. Satellite image from Google Earth., 2019. 158 
Figure 73. Shivaji Nagar. Satellite image from Google Earth., 2019. Adapted by Author.

Figure 74. Shivaji Nagar land use, 2019

Figure 75. Shanti Nagar, Mumbai, 2017. Photo by Author.

Figure 76. Single storey dwellings, Shanti Nagar, Mumbai, 2017. Photo by Author.

Figure 77. Two storey dwellings in Shanti Nagar, Mumbai, 2017. Photo by Author.

Figure 78. Multi-Storey dwellings and the open area of the Deonar landfill being used for recreational purposes. Shanti Nagar, Mumbai, 2017. Photo by Author.

Figure 79. Shanti Nagar, Mumbai, 2017. Photo by Author.

Figure 80. Open area of the Deonar landfill being used for recreational purposes.

Shanti Nagar, Mumbai, 2017. Photo by Author.

Figure 81. Rooftop of the Chintan operated school, Ghazipur fieldwork, February 2017. Photo by Author.

Figure 82. Participant Occupations, Ghazipur, 2017.................................................... 168

Figure 83. Bhalswa fieldwork, February 2017. Photo by Author........................................ 169

Figure 84. Participant Occupations, Bhalswa, 2017.

Figure 85. Shanti Nagar fieldwork location, Apnalaya community centre, February

2017. Photo by Author. 170

Figure 86. Participant Occupations, Shanti Nagar, 2017.

Figure 87. Thematic analysis of the Ghazipur interview data identifying a range of conflicting perspectives on slum-upgrading issues.

Figure 88. Thematic analysis of the Bhalswa interview data identifying a range of conflicting perspectives on slum-upgrading issues.

Figure 89. Thematic analysis of the Shanti Nagar interview data identifying a range of conflicting perspectives on slum-upgrading issues.

Figure 90. Exemplar diagram of a virtual SPS-UG environment.

Figure 91. Level One - Maslow’s Palace.

Figure 92. Level Two - Maslow’s Palace. 
Figure 93. Level Three - Maslow's Palace.

Figure 94. Level Four- Maslow’s Palace.

Figure 95. Level Five- Maslow’s Palace. .200

Figure 96. In-game instructions in English and Hindi, Maslow’s Palace. .203

Figure 97. In-game instructions in English and Hindi, Maslow's Palace. .204

Figure 98. CS1 - Ghazipur located within the visual timeline of the research methodology. 208

Figure 99. Chintan School location of the Ghazipur workshops. November 2017.

Figure 100. Entering the Chintan School, the location of the workshops, Ghaizpur, November 2017.

Figure 101. Participants of the Ghazipur Workshops, November 2017.

Figure 102. Floorplan of workshop space.

Figure 103. Ghazipur Workshop 2 participants playing Maslow's Palace, November 2017.

Figure 104. Pre-test / Post-test analysis of Ghazipur workshop groups. The diagram indicates some consensus building surrounding proximity to the landfill as a main slum-upgrading issue (right) as opposed to a variety of issues being identified before the SPS-UG process (left).

Figure 105. Workshop Group Three, Ghazipur. .223

Figure 106. Group Four, level five, Maslow's Palace. Ghazipur, November 2017. Participants removed the existing metro station, responding to the threat of forced eviction within their community.

Figure 107. Group Four, Level Five, Maslow's Palace. Ghazipur, November 2017. Participants designing community meeting spaces and public spaces close to their homes and work areas.

Figure 108. Group Two, Level Five, Maslow's Palace. Ghazipur, November 2017. Constructing housing within the landfill boundary - the in-game outcome functioning as a diagram .228

Figure 109. CS2 - Bhalswa located within the visual timeline of the research methodology. 
Figure 111. Participants of the Bhalswa Workshops, November 2017.

Figure 112. Floorplan of workshop space

Figure 113. Bhalswa Workshop 2 participants playing Maslow's Palace, November 2017.

Figure 114. Bhalswa Workshop One, Level Four outcome. Participants' outcome as a result of cooperative weighing of pros and cons of design options, November 2017.

Figure 115. Bhalswa Workshop Two, Level Four outcome. Participants' outcome as a result of a solution to a conflict, November 2017.

Figure 116. Pre-test / post-test analysis of Bhalswa workshop groups. The diagram indicates some solidarity surrounding access to drinking water, the construction of adequate housing, better drainage and access to hospitals.

Figure 117. Group Two, Level Five, Maslow's Palace. Ghazipur, November 2017. Participants designing housing, community meeting spaces and public spaces close to their homes and work areas.

Figure 118. Aerial image showing the undeveloped parcel of land (top, centre) behind the Bhalswa slum community. Image via Google Earth, 2019.

Figure 119. The game environment area that the participants of Group One cleared to explore upgrading ideas.

Figure 120. The game map before Group One's gameplay, Bhalswa, 2017. .250

Figure 121. The workshop outcome of Group One, Bhalswa, 2017. .250

Figure 122. Phase Three research procedure. Bhalswa, Group Two. .254

Figure 123. CS3 - Shanti Nagar located within the visual timeline of the research methodology. .258

Figure 124. The location of the Shanti Nagar workshops. November 2017. .261

Figure 125. The Apnalaya Community Hall, Shanti Nagar, Mumbai, December 2017.

Figure 126. Floorplan of the Shanti Nagar workshop space. .262 
Figure 127. Shanti Nagar Workshop 2 participants playing Maslow's Palace, November 2017.

Figure 128. Iteration one. Shanti Nagar, Group Five.

Figure 129. Iteration two. Shanti Nagar, Group Five.

Figure 130. Pre-test / post-test analysis of the Shanti Nagar workshop groups. The diagram indicates some solidarity surrounding access to drinking water for all workshop groups and lack of access to public toilets for Group Three.

Figure 131. Level Three research procedure. Shanti Nagar, Group Three

Figure 132. Level five outcome, Workshop Group Four. Shanti Nagar, Group Three. .274

Figure 133. Participant of Group One playing Level Five, Shanti Nagar. Left image via Google Earth, 2019. Right image by author. 


\section{List of Tables}

Table 1. Levels of Participatory Design Empowerment. Adapted from (Senbel \& Church, 2011).

Table 2. Summary of game features identified as key to player engagement. Adapted from (Rooney, 2012). .96

Table 3. Speculative Strategies for Urban Design Serious Gaming. Adapted from (McLaughlin, 2005, p. 133).

Table 4. SPS-UG content/information strategies derived from the literature.

Table 5. SPS-UG framing strategies derived from the literature. 114

Table 6. SPS-UG game mechanics derived from the literature. 116

Table 7. SPS-UG fictional space/narrative strategies derived from the literature. 118

Table 8. SPS-UG aesthetics/graphics strategies derived from the literature. 118

Table 9. Synthesising Action Research and design processes

Table 10. Phase One data collection purpose and methods - fieldwork 2017. 128

Table 11. Phase One interview questions. 130

Table 12. Phase Two purpose and SPS-UG development methods.

Table 13. Phase Three data collection purpose and methods - fieldwork 2017. 132

Table 14. Summary of the key variables identified between the case study sites. 166

Table 15. Identification of important contextual issues. 183

Table 16. Development of 3D Assets - Housing 186

Table 17. Development of 3D Assets - Public Spaces 187

Table 18. Development of 3D Assets - Public Buildings and Infrastructure 189

Table 19. Development of 3D Assets - Commercial Activities

Table 20. Parts, Subclasses and features for compositing urban morphological and contextual issues in the SPS-UG.

Table 21. Maslow's Palace Level Progression Summary 196 
Table 22. Demographic information about workshop participants - Ghazipur, Delhi..........210

Table 23. Maslow's Palace workshop outcomes - Ghazipur. …...........................................2214

Table 24. Demographic information about workshop participants - Bhalswa, Delhi..........236

Table 25. Maslow’s Palace workshop outcomes - Bhalswa ..............................................2239

Table 26. Demographic information about workshop participants - Shanti Nagar,

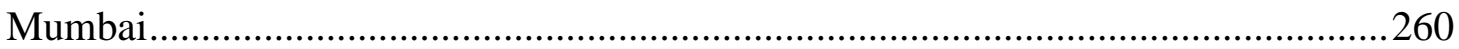

Table 27. Maslow's Palace workshop outcomes - Shanti Nagar .......................................263 


\section{Publications Information}

The following is a list of publications published during this dissertation.

Beattie, Hamish. Participatory Urban Design Gaming: A Perceptual Bridging Approach." Context: Design, Architecture, Culture (blog), September 9, 2018. https://contextbd.com/participatory-urban-design-gaming-perceptual-bridgingapproach/.

Beattie, Hamish and Daniel Brown. "Solidarity through Difference: Speculative, Serious Participatory Urban Gaming (SSP-UG)." International Journal of Architectural Computing 17 (Forthcoming).

Beattie, Hamish, Daniel Brown, and Morten Gjerde. "Generating Consensus: A Framework for Fictional Inquiry in Participatory City Gaming.” In Serious Games 4th Joint International Conference, JCSG 2018, Darmstadt, Germany, November 78, 2018, Proceedings, 126-37. Valencia: Springer, 2017.

Beattie, Hamish, Daniel Brown, and Sara Kindon. "Functional Fiction to Collective Action: Values-Based Participatory Urban Design Gaming." In Intelligent and Informed: Proceedings of the 17th International Conference on Computer-Aided Architectural Design Research in Asia. Wellington: The Association for ComputerAided Architectural Design Research in Asia, 2019.

_ "Perceptual Bridging as a Strategy for Stakeholder Social Capital Building and Ideation in Participatory Urban Design." Lisbon, Portugal: Centro de Estudos Internacionais, 2018.

—. "Speculative Participatory Serious Urban Gaming: Evaluating the SPS-UG Design Framework." In Anthropocene: Design in the Age of Humans: Proceedings of the 18th International Conference on Computer-Aided Architectural Design Research in Asia. Bangkok, 2020. (Forthcoming). 
Beattie, Hamish, and Tane Moleta. "Videogame Urbanism: Pedagogical Outcomes of Exploring Serious Architectural Design Games in the Academic Design Studio.” In Anthropocene Design in the Age of Humans: Proceedings of the 18th International Conference on Computer-Aided Architectural Design Research in Asia. Bangkok, 2020. (Forthcoming). 


\section{Glossary of Terms}

Agonistic Participatory Design. Participatory Design processes that create agonistic space. In Agonistic Participatory Design processes, consensus should not be forced (Boano \& Kelling, 2013); instead, opportunities should be provided for stakeholders to participate in contestation, or constructive controversies, among 'adversaries' who have opposing matters of concern but also accept other views as 'legitimate' (Björgvinsson et al., 2012; DiSalvo, 2012).

Agonistic Pluralism. Agonistic Pluralism is best understood in relation to antagonism, which is the struggle between enemies, while agonistic pluralism represents the contestation of multiple coexisting and conflicting perspectives between adversaries (Emilson, 2015, p. 50).

Agonistic Space. A situation where the different stakeholders do not necessarily reach a consensus surrounding a design, but rather create an arena that reveals conflict or tensions and that allows multiple opposing views to coexist (Hillgren, Seravalli, \& Emilson, 2011, p. 179; Huybrechts, Dreessen, Schepers, \& Salazar, 2016).

Agonistic Speculative Architecture. The creating of spaces for discussion and imagination of multiple possible futures by provoking a condition of pluralism and contestation through design that avoids presenting totalising hegemonic future "solutions" in the name of generating "consensus" (Leeuwen, 2015, p. 800).

Co-Design. A particular type of participatory design whereby expert designers and people not trained in design work together in collective creative ways throughout the whole design process (Sanders \& Stappers, 2008).

Explicit and Observable Knowledge. Participant knowledge that can generally reveal stakeholders' preferences for one thing over another.

Games. A system in which players engage in an artificial conflict, defined by rules, that results in a quantifiable outcome (Salen \& Zimmerman, 2004, p. 80).

Genuine Participation. A processes in which all participants within a design activity have equal power to determine the outcome of the decisions made, as opposed 
to merely being informants (Blundell-Jones et al., 2005, p. 27; Simonsen \& Robertson, 2012, p. 5).

Informal Settlements. Inhabitants have no security of tenure with regard to the land or dwellings they inhabit, with modalities ranging from squatting to informal rental housing; the neighbourhoods usually lack, or are cut off from, basic services and city infrastructure; the housing may not comply with current planning and building regulations and is often situated in geographically and environmentally hazardous areas (UN-Habitat, 2015a).

Instrumental Speculative Architecture. The speculative architectural design is part of other designerly activities such as participatory design. (Tharp \& Tharp, 2019). Instrumental speculative architectural projects behave similarly to participatory design research tools - explicitly framed to engage potential users and hopefully produce insight into their hopes, dreams, values, concerns, behaviours, etc. This type of design includes the observer as an active contributor to the speculation. (Tharp \& Tharp, 2013, p. 408).

Latent Needs. Needs that participants are not yet aware of. They are needs that become realised in the future.

Participation. The term "participation" masks the fact that participatory design processes range in degrees of stakeholder empowerment from partial participation, or what Jeremy Till calls "pseudo-participation", to full control of the process by the participants (Till, 2005, p. 25). These degrees are identified in Sherry Arnstein's frequently cited 'Ladder of Citizen Participation' model (Figure 18. Ladder of Citizen Participation. Adapted from Arnstein (1969).), in which she sets out a hierarchy of stakeholder control (Arnstein, 1969). At the bottom of the ladder is "manipulation" of participants and at the top is "citizen control".

Participatory design tools. The material components that are used in Participatory Design activities (Sanders, Brandt, \& Binder, 2010).

Participatory Design Tools. Tools include digital and physical games, mapping instruments, and visualisation systems among others, are used in participatory design activities to engage stakeholders in design thinking (Sanders, Brandt, \& Binder, 2010). They "scaffold" and "support collaborative [design] enquiry" and help to "bring 
together a network of actors with different backgrounds, competencies and experiences" (Brandt et al. 148).

Participatory Design. The direct involvement of users and stakeholders in the design of products, services, and systems they use (Kensing, 2003; Simonsen \& Robertson, 2012). The purpose of participatory design is to develop new knowledge geared towards participants' ability to take action in informed ways.

Participatory Slum-Upgrading. Slum residents are involved in the decisionmaking process of upgrading as project partners. This shift reflects wider movements in development practice towards a capacity building based approach (Minnery et al., 2013; Pugh, 1995, p. 381; Rigon, 2014)

Perceptual Bridge. A perceptual bridge between the audience's perception of their world and the speculative representation that roots the speculation within people's everyday actual world. The perceptual bridge can fill the gap between the viewer's actual world - present a state of mind, technical knowledge, psychological perception and cultural background - and the speculation's world (Auger, 2012, p. 66). In doing so a perceptual bridge can ground the speculation by employing typologically familiar design elements to "ensure that it connects with an identified audience's perceptions of the temporal world around them" (Auger, 2012, p. 180).

Serious Game Aesthetics. The category of Aesthetics describes the desirable emotional responses evoked in the player, when they interact with the game system. The aesthetics of the game help the designer describe the dynamics and the mechanics of the game to the player, set the tone, and give clear feedback to the players regarding scores, time, resources and progression.

Serious Game Dynamics. The category of Dynamics describes the run-time behaviour of the mechanics acting on players' inputs and each other's outputs over time. These may include time pressure, lack of resources to complete a certain task, or incentives and achievements that guide players toward a particular action.

Serious Game Mechanics. Mechanics are the various actions, behaviours and control mechanisms afforded to the player within a game context (Hunicke et al., 2004). Together with the game's content, such as levels and resources, the mechanics support overall gameplay dynamics.

Serious Game. A serious game is "a mental contest, played with a computer in accordance with specific rules that uses entertainment to further government or 
corporate training, education, health, public policy, and strategic communication objectives" (Zyda, 2005). The purpose of serious games is ultimately to be both educational and fun (Bellotti, Kapralos, Lee, Moreno-Ger, \& Berta, 2013a).

Slums. As a synonym of informal settlements, slums are defined as "large agglomerations of dilapidated housing often located in the most hazardous urban land" that also "lack supply of basic urban infrastructure and services, public space and green areas and are constantly exposed to eviction, disease and violence" (UN-Habitat, 2015a).

Slum-Upgrading. A process through which informal areas are gradually improved, formalised and incorporated into the city itself, through extending land, services and citizenship to slum dwellers (The Cities Alliance, 2014).

Social Design. Participatory approaches to researching, generating and realising new ways to make change happen towards collective and social ends, rather than predominantly commercial objectives (Armstrong et al., 2014).

Speculative Architecture. Designed to promote the consideration of alternate visions and possible futures and to scaffold discussions about what the future might look like. They can be, and have been, used as a means of imagining new possible ways of living as communities (Dunn, Cureton, \& Pollastri, 2014, p. 14)..."remove the commercial constraints that might normally limit the design process; use prototypes as the main method of enquiry; and use fiction to present alternative futures, pasts or presents to create space for thinking, questioning and dreaming" (Auger, 2012, p. 136).

Speculative Participatory Serious Urban Gaming (SPS-UG). SPS-UG's are concerned with drawing together speculative architecture, participatory design and serious games literature in order to go beyond the visualisation of design options, thinking about single speculations or aiding learning about collaborative design processes: it also aims to help participants in a given community or locale to reflect upon a plurality of possible futures that might help them to explore perspectives and corresponding goals surrounding the upgrading of their infrastructures and environments, i.e., to enhance both social outcomes and related design (slumupgrading) outcomes.

Tacit knowledge. Knowledge that cannot readily be expressed in words (Polanyi, 1967). 
Terminal Speculative Architecture. The design is the terminus of the design activity (i.e. the outcome or design solution). (Tharp \& Tharp, 2019).

Values. The enduring beliefs that we hold concerning "desirable modes of conduct" or "end-state of existence in different situations", societies and cultural contexts (Iversen, Halskov, \& Leong, 2012, p. 89). 


\begin{abstract}
People who are marginalised in slum-upgrading processes can benefit from participatory design strategies. When marginalised slum communities confront and explore conflicting perspectives, values, assumptions and goals through negotiation within participatory design processes, the ability to harness the collective intelligence of people to work towards collective action can be enhanced. However, a tension exists in the participatory design literature between those participatory processes that seek to facilitate social outcomes such as social capital building, and those that seek only to implement an urban development or upgrading project (slum upgrading) as the outcome. Exploring new methods of design participation that integrate both social outcomes and design processes can help alleviate this tension by recognising a diversity of stakeholder perspectives on urban-related issues and help them work towards implementing lasting communal change that explicitly takes into account cooperative development action.

The dissertation explores an innovative approach to participatory slum upgrading, which proposes bringing together speculative architecture, participatory design, and serious gaming approaches to help stakeholders to explore conflicting perspectives, assumptions and corresponding future visions surrounding architectural and urban issues. The research focusses on how these three areas can be brought together to help develop a new approach for designing participatory design tools for marginalised communities. The research explores how a "speculative, participatory, serious urban gaming" (SPS-UG) approach might be used to help marginalised communities consider past, future and present community experiences, reconcile dissimilar assumptions, and generate social outcomes and in-game design responses, while priming participants for further long-term, slum-upgrading design engagement processes. Empirical material for this research was gathered from a range of case study workshops prepared with three landfill-based communities and external partners throughout 2017, which utilised a new SPS-UG computer game I designed called Maslow's Palace to evaluate the approach.

The research shows that the SPS-UG approach was successful in guiding the design of a serious game to help reveal, develop and ground stakeholder knowledge, goals and values surrounding slum-upgrading issues. Through an exploration of social
\end{abstract}


complexities involved in the participatory design process, participants were stimulated to share diverse opinions and aspirations and thus deepen their understanding of self, others, norms and institutions. The SPS-UG approach contributed to slum-upgrading outcomes for communities by aiding slum-upgrading ideation, framing the consideration of alternate views and possible futures, and scaffolding discussions about what the future might look like through visual representation of possible design alternatives. Finally, the research discusses key methodological insights, and the challenges faced when working with marginalised communities while pursuing social and slum-upgrading outcomes through a gaming approach. This is significant when considering how the approach might interface with other slum-upgrading processes outside of the scope of this research or function as a catalyst for the transformation of other physical urban environments and socio-cultural contexts. 


\section{Introduction}

The research proposes to bring together speculative architecture, participatory design, and serious gaming approaches to help slum-dwellers explore conflicting perspectives, assumptions and corresponding future visions surrounding slumupgrading issues (Figure 1). The research focusses on how this approach can help develop participatory design tools for slum communities around the world using case study examples from India.

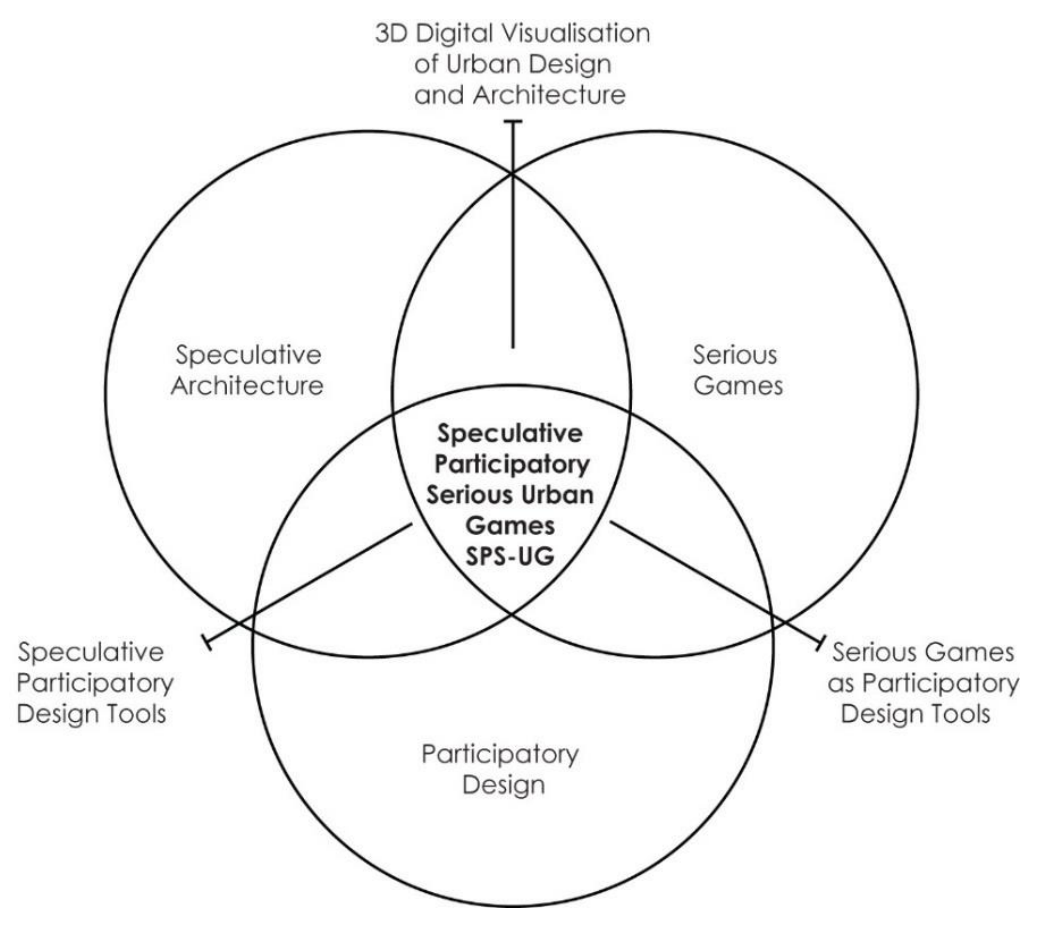

Figure 1. Diagram that shows the areas of interest, in particular the ones resulting in the intersection of the three main areas investigated in the literature review.

\subsection{Research Context}

Landfills, in many developing countries and indeed in some developed nations, can be catalysts for the development of unplanned informal settlements or slums. The 
United Nations Human Settlements Programme defines Informal Settlements as those in which:

inhabitants have no security of tenure with regard to the land or dwellings they inhabit, with modalities ranging from squatting to informal rental housing; the neighbourhoods usually lack, or are cut off from, basic services and city infrastructure; the housing may not comply with current planning and building regulations and is often situated in geographically and environmentally hazardous areas (UN-Habitat, 2015a).

Slums, as a synonym of informal settlements, are defined as "large agglomerations of dilapidated housing often located in the most hazardous urban land" that also "lack supply of basic urban infrastructure and services, public space and green areas and are constantly exposed to eviction, disease and violence" (UN-Habitat, 2015a).

As land surrounding landfills is generally seen as undesirable and usually initially vacant, it is often available for informal settlement. Living near landfills can also be attractive to migrants or economically disadvantaged people, as they can offer community members a means of livelihood through "waste-picking"-or the reclamation of reusable and recyclable materials from solid waste streams - as an adaptive response to poverty, forced resettlement, migratory pressures and employment scarcity (Medina, 2008). Some people work in the informal recycling sector as a migratory transitional occupation before finding more formal employment, and some engage with waste picking as an income supplementation strategy, and after some time, secondary or tertiary means of livelihood—such as small stores-are established to service the informal economy (Neuwirth, 2012). For many, however, collecting and processing materials from city streets, landfills and garbage trucks become a long-term livelihood solution, central to the functionality of these communities (Marello \& Helwege, 2014; Medina, 2008; The World Bank, 2013; Wilson, Velis, \& Cheeseman, 2006).

Once established, inhabitants of landfill-oriented slums can face a number of hardships. They generally illegally occupy land, which can result in issues regarding security of tenure and forced eviction, as well as harassment from government and law enforcement. Oftentimes people have the ability to construct better homes for themselves but choose not to allocate their resources to this due to the threat of forced 
eviction and the possibility of having to rebuild their homes somewhere else. Inhabitants of landfill-oriented slums can also suffer from an acute lack of access to adequate housing stock, water and electricity infrastructure, sanitation facilities, adequate roads and drainage, availability of public and community spaces, heath facilities and schools.

To compound matters, landfill-based communities often have very complex sociocultural structures with high proportions of children, single mothers, widows, the disabled and the ill. Recent migrants and refugees also often make up a large proportion of these communities due to rural-urban, intra-urban and inter-urban migration, meaning newcomers arrive with new and different cultural backgrounds, languages and worldviews. The resulting diversity can mean that if and when community members engage with urban development processes such as slumupgrading projects to work towards solutions to the aforementioned problems, individuals may enter workshops or community meetings with different assumptions, viewpoints, and interpretations of situations. While community members may have similar goals such as reaching the best decision or outcome for the community, their different worldviews and corresponding values may interfere with their ability to view and discuss issues in similar ways (Mohammed \& Ringseis, 2001).

As a result of differences in worldviews and values, communities can be limited in their ability to engage, decide, plan and lobby for effective future development action-either from bottom-up action or as part of a facilitated project (The World Bank, 2013). Community members can also be less likely to come up with solutions that benefit all inhabitants; completed projects might not be maintained by the community due to a "poor fit" of the design outcome; social rifts between different factions might eventuate and stall development processes; and projects might be less likely to attract funding or be seen as less beneficial to politicians who might look to endorse projects for the projects' merits or even their own political gain. This limitation, with its roots in the social-cultural intricacies of the context, can ultimately affect a landfill-oriented slum community's ability to become empowered to overcome problems through mutual understanding, ideation and collective action. 


\subsubsection{Slum Upgrading}

The demolition and resettlement of informal settlement and slum communities have traditionally been operationalised by local and national governments in order to remedy the "slum problem" (Baviskar, 2003; Macharia, 1992; Olthuis, Benni, Eichwede, \& Zevenbergen, 2015); however, demolition and involuntary resettlement are now generally considered to be ineffective, as they can result in the destruction of livelihood and social networks of community members (Roquet, Bornholdt, \& Lukic, 2015 , p. 2). Resettlement can result in the need for complex livelihood restoration processes and tailored social support surrounding the resettled community.

In response to the problems surrounding the resettlement approach, during the last two decades of the twentieth century, focus has shifted towards informal settlement upgrading processes - or "slum upgrading" and rehabilitating existing slums in-situ (Hamdi, 1991; Huchzermeyer, 2010; Lochner \& Ntema, 2013; Mukhija, 2017; Turley, Saith, Bhan, Rehfuess, \& Carter, 2013). Cities Alliance defines slum upgrading as: “A process through which informal areas are gradually improved, formalised and incorporated into the city itself, through extending land, services and citizenship to slum dwellers" (The Cities Alliance, 2014).

Slum upgrading refers to improvements in housing and/or basic infrastructure, social infrastructure such as community centres, education facilities, health services and economic infrastructure such as job growth in slum areas. More specifically, slumupgrading actions consist of physical, social, economic, organisational, and environmental improvements that are undertaken as a collaboration between individuals, community groups, businesses and local authorities (French, Popal, Rahimi, Popuri, \& Turkstra, 2018; United Nations, 2016; United Nations Human Settlements Programme, 2003, 2013). They try to increase security of tenure of informal settlement communities through working with local authorities (Olthuis et al., 2015, p. 272; The World Bank, 2013; The World Bank Group, 2001). These approaches would, ideally, foster social and economic inclusion, that can bring about such physical improvements (Skinner, French, Acioly, \& Reid, 2014, p. 3) and improve quality of life.

Some of the benefits of slum upgrading approaches are that they are more "inexpensive, feasible, and flexible than adopting common demolition and relocation mechanisms" (Olthuis et al., 2015, p. 271). According to Skinner et al; slum upgrading 
remains "the most financially and socially appropriate approach to addressing the challenge of existing slums" (Abebe \& Hesselberg, 2015; Patel, Siliuzas, \& Mathur, 2015; Roquet et al., 2015; Skinner et al., 2014, p. 17). In addition, it has become progressively clearer that single project-based approaches to upgrading-such as providing a building or a single piece of infrastructure to one specific communityhave been insufficient to alleviate the hardships faced by these communities (Skinner et al., 2014; UN-Habitat, 2015b). Consequently more holistic approaches to slum upgrading have become the international policy norm (UN-Habitat, 2016a).

\subsection{The Participatory Slum-upgrading Approach}

Over the past four decades a shift has taken place towards "participatory" slum upgrading where residents are increasingly involved in the decision-making process of upgrading as project partners, this shift reflects wider movements in development practice towards a capacity building based approach (Minnery et al., 2013; Pugh, 1995, p. 381; Rigon, 2014). Participatory architectural design and stakeholder participation in community upgrading and design have many benefits. They can increase the chance of successful project implementation improvements, as stakeholders are more likely to support plans that can reduce risk and timeframes for project completion (Majale, 2008). Carefully-orchestrated participatory processes generally also result in projects that are well-suited to community needs. They can be transformative through building the capacity of those who are traditionally omitted from city building procedures to engage with development processes (Angel, 1983). In this context, participatory slum upgrading can give those who are generally marginalised a space to express opinions and ideas, and provide a chance for them to be included in the decision making that will impact their lives, livelihoods, and wellbeing (Frediani, French, \& Ferrera, 2011, p. 18).

Majale (2008) argues that a participatory approach to upgrading, through which residents are able to provide meaningful input into the project, can lead to the empowerment of the residents (Majale, 2008). MacPherson (2013) explains that participation in slum upgrading allows people to expand their capabilities, and in turn, their freedom (p. 88). Frediani \& Boano describe this as the construction of "capability space" (Frediani \& Boano, 2012, p. 13). According to a UN-Habitat report, this 
participatory design in slum-upgrading can have both social and infrastructural/spatial value. "Community participation can at many stages both preserve residents' sense of belonging and ensure that the services provided are what local people want, value and are ready to look after" (UN-Habitat, 2016b, p. 62).

Davis and Garb posit that when marginalised communities confront and explore conflicting perspectives, values, assumptions and goals through negotiation within participatory design processes, the ability to "harness the collective intelligence" of people to work towards collective action can be enhanced (Davis \& Garb, 2017, p. 77). Through an exploration of social complexities involved in participatory design processes, participants can be stimulated to "share diverse opinions and aspirations [and] thus deepen their understanding of the self, others, norms and institutions" (Frediani \& Boano, 2012, p. 216). Carl DiSalvo argues in his article "Design, Democracy and Agonistic Pluralism" that participatory design processes can become processes that are guided by normative principles of being open to contestation and reconfiguration (DiSalvo, 2010). They can function as a catalyst for transformation of physical urban environments and socio-cultural contexts ${ }^{1}$.

\subsection{The Research Problem}

While stakeholder participation in community upgrading and design can be both socially and practically advantageous, creating fora for both social outcomes and slum-upgrading outcomes to be addressed can be challenging.

A tension exists in the participatory architectural design literature between those participatory processes and tools that seek to facilitate social outcomes-or so called "social design" - and those that seek to implement an architectural design project as the outcome (Armstrong, Bailey, Julier, \& Kimbell, 2014; Frediani, 2016). Design outcome focussed participatory processes have generally been well-intentioned but are often criticised as being short-sighted regarding their ability to effectively address issues of power dynamics and social relationships. They often do not adequately allow for an exploration of conflicting stakeholder perspectives, assumptions and

1 This mode of participatory architectural design is in direct opposition to dominant modes of pseudo-participation. The issues of manipulative and exploitive modes of "pseudo-participation" have been widely detailed (Arnstein, 1969; Cooke \& Kothari, 2001; Frediani \& Boano, 2012; Sinha, 2012). 
corresponding future visions surrounding architectural and urban issues and increasing cooperation and agency to affect change over their environment. As noted by Cook and Kothari in their book Participation: The New Tyranny, such processes often do not adequately deal with both the complex social structures shaped by various cultural nuances and asymmetries of power, when faced with implementation-driven design projects and short timeframes for project completion (Cooke \& Kothari, 2001) ${ }^{2}$. Jeremy Till posits that the challenge of the design outcome approach is linked to the way in which architecture is inherently a spatial problem-solving discipline. "In architectural practice, the 'problem' is what gives the profession something to act upon in a specialised manner" (Blundell-Jones, Petrescu, \& Till, 2005, p. 26). By not carefully considering people's tacit and latent feelings and values in participatory architectural practice, we unnecessarily limit design's engagement processes to "explicit and observable knowledge about contexts" and negate their ability to explore future alternatives with reference to non-physical attributes of setting (Sanya, 2016; Visser, Stappers, Van Der Lught, \& Sanders, 2005). Frediani argues that being overly fixated on a design outcome, at the cost of participants' tacit and latent feelings and values, can inadvertently "homogenise the needs and aspirations" of participants (Frediani, 2016).

Meanwhile "social design" participatory architectural design processes are those often motivated by challenging the drivers of socio-political issues and improving the conditions for a disadvantaged and often confined community. Social design processes can struggle to interface with design processes that meet the diverse needs of communities. Armstrong et al. define social design as participatory approaches to researching, generating and realising new ways to make change happen towards collective and social ends, rather than predominantly commercial objectives (Armstrong et al., 2014). Social design ${ }^{3}$ participatory processes are less focussed on the production of design outcomes, and instead focus primarily on building mutual understanding, networks and relationships between participants-or social capital.

While participants of social design participatory processes might see significant increases in their social capital, the often long duration and lack of focus on pragmatic

\footnotetext{
2 As Jeremy Till points out, it is important to note that no participatory process, however well intentioned, is going to completely dissolve asymmetries of power and inequalities between participants (Blundell-Jones, Petrescu, \& Till, 2005).

3 For a discussion on how "social design" differs from "social innovation" and "social entrepreneurship” see Markussen (2017).
} 
or spatial design outcomes can mean that those increases are not easily transferable to design processes and outcomes. Additionally, while some processes may provide transformative outcomes in the context of a specific workshop activity, the social outcome may not translate to the design process, which might be facilitated weeks or months afterwards. Discussions had in one social capital building process - such as an icebreaker session - can be lost in the transition to a design mapping activity. Discussion surrounding feelings relating to cultural history, or personal experience relating to gender inequality, for example, might be put aside when, at a later date, discussion turns to implementation and costing procedures for a proposed design. Design projects implemented at the conclusion of the social design process can therefore be subject to the same patterns of social conflict, domination and suppression that necessitated the social design process in the first place (Frediani \& Boano, 2012).

Exploring new methods of design participation that integrate both social outcome and design processes can help alleviate this tension. The investigation of the threshold between social outcome and slum-upgrading outcome participatory design processes forms the central research problem of this dissertation.

\subsection{Research Approach}

This thesis explores how design strategies derived from speculative architecture, participatory design and serious gaming approaches might be brought together to enhance both social outcomes and related design (slum-upgrading) outcomes for urban slum dwellers.

As Johansson points out, the challenge often faced by engaging non-experts in design processes is that the "trained designer may use a pen and a piece of paper to illustrate his ideas while other stakeholders need other kinds of design material to be able to sketch" (Johansson, 2005, p. 17). Architecture has a long history of visualising future possibilities through "speculative architectures" designed to promote the consideration of alternate visions and possible futures and to scaffold discussions about what the future might look like. They can be, and have been, used as a means of imagining new possible ways of living as communities (Dunn, Cureton, \& Pollastri, 2014, p. 14). Speculative architectures are designed for the purpose of fantasising, discussing and challenging perspectives, values and assumptions on architectural, 
urban, social, political and environmental concerns. Speculative architectures can generate discussion and pluralistic visions of the future in order to defamiliarise situations to open up space for thinking about sensitive topics. Interestingly, some scholars have argued that speculation could hold a potential for participantinvolvement and collaboration in participatory design processes. As pointed out by Knutz, Markussen, \& Lenskjold, with few exceptions (Blythe \& Wright, 2006; Dindler \& Iversen, 2007), the question of the relationship between speculation or even fiction and participatory design remains largely unexplored (Knutz, Markussen, \& Lenskjold, 2016).

"Participatory design" is a collection of design approaches, methods, tools and techniques that are shared between many disciplines. In defining "participatory design", it is important to differentiate between a number of often conflated terms. While the terms "participatory design" and "co-design" are often used interchangeably in the literature, co-design is actually a particular type of participatory design whereby expert designers and people not trained in design work together in collective creative ways throughout the whole design process (Sanders \& Stappers, 2008). Participatory design is much broader and encompasses actions at different stages of the design process, as well as being applicable to the design process holistically. While participatory design was developed mainly for ICT development, it is today applied in a wide range of fields such as urban design, architecture, slum upgrading, product development, industrial design and service design. Participatory design tools, which include digital and physical games, mapping instruments, and visualisation systems among others, are used in participatory design activities to engage stakeholders in design thinking (Sanders, Brandt, \& Binder, 2010). They "scaffold" and "support collaborative [design] enquiry" and help to "bring together a network of actors with different backgrounds, competencies and experiences" (Brandt et al. 148).

Participatory design can be positioned within slum-upgrading processes in a number of ways. It can be used to understand the slum situation, establish networks for slum-upgrading work, undertake capacity building activities, prioritise interventions at neighbourhood level, and support the implementation of projects identified by the participants, which includes concept development and detailed design, construction and maintenance (Skinner et al., 2014, p. 15). These participatory design functions can be organised under four broad categories: to prime participants for a design process by encouraging the exploration of future visions or the building 
of social capital, to help diagnose or define problems, to generate design ideas and/or to evaluate design outcomes (Figure 2). They are generally used throughout the early stages of a slum-upgrading process in order to generate a desired social impact and/or to facilitate the collaborative exploration or development of design ideas (Lucero, Vaajakallio, \& Dalsga, 2012; Lynch, 1984; Sanders et al., 2010). This thesis reflects this in its scope.

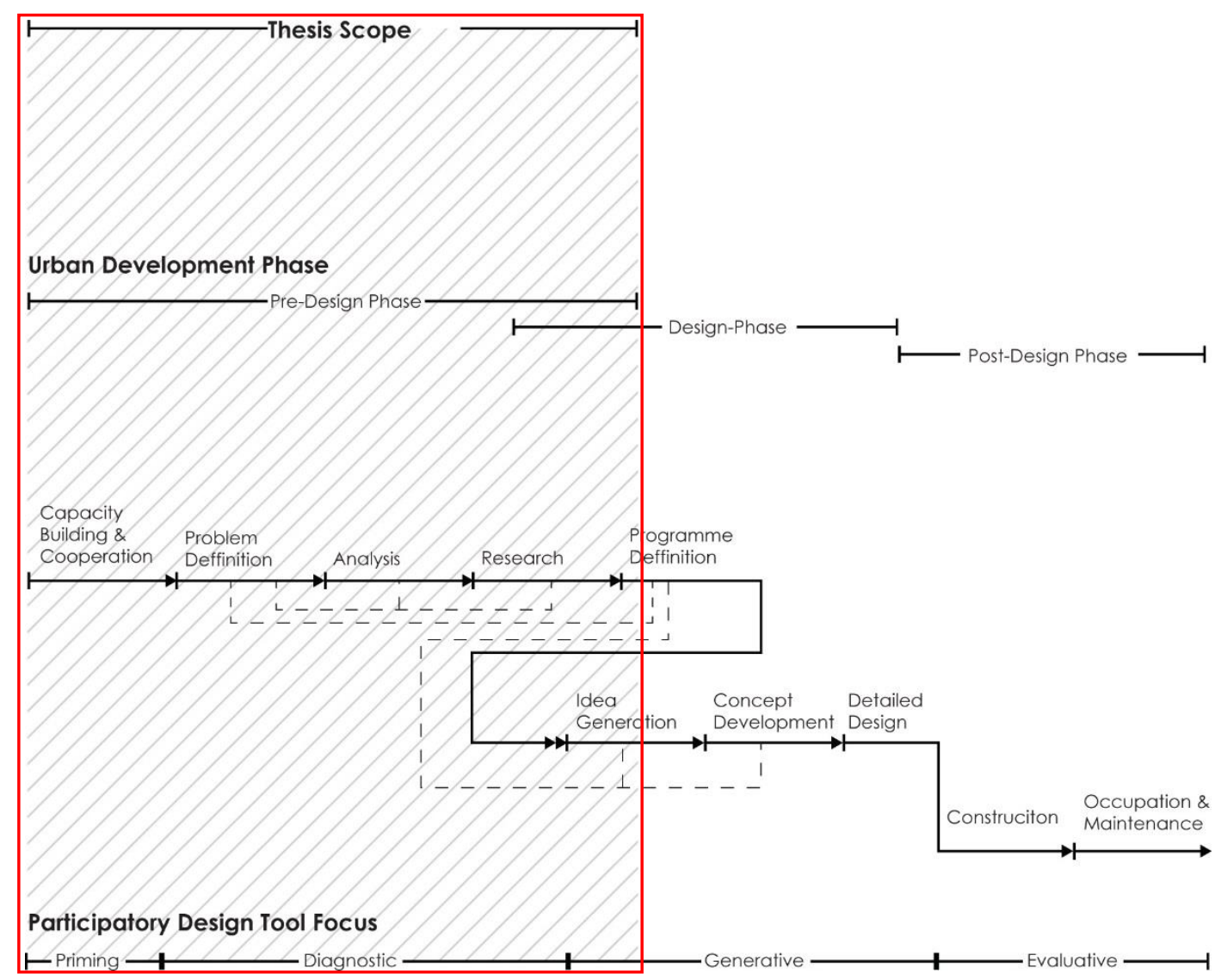

Figure 2. The research scope includes pre-design and some early design activities, specifically focussing on capacity building, problem definition, analysis, research, programme definition and idea generation, aligning with priming, diagnostic and generative participatory design activities. Adapted from (Lucero et al., 2012; Lynch, 1984; Sanders et al., 2010).

Recent developments in digital game creation software have opened up new research areas to explore the development of architectural serious games focussed on helping stakeholders explore conflicting perspectives, assumptions and corresponding future visions. Currently the development of digital urban design games is gaining prominence for their ability to draw stakeholders together in multiplayer environments, allowing players to collaboratively explore different perspectives, design alternatives 
and solutions in a medium with a low cost of failure (Poplin \& Vemuri, 2018; Shen, Ma, Sugihara, Lei, \& Shi, 2014; Vemuri, Poplin, \& Monachesi, 2014; Zhang, Shen, Wang, Kobayashi, \& Lin, 2017). Serious games are recursive, fluid, adaptable and responsive in their presentation of content and so are a promising medium for the development of speculative participatory design tools. Like other examples of new media approaches, serious games also offer new ways to gather data that is difficult to gather-such as tacit knowledge of participants about context-allowing for more comprehensively-informed and participatory decision-making processes. However most architectural and planning-oriented serious games tend to focus on "design outcomes" as the main objective (Ampatzidou et al., 2018; Mather \& Robinson, 2016; Poplin \& Vemuri, 2018; von Heland, Westerberg, \& Nyberg, 2015; Yamu, Poplin, Devisch, \& De Roo, 2017; Yan, Culp, \& Graf, 2011), while architectural and planningoriented serious games that focus specifically on implementing social change functions are much more scarce (Holland \& Roudavski, 2016; Vemuri et al., 2014). A lack of focus on the social dimension of serious games can limit constructive discourse surrounding goals and values that can lead to better idea exploration, discourse, decision making, and increases in consensus, cooperation and empowerment.

\subsection{Research Question and Aims}

Research Question: How can speculative architecture, participatory design and serious gaming approaches be brought together to enhance both social outcomes and related design (slum-upgrading) outcomes for urban slum dwellers?

\section{Research Aims:}

Aim 1: To identify how "speculative architecture" has enabled an exploration of possible futures, conflicting stakeholder perspectives, and corresponding goals surrounding social, architectural and urban issues.

Aim 2: To document how "participatory design" has enabled an exploration of possible futures, conflicting stakeholder perspectives, and corresponding goals surrounding social, architectural and urban issues. 
Aim 3: To question how "serious games" have enabled an exploration of possible futures, conflicting stakeholder perspectives, and corresponding goals surrounding social, architectural and urban issues.

Aim 4: To develop, implement and reflect on the use of a speculative, participatory, game-based approach to slum-upgrading in order to aid the generation of useful urban slum-upgrading oriented social outcomes and related architectural design slum-upgrading outcomes for disparate stakeholders in marginalised communities, more specifically, dwellers of landfill-oriented slums.

Aim 5: To generate insights, guidelines and recommendations for the future practice of a speculative, participatory, game-based approach in similar contexts.

\subsection{Research Design Overview}

To respond to the research question and aims, a qualitative Action Research methodology was used that was centred on case studies, that utilise participatory design workshops as a research method (Foth \& Axup, 2006; Frediani et al., 2011; Groat \& Wang, 2002; Pollastri, 2017; Reason \& Bradbury, 2001; Sanders, 2008; Silverman, 2015; Swann, 2002).

This approach was operationalised in participatory gaming workshops conducted with three case study (CS1-3) landfill-based slum communities in India. CS1 was conducted with the Ghazipur community in Delhi, CS2 was conducted with the Bhalswa community in Delhi and CS3 was conducted with the Shanti Nagar community in Mumbai.

This approach underlines the experimental nature and character of the work and provides a coherent way for discussing how the arguments are connected to the design work and to academic discourses.

\subsection{Outline of the Dissertation}

Chapter One lays out the research problem by detailing the current issues regarding participatory slum-upgrading processes. It defines the research context and scope. It 
defines social outcomes and urban upgrading outcomes within this context and scope and introduces speculative architecture, participatory design and serious games as the three strands of literature upon which Chapters Two and Three will draw. The research question has two main components (social outcomes and design (upgrading) outcomes). The first is in relationship to the social considerations of community members regarding the negotiation of conflicting perspectives and goals, and the second concerns slum upgrading as a design process that might be aided in a number of ways through collaborative ideation.

Chapter Two, Literature Review, responds to Aims 1 - 3 and positions the research within current discourses in participatory design, speculative architecture, and serious games. Chapter Two is divided into three sections. The first section addresses Aim 1 by reviewing how speculative architectural design strategies have been used to promote an exploration of conflicting stakeholder perspectives, to consider alternate visions and possible futures and to scaffold discussions about different futures might look like.

I first define speculative architecture as a future-focussed design genre that emphasises the importance of generating pluralistic visions of the future. I argue that speculative architectures have been a key instrument for designers to defamiliarise situations to open up space for thinking about sensitive or controversial topics. I review selected examples of speculative architecture in order to identify how previous speculative architectures have been used to critique the real world, how they have been legitimised and contextualised from the perspective of the viewer and how they have been framed to provoke urban, architectural social discourse. I then identify a number of strategies that can help facilitate an exploration of conflicting stakeholder perspectives, assumptions and corresponding goals surrounding architectural and urban issues. I highlight a disconnect between many works of speculative architecture and the context and people for which they are designed; the section indicates that many class, colonial and gender hierarchies and biases are often reinforced, thereby compounding inequality. The section concludes by recognising that, while speculative architectural projects have been internally valuable to architectural discourse and have raised important social and spatial issues for debate within the discipline, there are few examples of purposefully public-facing speculative architectures. Research regarding how speculative architecture can actively engage the communities it is addressing has been under-explored. 
The second section of Chapter Two addresses Aim 2 by considering how participatory design processes have been used to engage stakeholders and marginalised communities in both design and social capital building processes. Here, I address the complex semantic issues surrounding the term participatory design by defining and positioning it within current architectural discourse. I review the processes, techniques and tools employed by architects and designers to facilitate collaborative design and social capital building processes within impoverished communities. I argue that while participatory architectural design processes generally result in projects that are wellsuited to community needs, they often do not adequately allow for an exploration of conflicting stakeholder perspectives, assumptions and corresponding goals surrounding architectural and urban issues. Inadequately allowing for exploration can limit a group's ability to generate effective ideas, visions, concepts or solutions that benefit all inhabitants or users.

Finally, the third section addresses Aim 3 by first positioning serious games within the participatory design literature as a design tool for fostering collaboration between disparate non-expert participants via a collaborative digital medium. I next identify how digital games act as a medium for generative participatory design inquiries through a review of current approaches to serious games. I define key characteristics of serious games as effective tools for participatory social and slum-upgrading inquiries, as well as strategies for how they have resulted in either social and design oriented outcomes.

Chapter Three responds to Aim 4. In Section 3.1, I draw on the strengths of speculative architecture, participatory design and serious games to synthesise them into a "Speculative Participatory Serious Urban Gaming" framework or (SPS-UG). I then outline the action research approach and provide an overview of the research context. As noted in Section 1.6, empirical material for this research is informed by a computer game I designed and tested in three case studies with three landfill-oriented slum communities in India - Ghazipur, Delhi (CS1), Bhalswa, Delhi (CS2) and Shanti Nagar, Mumbai (CS3). I carried out research in these locations in association with external partners throughout 2017.

Chapter Four details the operationalisation of the SPS-UG framework and its application within the case study contexts. The chapter is composed of two sections. The first section details the documentation of each research context including the fieldwork procedures and analysis, while the second section details issues pertaining 
to the development of an SPS-UG for use in participatory design gaming workshops with the research communities. These include the creation of 3D assets and their composition into virtual environments and the definition of interactive game elements, mechanics and dynamics in line with the SPS-UG purpose of facilitating ideation and negotiation of conflicting perspectives.

Chapters Five - Seven document the experience of the three case study communities with whom I utilised the approach and methods outlined in Chapter Four.

Chapter Eight discusses the results arising from the computer game I designed and tested in all three case studies, their commonalities and the differences between them in relation to Aims 1-5. I discuss the method and the framework detailed in Chapter Three within the context of the research results. I then evaluate the approach is evaluated for its ability to generate both a range of social outcomes and design (slumupgrading) outcomes.

Chapter Nine concludes the dissertation by articulating key findings, insights and conclusions drawn from the learnings from the previous chapters and how they respond to the research question and aims. I critically reflect upon the implications of the research findings. Additionally, I discuss the implications for participatory design and community development, particularly for dwellers of landfill-oriented slums. I conclude by proposing directions for future research. 


\section{Literature Review}

The first three sections of this chapter position the research within current discourses in speculative architecture (2.1), participatory design (2.2) and architectural serious games (2.3), contributing specifically to the follow three research Aims:

Aim 1: To identify how "speculative architecture" has enabled an exploration of possible futures, conflicting stakeholder perspectives, and corresponding goals surrounding social, architectural and urban issues.

Aim 2: To document how "participatory design" has enabled an exploration of possible futures, conflicting stakeholder perspectives, and corresponding goals surrounding social, architectural and urban issues.

Aim 3: To question how "serious games" have enabled an exploration of possible futures, conflicting stakeholder perspectives, and corresponding goals surrounding social, architectural and urban issues.

The fourth section of this chapter (2.4) synthesises the literature into a framework that I call "Speculative Participatory Serious Urban Gaming" (SPS-UG), which is concerned with drawing together speculative architecture, participatory design processes, and serious games literature to address Aim 4:

Aim 4: To develop, implement and reflect on the use of a speculative, participatory, game-based approach to slum-upgrading in order to aid the generation of useful urban slum-upgrading oriented social outcomes and related architectural design slum-upgrading outcomes for disparate stakeholders in marginalised communities, more specifically, dwellers of landfill-oriented slums. 


\subsection{Speculative Architecture}

The important thing is not to offer any specific hope of betterment but, by offering an imagined but persuasive alternative reality, to dislodge my mind, and so the reader's mind, from the lazy, timorous habit of thinking that the way we live now is the only way people can live.

- (Le Guin, 2004)

\subsubsection{Introduction}

Speculative architectural representations of future urban environments and their associated ways of life contribute to our social imagery. They can be, and have been, used as a means of imagining new possible ways of living as communities (Dunn, Cureton, \& Pollastri, 2014, p. 14). Speculative architectural works are not intended to be built, but are designed for the purpose of fantasising, discussing and challenging perspectives, values and assumptions on architectural design, urban, and related social, political and environmental concerns. Such projects are often justified by arguing that they expand the territory of the discourse on what architecture might be (Pickersgill, 2017, p. 71).

The purpose of this section is to:

1. Define "speculative architecture" and key associated terms and attributes;

2. Review the approaches to generating future-oriented visioning through the design of speculative architecture;

3. Identify and analyse key speculative architectural strategies to help stakeholders explore possible futures, conflicting stakeholder perspectives and assumptions, and corresponding goals surrounding social, architectural and urban issues; 
4. Summarise the review by presenting relevant strategies derived from the literature that may be used in the design of effective speculative architectural visioning to address the Research Question.

\subsubsection{Defining Speculative Architecture}

Strategy SA-1: Consider the speculation's connection and position in relationship to plurality and temporality.

Implications for Research: This section discusses the temporal positioning of speculations within the possible or plausible temporal bands to help ground the speculation by creating a logical path from the present to the proposed speculative scenario, while facilitating a pluralistic temporal lens to challenge the viewer's assumptions through the proposed visualisation.

The use of the term "speculative architecture" was chosen for the purposes of this research for a number of reasons to differentiate speculative architecture from its many close relatives, such as visionary architecture, fantasy architecture, architecture fiction and paper architecture (Bingham, Carolin, Cook, \& Wilson, 2004; Gissen, 2009; Spiller, 2007). The intention of the research investigation is to provoke meaningful and useful debate that leads to social and design outcomes. Visionary architecture is not necessarily intended to provoke meaningful and useful debate, and examples that might provoke meaningful design or social debate do not necessarily deal explicitly with the future. The word "fantasy" faces a similar challenge, as it implies that the architecture is imaginary or not based in any perceivable reality or was conceived for entertainment purposes. The use of the word "fiction" in architecture also informs the viewer that the architecture is not related to reality and magnifies conjectural tendencies. While the term "paper" architecture explicitly implies architecture not meant to be built, it does not accurately reflect the current state of the largely digital architectural design practice. For these reasons, the term "speculative" is preferable as it suggests a relationship between 'here and now' and the speculative design proposal — which is considered important when considering slum-upgrading processes. Whilst the terms listed above overlap or lack commonly agreed definitions, they arguably share certain similarities in that they: "remove the commercial constraints that might normally limit the design process; use prototypes as the main 
method of enquiry; and use fiction to present alternative futures, pasts or presents to create space for thinking, questioning and dreaming" (Auger, 2012, p. 136).

Clear (2013) suggested in his article "Drawing Time" for the Drawing Architecture edition of AD magazine that "architects do not make buildings; they make a range of different types of representations that may be used in the construction of buildings or they may be used in a number of ways to create a wide array of spatial possibilities" (Clear, 2013, p. 72). Auger (2013) argues that speculative design projects primarily use visualisations at the heart of their inquiry to reframe discussions about alternative pasts, presents and futures. They allow observers of the speculation to not only consider how things might be, but also why things are the way that they are - as a way to reflect upon, critique or challenge existing powers, processes and systems (Auger, 2013, p. 2).

Self-described "speculative architect" Liam Young defines speculative architecture as a "future focussed domain of architectural design" that is focussed on creating "new narratives about how new technologies and networks influence space, culture, and community" (Young, 2017). Young asserts that in creating works of speculative architecture, designers "try to imagine where new forms of agency exist within the cities changed by these new processes" (ibid.). Design critic and science fiction author Bruce Sterling argues that speculative architectural projects use ideas for the built environment to express themselves in a way that is comparable to how storytellers use words (Sterling, 2012). Works of speculative architecture tell stories about cities, spaces and the possibilities of the future through architectural design. They also employ a careful balance of fiction and reality through more accessible visual language than conventional architectural representation (Auger, 2013). Speculative framing of architecture has also been used to help to disseminate ideas to much wider audiences than just those architecturally trained.

Some of the broader criticisms of speculative architecture are described below. Auger, whose research sought to formalise the methodology of speculative design, describes the term "speculative" as having "strong leanings towards conjecture or guesswork", meaning that works of speculation might be easily dismissed as not real or not worthy of careful consideration or critical thought (Auger, 2012, p. 137). Further, as Forlano and Mathew point out, much of the criticism faced by speculative design is directed at the elitist nature of speculative architecture and how non-expert audiences can struggle to engage with it (Forlano \& Mathew, 2014). 
The term "design" is used in a number of ways throughout this section. As Bannon and Ehn point out, one of the difficulties in any enquiry concerning the concept of design is that the term has so many different meanings that it can be difficult to determine exactly what kind of process, practice or product is being examined (Bannon \& Ehn, 2013, p. 40). In discussing speculation in this section, I refer to design as the creative process of designing generally in many cases - removed from the end product of the design process (i.e. a building, space or urban design) - as well as to the design process within the domain of architecture more specifically.

\subsubsection{Speculative Architecture and Plurality}

Discussing a plurality of possible futures through architectural speculations can lead to further understanding of the perspectives of others by challenging the viewer's assumptions through the proposed visualisation (Pollastri et al., 2017, p. 2). "Speculative design is distinct [from conventional architectural practice] in that it strives to open up a discursive space that is underwritten by the unavoidable plurality of the future" (Lindley, Sharma, \& Potts, 2014, p. 240). Design can convert ideas that exist in a plurality of possible futures into specific manifestations that are experienced in the present. Herbert Simon argued in his book The Sciences of the Artificial that "everyone designs who devises courses of action aimed at changing existing situations into preferred ones" (Simon, 1969, p. 111). Where built architectural design is concerned with existing situations and preferred design outcomes, speculative approaches generally acknowledge and work in full acceptance of the plurality of the future. Speculative architects engage in "prospective thinking" and try to create "new alternative images of the future-visionary explorations of the possible, systematic investigation of the probable, and moral evaluation of the preferable" (Toffler, 1978, p. $x)$. When designing architecture through a pluralistic temporal lens, "the audience is invited to engage and navigate the confluences and divergences in this complex dynamic space, in order to negotiate and trace out their most desirable paths ahead" (Rosenbak, 2019, p. 159).

Unlike the field of future studies, which specialises in corporate-orientated future visions, speculative design disciplines are not about anticipating what designs, spaces, relationships and technologies will be like. They are involved in provoking contemplation on possible alternate futures and using them as "tools to better 
understand the present and to discuss the kind of future people want, and of course, ones people do not want" (Dunne \& Raby, 2013, p. 2).

To highlight this separation between conventional design and speculative design practices, Dunne and Raby divide design into two broad categories: affirmative design and critical design. They posit that affirmative design encompasses conventional design practice and reinforces how things are now. Critical design, on the other hand, rejects the status quo as the only possibility (Dunne \& Raby, 2001). Pollastri expands these two categories by arguing that they can also be applied to other forms of design that explicitly engage with futures — such as speculative architecture (Pollastri, 2017, p. 50). Affirmative speculative design is primarily focussed on the development of future visions such as corporate design fictions as a form of foresight that explores future trends while simultaneously influencing areas of research, development, and investment, while critical speculative design is focussed on the design of future worlds or elements of future worlds as a way of critically questioning and provoking discussion on multiple possible futures and their implications (ibid.).

\subsubsection{Temporal Positioning of Speculative Architecture}

One of the most widely accepted temporal models used to position pluralistic works of critical speculative design is Joseph Voros's Foresight Framework (Voros, 2003). The framework was adapted from a taxonomy of futures developed by Henchley (1978) and first graphically represented (see Figure 3), as the "Futures Cone" by Hanckock and Bezold (1994). The framework provides a clear description of the multiple future possibilities and their degrees of probability - being categorised on a continuum that includes impossible futures at one end and probable futures at the other. This section outlines approaches to architectural speculations positioned within five temporal bands-impossible, possible, plausible, probable and preferable. 


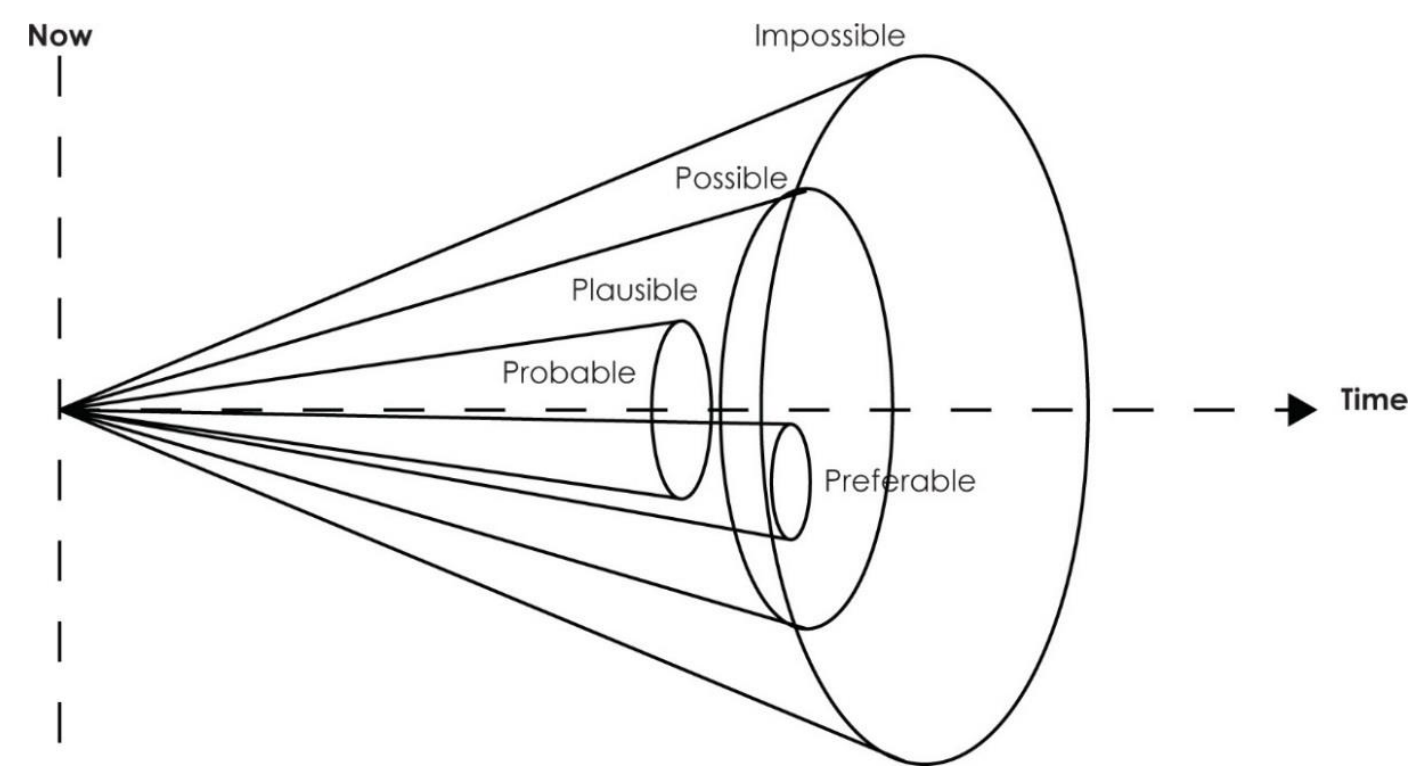

Figure 3. "The Futures Cone". Adapted from ( Hanckock and Bezold, 2003).

Impossible architectural speculations are those that are impossible based on current understandings of physical laws. In defining impossibility for the purposes of thinking about speculative architecture, Dunne and Raby draw on theoretical physicist Michio Kaku's definition of three classes of impossibility presented in his book Physics of the Impossible (2008). "Class one" impossibilities include technologies or systems that are impossible today, but that do not violate the known laws of physics (ibid.). "Class two" impossible speculations sit at the very edge of our understanding of the physical world, possibly taking thousands or millions of years to become available (ibid.). Finally "class three" impossibilities fundamentally violate the known laws of physics in some way (ibid.). This class of impossibilities might include speculations that require time travel or faster than light travel or buildings that violate a physical law such as Newton's law of universal gravitation. Speculations in this temporal band are not particularly useful for meaningful discussions leading to social and design outcomes, as they are too far removed from current reality (ibid.). Based on these definitions, a number of popular architectural speculations fall within the impossible temporal band, including fictional approaches to cities-ring worlds such as the Stanford Torus concept developed by NASA in collaboration with Stanford University, levitating cities, and space elevators, for example (Figure 4). This is generally the realm of superheroes, fantasy and entertainment, located in the far future and having little relationship to the actual world and therefore has little relevance to this thesis. 


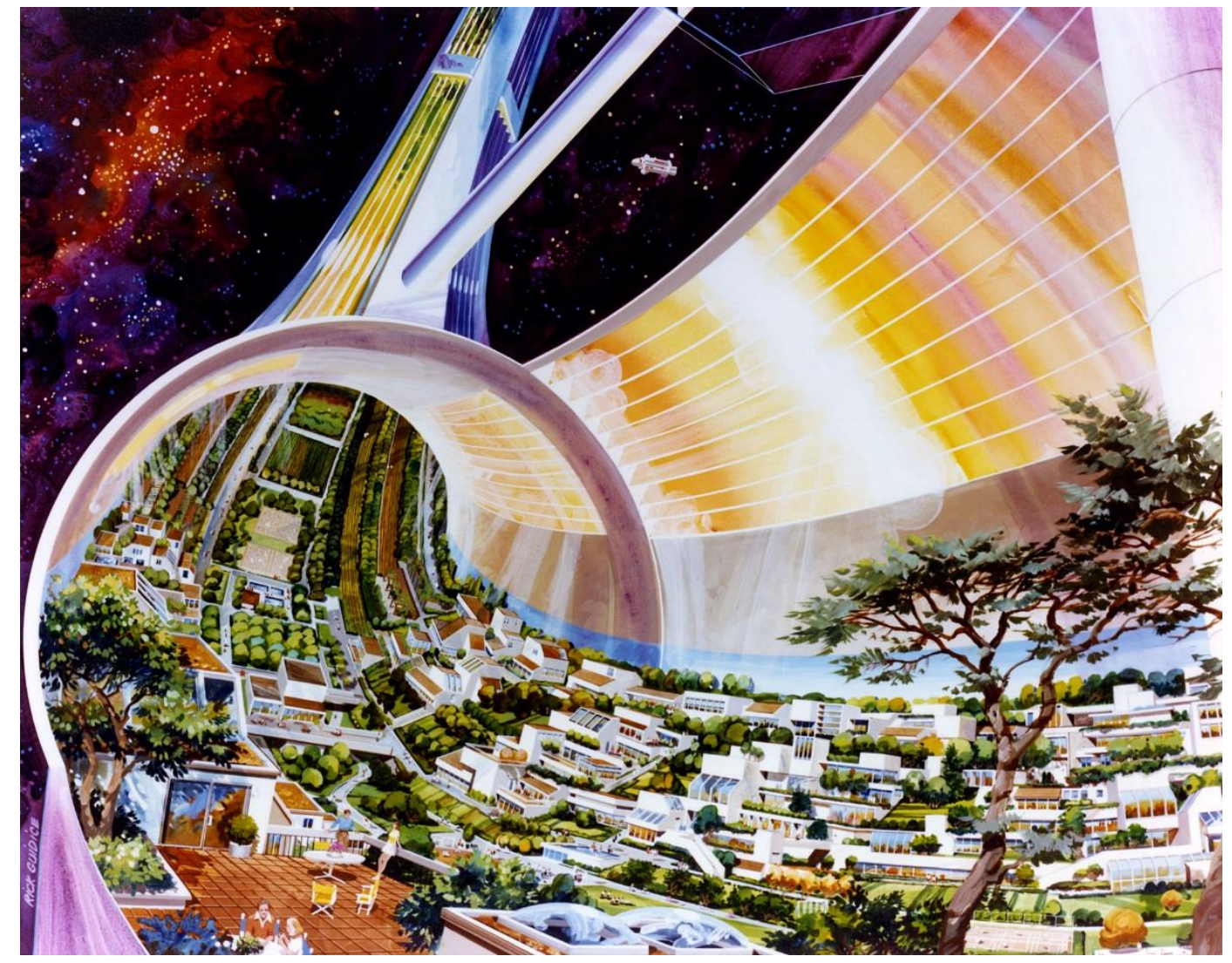

Figure 4. Stanford Torus cutaway view. NASA, 1975.

Possible architectural speculations are those that could happen but are improbable as they require either a large amount of knowledge to be attained first, or a large social or technological development to occur. For example, speculations such as Buckminster Fuller's Dome over Manhattan (1960) (see Figure 5), Ron Heron's Walking City (1964-1966) and Manuel Domínguez's Very Large Structure (2013) projected visions of the future focused on the mechanisation of the city through mobile architectures as a response to technological, environmental and social upheaval. While these technocratic futures are made more believable due to technological advancements and environmental pressures of the time, they still represent a significant departure from reality; however, possible speculations do have value as they question the status quo by highlighting risks, absurdities, and latent dystopias, and they provide unconventional alternatives to seemingly unavoidable outcomes. They often do this by pushing scenarios to their extremes and so have some relevance to this thesis (see urban extrapolations in section 2.1.4.1.2). 


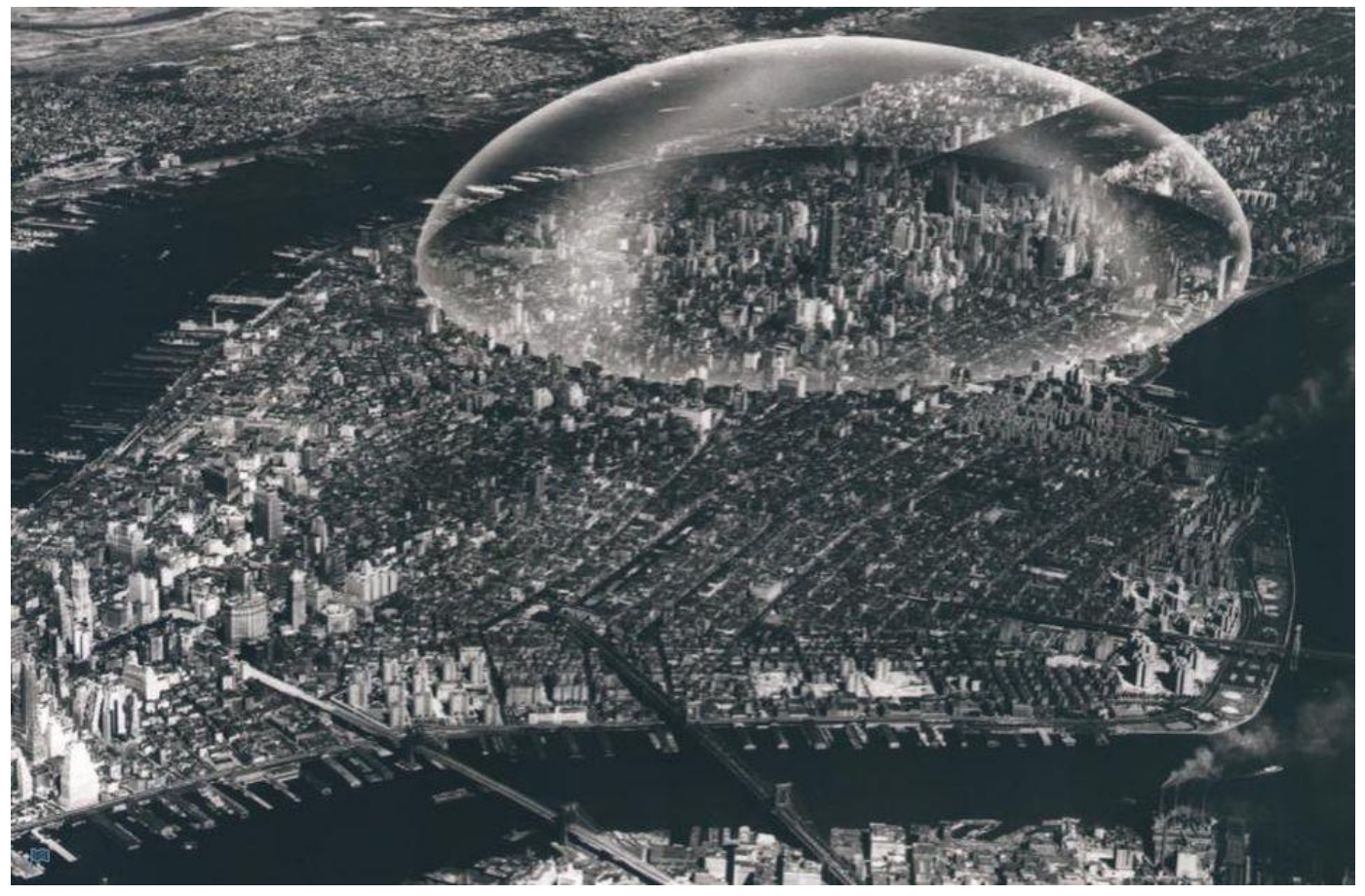

Figure 5. Buckminster Fuller, Dome Over Manhattan, 1960.

Plausible speculations are those that 'could' happen based on our current understanding of physical laws, technological understandings and social and political processes. Plausible speculations generally encompass foresight and scenario planning exercises and are not about prediction but about exploring alternative near-future situations (Dunne \& Raby, 2013, p. 4). Coulton et al. argue that it is the plausible and probable temporal bands that have most to offer when attempting to raise awareness or provoke discussion surrounding a speculative design that relates to the dual requirements of the research question of this thesis (Coulton, Burnett, \& Gradinar, 2016, p. 4). Similarly, Dunne and Raby claim that this is because plausible and probable scenarios generally have a logical path from the present to the proposed speculative scenario (Dunne \& Raby, 2013, p. 4). This path should encompass a believable series of events that led to the new situation, even if not entirely. This allows viewers to relate the scenario to their own world and to use it as an aid for critical reflection; however, it is important to note that the boundary between what is probable, plausible and possible is not a defined boundary, as different people might categorise a work of speculation differently. Additionally, Coulton et. al. point out that different attributes of a design situation might be considered plausible or probable depending on one's particular point of view (Coulton et al., 2016, p. 4). For example, Tange's 
radical scheme known as A Plan for Tokyo, 1960 - Toward a Structural Reorganization presented at the World Design Congress held in Tokyo in 1960 proposed to expand across Tokyo Bay at a time when many cities around the world were feeling the effects associated with urban sprawl (see Figure 6). Unlike other younger members of the Metabolist movement who presented fantastic distant future speculations and struggled to find acceptance of their works, Tange's speculation appeared to be more sophisticated and realistic and demonstrated that the idea of "city as process" could be carried through into a powerful, architectural language and thus gain widespread traction (Lin, 2007, p. 110).

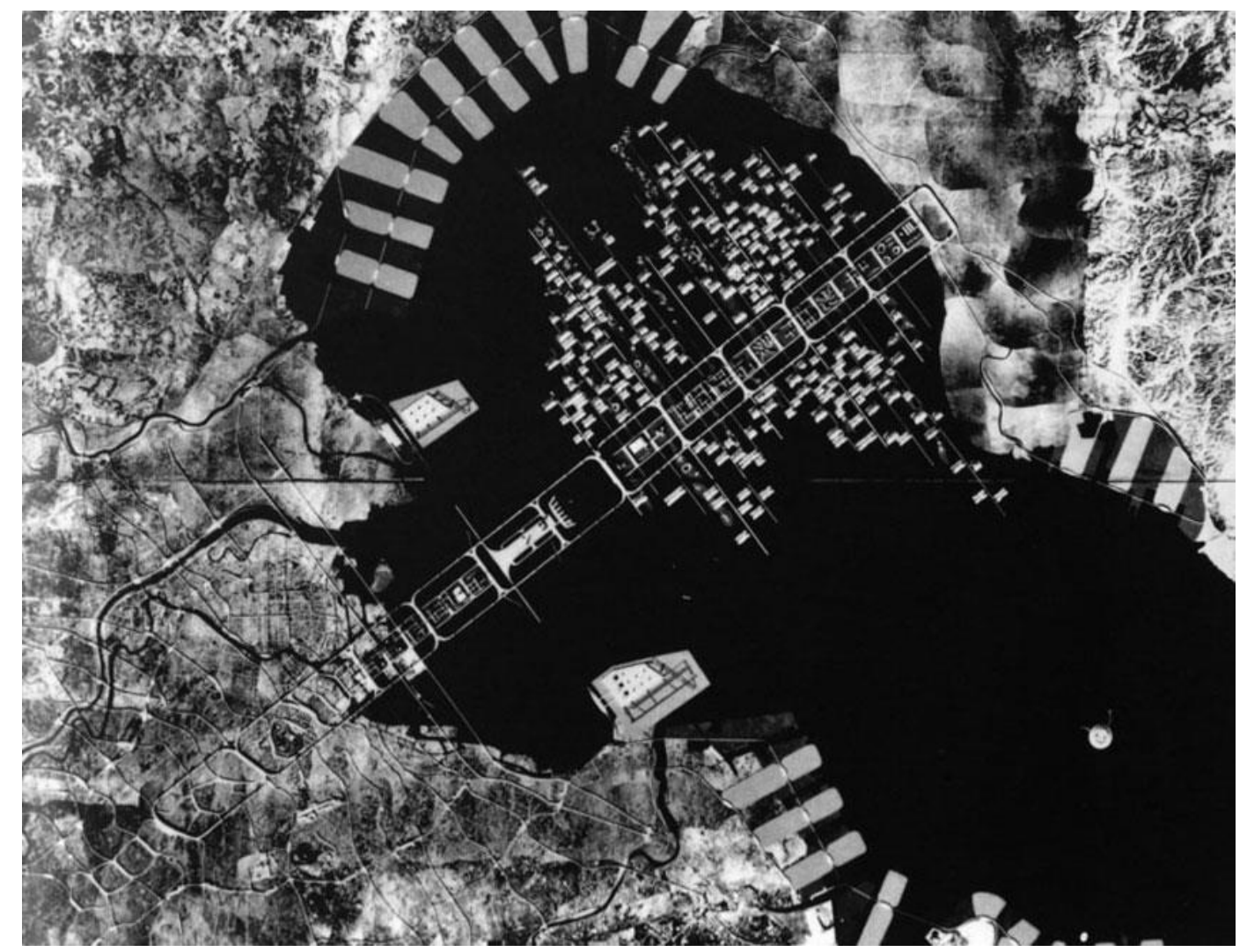

Figure 6. A plan for Tokyo 1960 by Kenzo Tange.

Likewise, Jeyifous, in his project Shanty Mega-structures (2016), juxtaposed the sprawling mega city of Lagos in 2050 with development of high-rise slum communities often displaced by urban development (see Figure 7). The project generated interesting discussion by presenting an extrapolation of the current urban environment of Lagos (Okwuosa, 2018). While the work was well received, it did create some confusion; Jeyifous stated in a CNN interview that "people will 
occasionally be inclined to confuse architecturally inspired artworks that make a social or political commentary with real-life, solutions-based design projects" (Gbadamosi, 2016). This assertion indicates that there can be a disparity between the designer's intention and how the design is received.

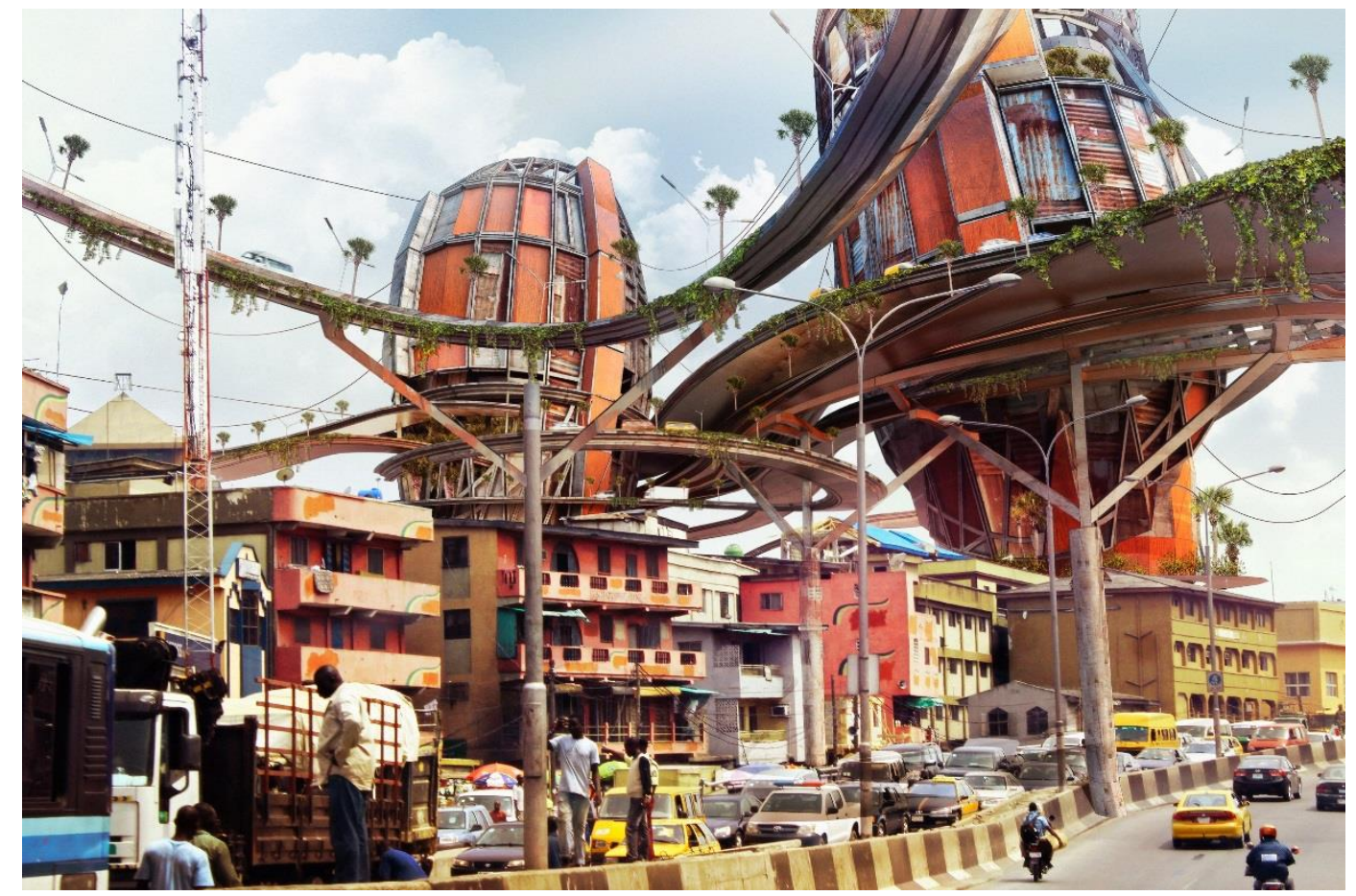

Figure 7. Architect Olalekan Jeyifous imagines what Lagos, Nigeria could look like in the future in his series Shanty Megastructures, 2016.

Probable architectural speculations are those that are likely to occur, usually based on (in many cases, quantitative) current trends (Voros, 2017). Most architectural projects are located within this temporal band and describe near-future scenarios that are likely to happen unless there is some extreme upheaval, and they are generally focussed on presenting very near future scenarios. This type is not of particular usefulness in the context of this research, as it represents the "business as usual" approach to architectural design.

Finally, Voros adds preferable speculations. These are those futures that one thinks 'should' happen. As preferable futures can intersect with the other temporal bands, Voros argues that these are based on normative value judgements as opposed to the mostly cognitive (Voros, 2017). 


\subsubsection{Ways of Speculative Architectural Worldmaking}

Speculation is based on the ability of the viewer to imagine possible alternate pasts, presents or futures, where the speculative design acts as a prompt for the imagining (Dunne \& Raby, 2013, p. 70). Speculative architectures employ a number of different methods of worldmaking, such as ensuring a balance between the fictional aspects of the speculation and real-world elements, composing them into new configurations. These include balancing the speculation and actual world referents, engaging viewers through typological familiarity and ensuring legitimacy of the speculation is maintained by ensuring internally consistent extensional expectations.

\subsubsection{Balancing Fiction and the Actual World}

Strategy SA-2: Ensure a careful balance of fictional and non-fictional elements.

Implications for Research: The review details how fictional attributes can allow speculative architectures to appear subversive, and create irreverent environments that are conducive to the exploration of ideas, which is a useful strategy for provoking both social and design oriented discussions.

Speculative architectures designed within each of the aforementioned temporal bands undertake a balancing act that is key to their success: the careful management of the "speculative" attributes that are in essence future focussed "fictions". If a speculative architecture strays too far from the actual world and presents clearly implausible concepts, the audience might struggle to relate to the proposal, resulting in a lack of engagement or connection. In a conventional sense, one might think of fiction as something completely unrelated to reality-something that is unreal. Conversely, Dindler describes fictional works as "not yet real", which implies more specifically a future relationship with time within what Ylipulli, Luusua, \& Ojala describe as a "hybrid reality" of speculative architecture (Dindler, 2010a, p. 73; Ylipulli, Luusua, \& Ojala, 2017).

As proposed by Malmgren in his book Fictional Space in the Modernist and Postmodernist American Novel (1985), fictional worlds are not stable constructs, but rather constantly emerging entities constantly recreated by differing viewers because of their different interpretations of the fiction - through what Neilsen, Phelan and 
Walsh call a "double exposure of the real and the imagined" (Doležel, 1998; Malmgren, 1985; Nielsen, Phelan, \& Walsh, 2015). The fluid state of these fictional attributes can allow speculative architectures to appear subversive, and create irreverent environments that are conducive to the exploration of ideas. This is a useful strategy for provoking both social and design oriented discussions.

\subsubsection{How is the Speculation in Architecture Legitimised?}

Strategy SA-3: Engage the viewers through typological familiarity in order to form perceptual bridges to ensure that the speculation connects with an identified audience's perceptions of the temporal world around them.

Implications for Research: The review highlights the importance of grounding the consideration of pluralistic pasts, presents and futures in the real-world experiences of the observer.

One of the key factors responsible for the legitimisation of a speculation from the perspective of the viewer is the careful management of the fictional attributes in relation to actual world referents (Auger, 2012, p. 140; Knutz, Markussen, \& Lenskjold, 2016). If the design strays too far into the impossible to present clearly implausible concepts, the audience may struggle to relate to the speculation, resulting in a lack of engagement, connection or discussion. Conversely if it is too familiar, the fiction is too easily assimilated into the normative, and thus the desired discursive space may not be facilitated.

Auger argues that in order for speculative design to be effective, a "perceptual bridge" must be created between the audience's perception of their world and the speculative representation that roots the speculation within people's everyday actual world. The perceptual bridge can fill the gap between the viewer's actual worldpresent a state of mind, technical knowledge, psychological perception and cultural background-and the speculation's world (Auger, 2012, p. 66). In doing so a perceptual bridge can ground the speculation by employing typologically familiar design elements to "ensure that it connects with an identified audience's perceptions of the temporal world around them" (Auger, 2012, p. 180). The strength of a speculation's perceptual bridge comes from achieving the right blend of factual authenticity from the present when scaffolding provocative future visions (Coulton et 
al., 2016). Once a perceptual bridge is created for the viewer, it can then be manipulated. Auger states that:

These perceptual 'bridges' can then be stretched in precise ways: this might be a technical perception such as extrapolating how they think a technology is likely to develop; a psychological perception such as not breaking taste or behaviour taboos; or a cultural perception such as exploiting nostalgia or familiarity with a particular subject. In this way the speculations appear convincing, plausible or personal, whilst at the same time new or alternative (Auger, 2012, p. 180).

Knutz et al. argue that if a perceptual bridge is well established, people may be willing to accept proposals that appear at first sight to be unfamiliar (Knutz et al., 2016).

\subsubsection{Ensuring Intentional and Extensional Legitimacy in Speculative Architecture}

Strategy SA-4: Ensure legitimacy of the speculation is maintained by ensuring internally consistent extensional expectations.

Implications for Research: The review shows the importance of the creation of coherent and legitimate speculations to enable the consideration of possible futures, conflicting stakeholder perspectives, and corresponding goals.

To enable constructive critique and discourse, a speculative possibility must have legitimacy in the eyes of the viewer. Kendall L. Walton's theory of make-believe, presented in his book Mimesis as Make-Believe, asserts that fictions "prescribe imaginings" and "generate fictional truths" (Walton, 1993, p. 39). Speculation functions in much the same way as fiction, in that "truths" are constructed from the foundation for acceptance of new interpretations of worlds and conditions.

Pickersgil argues in his article "Possibilia: Possible Worlds and the Limitless in Architecture" that "in a complex propositional world, such as those represented in many speculative architectures, there is a question regarding the extensional expectations of that world" (Pickersgill, 2017, p. 77). Extensionality, in this instance, means that the knowledge base of propositions can be checked against what is known 
and true about the speculation (ibid.), i.e. there is a logical chain from the present to the speculation and the speculation is internally consistent when advancing speculative truths.

Pickersgill also points out that in the absence of information provided, the extensional referents of the speculation adhere to the qualities of the actual world in order for it to have legitimacy (ibid.). In doing so, the speculation creates a reality that inherently presents, within the limits of the media, a maximally consistent possible world made of both speculative components and actual world referents (Pickersgill, 2017, p. 78). This means that architectural speculations should ideally be real in their world —or their intentional speculative properties — whilst also displaying extensional referents that make them appear to have family resemblances to other familiar worlds such as the actual world (Pickersgill, 2017, p. 78).

\subsubsection{Speculative Architectures to Promote Design Ideation}

Three main types of speculative architecture can be deduced, which are used in orientating the imaginings surrounding speculative architectures. These are utopias and dystopias, urban extrapolations and urban thought experiments.

\subsection{Utopias and Dystopias}

Probably the purest form of speculative worldmaking in architectural design is "utopia" and its opposite "dystopia" (N. Coleman, 2005; Levitas, 2013; Mitchell, 2010; Pinder, 2013). Lefebvre argues in his book Critique of Everyday Life that the use of utopias and dystopias in speculations is a way of imagining real possibilities out of what appear to be impossibilities in order to engage critically with the present (Lefebvre, 1991).

The 1920s and the 1960s resulted in two waves of utopian "communitarian" architecture in Europe. Some of the approaches such as Le Corbusier's Ville Radieuse (1924), or works by Italian futurist Antonio Sant'Elia, focused on emerging cultural conditions such as mobility and flexibility. Others such as Constant Nieuwenhuys's New Babylon (1959-74) and Yona Friedman's Ville Spatiale (1958-59) used utopias as instruments of societal change (Awan, Schneider, \& Till, 2013). Conversely, Archigram's technocratic consumerist cities including Plug-in-City, 1964, The 
Walking City, 1964 and Instant City 1968 extrapolated the technological advancement of the time. Similarly, Archizoom's No-Stop City (1969), an example of the Italian Anti-design movement, was an ironic response to Archigram's consumerist logic and their desire to detach architecture from politics. Like Archizoom, Superstudio (196678) were critical of mainstream architecture for ignoring and perpetuating social and environmental issues, designing critical projects that imagined dystopian worlds and using an infinite grid as a recurring motif for a continuous and uniform environment. Ant Farm's dystopian critique of the North American culture of mass media rejected those same notions of consumerism in their dystopian Clean Air Pod (1960) (see Figure 8) or their Inflatocookbook (1971) - an instruction manual for inflatables that constituted a type of participatory architecture that allowed the users to take control of their environment in the face of environmental concerns. TerreformOne's Rapid Re(f)use: Waste to Resource City (2009) envisions New York City in the year 2120 (Figure 9). The Rapid Re(f)use project supposes an extended New York reconstituted from its own landfill material and depicts a large-scale monument made from the garbage produced by New York City in one hour on a typical day.

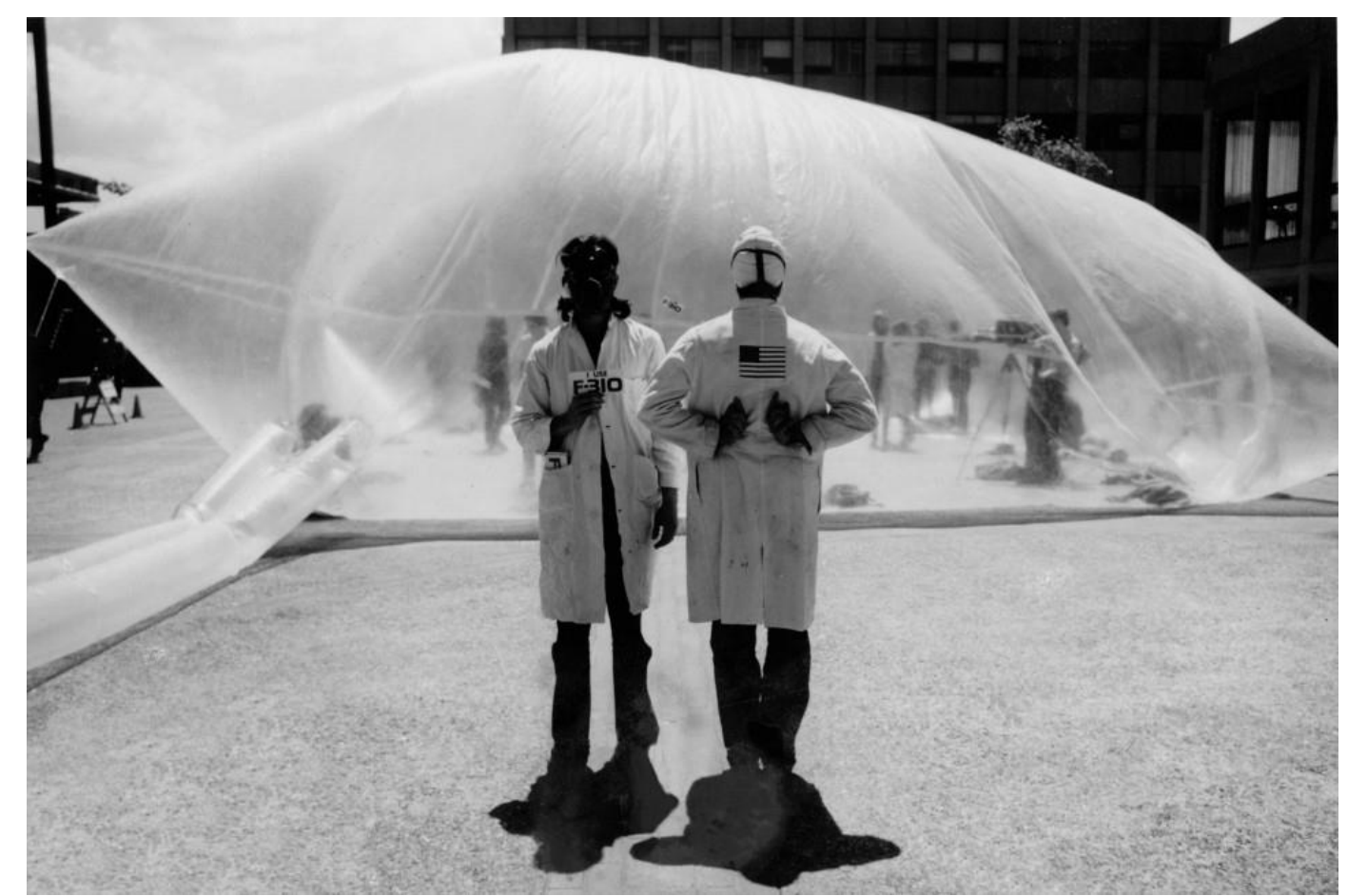

Figure 8. Clean Air Pod, Ant Farm, 1960. 


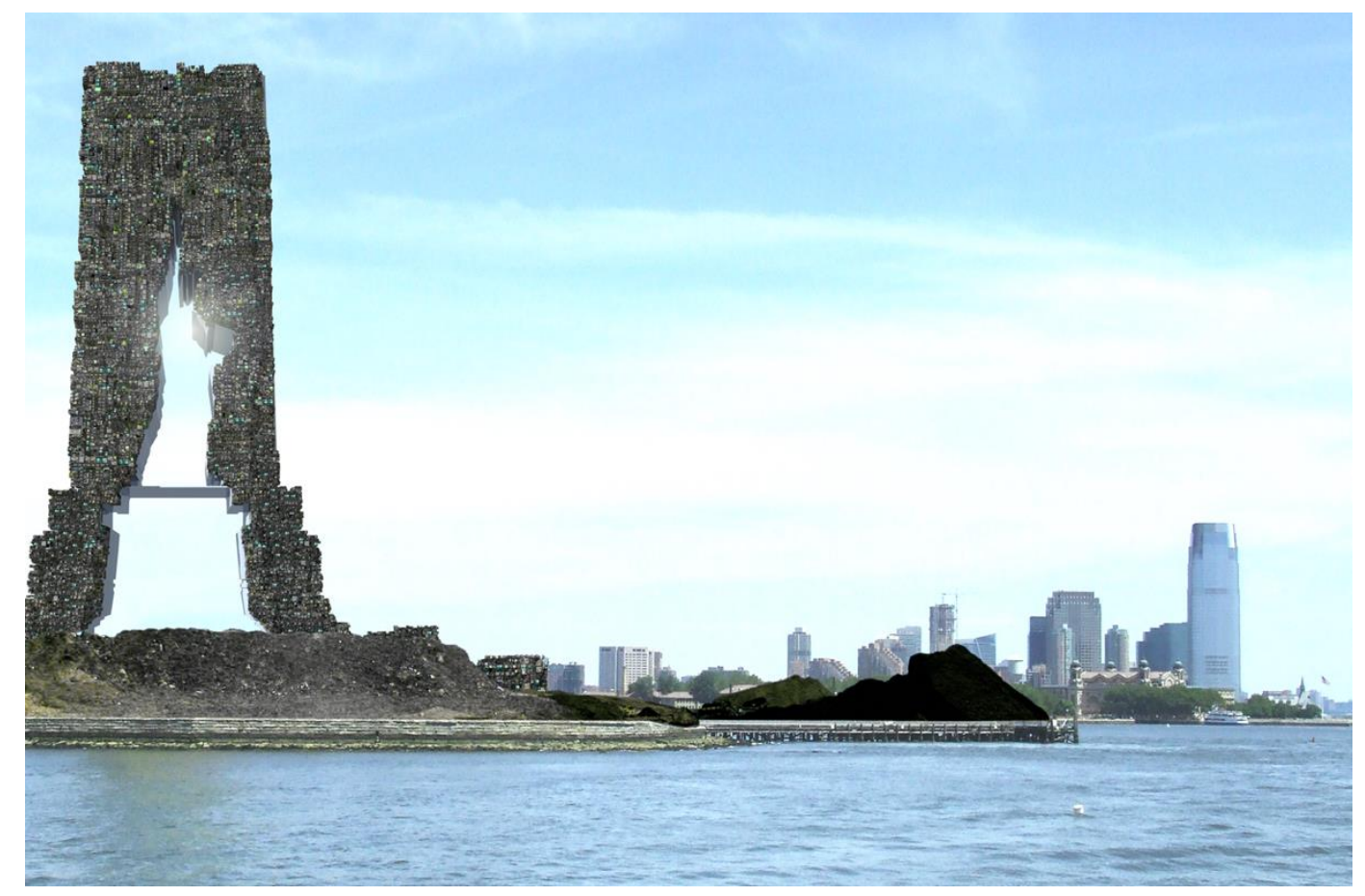

Figure 9. Rapid Re(f)use: Waste to Resource City, TerreformOne, 2009.

Darko Suvin uses the term "cognitive estrangement" to describe how alternate realities such as utopias or dystopias can aid critique of our own world through contrast (Canavan \& Suvin, 2016). However, the limitation of utopias and dystopias is that they are frequently viewed as a dangerous concept that resulted in Nazism, Fascism, and Stalinism, which are the fruits of utopian thinking (Dunne \& Raby, 2013, p. 73) or are dismissed by viewers due to the number of popular culture references-what Fear terms "dystopia fatigue" (Fear, 2017).

\subsection{Urban Extrapolations}

Many architectural speculations provide "extrapolations" or "what-ifs" based on current trends. Liam Young's speculative urban design project Under Tomorrow's Sky (2013) (Figure 10) assembled a think tank of architects, urbanists, scientists, technologists, futurists, illustrators and science fiction authors to collectively author a proposal for a future city - an imaginary urbanism, the landscapes that surround it and the stories it contains. "Emerging in the shadows of the decaying towers of a post oil Dubai, Under Tomorrow's Sky is imagined as a new terraformed urban island" (Young, 2013). Similarly, Jonah (2013) directed by Kibwe Tavares uses speculative 
architectural filmmaking to explore the socio-cultural impact of rapid tourism growth in Zanzibar (Figure 11).

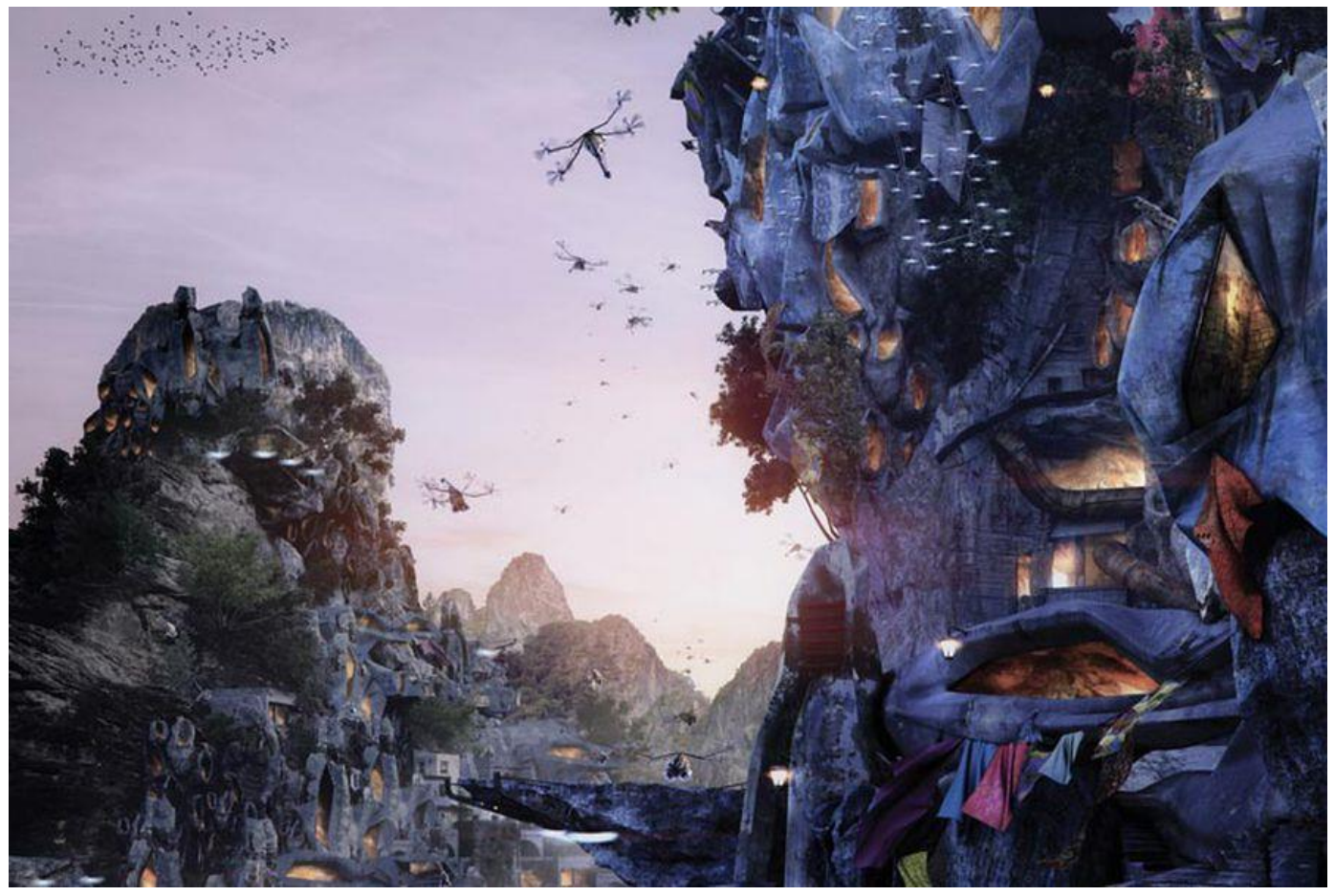

Figure 10. Under Tomorrow's Sky, Liam Young, 2013.

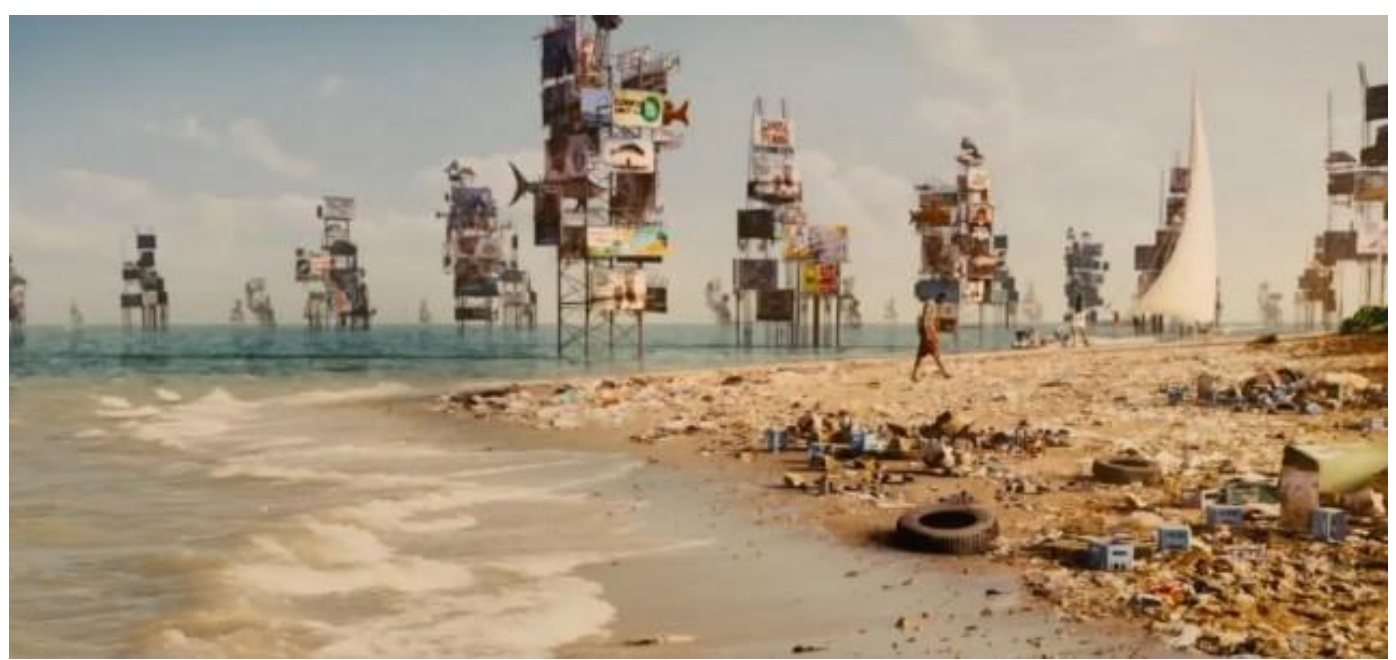

Figure 11. The film Jonah (2013, directed by Kibwe Tavares, explores the effects of tourism, globalisation, and commercialisation in Zanzibar through speculative architectural filmmaking.

\subsection{Urban Thought Experiments}

Another way of provoking thinking about what might be possible is to treat design speculations not as narratives or coherent "worlds" but as "thought experiments"- 
constructions, crafted from ideas expressed through design - that help us think about difficult issues (Dunne \& Raby, 2013), thought experiments such as presenting counterfactual architectures - those conceived after altering a historical fact to propose what might have happened - or taking generic propositions and pushing them to their logical extremes to derive an absurd or ridiculous outcome. The works of Léopold Lambert, described in his Weaponized Architecture (Figure 12), provide thought experiments by designing architecture as a political weapon. Lambert states that his goal is not to prove that architecture is always political, but to propose a discursive vision that is specifically filtered by its political and social implications to enlarge the field of the narratives that architecture carries (Lambert, 2010, 2011, p. 13). The work, which focuses on a dual programme for Palestinian farmers and the neighbouring Bedouin populations, addresses the fragmentation of the West Bank into areas, providing "ports" that are interpretable in the context of the nomadic way of life as counterfactual to the existing reality — an alternate reality.

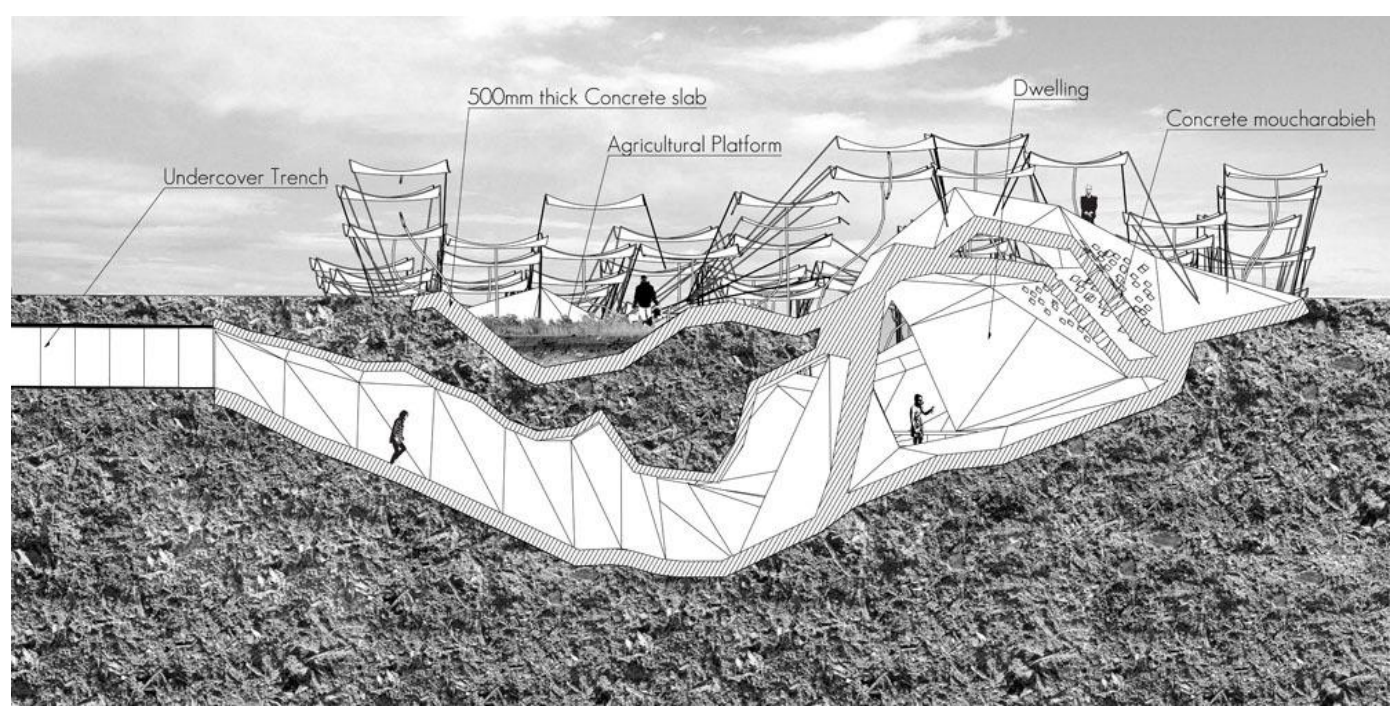

Figure 12. Weaponized Architecture, Léopold Lambert, 2010.

\subsubsection{Enabling Social Discourse Through Speculative Architecture}

Strategy SA-5: Ensure the design language and the medium of the speculation are appropriate to be both instrumental and externally focussed and discuss both social and design implications.

Implications for Research: This section discloses that speculations should be "externally" focussed in order to provoke exploration of possible futures, conflicting 
stakeholder perspectives, and corresponding goals amongst non-experts, while being examples of "instrumental" speculative architecture to produce insights into the viewers hopes, dreams, values, concerns and behaviours and thus both socially and slum-upgrading orientated.

In their book Discursive Design: Critical, Speculative and Alternative Things, Tharp and Tharp describe two orientations and two operational modalities of speculative design projects that can be used to frame how a specific work of speculative architecture is intended to drive discourse (Tharp \& Tharp, 2019). They describe speculative designs as both being internally or externally orientated and having an "instrumental" or "terminal" operational modality. These can be applied to the domain of speculative architecture in order to posit how different works of speculative architecture try to illicit and provoke discourse - by either prompting selfreflection, igniting the imagination, or affecting positive social change. These can be seen in Figure 13.

\section{Terminal}

\begin{tabular}{|l|l|}
\hline $\begin{array}{l}\text { The architecture is the terminus } \\
\text { of design activity. }\end{array}$ & $\begin{array}{l}\text { The architecture is the terminus } \\
\text { of design activity. } \\
\begin{array}{l}\text { Audience is the architecture } \\
\text { profession and related } \\
\text { disciplines. }\end{array}\end{array}$ \\
$\begin{array}{l}\text { Audience is those outside of } \\
\text { the architecture profession. }\end{array}$ \\
$\begin{array}{l}\text { The architecture is part of } \\
\text { other design activity. } \\
\begin{array}{l}\text { Audience is the architecture } \\
\text { profession and related } \\
\text { disciplines. }\end{array}\end{array}$ & $\begin{array}{l}\text { Tudience is those outside of } \\
\text { other design activity. } \\
\text { the architecture profession. }\end{array}$ \\
\hline
\end{tabular}

Figure 13. Positioning terminal-instrumental/ internal external Speculative Architecture. Adapted from (Tharp \& Tharp, 2019).

\subsubsection{Internally and Externally Oriented Speculations}


Tharp and Tharp describe internally oriented speculative projects as those used to help elicit reaction from other architects, critics, theorists, designers, engineers, marketers, executives, etc. They are generally not meant to be viewed or consumed by the public or the user group of the end design, and the focus of the criticality is largely directed at architecture itself (Tharp \& Tharp, 2013, p. 409). Many of the works previously described in this chapter, such as those by Archizoom or Superstudio, can arguably fall into this category as their critical practice is largely inwardly focussed, similar to the text-based field of architectural criticism. While useful for providing engaging visions of the future, the design does not have control over how information is gathered from the engagement process such as from observations or surveys.

Critics of this approach to generating discourse through speculative design have characterised it as often being "Eurocentric", highlighting its excessive focus on aesthetics (on the visual and narrative level), its vanity and its tendency to escape to dystopian scenarios and separate from the real world (Mitrović, 2016). In writing about internally orientated speculative design, Oliveira Prado's point out a "general disregard for race, class and gender within speculative design projects and publications" as a symptom of being inwardly focussed (Prado \& Oliveira, 2014). In line with this, some have argued that internally orientated speculations can often resort to reductionism of complex issues (Coulton et al., 2016). Cameron Tonkinwise, Head of Design Studies at the School of Design at Carnegie Mellon University, has criticised the lack of variation within the discourse and imagery of internally orientated speculative design practices, arguing that its white, intellectual, middle class, western-centric perspective stands in the way of truly engaging with meaningful debates about discrete and diverse futures (Tonkinwise, 2014, 2015, 2016). Pollastri argues that critical discourse surrounding internally orientated speculative architectural practice often uses the pronoun "we" to describe the whole of humanity while neglecting to acknowledge that visions of the world are not value-neutral, and no two 'cones of futures' are alike (Pollastri, 2017, p. 57). This is important as, in terms of temporality, there is no universal starting point for the futures cone (Tonkinwise, 2014, p. 174).

Conversely externally orientated speculative design projects are those that strive for impact beyond the domain of design experts by generating discourse that is external to the domain. Tharp and Tharp describe this form of design to generally be dealing with "non-design" topics and include those directly affected by the topics in the discussion. The goal of externally oriented speculative architecture is therefore not to use the 
design to communicate a critique of architecture itself. Instead design and the unique qualities of a specific speculative design are "leveraged as a unique brand of communication about issues beyond its traditional borders" (Tharp \& Tharp, 2019, p. 154).

\subsubsection{Terminal and Instrumental Operational Modality}

Typically, in speculative architecture a designer conceptualises, designs and instantiates a design in some physical or digital form — such as a drawing or physical model, for example. The speculative design is then released publicly, generally with the aim of generating discourse or engendering reflection about the design topic. Once the designer completes and distributes the speculative design, their job is basically finished; the hope of reflection and transformation is fundamentally beyond their control. This is what Tharp and Tharp refer to as a "terminal" form of speculative design - where the speculative design is the terminus of the designer's direct control.

Conversely there is growing discourse moving instead in the direction of "instrumental" speculative projects that behave similarly to participatory design research tools - explicitly framed to engage potential users and hopefully produce insight into their hopes, dreams, values, concerns, behaviours, etc. (Tharp \& Tharp, 2013, p. 408). This type of design includes the observer as an active contributor to the speculation. While much of the exploration of this type of instrumental speculative design has been in the creation of physical representations of speculative designs, some authors have been exploring this form of speculative design in media more conducive to the observer being an active contributor-such as digital games (Baumann, Stokes, Bar, \& Caldwell, 2017; Coulton et al., 2016; Forlano \& Mathew, 2014; Lindley et al., 2014; Rynning, 2017). Tharp and Tharp refer to this as instrumental speculative design (Tharp \& Tharp, 2013, p. 408). Instrumental speculative architectures are therefore those used differently than simply to project a vision of the future; they are more of a probe used to evoke user responses, unveiling views that may be difficult to assess otherwise (ibid.). Here the research value is not the speculative architecture itself but instead the subsequent conversation that it engenders. The design acts as a discussion instrument for some other means, and the designer/researcher is an active participant. Tharp and Tharp argue that in forming instrumental designs, ambiguity can be intentionally leveraged (ibid.). This is useful because, as Gaver et. al. discuss, 
ambiguity allows designers to "suggest issues and perspectives for consideration without imposing solutions... to raise topics or ask questions while renouncing the possibility of dictating [users'] answers" (Gaver, Beaver, \& Benford, 2003, p. 240).

\subsubsection{Agonistic Speculative Architecture as Discursive Provocateur}

Strategy SA-6: Ask questions through the speculative design language, instead of providing solutions, in order to enable open discussion in which diverse perspectives are able to be brought forward, contested and discussed.

Implications for Research: The review extends the focus of speculative architecture from merely creating discourse, to purposely eliciting conflicting voices in constructing pluralistic speculative visions through an external instrumental approach. This has implications for enabling the exploration of possible futures, conflicting stakeholder perspectives, and corresponding goals amongst disparate groups.

An external instrumental approach to speculative design, which has much in common with "agonistic" speculative design and employs agonistic theory developed by Mouffe (2000b) and detailed in Section 2.2.4.2, allows for the creating of spaces for discussion and imagination of multiple possible futures by provoking a condition of pluralism and contestation through design that avoids presenting totalising hegemonic future "solutions" in the name of generating "consensus" (Leeuwen, 2015, p. 800). Agonistic pluralism is often linked to speculative design disciplines through Carl DiSalvo's (2012) concept of adversarial design, which DiSalvo describes in his book Adversarial Design as: "Rather than framing the conflict as among enemies that seek to destroy one another, the term adversary is used to characterize a relationship that includes disagreement and strife but that lacks a violent desire to abolish the other" (DiSalvo, 2012, p. 6). Agonistic design reveals its roots in the Greek word for struggle or competition, "agon”, which Roger Caillois explains in Man, Play and Games (1961) as one for the four types of games - the others being "alea" or chance, "mimesis" or role playing and "ilinx" or vertigo, in the sense of altering perception (Caillois, 1961; DiSalvo, 2012, p. 6). In this way, adversarial design draws on this game-like situation to provide a platform for disparate "individuals, organisations, ideologies and actions" to engage in discourse surrounding sensitive or controversial issues (DiSalvo, 2012, p. 52). By posing questions, as opposed to solutions, to viewers through design, 
adversarial design can nurture a plurality of speculative ideas and futures and enable open discussion in which diverse perspectives are able to be brought forward.

Recently, there have been more attempts at including conflicting voices in constructing pluralistic visions for urban futures by giving agency to those affected by the design and by designing instrumentally external speculative design. These are designed to contextualise discussions and provoke debate about speculative pasts, presents and futures. For example, Laura Forlano and Anijo Mathew use a combination of speculative design techniques and co-design methods to explore how "design frictions"- or the conflicts, tensions and disagreements provoked by instrumental and external speculative design-can move complex socio-technical discussions embedded in urban infrastructures forward (Forlano \& Mathew, 2014). They detail how speculative design can engage participants in contestations about urban values that can be used to create "constituencies" around important "matters of concern" (Forlano \& Mathew, 2014, p. 20). Similarly, the Liveable Cities project, presented by Pollastri et al. (2017), focuses on ways of visualising possibilities for life in future cities by combining speculative design practice and agonism through an approach called "Visual Conversations on Urban Futures" (VCUF). The approach uses building blocks, mapping, participatory design methods and information visualisation techniques that engage participants in developing visions of urban futures (Pollastri, 2017; Pollastri et al., 2017). Through co-created speculations and "composite scenarios", the approach is able to capture the complexity of the discussions and showcase divergent, conflicting ideas, rather than just synthesising the results into a single, narrative vision.

The Million Dollar Blocks project (see Figure 14) by Laura Kurgan at the Spatial Information Design Lab at Columbia University provides an example of agonistic design. It uses designed maps to document patterns of incarceration and urban development, which serve as discursive objects that raise questions and proffer implicit judgements about allocation of capital and social resources within cities (Kurgan, 2012). The Million Dollar Blocks questions, and challenges, conditions and structures in the urban environment; it opens a space for contestation by challenging assumptions surrounding the question: "Where does the prison population come from?" (ibid.). 


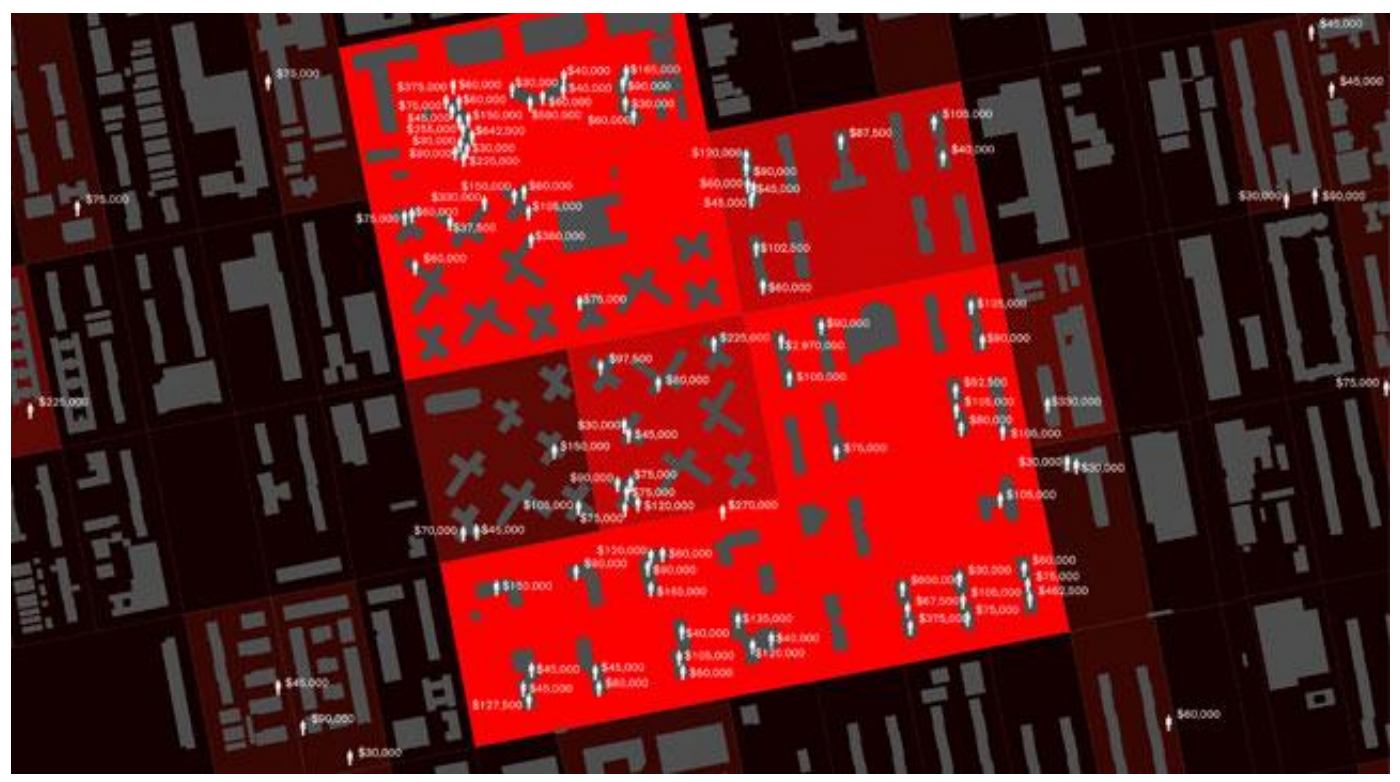

Figure 14. Million Dollar Blocks, Laura Kurgan, 2012.

Lebbeus Woods's Underground Berlin (1993) and his Radical Reconstruction proposal for Sarajevo (1993-1994) can be considered works of agonistically oriented speculative architecture (Figure 15). The projects propose architecture designed to invoke discussion about social structures on either side of the Berlin Wall and after the war in Bosnia and Herzegovina, respectively. His stated purpose for doing so was to (indirectly) liberate the under-privileged within the existing, tumultuous, socio-urban structures, by influencing architects dealing with the pragmatics of reconstruction to consider other potential spatial arrangements and thereby engender social healing (Fahey, 2013, p. 131). Woods invited autonomous interpretation and use through his concept of "freespaces", which are architectural spaces that must be: "1) free of preassigned purpose or meaning and 2) difficult to inhabit; intended for those willing to invent ways to inhabit them" (Woods, 2009). Freespaces therefore provoke the viewer to interpret them as they see fit. 


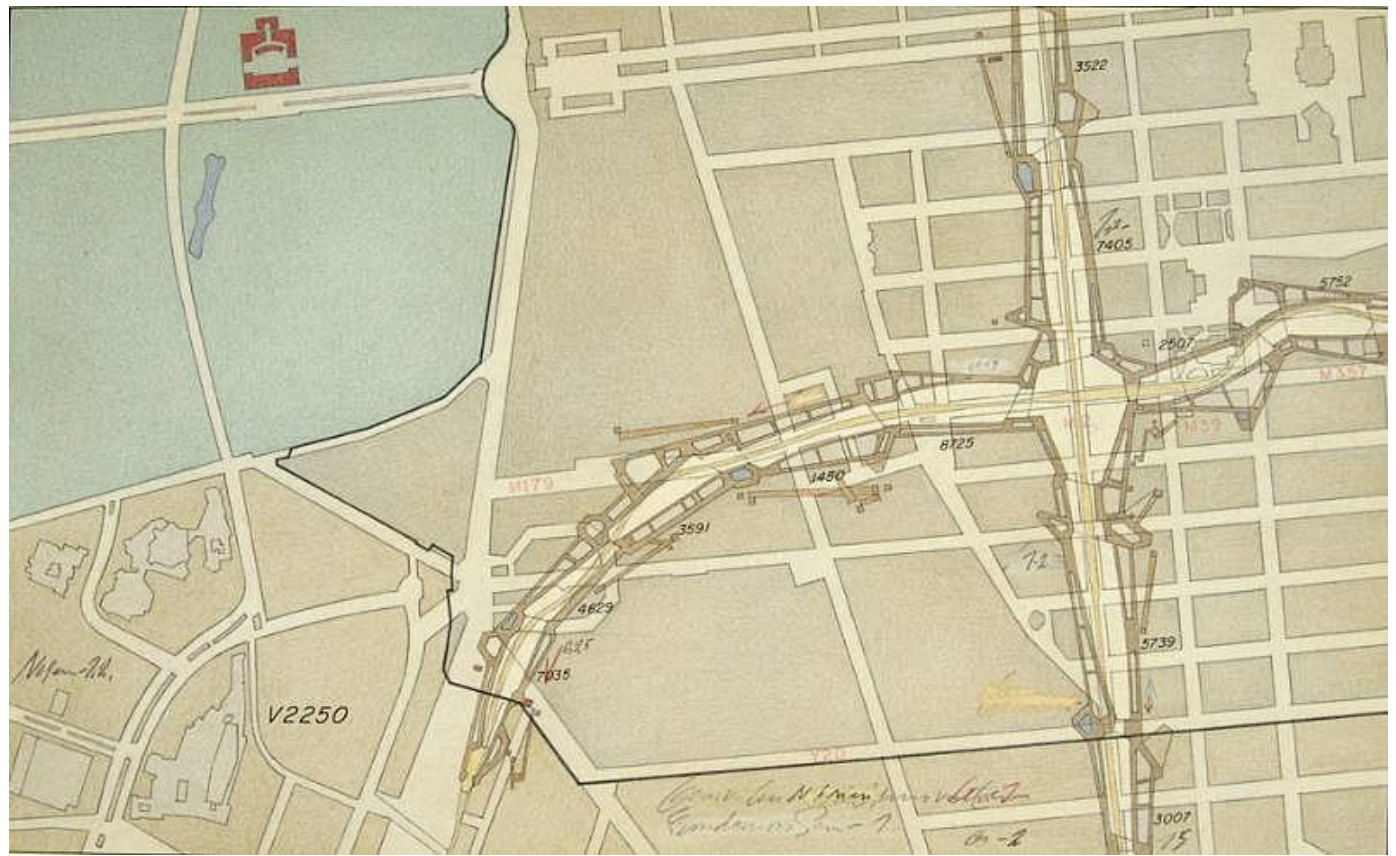

Figure 15. Underground Berlin 3, Lebbeus Woods, 1988.

Indicative of this, Woods's Sarajevo proposal, which could be described as both terminal and instrumental speculative design, was not about returning the city to its original state, or even a new definitive state at all, but about a transformation of society, politics and economics through architecture (Woods, 2007). Fahey argues that the extent to which Woods deals with social concerns in this theory is best captured in his concept of the 'heterarchical', a central proponent of his concept of free interpretation (Fahey, 2013, p. 132). Woods defines "hierarchy" as a 'religious-moral precept' of the 'patriarchal world view' and "heterarchy" as "the system of stasis, predictable patterns, determinacy, and unidirectional communication" (Woods, 2004). Woods designed spaces free of predetermined purpose that could be programmed by the transformed community corresponding to the new post-war conditions. The "visible signs of change become sites of transition in the process of creating a new as-yet-unknown social order" (Woods, 2004, p. 26).

\subsubsection{Participatory Speculation}

While speculative architecture is aimed at provoking debate and inspiring a diverse range of possibilities, it often does not succeed because of who is invited to participate in it. Recently “participatory speculation” has been gaining prominence as an approach to engage people in the crafting of the speculation (Clarke et al., 2018; Gerber, 2018; 
Jones, 2019). Participatory speculation involves using knowledge generated through research about a context — people, cultures, materials, histories, industries, and infrastructure - and then re-configuring this with the relevant people to speculate on alternative possibilities for that context. Generally, the approach includes developing a selection of provisional artefacts in the form of low-fi prototypes, and future scenarios from a participatory workshop to scaffold the speculation.

For example, Gerber, (2018) used a participatory speculation approach to engage community members in Ferguson, USA in imagining the design of urban environments that are kept safe without policing. Speculative props were designed to materialise community members' visions and to provoke conversation around utopias and their negative implications (see Figure 16).

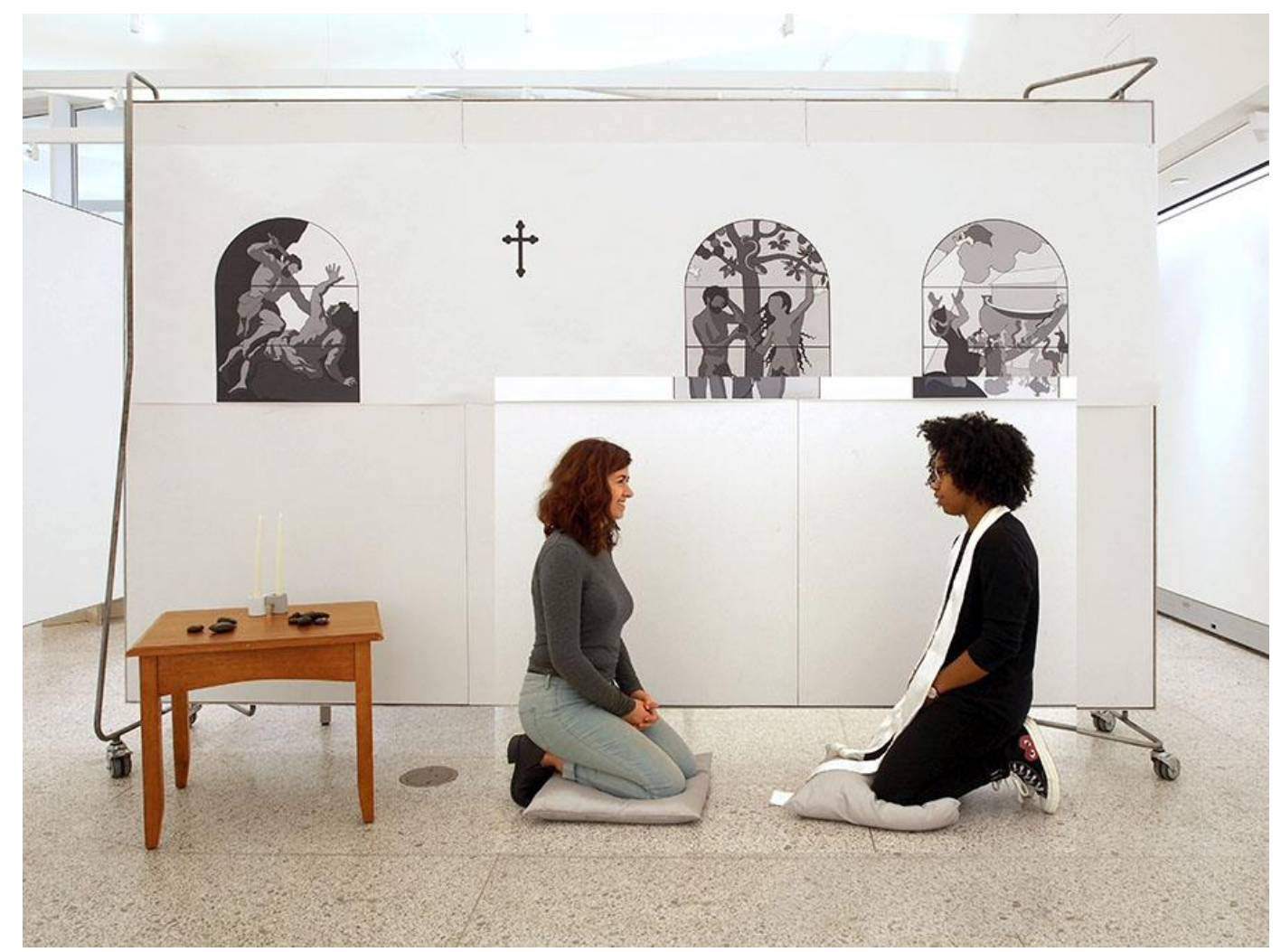

Figure 16. Future of Hearts and Minds scene (Gerber, 2018).

Similarly, Clarke et al., (2018) used a participatory speculation to explore different perspectives for smart cities to push forward a cultural change in relation to sustainable smart cities. The research focussed on using low-fi prototypes, and future scenarios to provoke the participants into situated participatory speculation during a group walk through Hasselt, Belgum (refer to Figure 17). 


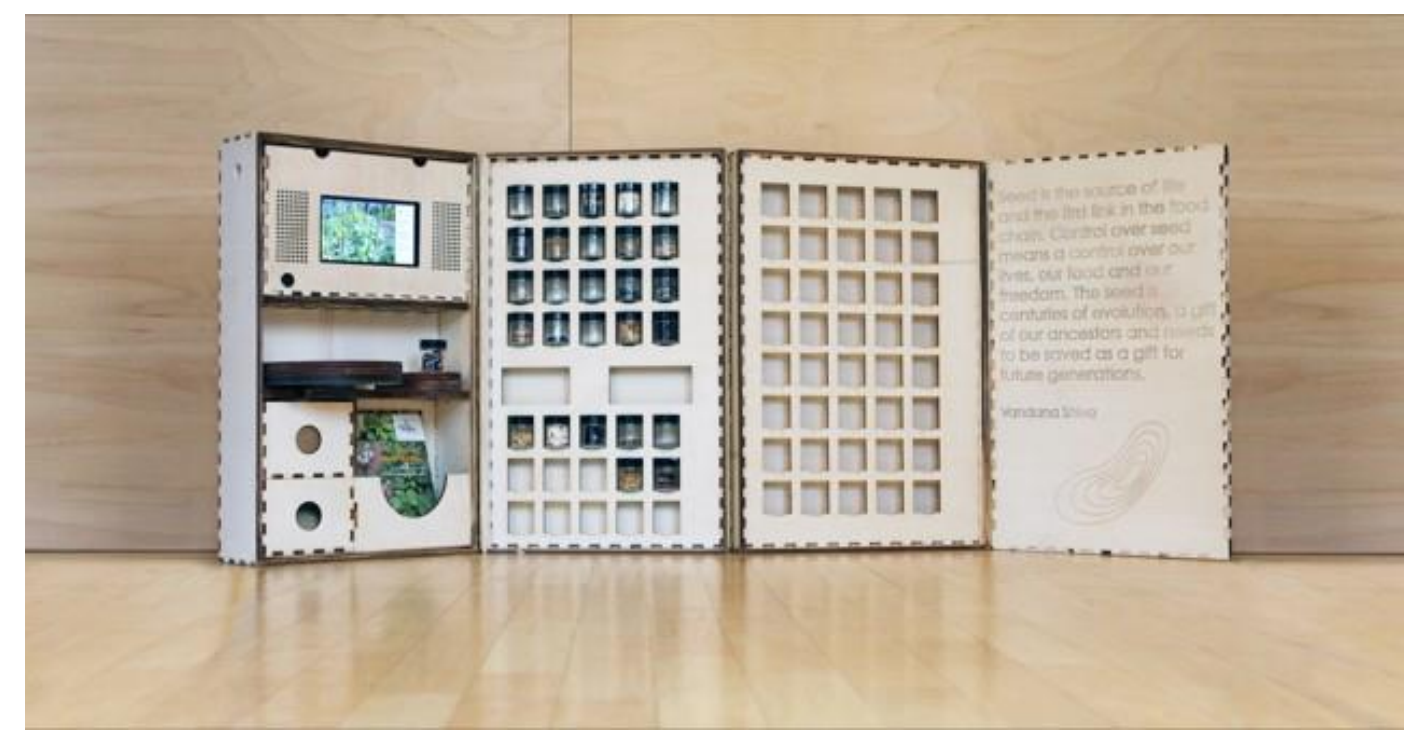

Figure 17. Driverless City: Scenario builder, mind map and visualisation to support citizen conversations for a future with driverless cars (Clarke et al., 2018).

While the existing practice of participatory speculation has explored engaging people in the co-creation of speculative visions, it lacks the fidelity of representational techniques, and the ease at which the participants can develop representations and test a range of speculative ideas or scenarios.

\subsubsection{Summary}

This section has summarised how speculative architecture has been designed to promote the consideration of alternate views and possible futures, and to scaffold discussions about what the future might look like. The chapter started by adopting a definition of speculative architecture that emphasises the importance of generating pluralistic visions of the future to defamiliarise situations to open up space for thinking about sensitive topics through multiple lenses. The section discussed temporal positioning and located examples of speculative architectural projects within temporal bands.

Designing externally oriented instrumental speculative architectures that are interested in involving the public as active co-creators has opened up new opportunities for arriving at design and social outcomes and exploration of possible futures, 
conflicting stakeholder perspectives, and corresponding goals surrounding social, architectural and urban issues; however, limited examples exist of purposefully engaging non-experts in speculative architectural design.

From this speculative architecture literature review, six strategies can be adapted from the literature that can help disparate stakeholders explore conflicting perspectives, assumptions and corresponding goals surrounding architectural and urban issues:

Strategy SA-1: Consider the speculation's connection and position to plurality and temporality;

Strategy SA-2: Ensure a careful balance of fictional and non-fictional elements;

Strategy SA-3: Engage the viewers through typological familiarity in order to form perceptual bridges to ensure that the speculation connects with an identified audience's perceptions of the temporal world around them;

Strategy SA-4: Ensure legitimacy of the speculation is maintained by ensuring internally consistent extensional expectations;

Strategy SA-5: Ensure the design language and the medium of the speculation are appropriate to be both instrumental and externally focussed and discuss both social and design implications;

Strategy SA-6: Ask questions through the speculative design language, instead of providing solutions, in order to enable open discussion in which diverse perspectives are able to be brought forward, contested and discussed.

The temporal positioning of speculations within the possible or plausible temporal bands help to ground the speculation by creating a logical path from the present to the proposed speculative scenario, while facilitating a pluralistic temporal lens to challenge the viewer's assumptions through the proposed visualisation. Speculative worldmaking strategies, which are employed in creating coherent speculative propositions to enable viewers to imagine other alternatives and the importance of grounding the consideration of these pluralistic pasts, presents and futures in the realworld experiences. Speculations can be "externally" focussed to provoke exploration of possible futures, conflicting stakeholder perspectives, and corresponding goals amongst non-experts, while also being "instrumental" to produce insights into the viewer's hopes, dreams, values, concerns and behaviours. Within the context of this 
research investigation, speculative architecture should purposely elicit conflicting voices in constructing pluralistic speculative visions through an external instrumental approach. In order to operationalise speculative architecture in this manner, there is a need to learn from participatory design, which I review in the next section. 


\subsection{Participatory Design}

Diversity encourages creativity, while repetition anaesthetizes it. Often architecture is too homogenous, sometimes because of a selfcentered desire to see buildings apart from their context, sometimes because of an exaggerated aesthetic commitment, which tends to a precious architects' architecture. But whatever the cause, such homogeneity makes it difficult for the users to add anything on their own, and we lose that rich source of popular creativity, which can transform a space into a place and give it life. If we were able to obtain the space and the means to allow the inhabitants to organize their own buildings, they would by their own efforts generate both the diversity and the close relations to the fabric which is lacking.

- (Kroll, 1986, p. 175)

\subsubsection{Introduction}

As introduced in Chapter One, over the past two decades a shift has taken place towards "participatory" slum upgrading where residents are increasingly involved in the decision-making process of upgrading as project partners (Cities Alliance, 2010; French et al., 2018; MacPherson, 2013; Minnery et al., 2013; Perten, 2011; Pugh, 1995, p. 381; Rigon, 2014; The World Bank Group, 2001; UN-Habitat, 2016a). Generally, "participatory design" techniques are used in participatory slum upgrading in order to structure collaborative design activities or workshops that actively contribute toward upgrading projects. The concept and applications of participation have been widely investigated in the integrated fields of political science and planning.

The purpose of this section is to:

1. Define "participatory design" and key associated terms and attributes (section 2.2.2); 
2. Review the approaches for enablement of design ideation in support of collaborative architectural design inquiry through the design of participatory design processes (section 2.2.3);

3. Identify and analyse participatory design strategies to help stakeholders explore conflicting stakeholder perspectives and the building of civic engagement and social capital in relation to social, architectural and urban issues (sections 2.2.4-2.2.5);

4. Summarise the review by presenting relevant strategies derived from the literature that may be used in the development of effective participatory design processes to address the primary Research Question (section 2.2.6).

\subsubsection{Positioning Participatory Design}

"Participatory design" is defined as the direct involvement of users and stakeholders in the design of products, services, and systems they use (Kensing, 2003; Simonsen \& Robertson, 2012). Simonsen and Robertson identify two fundamental aspects of participatory design. First, participatory design seeks to enable those who will use the design outcome to have a voice in its design, without needing to speak the language of professional designers. Second, people who are not professional designers, such as those living in informal settlements, may not be able to define what they want from a design process, without knowing what is possible (Simonsen \& Robertson, 2012, p. 2). The purpose of participatory design is to develop new knowledge geared towards participants' ability to take action in informed ways. Actions for change require that goals are discussed and shared among participants and that the actions are part of a plan constructed by all participants (Kensing \& Greenbaum, 2013, p. 26). One of the principal theorists explicitly addressing the notion of participatory design community participation and development has been Sanoff (1985, 2000, 2005, 2007). Sanoff has been influential in consolidating the field of participatory design by producing a series of methodologies that can be replicated and applied in the field. Sanoff expands the definition of participatory design as "an attitude about a force for change in the creation and management of environments for people" (Sanoff, 2007, p. 59).

In defining participatory design, it is important to differentiate between "design" and "planning", which are terms often used interchangeably, yet they are different from one another. While planning is defined as the act of devising a scheme, programme, or 
method worked out beforehand for the accomplishment of an objective, design is a conceptual activity involving formulating an idea intended to be expressed in a visible form or carried into action (Terzidis, 2007). Terzidis argues that "design is about conceptualization, imagination, and interpretation", while "planning is about realization, organization, and execution" ( Terzidis, 2007, p. 69).

Sinha explains in her book Architecture for Rapid Change and Scarce Resources that a participatory design oriented methodology ensures that everybody in a community including women and children can be empowered to transform their environment in a way that is responsive to community members' cultural and practical needs (Sinha, 2012, p. 175). Community "participation" is often described as a "bottom up" instrument of "inclusion"- as a genuinely inclusive process used to cultivate "collective power to reshape the processes of urbanization" through the introduction of a myriad of views, positions and interpretations of situations (Harvey, 2003). Frediani et al. point out the many benefits to participatory urban upgrading projects. They have a greater chance of attracting national and international funding due to a perception that, when stakeholders are included and outcomes are more likely to be realised; they cultivate "collective power" of constituents conducive to reforming development processes through the introduction of a myriad of views, positions and interpretations of situations; they are politically profitable in the eyes of local and national governments as well as Non-Governmental Organisations (NGOs); and they have "positive marketing potential" for donor or partner private organisations that might provide core business or project-specific funding to the development organisation, in exchange for the incorporation and use of their tools in the development process (Frediani et al., 2012, p. 18).

\subsubsection{Towards Genuine Participation}

Strategy PD-1: Ensure that all participants within a design activity have equal power to determine the outcome of the decisions made, as opposed to merely being informants.

Implications for Research: This section discusses the various types of design participation and argues that most participatory design processes can be categorised as "partial participation" processes, offering little more than consultation processes 
regarding professionally developed plans and thus limiting stakeholder empowerment through social and design outcomes.

The term "participation" masks the fact that participatory design processes range in degrees of stakeholder empowerment from partial participation, or what Jeremy Till calls "pseudo-participation", to full control of the process by the participants (Till, 2005, p. 25). These degrees are identified in Sherry Arnstein's frequently cited 'Ladder of Citizen Participation' model (Figure 18. Ladder of Citizen Participation. Adapted from Arnstein (1969).), in which she sets out a hierarchy of stakeholder control (Arnstein, 1969). At the bottom of the ladder is "manipulation" of participants and at the top is "citizen control".

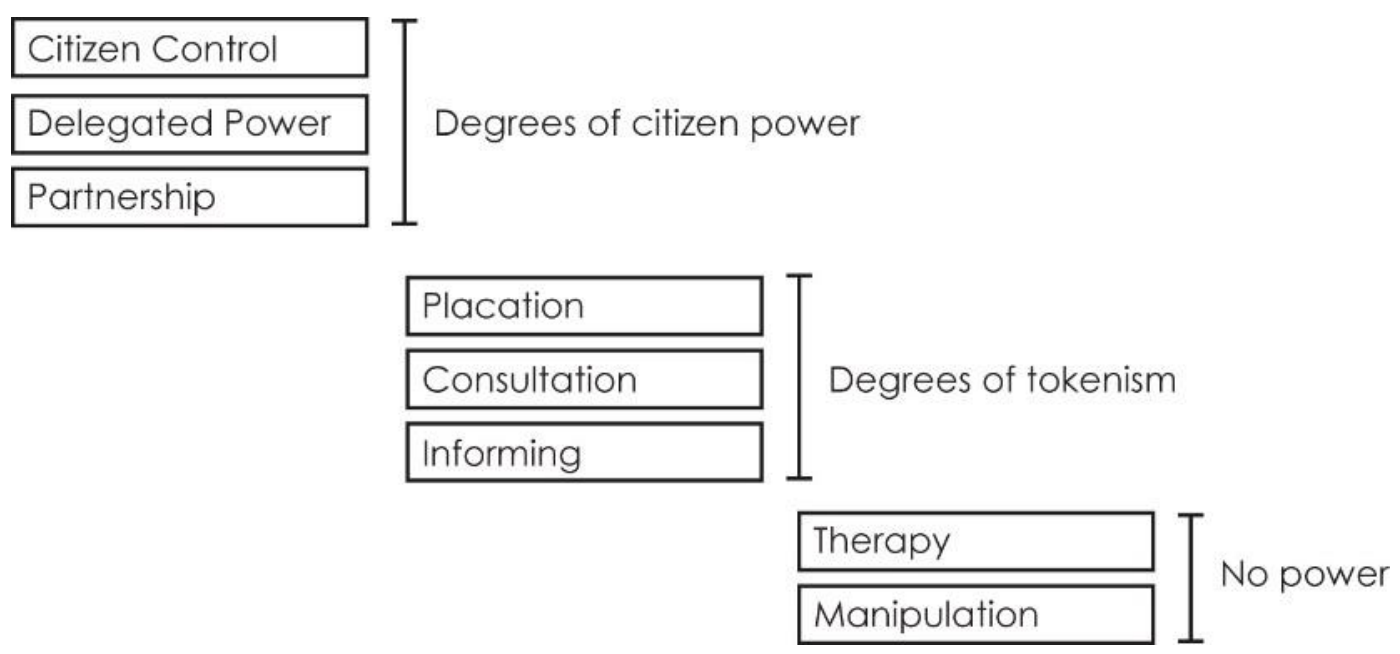

Figure 18. Ladder of Citizen Participation. Adapted from Arnstein (1969).

According to Bødker et al., "Participation is the core of Participatory Design. The fundamental developments in the field have come from efforts to investigate, understand, support and practise what can be labelled as 'genuine' participation in design (K. Bødker, Kensing, \& Simonsen, 2004) or what Arnstein calls "degrees of citizen power" (Arnstein, 1969). "Genuine participation" refers to processes in which all participants within a design activity have equal power to determine the outcome of the decisions made, as opposed to merely being informants (Blundell-Jones et al., 2005, p. 27; Simonsen \& Robertson, 2012, p. 5). Within a genuine participation-based approach, the architects, planners or other experts such as local government officials or NGO staff are no longer granted the role as master of the project. Petrescu argues 
that in genuinely participative approaches, "the experts should accept losing control and rather than being a master, they should understand themselves as one of the participants" (Petrescu, 2005, p. 55).

Genuine participation in design can also foster local catalyst actions and set precedents for more democratic forms of urban upgrading and empowerment through collective action (Frediani, 2016; Hamdi \& Goethert, 1997). Drawing on the notion of transformative theory developed by planning theorist John Friedman, Till describes this form of participation as "transformative participation" (Friedman, 1987; Till, 2005, p. 27). In this way Till argues that participatory design can function "not as a means for experts to mediate diverse interests, but rather as a forum for empowerment and contestation targeted at the social and physical production of the built environment (Till, 2005).

The term 'participation' is sometimes appropriated in situations that do not actually involve full participation. These forms of participative project can be referred to as "partial participation" or what Till describes as "placatory participation” (Till, 2005, p. 26). In terms of Arnstein's Ladder of Citizen Participation, they represent at best "degrees of tokenism and at worst "no power"” (Arnstein, 1969). Till argues that much of what passes for participation in architecture is actually only placatory, where the participant is lured by the term "participation", "whilst in fact being passive in the face of decisions already made by only one party" (Till, 2005, p. 27). Often partial participation based approaches offer no more than consultation processes of professionally developed plans in line with 'visions' defined by local government showcasing a predefined vision where little is done with the information gleaned from participatory processes (Frediani et al., 2011; Kindon, 2010). This is very common in projects dealing with those most marginalised - such as the inhabitants of informal settlements - who are rarely involved in actually defining and making the development decisions (Frediani et al., 2011). Their involvement is generally limited to providing feedback on design propositions or voicing their objections long after the project has been defined by officials, designed by architects, engineered by engineers, costed by surveyors, and put out to tender by building contractors (Frediani et al., 2011).

In order to classify levels of empowerment in participatory design processes, Senbel and Church propose an analytical framework that can be used for categorising different participatory design visualisation tools such as physical and digital models, as well as for the design of new ones (Senbel \& Church, 2011). They proposed six categories of 
participatory design empowerment: information inspiration, ideation, inclusion, integration and independence. In this framework, the highest level of design empowerment, independence, succeeds when residents are able to act to create their own plans and visions (Table 1).

Table 1. Levels of Participatory Design Empowerment. Adapted from (Senbel \& Church, 2011).

\begin{tabular}{ll}
\hline $\begin{array}{l}\text { Instances of Design } \\
\text { Empowerment }\end{array}$ & Form of Empowerment \\
\hline Information & $\begin{array}{l}\text { Participants gain a new understanding of planning issues and } \\
\text { possibilities through substantive and procedural knowledge. } \\
\text { Participants are compelled to act in response to the visualization } \\
\text { material. } \\
\text { Participants are able to generate and express ideas and thoughts about } \\
\text { the future of their urban environments. } \\
\text { The ideas and thoughts of participants are included among other } \\
\text { priorities in urban design decisions. } \\
\text { Inclusion }\end{array}$ \\
$\begin{array}{l}\text { Participants collaborate in the coproduction of plans and proposals. } \\
\text { Integration }\end{array}$ & $\begin{array}{l}\text { Participants are able to create their own independent plans and } \\
\text { visions. }\end{array}$ \\
\hline
\end{tabular}

This approach has been particularly successful when considering new media approaches to urban design participation such as the development of ICT approaches (Gün, Demir, \& Pak, 2019; Pak \& Verbeke, 2014) and the construction of virtual worlds and games for participatory design visualisation (Billger, Thuvander, \& Wästberg, 2017; Jutraz \& Zupancic, 2015).

\subsubsection{Exploring Conflicting Perspectives and Assumptions}

When marginalised communities confront and explore conflicting perspectives and assumptions through participatory design processes, the ability to "harness the collective intelligence" of people to work towards collective upgrading actions (Davis \& Garb, 2017, p. 77) can be enhanced. In order to do this, stakeholders must be given space to understand each other, "confront theories, perspectives and frames of thought" and be supported in "experiencing, testing, transforming, and developing early ideas" (Sanders \& Stappers, 2014). Sanders points out that discovering what people know helps disparate stakeholders to communicate with each other and that understanding what stakeholders feel gives participants the ability to empathise with each other (Sanders, 2001, p. 3). 
The two most important aspects of confronting and exploring conflicting perspectives are participants' knowledge bases and the values and goals each participant holds. Creating a broader understanding of these amongst stakeholders can help to create a level playing field by making everyone's positions known when working towards upgrading goals.

\subsection{Knowledge Bases}

Sanders and Dandavate (1999) propose that participants' experiences can be understood by studying what people say, do and make in participatory workshops. They highlight four types of knowledge that are observable within participatory design: explicit, observable, tacit and latent knowledge (Sanders \& Dandavate, 1999). Explicit knowledge refers to things about which people can talk, for example in interviews. Observable knowledge can be found in peoples' actions, practices and environments and can be approached by observing what people do and how they use things. Explicit and observable knowledge can generally reveal stakeholders' preferences for one thing over another. Tacit knowledge includes knowledge that cannot readily be expressed in words (Polanyi, 1967). Latent knowledge is the hardest to reveal, as this generally includes things of which participants are unaware but recognise as being relevant to them once satisfied (Bowen, 2010, p. 2; Sanders, 2001). Tacit knowledge and latent knowledge include people's dreams and feelings and are often subconscious.

\subsection{Values and Goals}

Values are enduring beliefs that we hold concerning "desirable modes of conduct" or "end-state of existence in different situations", societies and cultural contexts (Iversen, Halskov, \& Leong, 2012, p. 89). They act as a goal, and they guide attitudes, judgements and comparisons across specific objects and situations and beyond immediate goals to more long-term goals (Rokeach, 1973). As such, a participant's collection of values or value system is the generalised plan within whose frame or horizon they try to determine, from case to case, what is good or valuable, what is preferable or not, what we endorse or oppose and what we believe in or not (Iversen et al., 2012, p. 89). 


\subsection{Negotiation of Knowledge, Values and Goals in Participatory Design}

Participatory design is driven by social interaction, as users and designers learn together to create, develop, express and evaluate their ideas and visions. Researchers such as Soja (2010) and Schneider and Till (2009) have explored concepts such as "spatial justice" and "spatial agency" that build on the physical deterministic approach to participation by recognising the role of the built environment in challenging, sustaining or reproducing exclusionary processes in cities. Carroll and Rosson argue that participatory design is fundamentally about negotiating values—or a "moral proposition" (Carroll \& Rosson, 2007, p. 243). Iversen et al. argue that this moral position can be realised through participation in design activities to establish positions or level the playing field (Iversen et al., 2012, p. 87).

A useful negotiating tool that has been detailed widely in the participatory design literature is the "boundary object" (Bjögvinsson, Ehn, \& Hillgren, 2012; Brandt et al., 2013; Muller \& Druin, 2002; Sanders \& Stappers, 2014; Star, 1989; Vines, Clarke, Wright, McCarthy, \& Olivier, 2013). Susan Leigh Star suggests that boundary objects enable grounding by maintaining coherence across various social worlds — or between groups or individuals with disparate values (Star, 1989). "Boundary objects" are objects that are plastic enough to adapt to local needs and the constraints of the several parties employing them, yet robust enough to maintain a common identity across sites and able to manifest as physical entities, spaces, concepts or social systems. Brandt et al. argue that boundary objects can create continuity within a participatory design process by creating mutual ground for different interest groups so that they can contribute to the design process (Brandt et al., 2013). Thus, they can be useful for common language within the boundaries of a specific upgrading project. In participatory design, designers and users navigate the problem space through the use of boundary objects, including low fidelity prototypes, role-playing games, and sketches (Muller \& Druin, 2002; Sanders \& Stappers, 2008; Vines et al., 2013).

Shared experimentation, the sharing of knowledge and reflection on values, is an essential part of the participatory design process. Participatory design processes can make explicit the critical, and inevitable, presence of values (Suchman, 1993). Iversen et al. show that knowledge and values can be revealed through dialogue centred on design activities, where participants express their opinions, preferences, particular 
commitments and orientations that expose preferences, agreements and conflicts. Participants' knowledge and values can be highlighted by facilitating the revealing of values, developing them and supporting their grounding within participants' everyday experiences through participatory design activities (Iversen et al., 2012, p. 87).

\subsubsection{Revealing Participants' Knowledge, Values and Goals}

Strategy PD-2: Reveal stakeholder perspectives and assumptions in order to make positions known through design activities and ideation.

Implications for Research: The review highlights the importance of aiding participants to reveal conflicting perspectives, knowledge bases and the values and goals each participant holds. Successful approaches include the development of participatory tools for capturing and understanding not only explicitly articulated information, but also forms of tacit or experiential knowledge from non-expert participants.

One aspect of participation, which makes confrontation between conflicting perspectives and assumptions inevitable, is that the participants will bring to the table their personal beliefs (Till, 2005, p.34). Till argues that in the "negotiating space" created within participatory design activities, mutual cooperation, uncontested knowledge bases, open communication and eventual consensus do not exist, contrary to ideals of consensus-based participatory action (Hillier, 2003; Till, 2005, p. 34). Through ideation - the negotiation of design alternatives, the personal with the social, and the individual with the collective- "political space" emerges, revealing goals, assumptions and aspirations of the participants (Till, 2005, p. 34). Iversen et. al argue that the various methods used in enacting collaborative design activities, such as mockups, scenarios and sketching, act as reflective "tools to think with" (Iversen et al., 2012, p. 97). Through dialogue, discussions, observations and interpretations of design artefacts created by participants' design activities and ideation, participant values can emerge through explicit, observable, tacit and latent means (Iversen et al., 2012, p. 94).

\subsubsection{Priming Participants for Participatory Design}


Authors such as Sanders (2010), Holtzblatt et al. (2004), Visser et al. (2005), Gaver et al. (1999) and Lucero et al. (2012) stress the importance of sensitising participants to the topic central to participatory design activities before the actual participatory design session. Sanders et al. describe these as "priming activities" that operate at the front end of the participatory design process to help prepare participants and experts for the process of designing and to immerse them in the domain of interest (Sanders et al., 2010). In line with this, Visser et al. have focused on the process of establishing collaboration, and they have introduced a sequence of research steps that they call “contextmapping” (Visser et al., 2005). In contextmapping, co-design activities evolve from simple activities or exercises to more demanding ones. By emphasising the process view, they highlight the role of a step-by-step process that allows participants to become increasingly aware of their own experiences. This approach is also reflected in the work of Lucero et al., who posit that in conducting dialogue-labs sessions, they have sensitised participants to the topic of the design process by involving them in “probes studies" (Lucero et al., 2012) and contextual inquiries (Holtzblatt et al., 2004).

\subsubsection{Participatory Tools for Revealing Knowledge, Values and Goals}

Participatory design tools, which include mapping instruments, design toolkits, visualisation systems and games, are used in participatory design activities to engage stakeholders in design thinking (Sanders et al., 2010). An essential task of participatory design is to develop tools for capturing and understanding not only explicitly articulated information from experts and technicians, but also forms of tacit or experiential knowledge (Bjögvinsson, Ehn, \& Hillgren, 2012; Pollastri, 2017, p. 64). Participatory design tools are conventionally used as a strategy to engage those most marginalised in slum-upgrading (French et al., 2018; Hamdi, 2010; Sanoff, 2000, 2007), and they have been used to include participants at all stages of the development process, including decision-making, implementation, monitoring, evaluation, and maintenance stages (Brandt et al., 2013; MacPherson, 2013, p. 86). They have been shown to help support collaborative design enquiry, and they help to "bring together a network of actors with different backgrounds, competencies and experiences" to conceptualise or contribute to a design project (Brandt et al. 148). They are generally designed with four objectives: probing participants to express their experiences, feelings and attitudes in forms and formats that provide inspiration for designers 
through design exercises (Gaver et al., 1999; Mattelmäki, 2006); priming participants in order to immerse them in the domain of interest; obtaining a better understanding of their current experience; and generating ideas and design concepts for the future, for instance by creating and exploring future scenarios (Sanders et al., 2010).

Bjögvinsson et al. argue that identifying, mapping, and dealing with controversies and conflicting ideas provoked through collaborative design exercises is at the core of participatory design (Bjögvinsson et al., 2012). By letting people make something new, for example letting them create a simple mock-up or a collage, participatory design can help them to have a grasp of the knowledge values of other participants (Sanders \& Dandavate, 1999; Visser, 2009).

\subsection{Visualisations}

In Co-Design: A Process of Design Participation (1989), Stanley King et al. suggest that visualisation of design ideas, problems or concepts is crucial to effective participation in design processes, because it is the only common language between all participants - a language where technical thinking, the jargon of designers and the visions of participants may find equal footing (S. King, Conley, Latimer, \& Ferrari, 1989). Design visualisations have long been at the heart of the discourse of participation (Al-Kodmany, 1999; Pollastri, 2017; Simonsen \& Robertson, 2012). A visualisation is a design artefact — such as an image, drawing, physical model or digital model. The visualisation translates information, which by itself is not directly observable, into a visual representation that facilitates the understanding of such information by the creator or by an audience or participants. Visualisations in participatory design are cognitive tools that present working ideas and concepts for personal reflection or to facilitate a discussion among peers or with external stakeholders (Pollastri, 2017, p. 71). Visualisations are usually not truthful representations of perceptible reality, but records of how a participant sees something (Crowe \& Laseau, 1986; Dörk, Collins, Feng, \& Carpendale, 2013; Pollastri, 2017).

As Johansson points out, the challenge often faced in participatory design is that the "trained designer may use a pen and a piece of paper to illustrate his ideas while other stakeholders need other kinds of design material to be able to sketch" (Johansson 17). The materials are what Donald Schön calls "the materials of the design situation" and are frequently referred to in the participatory design literature (Agger Eriksen, 
2009; Brandt et al., 2013; Lanzara, 1991; Schön, 1983)". Eriksen classifies such materials as the ready-made content visualised or used within a given participatory design activity, such as pen and paper, clay, disposable cups, maps and images (Eriksen, 2009). They are generally brought into the participatory design gathering without specific meaning, and the meaning is attached to them through reinterpretations according to particular needs. They are the things participants discuss and with which they interact; they are the items that provoke ideation and influence the relationship between activities, participants and designers.

In line with the description of "tools-to-think-with" (i.e. enacting collaborative design activities, such as mock-ups, scenarios and sketching) Eva Brandt describes materials used in collaborative design processes as "things-to-think-with" (Brandt, 2007, p. 179). Bødker (2009) describes how participants "speak through" different types of participatory design workshop boundary objects that act as discursive "props" and give shape to their expectations, their outlook, their values and so forth (M. Bødker, 2009, p. 21). Walton (1993) argues that discursive props work by giving mandate to particular imaginings Walton (1993) . Dindler and Iverson (2007) show that these props do not need to be overly complex or be true representations of reality in order to provoke reflections on design situations, perspectives or goals. Instead, simple props such as a cardboard monitor, speakers and a microphone may be used to generate effective discourse during a participatory design activity (Dindler \& Iversen, 2007). Pollastri et al. show that simple props can be used to create what they call "Future Visioning Workshops" (see Figure 19) for reflecting, discussing and visualising aspirations, fears and expectations about urban futures amongst disparate participants (Pollastri et al., 2017). In this way, the participatory design approach has much in common with Schön's (1983) articulation of design as 'reflection-in-action', a process engaged in by an experienced and reflective design-practitioner. But while Schön takes the perspective of the individual designer, the direct involvement of future users in a participatory design process involves collective 'reflection-in-action' between multiple participants. 

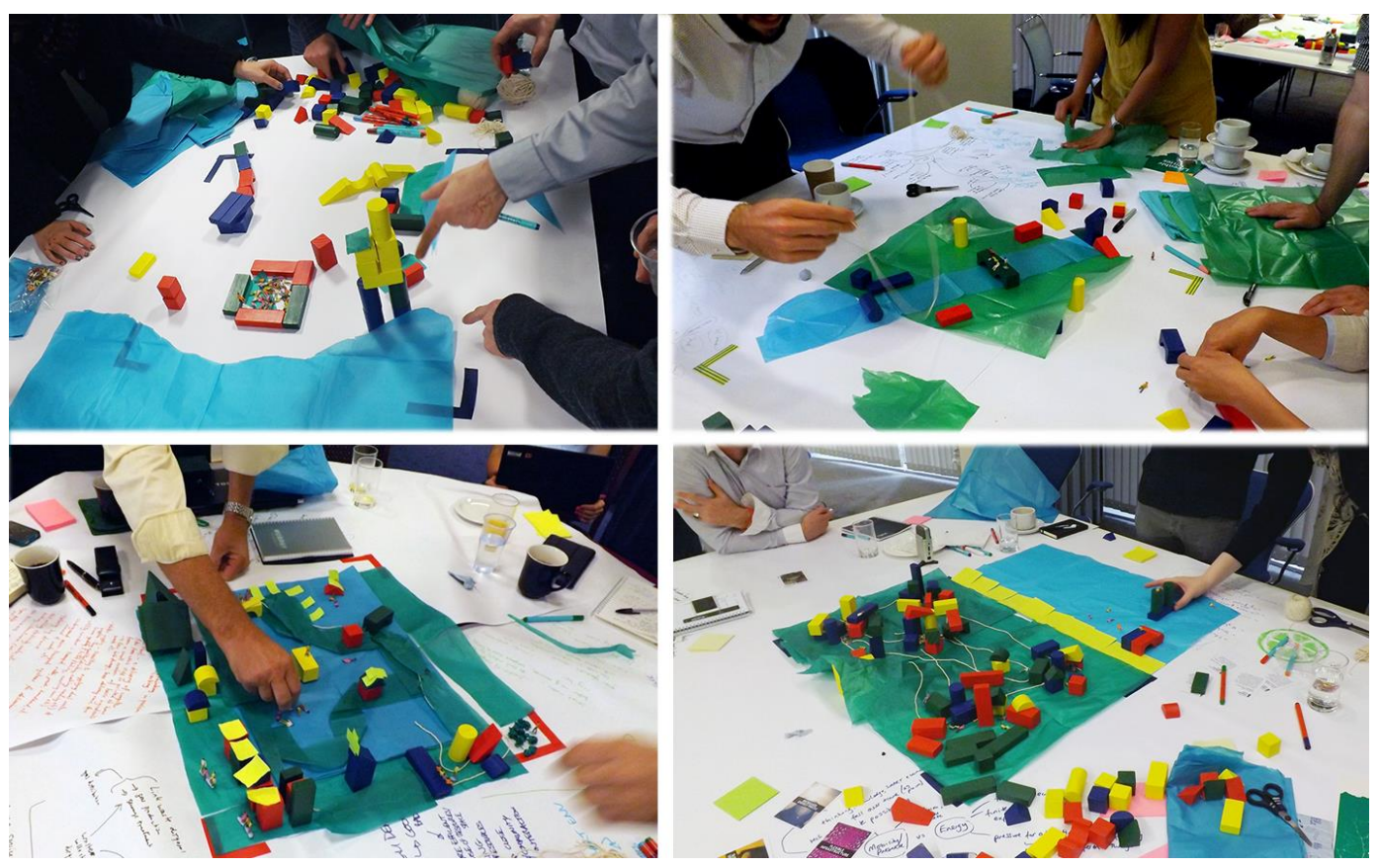

Figure 19. Future Visioning Workshops using simple props for reflecting, discussing and visualising future aspirations, fears and expectations about urban futures amongst disparate participants (Pollastri et al., 2017, p. 8)

\subsection{Participatory Design Activities}

Collaborative design techniques allow participants to test a range of design alternatives and to consider several overlapping perspectives/theories/frames as well as real-world systems. There are many different strategies, methods and techniques detailed in the literature that describe how stakeholders can be involved in the ideation, concept development and early prototyping phases of participatory design processes. The visualisation of ideas by participants through ideation allows those perspectives to be identifiable in abstraction and to become concrete through the creation of design artefacts that are more easily communicated to other participants (Sanders \& Stappers, 2014). These strategies, methods and techniques include future workshops (Kensing \& Madsen, 1992), generative participatory design (Brandt et al., 2013; Sanders, 2000), dialogue-labs (Lucero et al., 2012, p. 2), metaphorical design (Madsen, 1994), inspiration card workshops (Halskov \& Dalsgaard, 2006) and design games (Brandt, 2006; Brandt \& Messeter, 2004; Brandt, Messeter, \& Binder, 2008).

Many of these methods and techniques focus on discrete stages of the design process. For example, generative participatory design techniques, first defined by Elizabeth Sanders et al (1999), are an example of "priming activities". Using physical 
participatory design materials such as two-dimensional collages, mappings, visual and verbal triggers, physical games and props, participants are encouraged to "make designerly artefacts and then tell a story about what they have made" (Visser et al., 2005, p. 122). The artefacts and descriptions or enactments of their use developed by participants through the participatory design process can be analysed to find underlying patterns that can help participants build social capital and form useful analytical research as the foundation of further design explorations (Sanders \& Stappers, 2014). These tools generally provide invaluable information to designers by challenging participants to express their tacit knowledge of the participants or allow for the exploration of latent needs, aspirations and dreams (Sanders, 2000). They can allow participants to discover and express imagined conceptions of past, present and future experiences with one another, as well as responses to problems and alternatives to current situations. The purpose of these techniques is to help create a shared language between participants, and between experts and participants, for the communication of tacit and latent attributes of a design context.

\subsection{ICT based Approaches to Participatory Urban Design}

The use of ICT-based participatory urban design tools has become prominent over the last decade. Many new digitally-enabled participatory techniques, tools, and applications have been developed to facilitate the participation of stakeholders and residents in a variety of ways. Desouza \& Bhagwatwar argue that ICT-based participatory design tools are technology-enabled forums created to retrieve, analyse, visualise and share information, expertise and solutions that advance social causes and/or resolve social and policy problems (Desouza \& Bhagwatwar, 2014, p. 26).

Past research has examined technology-enabled participation platforms (Desouza \& Bhagwatwar, 2014) to demonstrate their potentials (Falco \& Kleinhans, 2018), to reveal the empowerment goals (Pak \& Verbeke, 2014), to identify types of mobile apps for citizen participation (Ertiö, 2015) and to offer evidence-based design guidelines for participation processes (Bryson, Quick, Slotterback, \& Crosby, 2013). Gün, Demir, \& Pak examined ICT-based participatory design platforms to reveal how these platforms empower and restrict citizens' engagement. Gün et al., (2019) found in an analysis of 25 ICT-based urban participation platforms, only 12\% of platforms' [Maptionnaire, MinStad (Tahvilzadeh, 2015) and Smarticipate (Z. Khan et al., 2017)] participants 
create their own design, plans and visions. Their findings also indicate that a majority of these platforms $(76 \%)$ focused on only two objectives: problem identification and feedback collection (Gün et al., 2019, p. 16).

However, many of these approaches use abstract visualisation techniques such as GIS based systems that can result in a lack of engagement. Smarticipate for example utilises the OpenStreetMap platform see Figure 20, below.

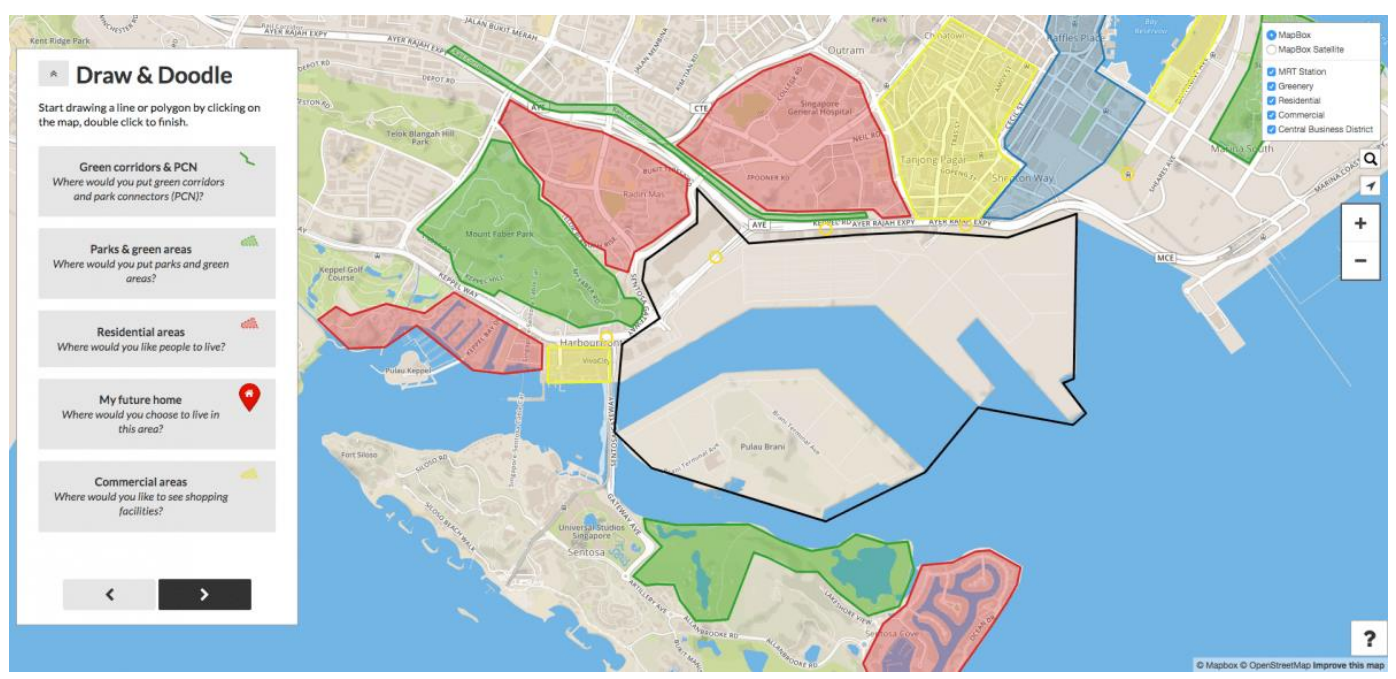

Figure 20. Screen shot from the Smarticipate participatory urban design tool (Z. Khan et al., 2017).

Others such as the City of Gothenburg's Min Stad web portal and application provide an annotated 3D visualisation of the city for urban planning and interaction, allowing for the inclusion of personal stories, interaction with the city's landmarks, as well as linking to the city museum's archive of historic images (Tahvilzadeh, 2015). The approach, which utilises un-textured, extruded urban forms in combination with satellite imagery, lacks in visual fidelity to represent emotive qualities of space (Figure 21). 


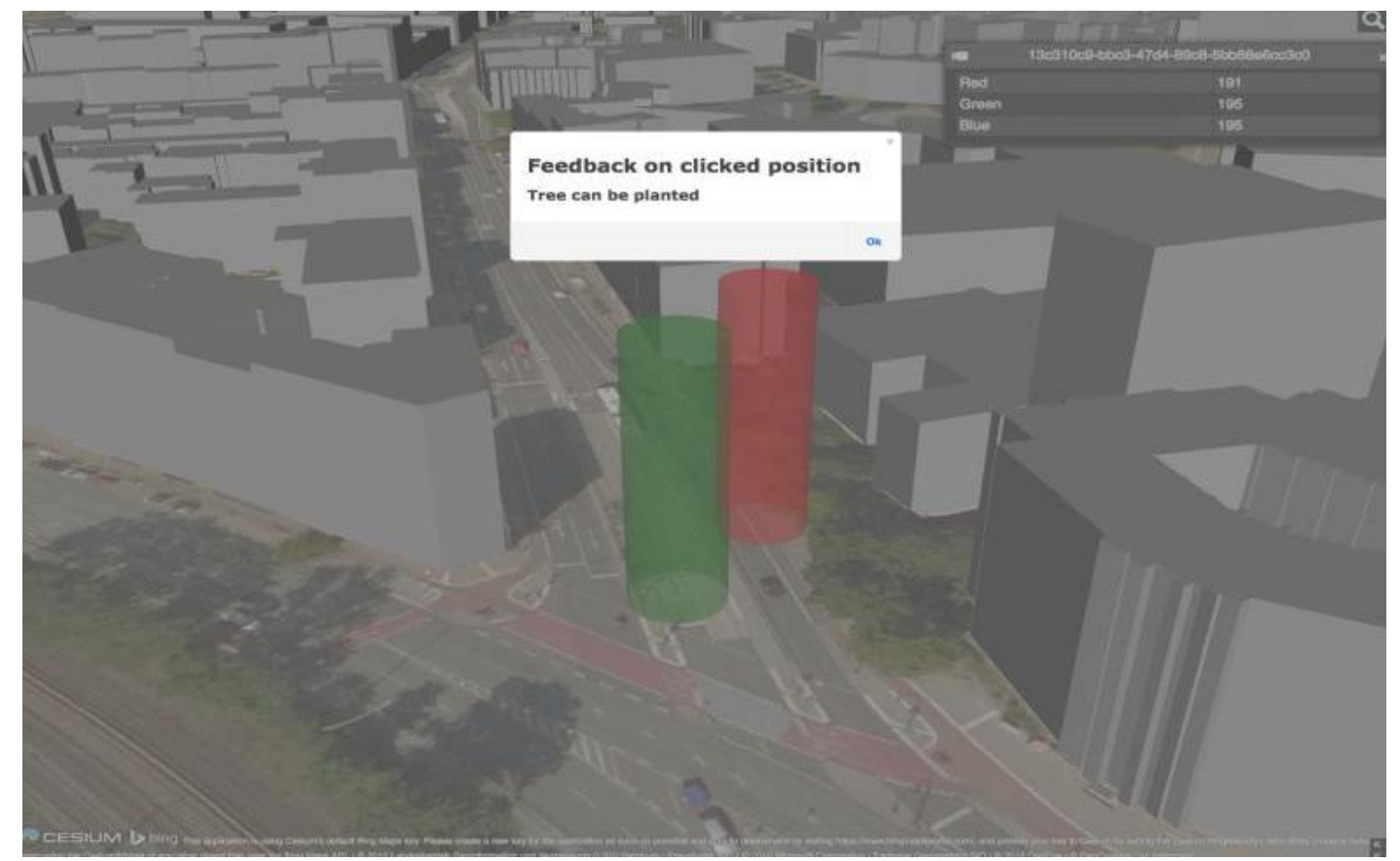

Figure 21. Placing feedback on a selected urban feature in Min Stad (Tahvilzadeh, 2015)

\subsubsection{Developing Knowledge, Values and Goals}

Strategy PD-3: Develop stakeholder collective knowledge, values and goals by clarifying and refining them to allow their translation from abstract formulations to more concrete design concepts.

Implications for Research: The review highlights the importance of aiding participants to develop conflicting perspectives, knowledge bases and the values and goals each participant holds. Adopted approaches include exploring, reframing or suspending assumptions through defamiliarisation strategies, games-based approaches or agonistic approaches.

Once participant knowledge, values and goals have been revealed, they can be developed in one of two approaches, depending on whether there is agreement or conflict. All revealed knowledge and values are brought to the fore in the participatory design process, even if particular values conflict and present dilemmas to the process. As Iversen et al. describe, either direction requires designers to decide how to facilitate and orchestrate this process with participants (Iversen et al., 2012, p. 95). 


\subsubsection{Agreement and Conflicting on Knowledge, Values and Goals}

In the first approach, if all participants are in agreement concerning knowledge, values and goals surrounding a design situation, then the participatory design process can focus on clarifying and refining the values, which allows a clearer translation of values from abstract formulations to more concrete design concepts (Iversen et al., 2012, p. 95). Through reflection and discussion surrounding collaborative design activities, participants can then hone their collective design preferences. Participants are prompted to reflect and verbalise their views of how they could envision the future design. This technique also allows participants to express aspects of their preferences pertaining to this design.

An alternative approach is used when conflict or contestation of knowledge or values is revealed in this approach; allowing participants to explore, reframe or suspend assumptions can be beneficial (Al-Kodmany, 1999; Frediani, 2016; Frediani et al., 2011; Hamdi, 2010; von Heland et al., 2015). Through an exploration of social complexities and conflict involved in participatory design processes, participants can be stimulated to "share diverse opinions and aspirations and thus deepen their understanding of the self, others, norms and institutions" (Frediani \& Boano, 2012, p. 216). Sharing opinions is important as values and knowledge are not always explicit and can emerge when users are challenged by other participants or stakeholders (Halloran, Hornecker, \& Fitzpatrick, 2009).

A number of methods are described in the literature to enable the sharing of opinions and ideas. One of the earliest is described by Ehn as the Verfremdungseffekt (or the theatrical "distancing effect"), which is used to "make well-known situations appear as something new" to the participants; this approach can allow participants to suspend assumptions (Ehn, 1988, p. 90). Similar concepts were also explored by Bell, Blythe, $\&$ Sengers (2005). They describe "defamiliarisation" as a useful tool for creating space for critical reflection, and thereby for opening up new possibilities for design. Making the design situation or context "strange" provides designers and participants with the opportunity to actively reflect on, rather than passively propagate, the existing politics and culture and develop new alternatives for design (Bell, Blythe, \& Sengers, 2005, p. 150). Further, Dindler and Iversen use physical props to construct a "fictional inquiry" scenario (Dindler \& Iversen, 2007). By having all stakeholders act out their traditional role in a fictional space, they were able to temporarily suspend their viewpoints and 
reframe this dilemma without participants feeling threatened. Dindler advocates that this is ultimately facilitated through the use of mock-ups, which can be used to separate participants from reality in what Walton calls a game-of-make-believe (Walton, 1993, p. 28). Such 'games-of-make-believe' have been tested in different ways by different theorists: Triantafyllakos et al. suggest introducing fictional characters to participatory design scenarios for a similar effect (Triantafyllakos, Palaigeorgiou, \& Tsoukalas, 2010); Morrison describes "Narrative Anthropomorphism”, which consists of creating personas and narratives for designed artefacts in order to understand and discuss their complexity (Morrison, 2014); Salvador and Howells describe what they call a "Focus Troupe" in which they use dramatic "vignettes" to create common contexts for design situations (Salvador \& Howells, 1998); Johnson uses "Science Fiction Prototyping", which uses science fiction based scenarios to discuss the implication of future design trajectories (Johnson, 2011); similarly, Blythe and Wright's "Pastiche Scenarios" (Blythe \& Wright, 2006) use fictional scenarios from novels and films to structure participatory design inquiries.

Participatory design games have been widely used to develop knowledge, values and goals by establishing "explorative design dialogues" through novel configurations of the game materials and the present and future practices to which these materials point (Brandt \& Messeter, 2004; Brandt et al., 2008, p. 51; Iversen \& Buur, 2002; von Heland et al., 2015; Westerberg \& von Heland, 2015). Participatory design games invariably have to have an "element of fun and irreverence, frankness and surprise along with interaction", which makes them successful (Sinha, 2012, pp. 177-178).

In describing design games, Brandt et. al draw on Caillois and Huizinga's seminal work on play and games to point to how play and games can help the participants step outside of the ordinary, which can enable critical reflection (Brandt et al., 2008, p. 51; Caillois, 1961; Huizinga, 1955). Participatory design games are useful for engaging a diverse group of players around a collaborative activity guided by simple and explicit rules and assigned roles, and supported by pre-defined gaming materials. As Brandt et al. describe, the game materials typically point to existing practices and/or future possibilities and are played within confined and shared temporal and spatial settings often removed from the everyday context of the players. At the end of the game, the players will have produced representations of one or more possible design options (Brandt et al., 2008, pp. 53-54). 
Participatory design games have successfully incorporated a number of the strategies above, such as role playing, scenario-oriented approaches and fictional approaches (Ampatzidou et al., 2018; Di Mascio \& Dalton, 2017; Iversen \& Buur, 2002). Mascio and Dalton demonstrate that the alternative ways of representing and communicating information in architectural and urban participatory design games can make the participatory design process more interesting and playful and hence more effective, and this can be an effective way to establish a dialogue between designers and participants (Di Mascio \& Dalton, 2017, p. 433). Iversen and Buur build on Habraken and Gross's concept design games but apply the idea in an educational setting organised around the notion of "design is a game" (Figure 22) (Habraken \& Gross, 1988; Iversen \& Buur, 2002). They propose that creating, playing and reflecting game playing can be an effective way of learning how to establish social interaction between stakeholders in the participatory design process. According to them, the "game frame encourages participants to pay attention to the social and communicative processes of design", which Vaajakallio argues is essential in participatory design to create and maintain collaboration between participants (Iversen \& Buur, 2002; Vaajakallio, 2012, p. 91).

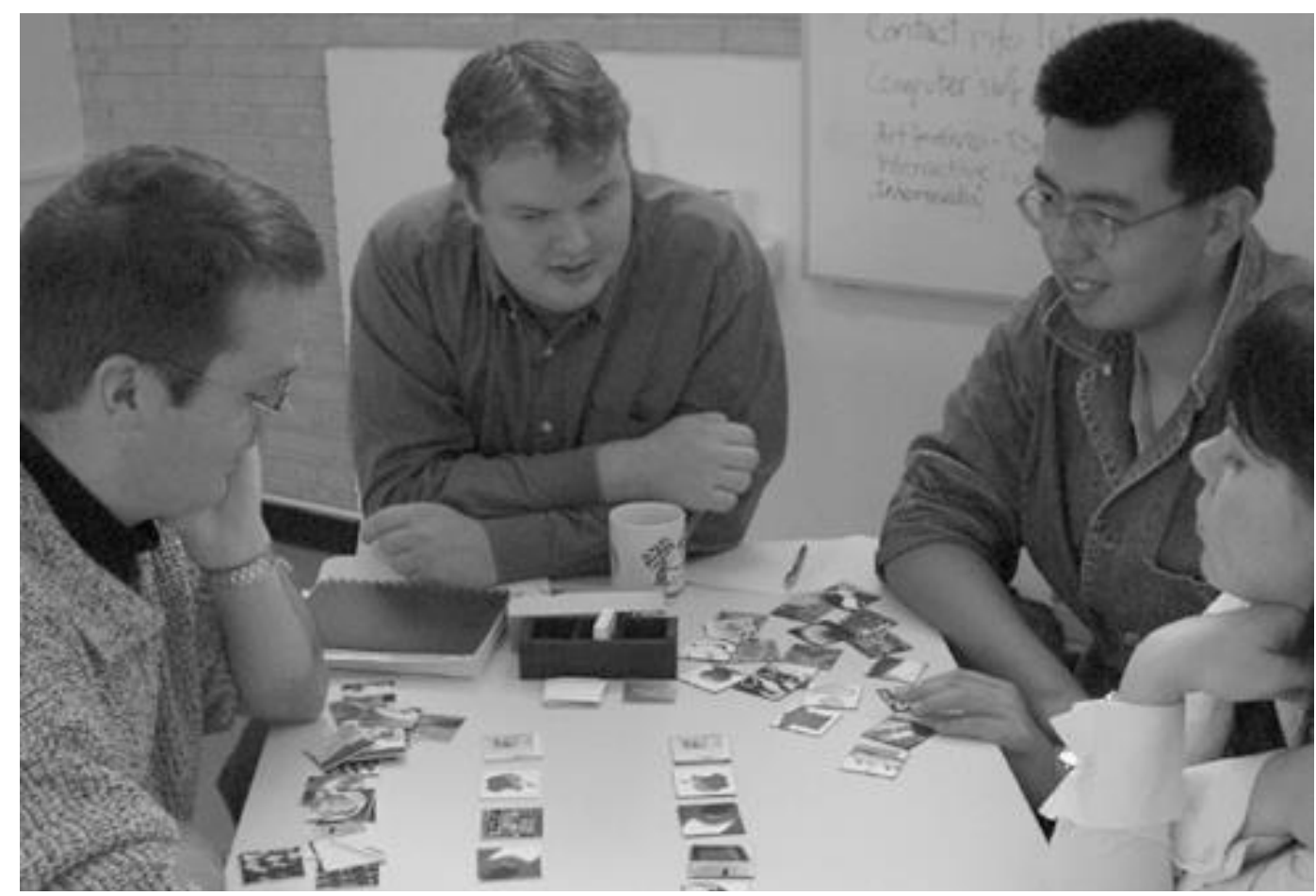

Figure 22. The Product Value Game: Two players negotiate silently which values they want to attribute to their product using colourful picture cards (Iversen \& Buur, 2002) 
The first architectural or urban design games typically revolved around topics such as land use, community development, public participation, city management, transportation, ecology and natural resources. The game Metropolis, created by Richard Duke, the father of planning simulation games, is a planning game in analogue format, created to engage members of a city council in urban development planning (Duke, 1995). More recent approaches, such as Generative City Gaming presented by Tan, detail participatory design games for "city making purposes" that do more than "teach, train, strategize, predict and entertain" (Figure 23) (Tan, 2014, 2016, p. 274). The approach seeks to add the design and decision-making dimensions, the social and political structures of cities, and the topological context through the design of the physical board game's style format.

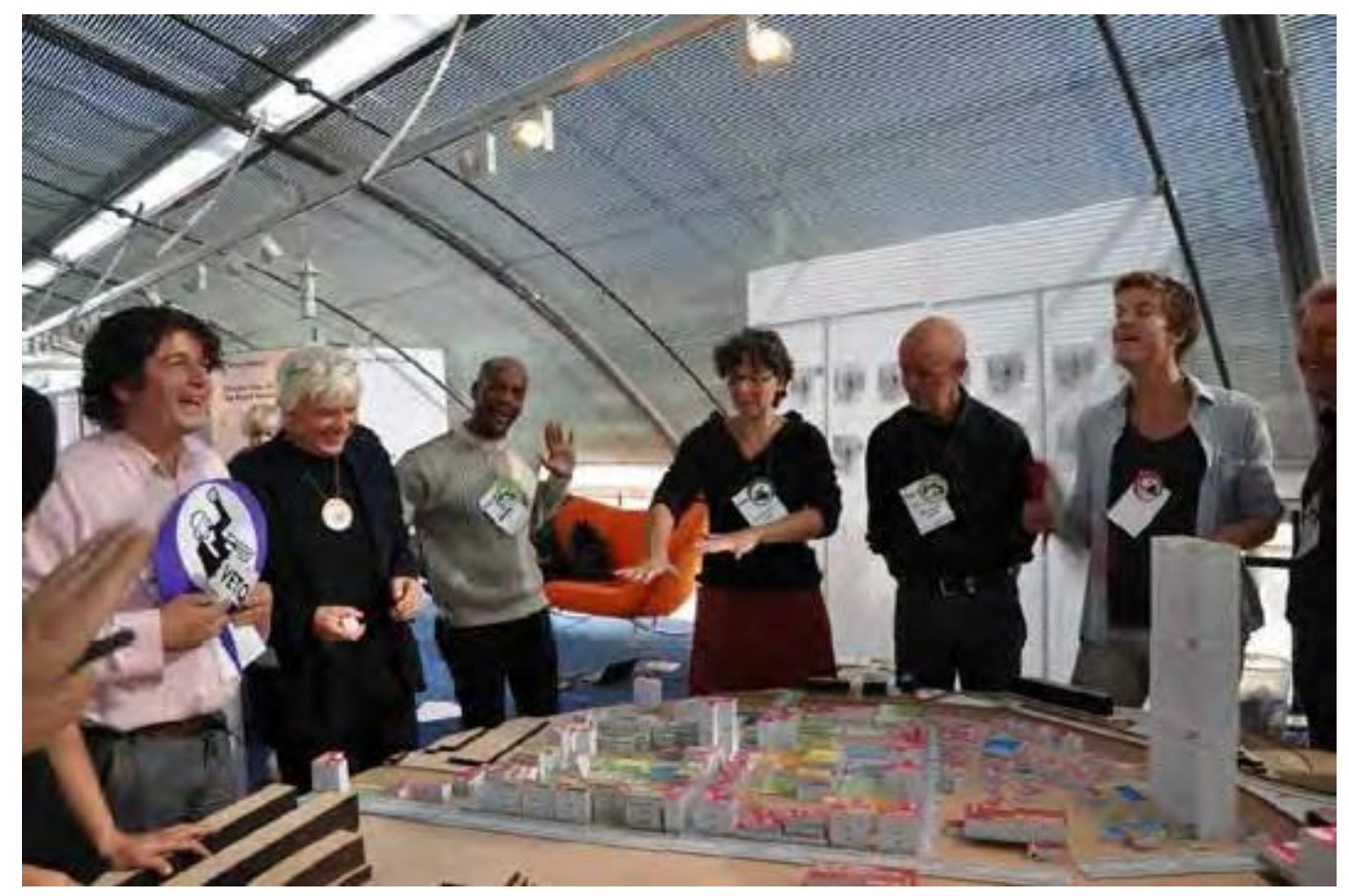

Figure 23. Participants playing "Play Noord" a Generative City Game designed to explore masterplanning by integrating typical and atypical urban actors through a City Game interface (Tan, 2014, p. 269)

Other participatory design approaches have shown success in using physical/digital interfaces to engage participants. Finding Places (2016), developed by FindingPlaces, is a collaborative project run by the CityScienceLab at Hafencity University and the 
city of Hamburg in partnership with M.I.T and their open-source program CityScope. Tangible-Interactive-Modelling (TIM) technology is used to find suitable spaces in Hamburg for constructing accommodation for a further 20,000 refugees (Figure 24). It utilises LEGO-tised 3D representations of existing urban areas in Hamburg, providing an analogue-digital interface that encourages non-expert stakeholder participation in rapidly prototyping urban interventions. Using Lego enables anyone to participate in the building of models without being intimidated by complex algorithms and interfaces (Noymana, Holtz, Kröger, Noennig \& Larson, 2017).

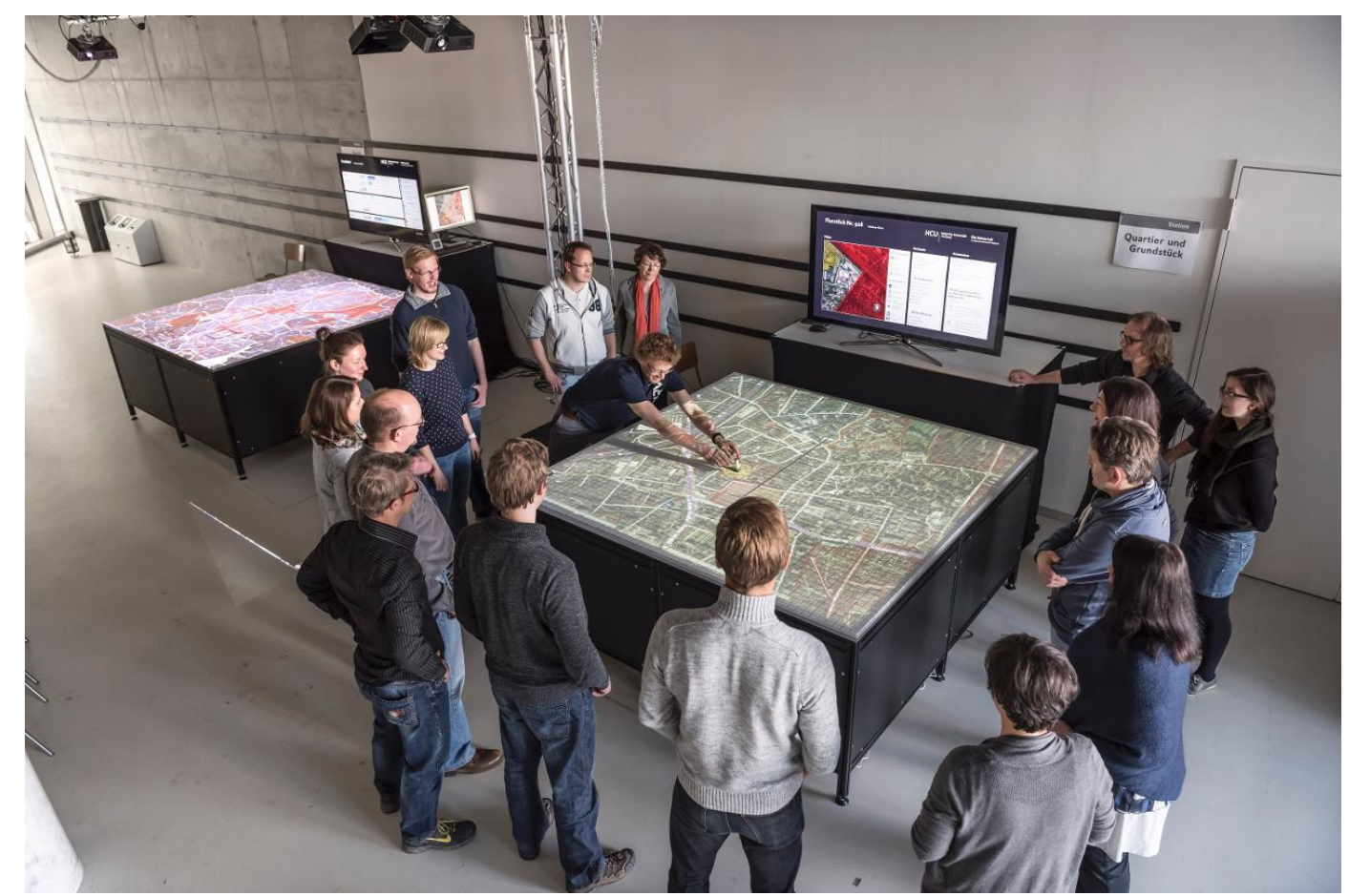

Figure 24. Finding Places by the CityScienceLab at Hafencity University and the city of Hamburg in partnership with M.I.T. (Noymana, Holtz, Kröger, Noennig \& Larson, 2017)

Digital approaches to participatory design games have shown some success in engaging stakeholders in design conversations. Block by Block (2012), which is a project in collaboration with the United Nations Human Settlements Programme (UNHabitat) uses the Minecraft platform as a community participation tool in the design of urban public spaces, with the goal to raise funds for the improvement of public spaces worldwide with a particular focus on poor communities in developing countries (see Figure 25) (von Heland et al., 2015; Westerberg \& von Heland, 2015). Likewise, Betaville (2011) is a 3D multiplayer environment for real cities, offering stakeholders a new collaboration tool for realising urban re/development projects. Open-source 
technology enables players-ranging from individuals and groups to professional design firms and planning offices - to upload projects in the form of 3D models. It is designed to empower stakeholders to float ideas and find common ground, proactively and cost-effectively gathering information for informed decision-making. The gamebased platform consequently has the capacity to filter more favourable ideas and catalyse cooperative action, while avoiding costly early-stage investments of time and money required by more traditional methods (Koplin \& Skelton, 2012). However the game is based around consensus building and does not purposely provoke contestation of ideas.

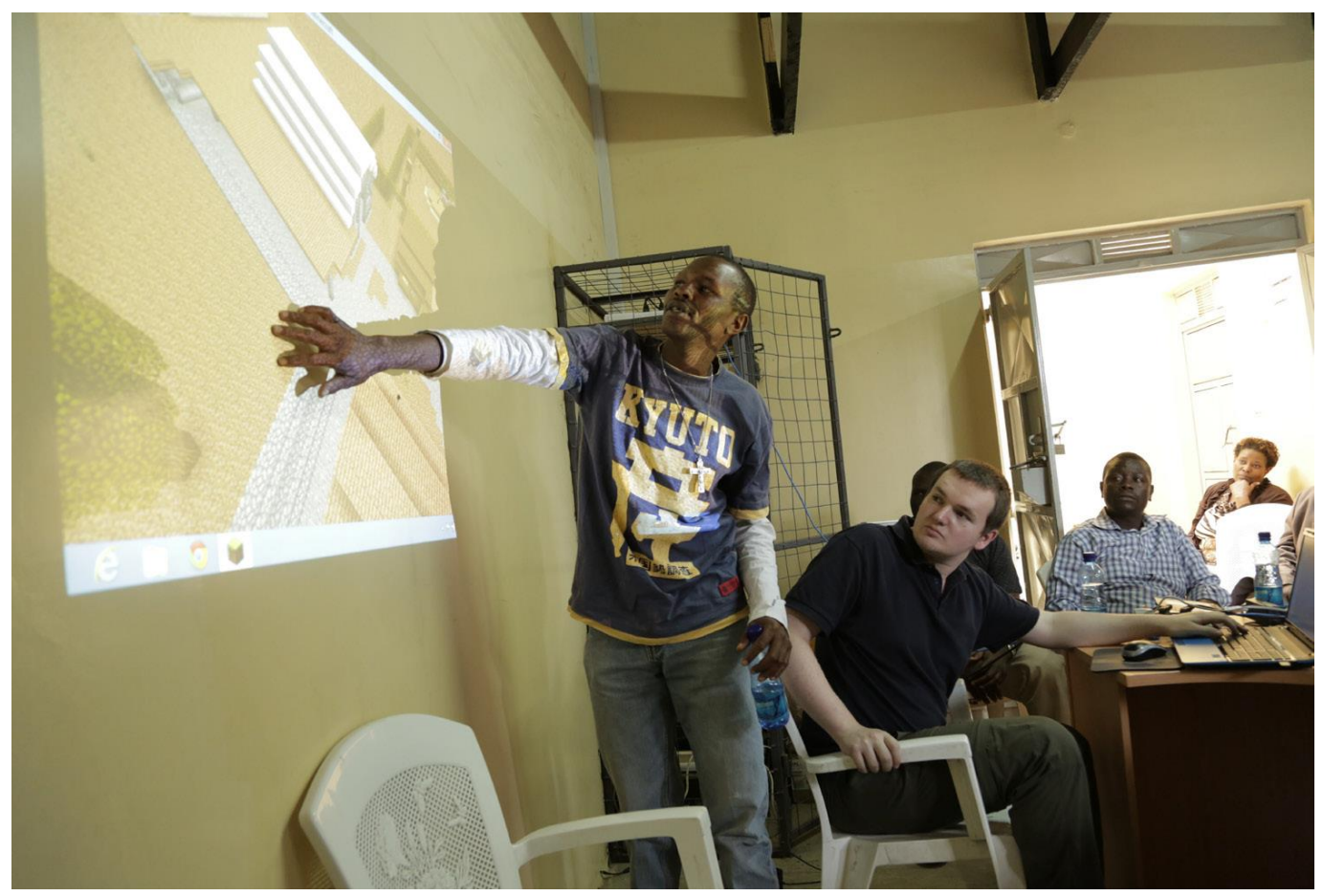

Figure 25. A participant in Kibera, Kenya highlights the size of the football pitch in the Minecraft model as part of a UN-Habitat participatory slum-upgrading project (Westerberg \& von Heland, 2015, p. 8)

\subsubsection{Agonistic Approaches to Participatory Design Activities}

The concept of agonism was brought forward by political scientist Chantal Mouffe (Mouffe, 2000a, 2004), primarily as a way to approach political hegemony and ensure the voices of marginalised actors are heard. "Agonistic pluralism" is best understood in relation to antagonism, which is the struggle between enemies, while agonistic pluralism represents the contestation of multiple coexisting and conflicting perspectives between adversaries (Emilson, 2015, p. 50). A number of designers have 
operationalised the "agonistic pluralism" for socio-political engagement through participatory design to address conflict and contestation of assumptions and perspectives (Björgvinsson, Ehn, \& Hillgren, 2012; Munthe-Kaas, 2015; Pløger, 2004).

There is growing interest in design practices that create "agonistic space", i.e., where the different stakeholders do not necessarily reach a consensus surrounding a design, but rather create an arena that reveals conflict or tensions and that allows multiple opposing views to coexist (Hillgren, Seravalli, \& Emilson, 2011, p. 179; Huybrechts, Dreessen, Schepers, \& Salazar, 2016). Animating the debate about urban poverty eradication, slum upgrading and participatory design, Boano et al. draw on Rancière's ontology of "dissensus" (Rancière, 2011) — in which he posits that "conflict within a group can and should be reframed as something fruitful" (Boano \& Kelling, 2013). Constructing a participatory "architecture of dissensus" "refers to the way in which community members reposition themselves as viable development partners, thereby interrupting the dominant - fundamentally exclusive-way in which urban development happens" (Boano \& Kelling, 2013).

Proponents of "Agonistic Participatory Design" argue that consensus should not be forced (Boano \& Kelling, 2013); instead, opportunities should be provided for stakeholders to participate in contestation, or constructive controversies, among 'adversaries' who have opposing matters of concern but also accept other views as 'legitimate' (Björgvinsson et al., 2012; DiSalvo, 2012). Providing such opportunities has been discussed in the literature as "infrastructuring"-providing the conditions needed for social change and aligning inscribed norms and values across contexts through socio-material negotiations (Björgvinsson, Ehn, \& Hillgren, 2010; Hillgren et al., 2011).

A number of authors have documented the operationalisation of agonistic participatory design. Architecture sans Frontières-UK (Frediani, 2016; Frediani et al., 2011) conducted a series of workshops organised by Architecture sans Frontières-UK, titled Change by Design (see Figure 26). The workshops in Salvador da Bahia, Brazil (2009 and 2010), Nairobi, Kenya (2011), and Quito, Ecuador (2013) consisted of two weeks of activities in close collaboration with local partners. Activities were organised into four different stages: diagnosing, dreaming, developing, and defining. They used what the authors describe as "catalyst themes", such as dignified housing growth, which were useful in defining the spatial principles based on values and daily practices 
(Frediani, 2016, p. 106). The authors argue that "solidarity is more deeply formed when sharing and discussing differences-when bonds are formed not by identities or histories of oppression in common, but by hope of what is yet to come (Frediani et al., 2011, p. 108). The project showed that participants formed solidarity through the recognition of difference and alliances through multiplicity (Frediani et al., 2011, p. 108).

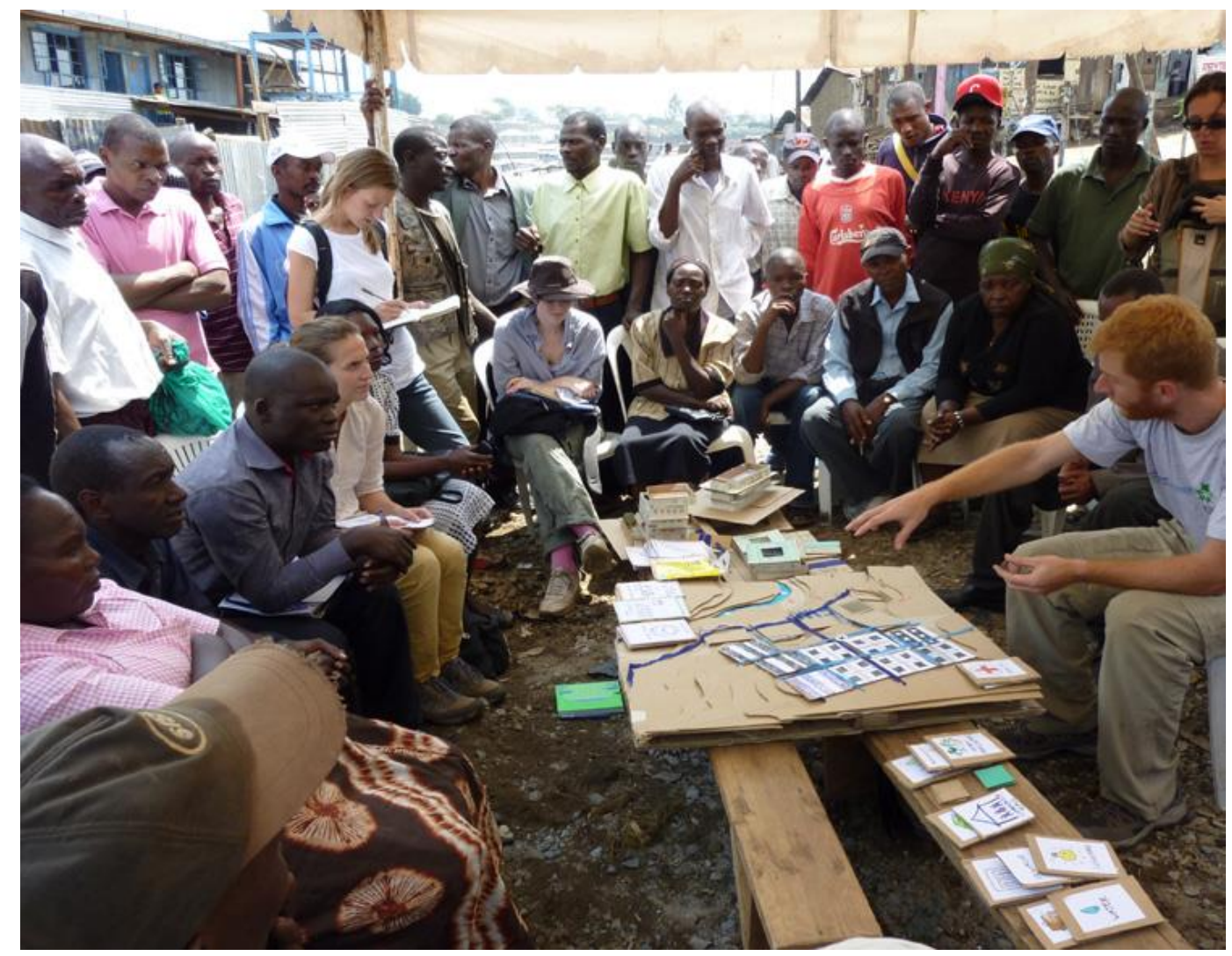

Figure 26. Participants contributing to the Change By Design project in Nairobi, Kenya (Frediani et al., 2011, p. 108).

Similarly, the PocketPedal project by Holland and Roudavski showed that agonistic space can be created through a digital game-based approach. The project utilises a purpose-built smartphone game to help participants discover and cultivate commonalities between cyclists and motorists surrounding the issues of implementing cycleways in inner city Melbourne. It facilitated the creation of a common language amongst participants and the alignment of inscribed norms and values across contexts through socio-material negotiations (Holland \& Roudavski, 2016). 


\subsubsection{Grounding Knowledge, Values and Goals}

Strategy PD-4: Ground the participant's everyday knowledge and experience to create common ground or shared language between participants.

Implications for Research: The review highlights the importance of aiding participants to ground conflicting perspectives, knowledge bases and the values and goals each participant holds. Adopted approaches include aiding participants to undertake collective design cycles of reflection and action, and applications of prototyping to connect their abstract participatory design experience to their realworld experience.

When perspectives and assumptions about values have been reconceptualised through negotiation and exploration within the participatory design process, they need to be "grounded" so that stakeholders can navigate this new-found conceptualisation successfully within their everyday interpretations of their built environment (Clement \& Besselaar, 1993; Iversen, Halskov, \& Leong, 2010; Iversen et al., 2012; Kensing, 2003). Büscher et al. describe how grounding can be achieved through a triangulation of "bricolage" - the construction of concepts that are combinations of various participants' ideas and experiences into a scenario that they collectively believe will work, prototyping in-situ, and what they describe as "future laboratories" as techniques that allow stakeholders to balance and negotiate between "blue-sky conceptualising and pragmatic issues of development and implementation" (Büscher, Eriksen, Kristensen, \& Mogensen, 2004; J. E. Innes \& Booher, 1999).

Drawing on the work of Schön, Büscher et al. state that in order to navigate grounding, stakeholders need to operate within cycles of "doing and reflecting"design by doing and design by reflecting (Argyris \& Schön, 1978; Büscher et al., 2004; Schön, 1983). Similarly, ideation can be grounded in the users' experiences through creative artefacts produced by the participants. Vaajakallio and Mattelmäki argue that when design is enacted, it "becomes manifested through a performance, visualizing the consequences to everyone present and allowing what Schön describes as "joint reflection-in-action" that engages all participants in the design situation" (Schön, 1983; Vaajakallio \& Mattelmäki, 2014). Iversen et al. state that grounding can be facilitated through the acceptance and use of a prototype in an existing practice, or with reference 
to the real world, which can be carried out by dissemination activities or the implementation of a prototype on-site (Iversen et al., 2012, p. 100).

\subsubsection{Summary}

This section has discussed how participatory design has been used to help disparate stakeholders explore conflicting perspectives and assumptions surrounding architectural and urban issues through collaborative design activities. The section positions participatory design as a conceptual activity that is useful in blue-sky approaches to participatory upgrading, and it emphasises that citizen control is more important than token participation approaches. The review has shown the importance of priming or preparing participants for participatory design activities by slowly leading them into the design process.

Collaborative ideation and design activities can help participants reveal their positions to one another through ideation and the negotiation of design alternatives; help them develop collective knowledge and values through the navigation of conflict and difference; and ground them in their real-world experience through in-situ prototyping.

From this participatory design literature review, four strategies can be adopted that can help disparate stakeholders explore conflicting perspectives, assumptions and corresponding goals surrounding architectural and urban issues:

Strategy PD-1: Ensure that all participants within a design activity have equal power to determine the outcome of the decisions made, as opposed to merely being informants.

Strategy PD-2: Reveal stakeholder's perspectives and assumptions in order to make positions known through design activities and ideation.

Strategy PD-3: Develop stakeholder collective knowledge, values and goals by clarifying and refining them to allow their translation from abstract formulations to more concrete design concepts.

Strategy PD-4: Ground the participant's everyday knowledge and experience to create common ground or shared language between participants. 
In the next section I build on this to discuss how digital games act as a medium for generative participatory design inquiries through a review of current approaches to serious games and define strategies for how they have resulted in either social and design oriented outcomes. 


\subsection{Architectural Serious Games}

People who know how to make games need to start focusing on the task of making real life better for as many people as possible (McGonigal, 2011).

\subsubsection{Introduction}

As part of the United States contribution to the 1967 International and Universal Exposition in Montreal (Expo 67), American architect, systems theorist, designer, and futurist R. Buckminster Fuller proposed The World Game: Integrative Resource Utilisation Planning Tool. Sometimes called the World Peace Game, it was an educational simulation game structured on the foundation of open cross-border collaboration between nations and even continents to help create solutions to problems such as overpopulation and the irregular distribution of global resources. Based on Fuller's Dymaxion map, it involved groups of players cooperatively responding to sets of problematic hypothetical scenarios, through a lens of a holistic world view, which consequently challenged the dominant nation-state system. The aim of the game was to explore how to "make the world work for $100 \%$ of humanity in the shortest possible time through spontaneous cooperation without ecological damage or disadvantage to anyone", thereby increasing levels of empowerment and quality of life for all (Fuller, 1971). While Fuller was commissioned to build his "geodome" structure for Expo 67, his proposal for the inclusion of the World Peace Game (see Figure 27) as a fundamental component of the exhibition was rejected by the United States Information Agency (USIA) (Fuller, 1971). The USIA, anticipating the communicative, collaborative and subversive power of Fuller's World Peace Game, deemed it too revolutionary, due to its proposal of the cooperative redistribution of resources and the suggestion of destabilising existing power structures via collaboration across international borders to solve global problems (ibid). It was feared 
that games would give the unskilled, uninformed masses the tools to subvert the status quo.

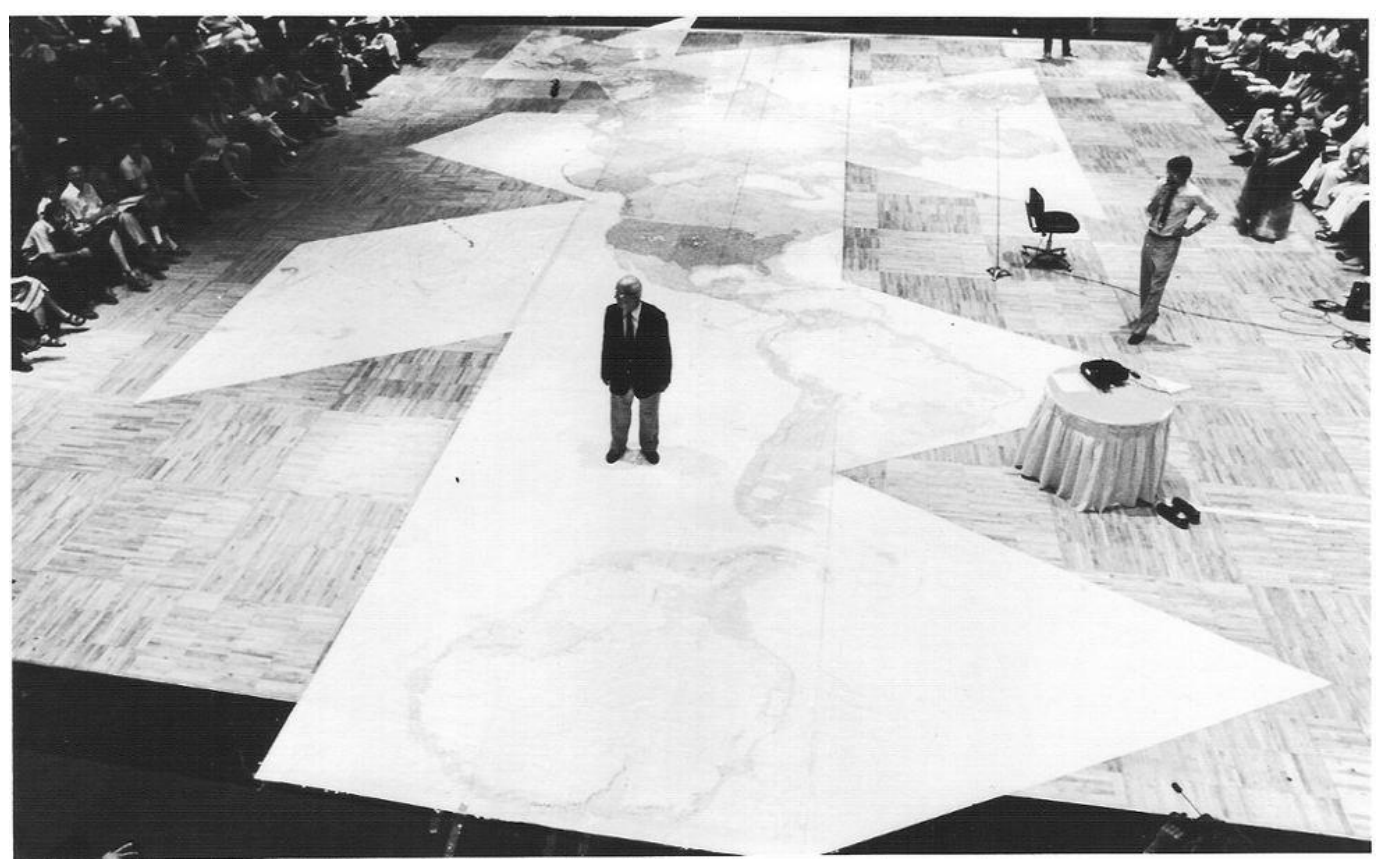

Figure 27. The World Game: Integrative Resource Utilisation Planning Tool, R. Buckminster Fuller, 1967.

This section discusses current serious game design approaches and frameworks, and it defines and evaluates previous approaches to architectural design games that can help support collaborative architectural design inquiry. The review then looks specifically at literature on serious games that are design ideation oriented-those designed to enable the effective generation and communication of ideas, visions, concepts or solutions to design problems. It then looks at literature on serious games that are socially oriented-more specifically, those designed to explore conflicting stakeholder perspectives and build civic engagement and social capital.

The purpose of this section is to:

1. Define "serious games" and key associated terms and attributes (section 2.3.2).

2. Review the approaches for enablement of future-oriented design ideation in support of collaborative architectural design inquiry through the design of serious games (section 2.3.4). 
3. Identify key socially oriented serious games strategies to help stakeholders explore conflicting stakeholder perspectives and the building of civic engagement and social capital in relation to social, architectural and urban issues (section 2.3.5).

4. Summarise the review by presenting relevant strategies derived from the literature that may be used in the development of effective speculations to address the Research Question (section 2.3.6).

\subsubsection{Defining Serious Gaming in Architecture and Planning}

\subsubsection{Games}

Strategy SG-1: Ensure that serious games are designed to be both educational and fun while being designed to interface with slum-upgrading design processes.

Implications for Research: This section suggests that bespoke serious games that are designed for a specific objective are more effective than appropriating games to participatory design processes that were designed for other purposes. It also suggests that the design language sometimes used by architectural or urban design serious games is not optimally accessible to non-expert players.

Before discussing serious games, it is important to define what a game is and how the term will be used in the context of this research, as a number of definitions exist in the literature. Salen and Zimmerman, in Rules of Play: Game Design Fundamentals, define games as "a system in which players engage in an artificial conflict, defined by rules, that results in a quantifiable outcome" (Salen \& Zimmerman, 2004, p. 80). Clarke Abt states that when "reduced to its formal essence, a game is an activity among two or more independent decision-makers seeking to achieve their objectives in some limiting context. A more conventional definition would say that a game is a contest with rules among adversaries trying to win objectives" (Abt, 1970, p. 6). As Alenka Poplin points out, one of the most interesting attributes, particularly with reference to architectural games, is the acknowledgement that a game is an activity in which players make decisions (Poplin, 2012, p. 198). In many planning games, winning a conflict between players is not the ultimate goal. Most design or planning games are non-competitive, shifting the focus away from winning toward the "fun of playing and win-win relationships" and in doing so can encourage playfulness and 
cooperation (ibid). Turner posits that the playfulness of games creates a liminal state in which hypothetical scenarios may be played out. Turner notes that:

part of [play] subverts past legitimacies and structures; part of it is mortgaged to the future in the form of a store of possible cultural and social structures, ranging from the bizarre and ludicrous to the utopian and idealistic, one of which may root in a future reality (Turner, 1987, p. 96).

Thus, through the experience of play, participants are able to forget the present, suspend disbelief, and accept the rules and space of action defined in the game by voluntarily participating in what Huizinga terms the "magic circle" in his book Homo Ludens (Huizinga, 1955). In relation to spaces within the magic circle, "all are temporary worlds within the ordinary world, dedicated to the performance of an act apart" (Huizinga, 1955, p. 10). As Salen and Zimmerman point out in applying the magic circle concept to the design of entertainment-based games, as a player steps in and out of a game, he or she is crossing that boundary - or frame-that defines the game in time and space (Salen \& Zimmerman, 2004).

\subsubsection{Serious Games}

Applications of serious games can already be found in a number of fields including cultural heritage, engineering, education, health and business (Ma \& Oikonomou, 2011). As Di Mascio and Dalton explain, this is due to the fact that their alternative way of representing and communicating information has the potential to make the learning process more interesting and playful and hence more effective (Di Mascio \& Dalton, 2017, p. 434).

The concept of "serious games" was first conceptualised by Clark Abt, in his seminal work Serious Games, as those designed to do more than just entertain (Abt, 1970). Zyda provides the following definition: a serious game is "a mental contest,

played with a computer in accordance with specific rules that uses entertainment to further government or corporate training, education, health, public policy, and strategic communication objectives" (Zyda, 2005). The purpose of serious games is ultimately 
to be both educational and fun (Bellotti, Kapralos, Lee, Moreno-Ger, \& Berta, 2013a). Paul Wilkinson provides an insightful and comprehensive review of the history of serious games that exceeds the scope of this review (Wilkinson, 2016).

It is important to highlight the distinction between serious games and "gamification". While games are considered to embody the experiential and behavioural qualities of gameplay, gamified applications are notably centred around the use of specific game elements invoking playful or ludic qualities (Ampatzidou et al., 2018; Deterding, Dixon, Khaled, \& Nacke, 2011). Gamification involves "the use of game design elements in non-game contexts" (Ampatzidou et al., 2018; Deterding et al., 2011) and became recently popular when game elements started being employed primarily for marketing purposes (Cunningham \& Zichermann, 2011; Huotari \& Hamari, 2011).

\subsubsection{Serious Games in Architecture and Planning}

In her essay "Gamespace Urbanism: City-Building Games and Radical Simulations for Failed Architecture", Federica Buzzi argues that city-planning computer games promise fresh potential for simulation and exploration of radical urban scenarios-and subsequent social, political, and ethical critique. She argues that "[b]eyond critique and virtual entertainment, the question they open up is whether games can be used as reliable systems to study and solve actual and theoretical conflicts" (Buzzi, 2017).

The use of custom serious games that influence real-world architectural and planning systems through virtual experimentation has received growing attention in recent years (Ampatzidou et al., 2018; Poplin, 2011; Poplin \& Vemuri, 2018; Veeningen, Szirbik, \& Blokhuis, 2017; Yamu et al., 2017). Approaches such as those by multimedia architectural designer and artist Lawrence Lek depict speculative worlds and site-specific simulations using gaming software such as Maya and Unity. Often based on real places, Lek's works such as Unreal Estate (2015) and Shiva's Dreaming (2014) use distortions of virtual time and space in order to present uncanny takes on an alternative reality, which are pitched at those seeking to subvert the authority institutional establishments. Likewise, the architectural design practice You+Pea, founded by Sandra Youkhana and Luke Caspar Pearson, has been investigating how architects can use video game technologies as an interactive means of understanding buildings and cities. Their projects, such as the London Developers 
Toolkit (2016) (see Figure 28), which is a satirical app referencing the frustration of being architects in London without much architectural agency amongst the many stakeholders, are all designed to impact on our perception of and interface with reality through virtual experiences and interactions.

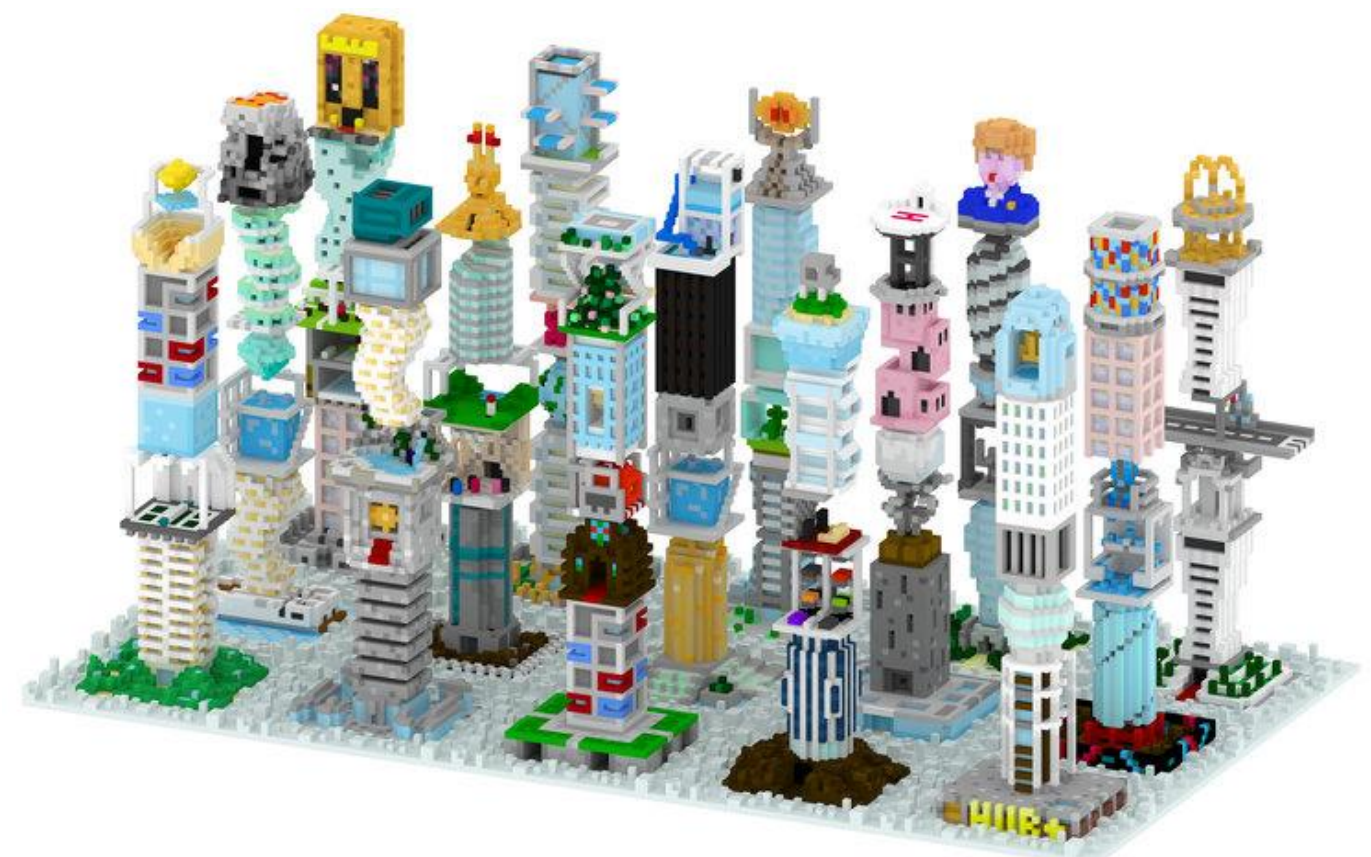

Figure 28. London Developers Toolkit, You+Pea.

The interest of urban scholars in serious games stems from games' specific ability to balance entertainment and learning (Jabbar \& Felicia, 2015; Boyle, Connolly, Hainey, \& Boyle, 2012; Whitton, 2011). Many early applications of table-top based serious games in architecture and planning have focussed predominantly on addressing topics such as land use, transportation, ecology, and management of natural resources through the interactive modelling of urban dynamics. Beginning in the 1960s and 1970s, Jay Forrester's (1969) work on urban dynamics, as well as Richard Duke's manual Metropolis: The urban systems games, inspired a number of simulation-based gaming approaches (Duke, 1975). For example Meadows et al. alarming report "The Limits to Growth" adopted system-dynamics based world models, predicting an emerging ecological, energy, and demographic crisis (Meadows, Meadows, Randers, $\&$ Behrens, 1972); the popular city-building game SimCity was influenced by this work (Mayer, 2009). More specifically in urban planning, the use of games for various design purposes in particular has remained a popular tool for spatial modelling, 
simulation and public participation (Ampatzidou et al., 2018; Devisch, Poplin, \& Sofronie, 2016; Poplin, 2012).

Di Mascio and Dalton divide more recent approaches to digital serious games in architecture into two categories. The first category uses game engines mainly for visualising a design scheme to present it to players or stakeholders, as opposed to allowing them to actively contribute to it - what was described in the previous section as a "partial participation" based approach (Borries, Walz, \& Bottger, 2007; Di Mascio \& Dalton, 2017, p. 439; Yamu et al., 2017). The majority of design proposals visualised through these technologies are also primarily developed by urban designers or architectural professionals, so the players are asked to provide their thoughts only at a later stage. In other words, the 'participatory' aspect of the 'serious game' is post hoc rather than concurrent (Di Mascio \& Dalton, 2017; Indraprastha \& Shinozaki, 2009). For example, O'Coill and Doughty created a virtual environment with the aim of improving the communication of an existing design proposal to residents of Hull in East Yorkshire, England; this game environment was displayed during a design workshop after which comments were solicited (O'Coill \& Doughty, 2004).

The second category represents the more recent approaches to serious games, where games are used for more design-oriented purposes. This category has become more popular in recent years due to increased access to videogame development packages that require less computer knowledge and computer coding ability to develop custom games, such as Unity3D and Unreal Engine (Korody, 2016; Poplin \& Vemuri, 2018; Westre, 2014). For example, Block'hood (2017) (see Figure 29), developed by Sanchez in Unity3D, is a crowd-sourced simulation-based serious game oriented towards ecological urbanism. The game, based on a rectangular voxel grid, allows the player to place modules - each of which represents a different unit such as housing, wind turbines, farms, water towers and parks - that provide fresh air, shops that produce income and clinics that reduce sickness (Sanchez, 2015). Players are challenged to maintain an ecological balance as each block placed will consume and produce resources of different kinds. Although Block'hood is mostly abstract and not situated within an existing urban condition, it establishes the significance of gaming and user participation in education and contemporary urbanism (Markopoulou, Ingrassia, Chronis, \& Richard, 2018, p. 226). Likewise, the custom serious game B3-Design your Marketplace! (2014), developed by Alenka Poplin, engaged the citizens of Billstedt, Germany in the redesign of the town square. The game provided them the 
opportunity to select and add street furniture objects (such as benches, lights and trees) and to (re)arrange the position of these elements around the 2D and 3D virtual representations of the square; the game allowed participants to share ideas and vote for each design solution, improving the communication between citizens and planners (Poplin 2011).

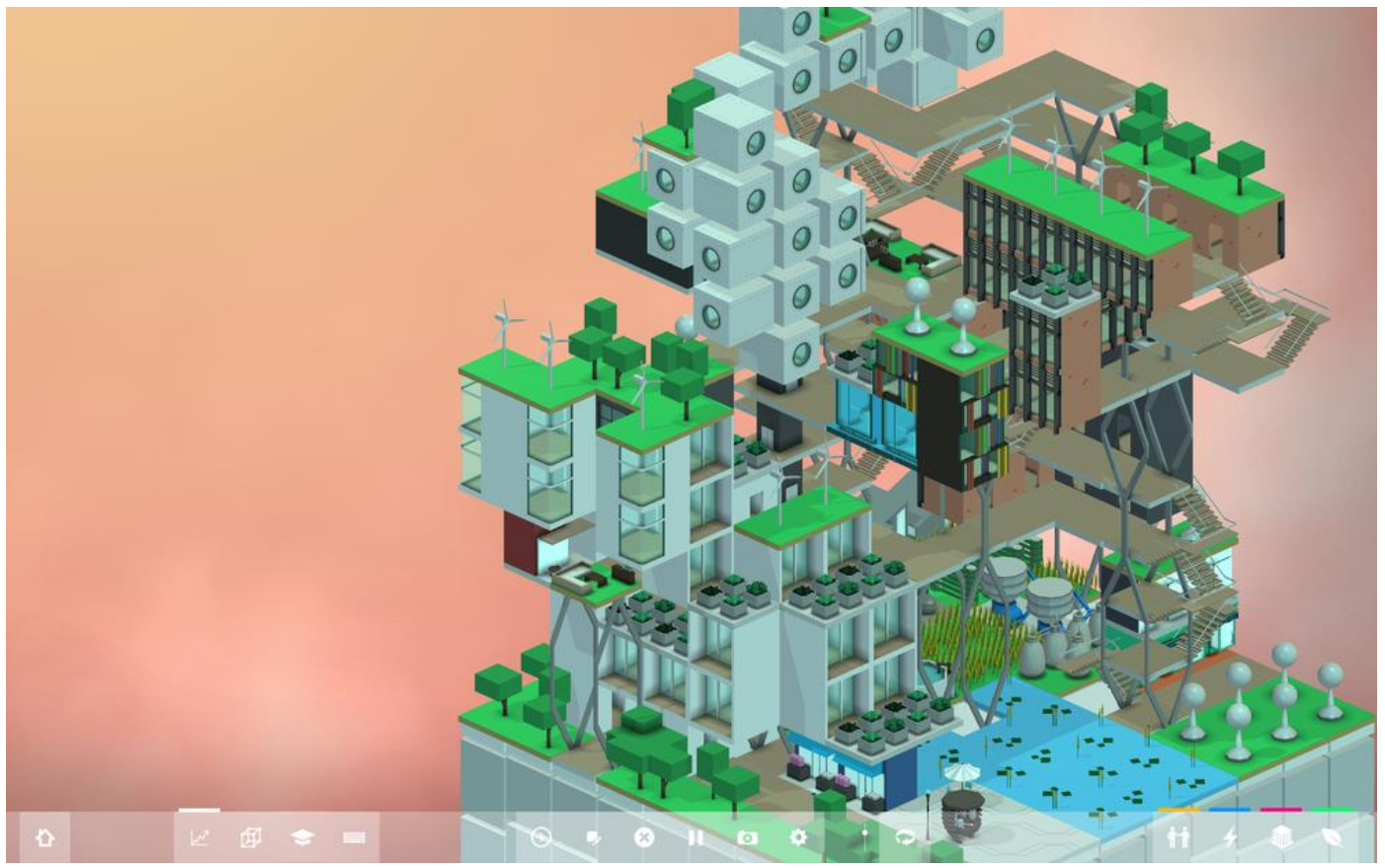

Figure 29. Block'Hood, Jose Sanchez, 2017.

The design-oriented category also includes those serious game approaches that repurpose commercial-off-the-shelf (COTS) games as a cost- and time-effective strategy for design purposes, which has had some positive impact. Urban design and architecture are topics in many commercially developed videogames designed for entertainment purposes, including simulation and strategy games such as SimCity (1989) (Figure 30, below), Minecraft (2009), Anno 2205 (2015) Cities Skylines (2015), Prison Architect (2015) and Parkitect (2018). Many have been utilised for serious design purposes. Often in a COTS-based approach, real-world sites are modelled within an existing city building style game with which players then experiment. The approach is not particularly flexible regarding the implementation of custom game rules or mechanics. 


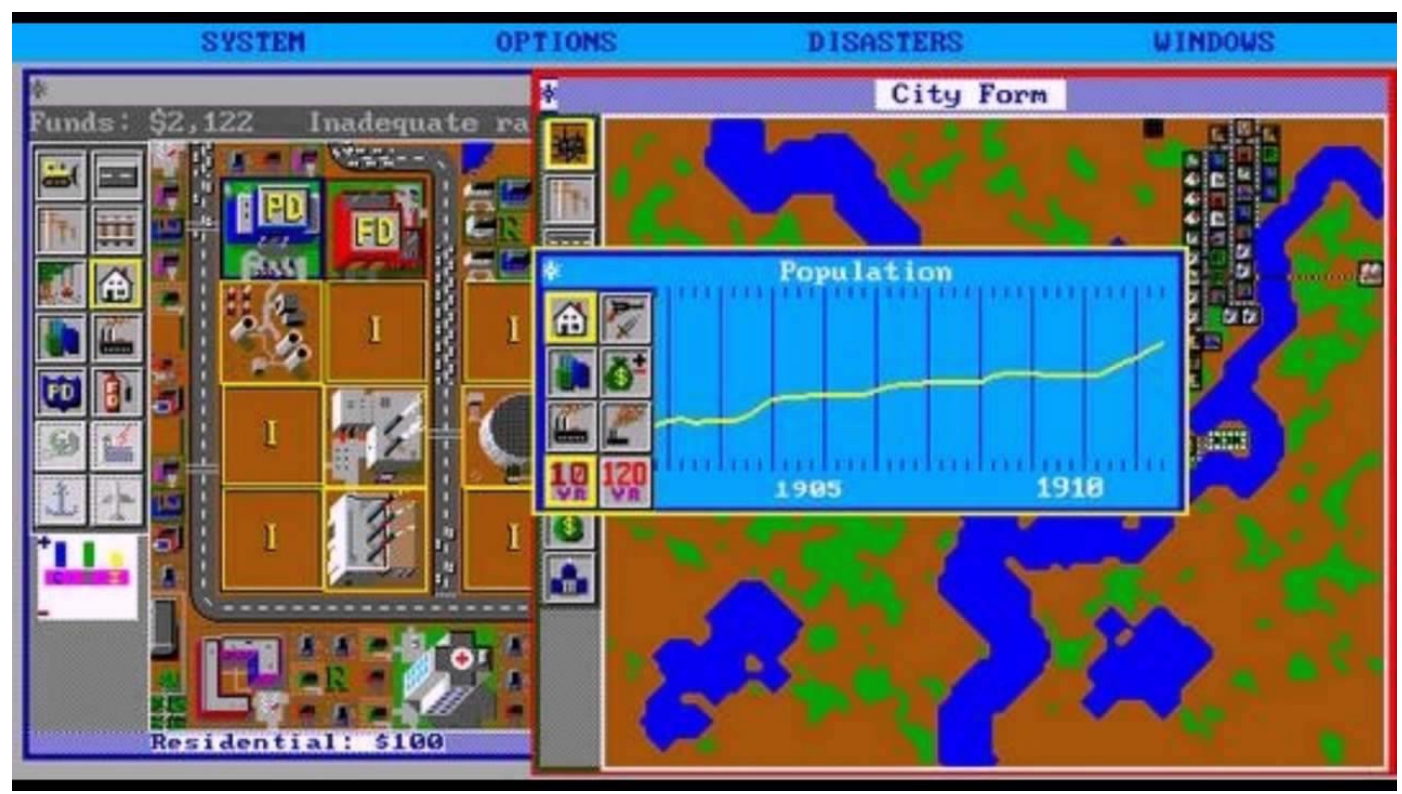

Figure 30. Sim City, Maxis, 1989.

For example, the city building game Cities Skylines (Figure 31) has been used for a number of serious game based urban design applications. It was used successfully in the design of a new transportation system being built in the Norra Djurgårdstaden district of Stockholm, Sweden that was planned using the game and documented in the film My Urban Playground (2016). Its primary success was that it enabled players to simulate the district in-game to test different scenarios and explore possible methods for Norra Djurgårdstaden to become sustainable, and versatile enough to support the needs of its residents, while adding 12,000 new homes and 35,000 workspaces to help combat accommodation shortages in the area (Wakefield, 2017). In addition to professional city builders and planners, the public were also involved in the project, offering ideas and modifications in line with the workshop's goals (Donnelly, 2016).

As Ulrich and Henrik-Helms (2017) and Poplin (2011) argue, COTS games are hindered by the fact that they are designed for entertainment - not participatory design processes (Poplin, 2011; Ulrich \& Henrik-Helms, 2017). The repurposing of COTS games for urban design purposes can also confuse players involved in the participatory process. For example, a participatory gaming workshop instruction given by a facilitator might contradict a built-in game mechanic or goal, creating confusion amongst participants. Some COTS games can be operated in an open world "build" mode for participatory design workshops, which removes built-in game rules; however, in this case the gaming process relies on a combination of verbal or written 
external workshop instructions provided by a facilitator to structure the gameplay activities, which can lead to issues regarding clarity of instruction.

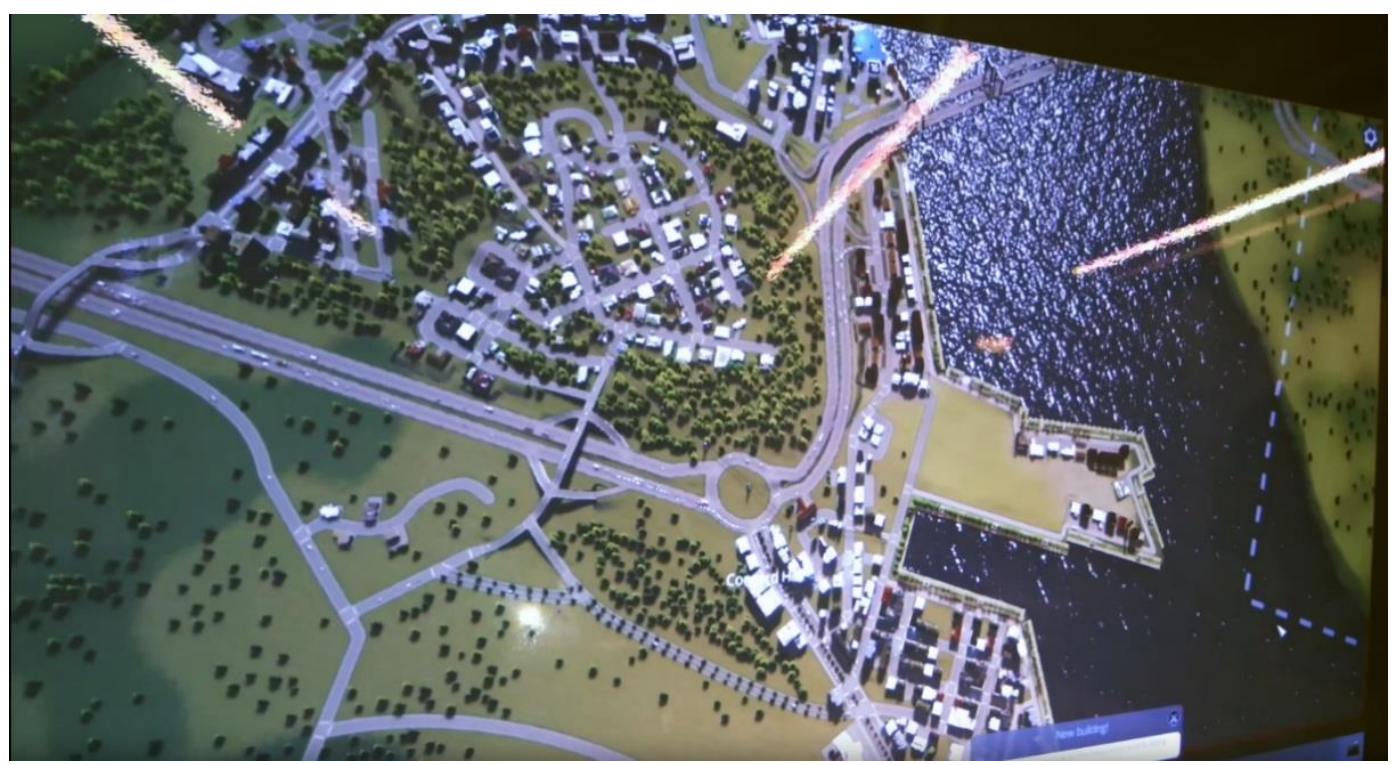

Figure 31. Cities Skylines being projected onto a wall for use in participatory design workshops in Norra Djurgårdstaden, Stockholm, Sweden, 2016.

\subsubsection{Serious Games Used in Slum-upgrading Research}

A number of examples exist where serious games have been used for slumupgrading purposes in various capacities.

GETH2O (2010) (Figure 32), developed by game developers Butterfly Works, is an online flash and mobile phone game that deals with the themes of poverty, corruption, water scarcity, crime, and community development. The aim of the game is for players to develop houses while dealing with the issue of a lack of potable drinking water. Its purpose is to enhance understanding of the basic dynamics of conflict, conflict escalation, the role of the community and the role of individuals in preventing conflict and promoting peace. The designers intent was that playing the single player mobile phone game fosters awareness about how to peacefully handle community problems and options, which are then flagged for common action and possible long-term results. As such, the game provides an engaging, self-reinforcing context in which to motivate and educate players; however, while the game focusses on exploring many of the issues faced by slum dwellers in upgrading processes, it is single player, meaning that collaboration between various stakeholders is not supported, and the board-game-like 
interface provides only two-dimensional pictorial representations of buildings and spaces, and so might struggle to interface with design processes if it were used in a pragmatic slum-upgrading context.

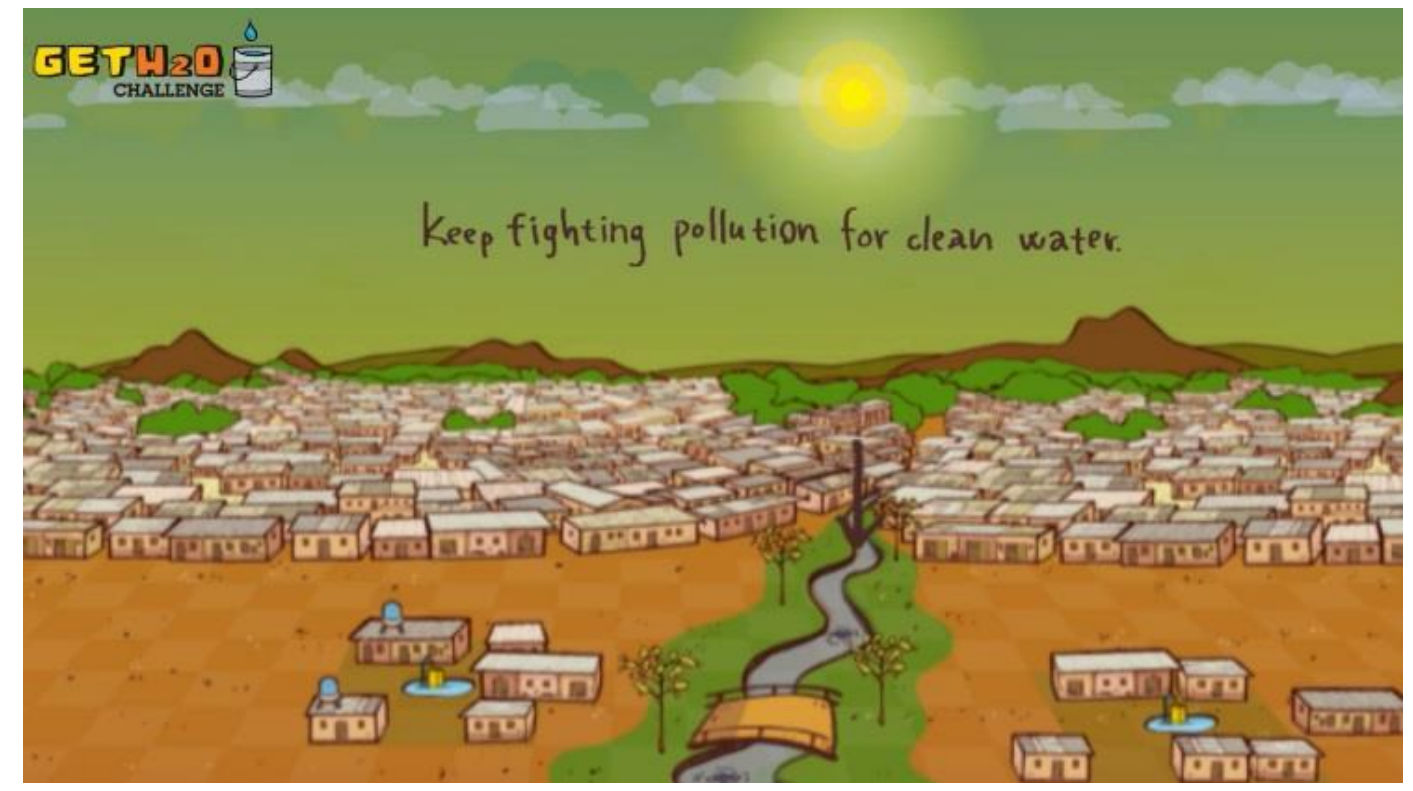

Figure 32. GetH20 (Butterfly Works, 2010).

Block by Block represents a serious application of the sandbox ${ }^{4}$ videogame Minecraft in a partnership between the game's makers Mojang and the United Nations Human Settlements Programme, the UN agency promoting sustainable towns and cities (see Figure 33). In this initiative, players are engaged in the redesign of specific urban public spaces using Minecraft to alter existing conditions represented within the game.

The Block by Block programme organises workshops with 30-to-50 people who live and work around the planned public spaces. Divided into groups of around three or four people, the local residents are taught how to build in the virtual landscape of Minecraft. The project has been successful in that several series of workshops have been coordinated in various countries including Kenya, India, Haiti, Mexico and Nepal, with a number of implemented public spaces resulting from the workshops; however, the methodology used by UN-Habitat (von Heland et al., 2015) is limited in its scope to the pragmatic upgrading of specific spaces and does not focus on an

\footnotetext{
${ }^{4} \mathrm{~A}$ sandbox is a style of game in which minimal character limitations (such as segmented areas via level progression) are placed on the gamer, allowing the gamer to roam and change a virtual world at will.
} 
exploration of possible futures, conflicting stakeholder perspectives, and corresponding goals surrounding social, architectural and urban issues.

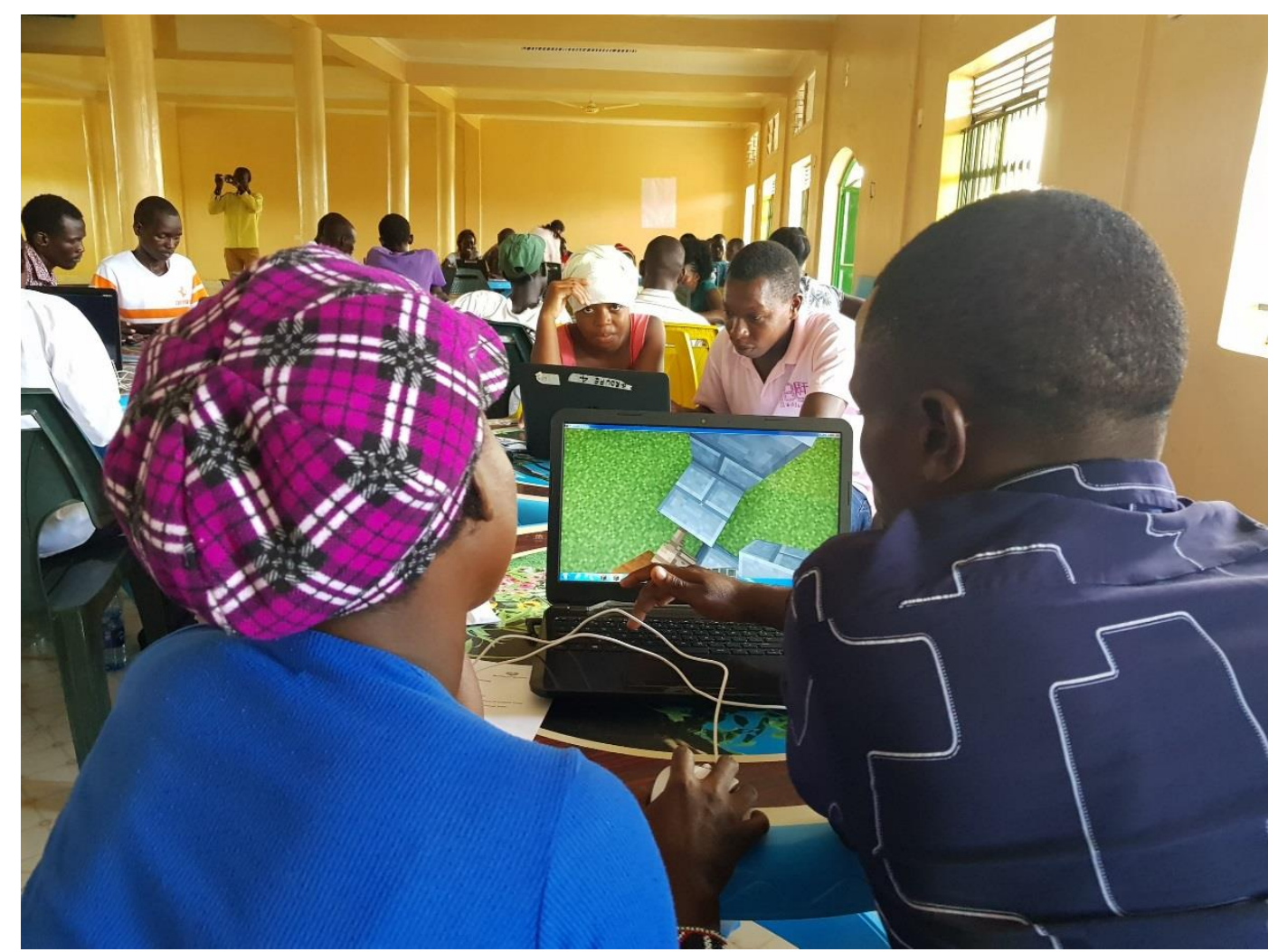

Figure 33. Block by Block participants in Nairobi Kenya collaborate in public space design (Block by Block, 2017).

YouPlaceIt! (2018) is an example of a Public Participation Geographic Information System (PPGIS) developed by Poplin \& Vemuri and implemented in the Dharavi slum area of Mumbai, specifically dealing with stakeholder negotiation and consensus building regarding upgrading issues via a digital GIS interface (Figure 34). YouPlaceit! enables the players to design their own urban space by using different objects such as benches, trees, lights, and fountains focusing around a road construction process. The purpose of YouPlaceIt! is to enable stakeholders to communicate and resolve specific urban planning issues. This game assumes that the stakeholders wish to redevelop the area, create something new, and resolve problems or disputes that parties wish to negotiate (Poplin \& Vemuri, 2018).

While the game was useful in driving negotiation, the GIS interface was found to be too complex for those with a low level of digital literacy. The approach did, however, open up a number of interesting questions relating to the aims of this 
research, including the role of language in spatial games and its power to create coalitions and power relations; the role of negotiations in spatial games and their role in consensus finding participatory processes, modelling negotiations in spatial games, issues of serious upgrading aspects and how to combine them with playful and experimental game elements; the forms and implementations of collective reflections about upgrading issues and how they can be facilitated by a spatial game; and what characteristics of spatial games can successfully support community planning and civic engagement processes (Poplin \& Vemuri, 2018, p. 86).
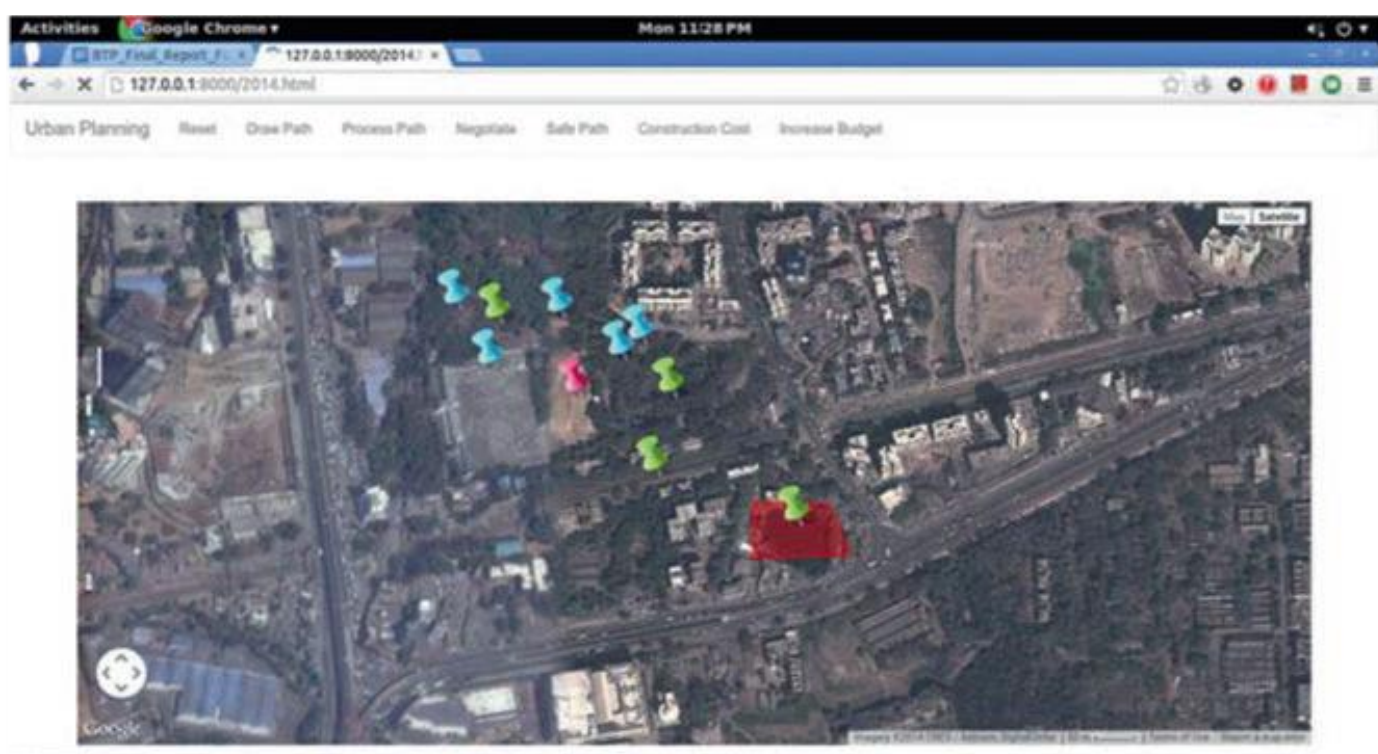

Figure 34. Places identified as different types of properties in YouPlaceIt (Poplin \& Vemuri, 2018, p. 78).

In a further example, Markopoulou et al. (2018) utilise a virtual and augmented reality-based approach to serious games to "create a channel of communication with the actual users of the projects and through our digital intervention to better understand their needs and communicate their design intentions to the designers and stakeholders" (Markopoulou et al., 2018, p. 227). Through a project, located in the slum area of the Worli district of Mumbai, India, the authors explored using Augmented Reality as an interface to allow the players, as inhabitants of the spaces, to explore and experiment with the different ideas and configurations of the physical space through a tablet-based serious game simulation. The approach was shown to help both digitally-literate and illiterate players effectively make collaborative design decisions and give designers feedback on the preferred proposals through a simplified graphical user interface 
(Markopoulou et al., 2018); however it was limited in terms of its collaborative capacity due to the single player nature of the Augmented Reality medium (see Figure 35 and Figure 36).

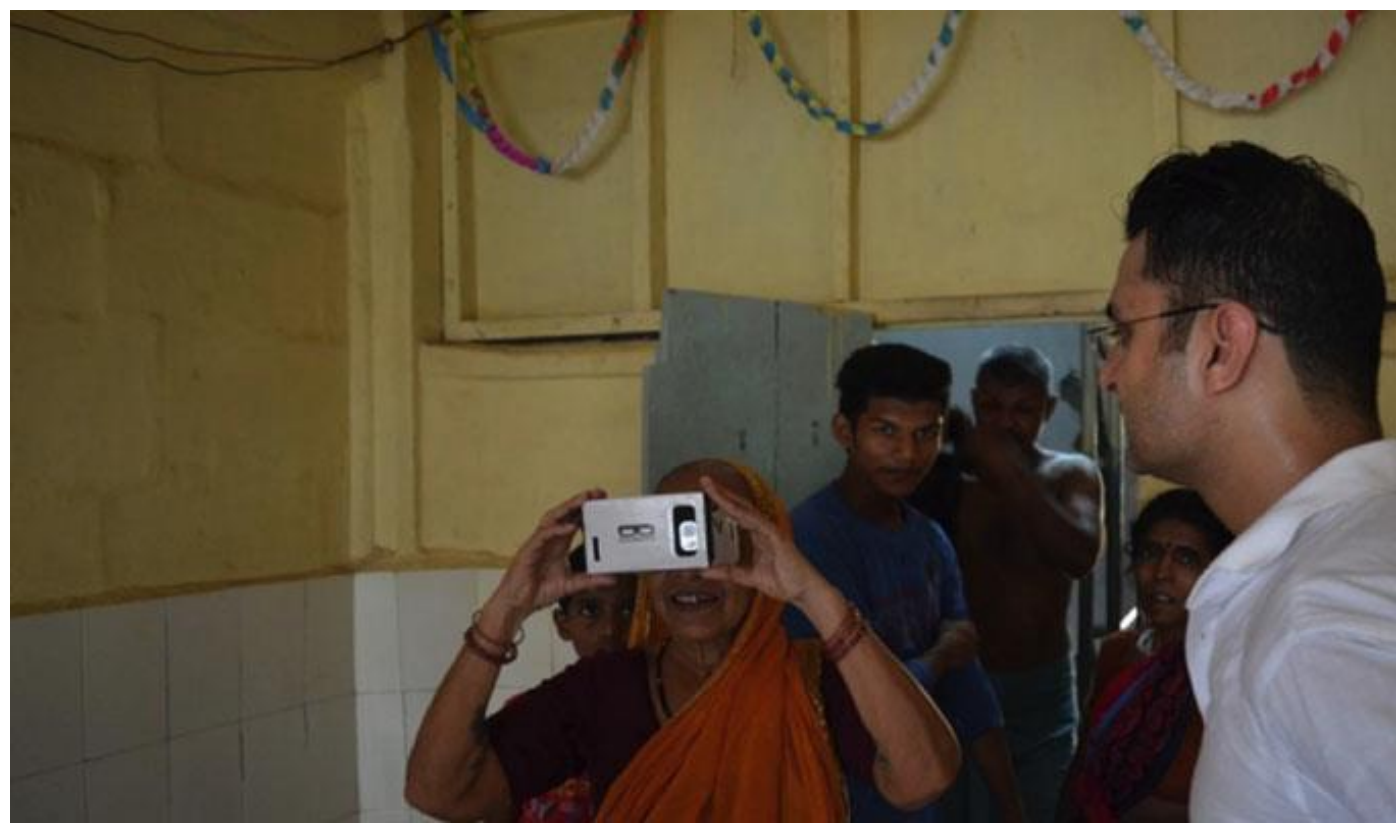

Figure 35. Participation event in Mumbai-residents using VR devices (Markopoulou et al., 2018, p. 229).

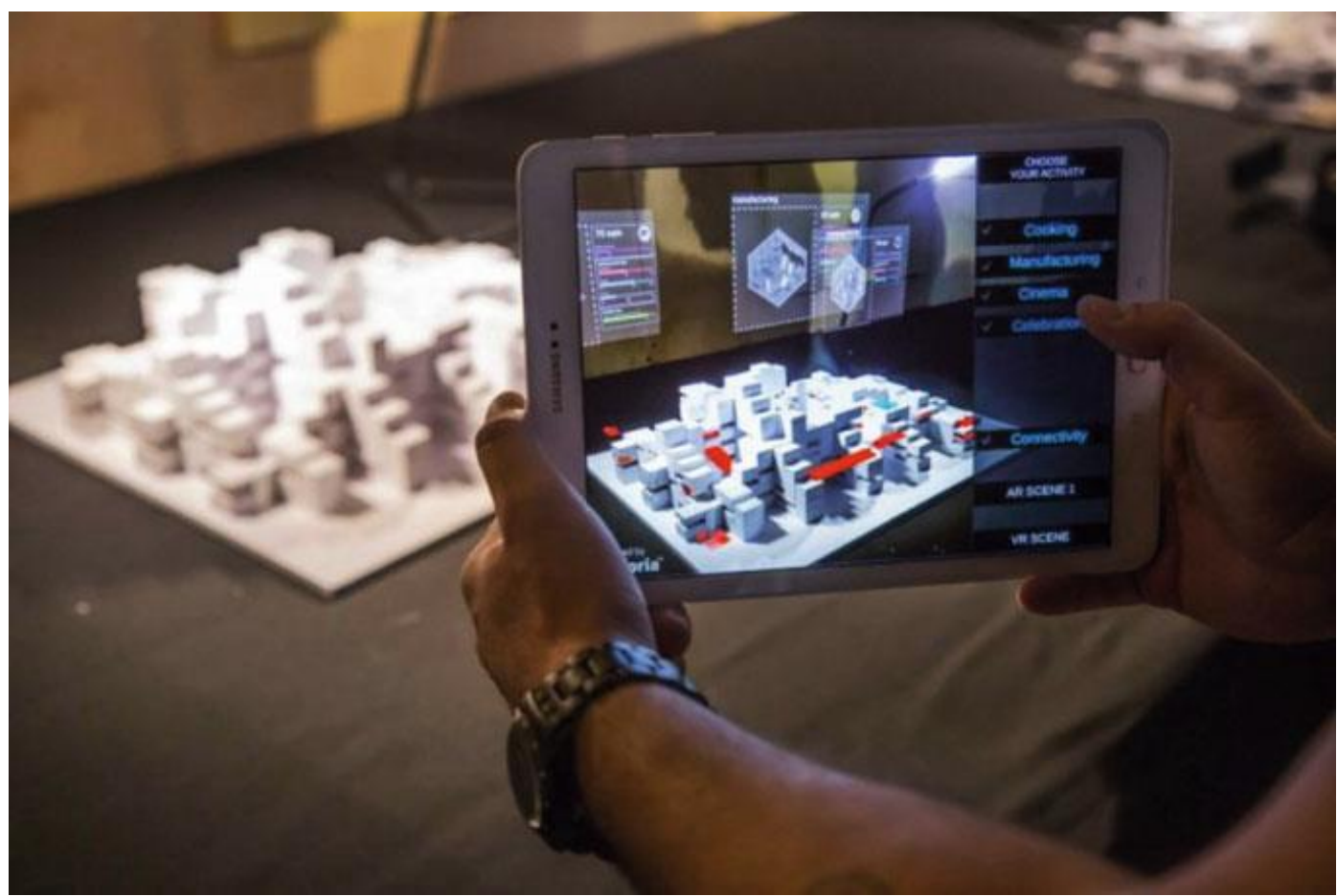

Figure 36. Participation event in Mumbai-residents using VR devices (Markopoulou et al., 2018, p. 229). 
These examples have shown that slum-upgrading orientated serious games provide an engaging, self-reinforcing context in which to motivate and educate players towards slum-upgrading objectives; however, while games generally focus on exploring many slum-upgrading processes, some are single player, meaning that collaboration between various stakeholders is not supported and some use simplistic visual languages that provide abstract representations of buildings and spaces, and so stakeholders might struggle to interface with design processes if it were used in a pragmatic slumupgrading context. Some examples, such as Block by Block, utilise off the shelf games that are not designed for participatory design purposes and so have a tension between the fictional objectives of the game designed for entertainment and the objectives of the participatory design activity. Some examples utilise GIS formats that have been shown to be too complex for those with low levels of digital literacy, which might reduce engagement and thus do not sufficiently allow players to address both social and design objectives.

\subsubsection{Serious Game Design}

Strategy SG-2: Develop serious game mechanics (various actions, behaviours and control mechanisms afforded to the player within a game context), the dynamics (the run-time behaviour of the mechanics acting on players' inputs and each other's outputs over time), and the aesthetics (which evoke desirable emotional responses evoked in the player, when they interact with the game system) to promote the objective of the serious game.

Implications for Research: Consider both the desired social and design outcomes within a participatory process and develop serious games mechanics, dynamics and aesthetics to promote these objectives.

The MDA (Mechanics, Dynamics, and Aesthetics) framework, developed by Hunicke, LeBlanc, and Zubek (2004) and taught as part of the Game Design and Tuning Workshop at the Game Developers Conference (GDC) between 2001 and 2004, has been widely adopted as an overarching framework guiding the design of digital games. It is also useful for the positioning of serious games. The framework describes how the three key components of "Mechanics" (detailed in section 2.3.3.1), 
"Dynamics" (detailed in section 2.3.3.2) and "Aesthetics" (detailed in section 2.3.3.3) help to formalise serious game design, which is useful when considering the design of serious games.

\subsubsection{Serious Game Mechanics}

Mechanics are the various actions, behaviours and control mechanisms afforded to the player within a game context (Hunicke et al., 2004). Together with the game's content, such as levels and resources, the mechanics support overall gameplay dynamics.

Some authors have provided useful frameworks for the design of serious game mechanics that have been utilised to add to this broader definition of game mechanics (Raphael, Bachen, Lynn, Baldwin-Philippi, \& McKee, 2010; Mitgutsch \& Alvarado, 2012; Ulrich \& Henrik-Helms, 2017). Ulrich and Henrik-Helms (2017) provide a particularly useful framework for the design of serious game mechanics that addresses game mechanics in the four key dimensions of: game mechanics (section 2.3.3.1.1), learning mechanics (section 2.3.3.1.2), social mechanics (section 2.3.3.1.3), and immersive mechanics (section 2.3.3.1.4) (Ulrich \& Henrik-Helms, 2017, p. 699).

\subsection{Game Mechanics}

Game mechanics are methods designed for interaction with the game state, which are invoked by the players, thus providing gameplay (Aldrich, 2009; Arnab et al., 2015; Bellotti, Kapralos, Lee, Ger, \& Berta, 2013; Sicart, 2008). They help to create games that are fun to play. Djaouti et al. use game mechanics as a reference for interactive in-game content and gameplay that defines the rules and objectives of a game (Djaouti, Alvarez, Jessel, Méthel, \& Molinier, 2008). More specifically, rules are those factors of influence that determine or limit a game player and their decisions (Tan, 2014, p. 83). Games are based on simple rules that are compulsory for all players. Using these simple rules, players create unpredictable complexities-especially in design oriented serious games (Tan, 2014, p. 129). Brandt et al. argue that in "design games", collaborative activity should be guided by simple and explicit rules, where: the game materials or environment typically point to existing practices and/or future possibilities; the games are played within a confined and shared temporal and spatial 
setting often removed from the everyday context of the players; the purpose of the game is to establish and explore novel configurations of the game materials and the present and future practices to which these materials point; and at the end of the game, the players will have produced representations of one or more possible design options (Brandt et al., 2008, pp. 53-54). In this way games can be a medium for other types of participatory design activity that comprise the rules, the game materials and the temporal or spatial setting.

\subsection{Learning Mechanics}

"Learning mechanics" are those that aim to facilitate player learning through gameplay, translating learning techniques, methods and models into game mechanics that enhance players' abilities to learn or interact with a specific topic, such as leaning a key design concept. These mechanics include providing feedback and guidance to players and allowing them to experiment. Many serious game researchers and designers draw on Arnab et al., who have listed a range of learning mechanics for use in serious games (Arnab et al., 2015).

Much of the serious games literature has put emphasis on informing serious game development with established instructional strategies and pedagogical theories (Arnab et al., 2015; Corrigan, Zon, Maij, McDonald, \& Mårtensson, 2015; Kebritchi \& Hirumi, 2008; Nazry \& Romano, 2017; Rooney, 2012). Many serious games designers utilise the theoretical model of experiential learning defined by Kolb (1984). Kolb defines learning as "the process whereby knowledge is created through the transformation of experience" (Kolb, 1984, p. 41) (see Figure 37).

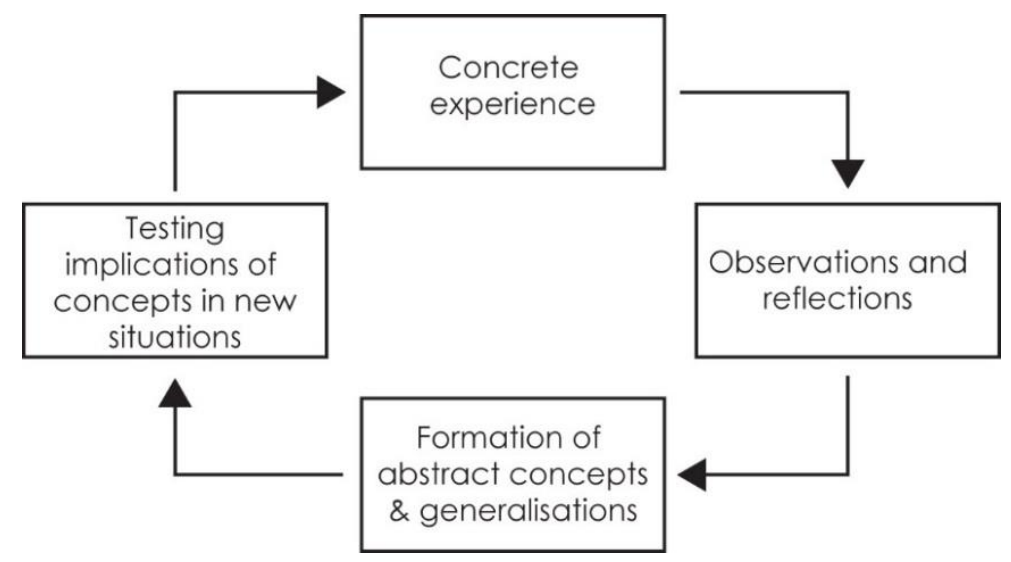

Figure 37. Kolb's experiential learning model. Adapted from (Kolb, 1984, p. 21). 
While various models of experiential learning have been proposed, Kolb's modelwhich has foundations in the philosophical traditions of Dewey, Lewin, and Piaget is a central work in the field of serious games. According to Kolb, learning is cyclical and consists of four main stages. In the first stage, learners have an experience and observe and reflect on this experience. In the second stage, they draw conclusions, and in the third stage they make generalisations based on this reflection, so that their new knowledge can be used in other scenarios. In the fourth stage, learners test these generalisations and hypotheses through experimentations and further experiences (ibid.).

\subsection{Social Mechanics}

Social mechanics are those designed to facilitate social interaction between players or between players and the $3 \mathrm{D}$ game environment. Social mechanics permit the establishment of communication pathways between players where "expert knowledge" - or knowledge that players bring with them to the game as personal experiences - can be exchanged between players. Ulrich \& Henrik-Helms argue that this allows for the formation of what Lave and Wenger earlier called "communities of practice" between participants (Lave \& Wenger, 1991; Ulrich \& Henrik-Helms, 2017; Wenger, 1998). Within these communities of practice, social norms can be created and institutionalised, form collective and individual actions (Postmes, Spears, \& Lea, 2000), create positive space for individual and group flourishing (Argenton, Triberti, Serino, Muzio, \& Riva, 2014) and induce inter-player cooperation (Morschheuser, Riar, Hamari, \& Maedche, 2017).

\subsection{Immersive Mechanics}

Finally, immersive game mechanics need to be designed with the right amount of fidelity to create an immersive experience and authentically represent reality. Ulrich and Henrik-Helms (2017) and Zyda (2005) describe how game designers can create immersive serious games by designing intuitive game interfaces, immersive sound effects, and visually simulative 3D representations (Ulrich \& Henrik-Helms, 2017, p. 700; Zyda, 2005). 


\subsubsection{Serious Game Dynamics}

As mentioned previously, the MDA (Mechanics, Dynamics, and Aesthetics) framework describes how the three key components of Mechanics, Dynamics, and Aesthetics help to formalise game design. The category of Dynamics describes the runtime behaviour of the mechanics acting on players' inputs and each other's outputs over time. These may include time pressure, lack of resources to complete a certain task, or incentives and achievements that guide players toward a particular action. For example, in the game Monopoly, as the winning players becomes increasingly wealthy, they can penalise poorer players more effectively. As the gap between the winning and losing players widens, the number of invested players decreases and can result in tensions between players and a loss of agency (Hunicke et al., 2004).

\subsection{Immersion Dynamics}

Immersion dynamics is an important aspect of maintaining player motivation throughout the gameplay processes in order to meet educational or design-oriented objectives. Brown and Cairns (2004) define immersion as the user's degree of involvement with a computer game (Brown \& Cairns, 2004), in a wide-ranging review exploring pedagogy, play and "fidelity"-using graphics, audio, video, threedimensional virtual worlds, and artificial intelligence to authentically represent reality in serious games. Serious games theorists argue that players should be given control over their experience and be provided with a means to make choices (Bowman, 1982; Garris \& Driskell, 2002; Hamari et al., 2016; Malone, 1981; Sweetser \& Wyeth, 2005). Authors have also highlighted the importance of presenting players with progressive challenges and in some instances competition in order to increase immersion, and that these are balanced with the progression of player skills (Bowman, 1982; Garris \& Driskell, 2002; Malone, 1981; Prensky, 2001; Sweetser \& Wyeth, 2005). Players should be given a clear task or goal where their roles and responsibilities in the task are clearly defined. The rules need to be clear for all players in order for the game to be considered fair (Bowman, 1982; Garris \& Driskell, 2002; Prensky, 2001; Sweetser \& Wyeth, 2005). Players should also be given direct and instant feedback on their progression towards achieving an objective (Prensky, 2001; Sweetser \& Wyeth, 2005). A summary can be found in Table 2, below. 
Table 2. Summary of game features identified as key to player engagement. Adapted from (Rooney, 2012).

\begin{tabular}{ll}
\hline Study & Game Design Features \\
\hline (Malone, 1981) & $\begin{array}{l}\text { Fantasy (graphics), control, challenge, curiosity, collaboration, } \\
\text { competition }\end{array}$ \\
(Bowman, 1982) & $\begin{array}{l}\text { Clear task, identifiable roles and responsibilities, player choice, } \\
\text { balance between player skills and challenges }\end{array}$ \\
(Prensky, 2001) & $\begin{array}{l}\text { Clear rules, continuous challenge and competition, clear goals and } \\
\text { objectives, direct and instant feedback, immersive story line }\end{array}$ \\
(Garris \& Driskell, 2002) & Clear rules/goals, sensory stimuli, challenge, mystery, control \\
(Sweetser \& Wyeth, 2005) & $\begin{array}{l}\text { Concentration, challenge, skills, control, clear goals, feedback, } \\
\text { immersion, social }\end{array}$ \\
\hline
\end{tabular}

\subsection{Creating Authenticity}

A number of authors, including Ulrich and Henrik-Helms, (2017), Coulton et al. (2014) and Charsky (2010), discuss how creating credible and authentic dynamics for players is important to achieve within serious games, but doing so can be challenging. Coulton et al. argue that in order to do this well, verifiable real-world data sources such as player experiences, environments and systems must be drawn upon throughout the design process of a serious game when designing game mechanics and 3D representations. In this way, the serious game may be anchored to the real world and the real-world experiences of the participants, which have been shown to have positive leaning and cooperative effects (Coulton et al., 2014; Morschheuser, Riar, et al., 2017).

Further, Charsky argues that serious games that require a high level of authenticity - those trying to educate or create realistic design proposals, i.e., with a high level of game "fidelity" - will help players transfer knowledge to the real world (Charsky, 2010); however, an issue that some highly realistic games face with regard to real-world design processes relates to their ability to visualise highly detailed outcomes. While realistic in-game representations can be engaging for participants, they can create confusion regarding pragmatic viability of in-game outcomes-such as design outcomes in a planning game created by participants. This has led to disappointment and tension amongst players and participants in some instances (von Heland et al., 2015). While in-game instructions might carefully explain the role of a 
digital game as a tool to be used within a given design or learning process, the visual language that is used to represent in-game environments may be such that participants perceive the game visualisations as reality—such as a finalised design outcome. This has also been shown in cases utilising Geographic Information Systems (GIS) based serious games research, with non-expert players who might have a lower level of digital literacy (Boroushaki \& Malczewski, 2010).

\subsubsection{Serious Games Aesthetics}

Strategy SG-3: Utilise simplistic or stylised 3D representation in order to reduce issues regarding the pragmatic viability of in-game design decisions from the perspective of the participants.

Implications for Research: Ensure that serious games are designed to clearly communicate the intended viability of the workshop outcomes and aid visual communication.

As mentioned previously, the MDA (Mechanics, Dynamics, and Aesthetics) framework describes how the three key components of Mechanics, Dynamics, and Aesthetics help to formalise game design. The category of Aesthetics describes the desirable emotional responses evoked in the player, when they interact with the game system. The aesthetics of the game help the designer describe the dynamics and the mechanics of the game to the player, set the tone, and give clear feedback to the players regarding scores, time, resources and progression. Hunicke et al. describe this relationship from the designer's perspective, where the "mechanics give rise to dynamic system behaviour, which in turn leads to particular aesthetic experiences. From the player's perspective, aesthetics set the tone, which is born out in observable dynamics and eventually, operable mechanics" (Hunicke et al., 2004, p. 2).

\subsection{D Representation}

Di Mascio and Dalton argue that in designing architectural serious games “people's understanding of 3D representations of buildings and urban environments can be facilitated by designing a virtual navigable architectural environment of an existing place that citizens are familiar with" (Di Mascio and Dalton, 2017, p. 444). According 
to Di Mascio and Dalton, the adjective 'architectural' means that particular care of architectural details is essential for two reasons: first, citizens can familiarise themselves with schematic 3D representations of architectural elements and 3D navigation; and second, a detailed 3D virtual environment increases people's interest, immersion and engagement during virtual navigation making more enjoyable, playful and effective experiences (ibid.).

Some academic inquiry into the effectiveness of serious games has focused on player 3D immersion as the determining factor (Bellotti, Kapralos, Lee, Ger, \& Berta, 2013; Susi, Johannesson, \& Backlund, 2007); this has led to the design of games that are structurally and visually similar to successful entertainment-oriented games (McLaughlin, Smith, \& Brown, 2010, p. 133). In line with this entertainment-oriented literature, Kickmeier-Rust et al. proposed that, for teaching and learning purposes, 3D immersive games are intrinsically superior to 2D games because the latter fail to hold a player's attention for extended periods of time (Kickmeier-Rust et al., 2007). 3D virtual environments can be explored using a first-person perspective and in real time. Such virtual journeys provide experiences of spaces and freedom of movement closer to reality than via any other medium (Di Mascio, 2010). In these environments, movement and points of view are not constrained to predefined paths, and players can collaboratively share their narratives, such as stories and memories linked to or about a specific place during gameplay (Di Mascio \& Dalton, 2017, p. 444).

As McLaughlin et al. argue, computer graphics in serious games, and games in general, can be divided into three primary categories: modelling (3D models), animation (the motion of 3D models), and rendering (how 3D lighting systems interact with surfaces of 3D models) (McLaughlin, Smith, \& Brown, 2010, p. 133). Drawing on (McLaughlin, 2005) in an effort to categorise the relationship between computer graphics techniques and the graphical style of 3D representation within serious games, McLaughlin, Smith, and Brown (2010) provide a framework for visualisation styles within serious games in which they divide visual styles into simplified (Figure 38), stylised (Figure 39) and realistic (Figure 40). 


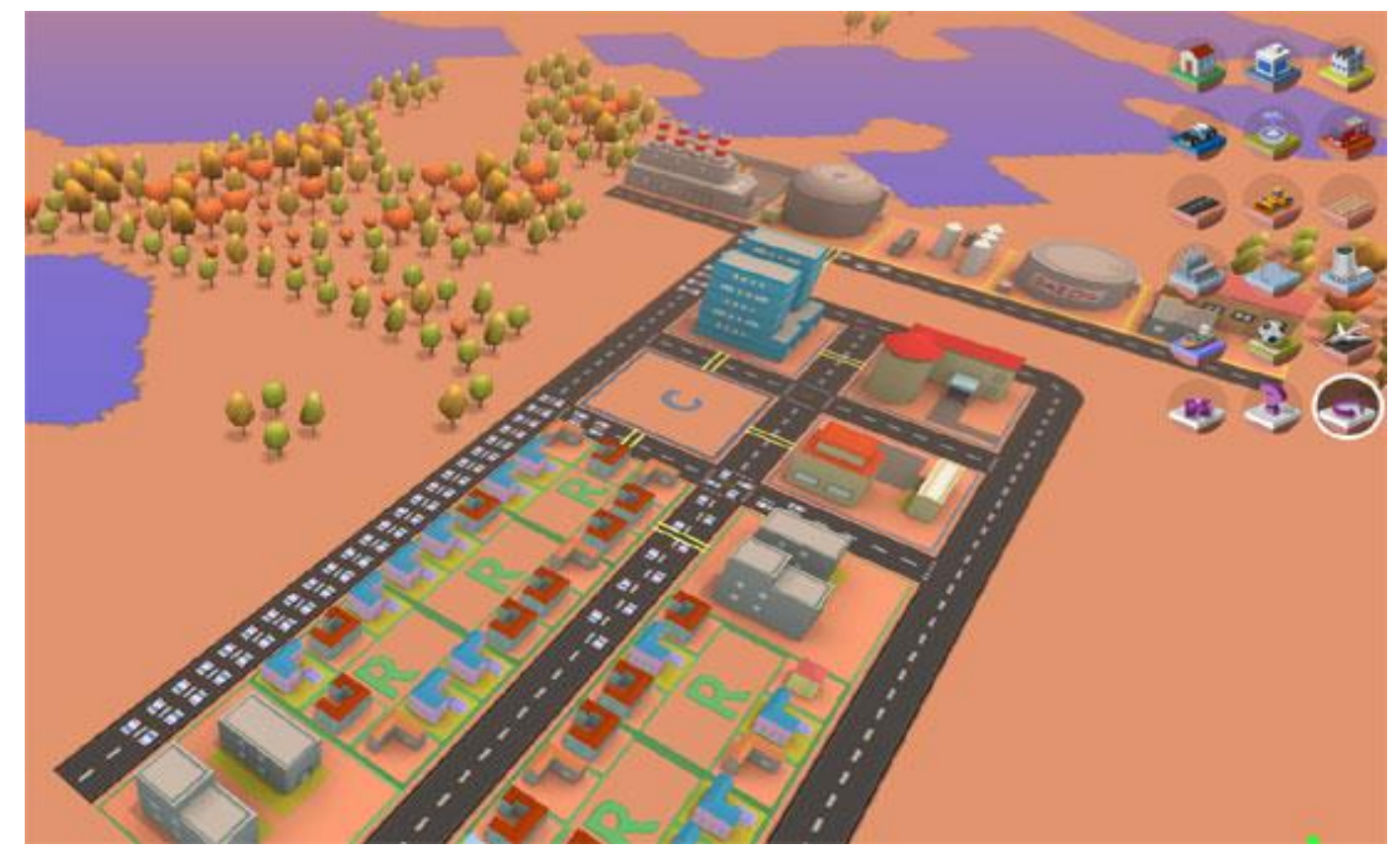

Figure 38.Simplified, low-polygon graphic style of 3D City Builder.

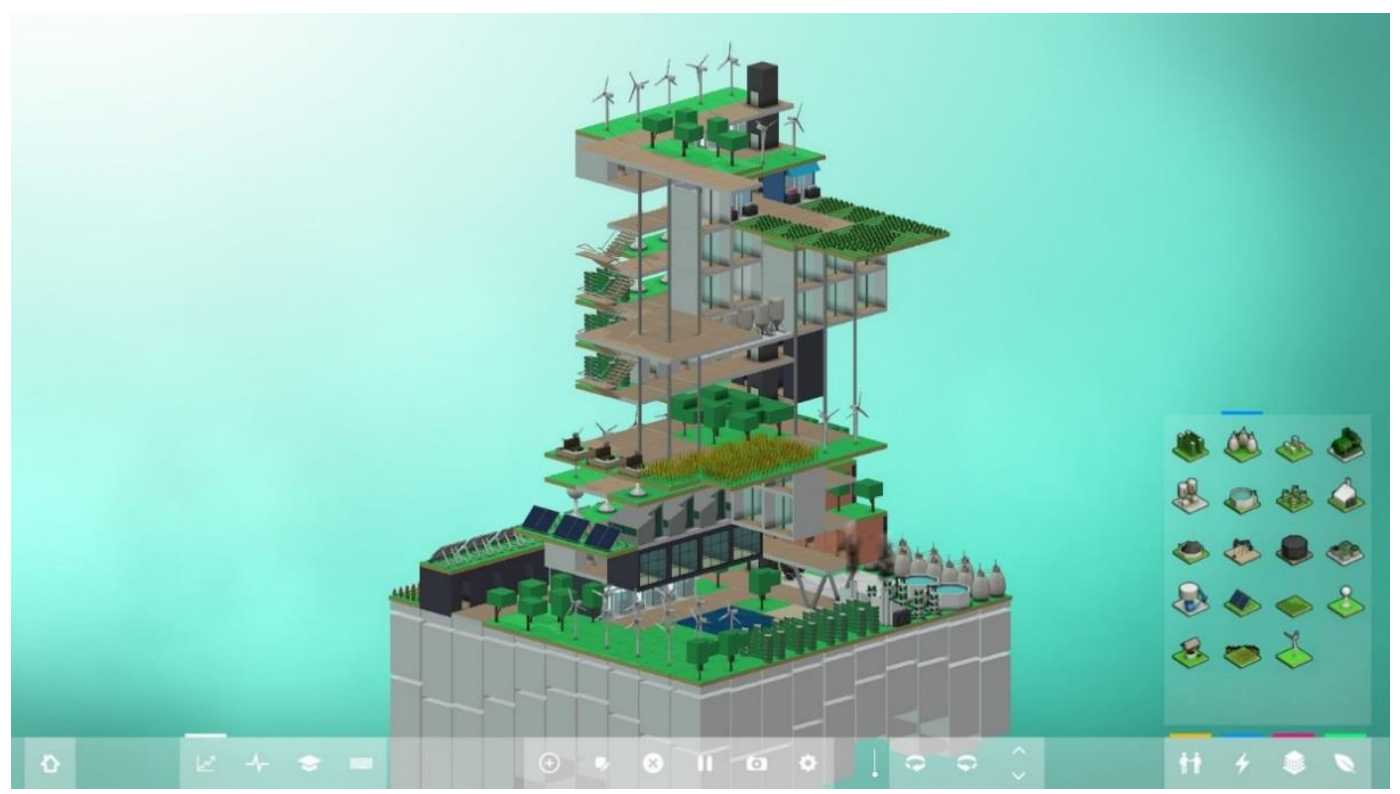

Figure 39. Stylised graphic style used in Block'Hood. 


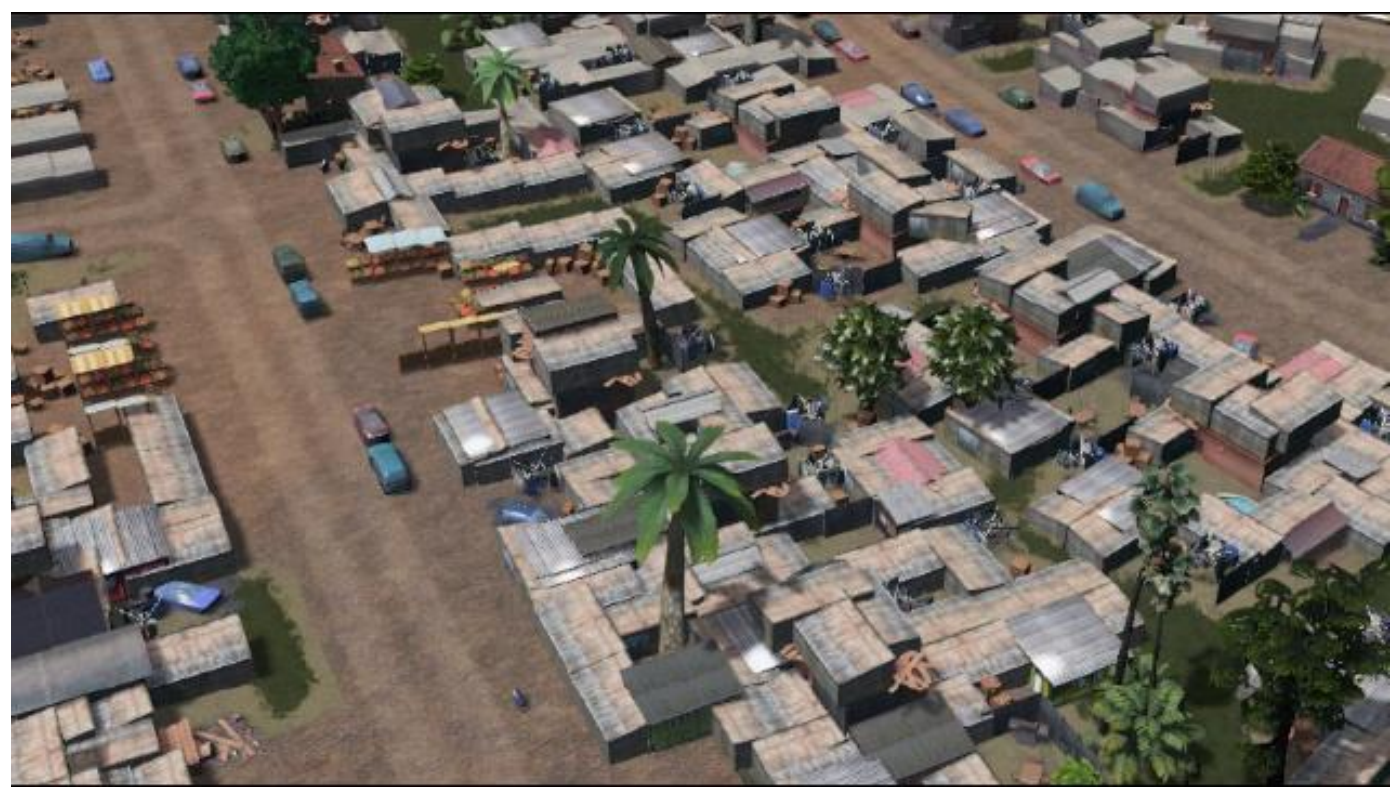

Figure 40. Realistic visual style of Cities Skylines with "Slums for Cities Skylines" modification.

McLaughlin et al. argue against the use of realistic representation for a number of reasons. 3D representations that are more realistic are inherently more complex and require a higher level of technical expertise to design, as well as more computational power to be accomplished (McLaughlin et al., 2010, p. 136). Realism also depends on a number of systems being simulated, for instance the presence of people in the environment and their credible behaviour or the motion of trees or other environmental entities, in order to be convincing. Players may have expectations about the design of serious games that are based on their experience with commercial computer games. In that case, it is not unlikely that they will become disappointed, which may be reflected in less motivation and learning; however, both Vogel et al. (2006) and Wouters, Nimwegen, van Oostendorp, and van der Spek, (2013) investigated the level of realism (photorealistic, high-quality cartoons, low-quality pictures, or unrealistic) in relationship to learning and found no differences between the levels. Both studies showed that from the perspective of learning, there is no argument to opt for photorealistic visual designs, because more basic designs such as schematic/textual and cartoonlike designs can be equally or more effective. Further, McLaughlin, et al. demonstrate that the overall effectiveness of serious games on learning does not rise as a consequence of greater realism (McLaughlin et al., 2010, p. 136). 
Table 3. Speculative Strategies for Urban Design Serious Gaming. Adapted from (McLaughlin, 2005, p. 133).

\begin{tabular}{|c|c|c|}
\hline Visual Style & Visualisation Categorisation & Characteristics \\
\hline Simplified & $\begin{array}{l}\text { Modelling: Objects and ideas } \\
\text { represented as symbolic forms. Level of } \\
\text { detail is low. } \\
\text { Animation: Non-articulation of figures. } \\
\text { Motion fidelity is low. } \\
\text { Rendering: Minimal shading of curved } \\
\text { surfaces and transparency. No texture } \\
\text { mapping. }\end{array}$ & $\begin{array}{l}\text { Shorter development cycle due to } \\
\text { simplistic modelling processes, low } \\
\text { level of rendering complexity. }\end{array}$ \\
\hline Stylized & $\begin{array}{l}\text { Modelling: Identifiable objects with } \\
\text { unrealistic proportions or juxtapositions } \\
\text { of parts. Level of detail can range from } \\
\text { low to high. } \\
\text { Animation: Articulation and } \\
\text { deformation of figures present. } \\
\text { Expressive actions are magnified. } \\
\text { Motion fidelity varies according to } \\
\text { expressive requirements. } \\
\text { Rendering: Shading of curved surfaces, } \\
\text { transparency, texture mapping. }\end{array}$ & $\begin{array}{l}\text { Shorter development cycle than realistic } \\
\text { representation. Stylised visual style } \\
\text { allows the designer to alter the level of } \\
\text { detail in game assets and use rendering } \\
\text { to narrative affect. }\end{array}$ \\
\hline Realistic & $\begin{array}{l}\text { Modelling: Photo-accurate modelling of } \\
\text { familiar objects. Level of detail is high. } \\
\text { Animation: Coordinated systems } \\
\text { defining both articulation and } \\
\text { deformation such as from performance } \\
\text { capture and physically based simulation. } \\
\text { Motion fidelity is high. } \\
\text { Rendering: Photo-realistic shadow } \\
\text { casting, reflections, caustics, light } \\
\text { scattering, radiosity. }\end{array}$ & $\begin{array}{l}\text { Time consuming, computationally } \\
\text { intensive, potentially confusing for } \\
\text { players regarding the pragmatic viability } \\
\text { of in-game actions. }\end{array}$ \\
\hline
\end{tabular}

While it would be easy to assume that the teaching and learning of complex subject matter requires the use of sophisticated computer graphics, the situation is more nuanced. Some games requiring high levels of cognitive accomplishment, such as requiring the player to assimilate and use knowledge to create novel objects or situations, may be best served by simplified or stylised graphic styles such as those with a low-polygon count or simple colour and texture pallets (McLaughlin et al., 2010, p. 136). These stylised 3D representations have been used effectively in a number of serious games, such as the low-poly approach in IDeEA Lab's serious games platform designed for fostering interdisciplinary design collaboration, led by Professor Jules Moloney at Deakon University (IDeEA Lab, 2017). 


\subsubsection{Facilitating Design Collaboration and Ideation in Serious Games}

Strategy SG-4: Ensure that serious games are used as a means to facilitate collectively creating ideas for the future and communicating a shared understanding of design problems.

Implications for Research: Utilise the simulation of reality, role-playing and support for faster collaboration such as visualisation, modelling and collaboration features to meet the requirements of ideation techniques for the collaborative process of idea generation.

Most serious games are used primarily as a tool to support the diffusion of wellidentified knowledge, for example to transfer a piece of knowledge (e.g., the use of a new procedure or best practice) to an individual player or players; however, some scholars have recently started to explore the use of serious games as a means to facilitate collectively creating ideas for the future. As Agogué, Levillain, and Hooge point out, the three characteristics of serious games-simulation of reality, roleplaying and support for faster collaboration-meet the requirements of ideation techniques for the collaborative process of idea generation (Agogué, Levillain, \& Hooge, 2015, p. 417). As pointed out by Finke, Smith and Ward, the generation of new ideas is a cognitive, creative process that is intended to combine and blend different pieces of knowledge to form a new original element of thought, i.e., a new idea (Finke, Smith, \& Ward, 1992). The production of new ideas, whether individually or collectively, requires knowledge retrieval, idea association and knowledge creation (McAdam \& McClelland, 2002), all of which are traits of knowledge manipulation activities that could be supported by serious games (Agogué et al., 2015, p. 417). For example, Couton et al. evidence this through the design of the serous game Cold Sun (2014), which allows players to effectively rehearse issues of climate change that will affect their plausible futures, and thus develop a greater understanding of some of these complex issues and consider ways to respond (Coulton et al., 2014). The authors show that the facilitation of a playful and subversive environment was conducive to encouraging greater exploration of ideas between players (Coulton et al., 2016; Salen \& Zimmerman, 2004).

Further, serious games have been shown to be well-suited to communicating a shared understanding of design problems, because they allow participants "to 
experiment with potential solutions in a safe setting and generate their own mental frames and responses to problems" (Swain, 2007). This participatory experimentation can be described as "collective tinkering" and can help stakeholders collaboratively generate ideas (Innes \& Booher, 1999, p. 9). Within the safe, restricted, and structured realm of multiplayer serious games, stakeholders can gain feedback from others on each experimental iteration, accumulating new knowledge from the game system and player interactions (Cheng, 1999, p. 97). Serious games not only have the ability to deliver messages and simulate systems, but also to simulate participant experiences (Bogost, 2007). Brandt argues that collaboratively simulating urban design scenarios can be transformative for participants, because they can rehearse scenarios with a low cost of failure and then interpret game events' personal experiences, on which they can draw in future situations (Brandt, 2006). In an example of this, Markopoulou et al. (2018) utilise a virtual and augmented reality based approach to serious games to "create a channel of communication with the actual users of the projects and through our digital intervention to better understand their needs and communicate their design intentions to the designers and stakeholders" (Markopoulou et al., 2018, p. 227). Through two projects, located in the Worli district of Mumbai, India and the SuperBlock project of Barcelona, the authors explored using Augmented Reality as an interface to allow the players, as inhabitants of the spaces, to explore and experiment with the different ideas and configurations of the physical space through a tablet-based serious game simulation. The approach was shown to help both digitally literate and illiterate players effectively make collaborative design decisions and give designers feedback on the preferred proposals through a simplified graphical user interface (Markopoulou et al., 2018).

\subsubsection{Conflicting Stakeholder Perspectives and Social Capital in Serious Games}

Strategy SG-5: Promote discourse surrounding goals and values that can lead to better idea exploration, discourse, decision making, and increases in consensus, cooperation and empowerment.

Implications for Research: Mitigate internal dynamics such as inequality between players or deviation from the aim of the design game during gameplay through ingame exploration of social and design issues. 
Most architectural and planning-oriented serious games tend to focus on "design outcomes" as the main objective (Ampatzidou et al., 2018; Mather \& Robinson, 2016; Poplin \& Vemuri, 2018; von Heland et al., 2015; Yamu et al., 2017; Yan et al., 2011), while architectural and planning-oriented serious games that focus specifically on implementing social mechanics are much more scarce (Holland \& Roudavski, 2016; Vemuri et al., 2014). A lack of focus on the social dimension of serious games can limit constructive discourse surrounding goals and values that can lead to better idea exploration, discourse, decision making, and increases in consensus, cooperation and empowerment. This facilitation is important because, as Tan argues, a stakeholder group's reliance on existing decision-making mechanisms, rules and regulations, or the balance of power between the involved parties, may hinder the link between the game and the reality it aims to influence (Tan, 2014, 2016). Internal dynamics such as inequality between players, or deviation from the aim of the design game during gameplay, can also impact on the performance of the participatory gaming process (Tan, 2016).

However, even though simulation and modelling still play a pivotal role in urban planning, policy and design games, the potential of games to create environments for cooperation, civic engagement, negotiation and deliberation-by creating a level playing field among players - is attracting increasingly more attention, which is also informed by the rising interest in gamification (Ampatzidou et al., 2018; Devisch et al., 2016; Gordon \& Baldwin-Philippi, 2014b; Poplin, 2012; Tan, 2014). Games processes have also been shown to help communities build cooperation as well as enhance social integration and connectedness, as shown in the work of (Argenton et al., 2014; Bagozzi \& Dholakia, 2002; Morschheuser, Maedche, \& Walter, 2017; Morschheuser, Riar, et al., 2017). They can have a direct impact on increasing decision making-giving disparate stakeholders, designers and planners new avenues to converse and shaping how players and their opinions are organised, become informed, collaborate and take action (Ben-Attar \& Campbell, 2015; Morschheuser, Riar, et al., 2017; Raphael, Bachen, \& Pedro F. Hernández-Ramos, 2012). Like other examples of new media approaches, serious games also offer new ways to gather data such as tacit knowledge of players about contexts-allowing for more comprehensively-informed and participatory decision-making processes. Foth et al. found that parallel development in the use of new media, such as narrative-driven serious games can 'democratise' urban development by allowing stakeholders to collaboratively express 
tacit "lived experience" through in-game interactions (Foth, Hearn, \& Klaebe, 2007, p. 6).

\subsubsection{Civic Engagement and Social Capital}

The social aspects of serious gaming have more recently been associated with a series of benefits for participation and civic engagement, such as raising awareness; increasing literacy on specific topics development; developing (complex) problem solving skills; testing difficult scenarios within a safe environment; and establishing networks and coalitions (Erhel \& Jamet, 2013; Granic, Lobel, \& Engels, 2014; Raphael et al., 2010; Raphael, et al., 2012). Multiplayer gaming has also been shown to foster "gaming social capital", a gaming-related community construct that has been shown to be a positive antecedent in predicting both face-to-face social capital and civic participation. Both Molyneux (2015) and Williams (2010) show that there is a spill over effect from the teamwork and collaborative aspects of video games to the ability to work together in a real-world community (Molyneux, Vasudevan, \& Zúñiga, 2015; Williams, 2010). Similarly, a study by Gordon \& Baldwin-Philippi asked community members to play a specially designed civic planning game (Gordon \& BaldwinPhilippi, 2014b). They observed "civic learning," a process in which, through in-game communication and interaction, players can build trust in one another and feel greater ties to their community.

Games can serve as socio-cultural levellers and are therefore a potentially useful medium central to future-orientated development discussions for three reasons. First, as they are outside typical daily tasks, or what Huizinga calls the "magic circle" detailed in section 2.3.2.1, the processes and artefacts related to the videogame are less likely to appear to be "owned" by one player at the expense of others. Second, in playing games that are novel to all players, players are likely to learn games at a similar rate, without large differences in learning due to rank, authority, or background. Learning at a similar rate can lead to greater sharing of ideas, as each player has a similar level of expertise in relation to the gaming task. Third, games can help players cohere together and communicate better, because one of the purposes of games is enjoyment, which can build commitment amongst groups of players (Muller \& Druin, 2002). 


\subsubsection{Summary}

This section has defined and discussed how serious games have been used for ideation purposes as well as how they might contribute to exploring conflicting stakeholder perspectives. Most approaches to architectural and planning games have focussed on the visualisation of design processes, and there is a lack of literature regarding how design-outcome and social-outcome oriented serious games might be combined. The section addressed this gap by looking at serious games literature that is not specific to the realm of architecture and planning. The review showed that ideation can be aided though the simulation of reality, role-playing and support player collaboration. Through playing serious games, players can arrive at a shared understanding of key in-game issues through the rehearsal of scenarios in a medium that has a low cost of failure, which can facilitate building social capital and aiding civic engagement.

The review also highlights the fact that simplistic or stylised 3D representation styles are easier to produce, have been shown to be as effective as realistic representation styles and require less computational power to be accomplished, which are important considerations when designing serious games for marginalised communities where there might be a lack of access to technical resources. I argue that commercially produced games for the purpose of entertainment can be repurposed for serious means, but care needs to be taken not to create confusion for players due to a conflict of the goals of entertainment and the potentially divergent goals of the serious application of the game.

Stylised visual styles might also reduce issues regarding the pragmatic viability of in-game design decisions from the perspective of the participants. Players' collaborative learning can also be aided by moving through cycles of experiencing, reflecting and testing. While serious games are engaging for their entertainmentoriented elements, authenticity must be created by drawing on real-world data and experiences, in order to anchor the serious game experience to the real world. Further, in order to orientate the design of serious games, game mechanics, learning mechanics, social mechanics and immersive mechanics must all be equally considered.

From this serious games literature review, five strategies can be adopted that can help disparate stakeholders explore conflicting perspectives, assumptions and corresponding goals surrounding architectural and urban issues: 
Strategy SG-1: Ensure that serious games are designed to be both educational and fun while being designed to interface with slum-upgrading design processes.

Strategy SG-2: Develop serious game mechanics (various actions, behaviours and control mechanisms afforded to the player within a game context), the dynamics (the run-time behaviour of the mechanics acting on players' inputs and each other's outputs over time), and the aesthetics (which evoke desirable emotional responses evoked in the player, when they interact with the game system) to promote the objective of the serious game.

Strategy SG-3: Utilise simplistic or stylised 3D representation in order to reduce issues regarding the pragmatic viability of in-game design decisions from the perspective of the participants.

Strategy SG-4: Ensure that serious games are used as a means to facilitate collectively creating ideas for the future and communicating a shared understanding of design problems.

Strategy SG-5: Promote discourse surrounding goals and values that can lead to better idea exploration, discourse, decision making, and increases in consensus, cooperation and empowerment.

Having established a range of speculative architecture, participatory design and serious games strategies that can be adapted that can help disparate stakeholders explore conflicting perspectives, assumptions and corresponding goals surrounding architectural and urban issues, the final section of this chapter explores how these might be synthesised into a framework to guide the development of speculative, participatory, serious urban games for use in slum-upgrading contexts. 


\subsection{Synthesising the Literature}

The review of the literature suggests that a serious gaming approach to collaborative speculative architecture - embedded in the participatory design tradition of ideation, exploring conflict and the negotiation of values - can support upgrading oriented ideation and the negotiation of conflicting stakeholder perspectives.; however, how these methods and techniques might be productively combined is an area that is relatively unexplored. The following sections describe how the three fields of literature-namely of speculative architecture, participatory design, and serious games - have been integrated to formulate a new "Speculative Participatory Serious Urban Gaming " theoretical framework designed to enhance social outcomes and related upgrading outcomes for urban slum dwellers. This original contribution to architecture is then discussed and evaluated in the remaining chapters of this thesis.

\subsubsection{Speculative Participatory Serious Urban Gaming (SPS-UG)}

The framework that I call "Speculative Participatory Serious Urban Gaming" (SPSUG), is concerned with drawing together speculative architecture, participatory design and serious games literature in order to go beyond the visualisation of design options, thinking about single speculations or aiding learning about collaborative design processes: it also aims to help participants in a given community or locale to reflect upon a plurality of possible futures that might help them to explore perspectives and corresponding goals surrounding the upgrading of their infrastructures and environments, i.e., to enhance both social outcomes and related design (slumupgrading) outcomes. Figure 41 displays this framework graphically. 


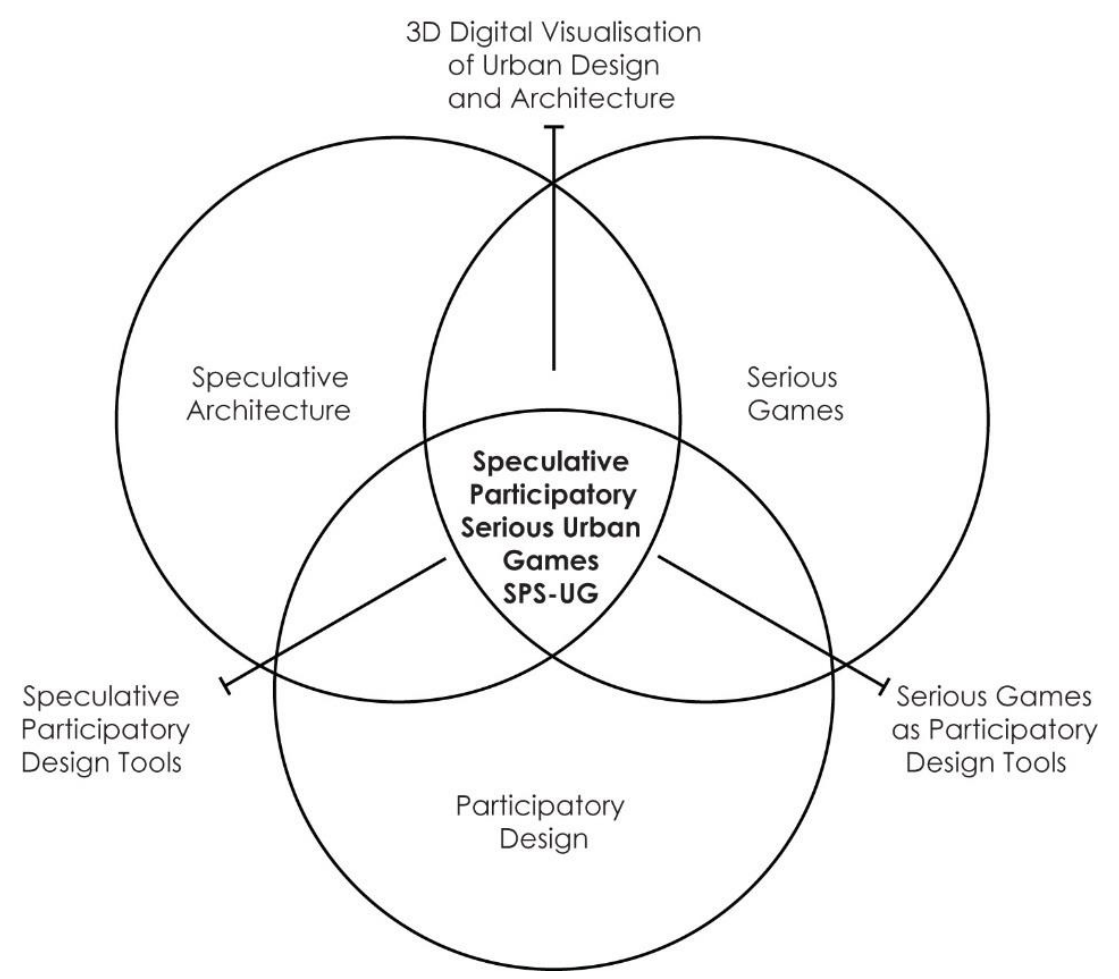

Figure 41. Synthesising the "SPS-UG" approach (author, 2019).

In light of previous matters discussed in sections 2.1-2.3, I developed the SPS-UG Framework specifically builds upon the work of Mitgutsch and Alvarado and their "Serious Game Design Assessment (SGDA) Framework" (2012). Mitgutsch and Alvarado's framework was developed as part of the Gambit Game Lab at the Massachusetts Institute of Technology. The SPS-UG is not an objective measurement instrument, but a generic framework to guide the study of how serious game design elements are configured formally and conceptually in relation to the game's aim and purpose (ibid.).

Mitgutsch and Alvarado identify six essential components of the formal conceptual structure underlying serious games that comprise the SGDA: purpose, content/information, framing, mechanic, fiction/narrative and aesthetics/graphics. The first component is the purpose of the game. Serious games are "purpose-based game systems" so the purpose should have "pivotal influence over all elements of the game design (Mitgutsch \& Alvarado, 2012, p. 4). Thus, the purpose should be reflected in all the other five elements that support the game system: content/information, framing, mechanic, fiction/narrative and aesthetics/graphics. The relation among these six core components impacts the coherence and cohesiveness of the formal conceptual design of the holistic game system as shown in Figure 42. 


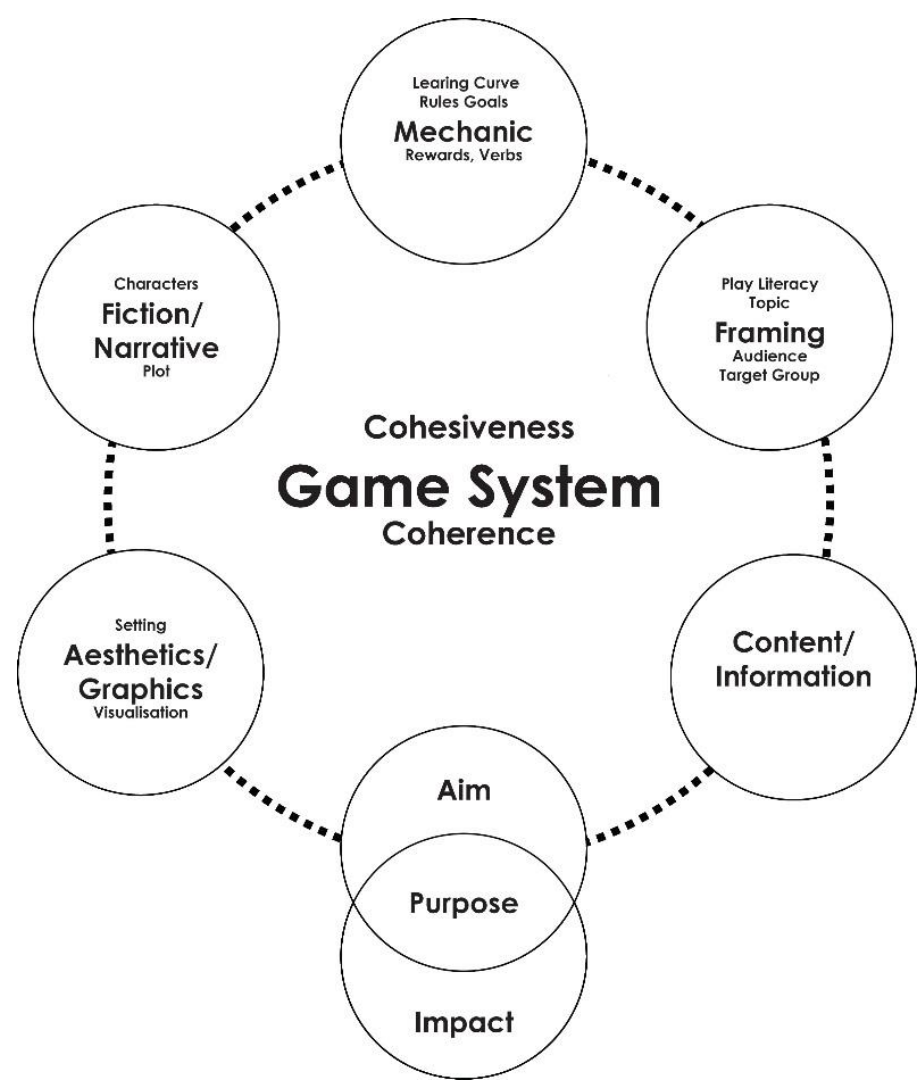

Figure 42. Serious Game Design Assessment Framework Adapted from (Mitgutsch \& Alvarado, 2012).

The thesis's SPS-UG Framework is oriented around the same six comprehensive game elements as Mitgutsch and Alvarado's SGDA Framework, which were derived from a comprehensive review of game design, serious game design and game assessment frameworks and mechanisms; however, the SPS-UG framework takes Mitgutsch and Alvarado's SGDA framework, which was developed for generic serious game design purposes, and adapts it for the specific purpose of this research in line with research Aim 4: To develop, implement and reflect on the use of a speculative, participatory, game-based approach to slum-upgrading in order to aid the generation of useful urban slum-upgrading oriented social outcomes and related architectural design slum-upgrading outcomes for disparate stakeholders in marginalised communities, more specifically, dwellers of landfill-oriented slums.

The following sections of this chapter detail how the speculative architecture, participatory design and serious game strategies derived from the literature in Chapter 2 are oriented within the SPS-UG framework in relation to these six basic game elements. 


\subsubsection{SPS-UG Purpose}

In designing a SPS-UG, I needed to ensure I was very clear about the games purpose. The purpose should be reflected not only in the aim of the game and its topic, but also in the designer's intentions to impact the players in specific ways.

The purpose of the SPS-UG developed in this investigation is to generate useful urban slum-upgrading oriented social outcomes and design outcomes for disparate stakeholders in marginalised communities who are the players. The aim of the game, or the goal the players are driven to reach within the gameplay, should directly reflect this purpose. The SPS-UG should also be clear as to its intentions in terms of the impact or outcomes, so there is no confusion about its objectives from the context of the players. Clarifying these intentions helps ensure that the game has an impact on the player/s in real life situations. If this investigation's SPS-UG has no impact on the player in a real-life context, it misses its pivotal purpose. For this reason, the game's purpose acts as the driving force that shapes the dynamic and the coherence of the game system as a whole.

\subsubsection{SPS-UG Content/Information}

Content/information refers to the graphic and audio information, facts and data that are presented to players within the game that orient their gameplay. At a simplistic level, and in line with serious games strategies in general, these relate to basic player information, the names of the characters/players and other supplementary information such as in-game costs of items, etc.- - all the data and words provided in the game that are visible and made approachable to the players (Mitgutsch \& Alvarado, 2012, p. 4). Strategies derived from the literature which are operationalised as SPS-UG content/information can be seen in Table 4, below. 
Table 4. SPS-UG content/information strategies derived from the literature.

\begin{tabular}{|c|c|c|c|}
\hline $\begin{array}{l}\text { SPS-UG } \\
\text { Element }\end{array}$ & Study & SPS-UG Design Strategies & Literature \\
\hline \multirow[t]{4}{*}{$\begin{array}{l}\text { Content and } \\
\text { Information }\end{array}$} & $\begin{array}{l}\text { (Lindley, Sharma, \& } \\
\text { Potts, 2014, p. 240) }\end{array}$ & $\begin{array}{l}\text { Strategy SA-1: Consider the } \\
\text { speculation's connection and } \\
\text { position to plurality and } \\
\text { temporality. }\end{array}$ & $\begin{array}{l}\text { Speculative } \\
\text { Architecture }\end{array}$ \\
\hline & $\begin{array}{l}\text { (Gaver et al., 2003, p. } \\
240)\end{array}$ & $\begin{array}{l}\text { Strategy SA-6: Ensure the } \\
\text { speculations ask questions through } \\
\text { the speculative design language } \\
\text { instead of providing solutions, in } \\
\text { order to enable open discussion in } \\
\text { which diverse perspectives are able } \\
\text { to be brought forward, considered } \\
\text { and discussed. }\end{array}$ & $\begin{array}{l}\text { Speculative } \\
\text { Architecture }\end{array}$ \\
\hline & (Auger, 2012, p. 180) & $\begin{array}{l}\text { Strategy SA-3: Engage the } \\
\text { viewers through typological } \\
\text { familiarity in order to form } \\
\text { perceptual bridges to ensure that } \\
\text { the speculation connects with an } \\
\text { identified audience's perceptions of } \\
\text { the temporal world around them. }\end{array}$ & $\begin{array}{l}\text { Speculative } \\
\text { Architecture }\end{array}$ \\
\hline & (Poplin, 2012, p. 198) & $\begin{array}{l}\text { Strategy SG-1: Ensure that serious } \\
\text { games are designed to be both } \\
\text { educational and fun while being } \\
\text { designed to interface with slum- } \\
\text { upgrading design processes. }\end{array}$ & Serious Gaming \\
\hline
\end{tabular}

More specifically the literature review suggests ways in which content/information should be developed for the SPS-UG. The content and information can be understood as being oriented towards opening up space for design ideation, which requires a degree of typological familiarity - the in-game representation of familiar spaces, buildings, artefacts or systems - in order to provoke design thinking and debate amongst players. In addition, content and information relating to the implications or consequences of decisions made in-game by the players can be important - such as cost, spatial requirements or the use of resources necessary for players to form ideas and future visions. This content must be generated from analysis and consultation with the prospective players, in order to ascertain the issues relevant to the SPS-UG framework's purpose.

The literature also suggests that pragmatic contextual factors - such as the exact location of an individual's home or a community space, or the exact cost of a design option-represented in-game might constrain the design process or discussion about the design or socio-political ideas by creating discursive impasses. SPS-UGs are 
intended to function as a "priming" activity or a "design orienting scenario" at the predesign phase. It may be useful for gameplay to gradually introduce typologically familiar elements to help the SPS-UG as a "priming activity" interface with the pragmatic participatory design process.

\subsubsection{SPS-UG Framing}

The framing of the SPS-UG includes ensuring the game is designed for the target group, their play literacy and the broader topic of the game. While the target group and the audience are often addressed as an important issue in serious games design, the play literacy of the target group is repeatedly overlooked, which may be especially important when designing for those with a low level of digital literacy, or when there is a large disparity in abilities amongst players (Mitgutsch \& Alvarado, 2012). Strategies derived from the literature which are operationalised as SPS-UG framing can be seen in Table 5, below.

Table 5. SPS-UG framing strategies derived from the literature.

\begin{tabular}{|c|c|c|c|}
\hline $\begin{array}{l}\text { SPS-UG } \\
\text { Element }\end{array}$ & Study & SPS-UG Design Strategies & Literature \\
\hline \multirow[t]{3}{*}{ Framing } & $\begin{array}{l}\text { (Tharp \& Tharp, 2013, } \\
\text { p. 408) }\end{array}$ & $\begin{array}{l}\text { Strategy SA-5: Ensure the design } \\
\text { language and the medium of the } \\
\text { speculation are appropriate to be } \\
\text { both instrumental and externally } \\
\text { focussed and discuss both social } \\
\text { and design implications. }\end{array}$ & $\begin{array}{l}\text { Speculative } \\
\text { Architecture }\end{array}$ \\
\hline & $\begin{array}{l}\text { (Auger, 2012, p. 140; } \\
\text { Knutz et al., 2016; } \\
\text { Pickersgill, 2017) }\end{array}$ & $\begin{array}{l}\text { Strategy SA-4: Ensure legitimacy } \\
\text { of the speculation is maintained by } \\
\text { ensuring internally consistent } \\
\text { extensional expectations. }\end{array}$ & $\begin{array}{l}\text { Speculative } \\
\text { Architecture }\end{array}$ \\
\hline & $\begin{array}{l}\text { (Agogué, Levillain, \& } \\
\text { Hooge, 2015, p. 417). }\end{array}$ & $\begin{array}{l}\text { Strategy SG-4: Ensure that serious } \\
\text { games are used as a means to } \\
\text { facilitate collectively creating ideas } \\
\text { for the future and communicating a } \\
\text { shared understanding of design } \\
\text { problems. }\end{array}$ & Serious Games \\
\hline
\end{tabular}

The play literacy can especially influence the gameplay experience if the target audience has trouble using the controls, understanding the user interface or recognising the fictional game elements. Ensuring understanding is important as they help ensure 
that legitimacy of the representations within the SPS-UG is maintained, by ensuring internally consistent extensional expectations. Mitgutsch and Alvarado argue that serious games should also consider what skills are needed in order to operate the system effectively, how easily those skills can be acquired through game play and how the genre of serious game might cause particular expectations (Mitgutsch \& Alvarado, 2012, p. 7). Generally, many serious games try to offer easy access to players, but often lack a balanced and engaging game play experience. Hence, well-balanced and attractive learning challenges are one of the most fruitful potentials of games to foster learning (Gee, 2003).

Based on the literature review in Chapter Two, instrumental speculation is an important consideration as a discussion tool in the design of SPS-UGs; this is because it is externally-focused and not expert-oriented, and it does not look for terminal visions of the future. The framing of the context presented to the players requires careful consideration, including how to utilise the defamiliarisation of issues to reframe discussions or to facilitate the creation of agonistic spaces, in order to provoke exploration of possible futures, conflicting stakeholder perspectives, and corresponding goals surrounding social, architectural and urban issues.

\subsubsection{SPS-UG Mechanics}

As discussed in section 2.3.3.1, game mechanics are methods invoked by players and designed for interaction with the game state, thus providing gameplay (Sicart, 2008). The mechanics involve the establishment of the rules that define the possible space for operations in the game world (Hunicke et al., 2004). In the SPS-UG in this research, these align with two main objectives: to provoke dialogue surrounding conflicting stakeholder perspectives (social outcomes; see section 5.2.4.1) and to facilitate upgrading ideation (slum-upgrading outcomes; see section 5.2.4.2). Strategies derived from the literature which are operationalised as SPS-UG mechanics can be seen in Table 6, below. 
Table 6. SPS-UG game mechanics derived from the literature.

\begin{tabular}{|c|c|c|c|}
\hline $\begin{array}{l}\text { SPS-UG } \\
\text { Element }\end{array}$ & Study & SPS-UG Design Strategies & Literature \\
\hline \multirow[t]{5}{*}{ Mechanics } & $\begin{array}{l}\text { (Frediani, 2016; } \\
\text { Hamdi \& Goethert, } \\
\text { 1997) }\end{array}$ & $\begin{array}{l}\text { Strategy PD-1: Ensure that all } \\
\text { participants within a design activity } \\
\text { have equal power to determine the } \\
\text { outcome of the decisions made, as } \\
\text { opposed to merely being } \\
\text { informants. }\end{array}$ & $\begin{array}{l}\text { Participatory } \\
\text { Design }\end{array}$ \\
\hline & $\begin{array}{l}\text { (Bowen, 2010; Iversen } \\
\text { et al., 2012, p. 87; } \\
\text { Sanders, 2001). }\end{array}$ & $\begin{array}{l}\text { Strategy PD-2: Reveal } \\
\text { stakeholder's perspectives and } \\
\text { assumptions in order to make } \\
\text { positions known through design } \\
\text { activities and ideation. }\end{array}$ & $\begin{array}{l}\text { Participatory } \\
\text { Design }\end{array}$ \\
\hline & $\begin{array}{l}\text { (Brandt, 2006; Brandt } \\
\text { \& Messeter, 2004; } \\
\text { Brandt et al., 2008; } \\
\text { Dindler \& Iversen, } \\
\text { 2007) }\end{array}$ & $\begin{array}{l}\text { Strategy PD-3: Develop } \\
\text { stakeholder collective knowledge, } \\
\text { values and goals by clarifying and } \\
\text { refining them to allow their } \\
\text { translation from abstract } \\
\text { formulations to more concrete } \\
\text { design concepts. }\end{array}$ & $\begin{array}{l}\text { Participatory } \\
\text { Design }\end{array}$ \\
\hline & $\begin{array}{l}\text { (Brandt, 2006; Brandt } \\
\& \text { Messeter, 2004; } \\
\text { Brandt et al., 2008; } \\
\text { Dindler \& Iversen, } \\
\text { 2007) }\end{array}$ & $\begin{array}{l}\text { Strategy PD-4: Ground the } \\
\text { participant's everyday knowledge } \\
\text { and experience to create common } \\
\text { ground or shared language between } \\
\text { participants. }\end{array}$ & $\begin{array}{l}\text { Participatory } \\
\text { Design }\end{array}$ \\
\hline & $\begin{array}{l}\text { (Argenton et al., 2014; } \\
\text { Bagozzi \& Dholakia, } \\
\text { 2002; Morschheuser, } \\
\text { Maedche, \& Walter, } \\
\text { 2017; Morschheuser, } \\
\text { Riar, et al., 2017) }\end{array}$ & $\begin{array}{l}\text { Strategy SG-5: Promote discourse } \\
\text { surrounding goals and values that } \\
\text { can lead to better idea exploration, } \\
\text { discourse, decision making, and } \\
\text { increases in consensus, cooperation } \\
\text { and empowerment. }\end{array}$ & Serious Gaming \\
\hline
\end{tabular}

The literature review revealed that dialogue surrounding conflicting stakeholder perspectives can be aided by establishing systems for facilitating multi-player interaction through built-in player mechanics. Split-screen approaches enable players to act simultaneously and collectively go through phases of action and reflection. Turns-based multiplayer systems, on the other hand, allow for a sequential process of reflection and action, where one player acts at a time, with the other players acting as observers. The literature suggests that the player interaction facilitated by both of the above can facilitate the creation of "communities of practice" through gameplay and the negotiation of social norms through the establishment of clear in-game communication pathways. Players might also be motivated through simple mechanics, such as time limits or restricted in-game resource allocation such as financial resources 
or limited three-dimensional space allocated for visualising their design ideas. Mechanics such as these have been shown to raise conflicts between players.

The SPS-UG approach must also include mechanics that allow players to visualise and communicate their ideation processes to other players in real time for discussion and contestation. These should include allowing for cycles, or "rehearsals", of action (gameplay) and reflection (discussion) in order to ground ideation and any configured values. The literature suggests that these should aid ideation processes through mechanics that can simulate reality and foster collaboration surrounding the simulation. Players should be permitted to collaboratively conceive pluralistic visions of the future, which the literature shows can aid ideation processes and social discourses surrounding conflict and values.

In conceptualising SPS-UG mechanics, it is also important to consider pivotal ingame objectives, the operation of any rewards systems and the main entertainmentrelated obstacles/challenges. Contextual factors, such as allocation of site-specific resources, can be built into the game mechanics that embed and highlight real-world systems and dynamics to which the players respond, in terms of social discourse and design-related discourse. Decision-making mechanics, such as "win states", should also be considered for their relevance.

\subsubsection{SPS-UG Fiction/Narrative}

While the "content" of the game holds the provided information and the "mechanic" impacts the gameplay possibilities, the dimension of "fiction and narrative" introduces fictional elements or the overall narrative arc to structure gameplay activities. DiSalvo argues that players should be presented with alternative presents, futures, systems or worlds as a means to provoke values-based discourse (DiSalvo, 2012, p. 52). According to Auger, a "perceptual bridge" should be created between the audiences' perceptions of their world and the speculative representation, by achieving a blend of factual authenticity and speculative elements in order to root the speculation to people's everyday experience (Auger, 2012, p. 66). The nature of the perceptual bridge may change throughout the SPS-UG gameplay - as players move through levels with various levels of fictional or non-fictional elements, for example. Strategies derived from the literature which are operationalised as SPS-UG fiction/narrative can be seen in Table 7, below. 
Table 7. SPS-UG fictional space/narrative strategies derived from the literature.

\begin{tabular}{|c|c|c|c|}
\hline $\begin{array}{l}\text { SPS-UG } \\
\text { Element }\end{array}$ & Study & $\begin{array}{l}\text { Speculative architecture } \\
\text { strategies }\end{array}$ & Literature \\
\hline $\begin{array}{l}\text { Fiction/Na } \\
\text { rrative }\end{array}$ & $\begin{array}{l}\text { (Dindler, 2010a, p. } \\
\text { 73). }\end{array}$ & $\begin{array}{l}\text { Strategy SA-2: Ensure a careful } \\
\text { balance of fictional and non- } \\
\text { fictional elements. }\end{array}$ & \\
\hline
\end{tabular}

\subsubsection{SPS-UG Aesthetics/Graphics}

Aesthetics/Graphics refers to the audio-visual language (aesthetic characteristics, imagery, style preferences, artistic media, and computer graphic techniques) conceptualised, chosen and used by the designers for the visualisation and display of elements involved in the game. The aesthetics and graphics define the overall formal aspects that frame the purpose, the content/information, the framing (target group), the mechanics (instructions, rewards) of the game, and the fiction/narrative (the world and characters of the game). Since the aesthetics/graphics present the game to the player from the first image onward, they play a fundamental role in the introduction of the game's purpose and its impact on the player (Mitgutsch \& Alvarado, 2012, p. 7). SPSUGs should utilise simplistic or stylised 3D representation in order to reduce issues regarding the pragmatic viability of in-game design decisions from the perspective of the participants (McLaughlin et al., 2010, p. 136). Such styles can reduce the computational resources required to run the software, meaning that the software can be executed on computers with lower graphic rendering capabilities. Strategies derived from the literature which are operationalised as SPS-UG aesthetics/graphics can be seen in Table 8 , below.

Table 8. SPS-UG aesthetics/graphics strategies derived from the literature.

\begin{tabular}{l|lll}
\hline $\begin{array}{l}\text { SPS-UG } \\
\text { Element }\end{array}$ & Study & $\begin{array}{l}\text { Speculative architecture } \\
\text { strategies }\end{array}$ & Literature \\
\hline $\begin{array}{l}\text { Aesthetics/Gr } \\
\text { aphics }\end{array}$ & $\begin{array}{l}\text { (McLaughlin et al., } \\
\text { 2010, p. 136) }\end{array}$ & $\begin{array}{l}\text { Strategy SG-3: Utilise simplistic } \\
\text { or stylised 3D representation in } \\
\text { order to reduce issues regarding the } \\
\text { pragmatic viability of in-game }\end{array}$ & Serious Gaming \\
\hline
\end{tabular}




\subsubsection{Summary}

Figure 43 below illustrates the synthesis of the literature into the SPS-UG framework, as applied to the game elements of purpose, context/information, framing, mechanics, fiction/narrative and aesthetics/graphics and in relationship to Aim 4.

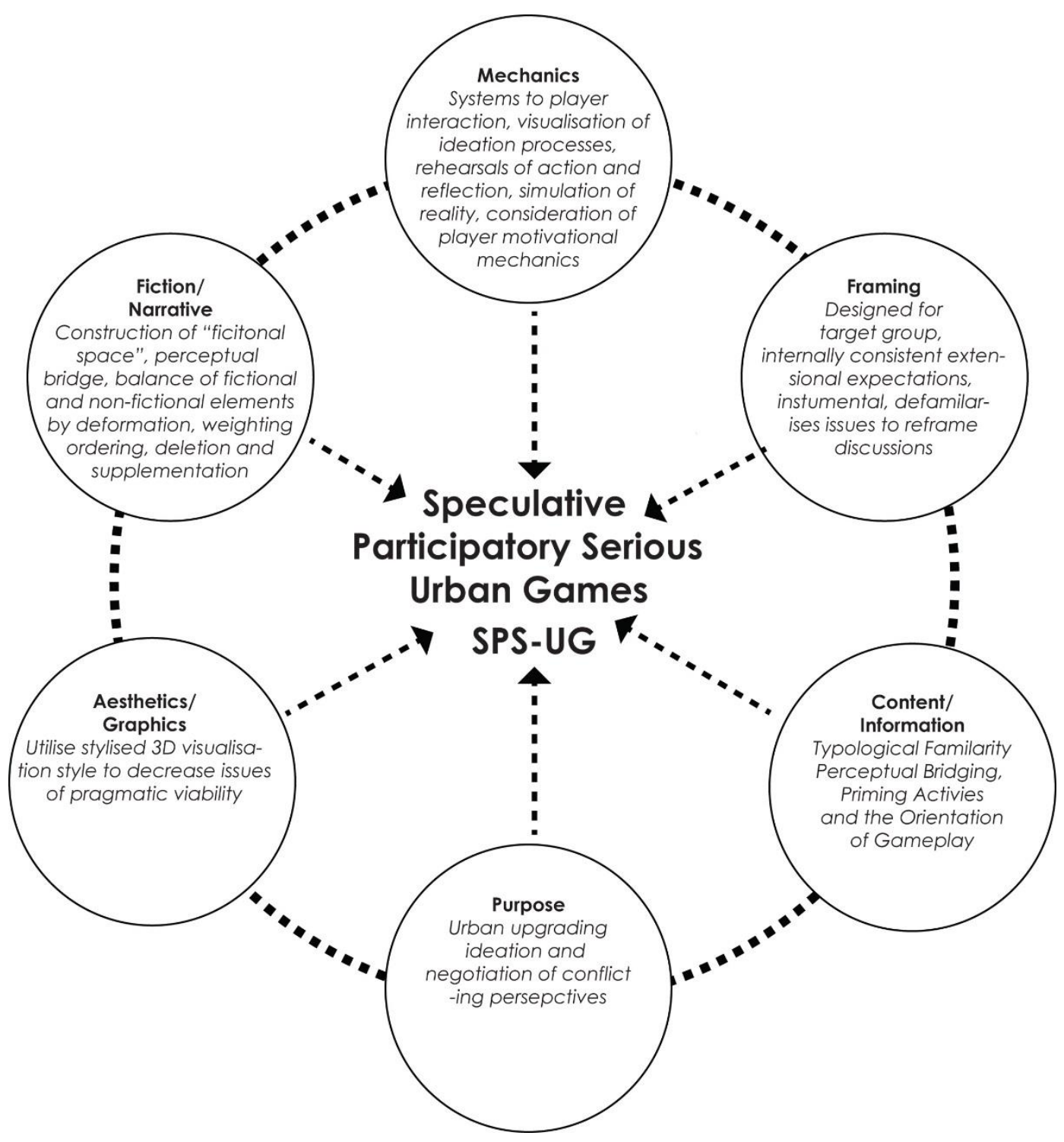

Figure 43. Synthesising the SPS-UG approach, contributing game elements (by author).

This chapter has outlined how the three bodies of literature-namely speculative architecture, participatory design, and serious games - can be integrated to formulate 
a new "Speculative Participatory Serious Urban Gaming" (SPS-UG) framework with the aims of enhancing social outcomes and related design (slum-upgrading) outcomes for urban slum dwellers. The strategies derived from the literature were organised into the game design elements of purpose, content/information, framing, mechanics, fiction/narrative and aesthetics/graphics.

While taking all the elements into account in the SPS-UG framework, Chapter Three, next, discusses the approach and methods used to develop the game and work with it in the three case study communities in India. 


\section{The Research Approach}

Participation without enablement is like trying to drive a car without fuel. And both, without flexibility, are like trying to drive the same car if it is programmed to move in only one direction and always predictably from A to B. The concept of steering becomes a pretence to freedom and the steering wheel no more than a symbol of control.

- (Hamdi, 1991, p. 88)

\subsection{Introduction}

The research approach adopted of a qualitative Action Research methodology centred on case studies, that utilises participatory design workshops as a research method (Foth \& Axup, 2006; Frediani et al., 2011; Groat \& Wang, 2002; Pollastri, 2017; Reason \& Bradbury, 2001; Sanders, 2008; Silverman, 2015; Swann, 2002). This approach was used to evaluate the SPS-UG framework through the development of an exemplar SPS-UG (detailed in Chapter Four), which was operationalised in participatory gaming workshops. The workshops were conducted within three case studies (CS1-3) in India with each case study exploring the approach with a different landfill-based slum community. CS1 was conducted with the Ghazipur community in Delhi, CS2 was conducted with the Bhalswa community in Delhi and CS3 was conducted with the Shanti Nagar community in Mumbai-in order to produce guidelines for effective practices dealing with similar problems.

Each case study consisted of three phases including Phase One: Ethnographic Documentation Studies and Analysis, Phase Two: SPS-UG Development and Phase Three: SPS-UG Workshops. See Figure 44, below. 


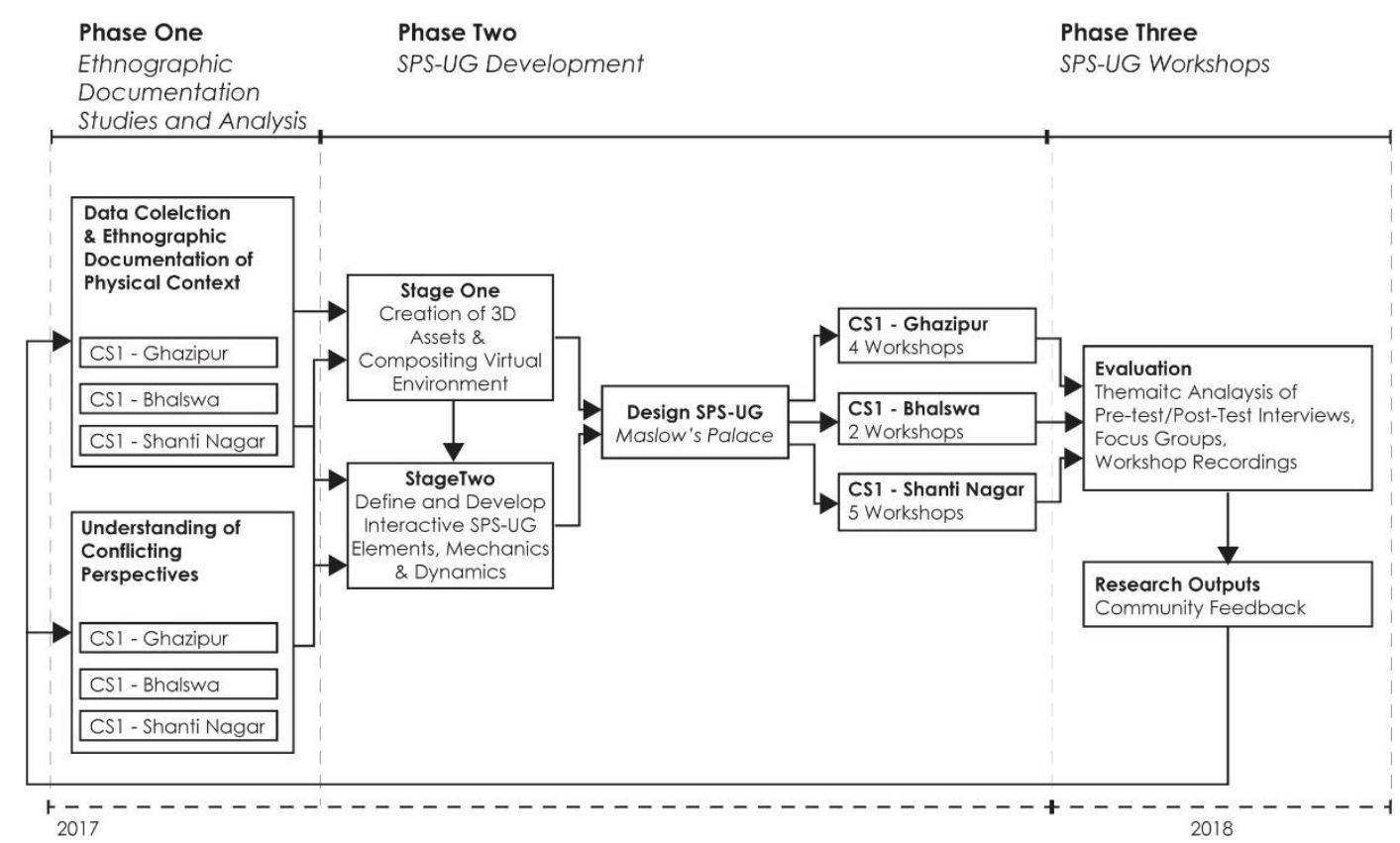

Figure 44. The research design.

Phase One included conducting ethnographic research in each community in February 2017 and had two objectives:

O1: to document the context of each of the communities for digitalisation into a virtual game environment;

O2: to gain an understanding of the range of conflicting perspectives regarding upgrading-related issues important to different community members to inform the subsequent design of an SPS-UG that might help in the negotiation of conflicting perspectives and stakeholder ideation.

Phase Two began in March 2017. The objective of Phase Two was:

O3: to develop one SPS-UG for use in participatory workshops within all case study communities.

Phase Two utilised the SPS-UG framework presented in Chapter Two and integrated the data gathered and analysed in the studies in Phase One.

Phase Three was conducted in November and December 2017. The objective of Phase Three was:

O4: to evaluate the SPS-UG developed in Phase Two through participatory design workshops in each case study site in relation to the research question.

Each workshop in Phase Three used a pre-test/post-test experimental research design approach to explore the effects of the SPS-UG approach with the participants' 
groups in line with serious games literature (Becker \& Parker, 2011; Bellotti, Kapralos, Lee, Moreno-Ger, \& Berta, 2013b; Buchinger \& Hounsell, 2018; DeSmet et al., 2016; Loh, Sheng, \& Ifenthaler, 2015; Morschheuser, Riar, et al., 2017; Neys, Looy, Grove, \& Jansz, 2012).

\subsection{Epistemological Orientation}

\subsubsection{Design as Action Research - A Methodological Approach}

Action Research focuses on the relevance of insights generated from experience; in the case of this research, this refers to the testing of the SPS-UG with the research communities. Action Research was initially developed to challenge positivistic views of knowledge creation in social science and anthropology (Brydon-Miller, Greenwood, \& Maguire, 2003). The goal of Action Research as a methodology is to generate new knowledge through the engagement of researchers in actions and interventions with people and contexts, as opposed to researchers being divorced from the people and contexts (Brydon-Miller et al., 2003; Elden \& Chisholm, 1993; Reason \& Bradbury, 2001). Denscombe (2010, p. 6) writes that Action Research's purpose is generally to solve a particular problem and to produce guidelines for effective practices dealing with similar problems.

Action Research involves actively participating in a change situation, often via an existing community, whilst simultaneously conducting research. Because of this, Action Research has been shown to be a viable methodology for dealing with "wicked" research problems (Brown, Harris, \& Russell, 2010; Kemmis, 2014; Rittel \& Webber, 1973), as it tries to support various stakeholders' efforts to define, understand, and articulate their responses to the problem and provide guidance for similar situations, while acknowledging that no two research situations are alike. Even though Action Research is considered a methodology, some call it a "family of practices of inquiry" in order to indicate the ways in which methods may be applied in relation to context and personal inclination (Dick, 2007; Huxam, 2003).

Design activities as a form of inquiry can be considered a form of Action Research (Swann, 2002). A clear link has been highlighted between Participatory Design research and Action Research in the literature (Foth \& Axup, 2006; Frediani et al., 2011; Groat \& Wang, 2002; Reason \& Bradbury, 2001; Sanders, 2008; Silverman, 2015; Swann, 2002). Cal Swann, in his article "Action Research and the Practice of 
Design", argues that both Design Research and Action Research are generative practices aimed at creating change (Swann, 2002), while Foth and Brynskov highlight the distinct similarities and the advantages of combining Action Research and Participatory Design practices to foster civic engagement (Foth \& Brynskov, 2016). These include ensuring the desired impact of the design processes is reached, while at the same time, the study may be able to encourage its participants to "determine and critically evaluate a range of open (and perhaps non-design specific) issues if action research principles are used" (ibid.). Because of the nature of design research, the research knowledge created might consist not only of design solutions intended for a given context, but also the production of tools for designing (Wood, 2008), which might include practices or methods for designing or explanations or theories grounded in the analyses of design that can form practice guidelines (Mortati \& Cruickshank, 2012). Because of this practice oriented approach, Action Research has been adopted by a number of researchers in architecture, participatory design and experimental design, including slum-upgrading projects (Frediani, 2016; Frediani et al., 2011; Majale, 2008; Pollastri, 2017).

Several ways in which Action Research is a suitable for this research, are summarised in Table 9 below.

Table 9. Synthesising Action Research and design processes.

Study

(Dick, 2007)

(Dick, 2007)

(Coghlan \& Brannick, 2005)

(Brydon-Miller et al., 2003)

(Dick, 2007; Huxam, 2003)
Action Research Features

Achieving change is central to Action Research and the research question.

Action Research is iterative in nature. Critical reflection on action facilitates the creation of knowledge in the form of understanding.

Action Research is receptive to the context in which it is conducted, as well as being influenced by participants in the research. Knowledge generated is specific to the context.

An Action Research approach rejects the notion of an objective or value-free concept of knowledge. Decisions made by the designer or researcher are based on judgements.

The research outputs of an Action Research approach are generally emergent, as they are contingent upon the research aims, the research context and the researchers' interventions and analytical preferences. It is difficult for the researcher to know what methods are best suited for the analysis in advance, as one cannot know what type of data will emerge and become relevant. 


\subsubsection{A Case Study Research Strategy Approach to Action Research}

A case study is a "research strategy which focuses on understanding the dynamics present within single settings" (Eisenhardt, 1989, p. 533). Yin, in a frequently cited article on case study research The Case Study as a Serious Research Strategy, defines case studies as "an empirical inquiry that investigates a contemporary phenomenon within a real-life context, especially when the boundaries between phenomenon and context are not clearly evident" (Yin, 1981, p. 9). Groat and Wang simplify this definition, as it applies to architectural research, as "an empirical inquiry that investigates a phenomenon or setting" (Groat \& Wang, 2002, p. 346). Yin suggests the importance of differentiation between "experiments" and "case studies". He argues that "an experiment deliberately divorces a phenomenon from its context" to allow the researcher to focus on specific variables, whereas the case studies are intimately tied to it and advocate for direct observation and "thick descriptions"; they value multiple perspectives of stakeholders and participants; and they prioritise qualitative and interpretive analysis of contexts and situations (Yin, 1981, p. 98).

The case study research approach is fundamental to an Action Research methodology, and it has been widely used for conducting design, co-design and participatory design situations (Dindler \& Iversen, 2007; French et al., 2018; Pollastri, 2017; Vaajakallio \& Mattelmäki, 2014). This is because the emphasis of Action Research is on knowledge emerging from localised settings, as opposed to abstract knowledge applicable to many settings. In conducting participatory design workshops -focussed case studies as part of an Action Research methodology, this research works with three "communities of inquiry" or groups of individuals who participate in the process of the experimental research (Reason \& Bradbury, 2001).

While participation through a community of inquiry is a necessary condition of Action Research, who participates, when, and how can vary. The type and degree of participation may vary for different groups of individuals within the process for various reasons, which reflects the fact that different objectives exist within the same research process (Morse, 1998). These objectives might be to conceive a design as part of a workshop, or they might be research-oriented objectives such as analytical work (Coghlan \& Brannick, 2005). In the various phases of this research (see section 3.3.1.1), different actors within a community of practice move between common objectives towards independent goals while fulfilling different roles at different stages. 


\subsubsection{Action Research Through Participatory Design Workshops}

"Participatory design workshops" have been used as a method within a case study based Action Research methodology in participatory design research to explore the impact of design and design processes within a given context (Björgvinsson et al., 2010, 2012; Dindler \& Iversen, 2007; Luck, 2018; Pollastri, 2017; Sanoff, 2000). Participatory design workshops in a research project generally build on or complement each other, and because of the way this can influence and change programmes and research questions, they tend to be planned and shaped throughout different moments of the research process (Eriksen and Bang 2013). Brandt and Binder, in their article "Experimental Design Research: genealogy, intervention, argument" (2007), argue for the importance of the "experiment" and "program" (or the design brief) within participatory design workshops in experimental design research. They suggest that the architectural program is an important intermediary between the primary research question and the empirical exploration (Brandt \& Binder, 2007, p. 4). Participatory design workshops $(\mathrm{P} / \mathrm{W})$ are used in this research to explore the SPS-UG framework detailed in the previous chapter (see Figure 45).

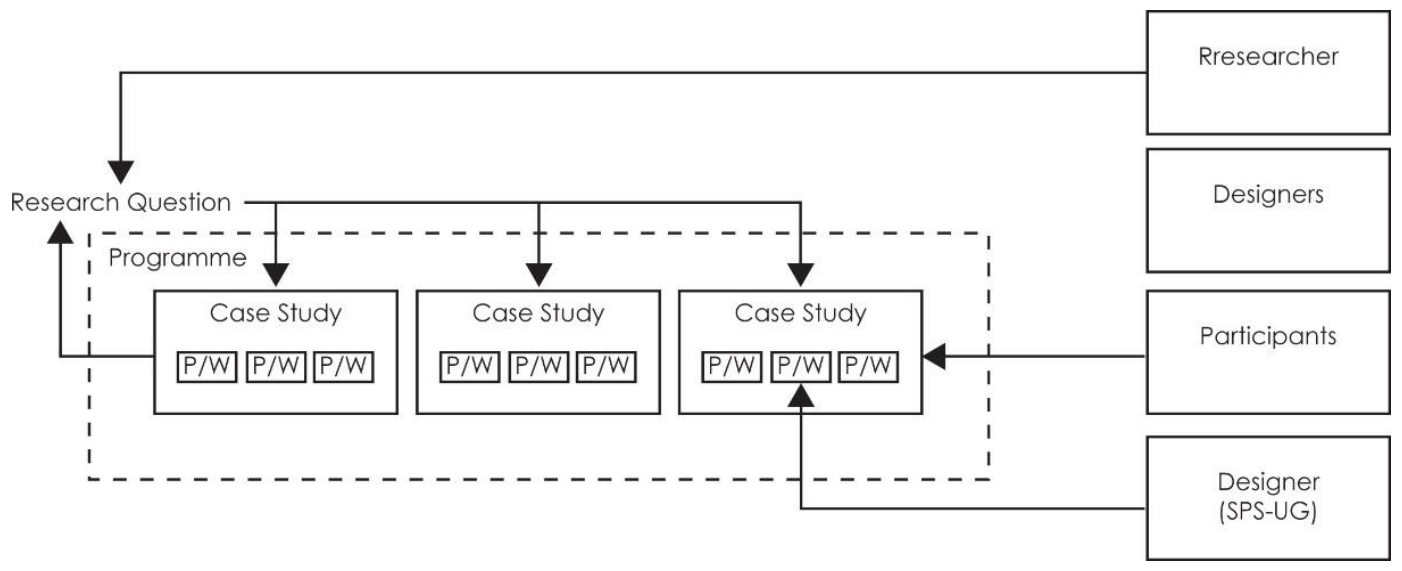

Figure 45. Visualising the central role of SPS-UG participatory design workshops with the case study communities.

In this research, participatory design workshops in Phase Three were oriented around a new SPS-UG game. In the context of this research, what was designed was: the tool for the design methodology from the position of the designer in the form of an example SPS-UG; and the architectural outcomes within the SPS-UG workshops when operated by the research participants. The participants undertook the two principal 
roles of both designers and users: as the designers they strove to learn the realities of the users' situation; as the users they strive to articulate their desired aims and learn appropriate means to obtain them. By taking on both roles simultaneously, a collaborative and participatory approach to speculation was established in the participatory design workshops.

\subsection{Research Design}

This chapter has so far discussed the epistemological framing of the research and the research approach of Action Research through participatory design workshops. Action Research and case studies that utilise participatory design workshops as a method frame the inquiry. This section details how this research framing has been operationalised by providing an overview of the research plan.

\subsection{The Research Plan}

Empirical material for this research is oriented around and informed by case studies (CS1-3) conducted with three landfill-based slum communities in India-Ghazipur, Delhi (CS1), Bhalswa, Delhi (CS2) and Shanti Nagar, Mumbai (CS3). These ran throughout the research process in 2017.

The case studies were conducted in association with the three communities and two external partners - Chintan Environmental Research and Action Group, based in Delhi; and Apnalaya, based in Mumbai-in 2017 in order to explore the SPS-UG framework approach. CS1 and CS2 explored the development and implementation of SPS-UG in practice and were carried out in collaboration with local communities living at the Ghazipur (CS1) and Bhalswa (CS2) landfills in Delhi, India. They were conducted in collaboration with the external partner Chintan Environmental Research and Action Group, who work for environmental justice with a number of marginalised communities in Delhi, with a focus on ensuring equitable and sustainable production and consumption of materials and improved disposal of waste. CS3 explored the development and implementation of the SPS-UG in practice and was conducted in collaboration with the Shanti Nagar community at the Deonar landfill in Shivaji Nagar, Mumbai, India. CS3 was conducted in collaboration with the external partner Apnalaya ("Our Space" in English), who are a non-profit organisation founded in 1973 
working with the most marginalised and under-served slums in Mumbai. Detailed accounts of each research context are provided in sections 4.2.1 (Ghazipur), 4.2.2 (Bhalswa) and 4.2.3 (Shanti Nagar).

\subsubsection{The Research Phases}

Each case study consisted of three phases including Phase One - Ethnographic Documentation Studies and Analysis, Phase Two - SPS-UG Development and Phase Three - SPS-UG Workshops. Phases One and Two are documented in Chapter Four, while Phase Three is documented in relation to each case study as follows: Chapter Five (Ghazipur), Chapter Six (Bhalswa) and Chapter Seven (Shanti Nagar).

\subsubsection{Phase One - Context Documentation Studies and Analysis}

Phase One included using a range of "design ethnography" methods (Crabtree, Rouncefield, \& Tolmie, 2012; Lindley et al., 2014) in each community in February 2017 to both document the physical environment and gain an understanding of the range of conflicting perspectives on upgrading-related issues important to a range of community members of each case study context. These are shown in Table 10, below in relationship to the two objectives of Phase One.

Table 10. Phase One data collection purpose and methods - fieldwork 2017.

\begin{tabular}{llll}
\hline Location & Date & Purpose & Methods \\
\hline Ghazipur & Jan 24- & O1 - Document physical environment of & Hand Drawings, \\
& Feb 2, & Ghazipur. & Photographs, Observations \\
& 2017 & & and Notes, Videography, \\
& & & Audio Recordings, \\
& & & Mapping
\end{tabular}

\begin{tabular}{llll} 
Ghazipur & $\begin{array}{l}\text { O2 - Gain an understanding of the range of } \\
\text { conflicting perspectives on upgrading- } \\
\text { related issues important to a range of } \\
\text { community members at Ghazipur. }\end{array}$ & $\begin{array}{l}\text { Interviews, Notes, Audio } \\
\text { Recordings }\end{array}$ \\
\hline Bhalswa & $\begin{array}{l}\text { Jan 24 - } \\
\text { Feb 2, }\end{array}$ & $\begin{array}{l}\text { O1 - Document physical environment of } \\
\text { Bhalswa. }\end{array}$ & $\begin{array}{l}\text { Hand Drawings, } \\
\text { Photographs, Observations } \\
\text { and Notes, Videography, } \\
\text { Audio Recordings, } \\
\text { Mapping }\end{array}$ \\
\end{tabular}




$\begin{array}{lll}\text { Shanti } & \text { Feb 3 }- & \text { O1 - Document physical environment of } \\ \text { Nagar } & \text { Feb 8, } & \text { Shanti Nagar. } \\ & 2017\end{array}$

Hand Drawings, Photographs, Observations and Notes, Videography, Audio Recordings, Mapping

\begin{tabular}{|c|c|c|}
\hline $\begin{array}{l}\text { Shanti } \\
\text { Nagar }\end{array}$ & $\begin{array}{l}\text { O2 - Gain an understanding of the range of } \\
\text { conflicting perspectives on upgrading- } \\
\text { related issues important to a range of } \\
\text { community members at Shanti Nagar. }\end{array}$ & $\begin{array}{l}\text { Interviews, Notes, Audio } \\
\text { Recordings }\end{array}$ \\
\hline
\end{tabular}

The first objective (refer to $\mathrm{O} 1$ in Table 10) was to undertake the documentation of the case study site of each of the communities for digitalisation into a virtual game environment. This was conducted in order to identify what content, information, aesthetics and graphics might be appropriate, as well as to ensure the SPS-UG's relevance to the target group and to determine their play literacy and the broader purpose of the game (e.g., the urban issues faced by the community). This process entailed qualitative, ethnographic documentation including photographic documentation, videography, audio recordings, mapping, CAD plan drawings, sketching and note taking. It identified and compared key morphological elements (street/cadastral pattern, plot patterns, building structures and land use patterns) of each research context.

The second objective (O2 in Table 10) was to gain an understanding of the range of conflicting perspectives regarding upgrading-related issues important to different community members. This data was used to inform the articulation of the SPS-UG's purpose, framing, mechanic, and the fictional or narrative elements, as well as to ascertain what site factors were important to community members that might help in the negotiation of conflicting perspectives and stakeholder ideation. Data was gathered through structured interview processes with a sample of key informants-namely the residents in each of the communities in January and February 2017.

The purpose of the interviews was to ascertain what conflicting perspectives exist relating to community upgrading, to identify what problems they perceive as important or prominent in relationship to the upgrading of their community, and what participants 
would like to improve within their community in the future (Table 11 and Appendix $1)$.

Table 11. Phase One interview questions.

\begin{tabular}{ll}
\hline Item No. & Structured Interview Item \\
\hline 1 & What do you like about your community? \\
\hline 2 & What do you dislike about your community? \\
\hline 3 & What are the main problems associated with living in your area? \\
\hline 4 & If you could change three things about your area what would they be? \\
\hline
\end{tabular}

Each interview also gathered information about the participants including their age, gender, religious affiliation, how long they had lived in their community, their local origin prior to migration and their primary daily activity. 23 residents of Ghazipur, 22 residents of Bhalswa and 21 residents of Shanti Nagar took part in the Phase One interviews.

A structured interview process was primarily chosen over a survey instrument due to the low levels of literacy within each community. In conducting the analysis of the interview data, a hybrid approach of deductive and inductive coding procedures was adopted to analyse the qualitative data to discern the range of conflicting perspectives of urban upgrading related issues in each research context and ensure rigour (Fereday \& Muir-Cochrane, 2006). This approach allowed for analyses to be made between the case study sites, while analysing the salient characteristics within each context. Deductive codes were developed based on needs-hierarchy literature that has been widely adopted in urban-related research (Carmona, 2003, p. 134).

As Carmona (2003) explains, the choices that individuals make in any particular environment are needs-hierarchy based-responsive to the individual's ego, personality, character, goals and values, available resources, past experiences, life stage, etc. (Carmona, 2003, p. 134). Despite the individualistic and complex nature of human values, goals and aspirations, a number of authors have proposed an overarching hierarchy of human needs that can be used to code the interview data (Lang, 1987, 2006; Maslow, 1968). Such hierarchies typically relate to Maslow's original work on human motivations (Maslow, 1968), which identified a five-stage hierarchy of basic human needs including physiological needs (warmth and comfort), safety and security needs (feeling safe from harm), affiliation needs (belonging to a community), esteem needs (feeling valued by others) and self-actualisation (e.g., 
artistic expression and fulfilment) (Maslow, 1968). Maslow's hierarchy of needs formed the deductive coding procedure.

The second method used for data coding was an inductive coding procedure. Inductive codes were derived from the dataset: the data was coded in terms of contextspecific categories that became apparent through the data analysis process. This combination of deductive and inductive coding allows for unique trends to be identified within each case, as well as those shared between each of the three case study communities. A detailed account of the methods and data collection procedures used with each community can be found in section 4.2.4.

\subsubsection{Phase Two - SPS-UG Development}

Phase Two began in March 2017 and included the development of one single SPSUG that would be used in participatory workshops within each case study site (refer to Table 12). It integrated the data gathered and analysed in the studies in Phase One, within the SPS-UG framework presented in Chapter Two. This process consisted of two stages. Stage One included the creation of three-dimensional digital models and their incorporation into virtual environments to be used in the SPS-UG in accordance with the SPS-UG framework. Stage Two used the interview data, which highlighted important issues or trajectories of urban upgrading from the perspective of the participants in each of the communities, in combination with the data gathered to document the physical environment of the communities, to develop three-dimensional digital models of buildings and spaces, or 3D assets, for use in the development of an SPS-UG. Stage Two included the design of interactive game elements, mechanics and dynamics in line with the SPS-UG purpose of facilitating ideation and negotiation of conflicting perspectives in line with the SPS-UG framework. The cross-platform realtime engine Unity3D was selected as the game development platform as it is a crossplatform all in one editor that supports the creation of multiplayer games more easily when compared with other development platforms. Autodesk 3DS Max was used as the 3D modelling software in developing digital models of spaces and buildings. 
Table 12. Phase Two purpose and SPS-UG development methods.

\begin{tabular}{llll}
\hline Location & Date & Purpose & Methods \\
\hline Wellington & $\begin{array}{l}\text { March }- \\
\text { September } \\
2017\end{array}$ & $\begin{array}{l}\text { O3 - Develop one SPS-UG for use in } \\
\text { participatory workshops within all case } \\
\text { study communities. }\end{array}$ & \\
\hline Wellington & $\begin{array}{l}\text { March }- \\
\text { June 2017 }\end{array}$ & $\begin{array}{l}\text { Stage One - Develop three-dimensional } \\
\text { digital models and their incorporation into } \\
\text { virtual environments to be used in the } \\
\text { SPS-UG in accordance with the SPS-UG } \\
\text { framework and the interview and context } \\
\text { analysis. }\end{array}$ & $\begin{array}{l}\text { Digital modelling using } \\
\text { Autodesk 3DS Max. }\end{array}$ \\
& & $\begin{array}{l}\text { Stage Two - Develop interactive game } \\
\text { elements, mechanics and dynamics in line } \\
\text { with the SPS-UG purpose of facilitating } \\
\text { ideation and negotiation of conflicting } \\
\text { perspectives in line with the SPS-UG } \\
\text { framework. }\end{array}$ & Game design using \\
& $\begin{array}{l}\text { June }- \\
\text { September }\end{array}$ & \\
& 2017 & &
\end{tabular}

\subsubsection{Phase Three - SPS-UG Workshops}

Phase Three included eleven SPS-UG workshops that were conducted with the communities in November and December 2017. Four workshops were conducted with the community at Ghazipur, two were conducted with the community at Bhalswa and five were conducted with the community at Shanti Nagar. The number of workshops held with each community reflects the number of participants available to participate in each community. Each of these utilised the SPS-UG developed in Phase Two. The purpose of each of these workshops was to evaluate the ability of the SPS-UG to contribute to aiding the generation of useful urban upgrading-oriented social outcomes and related architectural design outcomes for the community members in line with the research question.

Table 13. Phase Three data collection purpose and methods - fieldwork 2017.

\begin{tabular}{|c|c|c|c|}
\hline Location & Date & Purpose & Methods \\
\hline $\begin{array}{l}\text { Chintan } \\
\text { Community } \\
\text { School, } \\
\text { Ghazipur, } \\
\text { Delhi }\end{array}$ & $\begin{array}{l}8-14 \\
\text { November } \\
2017\end{array}$ & $\begin{array}{l}\text { O4 - Evaluate the SPS-UG developed in } \\
\text { Phase Two through participatory design } \\
\text { workshops with the Ghazipur community } \\
\text { in relation to the research question. }\end{array}$ & $\begin{array}{l}\text { Four participatory design } \\
\text { workshops using the SPS- } \\
\text { UG } 1-2 \text { hrs each, } \\
\text { Pretest/Posttest structured } \\
\text { interviews } 20 \text { mins each, } \\
\text { Video recording, Screen } \\
\text { capture, Focus Groups } 20 \\
\text { mins each. }\end{array}$ \\
\hline
\end{tabular}


Dwelling in 8-14 O4 - Evaluate the SPS-UG developed in Bhalswa, November Phase Two through participatory design Delhi $2017 \quad$ workshops with the Bhalswa community in relation to the research question.
Two participatory design workshops using the SPSUG, 1-2hrs each,

Pretest/Posttest structured interviews 20 mins each, Video recording, Screen capture, Focus Groups 20 mins each.

Apnalaya 16-23 O4 - Evaluate the SPS-UG developed in

Community November Phase Two through participatory design

Centre, 2017

Shanti

017 workshops with the Shanti Nagar community in relation to the research

Nagar,

Mumbai
Five participatory design workshops using the SPSUG, 1-2hrs each, Pretest/Posttest structured interviews 20 mins each, Video recording, Screen capture, Focus Groups 20 mins each.

Although various methods and techniques have been used to evaluate the effectiveness of serious games with participants (Arnab et al., 2015; Boughzala, Bououd, \& Michel, 2013; Boyle et al., 2012; Loh, Anantachai, Byun, \& Lenox, 2007; Loh et al., 2015), a pre-test/post-test experimental design (Dugard \& Todman, 1995) is the most widely used approach in serious games research to measure the effects of a serious games method with user groups (Becker \& Parker, 2011; Bellotti, Kapralos, Lee, Moreno-Ger, \& Berta, 2013; Buchinger \& Hounsell, 2018; DeSmet et al., 2016; Loh et al., 2015; Morschheuser et al., 2017; Neys et al., 2012).

Each workshop held as part of Phase Three followed a process of pre-test structured interview data collection, SPS-UG gameplay by the research participants, post-test structured interview data collection and focus group data collection to provide data triangulation (Figure 46) and carefully followed standards of qualitative and ethical participatory design research (Schuler \& Namioka, 1993; Simonsen \& Robertson, 2012). While the most common method of pre-test/post-test assessment in serious games is by way of a survey/test/questionnaire, structured interviews (Patton, 1991) were used because of the low levels of literacy in each case. These can be found in Appendix 1. This method is frequently employed because it is the simplest to implement, but it relies on the opinions of the player and does not depend on all of the information that can be collected regarding what happened within the game (Bellotti et al., 2013b; Shute, Ventura, Bauer, \& Zapata-Rivera, 2009). Each of the 11 gaming workshops was comprised of 4 community members per workshop: 16 residents took 
part at Ghazipur (4 workshops), 8 at Bhalswa (2 workshops) and 20 at Shanti Nagar (5 workshops) (see Figure 46).

Similar to Phase One, the purpose of the pre-test and post-test structured interviews was to ascertain what conflicting perspectives exist relating to community upgrading; to identify what problems community members perceive as important or prominent in relationship to the upgrading of their community; and to understand what participants would like to improve within their community in the future, both before and after the SPS-UG process. Repeating the data collection process in Phase One, each interview also gathered information about the participants including their age, gender, religious affiliation, how long they had lived in their community, where they had migrated from and their primary daily activity in order to help contextualise the responses. In conducting the analysis of the pre-test/post-test interview data documenting the conflicting perspectives of urban upgrading related issues, the same deductive and inductive coding procedures were adopted as were used in Phase One.

Focus group discussions-about the participants' overall experiences with the gaming process, the justification of their game movements, the effect the game had on their creativity and their participation/interaction with other players, and the evaluation of the game in general - were conducted at the conclusion of each workshop to provide supplementary information useful in the data analysis process. Focus groups were chosen over group interviews as they explicitly use group interaction as part of the method. Kitzinger explains that focus groups "encourage participants to talk to one another: asking questions, exchanging anecdotes and commenting on each other's experiences and points of view" (Kitzinger, 1995, p. 311). This makes the method particularly useful for exploring people's knowledge and experiences, and it can be used to examine not only what people think about their experiences with the SPS-UG, but how they think and why they think that way. 


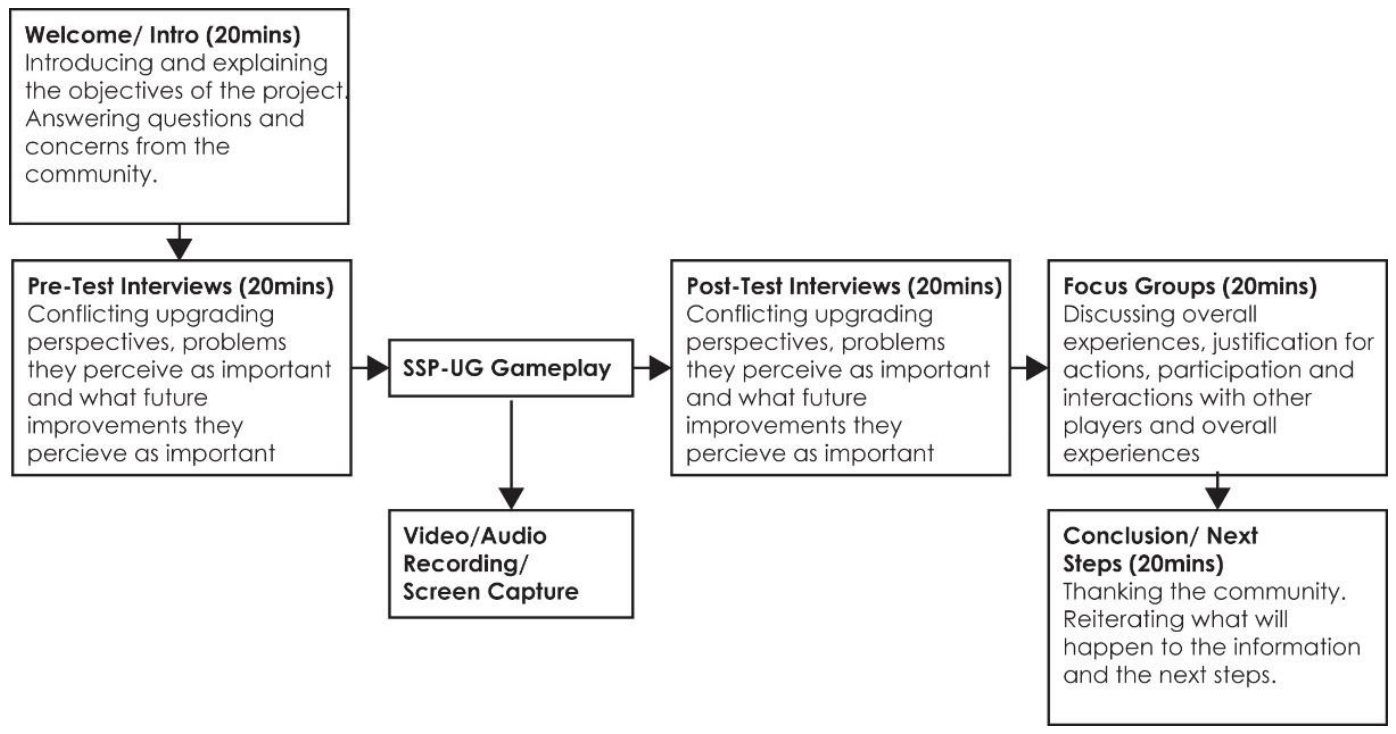

Figure 46. Phase Three research procedure.

A number of recording instruments also were used in order to supplement the structured interview and focus group data to aid in the data analysis process. The SPSUG was played by the participants via a laptop computer in all workshop groups. This was chosen due to its ease of mobility and operability with limited access to electricity sources in some communities, as well as increased graphic rendering capabilities over other platforms such as tablets. The screen video capture software Flashback was used to record the SPS-UG gaming process on screen for each workshop. This software also captured audio recordings of participants playing the game. This included discussions before and between each level played. The second mode of workshop recording was via a video recording of the workshop using a digital SLR camera and tripod positioned to capture all participants and facilitators, their interactions and the computer monitor. A still camera was also used in order to capture key moments within the workshop; however, the still camera's use was kept to a minimum so as to not distract the workshop participants. A detailed account of how the research methods were applied is discussed in relation to the application in Chapters Five, Six and Seven.

Translators were used to translate participants' responses and interactions. During the workshops, unpaid volunteers from both the Chinatan Environmental Research and Action Group in Delhi and from Apnalaya in Mumbai were used as translators. This was beneficial as they had detailed knowledge of the physical, social, cultural contexts of each case study, as well as knowledge of non-Hindi words that were frequently 
incorporated into some of the participants' language. They were chosen over paid professionals also because an expert may exert considerable power within a given ethnic group, and the participants may be dependent on maintaining a good relationship with them in order to have their voices heard (Temple \& Young, 2004). Translation of the gameplay was conducted by a paid translator after all of the workshops were completed. Researchers in translation and interpretation generally discuss validity in terms of 'correct' interpretations, ethics, matching of social characteristics and neutral stances (Harrington \& Turner, 2001; Phelan \& Parkman, 1995; Temple \& Young, 2004). In order to ensure accuracy of the translation, back translation was used where the translated version of the gameplay was sent to the workshop translator from each of the workshops and checked for errors (Baker, Saunders, \& Hussain, 1991). The triangulation of multiple data sources also provided a means of ensuring accuracy of the translations.

The workshop translators in each case also facilitated the workshops. Each facilitator was trained in the use and procedure of the SPS-UG. This included introducing the participant to the process, and ensuring that the facilitators played a minimal role during the gameplay and only responded to questions posed by the participants and only took control of the game system if necessary. I was also present during each workshop to answer any questions the facilitators might have during the gameplay process.

The gathered data - pre-test / post-test interviews, video recordings, photographs, game screen capture and focus group discussions-was analysed using thematic analysis detailed by Braun and Clarke (2006), which has been used by many participatory design researchers (Balestrini, 2017; Charnley, Lemon, \& Evans, 2011; Gooch et al., 2018; Kreutz, Derr, \& Chawla, 2018) to identify themes or patterns in the data when exploring new participatory design methods. Once the data was collected and transcribed where appropriate, thematic analysis was used to identify, analyse and report patterns (themes) within the data using the coding procedures described above. Thematic analysis was appropriate for a number of reasons. First, it allowed for an inductive-deductive hybrid approach to be used (Fereday \& MuirCochrane, 2006) in which patterns and themes could be identified from multiple sources of raw data, and it was well suited to the large datasets generated through the documentation of participatory design processes. Second, the themes generated through the data analysis could be used as a further part of the slum-upgrading action. 
Third, Braun \& Clarke (2006) and King (2004) argued that thematic analysis is a useful method for examining the perspectives of different research participants, highlighting similarities and differences, and generating unanticipated insights.

The Action Research approach usually comprises iterative stages of reflection and action (Foth \& Brynskov, 2016). Ideally, the three Phase Three workshops would have been conducted sequentially, with cycles of reflection between each of the case study workshops (the action) so that improvements to the methods and tools used might be made (ibid.). However, because of resourcing limitations related to the international travel component of this research, this was not possible. From a participant perspective, each workshop was orientated around cycles of reflection and action, as well as reflection and adaptation of methods to the unique research situations within each case. At the end of the study and after the analysis, research outputs were then fed back to the community members via the external partners. These points are relevant to affecting design and social outcomes as sought by the Aim 4.

\subsection{Ethics and Representation}

Issues of ethics and the representation of participants' experiences are central to both Action Research and participatory design.

A core principle of Participatory Design has always been to acknowledge participants as experts in their own work situation. This presumes respect for their expertise as well as mutual trust (Simonsen \& Robertson, 2012, p. 72). Care was taken to ensure that the trained facilitators and I, as a researcher, remained impartial to the participatory workshop process. This included ensuing that $\mathrm{I}$, as a trained designer, did not to tell users what their work is or what it means to them.

The production of representations of participants' work is critical to Participatory Design (M. Bødker, 2009). For the most part, the SPS-UG allows for participants to graphically represent their own design ideas. The development of the SPS-UG system involved creating 3D spaces and tools that participants could use to indicate desired changes and problems with their urban environment. As all possibilities could not be catered for, effort was made to provide some basic in-game modules (i.e. blank building blocks) that participants could use to represent urban entities that were not specifically catered for in the design. 
With regards to selecting participants, the research does not endeavour to select a representative sample of all participants affected by slum-upgrading issues within each case study context. Rather groups of residents within the community were included through the partner organisations.

It was also very important to manage participant expectations with regard to the outcomes of the workshop process. Here, it is important that the goals of the workshop are made clear to all participants (i.e. that the SPS-UG is a tool for exploring ideas, and not for designing interventions that will actually be built). If not carefully managed, participants could experience a tension between embracing creativity and the unknown budget reality of a slum-upgrading project resulting in disappointment and distrust.

\subsubsection{Reflexivity, Validity/Transferability and Relevance}

In her article Qualitative Research: Standards, Challenges, and Guidelines, Kirsti Malterud describes three criteria that should be considered in qualitative research: reflexivity, validity/transferability and relevance (Malterud, 2001, p. 484). Regarding reflexivity, I was aware of the influence of my own position, background and interest in the research setting and outcomes. Regarding validity, I endeavoured to ensure that findings could be transferred beyond the research context and relevance by ensuring that the knowledge that is created through the research process is useful for other practitioners.

Reflexivity requires systematic attention to the context of knowledge construction, especially the effect of the researcher, at every step of the research process. I was actively involved in conducting participatory inquiries in the case studies for this research. My personal background in architecture and urban design influenced my design and use of the participative tools and materials. In the context of using these participatory design processes in the research, I acted at different times, and sometimes simultaneously, as a researcher, a designer and an active participant in the design situations for the empirical cases. Throughout the thesis I attempt to be clear about my role within the cases being studied.

Because this research uses inductive and deductive coding procedures, detailed in Section 3.4.1, the research utilises a process of data triangulation (Cohen, Manion, \& Morrison, 2003) to help ensure validity/transferability. Validity and transferability 
have to do with transferring the findings beyond the research context. When discussing validity and transferability, Malterud points out that "the findings from a qualitative study are not thought of as facts that are applicable to the population at large, but rather as descriptions, notions, or theories applicable within a specified setting” (Malterud, 2001, p. 486).

In his thesis, I present the participatory design workshop accounts as first-person, step by step, subjective, qualitative recounts of research processes. I have, where appropriate, included my reflections as well as those of participants and collaborators. These descriptions are aimed at contextualising the design situations and decisions made within them in order to make the rationale behind them accessible. A detailed description of the research methods used is also presented in section 3.3 in order to enhance the research transferability. The development of the SPS-UG design framework was described in Chapter Two; I describe the overall methods and processes in section 3.3. In Chapter Four I describe the operationalisation of the SPSUG framework to design an SPS-UG, as well as how ethnographic methods were used to document the context of each of the communities for digitalisation into a virtual game environment and to gain an understanding of the range of conflicting perspectives regarding upgrading-related issues with the three communities, and in Chapters Five, Six and Seven I describe how the methods were employed in documenting and analysing the SPS-UG workshops.

This research uses inductive reasoning to generate understanding of the use of the SPS-UGs within each case study. This research works qualitatively with the data generated (Cross, 2011), to identify the dominant themes, which are then illustrated with descriptions of salient moments, relevant participant quotations and illustrative graphic media. This study also utilises a process of data triangulation in analysing the SPS-UG workshops in order to increase validity. This is detailed in Section 3.4.1. Cohen, Manion and Morrison define triangulation as an "attempt to map out, or explain more fully, the richness and complexity of human behaviour by studying it from more than one standpoint" (Cohen et al., 2003, p. 254). It is important to cross-check qualitative data from multiple sources in order to search for regularities in the data (Cohen et al., 2003; O’Donoghue \& Punch, 2003, p. 78).

In order to improve the reliability of my findings, all case studies were recorded in video and still images, and the player dialogues that occurred in each case study were transcribed. The analysis was undertaken using multiple data formats including video, 
photographs, audio recordings, screen-capture data, notes and survey responses. The results have been published in peer reviewed publications, which is another form of external testing and evidence of relevance. Each case study has been carefully documented with detailed descriptions to allow the reader to follow my line of argumentation.

\subsection{Summary}

The chapter has described the methodology used in exploring the SPS-UG approach through an Action Research methodology of "reflective practice", which is centred on case studies as a design research strategy. This approach underlies the experimental nature and character of the work and provides a coherent way for discussing how the arguments are connected to the design work and to academic discourses. Finally, the chapter introduced how the SPS-UG approach will be used as a research method through three phases including Phase One - Context Documentation Studies and Analysis, Phase Two-SPS-UG Development and Phase Three-SPS-UG Workshops.

Next, Chapter Four details how the SPS-UG approach was operationalised through the development of an exemplar SPS-UG framework as a computer game I designed that was tested within the three case studies. This SPS-UG framework forms the basis of each of the participatory design workshops. 


\section{Operationalising the SPS-UG Approach}

Compared with games, reality is hard to get into. Games motivate us to participate more fully in whatever we're doing. To participate wholeheartedly in something means to be self-motivated and selfdirected, intensely interested and genuinely enthusiastic. If we're forced to do something, or if we do it half-heartedly, we're not really participating. If we don't care how it turns out, we're not really participating. If we're passively waiting it out, we're not really participating.

- (McGonigal, 2011, p. 124)

\subsection{Introduction}

This chapter details the processes undertaken in operationalising the SPS-UG framework presented in the previous chapters through the process of documenting the case study contexts and the subsequent development of an SPS-UG as a computer game I designed called "Maslow's Palace”, which is used to evaluate the research approach within the three case study contexts. In order to develop a SPS-UG approach that is specific to exploring upgrading ideation and conflicting perspectives in the research context, two phases were followed as shown in Figure 47.

The chapter is composed of two primary sections. Section 4.2 details Phase One the documentation of the research context including the fieldwork procedures and analysis. Section 4.3 details Phase Two - Stage One: the development of threedimensional game assets and Phase Two - Stage Two: the development of the interactive mechanics and dynamics of the SPS-UG. 


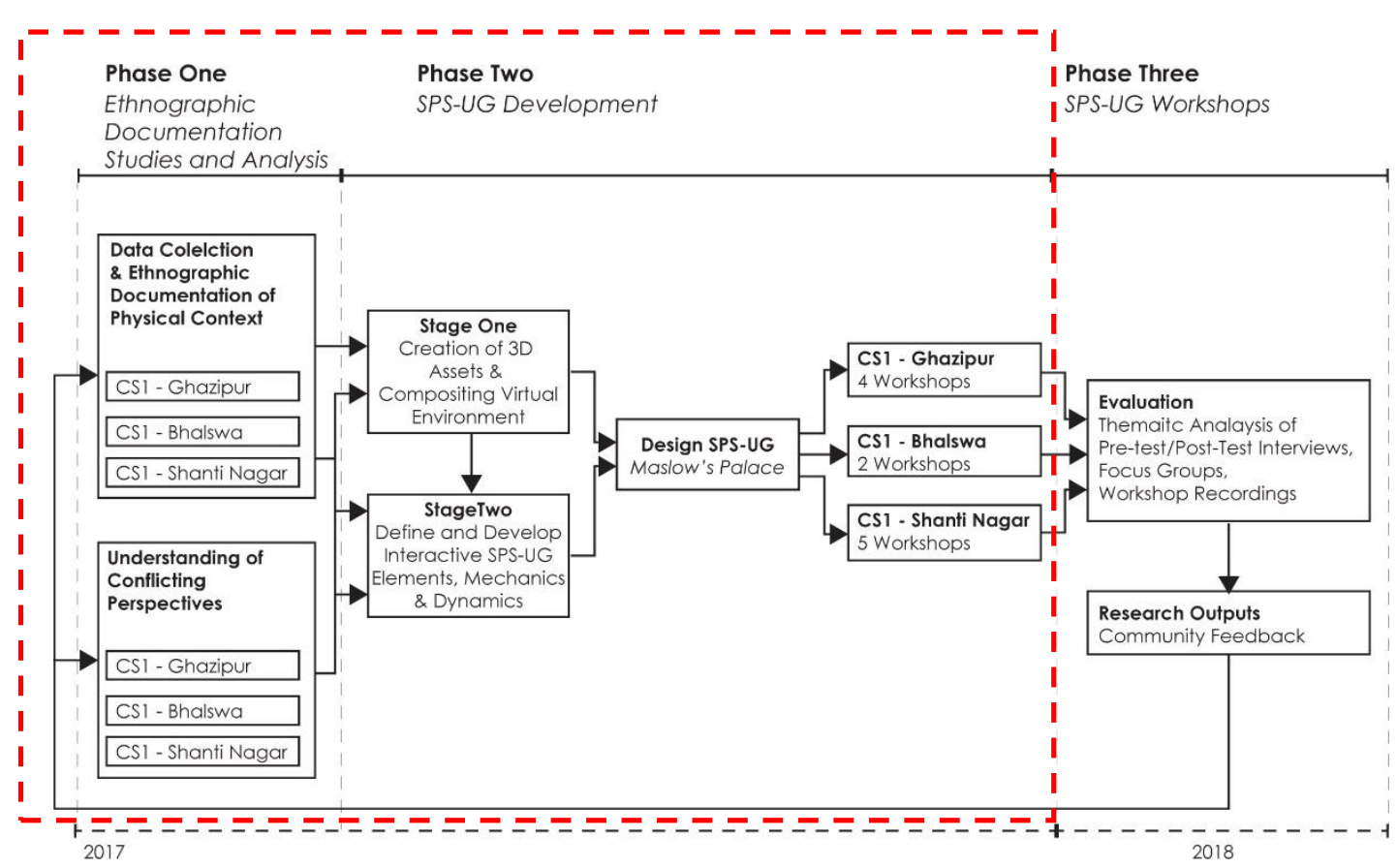

Figure 47. Research Phases One and Two detailed within this chapter.

\subsection{Phase One: Documentation of the Research Context}

This section details the results of the ethnographic documentation of each case study community to:

O2: to gain an understanding of the range of conflicting perspectives regarding upgrading-related issues important to different community members to inform the subsequent design of an SPS-UG that might help in the negotiation of conflicting perspectives and stakeholder ideation.

\subsubsection{Ghazipur-Documentation of Context}

The Ghazipur Landfill area is located approximately nine kilometres east of the centre of New Delhi, Delhi, India as shown in Figure 48 below.

The Ghazipur block, which is bordered by two large drainage canals on the southern and western sides, is shown in Figure 49. Both canals are tributaries of the Yamuna River, the second largest tributary of the Ganges River, which flows through India and Bangladesh. The Ghazipur landfill therefore directly adds to the well-documented pollution of the Ganges by contributing leachate and landfill run-off via this waterway. The Ganges is one of the most sacred rivers to Hindus as well as a lifeline to millions of Indians who live along its course and depend on it for their daily needs. 
Approximately half a kilometre north of the Ghazipur Landfill is Asian Highway 2 (AH2) (National Highway 24 Bypass), which spans 13,107 kilometres from Singapore to Khosravi, Iran on Iraq's eastern border. The Ghazipur block also shares its northeastern border with the border between Uttar Pradesh, which is the most populous state in India, and the National Capital Territory of Delhi (NCT). The NCT union territory and the state of Uttar Pradesh both operate under their own legislature.

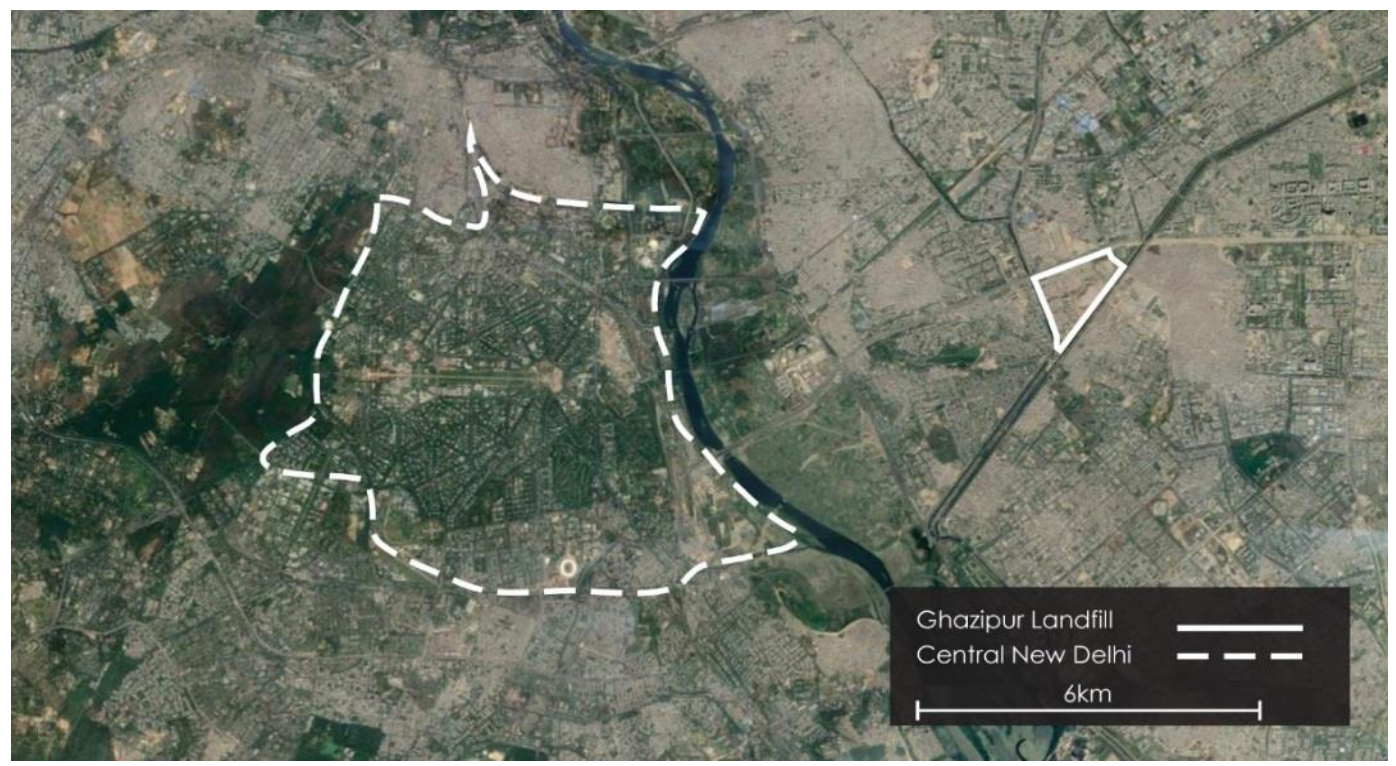

Figure 48. Ghazipur, Delhi, India. Satellite image from Google Earth., 2019. 


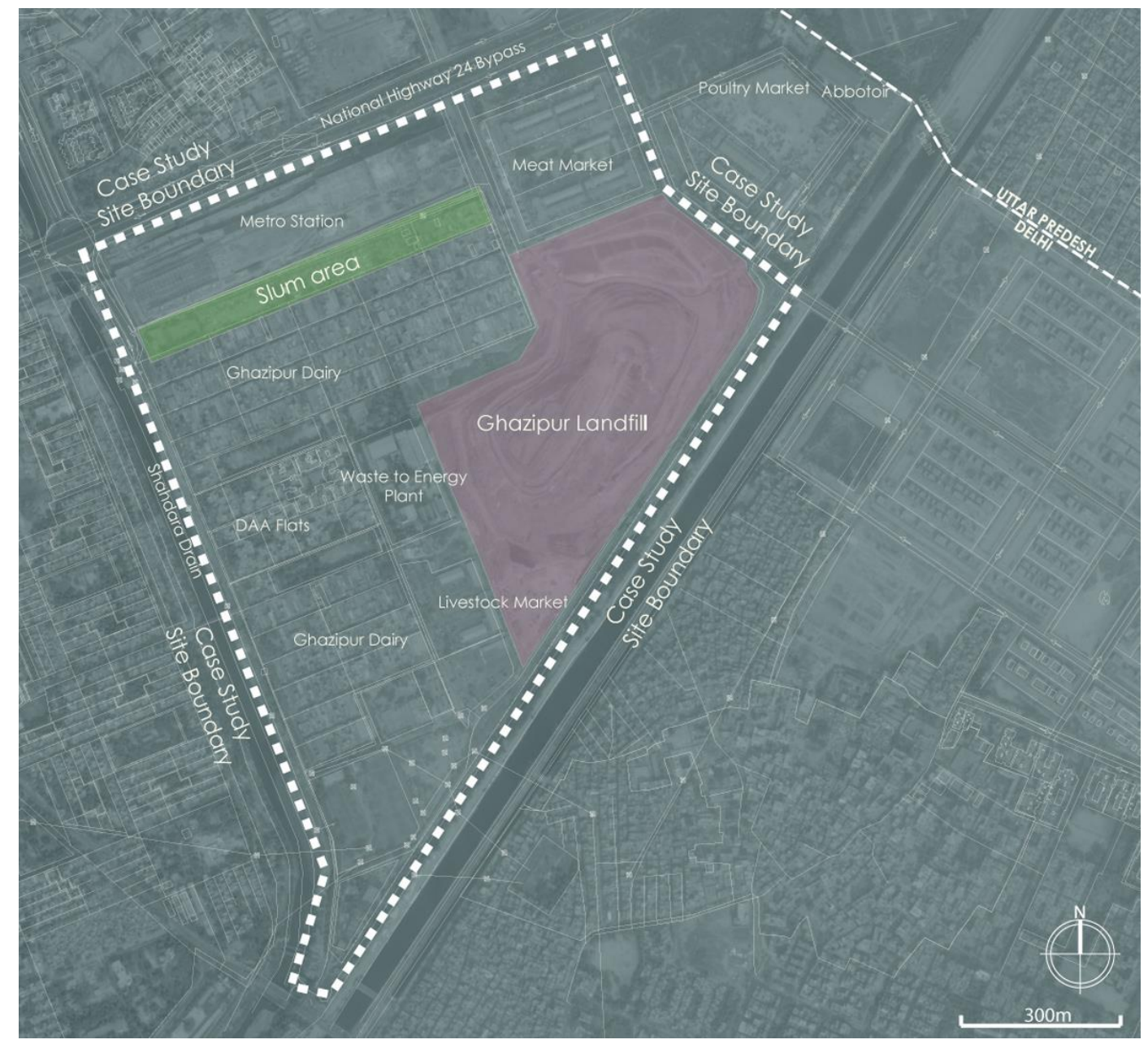

Figure 49. Ghazipur area, Delhi. Satellite image from Google Earth., 2019.

\subsubsection{Ghazipur Land Use}

The Ghazipur area includes a number of prominent land use features. The Ghazipur block developed around and is dominated by the landfill, which has been in operation since 1984 and is spread over an area of 11 hectares. According to estimates, there are over 12 million tonnes of waste in the landfill, and it stands 50 metres tall. The landfill therefore exceeds the 15-metre height limit for a landfill imposed by the Municipal Corporation of Delhi (MCD). The landfill surpassed this height restriction in 2002 (Singh, Rohit, Shivangi, \& Vipul, 2016). The landfill is a major landmark on the surrounding landscape due to its height. The environs of the landfill are typified by a mixture of industrial activities and farming land uses. Most industrial activities support the farming operations such as meat works and cold storage facilities and poultry and meat markets. Amongst these areas is energy generating infrastructure such as a power station in the southern corner of the Ghazipur block, and a waste-to-energy plant next 
to the landfill. A large proportion of the Ghazipur area is occupied by the Delhi IP Extension Metro station, which is still under construction in late 2019. The metro station occupies land that was formerly designated as Ghazipur District Park. When construction began at the end of 2014, a number of residents were forcibly evicted from their dwellings, constructed illegally on the site of the new metro station. The participants of this study inhabit a strip of slum development that is located between the metro station and the dairy farm areas. Peripheral to the Ghazipur block are areas of medium-high density mixed-use residential areas with pockets of both public and private greenspace. The area has a mixture of regular and irregular street grid patterns and is typified by large plot sizes; however, many of these have been illegally or informally subdivided in the process of unregulated development.

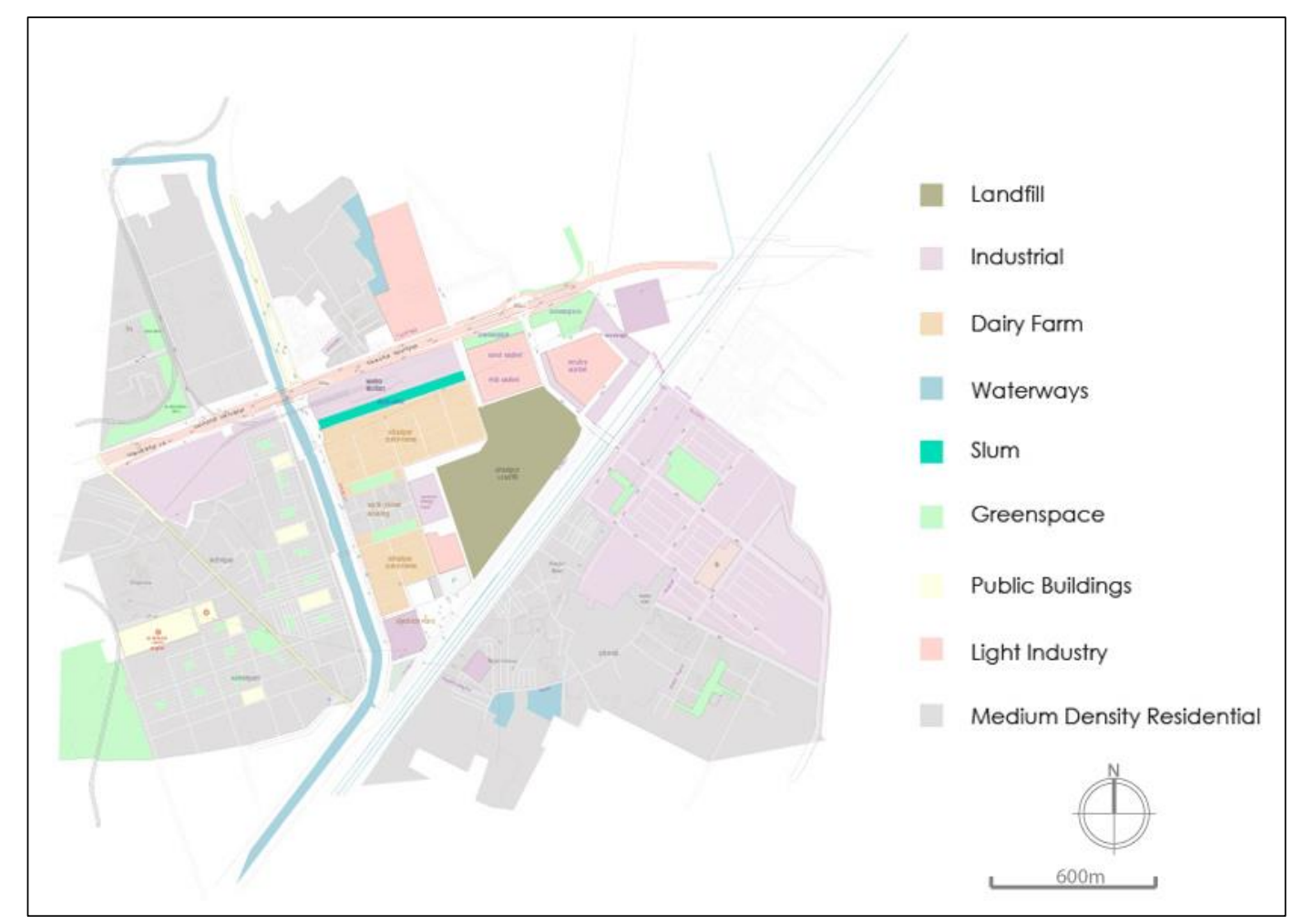

Figure 50. Ghazipur land use, 2019.

\subsection{Ghazipur Housing}

Approximately one thousand people live around the landfill's perimeter. The first residents moved to the Ghazipur block when the landfill opened in 1984. Most of these reside on a 50x500m land parcel between the rear wall of the Metro Station to the north 
and the indoor dairy farms to the south (see Figure 51). Most houses sit either side of a path that stretches the length of this area, while the southern half of this strip of land is used mainly for waste segregation (Figure 52).

Most homes are constructed of lightweight and recycled materials such as brick, tarpaulins, plastic sheets, cardboard, bamboo, corrugated iron, and blankets (Figure 53 and Figure 54). Other repurposed materials such as timber doors and steel panelling are also commonly used. The dwellings are all single story and are occupied by an average of five people.

The MCD provides running water to each dwelling, which is free if they use less than 2000 litres per month/household. The community is also connected legally to the MCD electricity grid. There is one public toilet facility within the Ghazipur block, which was constructed by the MCD in 2015. The block has one male toilet and one female toilet; however, most residents choose not to use it because of the frequency of harassment by other community members at this location. Alcohol and drug abuse are also a large problem within the community. This is in response to poverty faced by the community and is exacerbated as Uttar Pradesh law permits the sale of liquor twentyfour hours per day, with many stores in close proximity to the community.

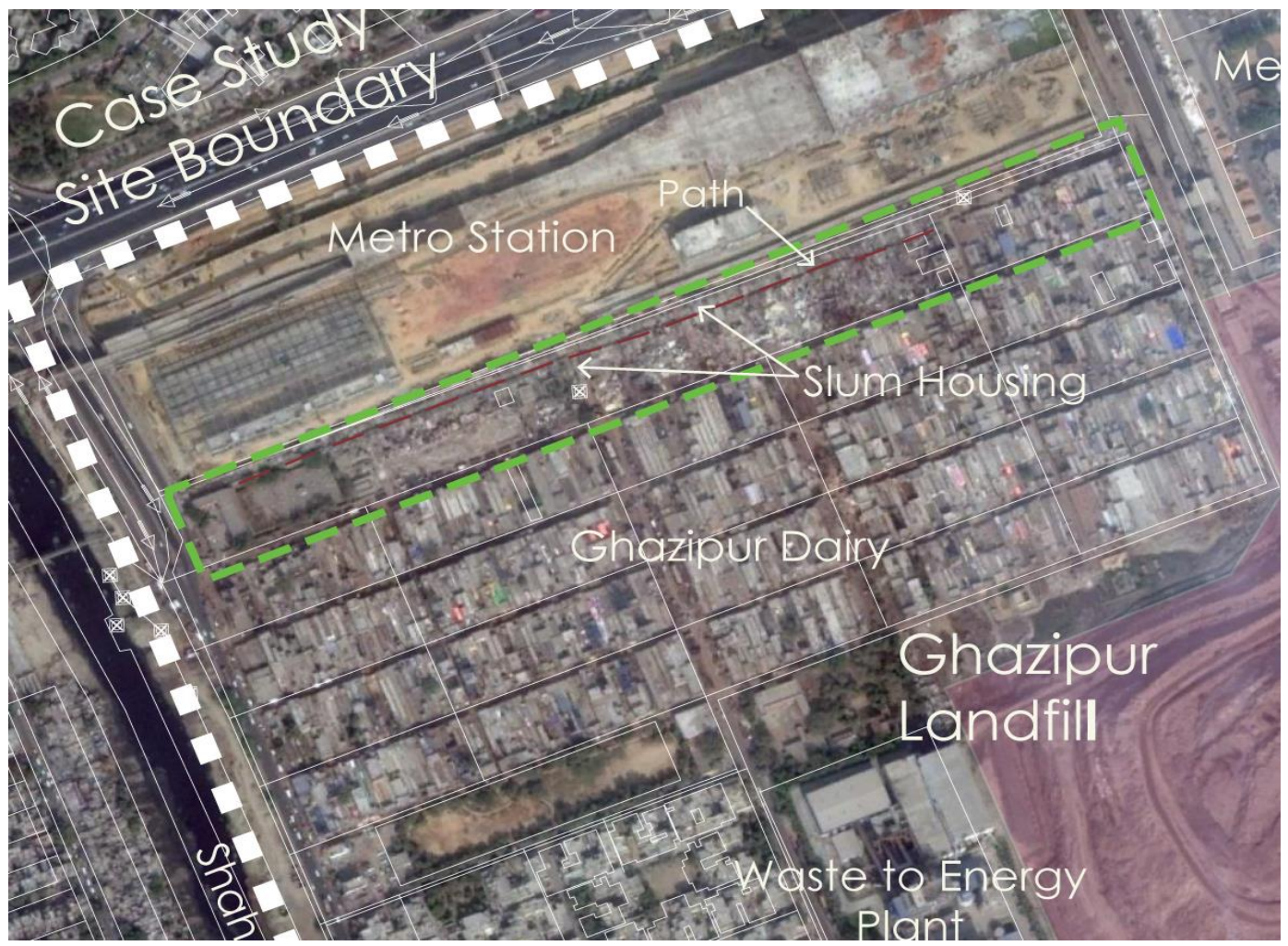

Figure 51. Ghazipur. Satellite image from Google Earth. Accessed 2019. 

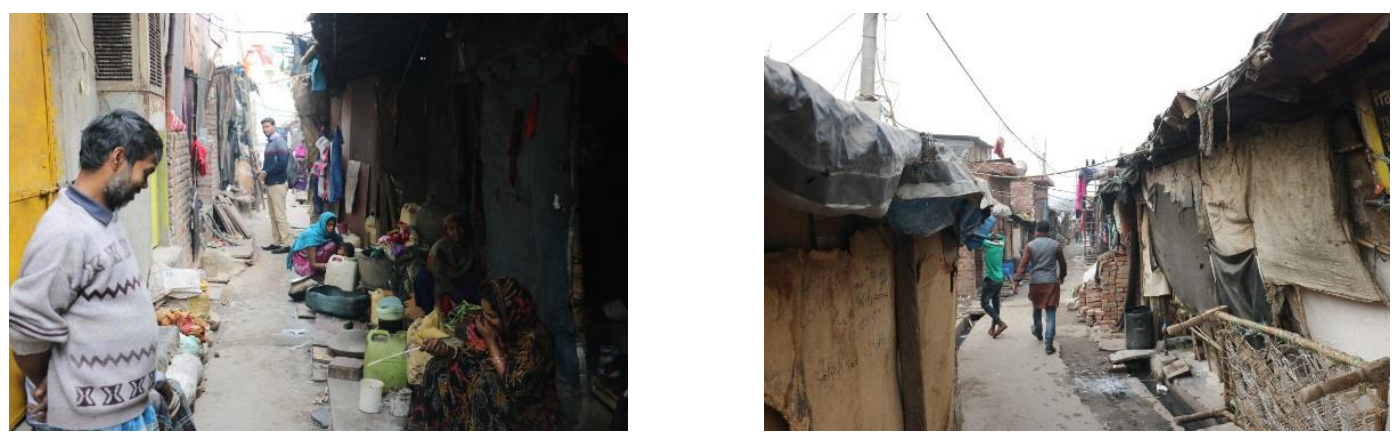

Figure 52, left. Residents cooking next to open drains, Ghazipur, 2017. Photo by Author.

Figure 53, right. Ghazipur dwellings, 2017. Photo by Author.

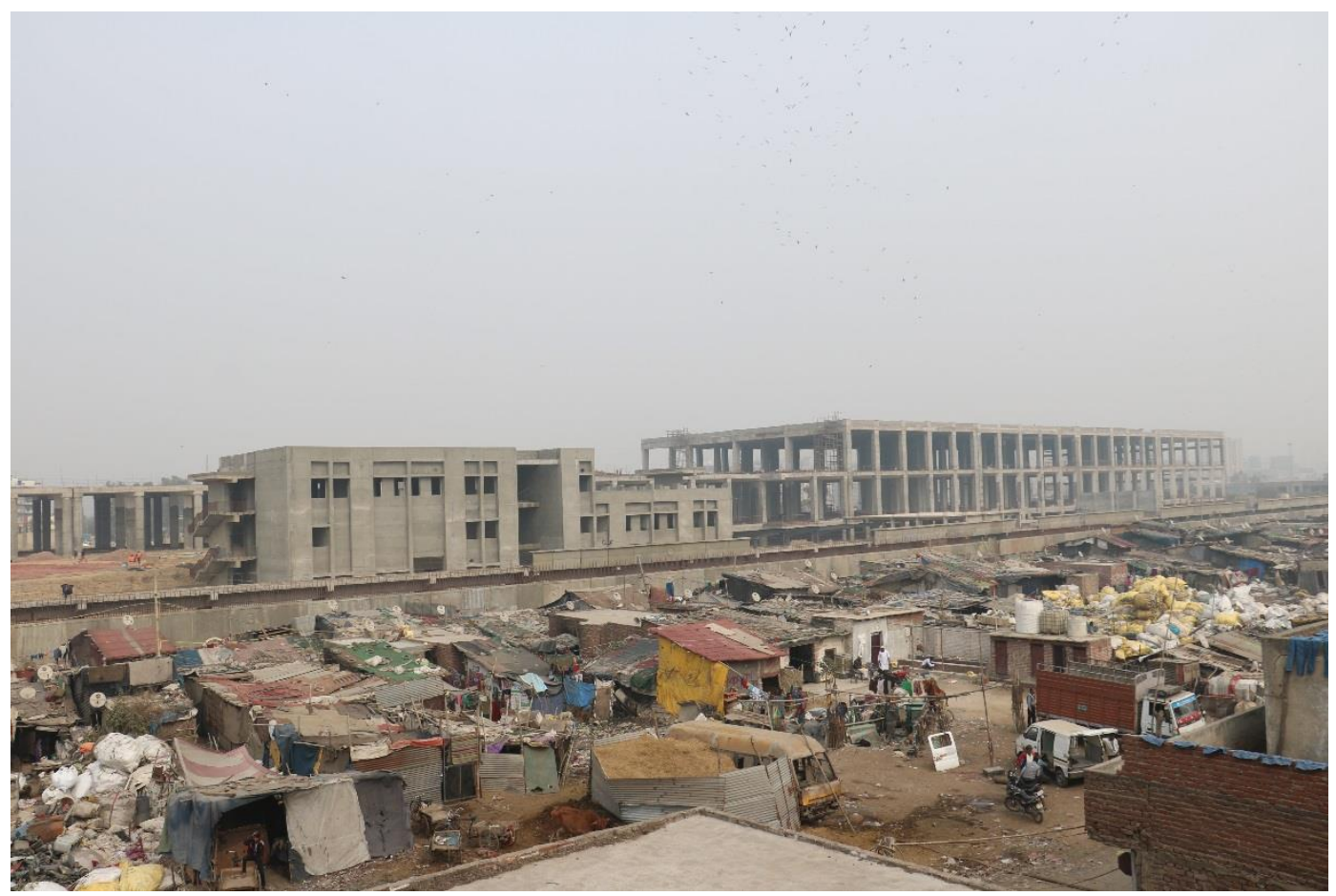

Figure 54. Delhi Metro Station under construction with residential area in the foreground, Ghazipur 2017. Photo by Author.

\subsubsection{Ghazipur Livelihood Generation}

Approximately one-third of the Ghazipur community works in the informal recycling sector-mainly as waste collectors or in the segregation of collected materials. 47 households do not have anyone working in the informal waste sector; however, many of these non-waste pickers own businesses that serve the needs of the residents on a daily basis, such as tailors, barbers, shopkeepers, or pharmacists (Heller \& Mukhopadhyay, 2014). In 2011, there were approximately 500 youth aged between 4 and 18 years living at Ghazipur, and $26 \%$ of these are waste pickers themselves 
(Chintan, 2011). 32\% of these youth attend local schools (Chintan, 2011). While no current census data exists, these are assumed to have grown significantly with the increase in number of dwellings over that time.

Waste picking at Ghazipur is a multi-step process. Waste pickers generally collect mixed waste from the landfill by hand. This is brought down to a number of sorting areas located in vacant lots between the dairy farms (Figure 55) or within the residential area. Plastics, for example, are sorted into 60 different categories. Shoes are collected and sold to brick makers who use them as fuel for their furnaces. Materials are generally sold to a transporter who moves the materials not more than $200 \mathrm{~m}$ to a larger specialised distributer within Ghazipur, who then sells the materials to external recyclers.

Many residents work in the informal recycling sector from within their homes. This is predominantly dealing with smaller materials such as sorting and cleaning human hair for wig-making (Figure 56) or processing electrical components to obtain valuable metals. A number of community members also work for local garment manufacturers from their homes (Figure 57). For example, some residents collect jeans from a local manufacturer in order to tie cord through the legs before delivering them back to the manufacturer to be distressed and then sold locally and internationally as shown in Figure 57.

The privately-operated waste-to-energy plant operated by IL\&FS Environmental Infrastructure \& Services Ltd (Figure 58), located on the western edge of the Ghazipur Landfill, employs some of the Ghazipur community members to sort waste within the plant.
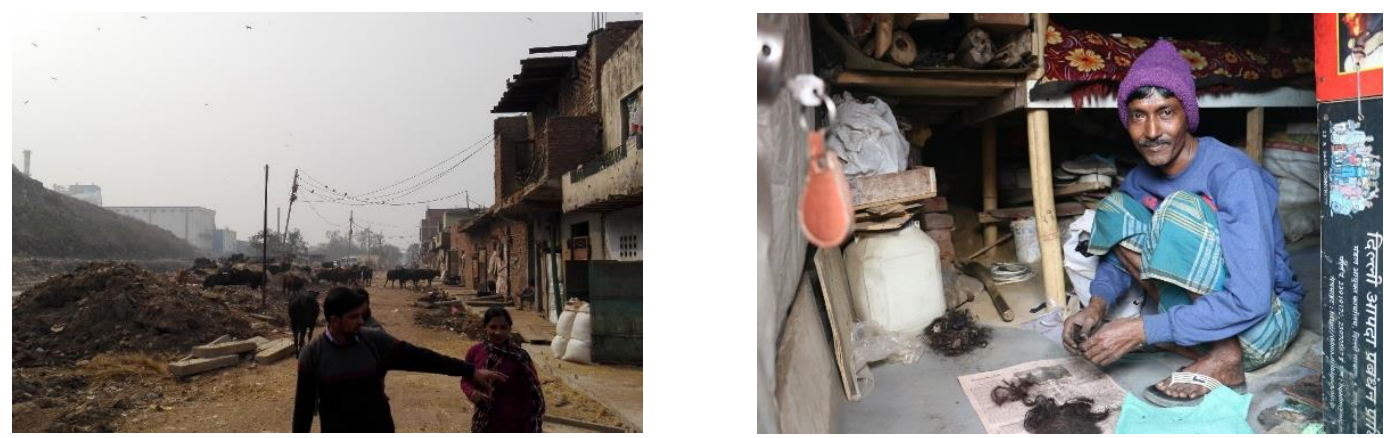

Figure 55, left. Ghazipur landfill, dairy farm buildings and dairy cows grazing on the landfill. Ghazipur 2017. Photo by Author.

Figure 56, right. Recycling human hair, Ghazipur, 2017. Photo by Author. 

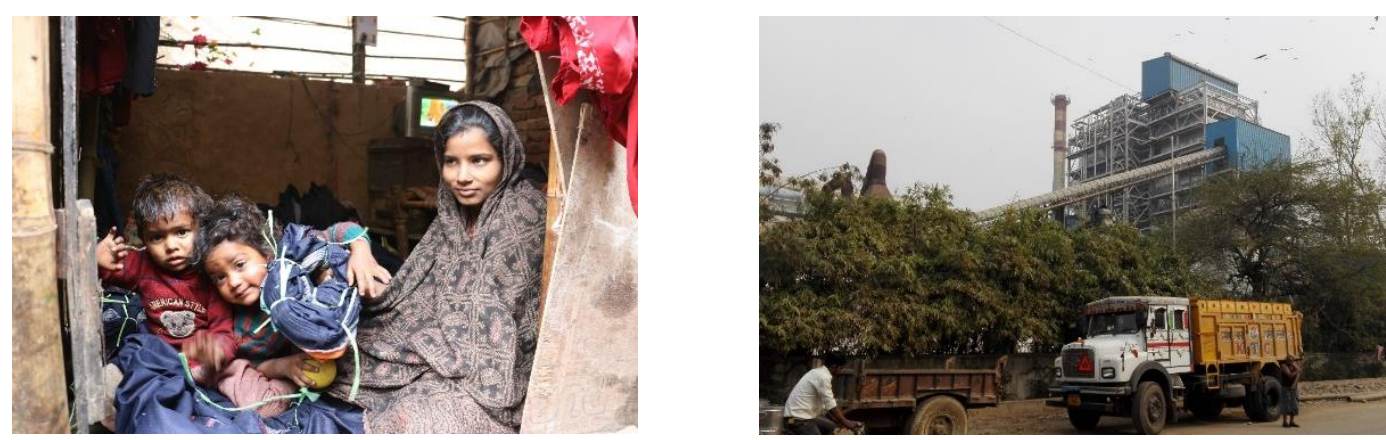

Figure 57, left. Outsourced garment labour, Ghazipur, 2017. Photo by Author.

Figure 58, right. Waste-to-energy Plant, Ghazipur 2017. Photo by Author.

\subsubsection{Main Slum-Upgrading Issues}

Ghazipur residents are subject to threat of widespread displacement and loss of livelihood as a result of privatisation of the waste management sector. Specifically, the waste-to-energy plant causes a number of problems for the community and inhabitants. Recyclable waste, which is collected from the landfill or delivered directly to the plant and incinerated, could otherwise sustain a number of inhabitants. The plant also only employs women from the community, primarily because of drug and alcohol abuse by male residents. Because of this, and because Ghazipur residents do not want to turn down formal employment, children within the community are often unsupervised.

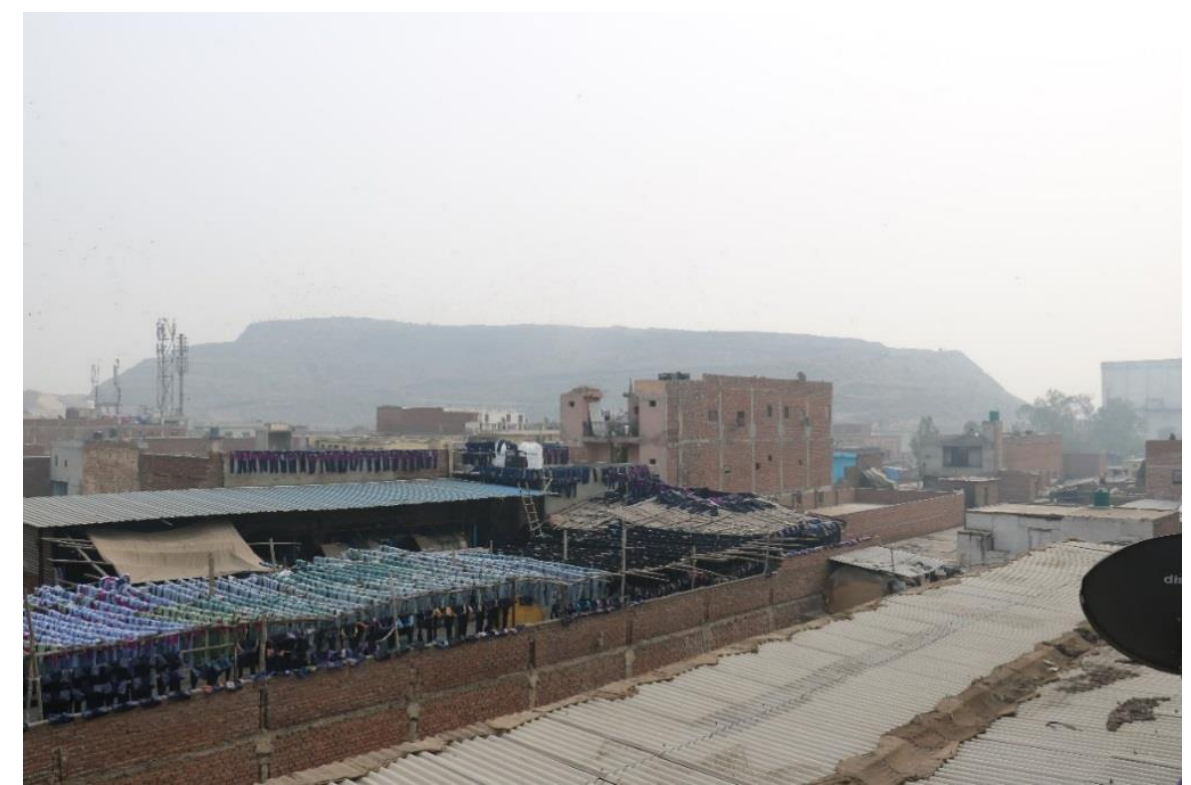

Figure 59. Overlooking garment factories and indoor dairy farms with Ghazipur landfill in the background, 2017. Photo by Author. 
A large proportion of the Ghazipur block is occupied by indoor dairy farms (Figure 55). Here, a large number of grain-fed cattle are kept in indoor or underground sheds and service Delhi with milk. Dairy effluent, which is meant to be trucked away from dairy farms for disposal, is typically pumped out of the shed and illegally onto the road into commonly blocked and overflowing open drainage systems, or directly onto the base of the landfill itself. The blocked drains are regularly cleared by diggers working for the MCD, and the cleared excrement is typically left in large piles on the paths and roads. Most people cook outside of their homes next to the open drain, which means that people are cooking next to the piles of drainage cleanings. During the wet season, the dwellings frequently flood, bringing the dairy excrement indoors. Cows are let out of the sheds often, and they can be seen grazing on the landfill within waste sorting areas or in residential areas. Chintan Environmental Research and Action Group has been in discussion with the dairy farm owners to explore composting systems for the excrement. This would allow it to be sold to gardeners and thereby be removed from Ghazipur block; however, this has not gained support from the MCD nor the dairy farm owners. The Ghazipur block also includes a fish market and a poultry market that contribute to the complex environmental problems relating to the disposal of waste products at the landfill.

The Ghazipur block has no safe open public spaces, and is subject to a threat of forced eviction due to a possible further expansion of the metro station in the future. 


\subsubsection{CS2 - Bhalswa - Documentation of Context}

\subsubsection{Bhalswa Land use}

The Bhalswa dairy area approximately $15 \mathrm{~km}$ north of New Delhi, Delhi, Figure 60 , is the research context for Case Study Two (Figure 60). It is defined by the drainage canal to the south and west of the site, the Bhalswa Lake to the east and the dairy industry area to the north.The residents of the slum area adjacent to the Bhalswa landfill are the primary stakeholders involved in the research (Figure 61 and Figure 62).

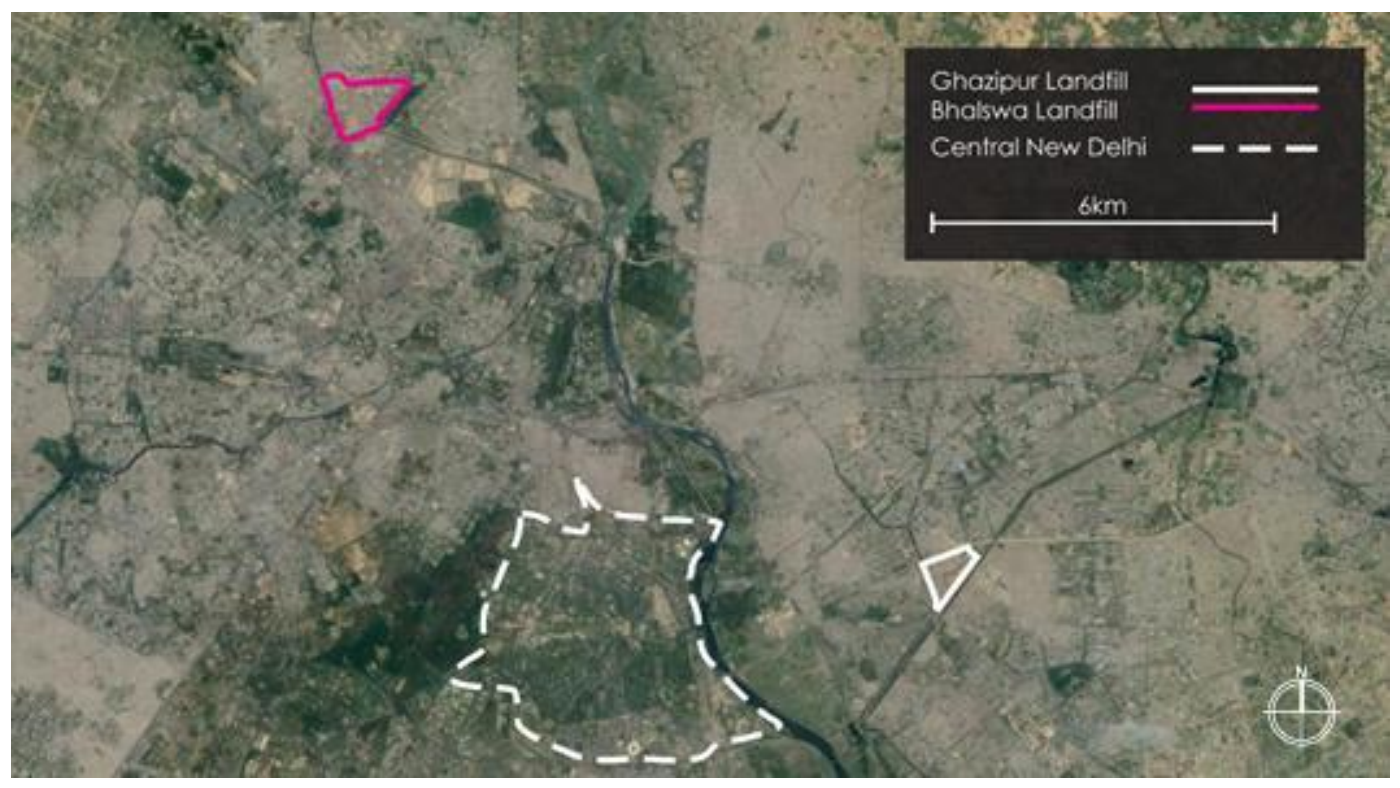

Figure 60. Bhalswa, Delhi. Satellite image from Google Earth., 2019.

The Bhalswa landfill is an un-engineered and unlined landfill that falls into the category of uncontrolled solid waste disposal facility (Singh \& Mittal, 2011). The landfill sits on a bend in a canal that flows directly into the Yamuna River, east of Bhalswa Dairy is Bhalswa Lake, one of Delhi's most important waterways, which is being severely degraded because of the effluent/sewage coming from the nearby landfill, dairy farms and residential areas (Singh, 2017). The landfill came into operation in 1993. The landfill occupies 8.5 hectares of land that was once used for sugar cane plantation. The landfill was declared at capacity in 2006; however, the nonavailability of land for a replacement location for a new landfill has led the Municipal Corporation of Delhi (MCD) to continue to dispose of municipal waste at Bhalswa. 


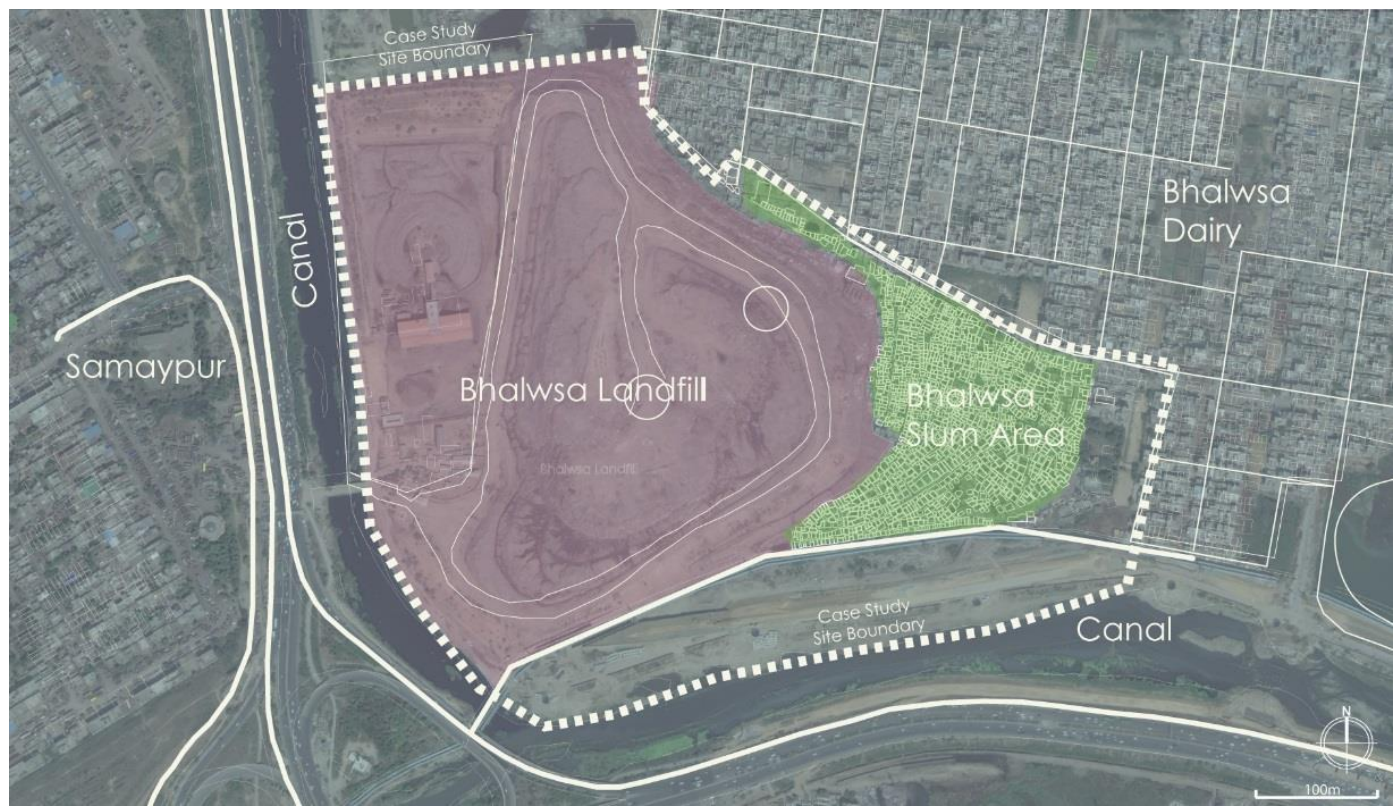

Figure 61. Bhalswa case study site. Satellite image from Google Earth., 2019.

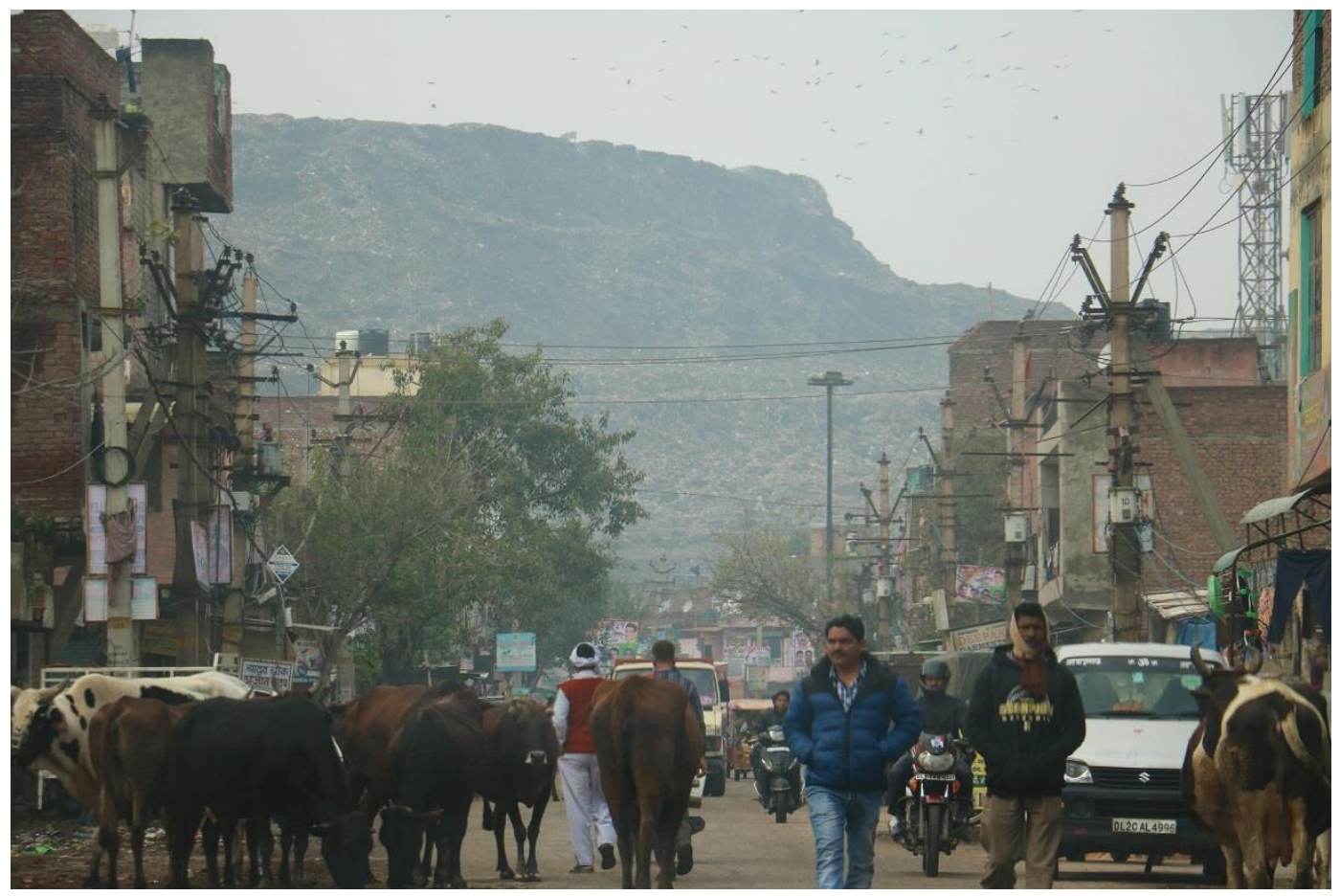

Figure 62. Bhalswa landfill as viewed from Bhalswa Dairy, 2017. Photo by Author.

The majority of the Bhalswa area is comprised of informal mixed-use residential development. Most current residents of the Bhalswa community were relocated to the community in November 2002 from eleven other jhuggi-jhompri clusters (slums) on the pretext of beautification of the city at the direction of the MCD. Most of these 
residents were originally migrants from other areas of India, with most arriving from West Bengal. The resettlement colony is located adjacent to the landfill and is composed of a regular gridded street pattern and an irregular grid slum area closest to the landfill. The land originally was owned by farmers; however, over the past thirty years, the land was divided into smaller parcels and sold predominantly for the unregulated development of medium density residential concrete structures, while the plots directly to the east of the landfill are subject to single-storey informal slum development, as shown in Figure 63. A large portion of the land towards the north of the site is occupied by light industry, which predominantly services the farming and construction industries.

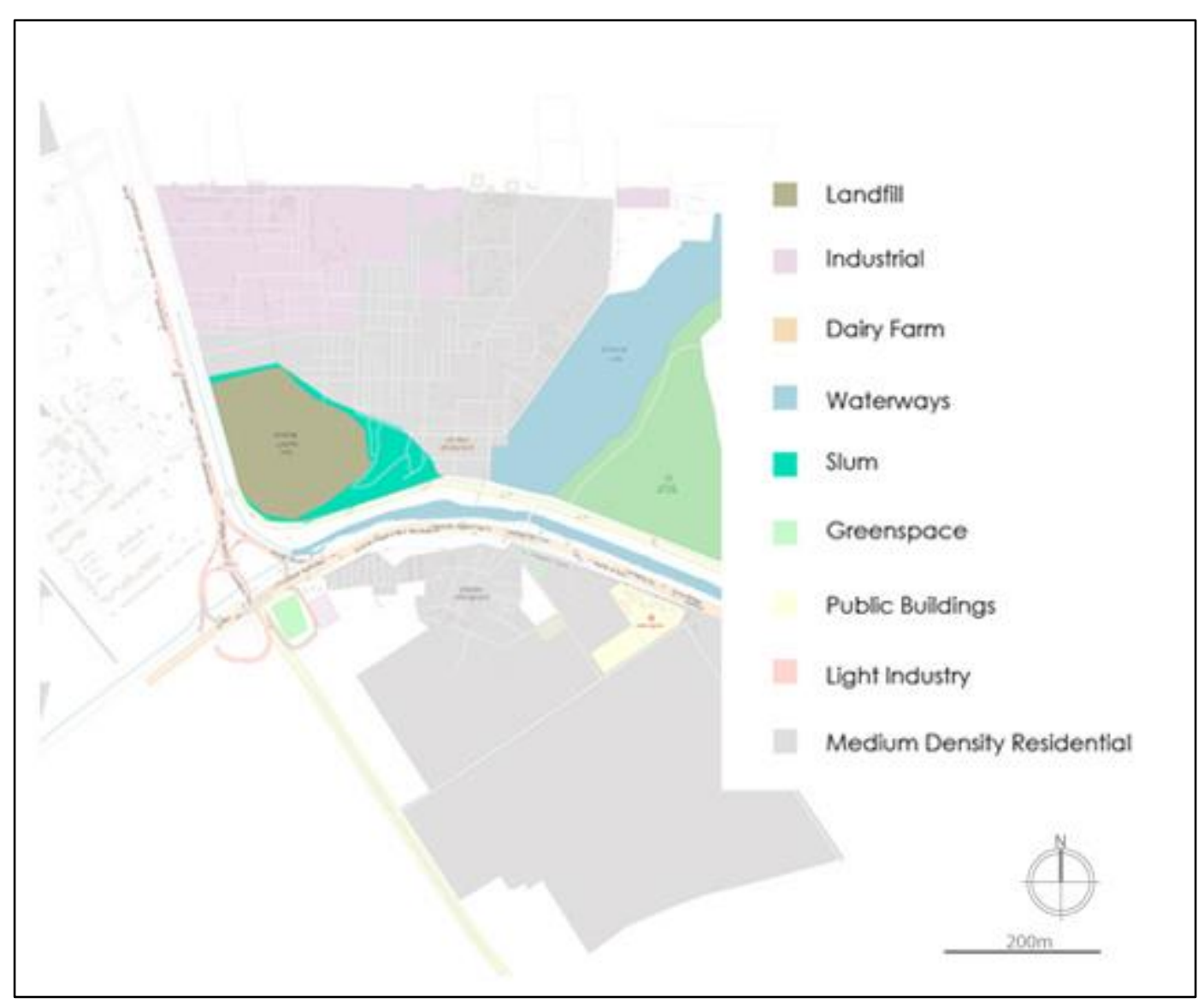

Figure 63. Wider Bhalswa area land use, 2019

Bhalswa has two main types of dwellings: brick and concrete (Figure 64) versus lightweight and makeshift (Figure 65 and Figure 66). The majority of the area is occupied by two and three storey brick and concrete dwellings. Most of these have 
street facing shops at ground level. The focus of this case study is on the residents who occupy the slum areas directly adjacent to the landfill. Dwellings in these areas are progressively more lightweight and makeshift as the landfill edge is neared. Dwellings closest to the landfill are constructed of a mixture of reclaimed bricks, concrete, timber, bamboo, cardboard, plastic tarpaulins and blankets. Homes are frequently dug into the ground as this minimises wall heights and therefore reduces construction costs; however, this also makes these dwellings prone to flooding.
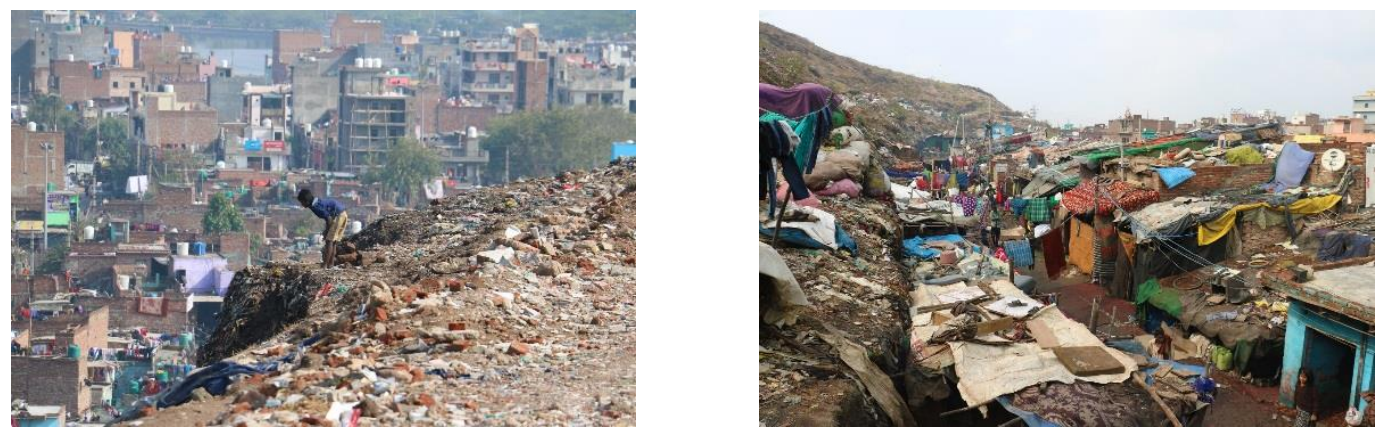

Figure 64, left. Bhalswa dwellings as viewed from the landfill, 2017. Photo by Author.

Figure 65, right. Bhalswa dwellings within the slum area next to the landfill, 2017. Photo by Author.

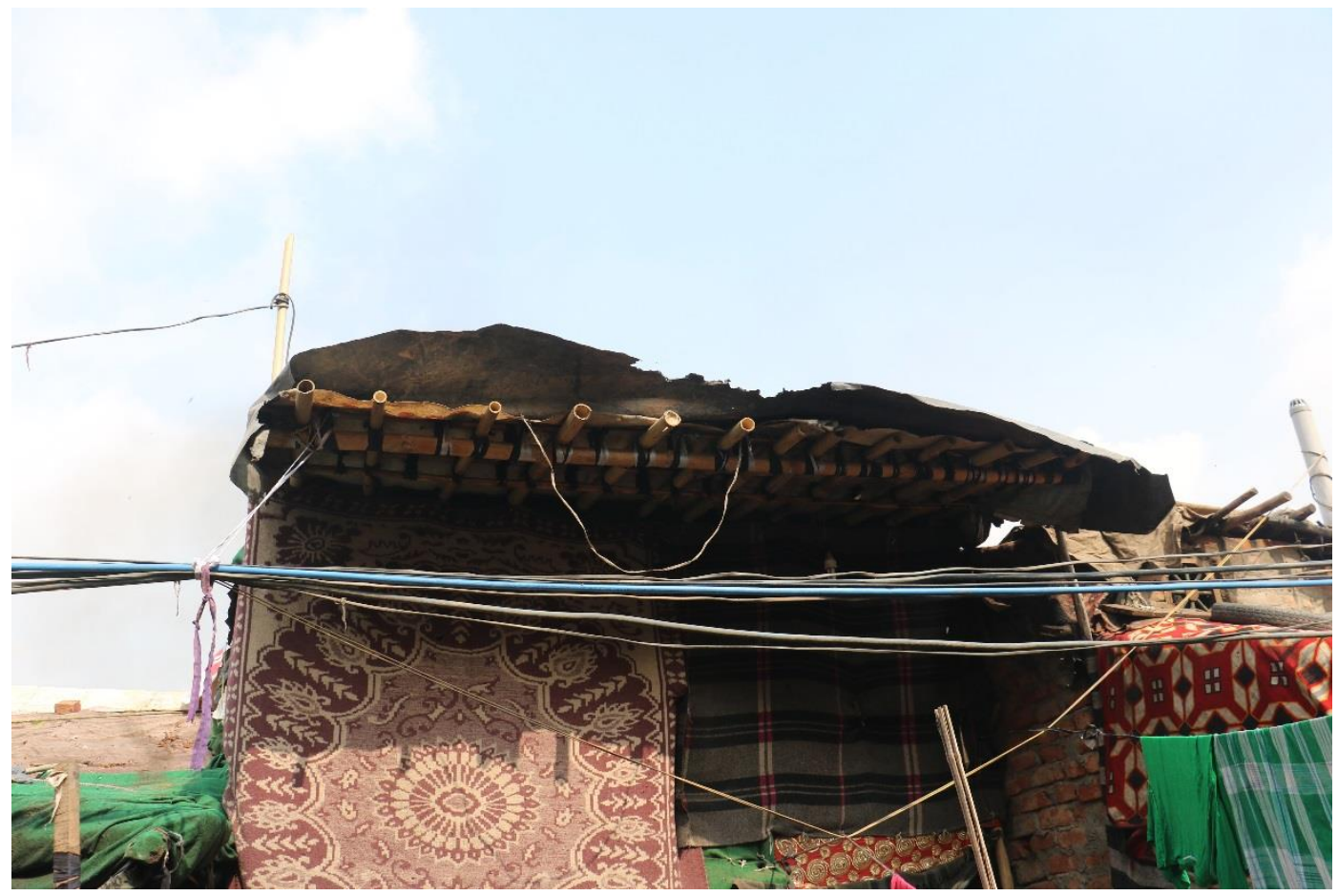

Figure 66. A typical dwelling within the slum area next to the landfill, Bhalswa, 2017. Photo by Author. 


\subsubsection{Bhalswa Livelihood Generation}

The vast majority of those who reside in the slum areas closest to the landfill work in the informal recycling sector-including children. Waste collection of reusable or sellable materials occurs predominantly at the top of the landfill as the waste is being deposited by trucks that deliver it from the city, Figure 67; however, some "mining" of the landfill also occurs further down with the aid of digging tools to collect sellable items that might have been buried. Generally, over 100 people collect waste at the top of Bhalswa landfill during daylight hours. Much of the collected materials are gathered in large sacks, which are then brought to areas further down the landfill (Figure 68) for sorting into various categories. Sorting is primarily done by women, disabled people and older residents, although some families do this together at the top of the landfill itself.
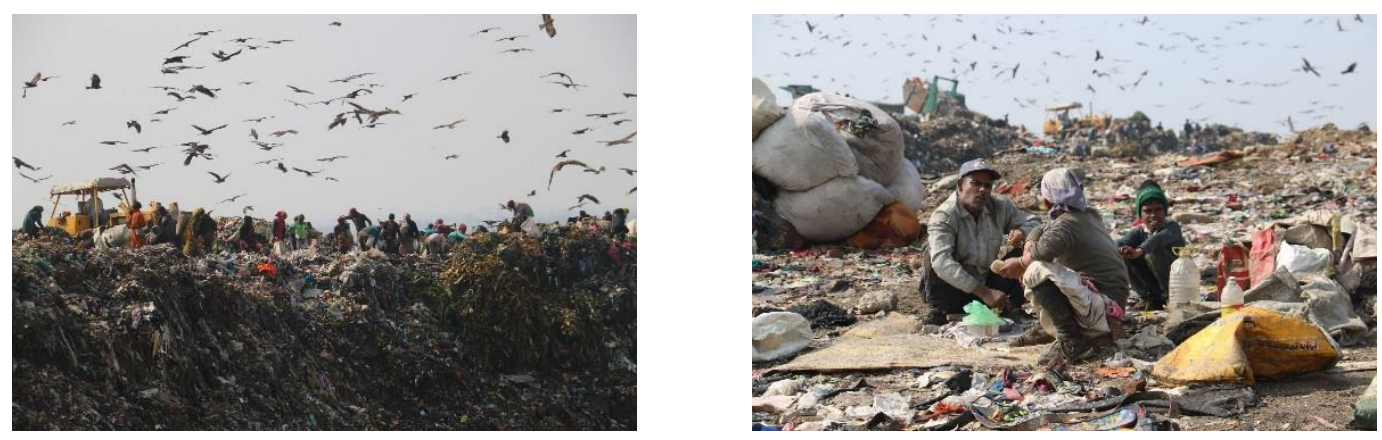

Figure 67, left. Waste collection at the top of Bhalswa Landfill, Bhalswa, 2017. Photo by Author.

Figure 68, right. Waste sorting, Bhalswa Landfill, 2017. Photo by Author.

\subsubsection{Main Slum-Upgrading Issues}

The community adjacent to the landfill is one of the most underserved slums in Delhi. The community lacks basic urban infrastructure such as access to water and electricity, sealed roads, sewage disposal, healthcare access, schools and public toilets or subsidised basic provisions generally provided under the Public Distribution Scheme (PDS) and bus services (Bhalswa Lok Shakti Manch, 2012).

The narrow "road" along which the houses are sited is unsealed and often flooded with a combination of rainwater run-off and leachate from the landfill. During heavy rain the road floods and water, landfill run-off and leachate flow directly into houses. There are no plumbed toilet facilities. Toilets are unplumbed and are often dug into the landfill (Figure 69). These have a tendency to overflow during heavy rain. There is 
also the possibility of landslides from the adjacent landfill, where the closest houses are at risk of being buried in garbage.

The most commonly reported danger to human health is from the use of groundwater that has been contaminated by leachate, as Bhalswa sits on the floodplain of the Yamuna River. The landfill is also subject to regular fires that are caused by an accretion and leakage of methane gas from within the landfill. These are a safety hazards for the waste pickers and residents living close to the landfill, as well as for the wider Delhi population due to increased air pollution. The site is also surrounded by a number of sewage ponds, which also add to health risks.

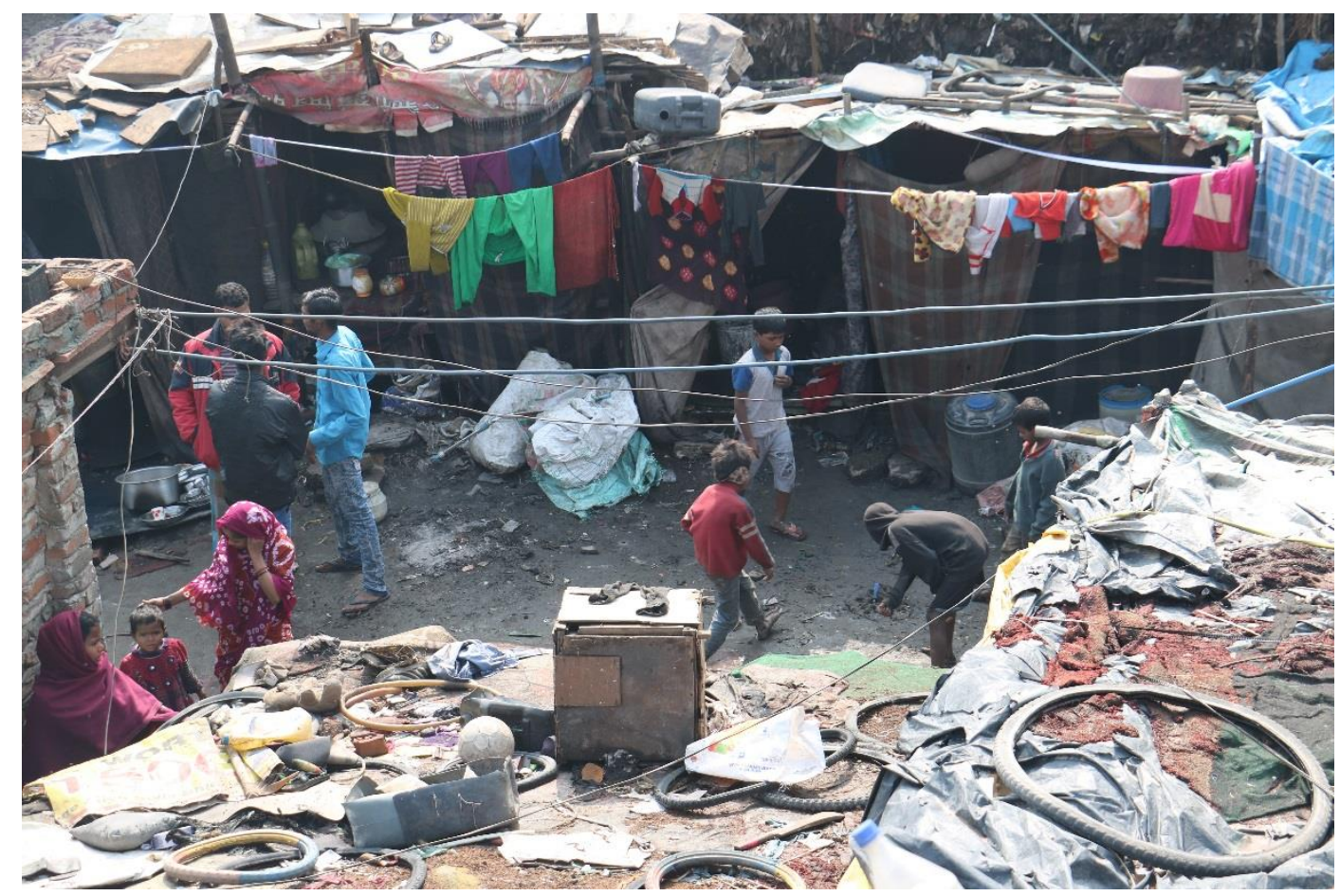

Figure 69. Toilets and storage spaces are located in the cloth covered shacks at the rear of the photo, which are partially dug into the landfill behind, Bhalswa, 2017. Photo by Author.

Waste picking is particularly hazardous at Bhalswa for a number of reasons. Medical waste, including sharps, medicines and chemicals, is openly disposed of at the site. Many waste pickers do not wear footwear while working in the landfill (Figure 70 and Figure 71). Waste pickers who work at the top of the landfill also work on foot around heavy machinery such as trucks and bulldozers that dump and move the waste. A number of waste pickers have been killed after being buried in waste moved by earthmoving equipment. Waste pickers also need to navigate around livestock such as 
pigs and cows that live on and consume waste at the landfill. The municipal authorities do not recognise waste pickers as official buyers or sellers of waste, and under the Indian Penal Code 1960, they stand the risk of being arrested if it is proven that what they are engaging in is essentially theft.
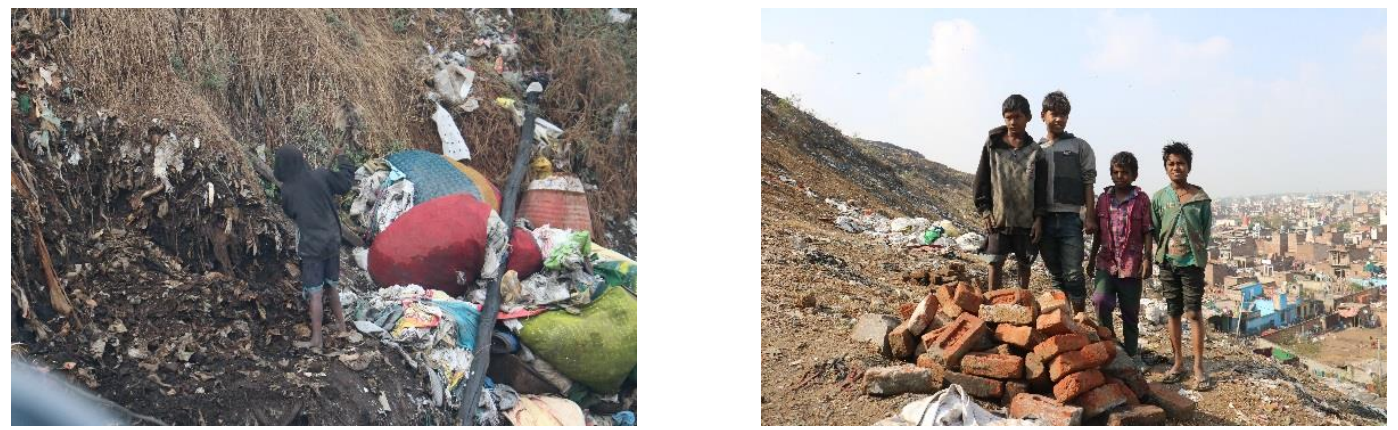

Figure 70, left. A child mining the landfill for salvageable items, Bhalswa Landfill, 2017. Photo by Author.

Figure 71, right. Children collecting discarded bricks for local construction from the landfill, Bhalswa Landfill, 2017. Photo by Author. 


\section{CS3 - Shanti Nagar - Documentation of Context}

\subsubsection{Shanti Nagar Land Use}

Shanti Nagar is one of twelve slum-settlements that comprise Shivaji Nagar, located in M-East Ward, Mumbai (Figure 72). Shivaji Nagar is a slum-settlement on preexisting swamp land next to Mumbai's largest landfill - Deonar landfill (Figure 73 and Figure 74). The area sits in north-eastern Mumbai, between the Mumbai Highway, which bridges the harbour to the south, and the Eastern Freeway to the north. Its boundaries are defined in Figure 72 below.

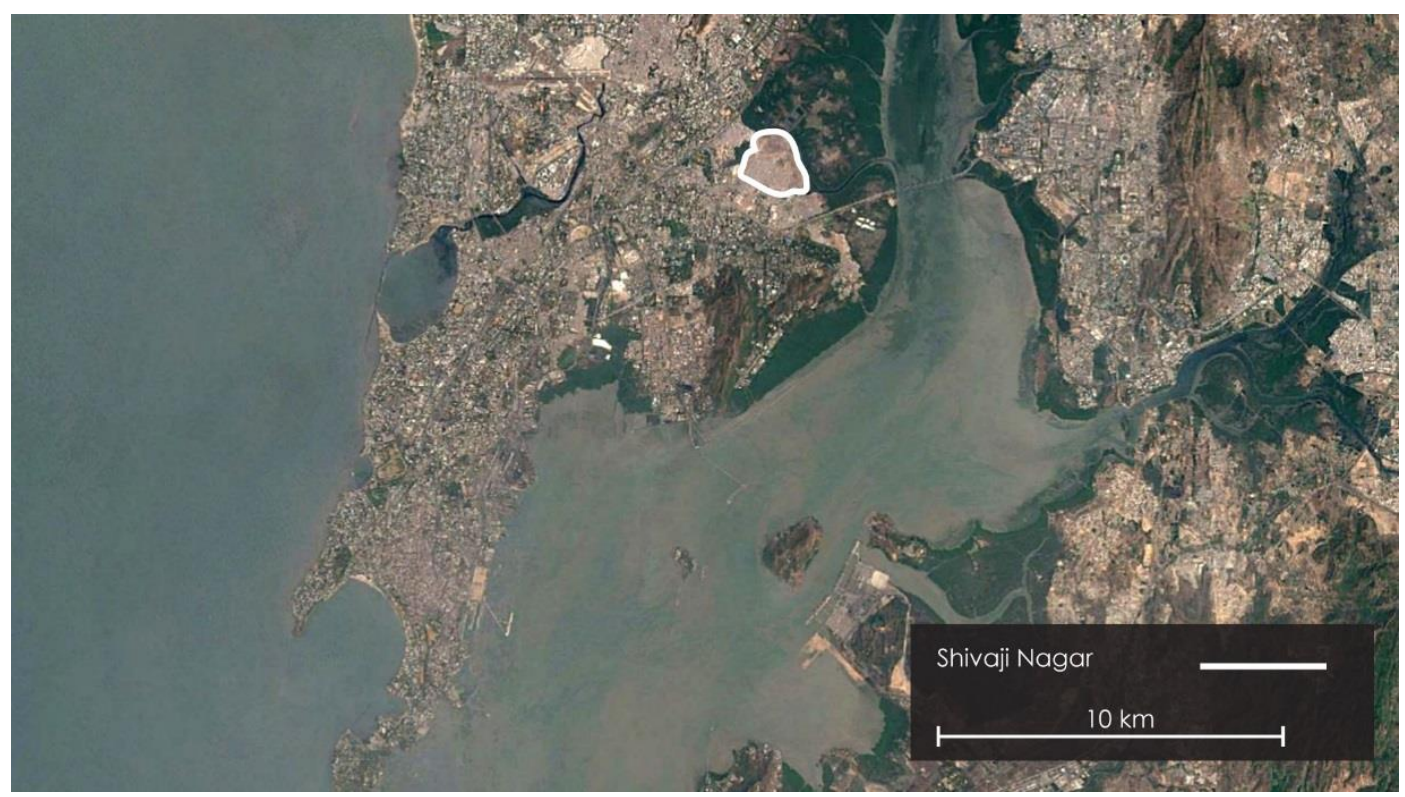

Figure 72, Shivaji Nagar, Mumbai. Satellite image from Google Earth., 2019.

Shivaji Nagar expanded significantly in the 1970s and 1980s on land surrounding an abattoir south of the area and Mumbai's Deonar dumping ground. The area was specifically designated for slum resettlement projects from other areas in the city (Ermacora \& Bullivant, 2016, p. 270). Slum dwellers from Matunga Labour Camp were relocated there in 1968. Additional neighbourhoods within the area were registered officially in 1982. Since the 1960s, Shivaji Nagar has been home to migrant populations that immigrate to the city from different parts of India, as well as those that have been resettled from slums in the city's wider area (Apnalaya, 2017; Tata Institute of Social Sciences, 2015). Because of this, the area is diverse, includes migrant communities from Maharashtra, Uttar Pradesh, Bengal and Gujarat and is composed of predominantly Hindus and Muslims (Apnalaya, 2017). The proportion of 
Muslim community is significant, and the area is said to have 101 mosques and madrasas-most of which are Sunni and Tablighi (Figure 75) ( (Echanove, 2014). The area is now home to approximately 550,000 people.

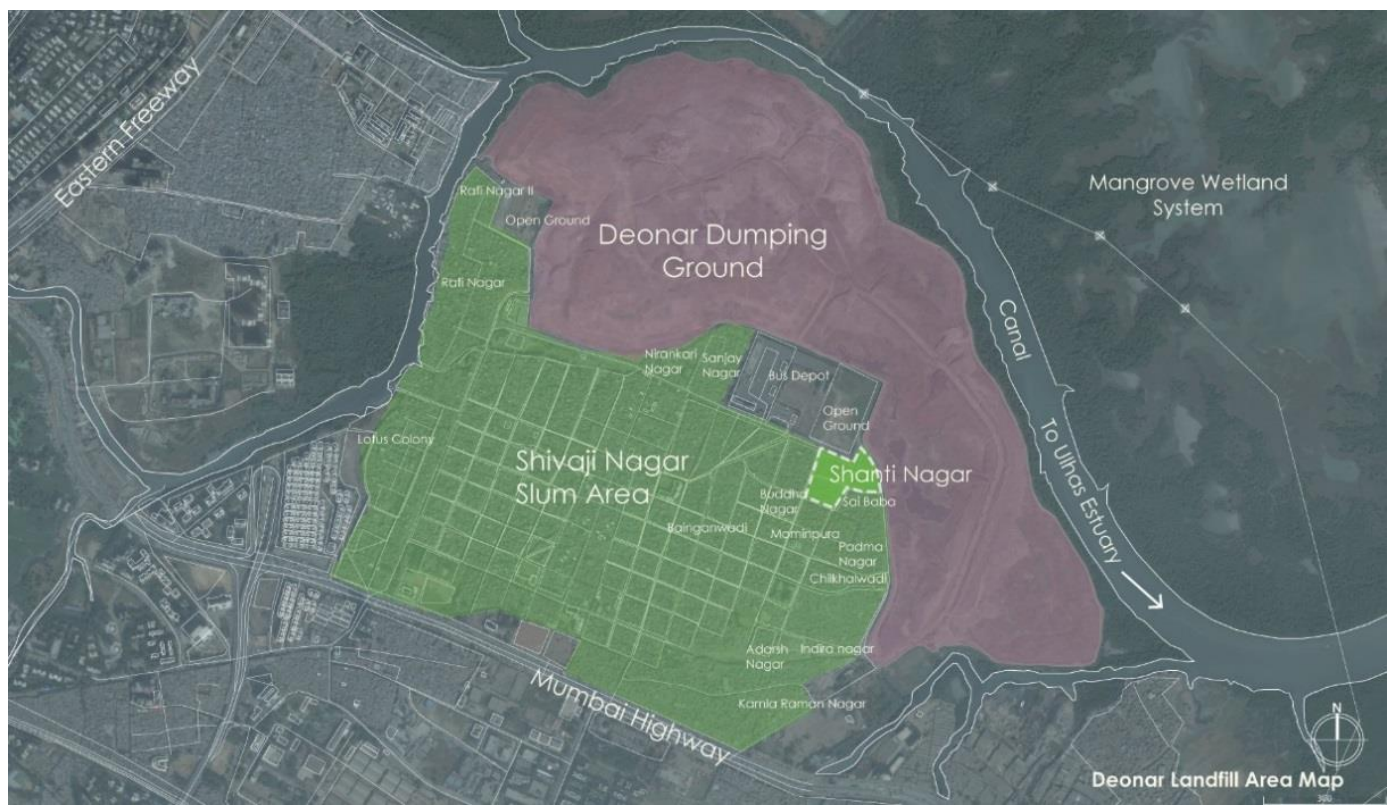

Figure 73. Shivaji Nagar. Satellite image from Google Earth., 2019. Adapted by Author.

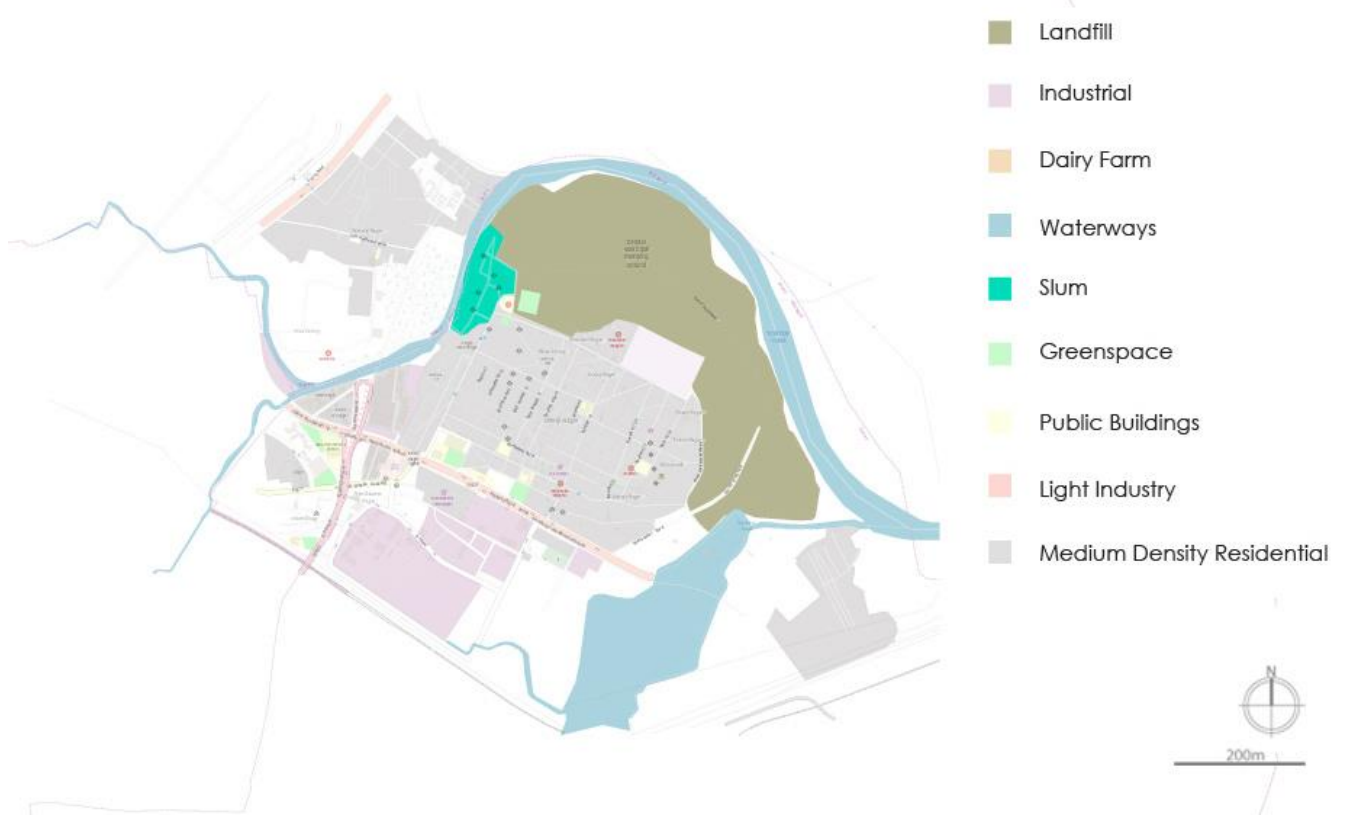

Figure 74. Shivaji Nagar land use, 2019.

Shivaji Nagar covers approximately 135 hectares, of which half has a regular gridded street layout and the other half is characterised as irregular slum development, 
constructed outside any planning considerations. In the past 30 years, shops, educational institutions and religious structures have developed in the area. Several parts of the neighbourhood have a large amount of commercial activity. The area includes a number of prominent site features, including a major bus depot and service centre adjacent to the landfill. A widely used open area next to this on the landfill site is used as a community cricket ground.

The "Deonar dumping ground" is a 132-hectare landfill operated by the Brihanmumbai Municipal Corporation or BMC, (also known as Municipal Corporation of Greater Mumbai), and located next to the Shivaji Nagar area. The landfill was opened in 1927 and is the oldest and largest in India (Joelsson \& Lord, 2016). The landfill itself is bordered by a canal and a mangrove and wetland system that flow into the southern portion of the Ulhas River estuary, which forms Mumbai Harbour.

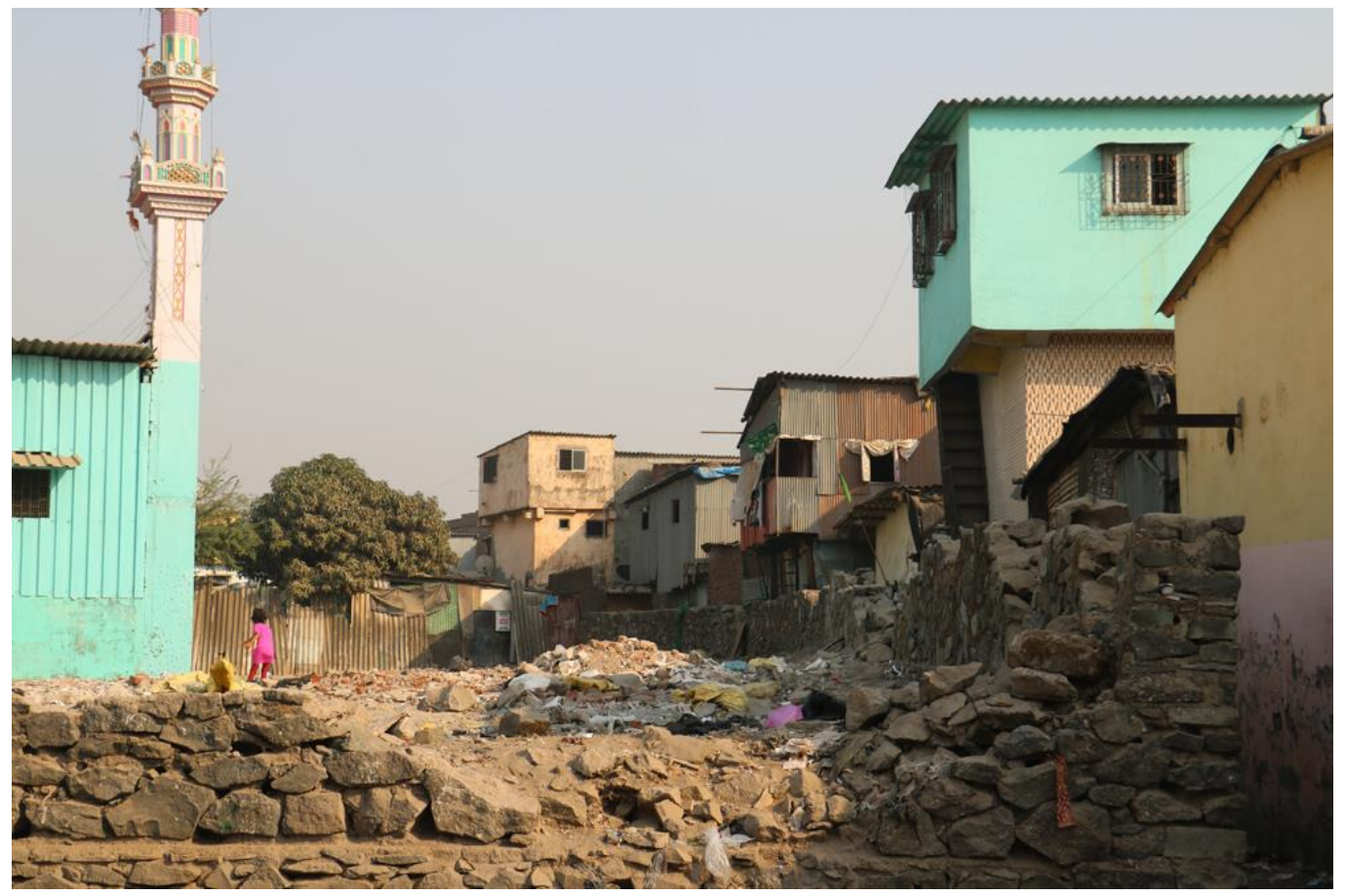

Figure 75. Shanti Nagar, Mumbai, 2017. Photo by Author.

Shanti Nagar is subject to a unique range of issues attributed to fluctuating population dynamics, environmental vulnerabilities, legal status, industrial proliferation, security of housing, availability of infrastructure, accessibility to education and health services and urban developmental plans. The M-East Ward area 
has the lowest human development index in Mumbai, ranking $24^{\text {th }}$ out of 24 wards (Municipal Corporation of Greater Mumbai, 2009).

\subsection{Shanti Nagar Housing}

Shanti Nagar is not legally a "slum" but rather is officially designated as a "planned resettlement colony" by the BMC; however after decades of neglect the authorities now treat it as, and even call it, a "slum" (Srivastava \& Echanove, 2014). The city's Municipal Corporation, under the Site and Service Resettlement Scheme of the Slum Act, developed the neighbourhood for inhabitants of slum communities that had been displaced, or forcefully evicted, from other areas of the city. Under the scheme, many residents gained occupancy rights of the government-owned land, and relocated households were allotted 10'x15' plots for self-development (Apnalaya, 2017; Tata Institue of Social Sciences, 2015).

Of all the homes in the area, around 30\% are single-storey, 60\% are two-storey structures (Figure 77) and about 10\% are three-storey (Figure 78). There are approximately 48,500 dwellings in the area. The cost of construction of each house ranges from Rs. 150,000 to Rs. 600,000 per structure. Dwellings fall into three categories. The first category includes so called "kaccha" houses. These are predominantly located in the informal areas of Shivaji Nagar. They are commonly constructed from lightweight materials, such as scavenged timber for framing, and they are typically built on a brick or cement plinth with corrugated iron cladding and roofing. Residents often choose this type in the informally planned colonies, such as Rafi Nagar closer to the landfill, as they have been subject to repeated government demolition of houses. The choice of lightweight and less expensive construction reduces personal financial losses in such circumstances. 


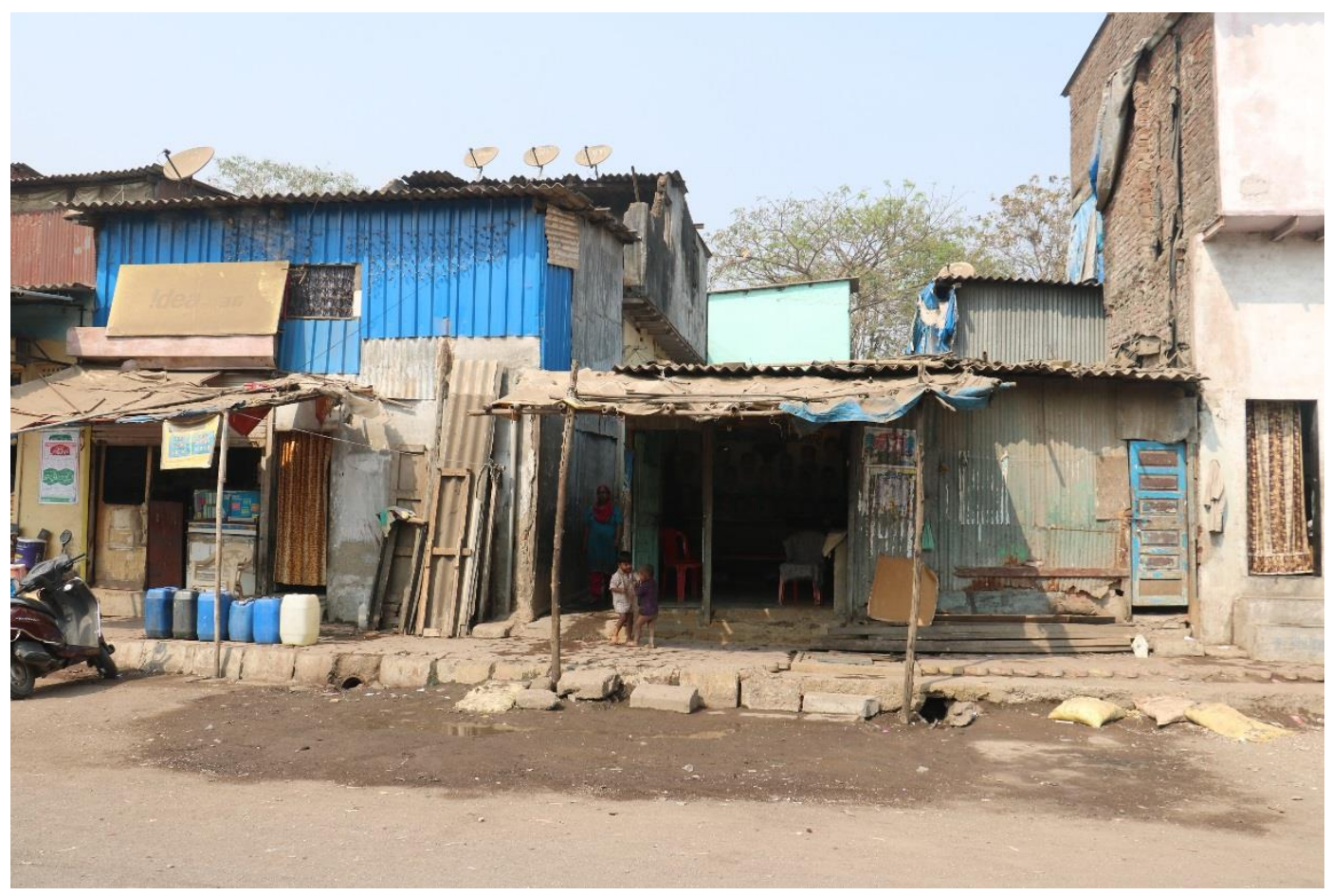

Figure 76. Single storey dwellings, Shanti Nagar, Mumbai, 2017. Photo by Author.

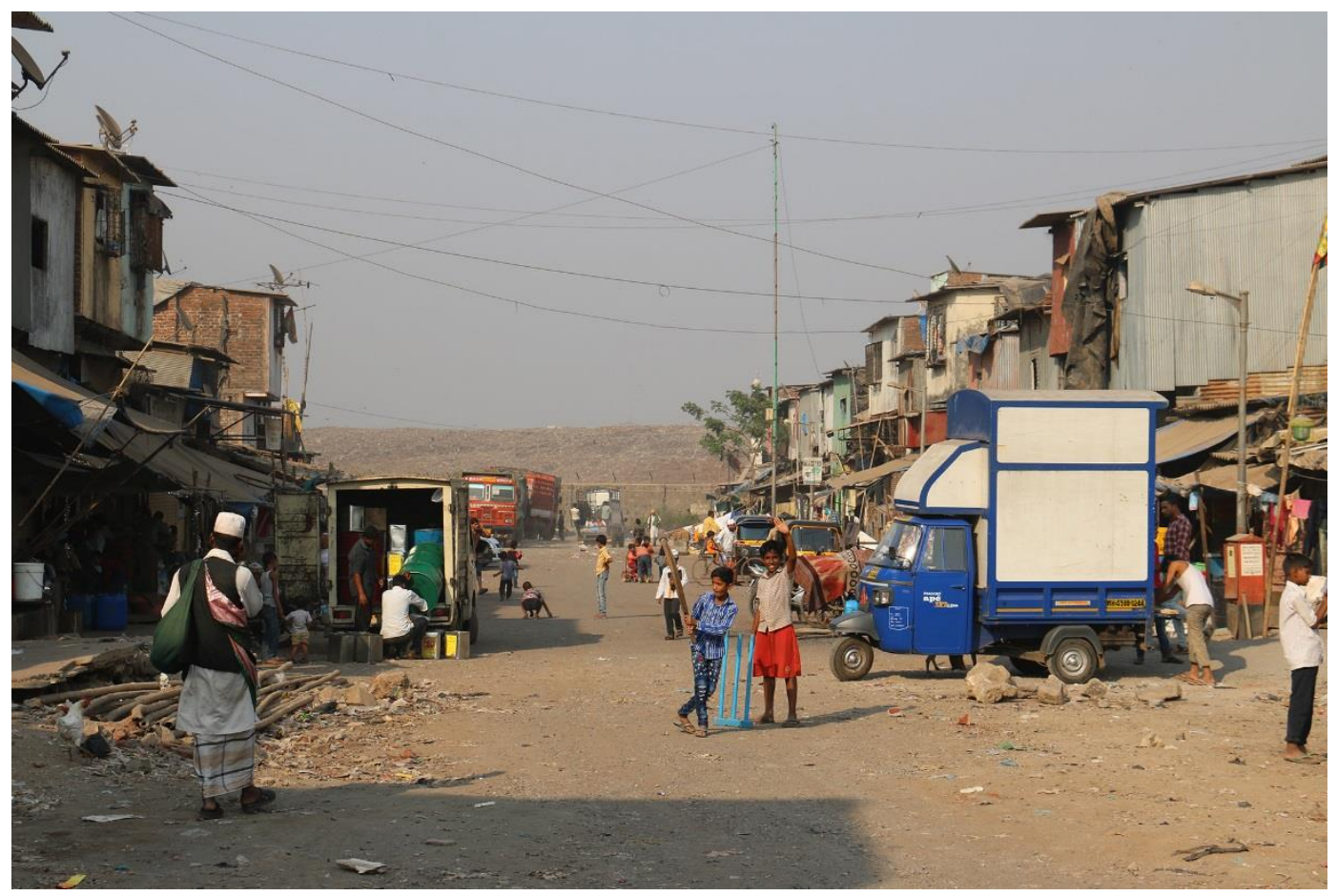

Figure 77. Two storey dwellings in Shanti Nagar, Mumbai, 2017. Photo by Author. 


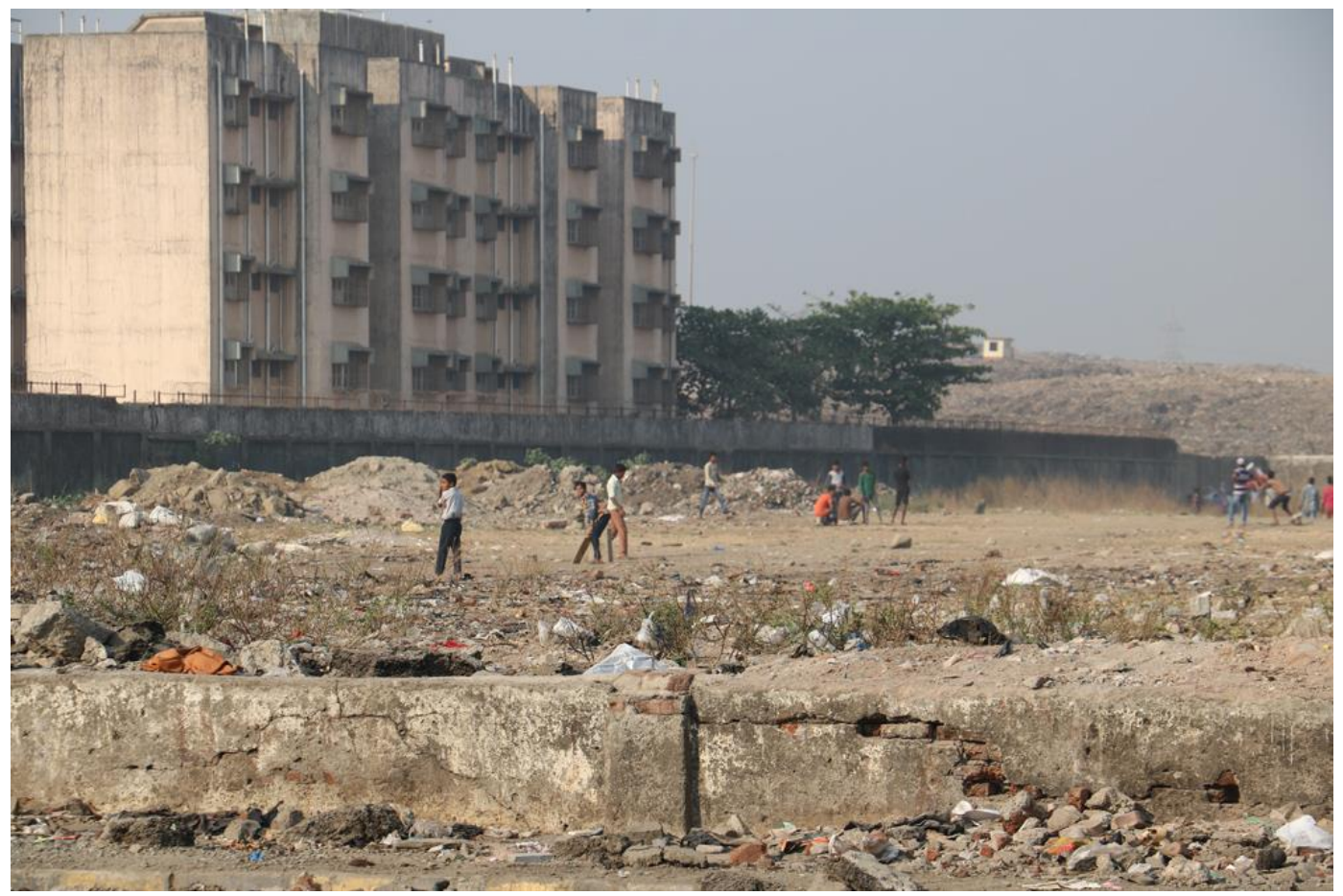

Figure 78. Multi-Storey dwellings and the open area of the Deonar landfill being used for recreational purposes. Shanti Nagar, Mumbai, 2017. Photo by Author.

The second category includes "pucca" houses, which are the most common in Shanti Nagar and make up the majority of development. They are typified by steel structural members and timber joists constructed on a concrete slab. Brick walls are commonly used to reduce costs, and these are often rendered with concrete. The third category includes reinforced concrete structures. These are the most expensive and make up a minority of structures within the gridded street zone. Many older structures of this type are altered or repaired with cheaper materials such as corrugated iron or brick. 


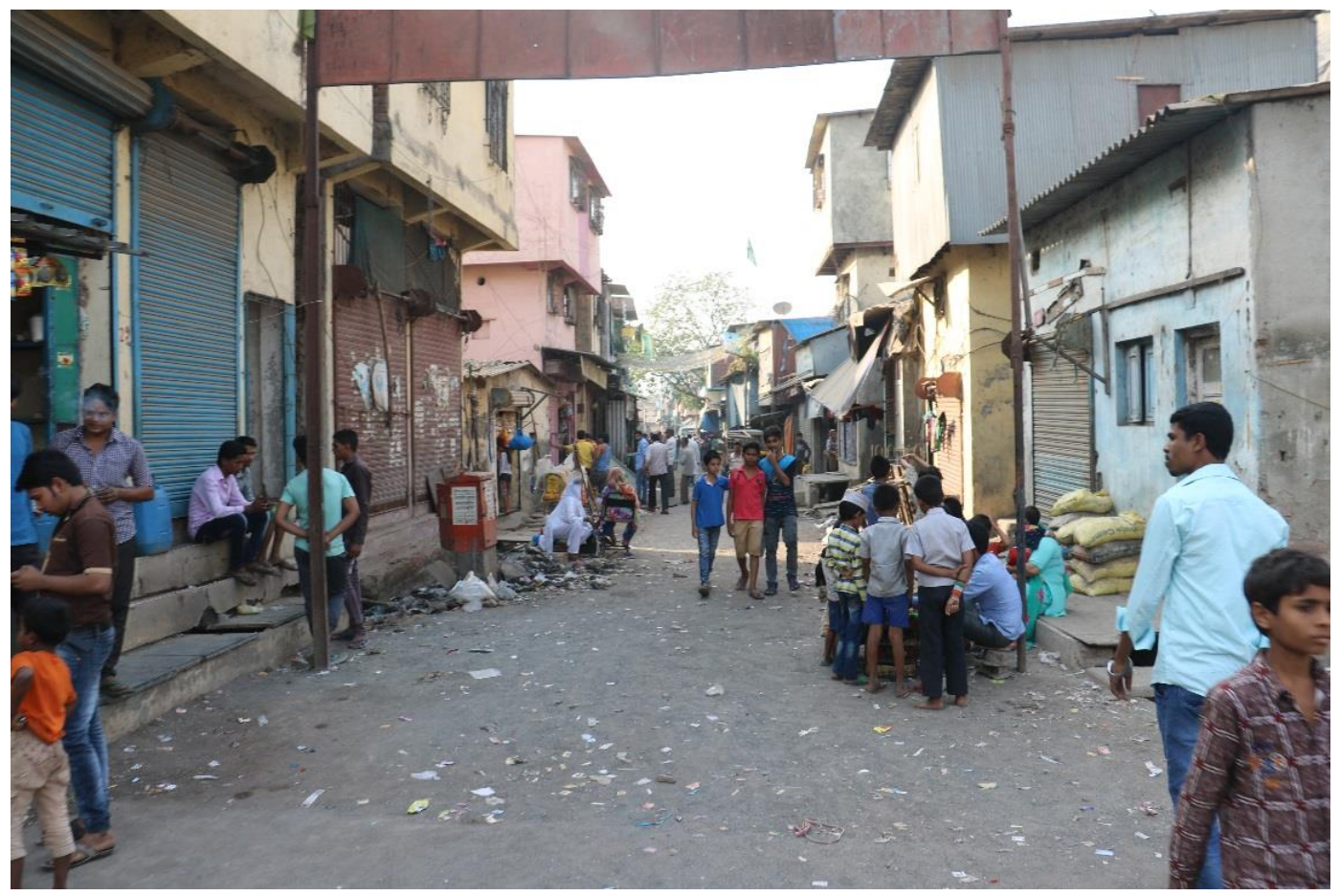

Figure 79. Shanti Nagar, Mumbai, 2017. Photo by Author.

\subsubsection{Shanti Nagar Livelihood Generation}

As the community is well established, livelihoods are generated in a large number of ways in Shanti Nagar. Contractual and temporary casual labour in the industries in adjoining areas is a major source of employment. $34.2 \%$ of men work in the construction industry, which constructs or reconstructs approximately 2,500 buildings in Shivaji Nagar alone each year. $34.7 \%$ of women do only household work with no payment. $25 \%$ of residents attend some form of educational institution. $30 \%$ of all men and women above the ages of 14 are pursuing some form of education. The average monthly income reported for men is between Rs. 7000 - 10,000 and for women is Rs. 1000 to $2000.13 .7 \%$ of females and $54.6 \%$ of men are employed (Apnalaya, 2017). Approximately 4,500 residents engage regularly in waste picking; however, this number is known to fluctuate greatly, as it is often used as an income supplementation strategy (Shetty, 2016). Currently only 500 waste pickers are registered with workers' union Kachara Vahatuk Shramik Sangh (KVSS) and have been provided medical insurance (ibid.). The abattoir is also a means of livelihood for a number of individuals in Shanti Nagar. 


\subsubsection{Main Slum-Upgrading Issues}

Like Ghazipur and Bhalswa, the landfill is subject to regular fires that are caused by accretion and leakage of methane gas from within the landfill. These fires gain widespread media attention when the smoke blankets the more affluent areas of Mumbai. In 2014, a wall was erected between the landfill and Shivaji Nagar in an effort to stop waste pickers gaining access to the landfill, although this merely results in waste pickers entering via the far side of the landfill.

Access to water is also a well-documented problem in Shanti Nagar, with water infrastructure regularly failing for long periods of time (Khan, 2015). Residents are forced to carry water containers long distances by foot, tuk-tuk or bicycle in order to obtain drinking water.

Due to its designation as an area for slum resettlement, the Shanti Nagar area is very dense and so lacks open public spaces. Community members use a flat area of the landfill as a cricket and general recreation ground.

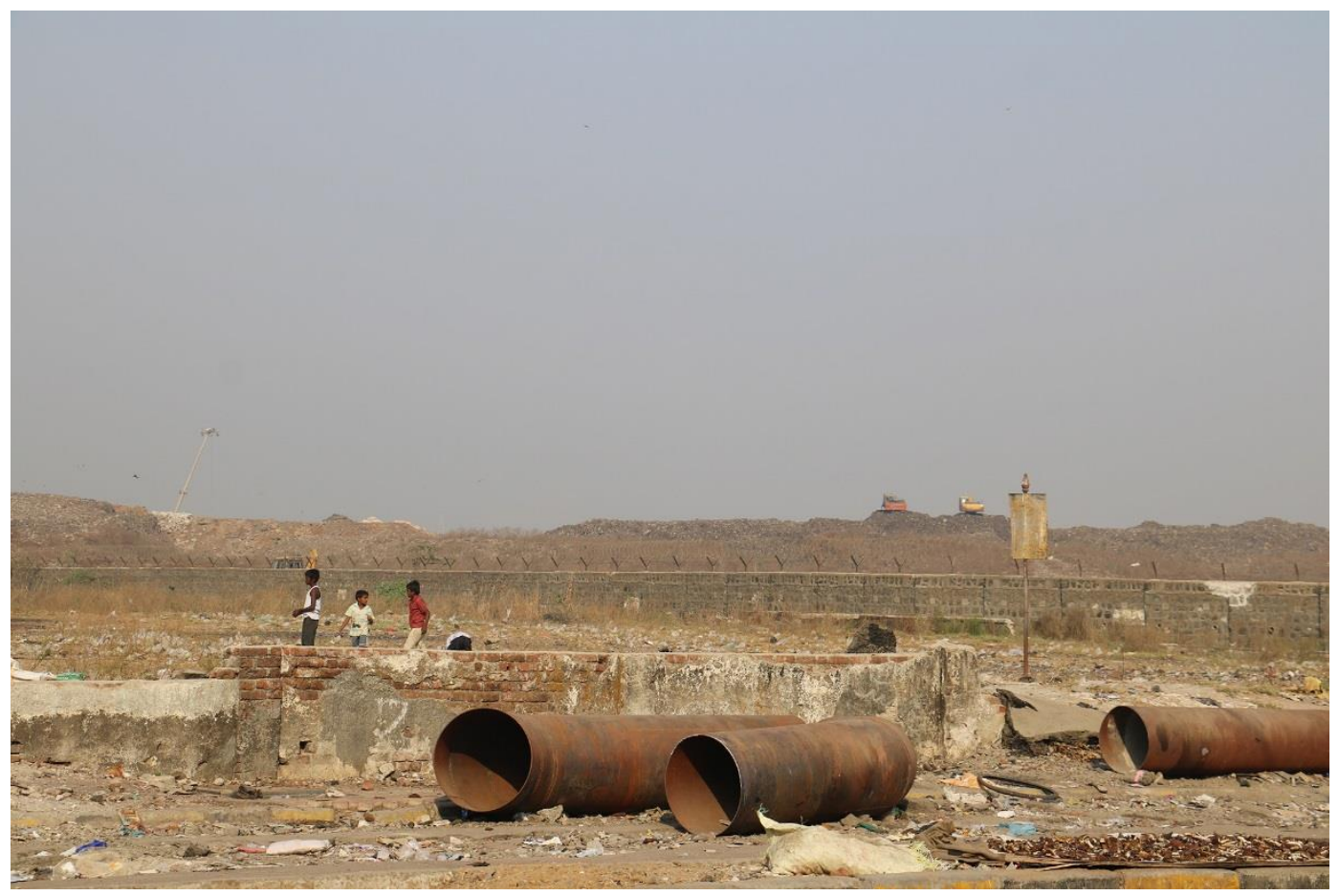

Figure 80. Open area of the Deonar landfill being used for recreational purposes. Shanti Nagar, Mumbai, 2017. Photo by Author. 


\subsubsection{Summary of Documentation of Context}

Table 14 below provides a comparative summary of the salient contextual factors identified through the ethnographic descriptions detailed above.

Table 14. Summary of the key variables identified between the case study sites.

\begin{tabular}{|c|c|c|c|}
\hline Location & Ghazipur & Bhalswa & Shanti Nagar \\
\hline $\begin{array}{l}\text { Case Study } \\
\text { Site Area }\end{array}$ & 112 Hectares & 48 Hectares & 302 Hectares \\
\hline Slum Area & 3.7 Hectares & 6.2 Hectares & $\begin{array}{l}\text { 2.2 Hectares } \\
\text { (Shivaji Nagar total slum } \\
\text { area } 135 \text { Hectares) }\end{array}$ \\
\hline Population & 1,000 & 25,000 & $\begin{array}{l}6,000 \\
\text { (Shivaji Nagar 600,000 } \\
\text { total) }\end{array}$ \\
\hline $\begin{array}{l}\text { Livelihood } \\
\text { generation }\end{array}$ & $\begin{array}{l}\text { Waste picking/self- } \\
\text { employed }\end{array}$ & $\begin{array}{l}\text { Waste picking/self- } \\
\text { employed }\end{array}$ & $\begin{array}{l}54 \% \text { men and } 13.7 \% \\
\text { women in formal } \\
\text { employment. }\end{array}$ \\
\hline Housing Type & $\begin{array}{l}\text { Lightweight Single } \\
\text { Storey. Found/ recycled } \\
\text { materials. }\end{array}$ & $\begin{array}{l}\text { Lightweight Single } \\
\text { Storey. Found/ recycled } \\
\text { materials. }\end{array}$ & $\begin{array}{l}30 \% \text { single-storey, } 60 \% \\
\text { two-storey structures, } \\
10 \% \text { are three-storey. } \\
\text { Concrete structures. }\end{array}$ \\
\hline Legal Tenure & No & No & Yes \\
\hline $\begin{array}{l}\text { Basic Urban } \\
\text { Services }\end{array}$ & $\begin{array}{l}\text { One Public Toilet } \\
\text { Electricity } \\
\text { Drinking Water }\end{array}$ & No & $\begin{array}{l}\text { Electricity } \\
\text { Limited access to } \\
\text { drinking water }\end{array}$ \\
\hline Road Layout & Informal & Informal & Formal \\
\hline $\begin{array}{l}\text { Urban } \\
\text { Environmental } \\
\text { Hazards }\end{array}$ & $\begin{array}{l}\text { Lack of basic } \\
\text { infrastructure } \\
\text { Lack of drainage } \\
\text { Dairy farm pollution } \\
\text { Poor quality housing } \\
\text { Landfill fires }\end{array}$ & $\begin{array}{l}\text { Lack of basic } \\
\text { infrastructure } \\
\text { Lack of drainage } \\
\text { Poor quality housing } \\
\text { Lack of sealed roads } \\
\text { Landfill fires }\end{array}$ & $\begin{array}{l}\begin{array}{l}\text { Lack of water } \\
\text { infrastructure }\end{array} \\
\text { Landfill fires } \\
\text { Lack of public open } \\
\text { areas }\end{array}$ \\
\hline Landfill Area & 11 Hectares & 8.5 Hectares & 132 Hectares \\
\hline Landfill Type & $\begin{array}{l}\text { Un-engineered and } \\
\text { unlined landfill }\end{array}$ & $\begin{array}{l}\text { Un-engineered and } \\
\text { unlined landfill }\end{array}$ & $\begin{array}{l}\text { Un-engineered and } \\
\text { unlined landfill }\end{array}$ \\
\hline Waterways & $\begin{array}{l}\text { Bordering canals flow } \\
\text { into Yamuna River }\end{array}$ & $\begin{array}{l}\text { Bordering canals flow } \\
\text { into Yamuna River }\end{array}$ & $\begin{array}{l}\text { Bordering canals flow } \\
\text { into Ulhas River estuary }\end{array}$ \\
\hline
\end{tabular}




\subsubsection{Data Collection for Understanding Conflicting Perspectives}

This section details the results of the structured interviews held with each case study community to:

O2: to gain an understanding of the range of conflicting perspectives regarding upgrading-related issues important to different community members to inform the subsequent design of an SPS-UG that might help in the negotiation of conflicting perspectives and stakeholder ideation.

\subsubsection{Data Collection Procedure}

The Phase One Ghazipur structured interviews were conducted with assistance from four Chintan Environmental Research and Action Group staff members who operate the school for waste-picker families at Ghazipur. The interviews were conducted on the roof space of the Chintan-operated school overlooking the landfill within the Ghazipur community (Figure 81). A translator/transcriber was used in each case, as most of the participants did not speak English and most were illiterate.

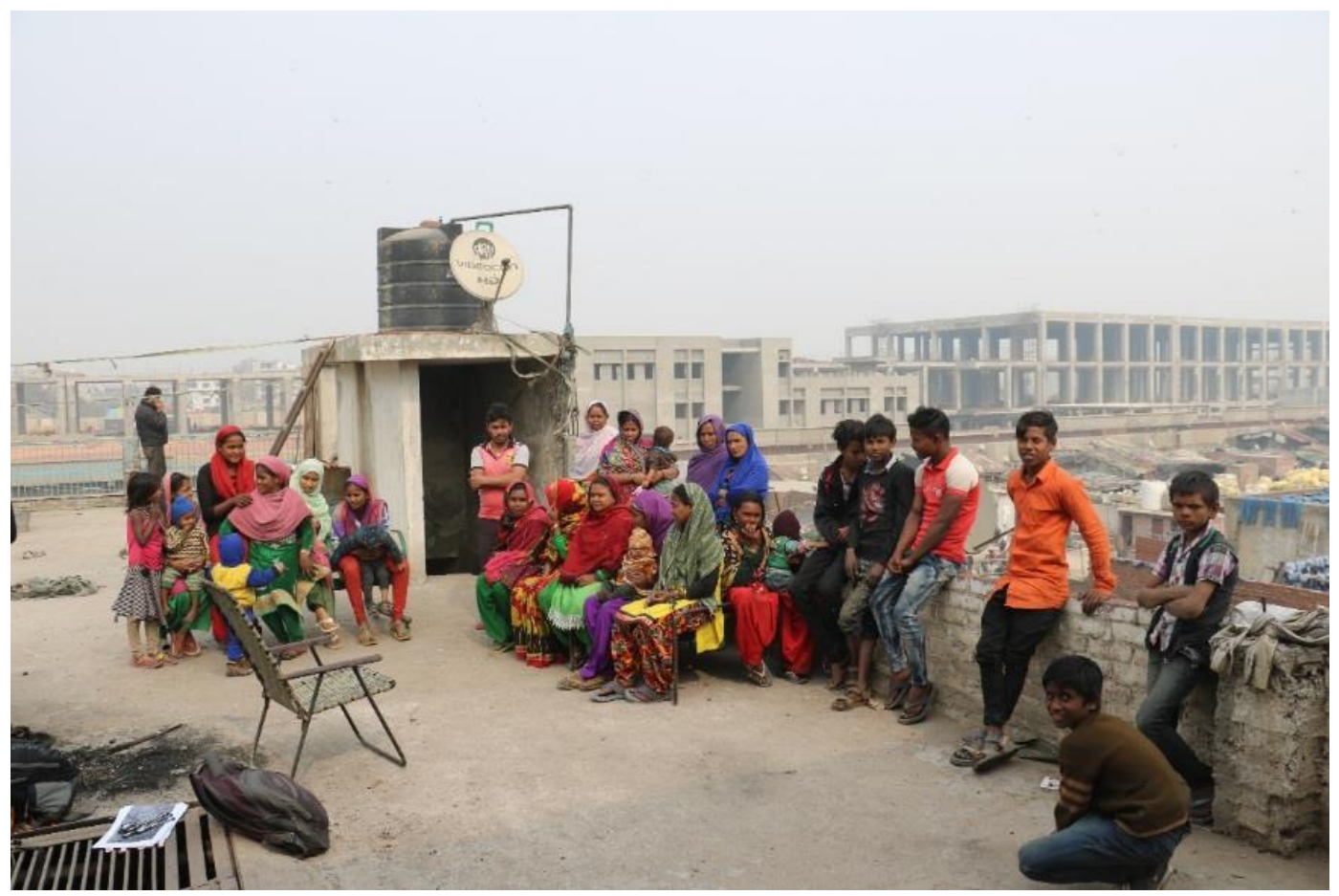

Figure 81. Rooftop of the Chintan operated school, Ghazipur fieldwork, February 2017. Photo by Author. 
Chintan staff had distributed information about the research to the community prior to the interviews being held. 23 interviewees agreed to be interviewed. 15 participants were female. Participants were aged between 16 and 63 years old with a mean age of 27.08 years. All but one participant identified as Muslim. The participants had lived at Ghazipur for between 1 and 25 years with a mean residency of 13.43 years. 18 participants had migrated to Ghazipur from outside of Delhi. Participants held a number of occupations shown in Figure 82 below.

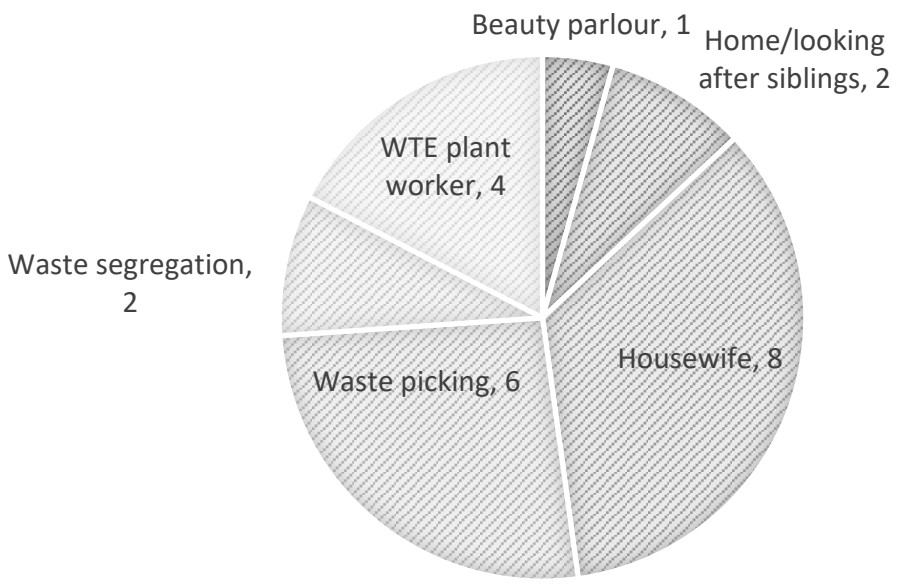

Figure 82. Participant Occupations, Ghazipur, 2017.

The Bhalswa interviews followed a similar process to the Ghazipur interviews. These were also facilitated by Chintan staff who coordinate a community development programme within the Bhalswa community. The interviews were mostly conducted on rooftop spaces of the homes of interviewees closest to the landfill (Figure 83).

A group of 22 participants took part in the interview process. 9 participants were female. Participants were aged between 16 and 60 years old with a mean age of 25.59 years. All but one participant identified as Muslim. Participants had lived at Bhalswa for between 2 and 52 years with a mean residency of 18.77 years. 17 participants had migrated to Bhalswa from outside of Delhi. Participants held a number of occupations shown in Figure 84 below. 


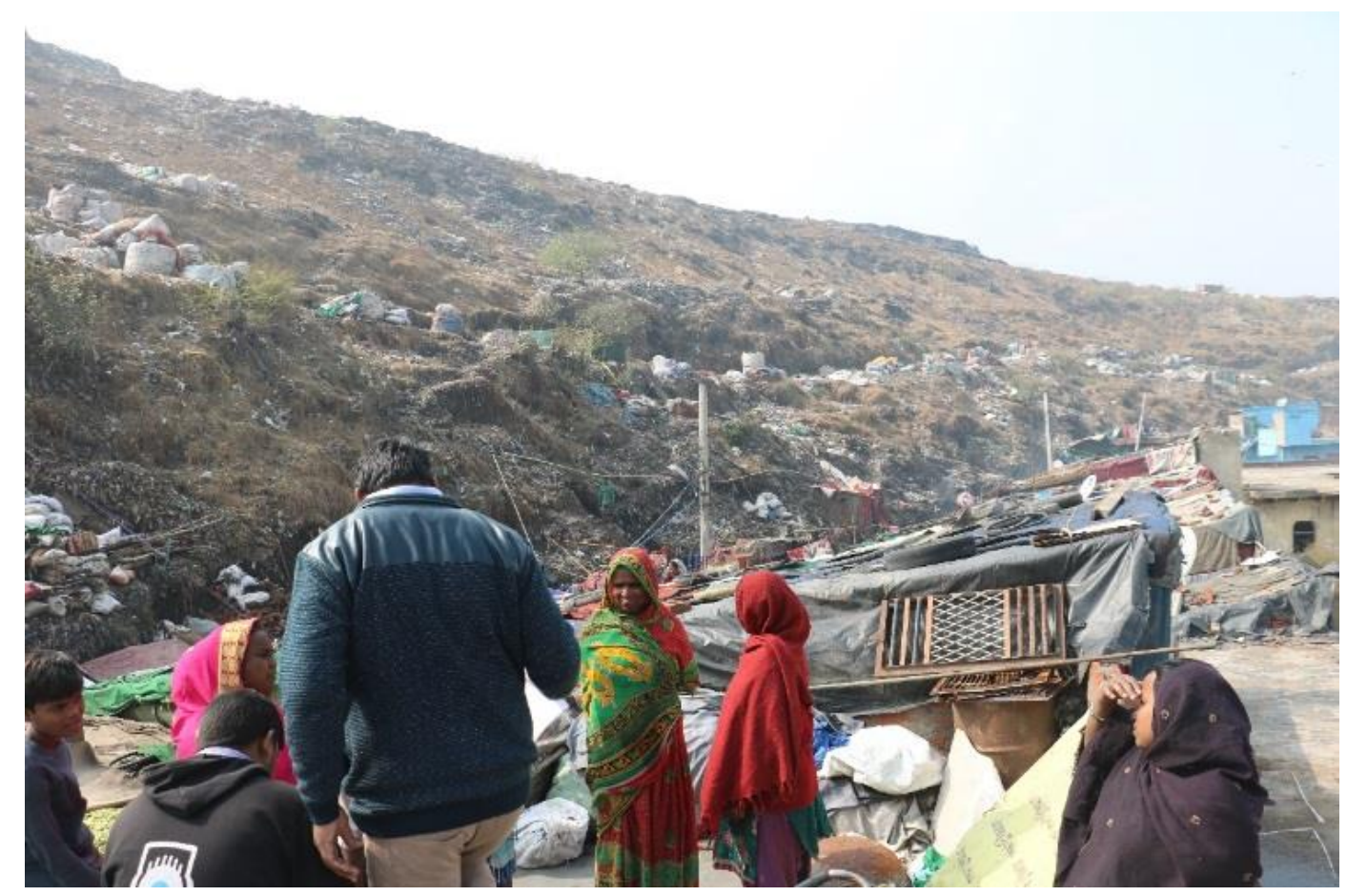

Figure 83. Bhalswa fieldwork, February 2017. Photo by Author.

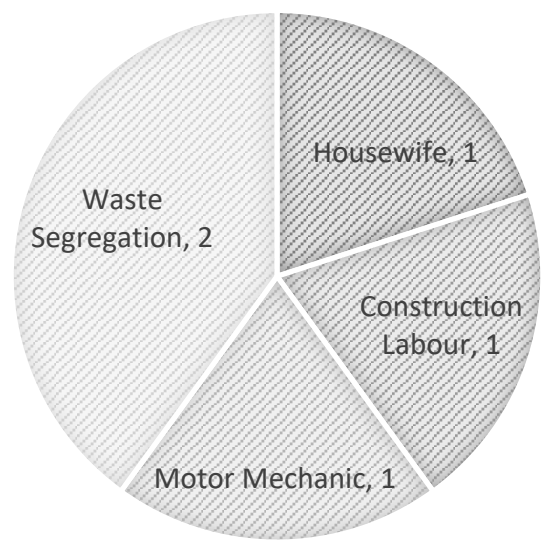

Figure 84. Participant Occupations, Bhalswa, 2017.

The Shanti Nagar interviews were conducted in collaboration with Apnalaya staff in their well-used community centre (Figure 85). A translator/transcriber was used in each case, as most of the participants did not speak English and some were illiterate. 


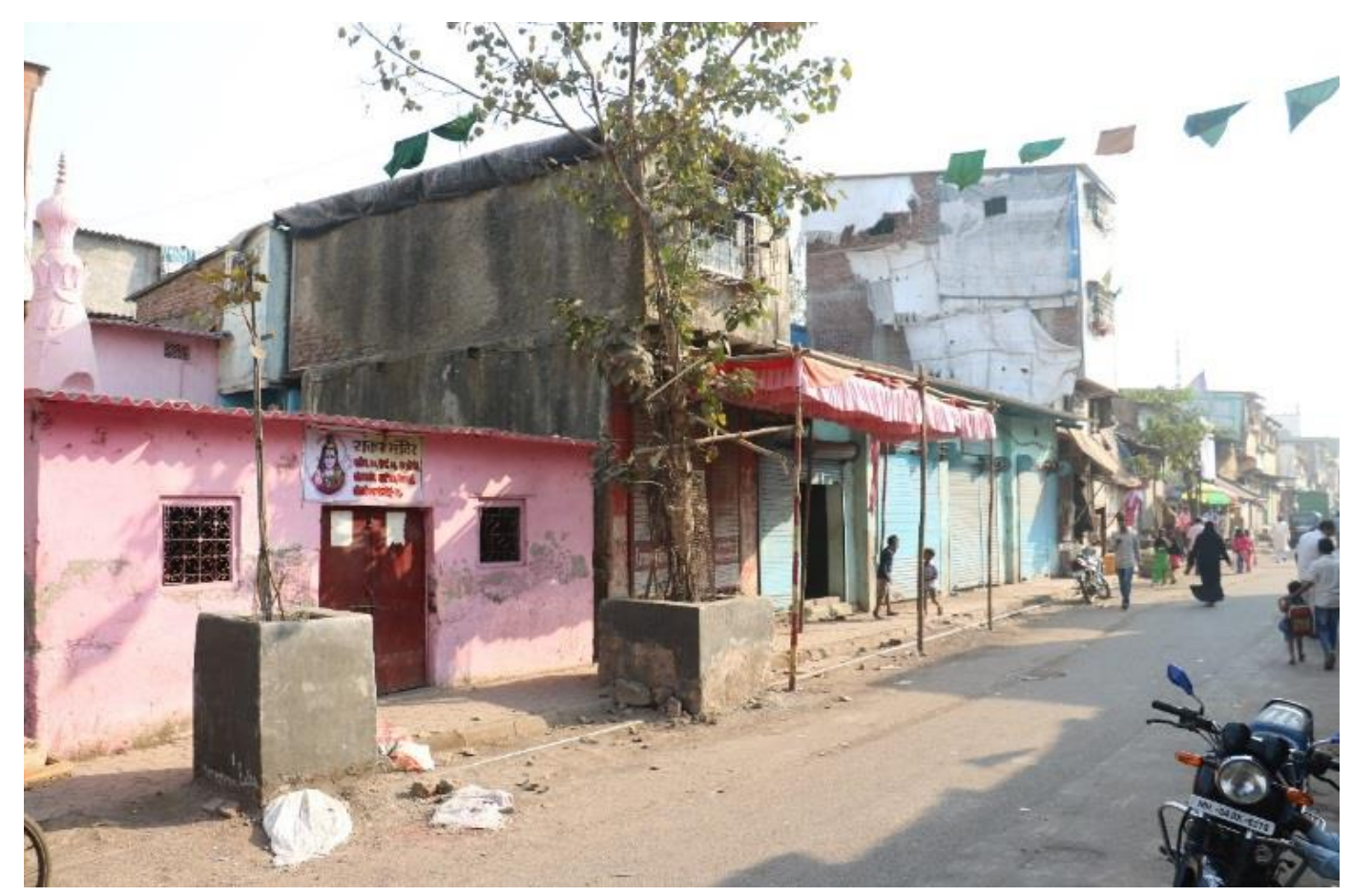

Figure 85. Shanti Nagar fieldwork location, Apnalaya community centre, February 2017. Photo by Author.

21 interviewees took part in the interview process. 8 participants were female. Participants were aged between 14 and 45 years old with a mean age of 19.95 years. All but four participants identified as Muslim. Participants had lived at Shanti Nagar for between 10 and 23 years with a mean residency of 17.38 years. 17 participants had migrated to Shanti Nagar from outside of Delhi. Participants held a number of occupations shown in Figure 86 below.

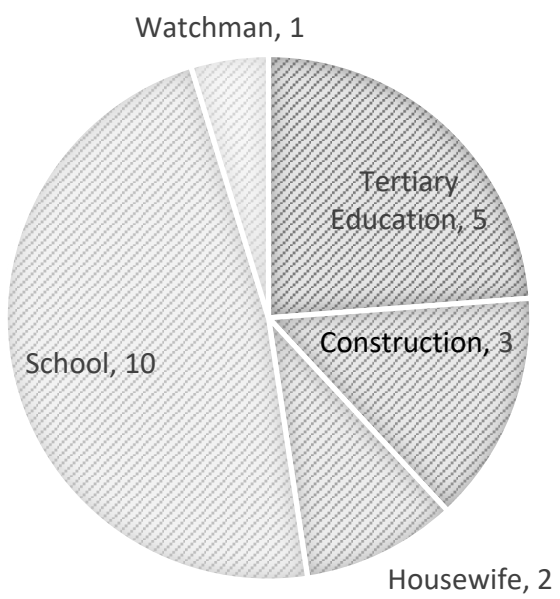

Figure 86. Participant Occupations, Shanti Nagar, 2017. 


\subsection{Ghazipur Perspectives}

As shown in the diagram in Figure 87, the urban issues identified by participants through the interview process at Ghazipur were located predominantly at the lower end of the needs hierarchy with most community problems and desired changes being identified as physiological (basic needs), safety and security, or belonging related. The participants generally did not like many aspects of their community; however, some participants did highlight that they liked the people who live in Ghazipur.

Many dislikes identified were categorised as housing, infrastructure, health, pollution/physical environment issues such as a lack of toilet facilities and adequate housing, the uncleanliness of the community including excessive cow excrement that can be a problem during the wet season, and garbage in residential areas. Some also highlighted social capital related issues such as fighting and harassment. This was prominent amongst the younger respondents of Ghazipur. The lack of toilets was identified as one of the main problems across all interviewees as well as being one of the most widely desired improvements.

The Ghazipur interview process highlighted a large range of desired changes to their environment including the construction of higher quality houses, better sanitation facilities, stopping forced evictions, removal of waste from living areas and a number of social capital related changes, including reduction of harassment by MCD officials, obtaining child support, support of addicts, drug awareness and reducing fighting/ conflict within the community.

One major trend identified in the data was that, while the likes, dislikes and main problems were commonly agreed between interviewees, the desired changes — or what the interviewees wanted to do about those problems - varied greatly. This indicates a significant range of conflicting perspectives relating to future upgrading processes. 


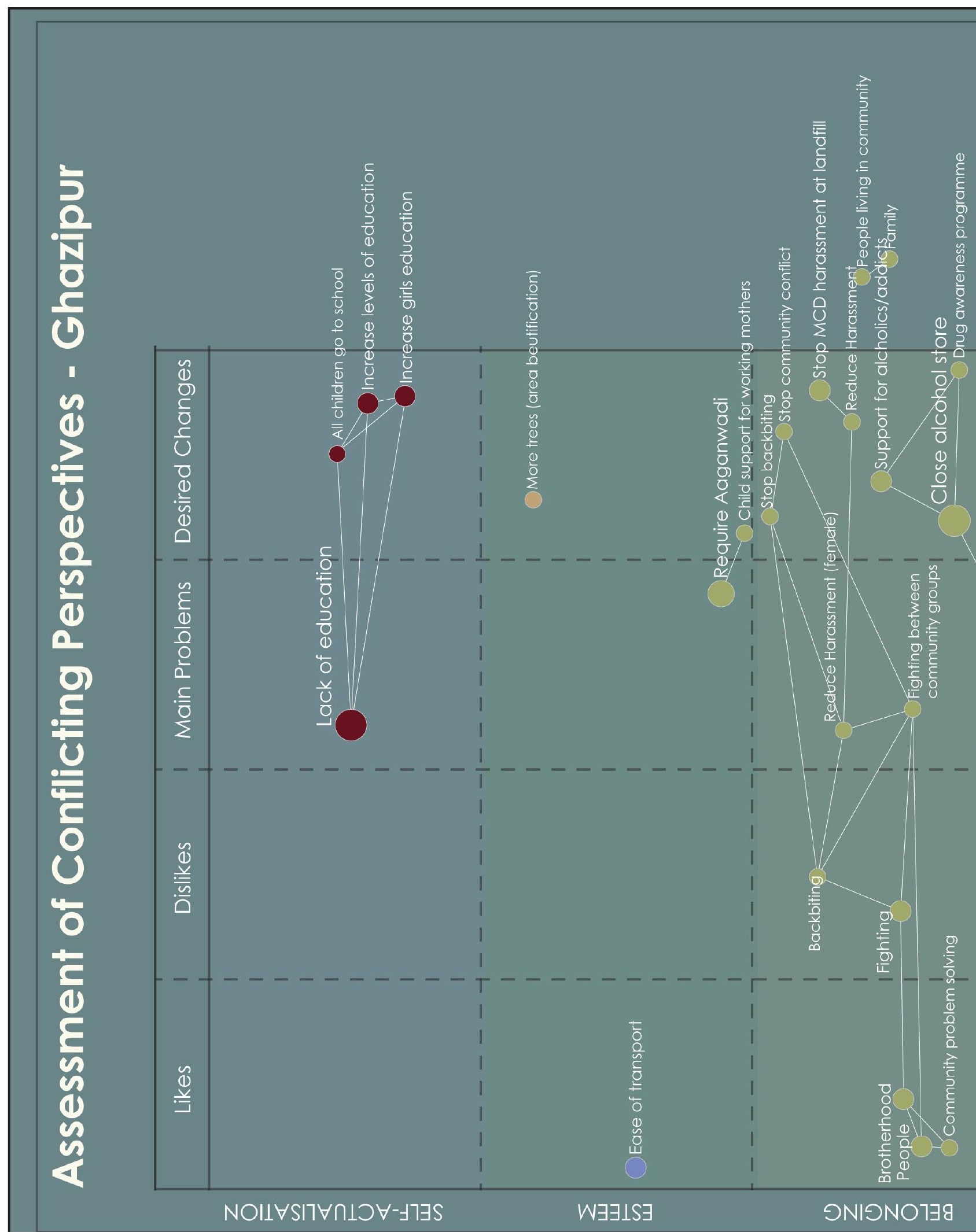

Figure 87. Thematic analysis of the Ghazipur interview data identifying a range of conflicting perspectives on slum-upgrading issues. 


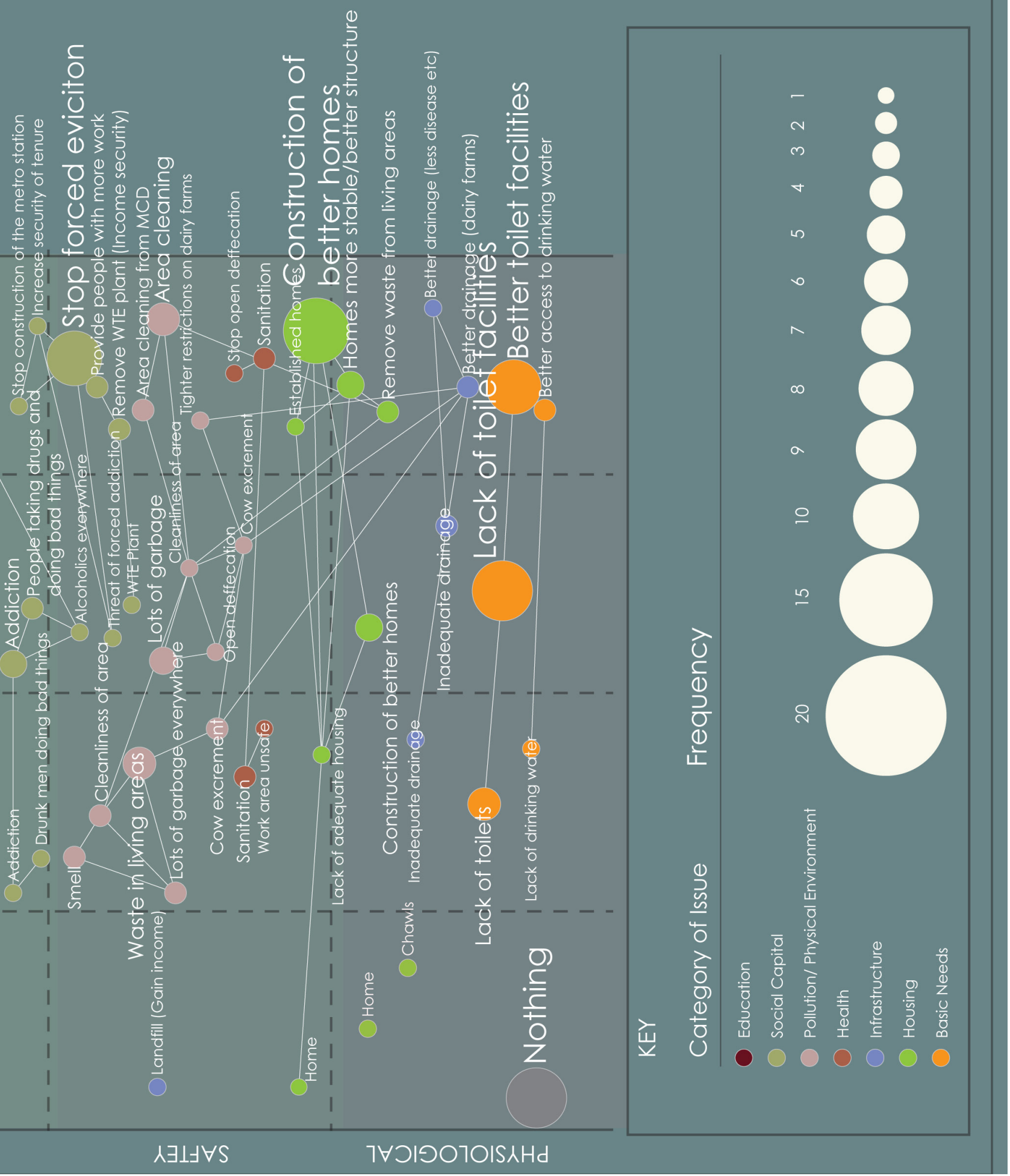




\subsection{Bhalswa Perspectives}

Urban issues identified by the Bhalswa participants were located almost entirely within the physiological and safety categories of the needs hierarchy as seen in Figure 88. This reflects the acute nature of the urban problems and needs of the participants.

The participants identified few aspects that they liked about their community; however, similar to Ghazipur, some participants did highlight that they liked the people who live within in. Dislikes identified were predominantly physiological or safety oriented, such as disliking a lack of access to water and food. Inadequate drainage means that landfill run-off often flows into homes. Lack of sanitation facilities, pollution, as well as open defecation and the prevalence of waterborne diseases associated with the rainy season were also highlighted by a number of participants. The main problems identified by the community generally reflected the attributes they disliked including lack of adequate sealed roads and drainage infrastructure around the perimeter of the landfill and between houses in order to alleviate flooding. Participants also highlighted a lack of potable drinking water and general pollution as being concerns.

There were two main upgrading actions favoured by many community members. The first related to gaining reliable access to potable drinking water through the implementation of water infrastructure. The second was the desired construction of adequate roads and drainage. In line with this, a number of satellite issues were also identified such as strategies to alleviate landfill run-off and leachate.

The analysis indicates a marked similarity between the issues identified by each participant, as well as the similar numbers of likes, dislikes, and desired upgrades identified across the sample as a whole. Most likely this is caused by the acute nature of the problems relating to living in Bhalswa that were common to all participants. It indicates that participants generally displayed a higher level of agreement about upgrading issues and lower degree of conflicting perspectives than within the Ghazipur study. 


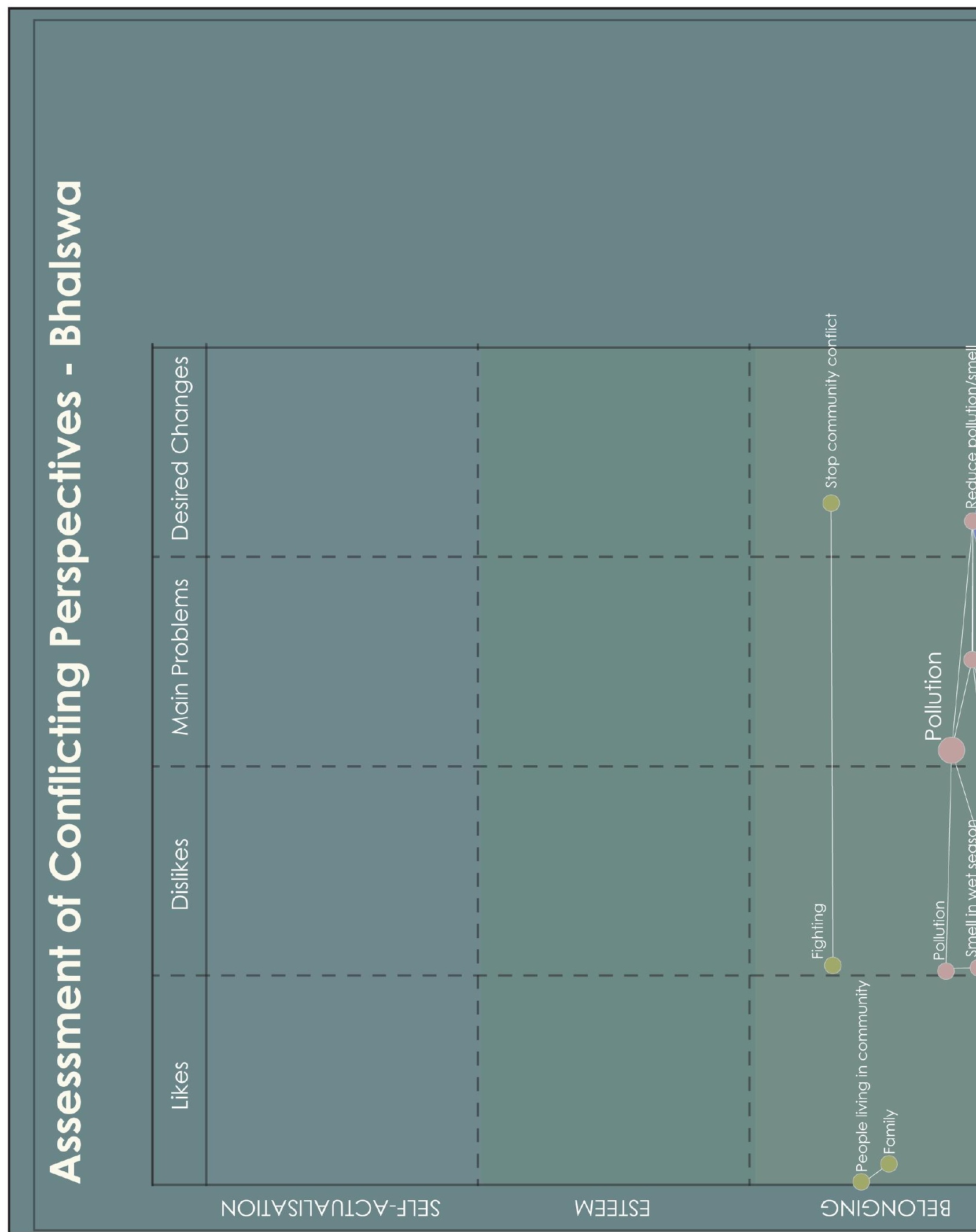

Figure 88. Thematic analysis of the Bhalswa interview data identifying a range of conflicting perspectives on slum-upgrading issues. 


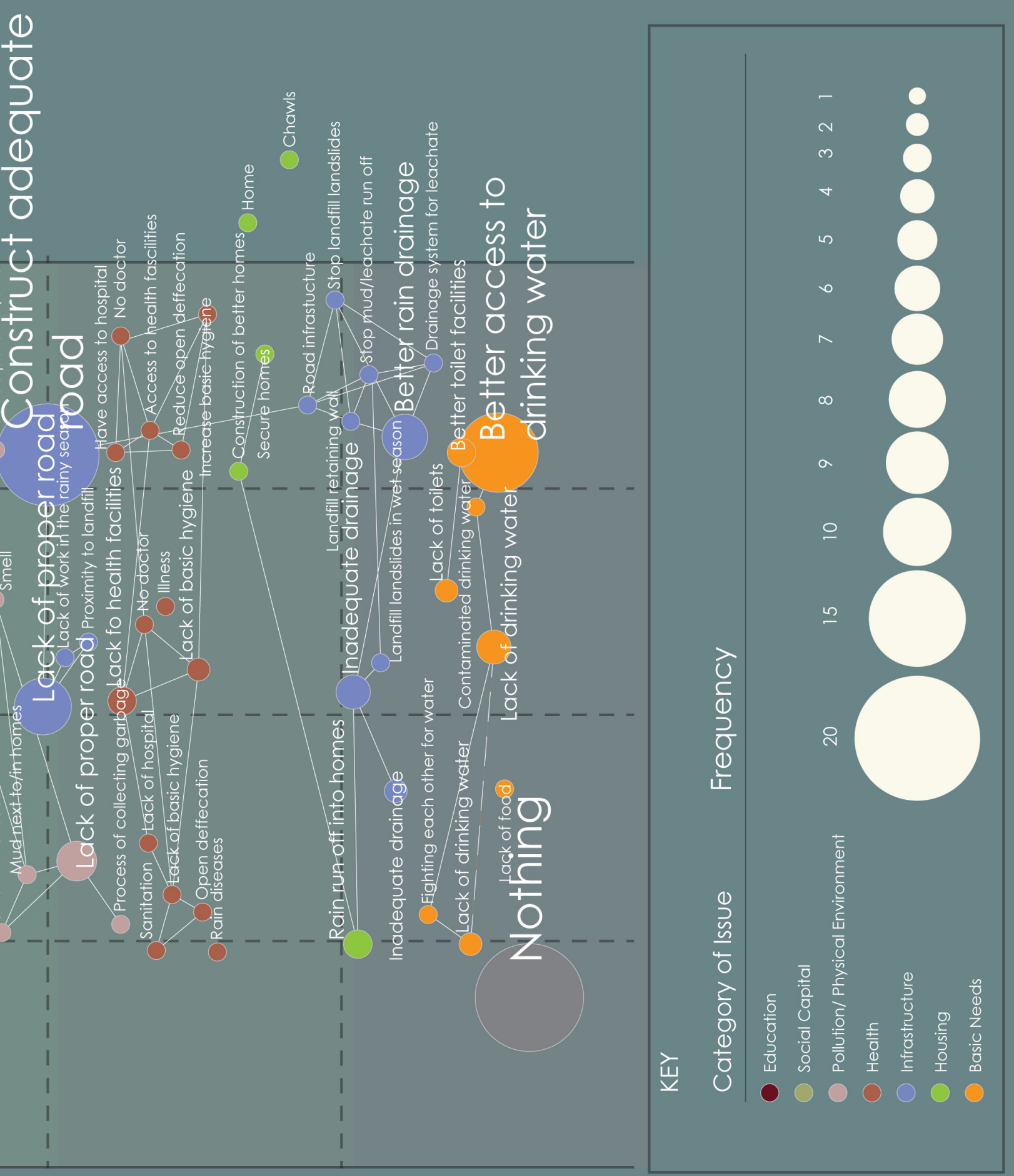




\subsection{Shanti Nagar Perspectives}

Urban issues identified by the Shanti Nagar participants were located across the full range of the needs spectrum with few physiological needs identified, as seen in Figure 89. Participants identified belonging needs being met such as having spaces to meet friends, the respect shown between community members, esteem from playing sports such as cricket and kabbadi with friends, exercising and self-actualisation needs such as reading, drama and gaining an education as enjoyable aspects of their community; however, belonging and safety-related issues such as fighting, harassment and domestic violence were identified as dislikeable attributes of their community, predominantly amongst female participants. General uncleanliness was also highlighted as a disliked attribute. Compared with the other two case study communities, participants identified few problems with their community; however a lack of educational opportunities and a lack of potable drinking water were highlighted by some. Interestingly, participants identified a large range of desired changes to their community. These were located across the full needs hierarchy, covering basic needs, housing, infrastructure, health, pollution/physical environment, social capital and education related upgrades. These included securing access to potable drinking water and health facilities, reducing pollution, facilitating support for alcoholics and addicts, constructing public spaces and playgrounds and increasing access to education.

The analysis shows that the Shanti Nagar participants identified the largest range of likes, dislikes and desired changes of the three case study communities, while identifying few problems that were coded as physiological. It indicates that participants generally displayed a lower level of agreement about upgrading issues and a higher degree of conflicting perspectives than within the Ghazipur and Bhalswa studies. This reflects the longer established and slightly less impoverished nature of the community and possibly indicates the level of agency the community perceives it has in relation to affecting change over their real-world situation. The analysis also reflects the acute nature of some of the urban issues that were identified by the Bhalswa community in terms of the level of consensus that was expressed around these issues. 


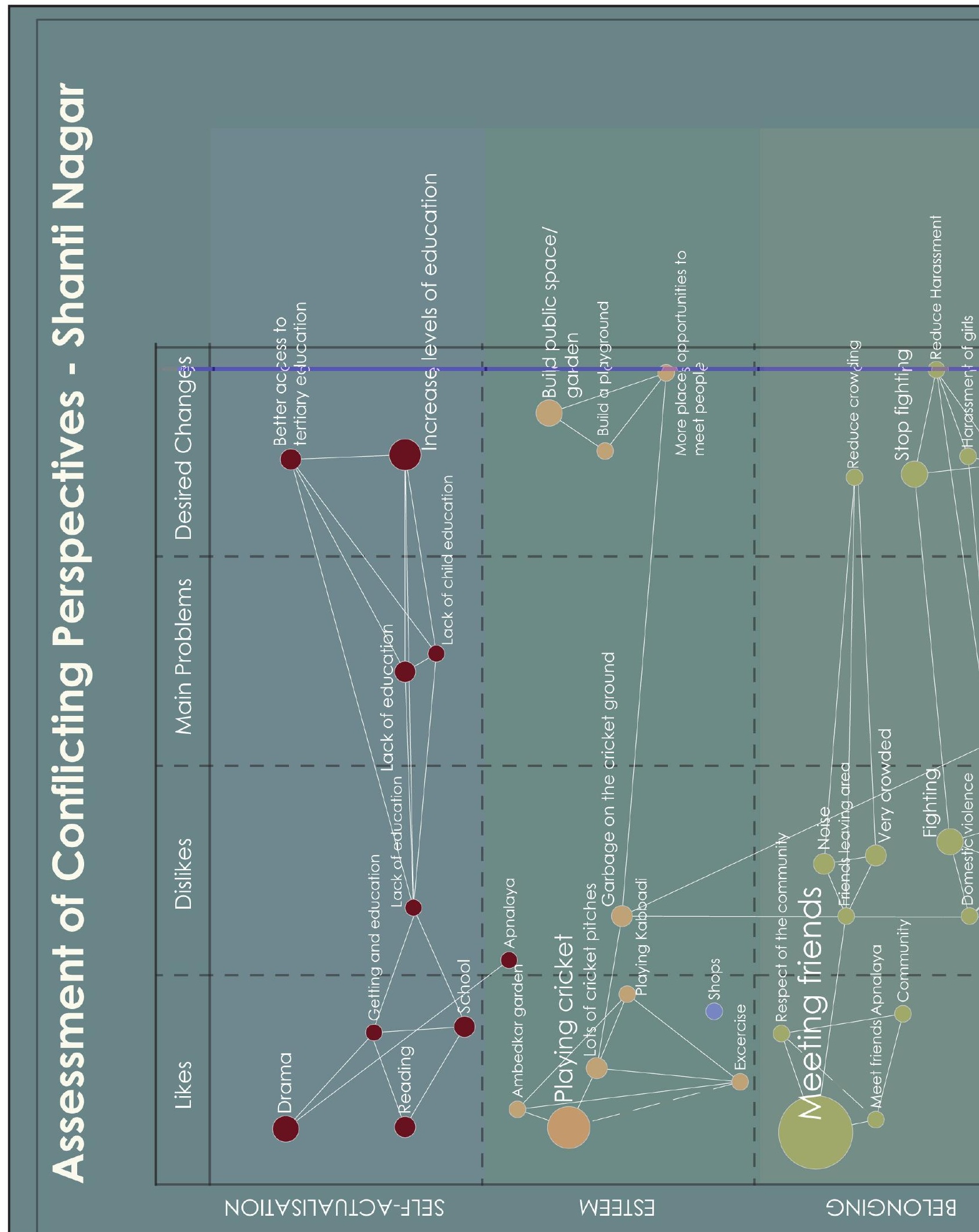

Figure 89. Thematic analysis of the Shanti Nagar interview data identifying a range of conflicting perspectives on slum-upgrading issues. 


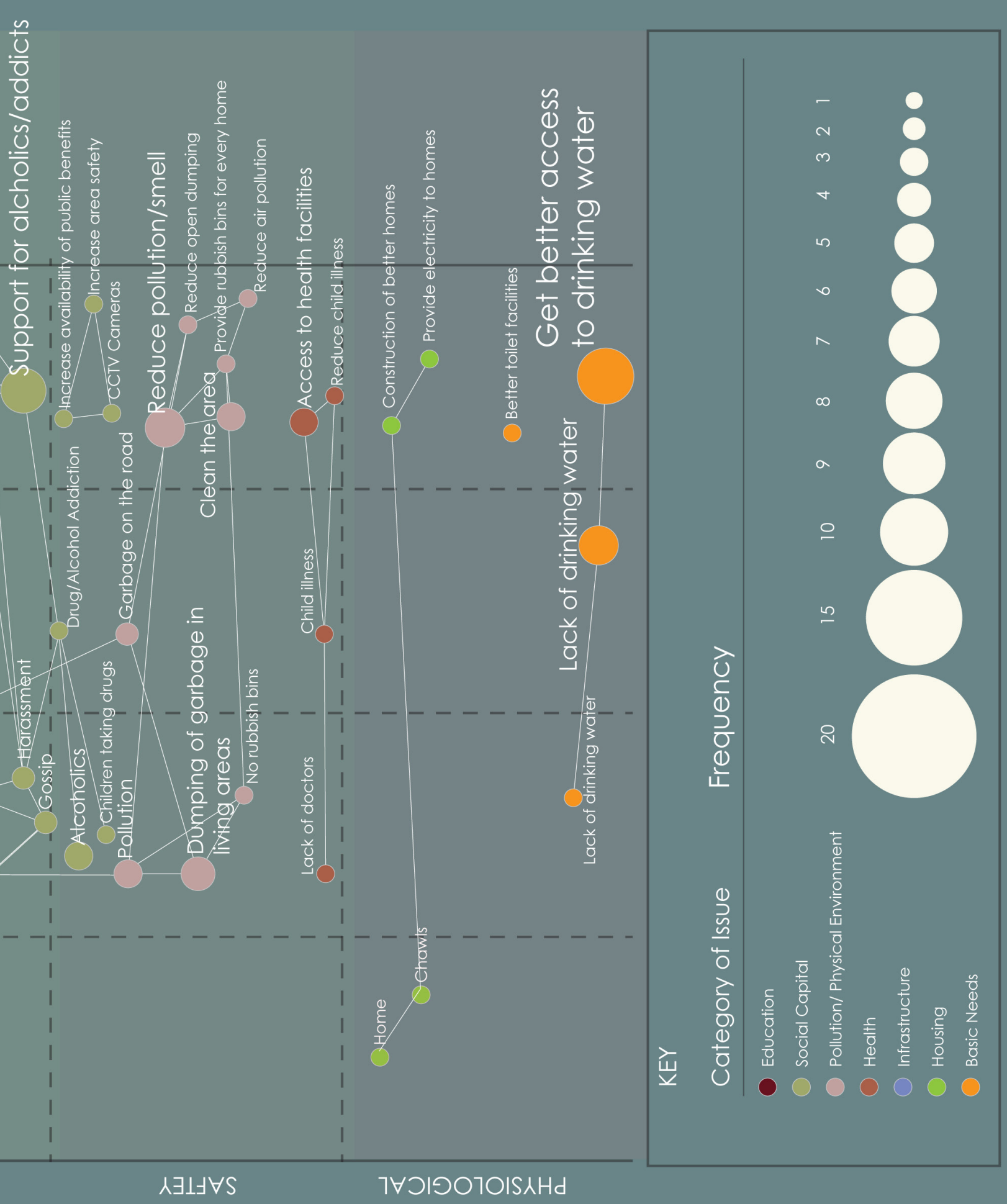




\subsubsection{Identification of Important Contextual Issues}

From this analysis a range of issues was identified across the research sites for incorporation into the SPS-UG approach. Through the mapping and interview process, a number of key relationships were identified as being specific to the Ghaizpur area. These include the slum area's proximity to the Delhi Metro station, waste sorting area, the landfill, public toilets and the dairy farms. These are detailed in Table 15, below.

Table 15. Identification of important contextual issues

\begin{tabular}{|c|c|c|}
\hline Ghazipur & Bhalswa & Shanti Nagar \\
\hline $\begin{array}{l}\text { - Waste sorting areas in/near housing } \\
\text { - Housing close proximity to landfill } \\
\text { - Housing against metro retaining } \\
\text { wall } \\
\text { - Location of dairy farms, improper } \\
\text { effluent disposal } \\
\text { - Light industry integration into } \\
\text { community } \\
\text { - Development of new Metro station } \\
\text { - Waste-to-energy plant and } \\
\text { associated livelihood/ social issues }\end{array}$ & $\begin{array}{l}\text { - Waste sorting areas in/near housing } \\
\text { - Integration of religious sites - } \\
\text { Mosques } \\
\text { - Housing close proximity to landfill } \\
\text { - Landfill perimeter wall } \\
\text { - High density housing } \\
\text { - Access to bus station } \\
\text { - Availability of high-rise/density } \\
\text { housing }\end{array}$ & $\begin{array}{l}\text { - Integration of religious sites - } \\
\text { Mosques } \\
\text { - Landfill perimeter wall } \\
\text { - High density housing } \\
\text { - Access to bus station } \\
\text { - Availability of high-rise/density } \\
\text { housing }\end{array}$ \\
\hline
\end{tabular}

\begin{tabular}{l|l|l}
\hline - The landfills and associated & - The landfills and associated & - The landfills and associated sanitation, \\
sanitation, livelihood and & sanitation, livelihood and & livelihood and environmental concerns \\
environmental concerns & environmental concerns & - Landfill fires \\
- Landfill fires & - Landfill fires & - Proximity to waterways \\
- Proximity to waterways & - Proximity to waterways & - Proximity to transport networks \\
- Proximity to transport networks & - Proximity to transport networks & - Community halls \\
- Community halls & - Community halls & - Access to hospitals \\
- Access to hospitals & - Access to hospitals & - Access to toilets and sanitation \\
- Access to toilets and sanitation & - Access to toilets and sanitation & facilities \\
facilities & facilities & - Access to drinking water \\
- Access to drinking water & - Access to drinking water & infrastructure \\
infrastructure & infrastructure & Access to schools \\
- Access to schools & - Access to schools & space \\
- Access to public green/ recreational green/ recreational \\
space & - Access to public green/ recreational & - Higher quality roads \\
- Higher quality roads & space & - Waste-to-energy plant \\
- Waste-to-energy plant & - Higher quality roads & \\
\hline
\end{tabular}

Other key relationships included the waste-to-energy plant, the dairy farms and the poultry and meat markets' connections to the landfill. Furthermore, a number of key relationships were identified as being specific to the Bhalswa area. These include dwellings in the slum area being in close proximity to the landfill-especially 
regarding issues of drainage and landslides, pedestrian and vehicle access to the landfill, landfills' proximity to waterways and accessibility of toilets from the slum area. Key relationships identified as being specific to the Shanti Nagar community include access to potable drinking water from dwellings, mosques' relationships to the street grid, the relationship between gridded streets and informal dwelling areas, the bus depot and the cricket grounds and open areas' proximities to the landfill, the landfill's proximity to the mangroves and wetlands and the location of schools within the community.

\subsection{Phase Two: SPS-UG Development}

This section details how the results detailed within the previous sections were used to develop an SPS-UG for use with each case study in line with objective 3:

O3: to develop one SPS-UG for use in participatory workshops within all case study communities.

\subsubsection{Stage One: Development of 3D Assets}

As highlighted by the data presented in Section 4.2.4, the case study communities exhibited a range of opinions about the advantages, problems and challenges they face by living in their communities, and what they would like to do about them or improve in the future. Phase two of the SPS-UG development process included the conversion of data gathered in Phase One into three-dimensional models for application within a gaming engine. Phase Two used the interview data, which highlighted important issues or trajectories of urban upgrading from the perspective of the participants, in combination with the data gathered in documenting the physical environment of the communities, to develop three-dimensional models of buildings and spaces, or 3D assets, for use in the development of an SPS-UG.

The cross-platform real-time engine Unity3D was selected as the game development platform as it is a cross-platform all in one editor that supports the creation of multiplayer games. Autodesk 3DS Max was used as the 3D modelling software in developing digital models of spaces and buildings.

A low-polygon style of 3D modelling, with limited digital texturing, was chosen as the graphic style (McLaughlin et al., 2010, p. 136). This was chosen for three reasons. The first is that the literature review showed that using simplified or stylised 3D 
representation styles reduces player confusion regarding the pragmatic viability of ingame (Wattanasoontorn, 2013). The second is that high detail modelling is time consuming, which is a significant factor within research-oriented game development with limited resources. The third is that lower polygon counts allow for faster real-time rendering and therefore allow for a game to run on a computer with low graphics processing capabilities such as a laptop. This is an important factor when using games as part of fieldwork where all equipment needs to be transported and access to IT resources is limited.

One SPS-UG was developed to be used in conducting all participatory design workshops across all three research case studies. This presented a challenge, as a common game environment needed to be able to be used to facilitate ideation and the negotiation of perspectives within all communities and between all participants, while having the ability to prompt debate surrounding context specific issues - or create a perceptual bridge between the game and the player's real-world experience in each case context (Auger, 2013, 2013).

In order to achieve this a number of strategies were used. First, buildings and spaces were categorised as either "generic" or "site-specific". Real-world spaces designated as "generic" are those in which a large number of typologically similar buildings exist. These include buildings and spaces that are typologically common to each of the three case study communities - such as the landfill, waste sorting areas, houses or shops. Those designated as "site-specific" could be considered unique to the built environment of a specific community. These include buildings such as the waste-toenergy plant at Ghazipur or the bus terminal at Shanti Nagar, for example. Here, references to specific buildings and spaces within the interview data were used to inform judgements on the level of "uniqueness" of site-specific buildings and spaces for three-dimensional development and inclusion in the SPS-UG. These were then classified into the categories of housing, public spaces, public buildings, infrastructure and commercial spaces.

The adjacencies between each of the classified spaces within each community were then documented and mapped. The "site-specific" and "generic" examples of housing, public spaces, public buildings, infrastructure and commercial spaces were composited with these mappings in order to create a virtual environment that was typologically familiar to all communities in terms of its overall urban form. 


\subsubsection{Housing}

The dwellings digitised into 3D assets fall into three categories in line with those identified though the documentation of the research contexts in Section 4.2.4. These include light-weight, single-storey structures typically found in informal slum areas of the three communities, two-storey concrete dwellings and commercial structures and multi-storey, high-density residential buildings. All housing types were classified as "generic" as all dwelling types are found in all communities. Through this conceptual framing of real-world spaces, the SPS-UG allows a reframing of the structures of meaning in a context, creating a filter to pragmatic impasses that can often thwart negotiation processes (Dindler, 2010a, p. 84; Iser, 1993). The generic classification means that no one person is able to recognise their own home within the SPS-UG environment and therefore be protective of it; however, in maintaining typological familiarity, building components such as floors, walls, windows, doors and awnings were modelled with reference to real-world structures. These were then composited onto a variety of buildings in order to establish typologically familiar, yet not contextspecific, digital models.

Table 16. Development of 3D Assets - Housing

\begin{tabular}{|c|c|c|c|c|c|}
\hline Location & Category & Type & Description & Context Image & Example \\
\hline $\begin{array}{l}\text { Ghazipur } \\
\text { (CS1) }\end{array}$ & $\begin{array}{l}\text { Light-weight } \\
\text { single-storey } \\
\text { dwelling. }\end{array}$ & Generic & $\begin{array}{l}\text { Timber framing, } \\
\text { brick plinth, iron or } \\
\text { scavenged brick } \\
\text { cladding. }\end{array}$ & & \\
\hline $\begin{array}{l}\text { Bhalswa } \\
\text { (CS2) }\end{array}$ & $\begin{array}{l}\text { Light-weight } \\
\text { single-storey } \\
\text { dwelling. }\end{array}$ & Generic & $\begin{array}{l}\text { Timber framing, } \\
\text { brick plinth, iron or } \\
\text { scavenged brick } \\
\text { cladding. }\end{array}$ & & \\
\hline $\begin{array}{l}\text { Bhalswa } \\
\text { (CS2) }\end{array}$ & $\begin{array}{l}\text { Dwelling/ } \\
\text { Commercial. }\end{array}$ & Generic & $\begin{array}{l}\text { Two-storey. } \\
\text { Commercial and } \\
\text { residential. } \\
\text { Structural steel, } \\
\text { brick, iron and } \\
\text { concrete. }\end{array}$ & & \\
\hline
\end{tabular}




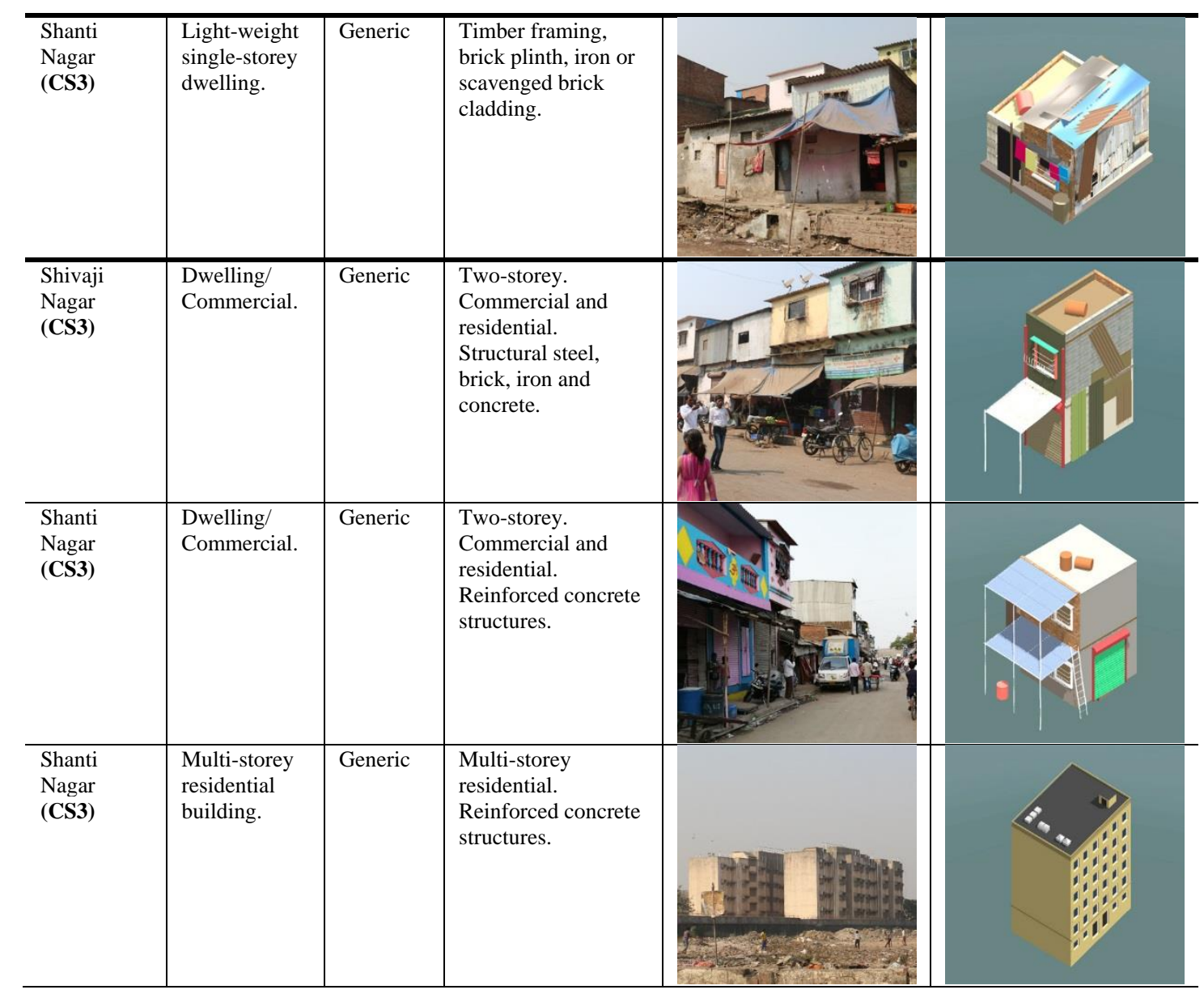

\subsubsection{Public Spaces}

The development of public space assets followed a similar development process as was followed for housing development. All public space elements were designated "generic", as the types of spaces such as landfills, waste sorting areas and waterways are common features shared among all sites.

Table 17. Development of 3D Assets - Public Spaces

\begin{tabular}{|c|c|c|c|c|c|}
\hline Location & Category & Type & Description & Context Image & Example \\
\hline $\begin{array}{l}\text { Bhalswa } \\
\text { (CS2) }\end{array}$ & Landfill & Generic & $\begin{array}{l}\text { Landfill. Multi- } \\
\text { layered, access } \\
\text { roads to summit } \\
\text { for trucks. Major } \\
\text { landmark. Housing } \\
\text { adjacent. }\end{array}$ & & \\
\hline
\end{tabular}




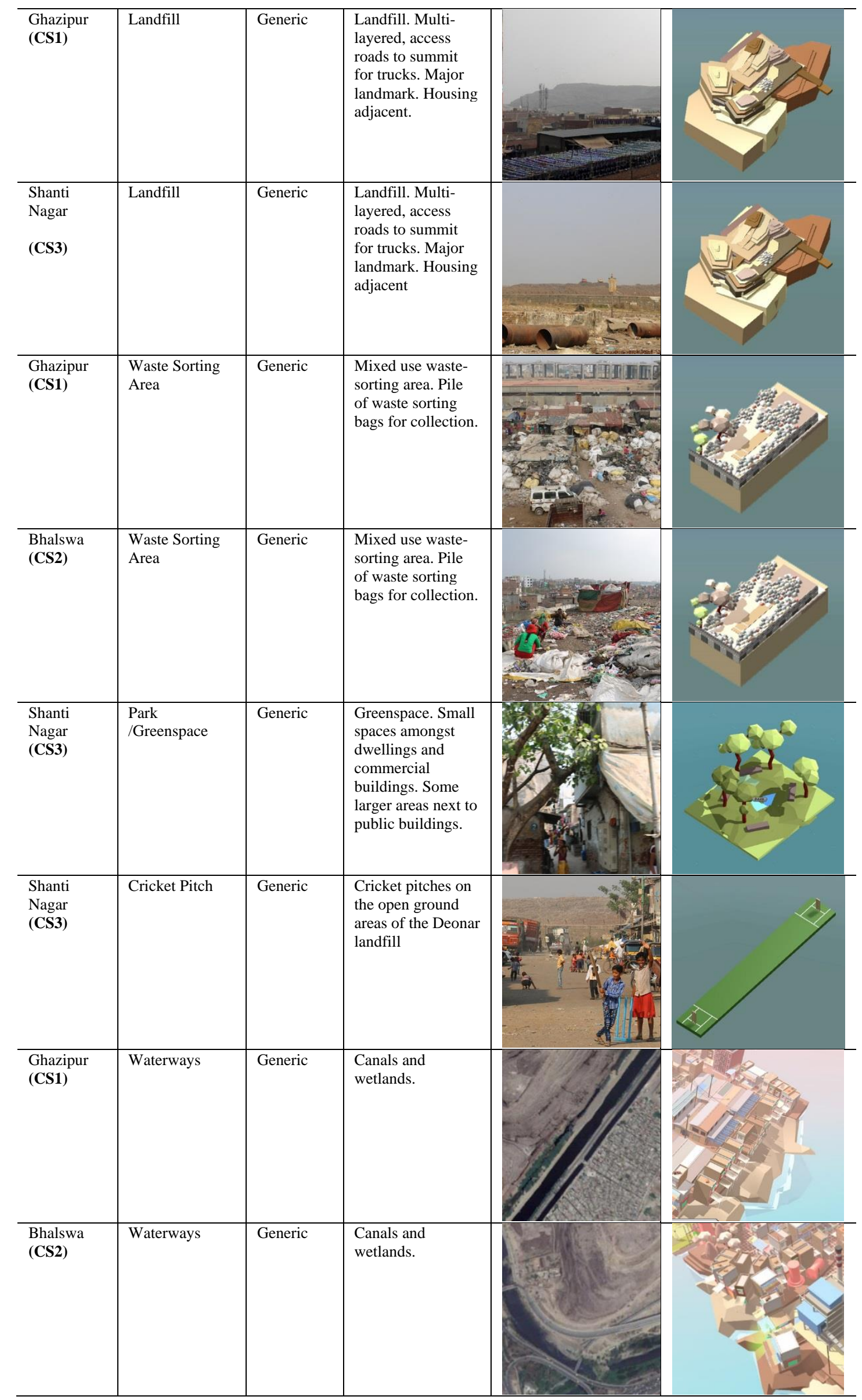




\begin{tabular}{l|l|l|l|l|l|}
\hline $\begin{array}{l}\text { Shanti } \\
\text { Nagar } \\
\text { (CS3) }\end{array}$ & Waterways & Generic & $\begin{array}{l}\text { Canals and } \\
\text { wetlands. }\end{array}$ & & \\
& & & & & \\
\hline
\end{tabular}

\subsubsection{Public Buildings and Infrastructure}

The development of public buildings and infrastructure 3D assets are categorised as a mixture of generic and site-specific. Infrastructure such as roads, toilets, water infrastructure and hospitals are designated as generic while entities such as local schools, community meeting halls (Shanti Nagar) and the metro station (Ghazipur) are modelled to be site-specific.

Table 18. Development of 3D Assets - Public Buildings and Infrastructure

\begin{tabular}{|c|c|c|c|c|c|}
\hline Location & Category & Type & Description & Context Image & Example \\
\hline $\begin{array}{l}\text { Shanti } \\
\text { Nagar } \\
\text { (CS3) }\end{array}$ & School & Site-specific & $\begin{array}{l}\text { Bharal Nagar Urdu } \\
\text { High School. }\end{array}$ & & \\
\hline $\begin{array}{l}\text { Shanti } \\
\text { Nagar } \\
\text { (CS3) }\end{array}$ & Mosque & Generic & $\begin{array}{l}\text { Mosque } \\
\text { constructed from } \\
\text { reinforced concrete } \\
\text { and cinderblock. } \\
\text { Iron roof. } \\
\text { Orientated towards } \\
\text { Mecca. }\end{array}$ & & \\
\hline $\begin{array}{l}\text { Shanti } \\
\text { Nagar } \\
\text { (CS3) }\end{array}$ & $\begin{array}{l}\text { Community } \\
\text { meeting hall }\end{array}$ & Site-specific & $\begin{array}{l}\text { Two-storey, } \\
\text { constructed from } \\
\text { reinforced concrete } \\
\text { and cinderblock. } \\
\text { Iron roof. }\end{array}$ & & \\
\hline $\begin{array}{l}\text { Shanti } \\
\text { Nagar } \\
\text { (CS3) }\end{array}$ & $\begin{array}{l}\text { Water } \\
\text { infrastructure }\end{array}$ & Generic & $\begin{array}{l}\text { Water collection } \\
\text { tank. Tap access as } \\
\text { specific locations } \\
\text { within the } \\
\text { community. }\end{array}$ & & \\
\hline
\end{tabular}




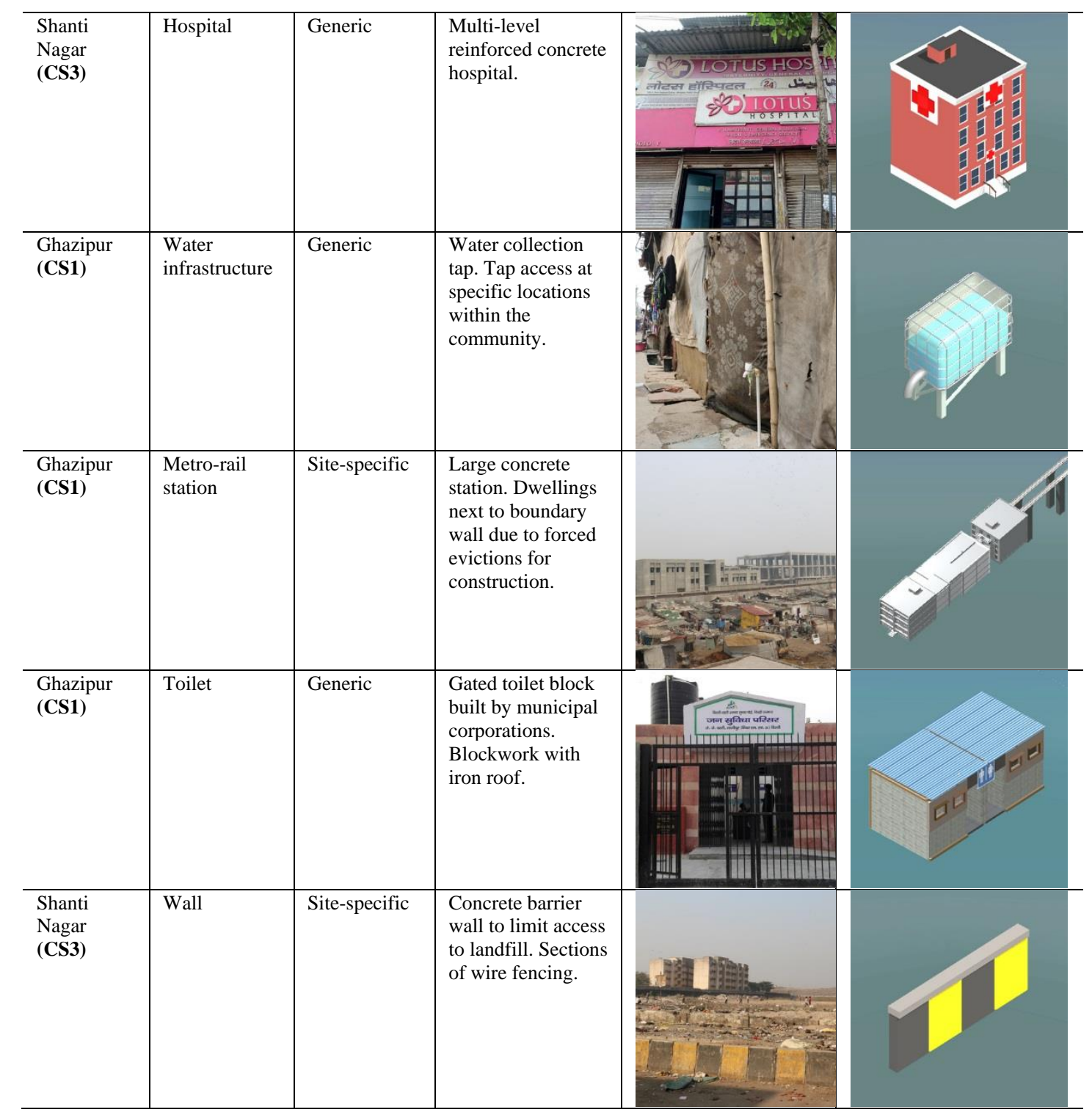

\subsubsection{Commercial Activities}

Commercial activities such as shops are mostly designated as site-specific as they were highlighted in the context documentation and interview analysis as causing a number of tensions within the communities - such as the dairy farms or the waste-toenergy plant at Ghazipur, for example. Shops and market stalls are designated as generic, as similar examples are found within each research context and were not specifically prominent within the data. 
Table 19. Development of 3D Assets - Commercial Activities

\begin{tabular}{|c|c|c|c|c|c|}
\hline Location & $\overline{\text { Category }}$ & Type & Description & Context Image & Example \\
\hline $\begin{array}{l}\text { Shanti } \\
\text { Nagar } \\
\text { (CS3) }\end{array}$ & Shop & Generic & $\begin{array}{l}\text { Food and fabric } \\
\text { shops. Blockwork } \\
\text { with iron roof. }\end{array}$ & & \\
\hline $\begin{array}{l}\text { Ghazipur } \\
\text { (CS1) }\end{array}$ & Stall & Generic & $\begin{array}{l}\text { Market stall. } \\
\text { Timber structure } \\
\text { with canvas or iron } \\
\text { cladding. }\end{array}$ & & \\
\hline $\begin{array}{l}\text { Ghazipur } \\
\text { (CS1) }\end{array}$ & $\begin{array}{l}\text { Waste-to- } \\
\text { energy plant }\end{array}$ & Site-specific & $\begin{array}{l}\text { Waste-to-energy } \\
\text { complex. Main } \\
\text { landmark. Fenced } \\
\text { off from wider } \\
\text { community. }\end{array}$ & & \\
\hline $\begin{array}{l}\text { Ghazipur } \\
\text { (CS1) }\end{array}$ & Dairy farm & Site-specific & $\begin{array}{l}\text { Single and double- } \\
\text { storey dairy farm } \\
\text { buildings. } \\
\text { Reinforced } \\
\text { concrete and } \\
\text { masonry. }\end{array}$ & & \\
\hline $\begin{array}{l}\text { Ghazipur } \\
\text { (CS1) }\end{array}$ & $\begin{array}{l}\text { Garment } \\
\text { factory }\end{array}$ & Site-specific & $\begin{array}{l}\text { Garment factory } \\
\text { buildings. Single } \\
\text { and double-storey. } \\
\text { Drying area } \\
\text { between buildings. }\end{array}$ & & \\
\hline $\begin{array}{l}\text { Shanti } \\
\text { Nagar } \\
\text { (CS3) }\end{array}$ & Bus terminal & Site-specific & $\begin{array}{l}\text { Bus depot. Fenced } \\
\text { from rest of the } \\
\text { community. }\end{array}$ & & \\
\hline
\end{tabular}

\subsubsection{Compositing Urban Form for SPS-UG's}

Similar to the challenges faced in the development of digital models for individual buildings, in designing the virtual urban form of the SPS-UG environment for this research, I was presented with two challenges. The first was how to create a virtual environment that "defamiliarises" the research context to open up "discursive space" 
and aid negotiation and critical ideation discussions through a consideration of a plurality of future possibilities (Bell et al., 2005; Lindley et al., 2014, p. 240). The second was how to ensure a coherent and typologically familiar virtual environment is presented that is legitimate in terms of being internally consistent and having extensional expectations that are relevant to all players across the three case study communities (Auger, 2012, p. 140; Knutz et al., 2016; Pickersgill, 2017).

\subsection{Compositing Urban Morphology and Contextual Issues}

A strategy to address these issues was adopted in which the morphological elements of each research context identified in section 4.2 were woven together with issues identified through the interview process, and this configuration was then populated with the $3 \mathrm{D}$ digital assets documented throughout this section. This roots the virtual environment in the familiar while providing novel configuration of contextual elements (Dindler, 2010a, p. 75; Malmgren, 1985, p. 18). In line with the world creation literature presented in chapter two (Dindler, 2010a; Goodman, 1978; Malmgren, 1985), the novel configuration is composed of parts (areas such as neighbourhoods or larger areas of a particular land use), subclasses (generic buildings or spaces), and features (site-specific real-world buildings, spaces and relationships). Key parts, subclasses and features from the analysis of the interview data for the compositing process are detailed in Table 20.

Table 20. Parts, Subclasses and features for compositing urban morphological and contextual issues in the SPS-UG.

\begin{tabular}{l|l|l}
\hline Parts & Subclasses & Features \\
\hline $\begin{array}{l}\text { Urban form, land-use patterns, } \\
\text { grain, road and pathway } \\
\text { configurations }\end{array}$ & $\begin{array}{l}\text { Dwelling types and development } \\
\text { patterns; }\end{array}$ & $\begin{array}{l}\text { Key site-specific urban } \\
\text { nodes such as mosques, } \\
\text { schools and greenspaces }\end{array}$ \\
\hline Topography & $\begin{array}{l}\text { Commercial zones and } \\
\text { patterning }\end{array}$ & $\begin{array}{l}\text { Key site-specific } \\
\text { adjacencies such as housing } \\
\text { proximity to the landfill }\end{array}$ \\
\hline $\begin{array}{l}\text { Canals, highways and } \\
\text { commercial activities providing } \\
\text { site boundaries; }\end{array}$ & $\begin{array}{l}\text { Connection to open public } \\
\text { spaces }\end{array}$ & $\begin{array}{l}\text { Canals, highways and } \\
\text { commercial activities providing } \\
\text { site boundaries }\end{array}$ \\
\hline & Mixed use & \\
\hline & Transportation/public utilities &
\end{tabular}


The parts, subclasses and features were then recomposed into novel configurations using strategies of weighting and deformation (Figure 90). Weighting was judged based on the prominence of key contextual features and land use compositions within each case study site (i.e. the landfill being central to all communities) as well as the importance of issues identified through the interview data (i.e. the recently constructed Delhi metro station in relationship to the threat of forced eviction for Ghazipur residents). Deformation was also used as a world-making strategy through the compositing of the three case study sites. This occurred at the urban scale as well as through the compositing of parts, subclasses and features. This is intended to act as a defamiliarisation strategy to distort perspectives leading to new-world formations, ideation and negotiation of perspectives. It also allowed for key real-world systems and adjacencies to be embedded within the virtual environments, while maintaining defamiliarisation.

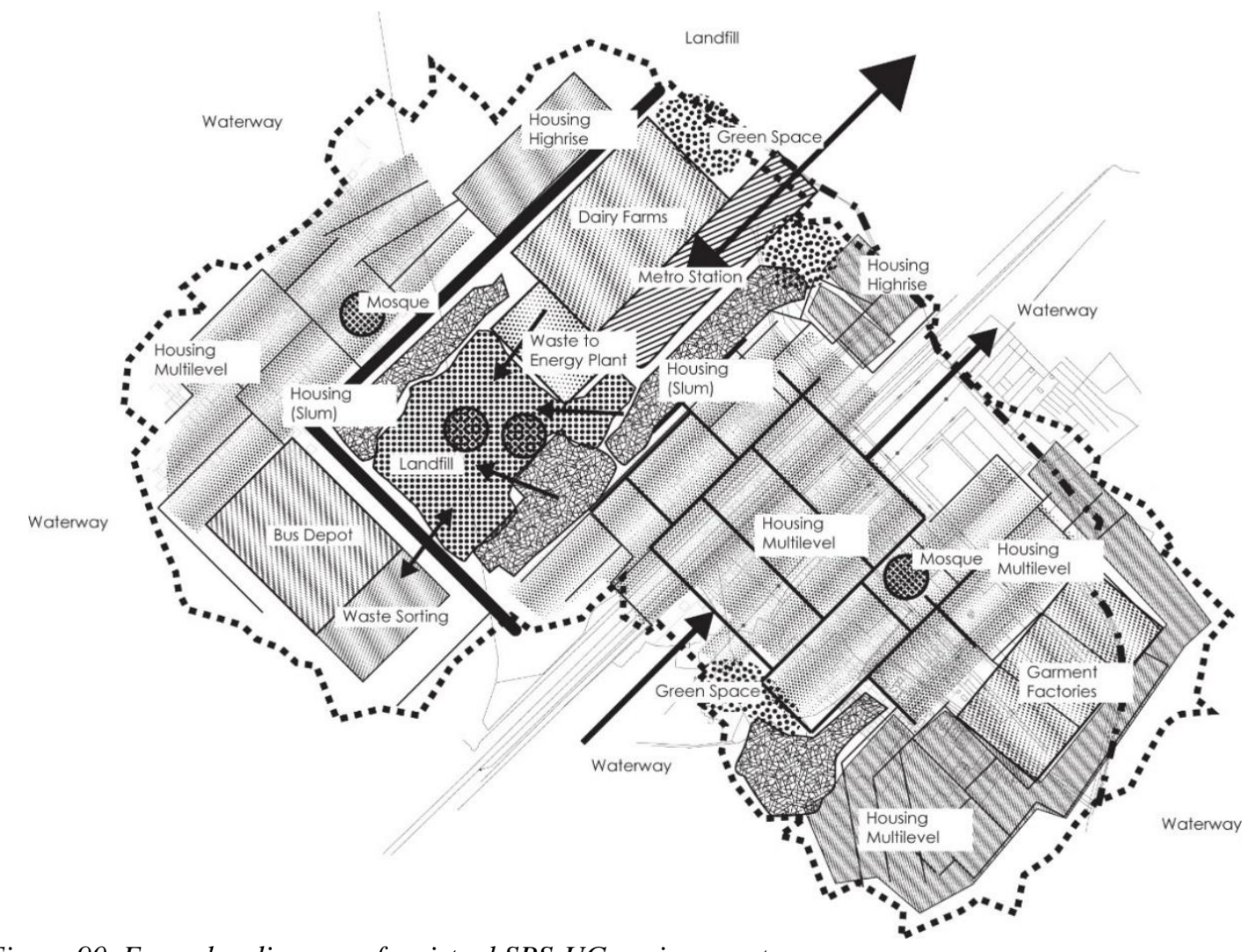

Figure 90. Exemplar diagram of a virtual SPS-UG environment. 


\subsubsection{Stage Two: Development of Interactive Mechanics and Dynamics SPS-UG 4.3.2.1 Purpose/Aim/Goal}

The previous two phases were operationalised as a SPS-UG computer game I designed, which I call "Maslow's Palace". The name was chosen in alignment with the deductive coding used to analyse the hierarchy of needs within each community. The game represents urban design issues in Ghazipur, Bhalswa and Shanti Nagar with the purpose of revealing disparities of views and opinions within the communities to help them move toward a common vision regarding their urban design challenges. The game seeked to expose these differences and to foster empowerment by enabling groups to better understand each other's points of view regarding a range of problems to help them collaborate better in the future. The goal of the game is for players to collaboratively design speculative community upgrades through five levels of gameplay (Malone, 1981) that ascend in representational realism. Players collaboratively respond to increased numbers of challenges, typologically familiar entities and details of context as the game unfolds (Auger, 2012, p. 180). In this way, Maslow's Palace functions as a focussed 'priming' activity, as a precursor to pragmatic participatory slum-upgrading design processes to reveal stakeholder positions, values, and explicit, observable, tacit and latent knowledge (Iversen et al., 2012; Sanders \& Dandavate, 1999) through consideration of alternative presents, futures, systems or worlds to provoke values-based discourse (DiSalvo, 2012, p. 52), using the SPS-UG as a "boundary object" in the creation of low fidelity digital prototypes (Bjögvinsson et al., 2012; Brandt et al., 2008). It has the goal of facilitating ideation and the negotiation of conflicting perspectives through collaborative learning and collective tinkering within cycles of experiencing, reflecting and testing (Jarvis, Holford, \& Griffin, 2003; Kebritchi \& Hirumi, 2008).

\subsubsection{Framing}

The target group of the SPS-UG is residents of the three case study communities. Residents in each community had a range of digital literacy levels. Some community members had very little computer knowledge, while some were quite familiar and regularly play smartphone-based digital games. Because of the disparities in digital literacy, a comprehensive tutorial system was needed to ensure a level playing field so that disparities in digital literacy did not affect gameplay or player discourse. To 
achieve this, the first two levels of Maslow's Palace focus on players learning the game mechanics, such as navigation of the user interface, avatar movement, using the inventory system and the mechanics involved in collaboratively completing levels. Subsequent levels introduce more typologically familiar elements and other game mechanics.

Legitimacy in terms of internally consistent extensional expectations (Pickersgill, 2017, p. 78; Walton, 1993) was ensured via the digitisation processes of the physical context outlined in section 4.2.2. Maslow's Palace is framed to allow for instrumental speculation as a discussion tool, as opposed to terminal visions of the future, and it is externally focussed and not expert-oriented. Here the players are given agency to design speculative urban environments within the in-game context, as opposed to merely using a terminal speculative design as a discursive provocateur.

Defamiliarisation strategies (Bell et al., 2005), such as the use of fictional game entities and compositing strategies, were used to reframe discussions or to facilitate the creation of "agonistic spaces" (DiSalvo, 2010). Level One is designed to be situated at the less plausible end of the temporality spectrum, representing a significant departure from reality. This is designed to remove the pragmatic discursive impasses entangled with real-world issues and foster collaboration between participants through an abstract task. Contextual factors, such as the exact location of an individual's home or community spaces, which might constrain the design process or discussion about the design or socio-political ideas by creating discursive impasses, are minimised. Subsequent levels gradually introduce more familiar contextual elements such as familiar buildings, spaces and real-world adjacencies. Level five includes a simple ingame economy and a range of typologically identifiable site features, buildings and spaces to which the participants respond (Auger, 2012, p. 180).

\subsection{SPS-UG Level Progression}

Table 21 below summaries the level progression of Maslow's Palace, which is followed by detailed descriptions of each level. 
Table 21. Maslow's Palace Level Progression Summary

\begin{tabular}{|c|c|c|c|c|}
\hline & Plausibility & $\overline{\text { Aim }}$ & Features & Screenshot \\
\hline $\begin{array}{l}\text { Level } \\
\text { One }\end{array}$ & $\begin{array}{l}\text { Low } \\
\text { Un-identifiable } \\
\text { blocks. No } \\
\text { Context. }\end{array}$ & $\begin{array}{l}\text { Players experiment and } \\
\text { familiarise themselves } \\
\text { with core game } \\
\text { mechanics such as player } \\
\text { movement, inventory } \\
\text { navigation, door opening } \\
\text { and game piece/ building } \\
\text { placement and } \\
\text { demolition. }\end{array}$ & $\begin{array}{l}\text { A basic inventory of } \\
\text { blank blocks of various } \\
\text { sizes and shapes, as well } \\
\text { as a pre-placed array of } \\
\text { destroyable blocks that } \\
\text { players can imbue with } \\
\text { their own meanings. }\end{array}$ & . \\
\hline $\begin{array}{l}\text { Level } \\
\text { Two }\end{array}$ & $\begin{array}{l}\text { Low } \\
\text { Unidentifiable } \\
\text { context. } \\
\text { Housing } \\
\text { modules only. }\end{array}$ & $\begin{array}{l}\text { Players experiment and } \\
\text { familiarise themselves } \\
\text { with core game } \\
\text { mechanics including } \\
\text { module placement in } \\
\text { relationship to other } \\
\text { players actions. }\end{array}$ & $\begin{array}{l}\text { A basic inventory of } \\
\text { blank blocks of various } \\
\text { sizes and shapes, } \\
\text { placeable housing } \\
\text { modules, as well as a } \\
\text { pre-placed array of } \\
\text { destroyable blocks that } \\
\text { players can imbue with } \\
\text { their own meanings. }\end{array}$ & \\
\hline $\begin{array}{l}\text { Level } \\
\text { Three }\end{array}$ & $\begin{array}{l}\text { Low } \\
\text { Some } \\
\text { identifiable } \\
\text { buildings. }\end{array}$ & $\begin{array}{l}\text { Players experiment with } \\
\text { module housing and } \\
\text { public building } \\
\text { placement in relationship } \\
\text { to other players' actions. }\end{array}$ & $\begin{array}{l}\text { An inventory of housing } \\
\text { and public space } \\
\text { modules as well as blank } \\
\text { blocks of various sizes } \\
\text { and shapes, that players } \\
\text { can imbue with their } \\
\text { own meanings. }\end{array}$ & \\
\hline $\begin{array}{l}\text { Level } \\
\text { Four }\end{array}$ & $\begin{array}{l}\text { Medium } \\
\text { Some } \\
\text { identifiable } \\
\text { buildings and } \\
\text { spaces. }\end{array}$ & $\begin{array}{l}\text { Players discuss the } \\
\text { importance of particular } \\
\text { site features in relation } \\
\text { to in-game actions. }\end{array}$ & $\begin{array}{l}\text { An inventory of housing } \\
\text { and public space } \\
\text { modules as well as blank } \\
\text { blocks of various sizes } \\
\text { and shapes. } \\
\text { Some existing site } \\
\text { contextual site features } \\
\text { to respond to. }\end{array}$ & \\
\hline $\begin{array}{l}\text { Level } \\
\text { Five }\end{array}$ & $\begin{array}{l}\text { Medium-high. } \\
\text { Identifiable } \\
\text { buildings and } \\
\text { spaces. }\end{array}$ & $\begin{array}{l}\text { Players discuss the } \\
\text { relationships between } \\
\text { site problems and } \\
\text { desired changes. }\end{array}$ & $\begin{array}{l}\text { An inventory of housing } \\
\text { and public space } \\
\text { modules as well as blank } \\
\text { blocks of various sizes } \\
\text { and shapes. } \\
\text { In-game economy, } \\
\text { typologically identifiable } \\
\text { site features, buildings } \\
\text { and spaces. }\end{array}$ & \\
\hline
\end{tabular}

In Level One, players are introduced to an abstract game level (Figure 91), where they may experiment and familiarise themselves with core game mechanics such as player movement, inventory navigation, door opening and game piece/ building placement and demolition. This level is visually designed to be situated at the less plausible end of the temporality spectrum (Voros, 2003), representing a significant departure from reality with the goal of levelling socio-cultural structures and enabling discourse through the collaborative learning of the game mechanics (Arnab et al., 2015; Kebritchi \& Hirumi, 2008). It is also designed to slowly introduce players to 
game functionality in order to remove any advantage a player might have over another from being familiar with computer games. Players are provided with a basic inventory of blank blocks of various sizes and shapes, as well as a pre-placed array of destroyable blocks that players can imbue with their own meanings. This is designed to allow players space to experiment and "play" with the software before they are required to make more refined decisions in later levels (Brandt, 2006). The level introduces the core game mechanic of unanimity - whereby each player must locate their avatar next to the gate in order for the level to be completed once they are satisfied with all changes made to the game map, thus requiring negotiation in order to reach this state.

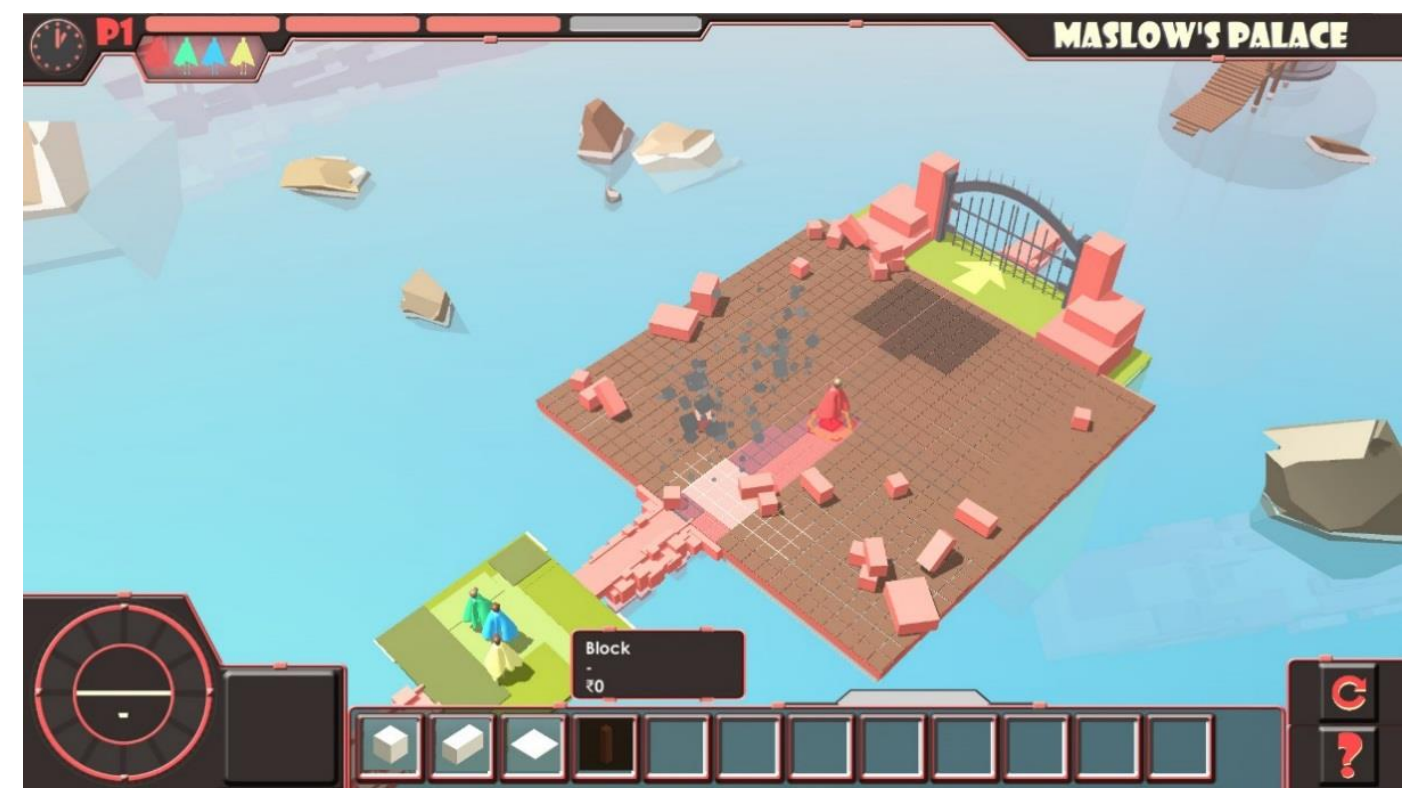

Figure 91. Level One-Maslow's Palace.

Level Two (Figure 92) is very similar to Level One; however, a new rule is introduced in which each player must construct a house for themselves within the playable space on the game map in order to complete the level. This is intended to introduce a degree of ownership and associated tension to create agonistic space (DiSalvo, 2010) and generate negotiation and cooperation between the players through a pluralistic future lens (Rosenbak, 2019, p. 159). 


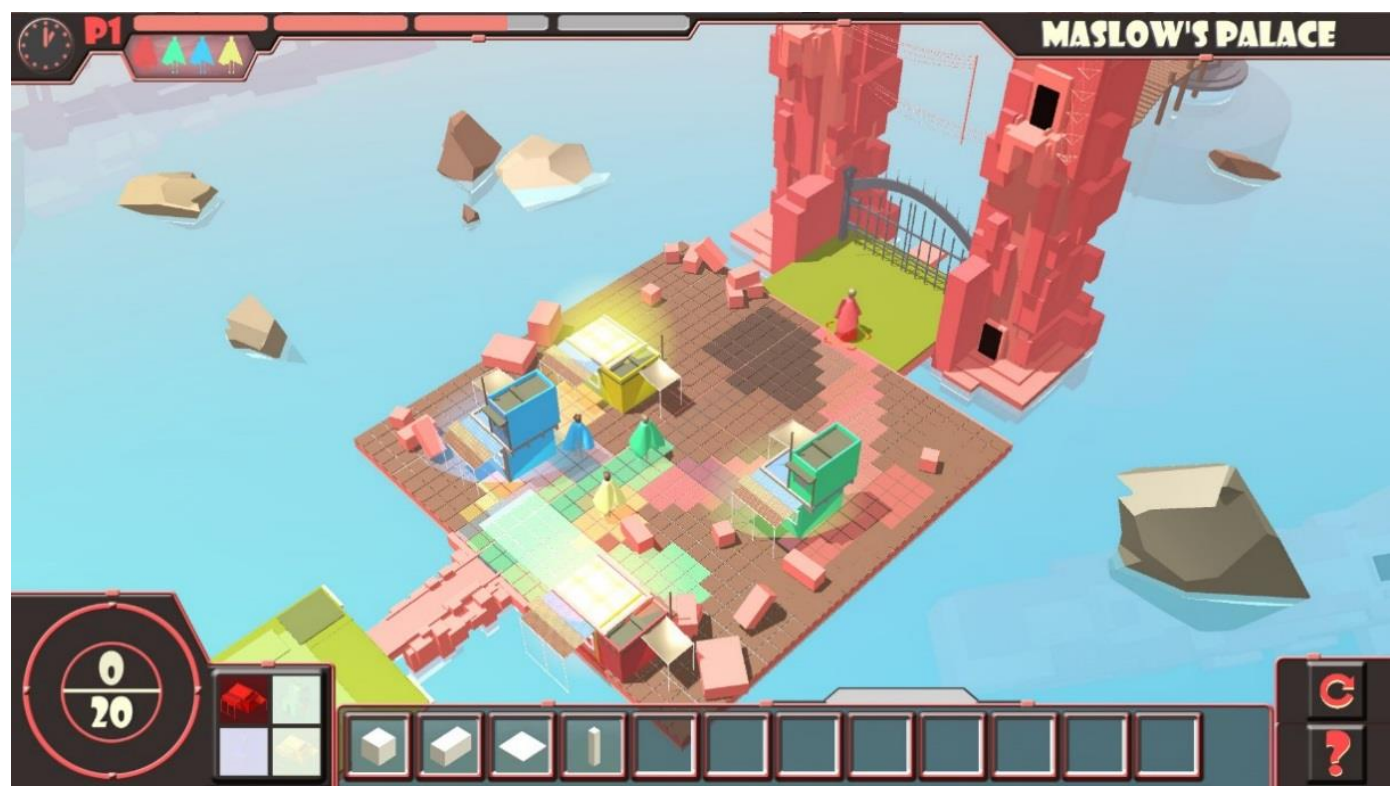

Figure 92. Level Two-Maslow's Palace.

Level Three (Figure 93) builds on the rules of the previous two levels and adds two new features with which players can experiment - new buildings/spaces located in the inventory and dynamic world events to which the players must respond. In this level, in addition to constructing one house per player, players must collectively decide on and construct five buildings or spaces within the game environment chosen from the inventory. Players are provided with a selection of shops, sanitation facilities, hospitals, mosques and parks in addition to the blank blocks available in the previous levels. Dynamic world events in the form of landslides (responding to the frequent landfill landslide events that take place within the selected communities) may be triggered by the game players.

Level Four (Figure 94) builds on the mechanics of Level Three but adds a great degree of editable context in the form of familiar building typologies to provoke players to identify with and discuss controversies and conflicting ideas through the collaborative design exercises (Bjögvinsson et al., 2012) and aid grasping of the knowledge values of other participants (Sanders \& Dandavate, 1999; Visser, 2009). The level also provides very little open space into which players can build, requiring that they demolish existing context in order to modify the environment. Additional buildings and spaces are also added to the inventory. These include drinking water tank infrastructure, toilets, schools, trees, community meeting halls and markets. 


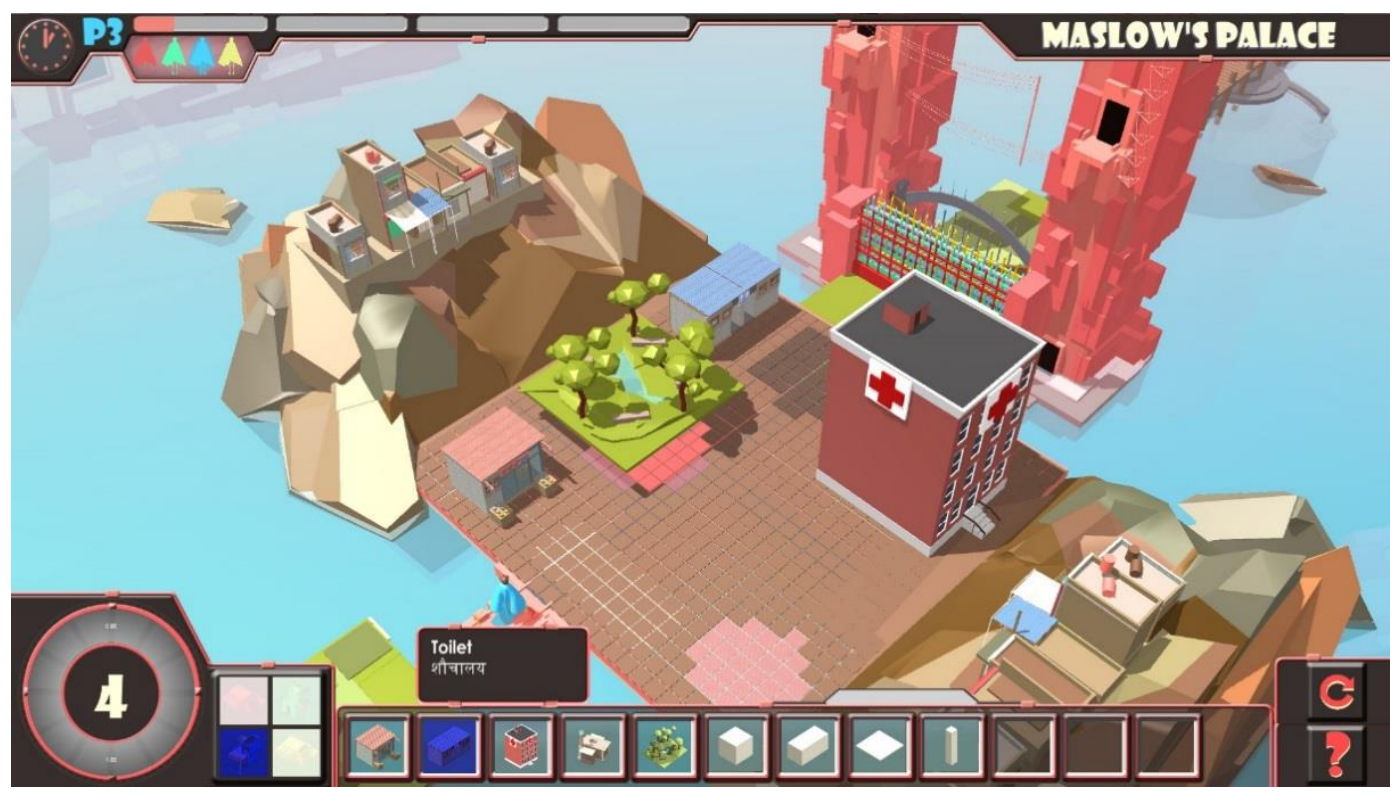

Figure 93. Level Three-Maslow's Palace.

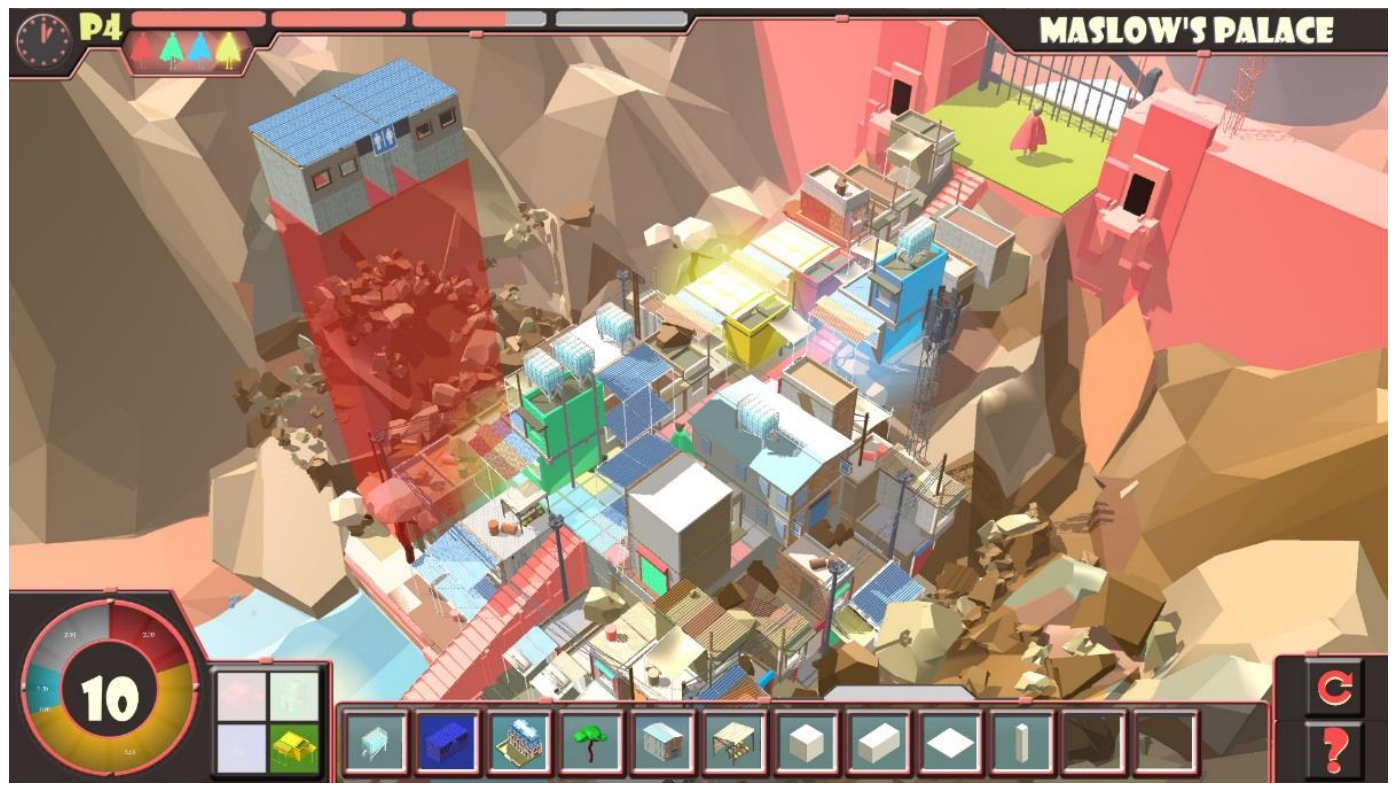

Figure 94. Level Four-Maslow's Palace.

Level Five (Figure 95) represents the most realistic of all five levels. Level Five aids players to "reveal" their perspectives and assumptions through proposing in-game design ideas in order to make positions known through design activities and ideation. It then encourages them to "develop" these through collaboratively clarifying and refining them to allow their translation from abstract formulations to more concrete design concepts. Finally it encourages them to "ground" the construction of concepts that are combinations of various participants' ideas and experiences into a scenario 
that they collectively believe will work, and to use the environment of Maslow's Palace to "prototype" design ideas in relation to their real-world experience (Clement \& Besselaar, 1993; Iversen et al., 2010, 2012; Kensing, 2003).

In this level, the game map has been carefully designed to integrate a large number of contextual issues from each of the three case study sites. These have all been designed to include familiar urban adjacencies and relationships to which players must respond and have been designed to create a fictionalised speculative representation of all three communities to which participants may respond. In this level players are required to construct a total of 20 buildings - responding to the size and complexity of the level or other game pieces from the inventory-in addition to constructing a house for each player in order to complete the level. This level is also designed to provoke collaboration and discussion by incorporating a basic economy, with all players sharing a collective "bank account" balance representing a resource the use of which they must collectively negotiate. Each inventory building costs an arbitrary amount of 10 rupees, while each demolition costs a further 10 rupees. The inventory in Level 5 is extensive, including all of the building modules from previous levels and the addition of restaurants, walls, cricket pitches, roads, houses, apartments, and recycling plants.

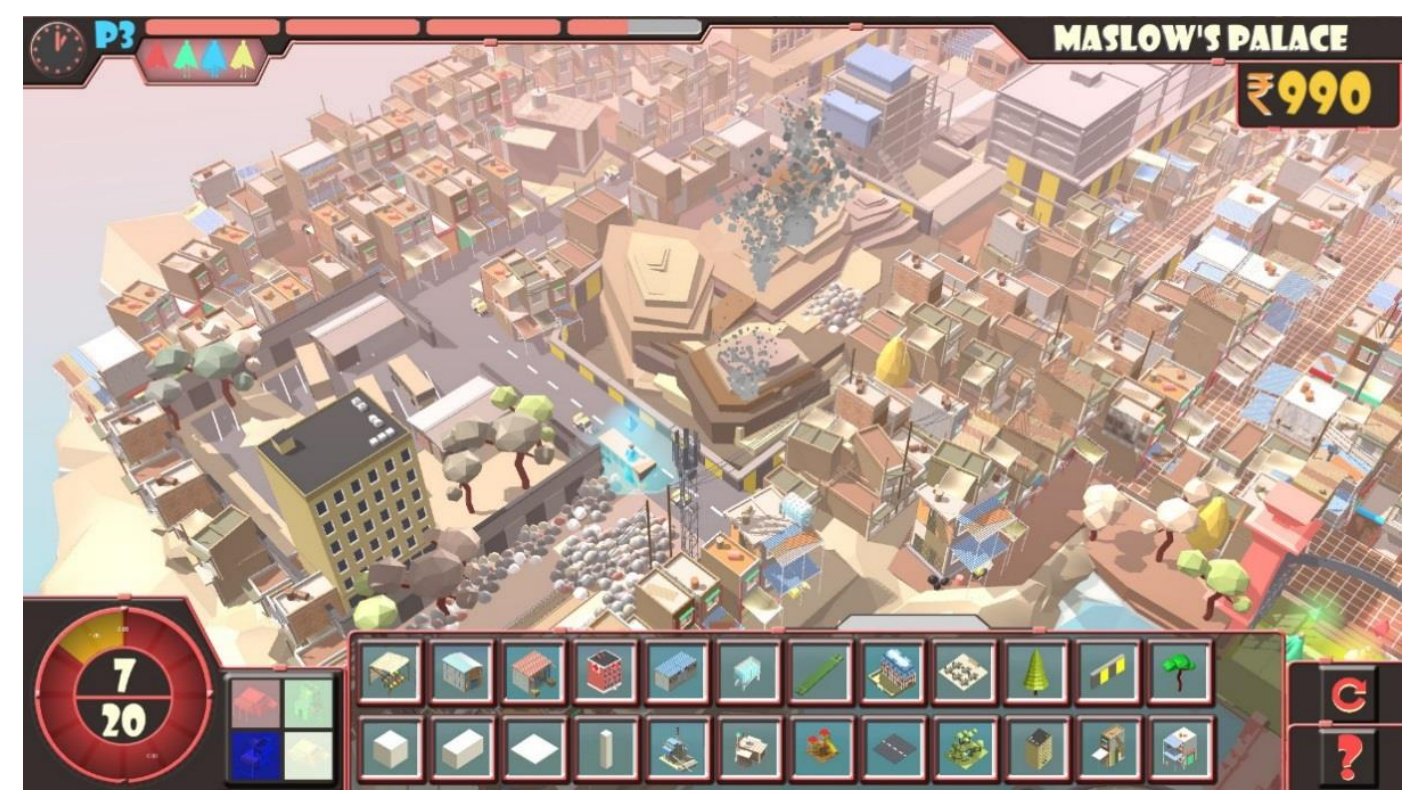

Figure 95. Level Five-Maslow's Palace. 


\subsubsection{Mechanics}

Navigation of the game interface is controlled by computer mouse only to reduce user interface complexity. Player movement is defined by a baked navigation mesh (nav-mesh) constructed through Unity3D's navigation system. Players can direct their characters around this nav-mesh by clicking on the desired area of the map. Inventory items and menus are accessed via mouse click. A turns-based multiplayer mechanic was chosen to allow for cycles of experiencing, reflecting and testing (Jarvis et al., 2003; Kebritchi \& Hirumi, 2008).

Through an inventory system, participants are provoked to address and discuss issues such as access to adequate housing stock, water and electricity infrastructure, sanitation facilities, adequate roads and drainage, availability of public and community spaces, health facilities and schools. Players are instructed via in-game prompts (Appendix 2) to construct a home for each player, as well as to design the area around it to incorporate necessary changes, wants and needs. Each level is completed when all players are satisfied with the chosen actions within a particular level by moving their character to a specific area of the map. This mechanic requires players to reach a state of unanimity, argue for their decision preferences and negotiate compromises. It therefore seeks to provoke discussion about differences in norms, values and understandings of social and urban design orientated issues to better understand each other's points of view regarding a range of problems (Iversen et al., 2012; Sanders \& Dandavate, 1999).

Employing agonistic and adversarial design theory of DiSalvo, the game purposefully provokes contestation of ideas between participants and acts as a "boundary object" between disparate participants to facilitate finding mutual ground (DiSalvo, 2012). The game functions as a boundary object, as it provides open-ended and ambiguous space to create low fidelity prototypes, and it then invites players to imbue them with meaning potentially unforeseen by designers through in-game role play (Barley, Leonardi, \& Bailey, 2012). In line with this view, I loosely defined the narrative of the game, as I hoped to keep the design space as an unstable construct to permit players to offer different interpretations (Doležel, 1998; Malmgren, 1985). A simple in-game economy is designed to allow for the exploration of tensions regarding the allocation of collective resources. Playful game elements such as explosion effects triggered when buildings are deleted are designed to create an element of "fun", while 
in-game events such as landslides, designed to mimic the landfill landslide threat within each community, are designed to create tension between players.

Each level follows a similar rule structure in order to orient the collaborative gameplay activities, which is graphically communicated to players. The following built-in game rules are designed to fulfil the necessary conditions for ideation and the negotiation of conflicting perspectives:

1. Participants play in sequence (turns-based). Each player starts their turn by selecting their avatar. Players may have multiple turns per level.

2. Players make modifications to the game map urban environment based on their wants/needs in their (real) community, and the number of houses and other modules required to be placed. This rule is designed to cause a degree of tension amongst the players, as they cannot just move directly to the end of the map to complete the level.

3. Once a player is happy with the changes made to the game environment, they place their character within the exit zone.

4. Once all players' characters are located in the exit zone the level is completed.

5. Players are able to ask questions regarding the game, during the process of play, to the game facilitator.

\subsubsection{Aesthetics/Graphics}

As described in section 4.3, the computer game Maslow's Palace adopted a low polygon style in order to reduce player confusion regarding the pragmatic viability of in-game design outcomes as well as to reduce development cycle time (Wattanasoontorn, 2013). In line with this style, the game is rendered with minimal use of 3D textures (Gai \& Wang, 2016). The scene lighting utilises a mixture of realtime and baked lighting. Baked lighting is used for much of the lighting to create local ambience, rather than fully featured lights, while real-time lighting is kept to a minimum to reduce rendering calculations at run-time (McLaughlin, Smith \& Brown, 2010, p. 133).

The game utilises a primary colour based user interface that is designed to be complementary to the low-polygon style in order to create cohesiveness (Gai \& Wang, 2016). The user interface is also designed to enhance "playfulness", which the literature review showed to be conducive to aiding ideation processes (Gordon \& 
Baldwin-Philippi, 2014a; Poplin, 2012). Player characters are designed to be gender neutral. A player selection menu is designed in order to give players agency over their in-game avatar.

Information and content is presented in Maslow's Palace in two ways - graphically and in text form (Figure 96 and Figure 97) (McLaughlin, Smith \& Brown, 2010, p. 133). Text information includes in-game instructions, which are given to players in English and Hindi to orient play activities as well as user interface information rollovers to detail names of entities and costs of in-game items (Bogost, 2007). Text-based instructions also utilised simple graphic design language widely used in public signage for non-text based communication. In cases of low levels of literacy, workshop facilitators can give these instructions verbally. Graphic or three-dimensional information includes spaces, buildings and graphic user interface elements such as inventory items. Images are used where possible on in-game buttons to describe their functionality.

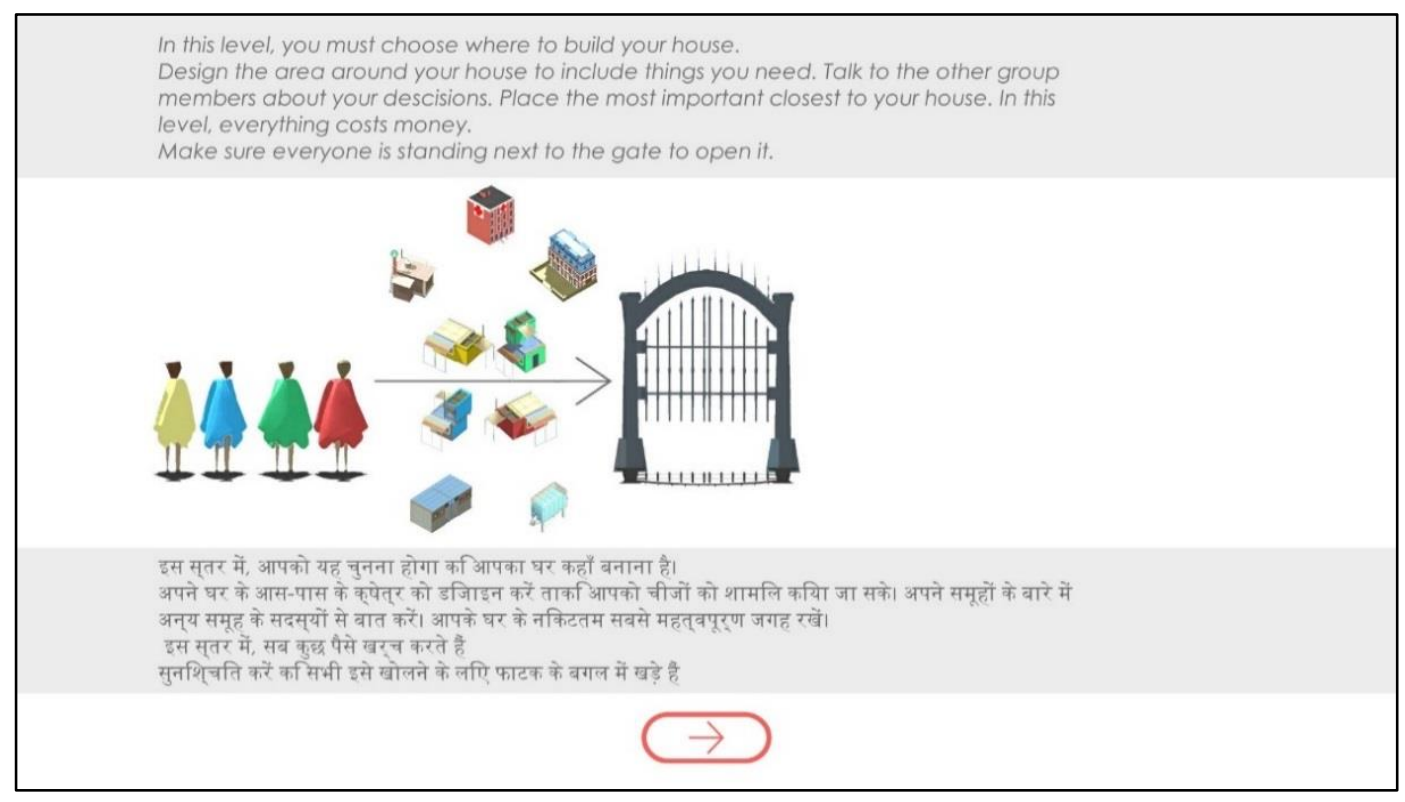

Figure 96. In-game instructions in English and Hindi, Maslow's Palace. 


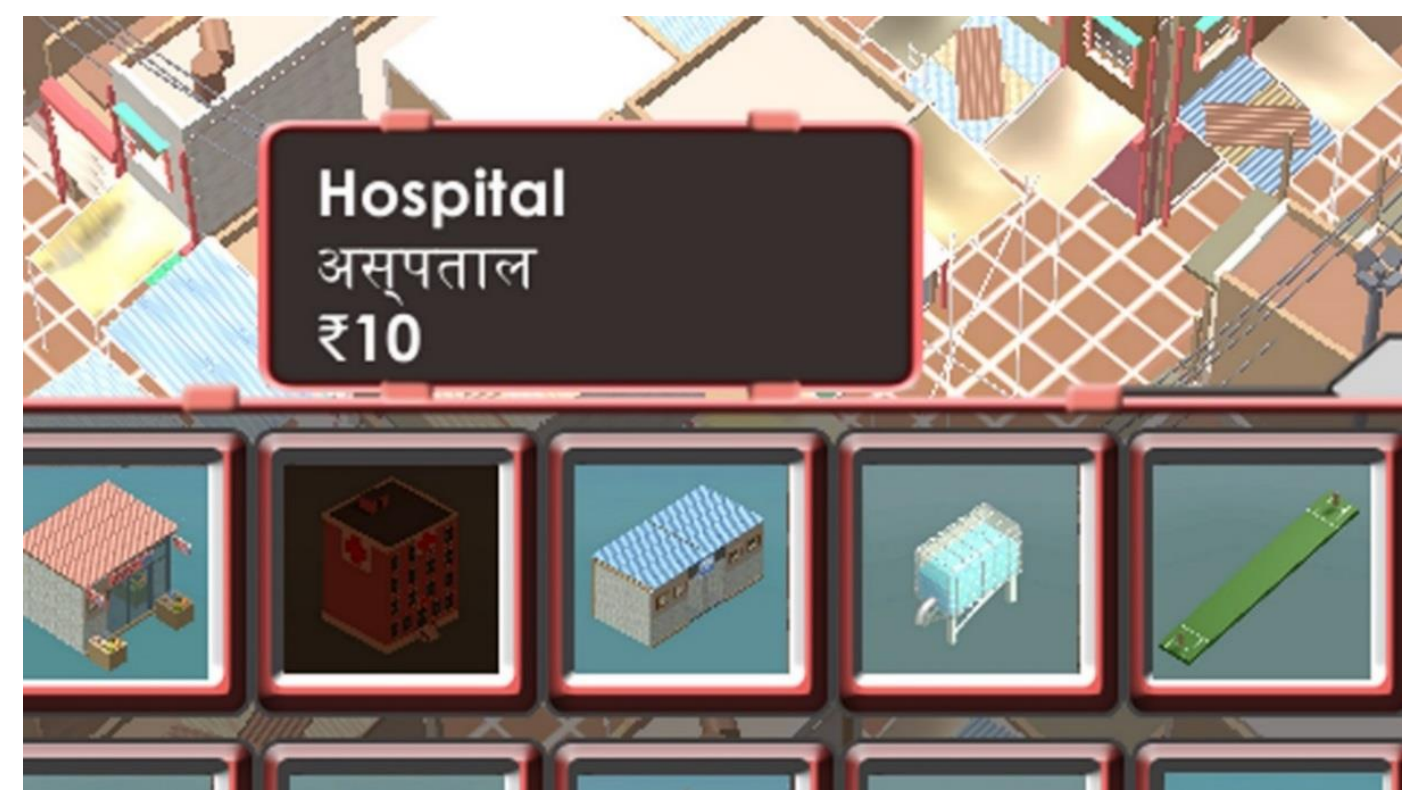

Figure 97. In-game instructions in English and Hindi, Maslow's Palace.

Fictional elements are used throughout the game, which operate as defamiliarisation elements or "playful" game entities in line with the game's framing outlined above. These are primarily located in peripheral areas of the game map in order to dislocate the play experience from reality, in order to create playful or irreverent spaces conducive to the reconceptualisation of values, yet not affect the serious content of the game or the relationships between game entities that are designed to scaffold discourse (Auger, 2013; Iversen et al., 2012).

\subsection{Summary}

This chapter has presented a range of conflicting perspectives across each of the research contexts in terms of the participants' perceptions of the communities and what they would like to upgrade in the future. The perspectives identified in the Ghazipur community identified some pressing contextual issues that were important to community members that had consensus, while a range of other issues were identified as being important to only one or a few members. The perspectives identified within the analysis of the Bhalswa data showed that the acute nature of the problems associated with their living situation was indicated through a small range of perspectives at primarily the physiological and safety levels of the needs hierarchy. Those identified with the Shanti Nagar community, which is subject to less acute urban 
issues, identified a large range of future upgrading options across the full range of the needs hierarchy.

This analysis and documentation of the research contexts informed the development of 3D game assets as generic entities or site-specific features. References to specific real-world buildings were used to create a perceptual bridge between the digital assets and the player's real-world experience in each case context. A strategy was adopted in which the morphological elements identified for each research context were woven together with issues identified through the interview process, and this configuration was then populated with the 3D digital assets.

The chapter then detailed the operationalisation of the virtual environments, utilising the SPS-UG framework detailed in Chapter Two, into an exemplar SPS-UG through the development of interactive game mechanics, in line with current serious game development practices detailed in Chapter Two, which orientate the collaborative gameplay activities. It detailed the SPS-UG's level progression and its consideration in terms of the SPS-UG framework presented in Chapter Three. This resulted in the computer game Maslow's Palace that is designed specifically for the contextual factors identified through the Phase One ethnographic documentation (section 4.2) and to aid both social and design outcomes with design strategies distilled and incorporated from Chapter One.

Next, Chapters Five, Six and Seven will present an analysis of the gameplay workshops that were held with the three case study communities that utilised the SPSUG approach and method outlined in this chapter and a discussion of the social and design outcomes within each case in line with the research question. 


\section{Case Study One-Ghazipur}

"We made sure that if a few of us placed houses in a specific area that there should be public toilets, parks, restaurants, hospital — all the things to live in a community."

- (Participant Three, Group Four, Ghazipur Workshops, 2017)

\subsection{Introduction}

The previous chapters detailed the theoretical underpinnings, the research contexts and the research methods used to operationalise the SPS-UG framework within the development and application of an SPS-UG computer game I designed called "Maslow's Palace". This chapter reports on the findings of the Ghazipur case study (CS1), which evaluated Maslow's Palace as a tool and method of participatory design engagement. The chapter details the primary design inquiries and conducts thematic analysis of the pre-test and post-test structured interviews and workshop recordings and observations. This chapter contributes toward:

Aim 4: To develop, implement and reflect on the use of a speculative, participatory, game-based approach to slum-upgrading aid the generation of useful urban upgrading oriented social outcomes and related architectural design slum-upgrading outcomes for disparate stakeholders in marginalised communities, more specifically, dwellers of landfill-oriented slums.

Chapters 5-7 all respond to this Aim 4 focussing on each case study community.

\subsubsection{Summary of Case Study One - Ghazipur}

This chapter summarises the experience and evaluation of the Phase Three participatory design workshops utilising the SPS-UG approach with the Ghazipur 
community in accordance with the methods of data collection and analysis detailed in Chapter Three (Figure 98). To respond to the research question, data was gathered through the coordination and recording of a series of four participatory workshops using Maslow's Palace, held with residents of the Ghazipur community in collaboration with the Chintan Environmental Research and Action Group between 8 and 14 November 2017.

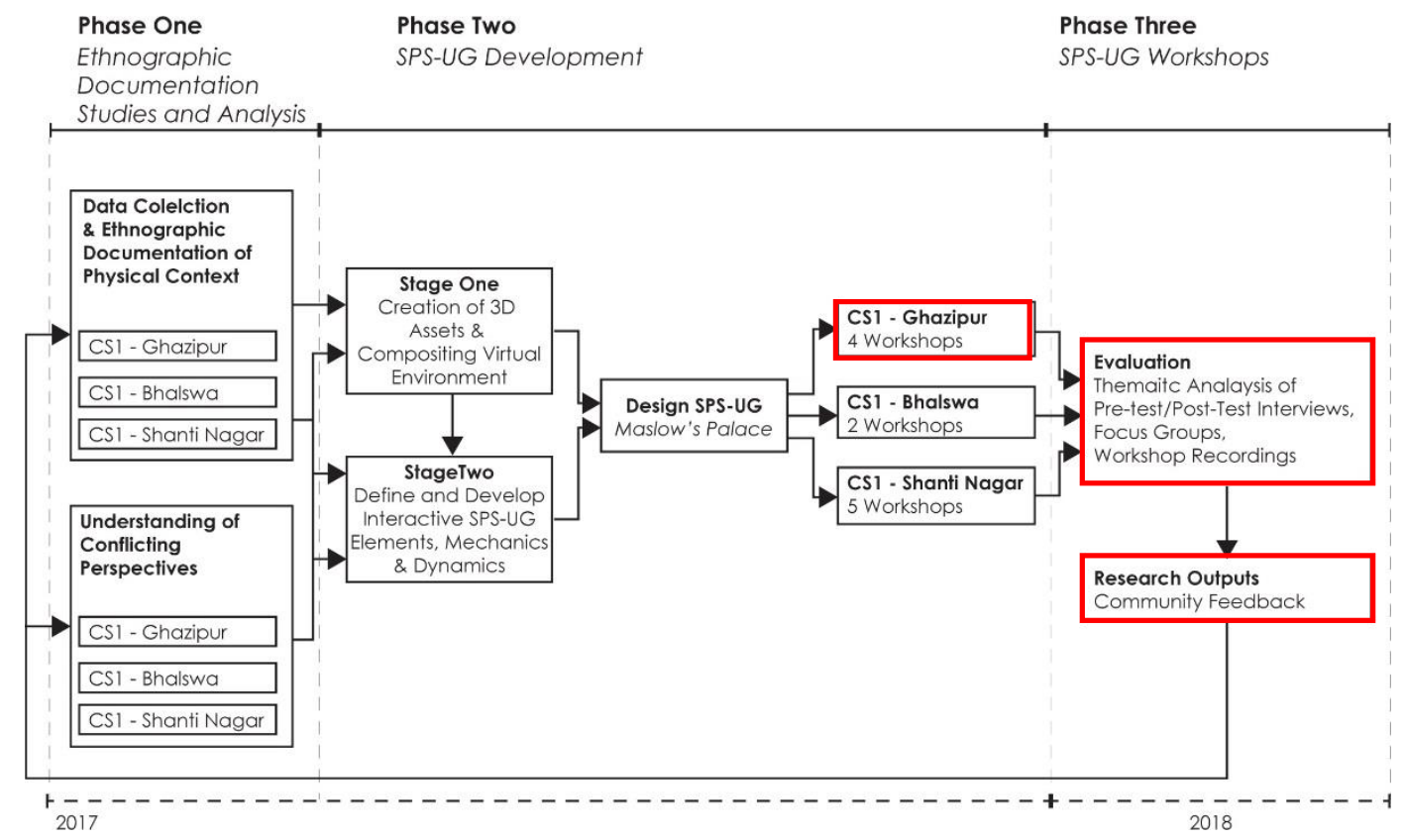

Figure 98. CS1 - Ghazipur located within the visual timeline of the research methodology.

The thematic analysis of the workshop data resulted three socially-orientated outcomes:

- revealing conflicting perspectives;

- aiding cooperation and understanding;

- dissemination of workshop outcomes and experiences.

The analysis also exposed four examples of design-oriented slum-upgrading consensus:

- the importance of housing being in close proximity to the landfill;

- the community problems associated with lack of security of tenure;

- the role of the waste-to-energy plant within the community; and

- the importance of location and use of public spaces and amenities. 
Finally, the chapter discusses the role of speculation in aiding the exploration of ideas and conflicting perspectives and the relationship between the speculative and the real and how this relationship can be affected by the actions of the workshop facilitator.

\subsection{Case Study: Ghazipur}

\subsubsection{Aim of the Workshops}

The four CS1 participatory design workshops were conducted with the Ghazipur community from 8-14 November 2017. Each aimed to explore, but was not limited to, a range of key slum-upgrading related issues identified by the community during Phase One that were embedded into the design of the game (SPS-UG) Maslow's Palace. Specifically, the workshops aimed to aid the Ghazipur participants in upgrading ideation and exploring conflicting upgrading perspectives, with the aid of the Chintan Environmental Research and Action Group, to create solidarity through a recognition of difference via conceiving a plurality of possible futures.

\subsubsection{Ghazipur Participants}

A total of four participatory design workshops were conducted with the Ghazipur community, involving sixteen participants (four per workshop). The Ghazipur community members were informed of the workshops in advance by the Chintan Environmental Research and Action Group via a series of community meetings. The participants voluntarily attended the workshops, and were not explicitly the same participants as recruited for Phase One-although eight participants who participated in the Phase One initial survey also participated in the Phase Three workshops. The participants who participated were aged between 19 and 40 years old with a mean age of 26.75 years. Due to a number of factors, including the prevalence of addiction for men and other related social issues within the community, all participants were female. The majority (10) of the participants were Muslim migrants to the community from Kolkata, with the remainder arriving from other areas of Delhi (5) or nearby Uttar Pradesh (1). Participants had all resided within the community for between 3 and 22 years, with a mean of 15.8 years.

Although participants involved with the workshops shared a common purpose (slum-upgrading), they all had different motivations and expectations regarding the 
project, which were initially discussed as part of a group discussion and welcome session that was held before the workshops. Some participants reported being interested in how they could improve their own home, while others were interested in how the whole community could be upgraded. All participants engaged in the formal or informal recycling sector in some capacity. Twelve participants identified their occupations as waste pickers, two engaged in waste sorting in the informal recycling sector and two were employed in the local waste-to-energy plant. All participants' homes were located in the informal housing cluster adjacent to the recently constructed Delhi metro station located on the Ghazipur District Park site. A table of participant demographics in relationship to their workshop group number is shown below.

Table 22. Demographic information about workshop participants - Ghazipur, Delhi.

\begin{tabular}{|c|c|c|c|c|c|c|c|c|}
\hline $\begin{array}{l}\text { Grp. } \\
\text { No. }\end{array}$ & $\begin{array}{l}\text { Part. } \\
\text { No. }\end{array}$ & Age & Sex & $\begin{array}{l}\text { Digital } \\
\text { Literacy }\end{array}$ & Religion & $\begin{array}{l}\text { Year } \\
\text { Arrived }\end{array}$ & Arrived from & Occupation \\
\hline 1 & 1 & 30 & $\bar{F}$ & Medium & Muslim & 2007 & Kolkata & $\begin{array}{l}\text { WTE plant } \\
\text { worker }\end{array}$ \\
\hline 1 & 2 & 26 & $\mathrm{~F}$ & High & Muslim & 1995 & $\begin{array}{l}\text { Nandiram (West } \\
\text { Bengal) }\end{array}$ & Waste picking \\
\hline 1 & 3 & 35 & $\mathrm{~F}$ & Low & Muslim & 2002 & $\begin{array}{l}\text { Loni (Uttar } \\
\text { Pradesh) }\end{array}$ & Waste picking \\
\hline 1 & 4 & 40 & $\mathrm{~F}$ & Low & Muslim & 2002 & $\begin{array}{l}\text { Seemapuri } \\
\text { (Delhi) }\end{array}$ & Waste picking \\
\hline 2 & 1 & 22 & $\mathrm{~F}$ & Low & Hindu & 1997 & $\begin{array}{l}\text { Khichdhipuri } \\
\text { (Delhi) }\end{array}$ & Waste picking \\
\hline 2 & 2 & 20 & $\mathrm{~F}$ & Low & Muslim & 1997 & $\begin{array}{l}\text { Seemapuri } \\
\text { (Delhi) }\end{array}$ & Waste picking \\
\hline 2 & 3 & 19 & $\mathrm{~F}$ & Low & Muslim & 2014 & Jahangirpuri & Housewife \\
\hline 2 & 4 & 22 & $\mathrm{~F}$ & Low & Muslim & 2007 & Kolkata & Waste picking \\
\hline 3 & 1 & 40 & $\mathrm{~F}$ & Low & Muslim & 1997 & Kolkata & Waste picking \\
\hline 3 & 2 & 22 & $\mathrm{~F}$ & Low & Muslim & 1997 & $\begin{array}{l}\text { Seemapuri } \\
\text { (Delhi) }\end{array}$ & $\begin{array}{l}\text { WTE plant } \\
\text { worker }\end{array}$ \\
\hline 3 & 3 & 22 & $\mathrm{~F}$ & Low & Muslim & 2007 & Kolkata & Housewife \\
\hline 3 & 4 & 22 & $\mathrm{~F}$ & Low & Muslim & 1997 & Kolkata & Waste picking \\
\hline 4 & $\overline{1}$ & 24 & $\bar{F}$ & Low & Muslim & 1995 & Kolkata & Housewife \\
\hline 4 & 2 & 25 & $\mathrm{~F}$ & Low & Muslim & 2008 & $\begin{array}{l}\text { Laxmi Nagar } \\
\text { (Delhi) }\end{array}$ & Waste picking \\
\hline 4 & 3 & 24 & $\mathrm{~F}$ & Low & Muslim & 1997 & Kolkata & Waste picking \\
\hline 4 & 4 & 22 & $\mathrm{~F}$ & Low & Muslim & 1997 & Kolkata & $\begin{array}{l}\text { WTE plant } \\
\text { worker }\end{array}$ \\
\hline
\end{tabular}

\subsubsection{Workshop preparation process}

The Ghazipur workshops were held within the Chintan Environmental Research and Action Group operated school within the Ghazipur community, adjacent to the 
landfill, the Delhi metro station and the slum area (Figure 99, Figure 100 and Figure 101).

The Ghazipur workshops were organised and facilitated by three male staff members and one female staff member from Chintan Environmental Research and Action Group. The facilitators were trained in the use of Maslow's Palace and its objectives before the workshops, and they were given a specific set of workshop and facilitation instructions to follow (Appendix 3). They were instructed to let the participants play the game by themselves and only provide assistance if a participant specifically asked for help. The sixteen participants were divided into four workshop groups (see Table 22. above). Within these groups the facilitators conducted the pretest structured interviews (Appendix 4). Upon completion each group played Maslow's Palace. Each gameplay session took between 45 and 90 minutes. Upon completion, the facilitators conducted the post-test structured interviews.

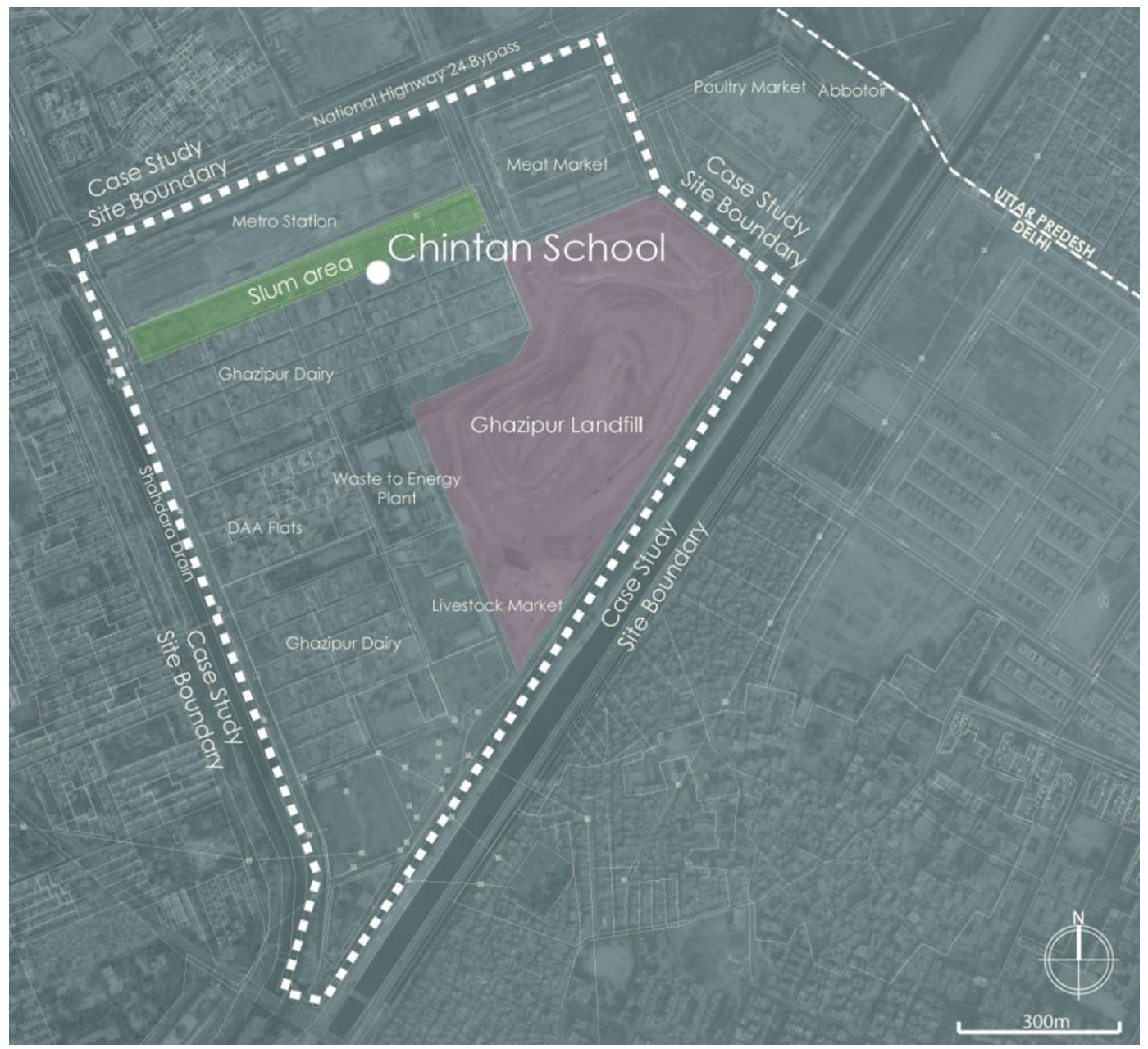

Figure 99. Chintan School location of the Ghazipur workshops. November 2017. 


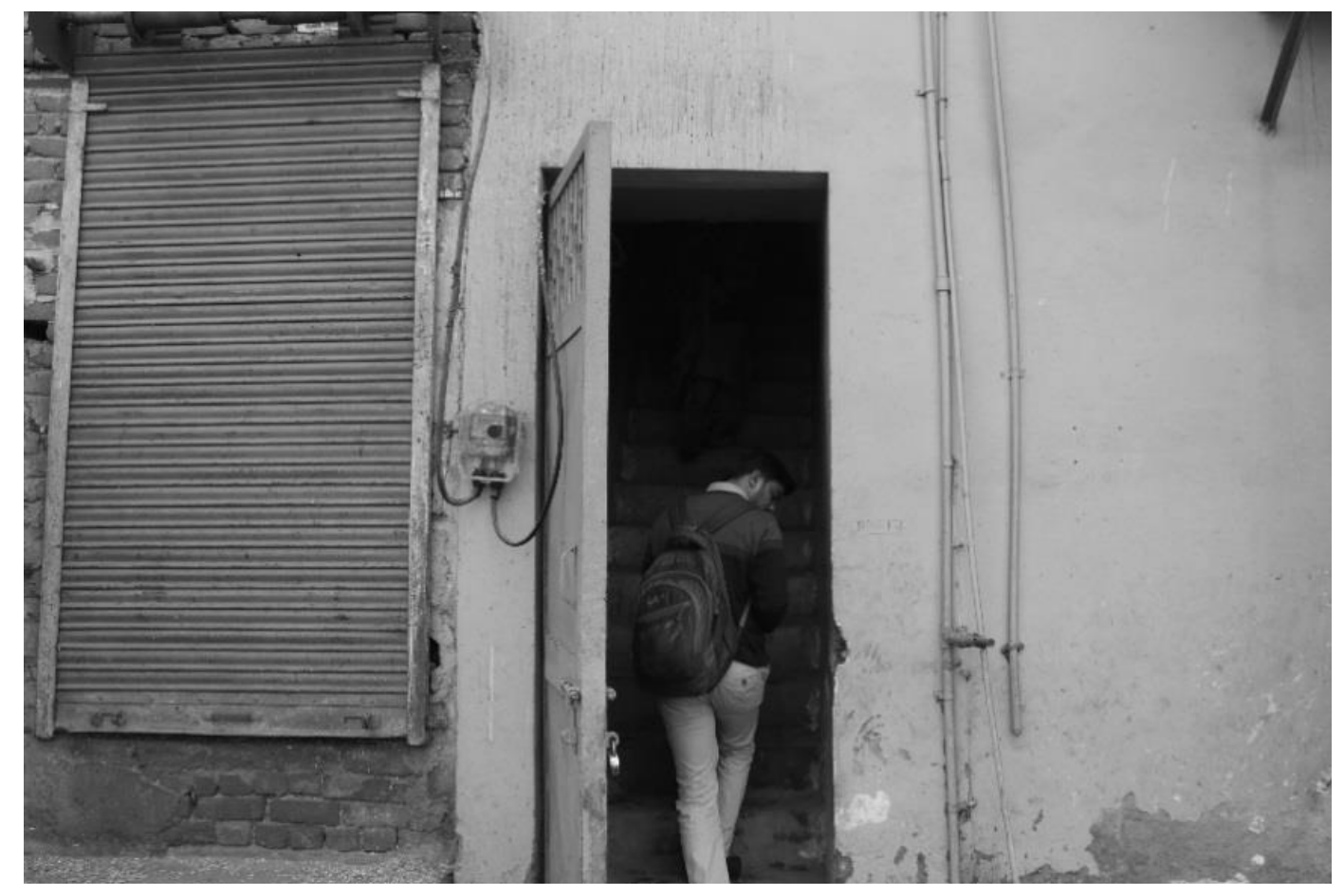

Figure 100. Entering the Chintan School, the location of the workshops, Ghaizpur, November 2017.

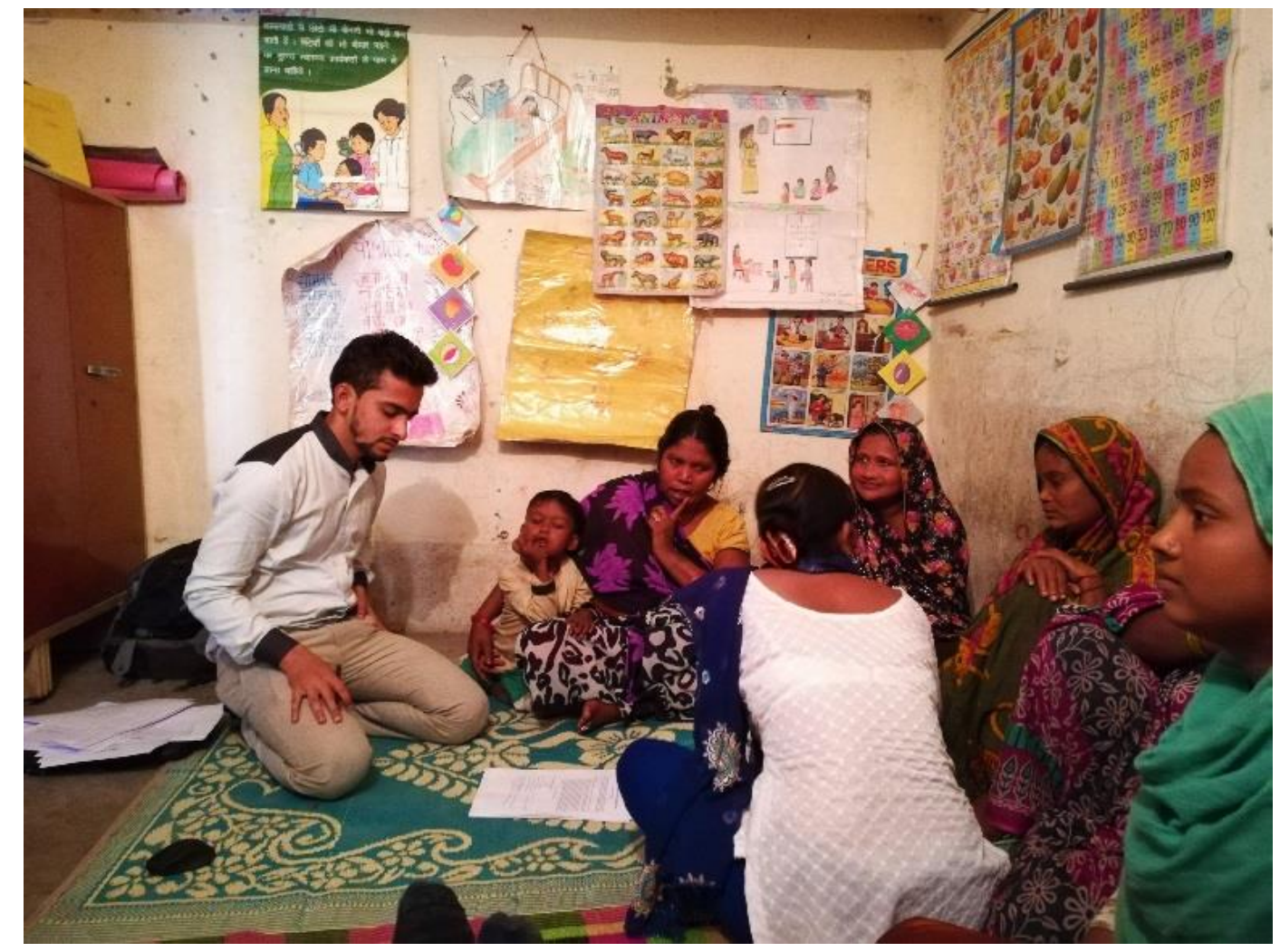

Figure 101. Participants of the Ghazipur Workshops, November 2017.

The participatory workshop space is diagrammed in Figure 102, below. Maslow's Palace was played by the participants on a laptop, which recorded screen capture 
footage of the gameplay, with participants sitting on the ground (Figure 103). A digital SLR camera recorded video images the workshop procedure, while the researcher recorded photographs and observations.

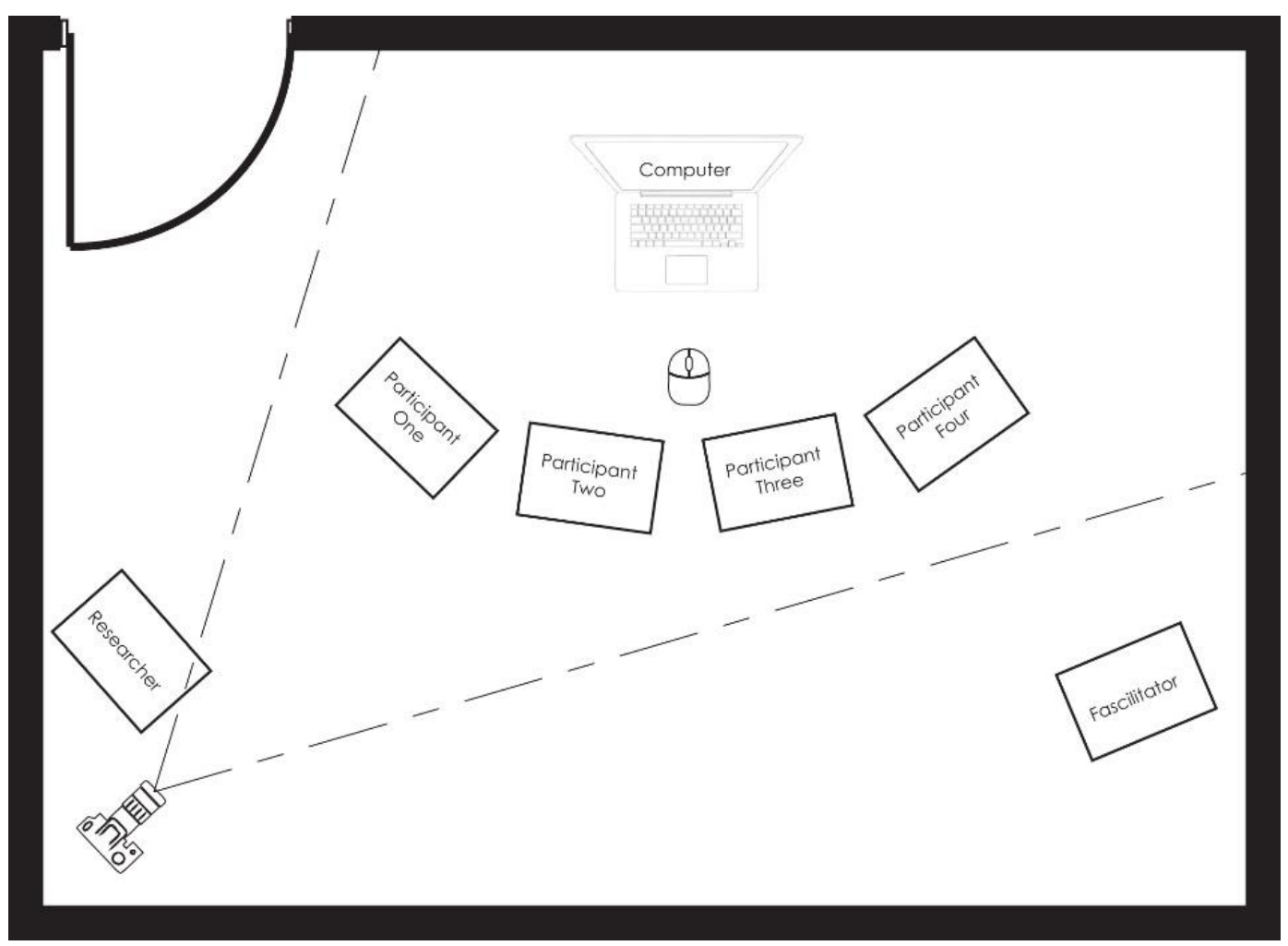

Figure 102. Floorplan of workshop space.

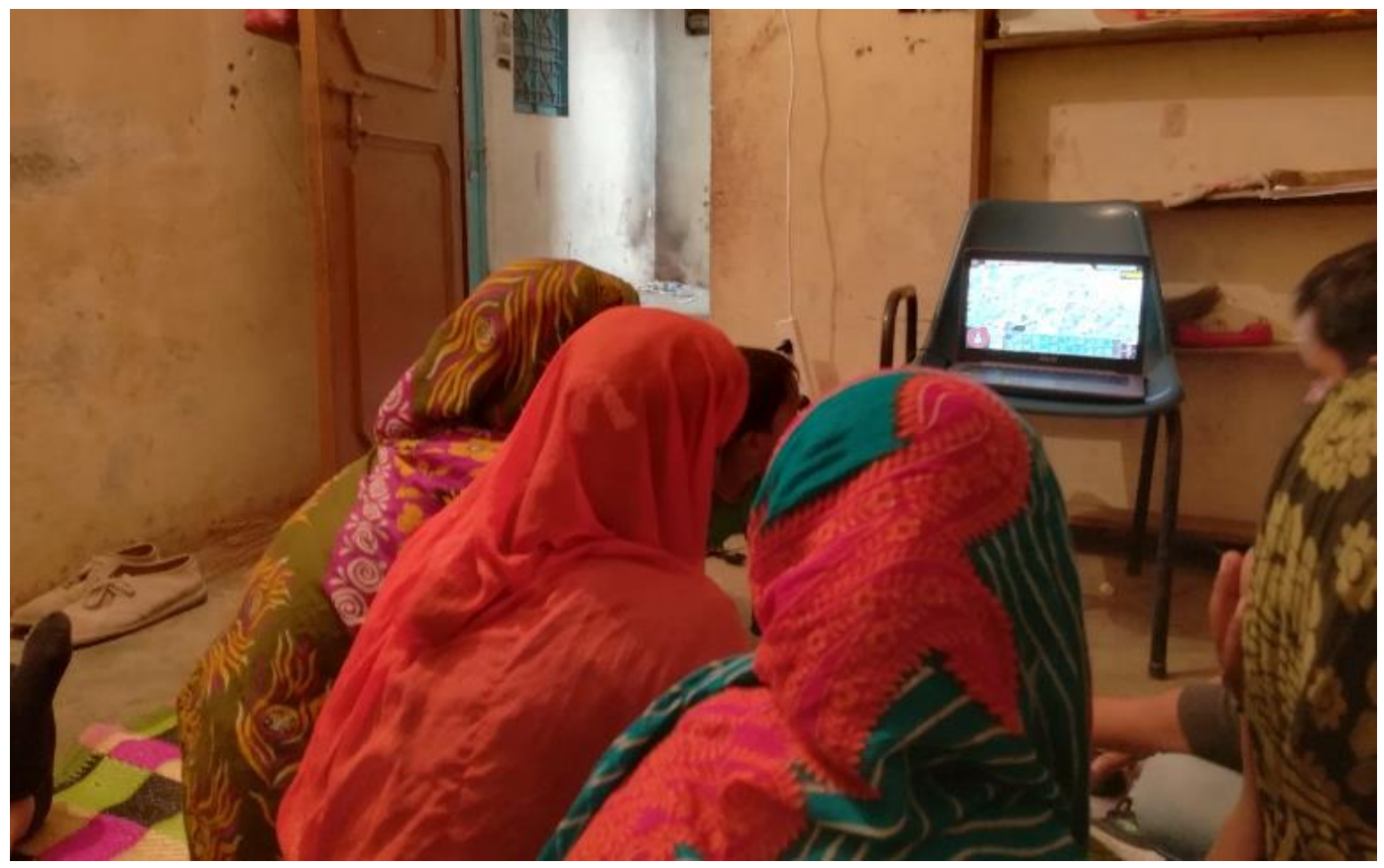

Figure 103. Ghazipur Workshop 2 participants playing Maslow's Palace, November 2017. 


\subsubsection{Findings}

A level by level summary of workshop outcomes is provided in Table 23 below. This is followed by findings of the thematic analysis of the workshop data. Firstly, qualitative assessment of social outcomes, in terms of slum-upgrading ideation resulting during gameplay is presented (section 5.2.4.1). This is followed by an assessment of slum-upgrading outcomes, in terms of generating consensus around particular design outcomes (slum-upgrading ideas) resulting during gameplay is presented (section 5.2.4.2).

Table 23. Maslow's Palace workshop outcomes - Ghazipur.

\begin{tabular}{|c|c|c|c|c|}
\hline & Group 1 & Group 2 & Group 3 & Group 4 \\
\hline Level 1 & $\begin{array}{l}\text { • Facilitator } \\
\text { Influence } \\
\text { Evidence: Facilitator } \\
\text { reinforced that the game } \\
\text { was for community } \\
\text { development purposes. } \\
\text { - Disparities in } \\
\text { digital literacy } \\
\text { resulted in some } \\
\text { participants } \\
\text { progressing through } \\
\text { the game levels at } \\
\text { different speeds, and } \\
\text { thus resulting in less } \\
\text { discussion and } \\
\text { collaboration. }\end{array}$ & $\begin{array}{l}\text { - Collective } \\
\text { Tinkering (J. E. } \\
\text { Innes \& Booher, } \\
\text { 1999, p. 9) } \\
\text { Evidence: } \\
\text { Participants built } \\
\text { with the abstract } \\
\text { blocks for longer } \\
\text { than the other groups, } \\
\text { taking turns and } \\
\text { "designing" with } \\
\text { them. } \\
\text { - Facilitator } \\
\text { reinforced that the } \\
\text { game was for } \\
\text { community } \\
\text { development } \\
\text { purposes. }\end{array}$ & $\begin{array}{l}\text { • Collective } \\
\text { Tinkering (J. E. } \\
\text { Innes \& Booher, } \\
\text { 1999, p. 9) } \\
\text { Evidence: } \\
\text { Participants built } \\
\text { with the abstract } \\
\text { blocks for longer } \\
\text { than the other groups, } \\
\text { taking turns and } \\
\text { "designing" with } \\
\text { them. } \\
\text { • Collective } \\
\text { Tinkering } \\
\text { Evidence: } \\
\text { Conducted "area } \\
\text { cleaning", which } \\
\text { they described as the } \\
\text { "removal of waste } \\
\text { [the pink blocks] } \\
\text { before they could } \\
\text { build homes". }\end{array}$ & $\begin{array}{l}\text { - Collective } \\
\text { Tinkering (J. E. } \\
\text { Innes \& Booher, } \\
\text { 1999, p. 9) } \\
\text { Evidence: } \\
\text { Participants built } \\
\text { with the abstract } \\
\text { blocks for longer } \\
\text { than the other } \\
\text { groups, taking turns } \\
\text { and "designing" } \\
\text { with them. }\end{array}$ \\
\hline Level 2 & $\begin{array}{l}\text { - No slum- } \\
\text { upgrading or social } \\
\text { issues were discussed. }\end{array}$ & $\begin{array}{l}\text { - No slum- } \\
\text { upgrading or social } \\
\text { issues were } \\
\text { discussed. }\end{array}$ & $\begin{array}{l}\text { • Perceptual } \\
\text { bridging (Auger, } \\
\text { 2012) } \\
\text { Evidence: Conducted } \\
\text { "area cleaning", which } \\
\text { they described as the } \\
\text { "removal of waste [the } \\
\text { pink blocks] before } \\
\text { they could build } \\
\text { homes". }\end{array}$ & $\begin{array}{l}\text { - No slum- } \\
\text { upgrading or social } \\
\text { issues were } \\
\text { discussed. }\end{array}$ \\
\hline Level 3 & $\begin{array}{l}\text { - No slum- } \\
\text { upgrading or social } \\
\text { issues were discussed. }\end{array}$ & $\begin{array}{l}\text { - No slum- } \\
\text { upgrading or social } \\
\text { issues were } \\
\text { discussed. }\end{array}$ & $\begin{array}{l}\text { - Speculative } \\
\text { urban } \\
\text { arrangements } \\
\text { function as a } \\
\text { "diagram" } \\
\text { Evidence: The } \\
\text { importance of centrally } \\
\text { locating public } \\
\text { amenities-particularly } \\
\text { toilets, hospitals and } \\
\text { schools, as well as } \\
\text { community meeting } \\
\text { buildings and public } \\
\text { spaces during game } \\
\text { play in Level Two. }\end{array}$ & $\begin{array}{l}\text { - Speculative } \\
\text { urban } \\
\text { arrangements } \\
\text { function as a } \\
\text { "diagram" } \\
\text { Evidence: The } \\
\text { importance of } \\
\text { centrally locating } \\
\text { public amenities- } \\
\text { particularly toilets, } \\
\text { hospitals and schools, } \\
\text { as well as community } \\
\text { meeting buildings and } \\
\text { public spaces during } \\
\text { game play in Level } \\
\text { Two. }\end{array}$ \\
\hline
\end{tabular}




\begin{tabular}{|c|c|c|c|c|}
\hline Level 4 & $\begin{array}{l}\text { - No slum- } \\
\text { upgrading or social } \\
\text { issues were discussed. }\end{array}$ & $\begin{array}{l}\text { - No slum- } \\
\text { upgrading or social } \\
\text { issues were } \\
\text { discussed. }\end{array}$ & $\begin{array}{l}\text { - No slum- } \\
\text { upgrading or social } \\
\text { issues were } \\
\text { discussed. }\end{array}$ & $\begin{array}{l}\text { - No slum- } \\
\text { upgrading or social } \\
\text { issues were } \\
\text { discussed. }\end{array}$ \\
\hline \multirow[t]{2}{*}{ Level 5} & $\begin{array}{l}\text { - Facilitate } \\
\text { collectively creating } \\
\text { ideas for the future } \\
\text { and communicating a } \\
\text { shared understanding } \\
\text { of design problems } \\
\text { (Agogué, Levillain, \& } \\
\text { Hooge, 2015, p. } 417 \text { ). } \\
\text { - Evidence: The } \\
\text { importance of their } \\
\text { homes being in close } \\
\text { proximity to their place } \\
\text { of work for income } \\
\text { security, reducing costs } \\
\text { and supervising } \\
\text { children. }\end{array}$ & $\begin{array}{l}\text { - Facilitate } \\
\text { collectively creating } \\
\text { ideas for the future } \\
\text { and communicating a } \\
\text { shared understanding } \\
\text { of design problems } \\
\text { (Agogué, Levillain, \& } \\
\text { Hooge, 2015, p. 417). } \\
\text { Evidence: The } \\
\text { importance of their } \\
\text { homes being in close } \\
\text { proximity to their place } \\
\text { of work for income } \\
\text { security, reducing costs } \\
\text { and supervising } \\
\text { children. }\end{array}$ & $\begin{array}{l}\text { - Facilitate } \\
\text { collectively creating } \\
\text { ideas for the future } \\
\text { and communicating a } \\
\text { shared understanding } \\
\text { of design problems } \\
\text { (Agogué, Levillain, \& } \\
\text { Hooge, 2015, p. 417). } \\
\text { Evidence:" The } \\
\text { importance of their } \\
\text { homes being in close } \\
\text { proximity to their place } \\
\text { of work for income } \\
\text { security, reducing costs } \\
\text { and supervising } \\
\text { children. }\end{array}$ & $\begin{array}{l}\text { - Participants } \\
\text { forming a "hybrid- } \\
\text { reality" debate } \\
\text { Evidence: The } \\
\text { importance of their } \\
\text { homes being in close } \\
\text { proximity to their } \\
\text { place of work for } \\
\text { income security } \\
\text { which was conducive } \\
\text { to conflict resolution } \\
\text { and consensus } \\
\text { building (Boroushaki } \\
\& \text { Malczewski, 2010). }\end{array}$ \\
\hline & $\begin{array}{l}\text { - No slum- } \\
\text { upgrading or social } \\
\text { issues were discussed. }\end{array}$ & $\begin{array}{l}\text { - Revealing } \\
\text { conflicting } \\
\text { perspectives (Bowen, } \\
\text { 2010; Iversen et al., } \\
\text { 2012, p. 87; Sanders, } \\
\text { 2001). } \\
\text { Evidence: Discussed } \\
\text { issues of security of } \\
\text { tenure and the } \\
\text { probability of being } \\
\text { evicted from the site } \\
\text { in relationship to the } \\
\text { development of the } \\
\text { new Metro Station. }\end{array}$ & $\begin{array}{l}\text { - Revealing } \\
\text { conflicting } \\
\text { perspectives (Bowen, } \\
\text { 2010; Iversen et al., } \\
\text { 2012, p. 87; Sanders, } \\
\text { 2001). } \\
\text { Evidence: the } \\
\text { pros/cons of the waste- } \\
\text { to-energy plant for the } \\
\text { wider community/ } \\
\text { generation of livelihood } \\
\text { using the game as a } \\
\text { "prop" explore each } \\
\text { other's perspectives } \\
\text { - Discussed issues } \\
\text { of security of tenure } \\
\text { and the probability of } \\
\text { being evicted from } \\
\text { the site in } \\
\text { relationship to the } \\
\text { development of the } \\
\text { new Metro Station. }\end{array}$ & $\begin{array}{l}\text { • Discussing the } \\
\text { need for community } \\
\text { spaces } \\
\text { - Revealing } \\
\text { conflicting } \\
\text { perspectives (Bowen, } \\
\text { 2010; Iversen et al., } \\
\text { 2012, p. 87; Sanders, } \\
\text { 2001). } \\
\text { Evidence: Discussed } \\
\text { issues of security of } \\
\text { tenure and the } \\
\text { probability of being } \\
\text { evicted from the site } \\
\text { in relationship to the } \\
\text { development of the } \\
\text { new Metro Station/ } \\
\text { possibility of moving } \\
\text { back to rural villages. } \\
\text { • Demolished the } \\
\text { metro station. } \\
\text { • Suggested } \\
\text { action in the form } \\
\text { of lobbying local } \\
\text { politicians for help } \\
\text { in gaining } \\
\text { alternative modes } \\
\text { of employment and } \\
\text { childcare. }\end{array}$ \\
\hline $\begin{array}{l}\text { Pre- } \\
\text { test/Post- } \\
\text { test } \\
\text { Findings }\end{array}$ & $\begin{array}{l}\text { - Developing and } \\
\text { Grounding } \\
\text { Knowledge, Values } \\
\text { and Goals (Brandt, } \\
\text { 2006; Brandt \& } \\
\text { Messeter, 2004; Brandt } \\
\text { et al., 2008; Dindler \& } \\
\text { Iversen, 2007) } \\
\quad \text { Evidence: Solidarity } \\
\text { around access to } \\
\text { hospitals }\end{array}$ & $\begin{array}{l}\text { - Developing and } \\
\text { Grounding } \\
\text { Knowledge, Values } \\
\text { and Goals (Brandt, } \\
\text { 2006; Brandt \& } \\
\text { Messeter, 2004; Brandt } \\
\text { et al., 2008; Dindler \& } \\
\text { Iversen, 2007) } \\
\text { Evidence: Solidarity } \\
\text { around access to } \\
\text { hospitals }\end{array}$ & $\begin{array}{l}\text { • Developing and } \\
\text { Grounding } \\
\text { Knowledge, Values } \\
\text { and Goals (Brandt, } \\
\text { 2006; Brandt \& } \\
\text { Messeter, 2004; Brandt } \\
\text { et al., 2008; Dindler \& } \\
\text { Iversen, 2007) } \\
\text { Evidence: Solidarity } \\
\text { around housing } \\
\text { proximity to landfill } \\
\text { - Solidarity around } \\
\text { reducing pollution }\end{array}$ & $\begin{array}{l}\text { - Developing and } \\
\text { Grounding } \\
\text { Knowledge, Values } \\
\text { and Goals (Brandt, } \\
\text { 2006; Brandt \& } \\
\text { Messeter, 2004; } \\
\text { Brandt et al., 2008; } \\
\text { Dindler \& Iversen, } \\
\text { 2007) } \\
\quad \text { Evidence: } \\
\text { Solidarity around } \\
\text { access schools }\end{array}$ \\
\hline $\begin{array}{l}\text { Focus } \\
\text { Group } \\
\text { Findings }\end{array}$ & $\begin{array}{l}\text { No discursive } \\
\text { findings of note. }\end{array}$ & $\begin{array}{l}\text { No discursive } \\
\text { findings of note. }\end{array}$ & $\begin{array}{l}\text { - Grounding } \\
\text { Knowledge, Values } \\
\text { and Goals (Brandt, } \\
\text { 2006; Brandt \& } \\
\text { Messeter, 2004; Brandt } \\
\text { et al., 2008; Dindler \& } \\
\text { Iversen, 2007) } \\
\text { • Evidence: } \\
\text { Gaining further } \\
\text { understanding of } \\
\text { each other's } \\
\text { perspectives and that }\end{array}$ & $\begin{array}{l}\text { - Gameplay was } \\
\text { fun for imagining } \\
\text { community } \\
\text { development (Poplin, } \\
\text { 2012). }\end{array}$ \\
\hline
\end{tabular}




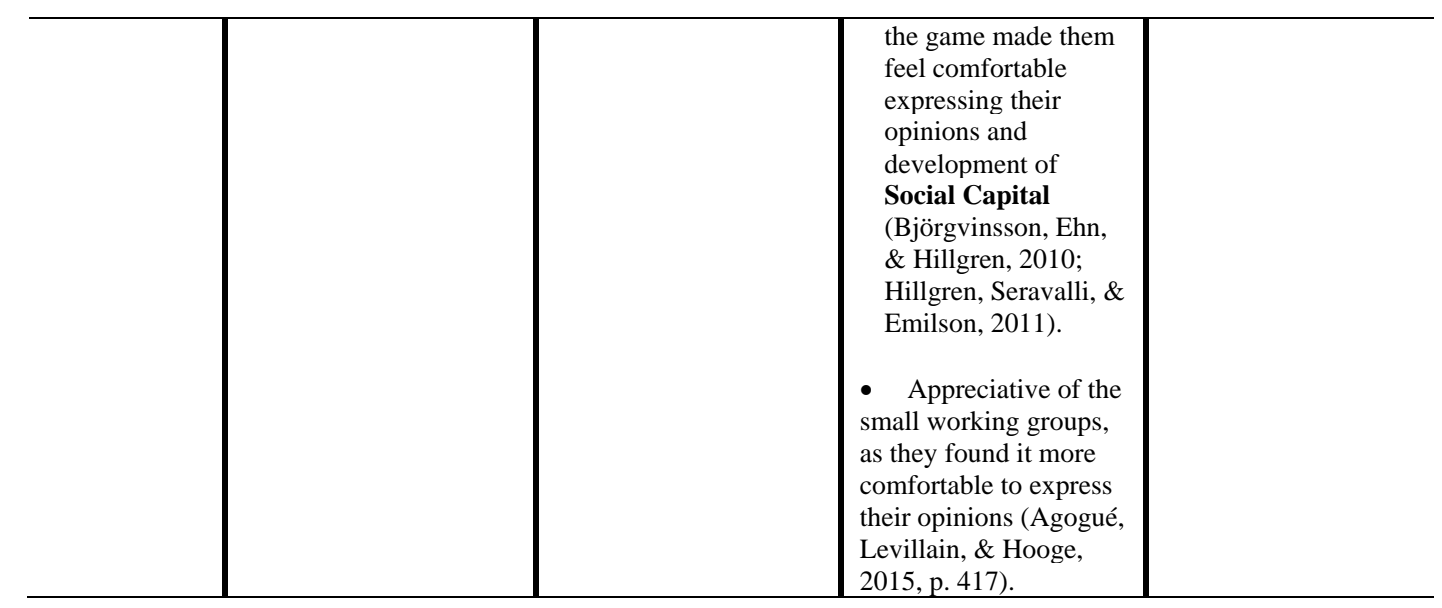

\subsubsection{Social Outcomes}

\subsection{Revealing Conflicting Perspectives}

In most instances where groups had detailed debate stemming from in-game action, agreement was reached around those issues. This was observed to happen more readily when participants were discussing smaller, more tangible issues such as the placement of public toilets and hospitals or the need for houses to be close to the landfill. The transcript excerpt detailing the interactions of Group Two participants playing Level Four of Maslow's Palace evidences this process below:

Participant Two: "I think we should have houses there [by the landfill]. Better ones than we have now."

Participant One: "Yes, but we need to have no floods. That's how people get sick. So maybe not so close."

Participant Three: "But that is far away from the toilets at Ghazipur. We [the houses] should be closer."

Participant One: "Yes there, I think that is good. This will be better for our Ghazipur".

Participant Three: "Yes, and far from the sorting area."

Participant Two: "Yes, but not far from the landfill."

As the variables that could be introduced surrounding these issues were limited, these spatial discussions were easily defined, and thus the pros and cons are easily weighed by participants, resulting in swift resolution of conflict and negotiation; however, in some cases, even small in-game design decisions provoked urban development-focussed conflict and debate that was not easily negotiated into 
consensus - such as when discussing the role of community spaces in Group Four or the merits of the waste-to-energy plant for the wider community in Group Three. Additionally, in many instances, participants' "biggest urban issues" became orientated towards future action. Before the gaming process, these groups were likely to identify "lack of employment" as the main community issue; however, after the workshop they were more likely to identify specific solutions as a main issue, e.g. "the need to live close to the landfill" or "access to schooling so youth can gain better employment". The proposal for "potential solutions" may indicate an increase in agency over their situation.

The workshop unearthed some conflicts and differences in opinion within the workshop participants. The primary urban development related conflict of Group Three centred upon the role of the waste-to-energy plant within the community and the tensions it created in different ways for different community members relating to livelihood generation and social and family pressures. This was exhibited within level five. While this stalemate was not resolved by the participants, the exploration using the urban environment of the game as a prop for discussion allowed the participants to explore each other's perspectives, and incorporate them into their own interpretations of the situation to find common ground.

\subsection{Evaluation of participant cooperation and understanding}

In focus group sessions held after the workshop, participants of Group Three reported gaining further understanding of each other's perspectives, and that the game made them feel comfortable expressing their opinions, as they knew other participants would understand their points if they could make them visually.

"I liked it [Maslow's Palace]. Could show them [the other participants] where the houses go and what it would be like." (Participant Three, Group Three)

"It was fun to plan how the community could be." (Participant Two, Group Four) 
Of particular note is the increase in detail in which the participants expressed their "main urban issues", when discussing them after the gameplay process. Post-test, participants were listening to others and incorporating information expressed by others into their own interpretations of situations, as well as making personal discoveries through ideation processes during gameplay. When conflict arose-generally around a more complex issue such as livelihood generation and security-peripheral issues or other facets of the issue were voiced and explored, allowing participants to gain a better understanding of each other's perspectives through discussion.

Participants exhibited collective learning (Jabbar \& Felicia, 2015; Boyle, Connolly, Hainey, \& Boyle, 2012; Whitton, 2011) about each other's positions, which can lead to strengthening of relationships and a building of trust and social capital (Dalisay, Kushin, Yamamoto, Liu, \& Skalski, 2015; Molyneux et al., 2015). All groups found common ground around a number of slum-upgrading issues that they through might be able to work in the future (detailed in Section 5.2.4.2). By seeing the differences and commonalities in a tangible way, visualised and illustrated through the workshop game, participants could take in the information in a different way (visually). Participants of Group Three also noted they were especially appreciative of the small working groups, as they found it more comfortable to express their opinions. The participants also reported on the workshop experience as valuable and enjoyable.

\subsection{Dissemination of workshop outcomes and experiences}

Learning and knowledge produced from the workshops were shared by others beyond the immediate group; Chintan agents reported that participants discussed issues raised during the workshop with them after the workshop. While no follow up actions at the conclusion of the workshops were planned to be conducted by the principal investigator, at the conclusion of the workshop, a copy of Maslow's Palace was given to Chintan Environmental Research and Action Group. Chintan staff expressed their interest in conducting future workshops between themselves and the community members using Maslow's Palace, in order to distil more concrete plans for future action. Similar to the findings of Gordon and Baldwin-Philippi the staff members reported that it was useful to have an entertaining task to do (the game) whilst having development-focussed conversations, because it put everyone at ease (Gordon $\&$ Baldwin-Philippi, 2014a). The gaming process also allowed participants to explore 
each other's perspectives and highlight points of tension regarding urban development issues, which may help them respond to future scenarios - particularly the threat of forced eviction due to the possible expansion of the metro station. Further workshops using Maslow's Palace conducted between the community and other NGOs and politicians in the future, facilitated by Chintan, may help.

219

\subsubsection{Slum-Upgrading Outcomes}

The workshop process produced a number of slum-upgrading ideas, as well as agreements and disagreements surrounding urban issues faced by the Ghazipur communities. These included participants exploring importance of housing being in close proximity to the landfill, identifying the community problems associated with lack of security or tenure, debating the role of the waste-to-energy plant within the community and illustrating the importance of location and use of public spaces and amenities.

These are reflected in the pre-test / post-test analysis of the structured interview data shown in Figure 104, below. The analysis indicates some increate in solidarity surrounding access to hospitals, the need for houses to be close to the landfill for income security, the reduction of pollution and access to schools. Similar to the pretest responses, all groups expressed a large range of perspectives surrounding the desired changes for their environment. The responses were also deductively coded often as physiological, safety and security and belonging, with few esteem and selfactualisation responses. 


\section{Assessment of Conflicting Perspectives - Ghazipur}

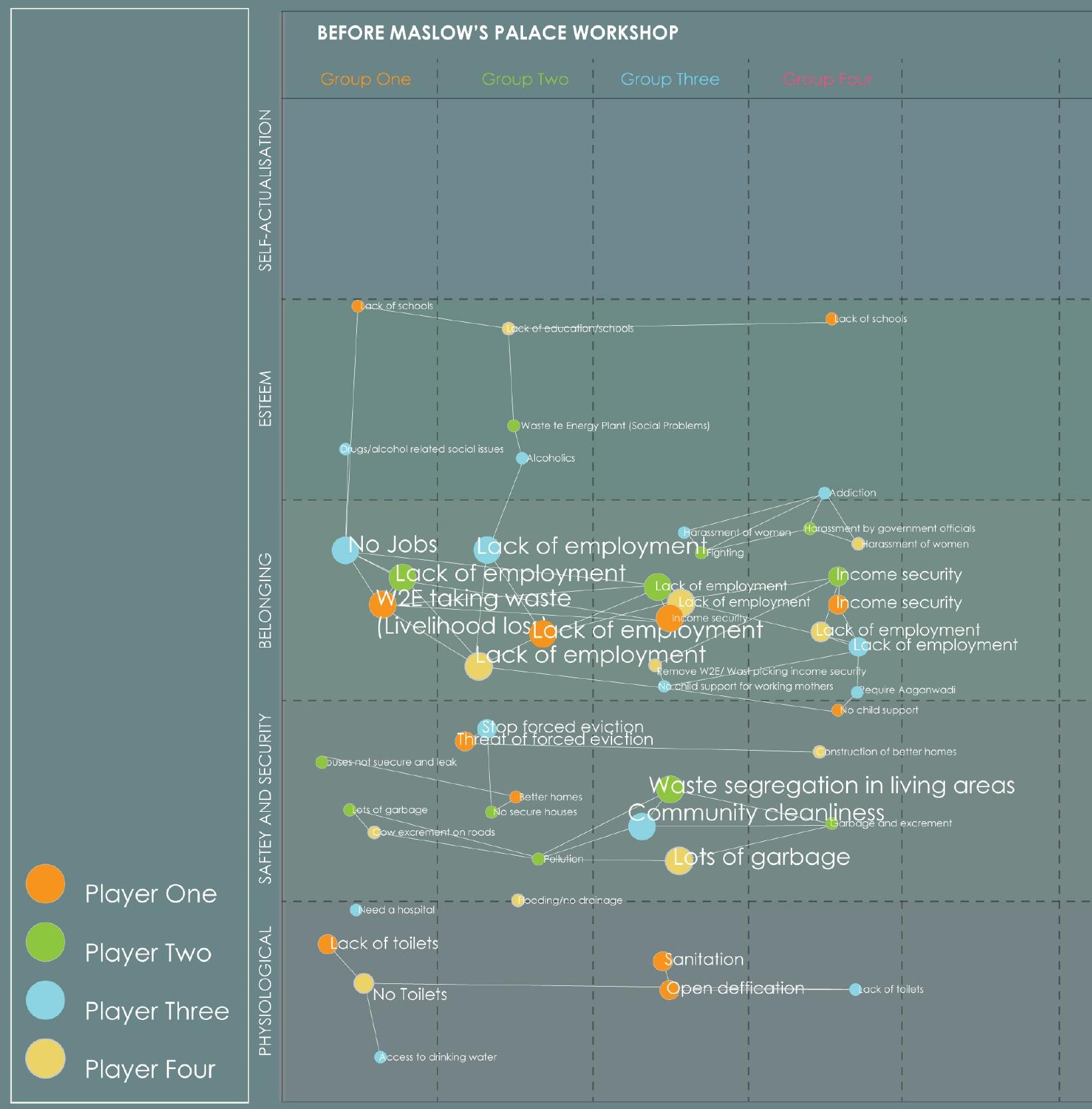

Figure 104. Pre-test / Post-test analysis of Ghazipur workshop groups. The diagram indicates some consensus building surrounding proximity to the landfill as a main slum-upgrading issue (right) as opposed to a variety of issues being identified before the SPS-UG process (left). 


\subsection{The importance of housing being in close proximity to the landfill}

All workshop groups raised the importance of their homes being in close proximity to their place of work-being either in the informal recycling sector or next to the waste-to-energy plant. The most noticeable observation common to all of the Ghazipur workshop groups was that in gameplay, they all located their homes, and other interventions, as close as possible to the landfill (Figure 105). In each group, this was discussed as a direct response to issues of income security, while acknowledging the negative health implications that come with living next to the landfill. All groups noted that the community's access to the solid waste stream is reliant upon their immediate and continued presence within the Ghazipur site.

"If we are evicted, we have no way to earn money... We need to make sure we live close to the landfill and have access to waste... But we need our children to go to school so they do not have to do this dirty work for their children." (Participant Four, Group Three)

It was also discussed amongst groups two and three that positioning of homes near the landfill cuts down commuting time and costs, as well as the ability to be close to their children, who are often left at home unsupervised - especially for those mothers who work in the waste-to-energy plant, and other community members whom they rely upon for support.

"Living close to landfill ensures the ability to take care of income and children. That's why I built the buildings there. We need to make this place better." (Participant Two, Group Three)

These discussions indicated that the participants were responding directly to and considering the real-world implications of their in-game decisions. This was reflected in the post-test-interview responses, where after playing the game, participants were more likely to identify proximity to the landfill as a main community issue-indicating some creation of solidarity through a recognition of difference amongst participants. 


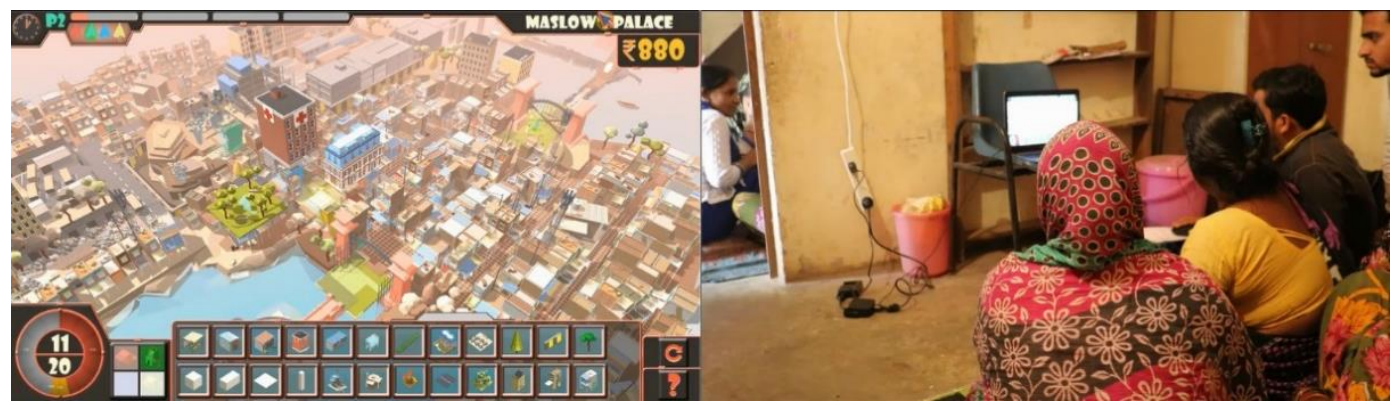

Figure 105. Workshop Group Three, Ghazipur.

\subsection{The community problems associated with lack of security or tenure}

Participants discussed issues of security of tenure and the probability of being evicted from the site in relationship to the development of the Delhi metro station. This was collectively demolished by the participants of Group Four-with each participant destroying a small part of it and therefore indicating a degree of unanimity (Figure 106), while it was left there and only discussed by the other three groups. None of the groups discussed any advantages of the new metro station for their community, nor any disadvantages of removing it.

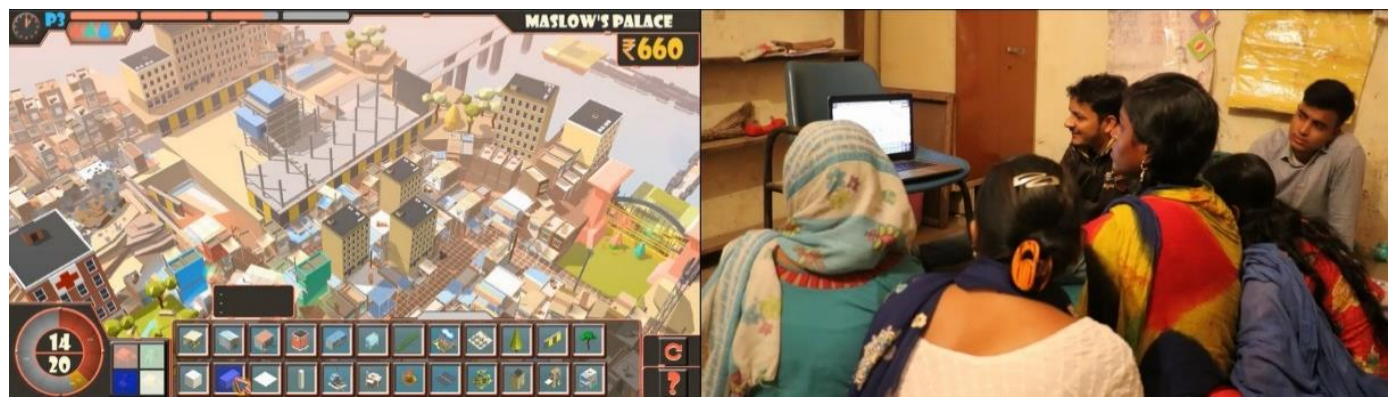

Figure 106. Group Four, level five, Maslow's Palace. Ghazipur, November 2017. Participants removed the existing metro station, responding to the threat of forced eviction within their community.

In response to this issue, participants of Group Four discussed the possibility of moving back to rural villages if they were forcefully evicted; however, Participant Three noted that this was problematic as many of the rural villages in Uttar Pradesh and West Bengal were in drought and there was no food or work for them if they returned-and thus, such a move would place undue stress on the rural communities. 
"We could go back to the village. Some people have already gone after the construction of the metro station." (Participant Three, Group Four)

"They (Uttar Pradesh and West Bengal) are in drought. There is no rain and there is no food." (Participant Two, Group Four)

This process indicated that talking about an urban problem within the game can help participants consider alternatives to issues they face that are not necessarily spatial in nature.

\subsection{The role of the waste-to-energy plant within the community}

Groups debated the role of the waste-to-energy plant within the community, as an urban entity that provides a means of livelihood, but also one that causes social strain for some community members - as the plant only employs women due to drug and alcohol issues within the community; however, participants acknowledged that the plant endangers livelihood-generating opportunities for others due to decreased access to solid waste streams for informal recycling. The participants of Group Four suggested action in the form of lobbying local politicians for help in gaining alternative modes of employment. It was also agreed in Group Four that access to child care would reduce strain on working mothers, and it was suggested that Chintan could help with this process. Here participants exhibited collective planning for future actions outside of the workshop. This is a key indication of strong consensus building in Group Four and was provoked by the fictional representation of the community within the game. Here the spatial representation of the waste-to-energy plant within the game served as a marker to provoke discussion surrounding a non-spatial issue, child care. Instead of participants being required to "design" the space around it, they were permitted to merely contemplate its existence, which allowed them to discuss tangential issues to the workshop's main tasks. 


\subsection{The importance of location and use of public spaces and amenities}

Participants in groups three and four highlighted the importance of centrally locating public amenities, particularly toilets, hospitals and schools, as well as community meeting buildings and public spaces during game play in Level Two. Participants in Group Four highlighted the importance of community meeting spaces and orientated their plans around central meeting spaces, such as schools or meeting halls, as this was important to them as central focal points within their community. Other amenities were placed peripherally to these elements to be accessed by all community members (Figure 107).

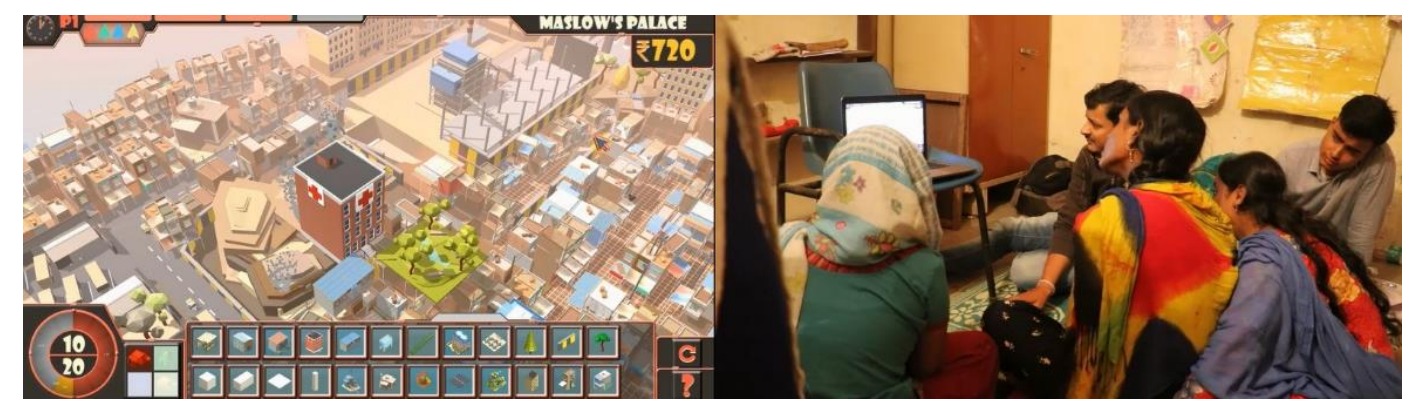

Figure 107. Group Four, Level Five, Maslow's Palace. Ghazipur, November 2017. Participants designing community meeting spaces and public spaces close to their homes and work areas.

In Group Four, participants were observed collectively deliberating in a "hybridreality" state (Ylipulli et al., 2017) —where speculative in-game issues and actions were hybridised with real-world issues and actions. The transcript excerpt detailing the interactions of Group Four participants playing Level Four of Maslow's Palace evidences this process below:

Participant Two: "We should build the meeting room close to the houses and to work. Over there."

Participant Three "No."

Participant One: "No. There is no room for it there. There are all of the houses."

Participant Three: "But if we build that there, we will have to demolish a house that someone lives in."

Participant Two: "But we need one." 
Participant One: "But there is already a school there. We should use that. We are in the school now. We could meet here."

Participant Two: "A meeting hall would be better. Then we can use it when school is underway as well."

Participant Three: "We could move our houses, and group them together. Then we can make space there for a hall."

Participant Four: "What if they (the government) tells us to leave? Then we have no houses. That might happen soon."

Participant Two: "But if we can have meetings then we can plan."

Participant Four: If I move my house, I cannot afford to build it again. We should use the school."

Participant One: "Yes that is a good idea."

Participant Two: "Okay, but we need to make sure that the school is in Ghazipur. By those houses (points). Then we can build the toilets, and all use them."

Participant Three: "Okay but we should talk to them, to make sure it is okay. The school might not let us."

Participant One: "Yes."

Participant Two: "Okay we will do that."

This exchange between participants was observed to be conducive to conflict resolution and consensus building, allowing participants to introduce more facets of issues - such as community access, forced eviction, real world affordability of options, position in relationship to other needed community spaces and consultation to ensure the proposed spaces (schools) could be used for their intended in-game purpose (community meetings). In this way participants were able to gain a deeper understanding of each other's perspectives on a number of real-world issues.

\subsubsection{The role of "speculation" in aiding the exploration of conflicting perspectives and ideation}

The Ghazipur workshops indicated the role of speculation as a tool for provoking discourse and engagement in community design workshops. In line with Innes and Booher (1999), in many of their most productive moments, participants engaged not 
only in discussing scenarios, but also in a kind of collective, speculative tinkeringsuch as destroying typologically-familiar buildings or constructing smaller, lesssignificant items while other issues were discussed by the group. Similar to the findings of Devisch et al, these heterogeneous actions were sometimes combined with discourse until they created significant development of the scenario that they collectively believe will work or "collective reflection" (Devisch et al., 2016). For example, participants in Group Three spent a substantial amount of time building with the inventory blocks collaboratively during Level One, as opposed to moving quickly through the level as the other three groups did. This enabled participants of this group to take turns designing, sharing experiences and building rapport with one another before moving on to other levels of the game in which they would make more detailed design decisions.

Digital literacy parity allowed some groups to progress to experimentation within the game more evenly, such as groups 2-4, as they learned the game system at similar rates, which opened up new avenues for discussion in earlier levels, as well as increased "collective tinkering" with fictitious and realistic spatial systems conducive to consensus building. Disparities in digital literacy (Mitgutsch \& Alvarado, 2012), such as Group One, resulted in some participants progressing through the game levels at different speeds, and thus resulting in less discussion and collaboration. Higher levels of collective tinkering resulted in more ideas being generated, more in-depth conversations and more frequent perceptual bridging - with more real-world issues being raised (e.g. Group Three). Perceptual bridging is a creative act (Auger, 2012, p. $180)$; therefore, a more relaxed environment is more conducive to higher perceptual bridging, which can lead to a more effective workshop.

In line with the findings of Dindler and Blythe and Wright, fictional elements permitted participants to project metaphorical or real-world issues and personas onto game entities, to enable more clearly defined parameters for discourse - such as someone actually living in an in-game house (Blythe \& Wright, 2006; Dindler, 2010b). Speculative urban arrangements of in-game buildings allowed participants to focus on the relationship between buildings and spaces, as opposed to their exact locationallowing the game response to function as a "diagram", which could interface with traditional participatory design methods and practices. For example, Group Two constructed their homes within the boundary of the landfill within level five to indicate the importance of this proximity (Figure 108). 


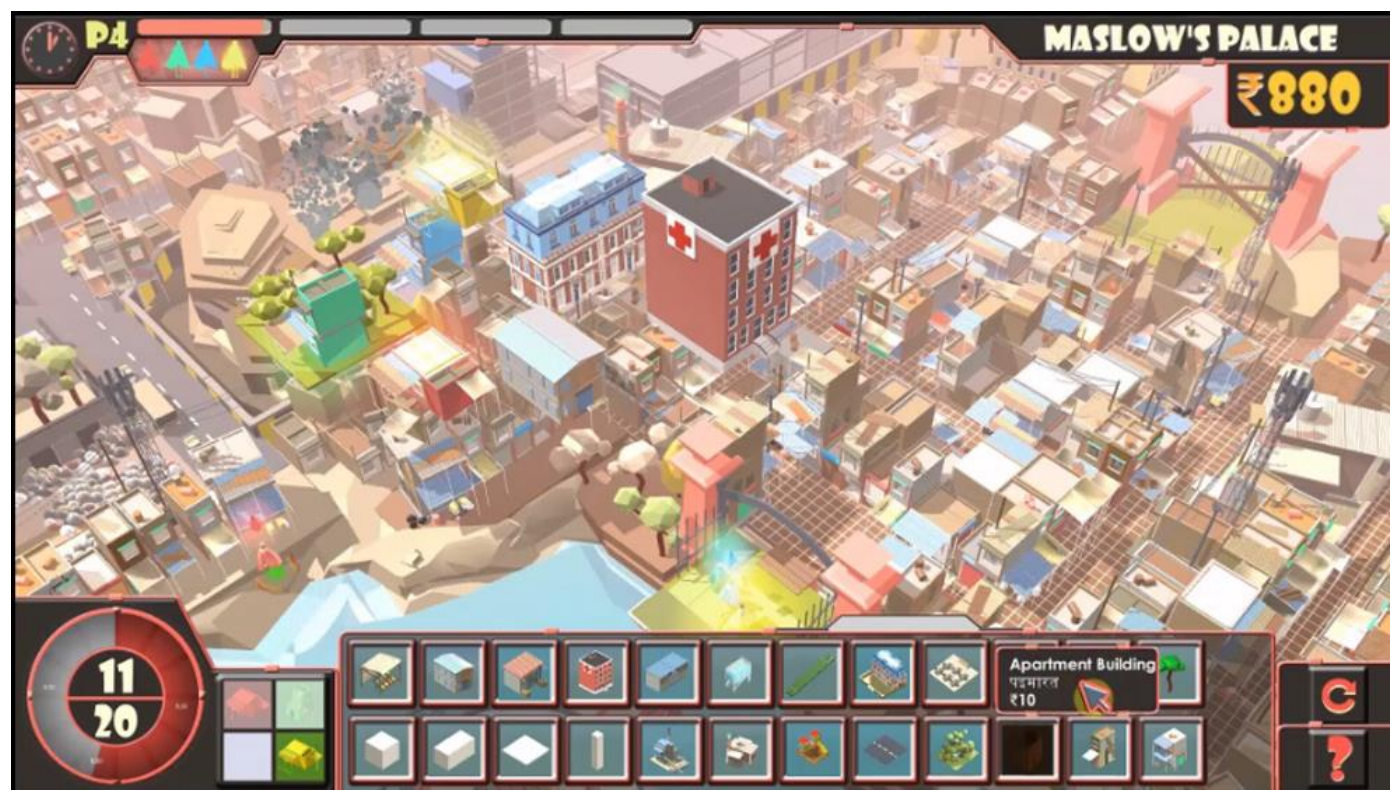

Figure 108. Group Two, Level Five, Maslow's Palace. Ghazipur, November 2017. Constructing housing within the landfill boundary - the in-game outcome functioning as a diagram.

Similar to the findings of Boroushaki and Melczewski, consensus building happened more readily when participants were discussing smaller scale, more tangible issues such as the placement of a toilet-as opposed to issues such as livelihood generation, which resulted in more facets of the issue being revealed rather than consensus being delivered (Boroushaki \& Malczewski, 2010). The variables in small scale spatial discussions were more easily defined by the participants, and the pros and cons could be more easily weighed, such as in the example given in Section 5.2.4.2.4 above.

\subsubsection{The relationship between the speculative and the real}

Throughout the workshops, it became clear the fictional and nonfictional elements within the game were inextricably linked - and that often assumed the same role in the eyes of the participants. Similar to the findings of Dindler (2010b), it may be noted that the participants readily conflated elements from everyday experiences with game elements and transformed them into new configurations that incorporated their own perspectives and those of others (such as projecting real issues onto fictional in-game urban elements). To this end the fluid nature of this state of hybridity created an environment where participants felt comfortable debating urban development issues. 
From this state, participants were able to iteratively scaffold arguments and ideas through subsequent levels of realism to help visualise (Billger et al., 2017), reflect (Gordon \& Baldwin-Philippi, 2014b) and communicate(Sanders \& William, 2002) real-world urban issues to one another.

In some instances, the fictional and nonfictional game elements were discussed in the way in which they had been designed; and in others the participants projected new interpretations and meanings onto them. In doing so, participants formed "perceptual bridges" - or links between their in-game experiences and real world experienceswhen responding to both fictional and nonfictional elements and spatial arrangements within the game. For example, during Level One, participants of Group Three conducted "area cleaning", which they described as the "removal of waste before they could build homes". Here the participants perceived the pink cubes within the level as "waste" (i.e. actual garbage in their community) and therefore ascribed a nonfictional, metaphorical identity to a fictional game element. In doing so the "perceptual bridge" grounded the speculation through extensional referents and connected it to the temporal world around them. This was also shown multiple times in each group throughout the later levels of gameplay where participants formed perceptual bridges between nonfictional game elements - such as the new metro station or the location of in-game housing with reference to real-world housing.

The introduction of real-world issues to the workshop by participants was also affected by the workshop facilitator. At the beginning of groups one and two, the facilitator explained the game was for community development purposes, which prompted participants to form perceptual bridges between the most abstract levels and real-world issues at an earlier stage, than if they had not been prompted as to the purpose of the game.

"It is to teach you how to support each other. What it's teaching you is that when you help each other everything becomes easier". (Facilitator, Group One)

“This is to design a new Ghazipur”. (Facilitator, Group Two)

This instruction by the facilitator allowed participants to begin to discuss urban development issues earlier, and in some cases in more depth, but reduced "collective 
tinkering" or playing with fictional elements in earlier levels. This differed from groups three and four, where participants were given no extra instructions by the facilitator outside of the in-game instructions.

Schön (1983) uses the term "problem setting" to stress that design must simultaneously strive to develop as well as address the "problem". Maslow's Palace helped the participants of the workshops to explore particular design problems within the game, as well as acting as a discursive provocateur to aid participants to raise different attributes of contextual problems. A strength of the speculative approach to urban gaming is, therefore, to provoke discussion surrounding what Holt et al. (1985) term "the imaginative leap beyond what already exists". The leap, however, is not one of fantasy, but a product of future users exploring how their urban environment could plausibly be. Data generated throughout the gaming process consequently allows for the creation of a "pseudo-ethnography" - one focussed on the "culture" of discussing and identifying urban related avenues for change rather than focussed on tangible outcomes; this emphasis can be invaluable to future pragmatic design and development processes.

\subsubsection{Summary}

The Ghazipur workshop had many benefits including the rapidity of the workshops, when considering the number of ideas explored by participants in a short time period and benefits such as enjoyment, creativity and engagement for the participants.

One of the main benefits of the gaming process was rapidity of the workshops, when considering the number of ideas explored by participants in a short time period. The workshop permitted a large range of ideas to be explored in reasonable detail. As all group sessions took no more than two hours to complete, this compares favourably with other participatory design techniques dealing with communities of this size and with issues of this scope and complexity. Most participants reported enjoying the workshop and particularly enjoyed being able to show each other their ideas and experiment with ideas as a group (Poplin, 2012) - as opposed to the decisions they make being understood as final.

While the workshop did not produce feasible urban development ideas for the most part, all groups explored urban issues and created a diverse range of responses raised by the game and other workshop participants from the perspectives of built form, 
political and economic considerations and social implications-indicating that the game is conducive to provoking a far greater range of urban focussed discourse than simply formal or spatial issues. While there were ordering systems present at the urban scale-such as participants considering proximities of buildings or spaces in relationship to one another as opposed to whether or not individual buildings were beneficial or not by themselves - formal architectural choices within the game remained limited, mainly because of the abstract nature of the game scale in architectural design, even though it was possible for participants to zoom in for more detail. Urban organisation-particularly the relationships between certain urban elements like schools, toilets and places of work-dominated the formal outcomes of the inquiry. Level Four generated no discussion around social or upgrading issues in any of the groups. This was seemed to be in relationship to the limited amount to buildable terrain within the level. Participants seemed to focus more on meeting the game objectives in terms of the required number of buildings, as opposed to experimenting with arrangements.

The workshop created three ideas for action, indicating that the fictional approach may be useful for generating real-world development ideas and may be able to interface with traditional participatory design strategies and processes in a more conventional manner. These included 1) the lobbying of politicians and NGOs for help with access to alternative means of income generation and child support, 2) the exploration of moving back to rural villages due to the threat of forced eviction and 3) the use of a centrally-located school for further meetings to help address community issues; however, only the first and third ideas were universally accepted by the group, as the second was found to be flawed after debate within the workshop group. 


\section{Case Study 2 - Bhalswa}

"We need to live here. There is nowhere for us. We help each other here when it is hard."

- (Participant Two, Group One, Bhalswa Workshops, 2017)

\subsection{Introduction}

The previous chapter detailed the research findings of the Ghazipur case study through a thematic analysis of participatory design workshops utilising the SPS-UG approach with the Ghazipur community. This chapter reports on the findings of the Bhalswa case study (CS2), which evaluated Maslow's Palace as a tool and method of participatory design engagement. The chapter details the primary design inquiries and conducts thematic analysis of the pre-test and post-test structured interviews and workshop recordings and observations. This chapter contributes toward:

Aim 4: To develop, implement and reflect on the use of a speculative, participatory, game-based approach to slum-upgrading in order to aid the generation of useful urban slum-upgrading oriented social outcomes and related architectural design slum-upgrading outcomes for disparate stakeholders in marginalised communities, more specifically, dwellers of landfill-oriented slums.

\subsubsection{Summary of Case Study Two - Bhalswa}

This chapter summarises the experience and evaluation of the Phase Three participatory design workshops utilising the SPS-UG approach with the Bhalswa community in accordance with the methods of data collection and analysis detailed in Chapter Three (). To respond to the research question, data was gathered through the 
coordination and recording of a series of four participatory workshops using Maslow's Palace, held with residents of the Bhalswa community in Delhi, in collaboration with the Chintan Environmental Research and Action Group between 8 and 14 November 2017.

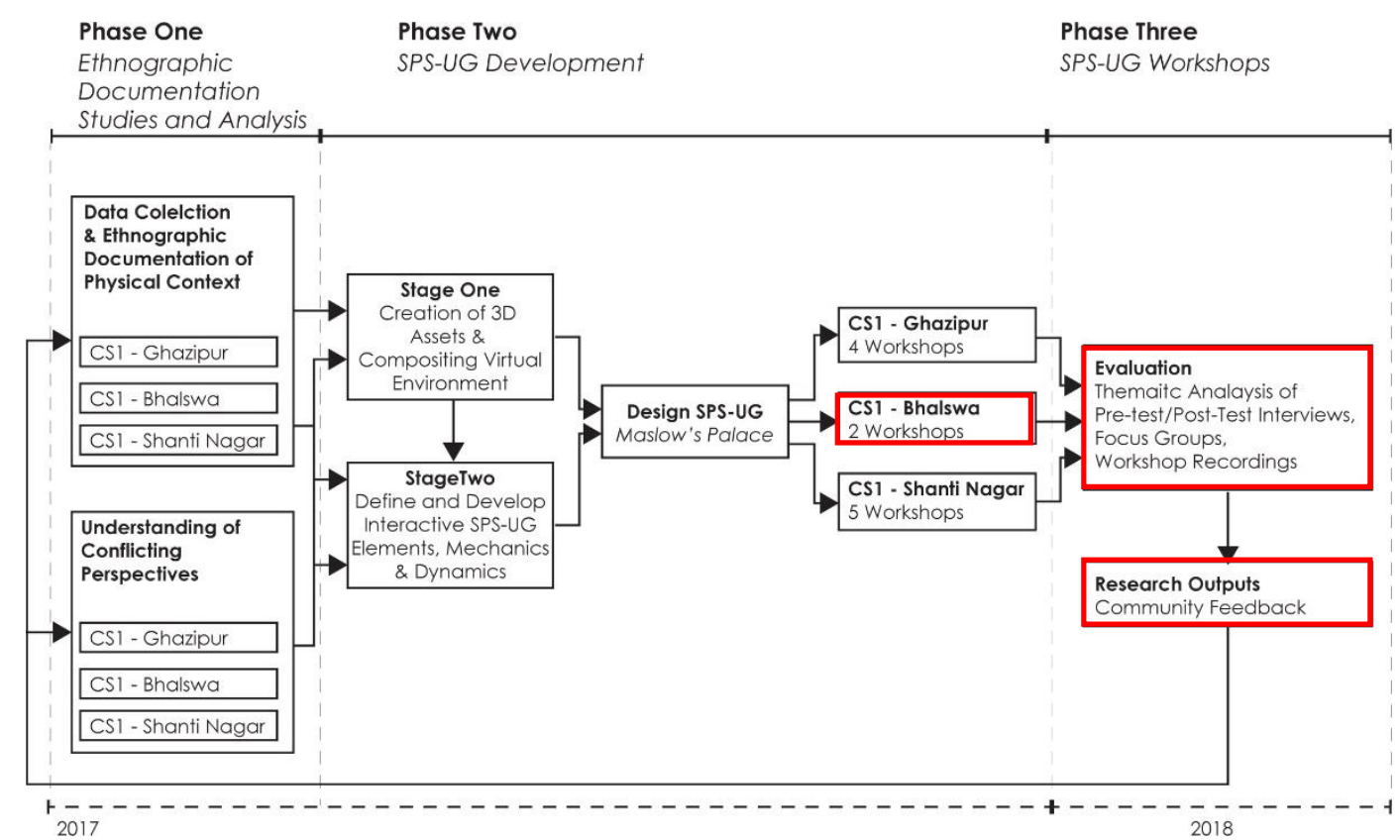

Figure 109. CS2 - Bhalswa located within the visual timeline of the research methodology.

The thematic analysis of the workshop data revealed three socially-orientated outcomes:

- conflict as a generator of creative solutions to problems;

- the benefits of cooperative weighing of pros and cons;

- participants galvanising around matters of concern.

The analysis also revealed three design-oriented (slum-upgrading) outcomes:

- the importance of the construction of higher quality housing;

- the importance of access to basic infrastructure;

- the adaption of the digital SPS-UG context to explore ideas.

Finally, the chapter discusses how participants used stories of experiences as a means to explore social and spatial tensions and ideas as well as the challenges of conducting ICT-based participatory design workshops within marginalised communities. 


\subsection{Case Study: Bhalswa}

\subsubsection{Aim of the Workshops}

The participatory design workshops were conducted with the Bhalswa community between 8 and 14 November. Each aimed to explore, but was not limited to, a range of key slum upgrading-related issues identified by the community during Phase One, which were embedded into the design of the game Maslow's Palace. Specifically, the workshops aimed to aid the Bhalswa participants in upgrading ideation and exploring conflicting upgrading perspectives with the Chintan Environmental Research and Action Group to create solidarity through a recognition of difference via conceiving a plurality of possible futures.

\subsubsection{Bhalswa Participants}

A total of two workshops using Maslow's Palace were conducted, comprising four members each. Participants were selected on a voluntary basis by Chintan staff and were not explicitly the same group of participants as recruited for the Phase One analysis stage-although four participants who participated in the initial survey also participated in the workshops. The eight participants who took part in the workshops were recruited by Chintan's local community coordinator in advance. Some participants were waste-pickers affiliated with the local school for waste-picker children; some were those who lived next to the landfill; and some lived in the more formal community on the main road. Any further participants who wished to participate while the workshop was in progress were also welcome to be included in a subsequent group - as many wished to have their voices heard. As the workshop was conducted in a private home, this was difficult to control. Many community members were interested in the workshop and would walk into the room where the workshop was being conducted (see Figure 111). The participants were aged between 25 and 60 years old with a mean age of 35 years of age. Effort was made to recruit an even number of male and female participants; however, due to a number of factors including addiction and other related social issues within the community, all participants but one were female. All participants were Muslim migrants who had migrated to Delhi from Kolkata (5), Shantri Peuk (1), Jhangi Puri (1) or Uttar Pradesh (1). Participants had 
lived within the community between 15 and 40 years with a mean of 21.8 years. A table of participants is shown below (Table 24).

Table 24. Demographic information about workshop participants - Bhalswa, Delhi

\begin{tabular}{lllllllll}
\hline $\begin{array}{l}\text { Grp. } \\
\text { No. }\end{array}$ & $\begin{array}{l}\text { Part. } \\
\text { No. }\end{array}$ & Age & Sex & $\begin{array}{l}\text { Digital } \\
\text { Literacy }\end{array}$ & Religion & $\begin{array}{l}\text { Year } \\
\text { Arrived }\end{array}$ & Arrived from & Occupation \\
\hline 1 & 1 & 26 & F & Low & Muslim & 2002 & Shantri Peuk & Waste picking \\
1 & 2 & 25 & F & Low & Muslim & 2002 & Kolkata & Waste picking \\
1 & 3 & 33 & F & Low & Muslim & 1992 & Kolkata & Waste picking \\
1 & 4 & 29 & M & Low & Muslim & 2002 & Kolkata & Waste picking \\
\hline 2 & 1 & 42 & F & Low & Muslim & 2002 & Kolkata & Waste picking \\
2 & 2 & 30 & F & Low & Muslim & 1987 & Kolkata & Waste picking \\
2 & 3 & 35 & F & Low & Muslim & 1997 & Uttar Pradesh & Waste picking \\
2 & 4 & 60 & F & Low & Muslim & 1977 & Jhangi Puri & Waste picking
\end{tabular}

\subsubsection{Workshop Preparation Process}

The Bhalswa workshops were held within a home Participant Three of Group One next to the landfill (Figure 110 and Figure 111), as this was the only space available within the slum area to conduct the workshop. This was a space in which participants stated they felt comfortable. Although it may have introduced a power imbalance in workshop Group One. However no findings suggest that this was the case.

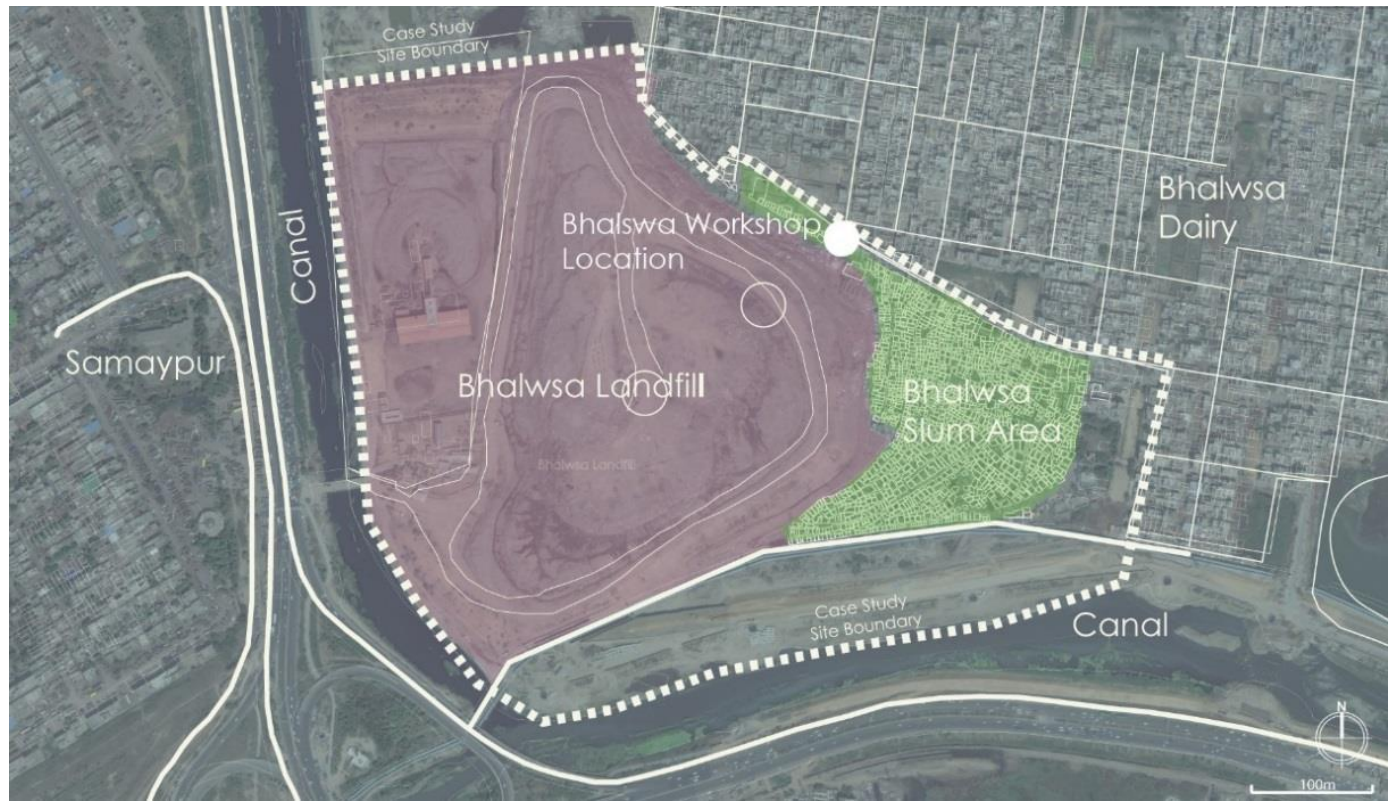

Figure 110. The location of the Bhalswa workshops. November 2017. 


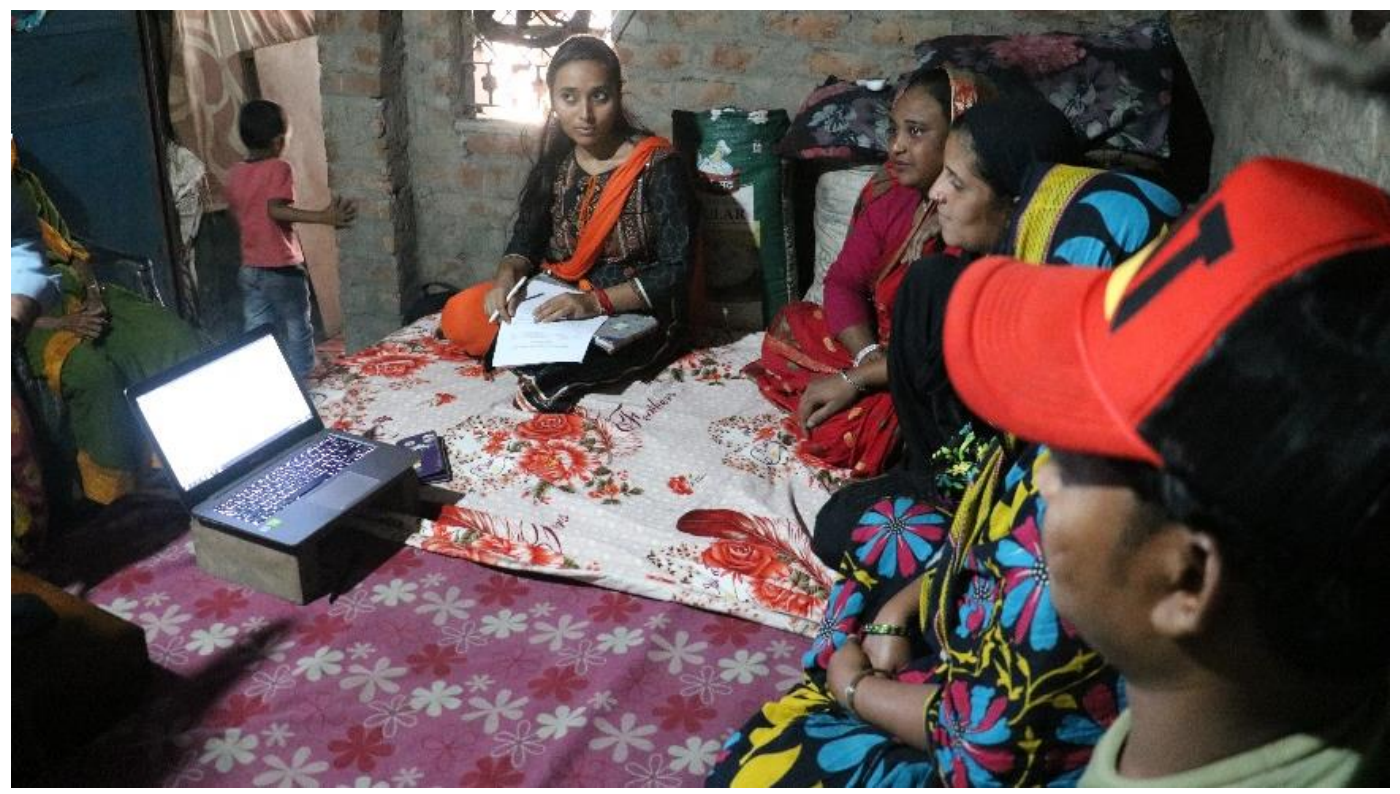

Figure 111. Participants of the Bhalswa Workshops, November 2017.

The Bhalswa workshops were organised and facilitated by six staff members from Chintan Environmental Research and Action Group. The facilitators were trained in the use of Maslow's Palace and its objectives before the workshops, and they were given a specific set of workshop and facilitation instructions to follow (Appendix 3). They were instructed to let the participants play the game by themselves and only provide assistance if a participant specifically asked for help. The eight participants were divided into two workshop groups (see Table 24, above). Within these groups the facilitators conducted the pre-test structured interviews (Appendix 4). Upon completion each group played Maslow's Palace. Each gameplay session took between 45 and 90 minutes. Upon completion, the facilitators conducted the post-test structured interviews.

The participatory workshop space is shown in Figure 112 and Figure 113 below. Maslow's Palace was played by the participants on a laptop, which recorded screen capture footage of the gameplay, with participants sitting on the ground. A digital SLR camera recorded video the workshop procedure, while the researcher recorded photographs and observations. 


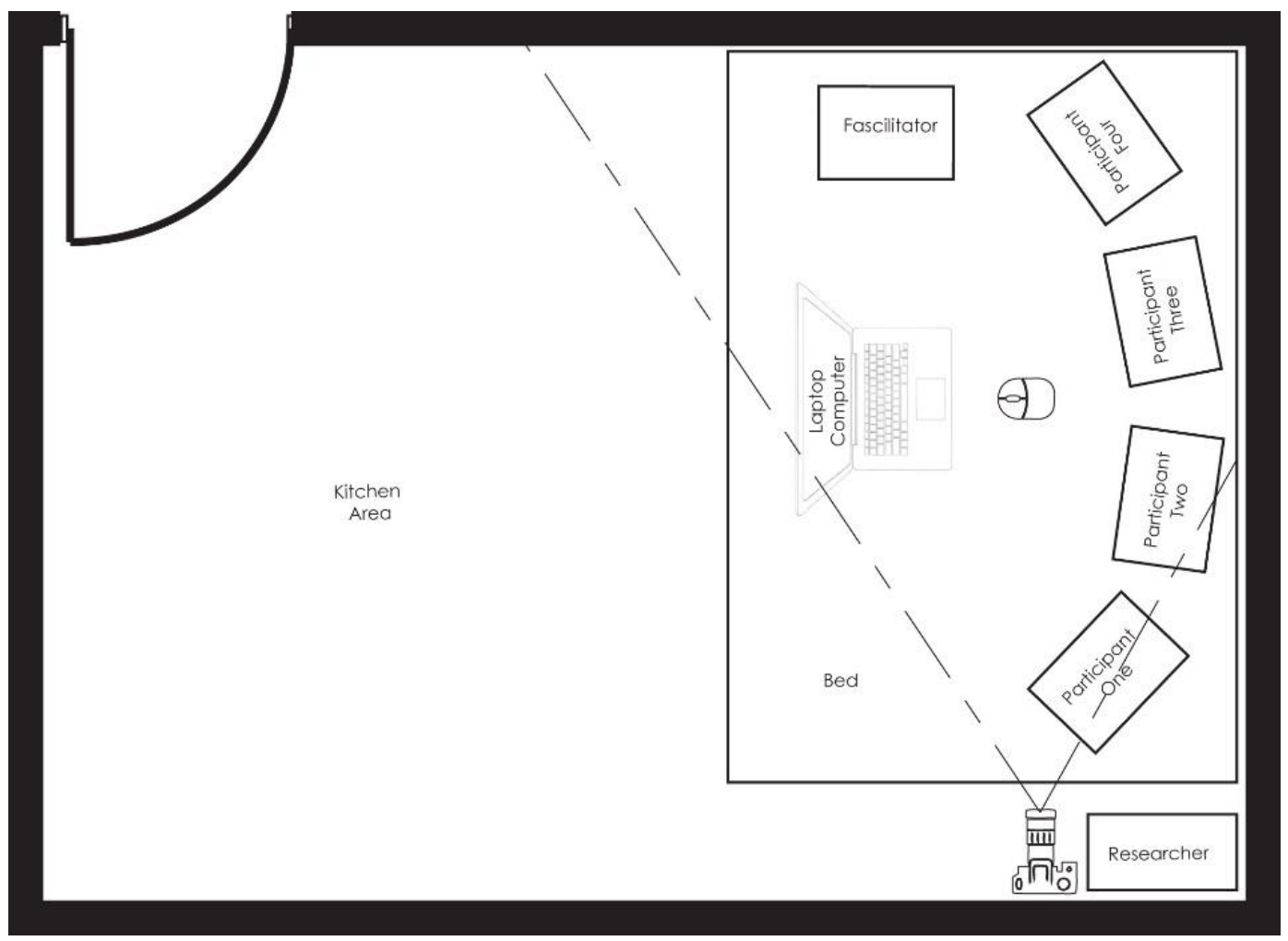

Figure 112. Floorplan of workshop space.

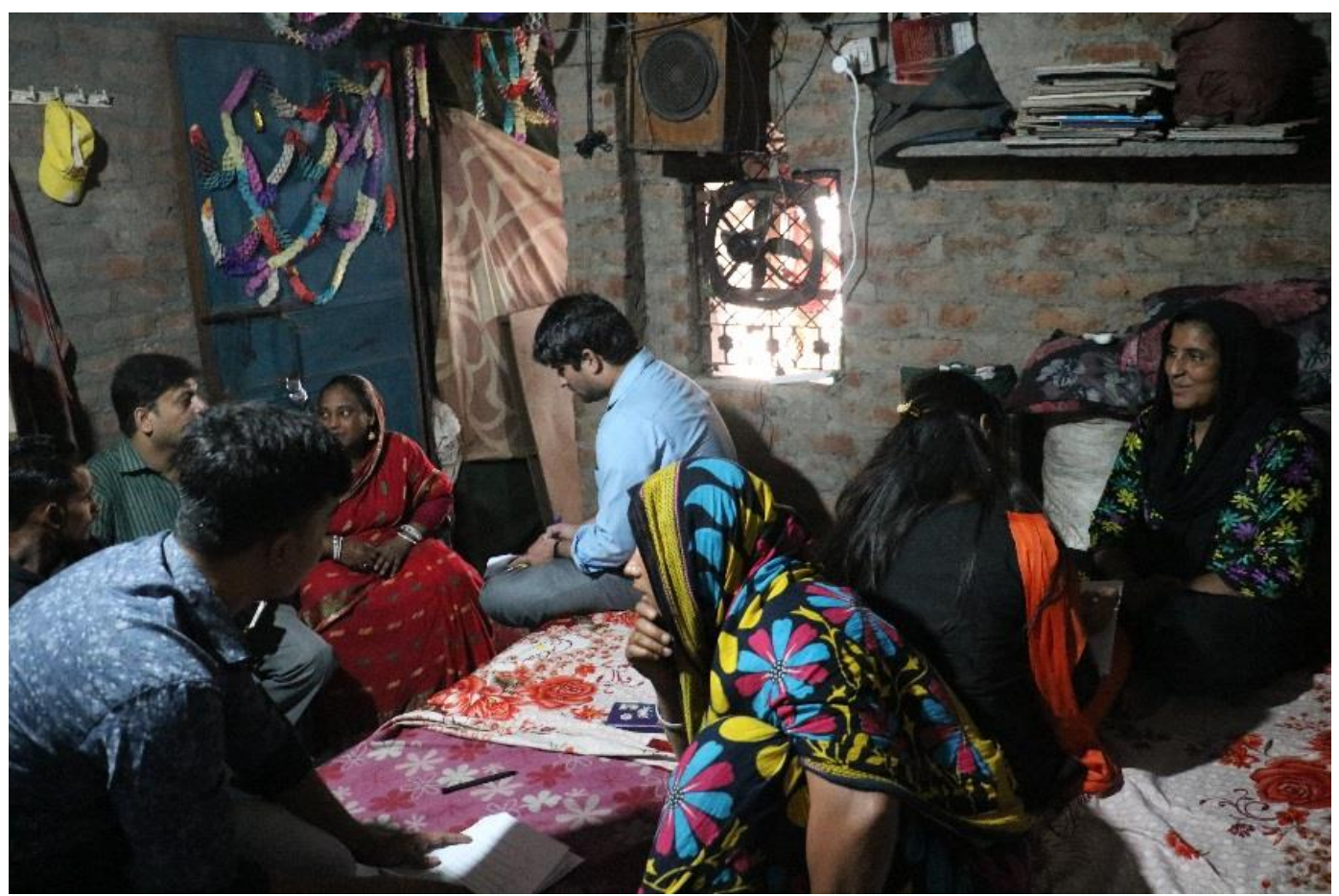

Figure 113. Bhalswa Workshop 2 participants playing Maslow's Palace, November 2017. 


\subsubsection{Findings}

A level by level summary of workshop outcomes is provided in Table 25 below. This is followed by findings of the thematic analysis of the workshop data. Firstly, qualitative assessment of social outcomes, in terms of slum-upgrading ideation resulting during gameplay, is presented (section 6.2.4.1). This is followed by an assessment of slum-upgrading outcomes, in terms of generating consensus around particular design outcome slum-upgrading ideas resulting during gameplay (section 6.2.4.2).

Table 25. Maslow's Palace workshop outcomes - Bhalswa

\begin{tabular}{|c|c|c|}
\hline & Group 1 & Group 2 \\
\hline Level 1 & $\begin{array}{l}\text { Facilitator Influence } \\
\text { Evidence: The facilitator showed the } \\
\text { participants how to move their participants } \\
\text { to the end of the level. Each participant did } \\
\text { this without experimenting with the game } \\
\text { mechanics }\end{array}$ & $\begin{array}{l}\text { Facilitator Influence } \\
\text { Evidence: The facilitator showed the } \\
\text { participants how to move their participants } \\
\text { to the end of the level. Each participant did } \\
\text { this without experimenting with the game } \\
\text { mechanics }\end{array}$ \\
\hline Level 2 & $\begin{array}{l}\text { - Facilitator Influence } \\
\text { Evidence: The facilitator showed the } \\
\text { participants how to move their participants } \\
\text { to the end of the level and build houses. } \\
\text { Each participant did this without } \\
\text { experimenting further with the game } \\
\text { mechanics }\end{array}$ & $\begin{array}{l}\text { Facilitator Influence } \\
\text { Evidence: The facilitator showed the } \\
\text { participants how to move their } \\
\text { participants to the end of the level and } \\
\text { build houses. Each participant did this } \\
\text { without experimenting further with the } \\
\text { game mechanics }\end{array}$ \\
\hline Level 3 & $\begin{array}{l}\bullet \quad \text { No slum-upgrading or social issues } \\
\text { were discussed }\end{array}$ & $\begin{array}{l}\text { Revealing conflicting perspectives } \\
\text { (Bowen, 2010; Iversen et al., 2012, p. 87; } \\
\text { Sanders, 2001) and Perceptual bridging" } \\
\text { (Auger, 2012) } \\
\text { Evidence: Discussion of the challenges of } \\
\text { waste segregation encroaching on living } \\
\text { areas, and that it would be better if this was } \\
\text { conducted further from homes }\end{array}$ \\
\hline Level 4 & $\begin{array}{l}\text { Revealing conflicting perspectives } \\
\text { (Bowen, 2010; Iversen et al., 2012, p. 87; } \\
\text { Sanders, 2001) and perceptual bridging" } \\
\text { (Auger, 2012) - Evidence: Conflict as a } \\
\text { generator of creative solutions. Projecting } \\
\text { real-world residents into the game, and } \\
\text { using that in combination with the lack of } \\
\text { available space to build in-game } \\
\text { structures as the parameters of the design } \\
\text { problem. Solution: Constructing homes } \\
\text { on a hillside } \\
\text { - The importance of better water } \\
\text { infrastructure }\end{array}$ & $\begin{array}{l}\text { - Revealing conflicting perspectives } \\
\text { (Bowen, 2010; Iversen et al., 2012, p. } \\
\text { 87; Sanders, 2001). } \\
\text { - Evidence: Conflicts regarding } \\
\text { positioning of toilets and how the } \\
\text { construction of adequate drainage } \\
\text { systems should take place in relation to } \\
\text { homes. Solution: Constructing a toilet on } \\
\text { a series of pylons } \\
\text { - The importance of better water } \\
\text { infrastructure }\end{array}$ \\
\hline Level 5 & $\begin{array}{l}\text { - Perceptual bridging" (Auger, 2012) } \\
\text { Evidence: The group orientated themselves } \\
\text { by exploring the level by pointing out all of } \\
\text { the familiar site features to all participants } \\
\text { and discussing the value of each in turn. } \\
\text { - The importance of housing in } \\
\text { proximity to other community members' } \\
\text { homes and the landfill } \\
\text { - The importance of better water } \\
\text { infrastructure } \\
\text { - Adapting the digital SPS-UG } \\
\text { environment to represent spaces not } \\
\text { designed into the game level-such as the }\end{array}$ & $\begin{array}{l}\text { - Perceptual bridging" (Auger, } \\
\text { 2012) } \\
\text { Evidence: The value of housing in close } \\
\text { proximity to hospitals } \\
\text { - The importance of better water } \\
\text { infrastructure } \\
\text { - Moving real-world houses in order } \\
\text { to construct adequate roads and drainage }\end{array}$ \\
\hline
\end{tabular}




\begin{tabular}{|c|c|c|}
\hline & $\begin{array}{l}\text { open ground to the north of the } \\
\text { community's houses. }\end{array}$ & \\
\hline $\begin{array}{l}\text { Pre-test/Post-test } \\
\text { Findings }\end{array}$ & $\begin{array}{l}\text { - Developing and Grounding } \\
\text { Knowledge, Values and Goals (Brandt, } \\
\text { 2006; Brandt \& Messeter, 2004; Brandt et } \\
\text { al., 2008; Dindler \& Iversen, 2007) } \\
\text { Evidence: Solidarity around improved } \\
\text { access to drinking water }\end{array}$ & $\begin{array}{l}\text { • Developing and Grounding } \\
\text { Knowledge, Values and Goals (Brandt, } \\
\text { 2006; Brandt \& Messeter, 2004; Brandt } \\
\text { et al., 2008; Dindler \& Iversen, 2007) } \\
\text { Evidence: Solidarity around improving } \\
\text { housing quality } \\
\text { - Solidarity around improving } \\
\text { drainage systems and roads } \\
\text { - Solidarity around gaining access to } \\
\text { hospital treatment } \\
\text { - Creating "meaningful alternatives" } \\
\text { (Leong \& Iversen, 2015) through } \\
\text { collaborative, participatory storytelling } \\
\text { (Baumann, Caldwell, Bar, \& Stokes, 2018 } \\
\text { Baumann et al., 2017). } \\
\text { Evidence: Describing the challenges of } \\
\text { waste segregation encroaching on living } \\
\text { areas }\end{array}$ \\
\hline $\begin{array}{l}\text { Focus Group } \\
\text { Findings }\end{array}$ & $\begin{array}{l}\text { • Grounding Knowledge, Values and } \\
\text { Goals (Brandt, 2006; Brandt \& Messeter, } \\
\text { 2004; Brandt et al., 2008; Dindler \& } \\
\text { Iversen, 2007) } \\
\text { Evidence: Participants suggested that } \\
\text { exploring ideas in the adapted SPS-UG } \\
\text { environment allowed them to understand } \\
\text { each other's ideas }\end{array}$ & $\begin{array}{l}\text { - Grounding Knowledge, Values } \\
\text { and Goals (Brandt, 2006; Brandt \& } \\
\text { Messeter, 2004; Brandt et al., 2008; } \\
\text { Dindler \& Iversen, 2007) } \\
\text { Evidence: Participants stated that they } \\
\text { enjoyed the workshop and the game was } \\
\text { useful for communicating ideas to to other } \\
\text { players. }\end{array}$ \\
\hline
\end{tabular}

\subsubsection{Social Outcomes}

\subsection{Conflict as a generator of creative solutions to problems}

The introduction of fictional game spaces into debates combined with personal experiences of real world spaces and situations, provided new ways for participants to engage in, as well as back out of, conflict. These novel combinations functioned not only as a way to test potential upgrading ideas but also as 'agonistic space', where the participants did not reach consensus surrounding an idea and helped participants explore those ideas. For example, Group One began Level Four with a discussion centred on the existing context presented in the game and the inventory items that were available to the group. Participant One pointed out that there was no available free space in the game environment.

\section{"There is nowhere to build." (Participant One, Group One)}

“We can't destroy those houses. People live there." (Participant Four, Group One) 
"Well we have to build them somewhere. Maybe we destroy them." (Participant Three, Group One)

This moment represented an impasse, where participants were projecting real-world residents into the game, and using that in combination with the lack of available space to build in-game structures as the parameters of the design problem.

Participant Four proposed that houses be built on the hill overlooking the existing development, so that new houses would not be flooded and the existing buildings would not need to be destroyed, adding a further real-world parameter of flooding, which does not exist within the game, to the design problem (Figure 114).

"If we build them up there, there will be less water." (Participant Four, Group One)

This action was then carried out by Participant Three.

Participant Two stated:

“We can't get though there. There's no path. We should build our houses in the valley and make a road."

Participant Two then built their house in the valley. Participant Three stated the houses were still "close to work" indicating the participants were perceiving the hills as the landfill itself. Participant Four suggested:

"We can walk up the hill. It's better than having water in our houses, and the garbage can fall on us".

All participants agreed. 


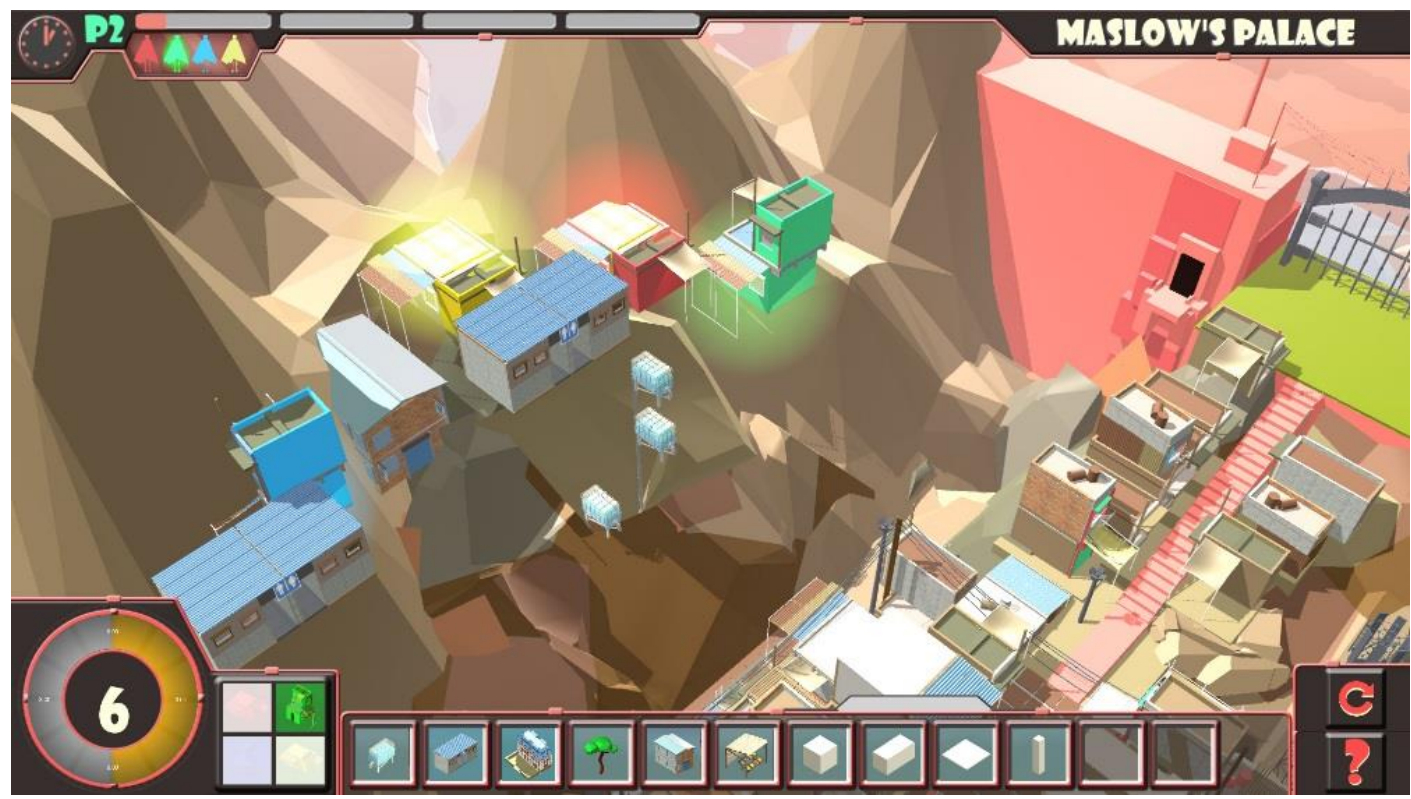

Figure 114. Bhalswa Workshop One, Level Four outcome. Participants' outcome as a result of cooperative weighing of pros and cons of design options, November 2017.

This example indicates a cooperative weighing of pros and cons. The tension around housing positioning allowed for creative problem solving and an interesting design solution that fostered cooperation. This example demonstrates a "hybrid reality", where the participants drew design considerations from both the real and speculative game world (Ylipulli et al., 2017). Participants drew on their knowledge of the game and real-world urban problems such as flooding and landfill run-off to arrive at a creative solution to a problem that was found after an impasse was reached. This indicates agency (Ibrahim \& Alkire, 2007), consensus building (Boroushaki \& Malczewski, 2010) through prototyping (Sanders \& Stappers, 2014) and creative thinking.

Expectedly, as participants played through Maslow's Palace, they had more discussions surrounding realistic attributes in later levels. Conflicts resulted in participants gaining insights into each other's points of view through discussion centred on in-game actions.

Group Two, for example, faced a number of conflicts within the workshop that centred on the positioning of toilets and how the construction of adequate drainage systems should take place in relation to homes. The participants could not find space within their game level to build toilet facilities. Group Two created a solution to the problem of flooding by constructing a toilet on a series of pylons-after arguing about 
participants' houses occupying all of the available space within the game, as exemplified in the exchange below (Figure 115).

"There's no room. Your house is there. We need a toilet as there is none in Bhalswa. Move it." (Participant One, Group Two)

"Why don't we build on the hill? It will be quiet there." (Participant Two, Group Two)

"No. Just move your house. You always think about yourself only." (Participant One, Group Two)

"I'll build one then you build one." (Participant Four, Group Two)

Okay, only if we can also have water there." (Participant One, Group Two)

"See like this, these are steps, we can walk up." (Participant Three, Group Two)

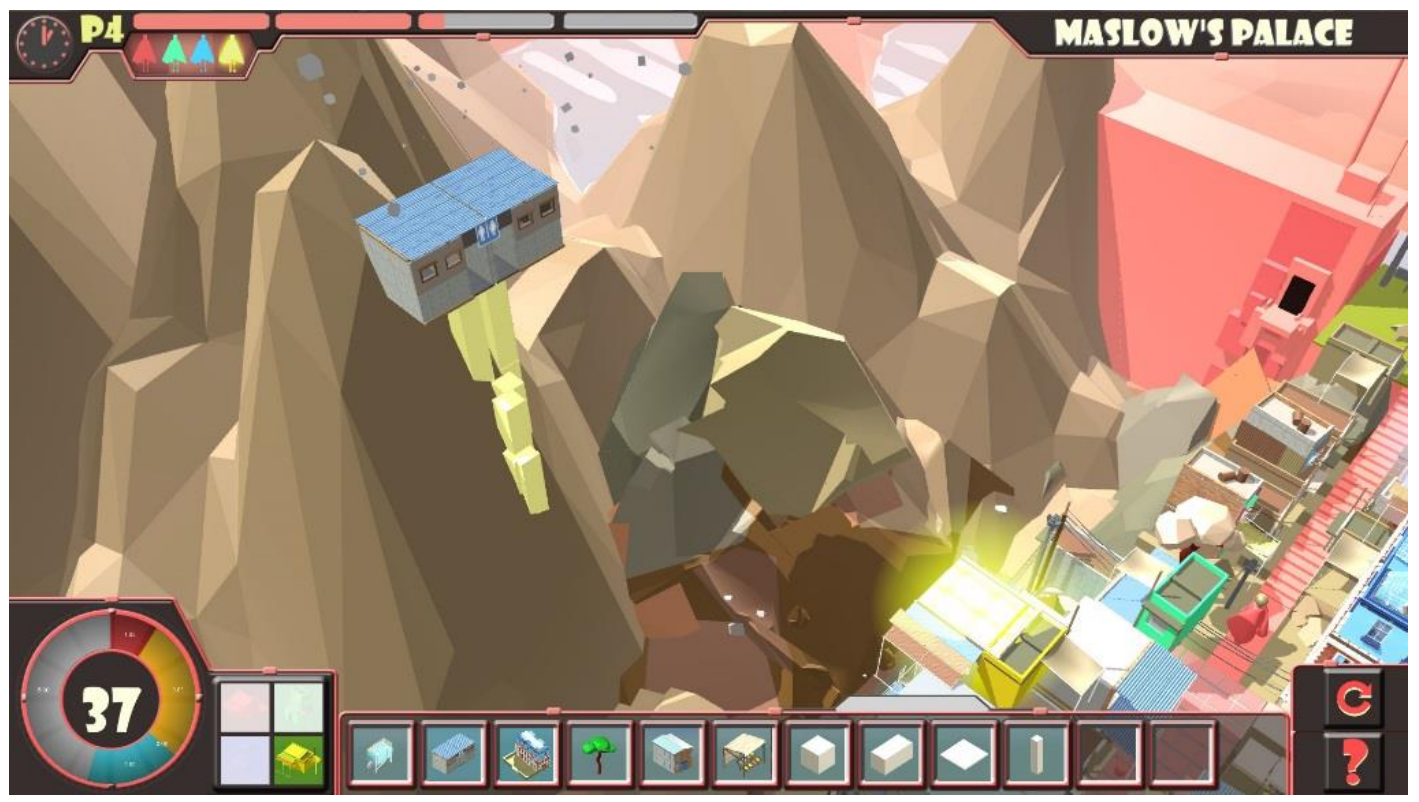

Figure 115. Bhalswa Workshop Two, Level Four outcome. Participants' outcome as a result of a solution to a conflict, November 2017.

\subsection{Galvanising around Matters of Concern}

One attribute highlighted in the data is the similarity between the pre-test and posttest responses to the main urban issues expressed by the participants, shown in below. 


\section{Assessment of Conflicting Perspectives - Bhalswa}

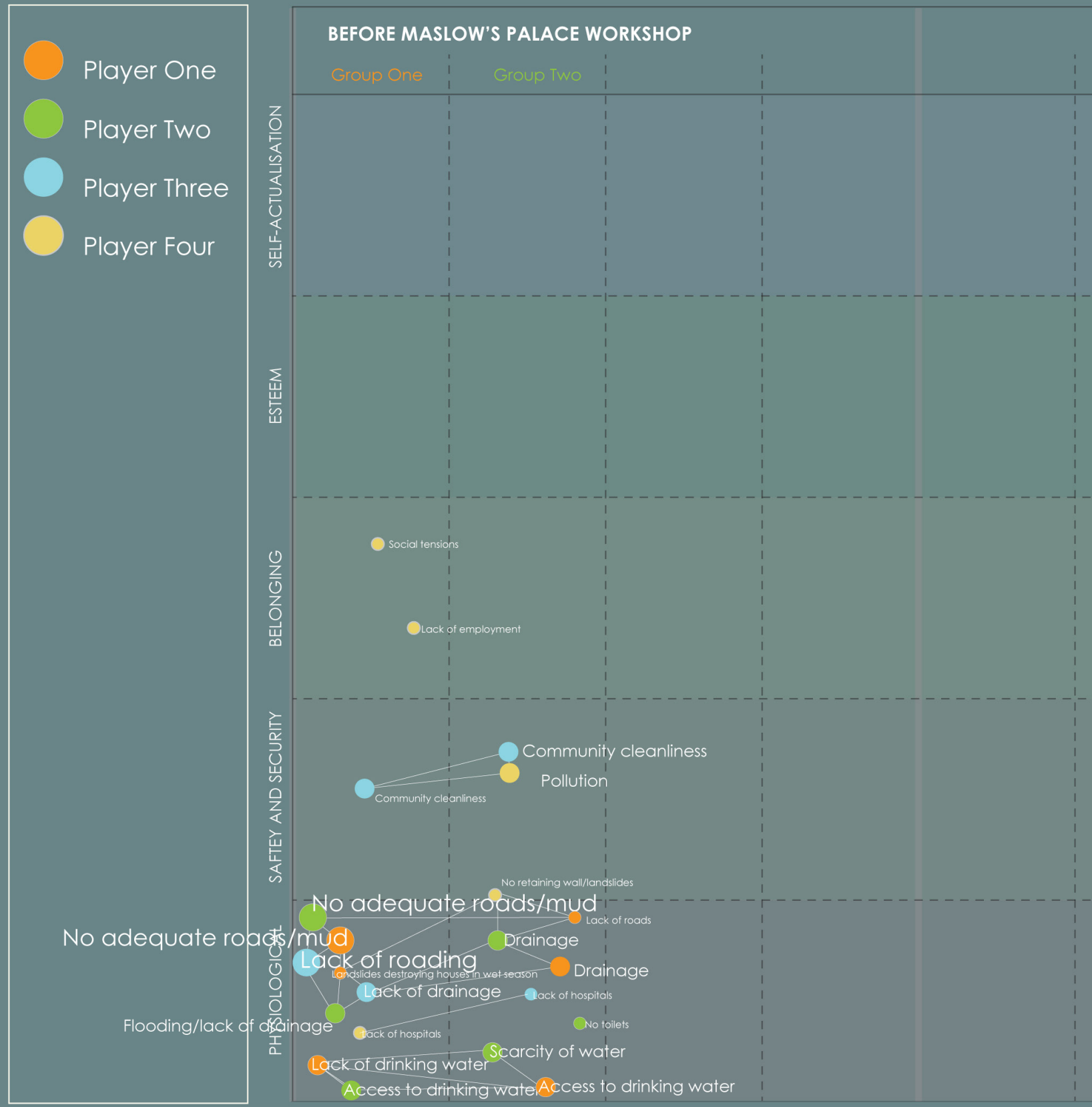

Figure 116. Pre-test / post-test analysis of Bhalswa workshop groups. The diagram indicates some solidarity surrounding access to drinking water, the construction of adequate housing, better drainage and access to hospitals. 
AFTER MASLOW'S PALACE WORKSHOP

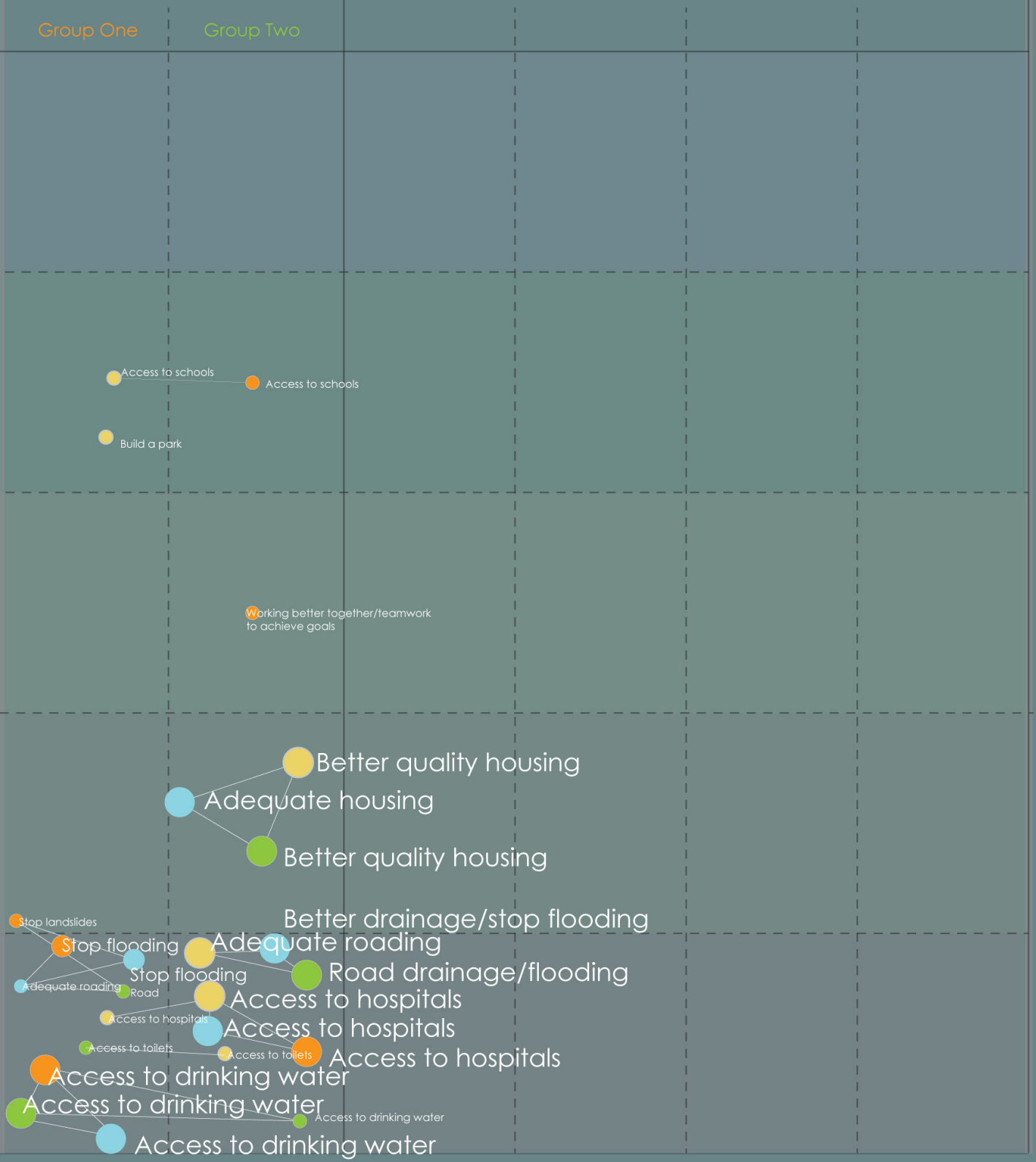


The urban issues that participants identified as most important in both the pre-test and post-test interviews were predominantly located in the physiological and safety and security end of the spectrum, and they were thematically similar, i.e. both workshop groups identified similar issues in both interview rounds, which relate to the acute urban issues faced by the community, such as lack of access to drinking water, lack of drainage to stop rainwater and leachate entering dwellings.

However, post-test interview data suggests that the participants formed some solidarity through the process of completing the workshop activities. For example, while issues such as access to drinking water in workshop Group One, and access to hospitals, better drainage/stopping flooding and the construction of better-quality houses were identified in both pre-test and post-test interviews, there were more common concerns by all participants in post-test interviews.

\subsubsection{Slum-upgrading Outcomes}

The workshop process produced a number of ideas, explorations and agreements surrounding urban issues faced by the Bhalswa community detailed in the sections below. These included access to better housing, the construction of adequate drainage systems and access to hospitals and are reflected in the pre-test post-test analysis of the structured interview data shown above in

\subsection{The construction of higher quality housing}

Both workshop groups raised the importance of housing being in close proximity to the landfill, for both a sense of community-i.e. not being moved to a resettlement colony - and to ensure access to the solid waste stream for livelihood generation. They also highlighted the importance of other community amenities for increasing their quality of life within the community, such as public toilets, hospitals, schools and community meeting spaces such as parks.

"We need to live here. There is nowhere for us. We help each other here when it is hard." (Participant Two, Group One). 
"We need to have hospitals. My child gets sick. He is left at home when I work in the landfill when he is sick, and I cannot look after him. If the hospital was close to home, he could get better and I could earn money for my family doing this work [waste picking]." (Participant Three, Group Two).

Similar to the Ghazipur workshops, at least one member from both groups immediately formed a strong perceptual bridge (Auger, 2013) between Level Five and the real world by pointing out familiar site features unprompted. Group Two initially explored the placement of buildings within the initial field of view of Level Five (Figure 117). The group quickly orientated themselves, with the help of Participant Two stating: "The houses should be by the landfill". Each participant placed their house in turn next to the landfill represented in the level. Participants then began discussing the different inventory items available and their relevance to their community. The discussion was directed by Participant Two, who had control of the mouse, pointing at each of the items in order to read the rollover caption with the help of the facilitator. The participants then discussed the degree to which they wanted those buildings or facilities in their representation of the Bhalswa community within the game. This discussion indicates a high level of perceptual bridging. The participants built roads right next to the housing area they had created - although the roading modules were not placed in a conventional fashion; they were piled on top of one another. This was prioritised and shows a link between their survey results and their actions within the game, as adequate roading was a predominant issue.

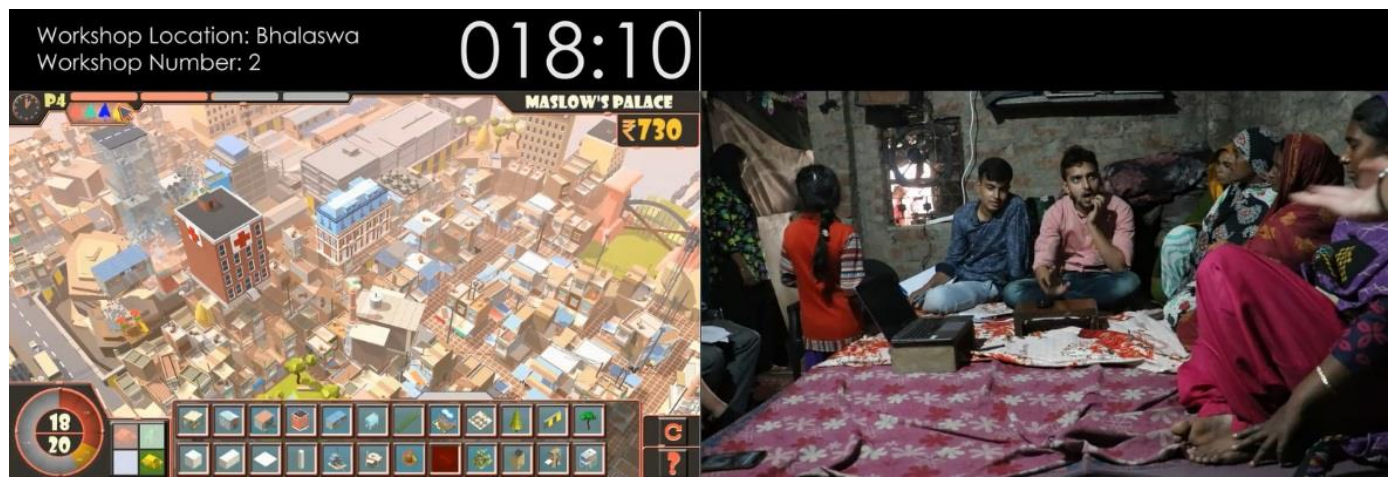

Figure 117. Group Two, Level Five, Maslow's Palace. Ghazipur, November 2017. Participants designing housing, community meeting spaces and public spaces close to their homes and work areas. 


\subsection{Access to basic infrastructure}

One of the most widely discussed topics amongst both workshop groups was the provision of basic infrastructure such as access to safe drinking water and the construction of drainage systems to prevent storm water and leachate from entering dwellings. Access to drinking water was highlighted by participants in both groups in the pre-text and post-test interviews. Participants responded to the need for basic infrastructure in-game by constructing water tanks in both Levels Four and Five. Little discussion surrounded these actions as participants were seemingly in agreement. Likewise, while better quality housing was acknowledged to be important, it was widely accepted amongst participants that inadequate drainage was one of the most pressing concerns the community faced. This concern was highlighted in the pre-text / post-test interviews as well as discussed within both workshop groups. Group Two also discussed during Level Five that houses would need to be moved in order to construct adequate drainage and roading infrastructure. In response to this tension, Group Two explored a range of ideas within the game by clearing an area of the map of buildings and using that area to design new configurations.

\subsection{Adapting the digital SPS-UG context to explore ideas}

During workshop Group One, Participants Two and Four proposed the improvement of the Bhalswa area through the provision of adequate drainage systems instead of just improving housing. Participant Two argued that they liked their houses where they were already, and they "just needed a better road" (Participant Two, Group One). This assertion was rejected by participants one and three, arguing that "we need better houses to keep water out" (Participant Three, Group One). Participants discussed using the vacant land currently behind their own homes in the real world (Figure 118) as a site for new homes that could have adequate roading and drainage systems built on them away from the landfill edge. As no such space existed within the digital game, participants adapted the digital game environment by collectively clearing buildings from an area of it and exploring ideas for upgrading action through a negotiation of values within this cleared area that represented a real-world space (Figure 119, Figure 120 and Figure 121). 


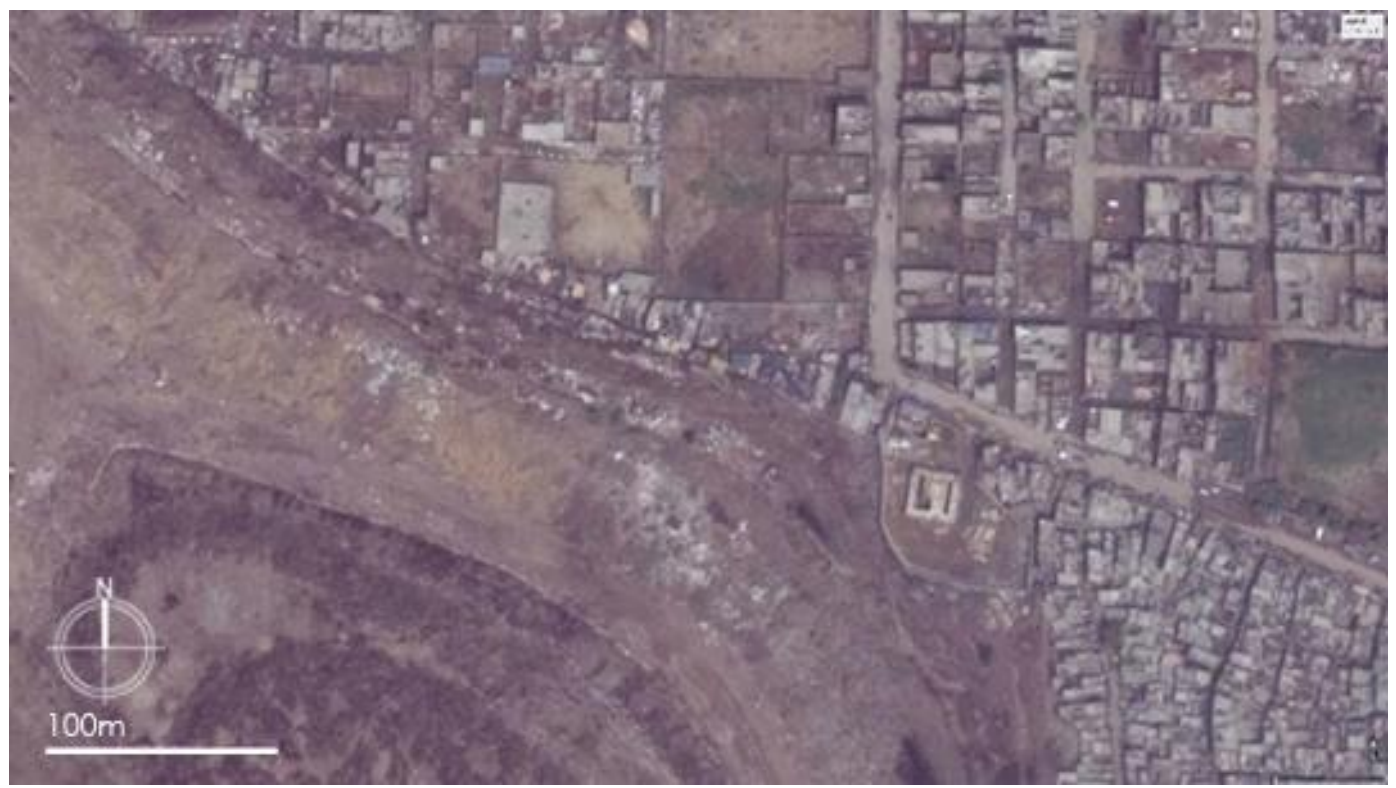

Figure 118. Aerial image showing the undeveloped parcel of land (top, centre) behind the Bhalswa slum community. Image via Google Earth, 2019.

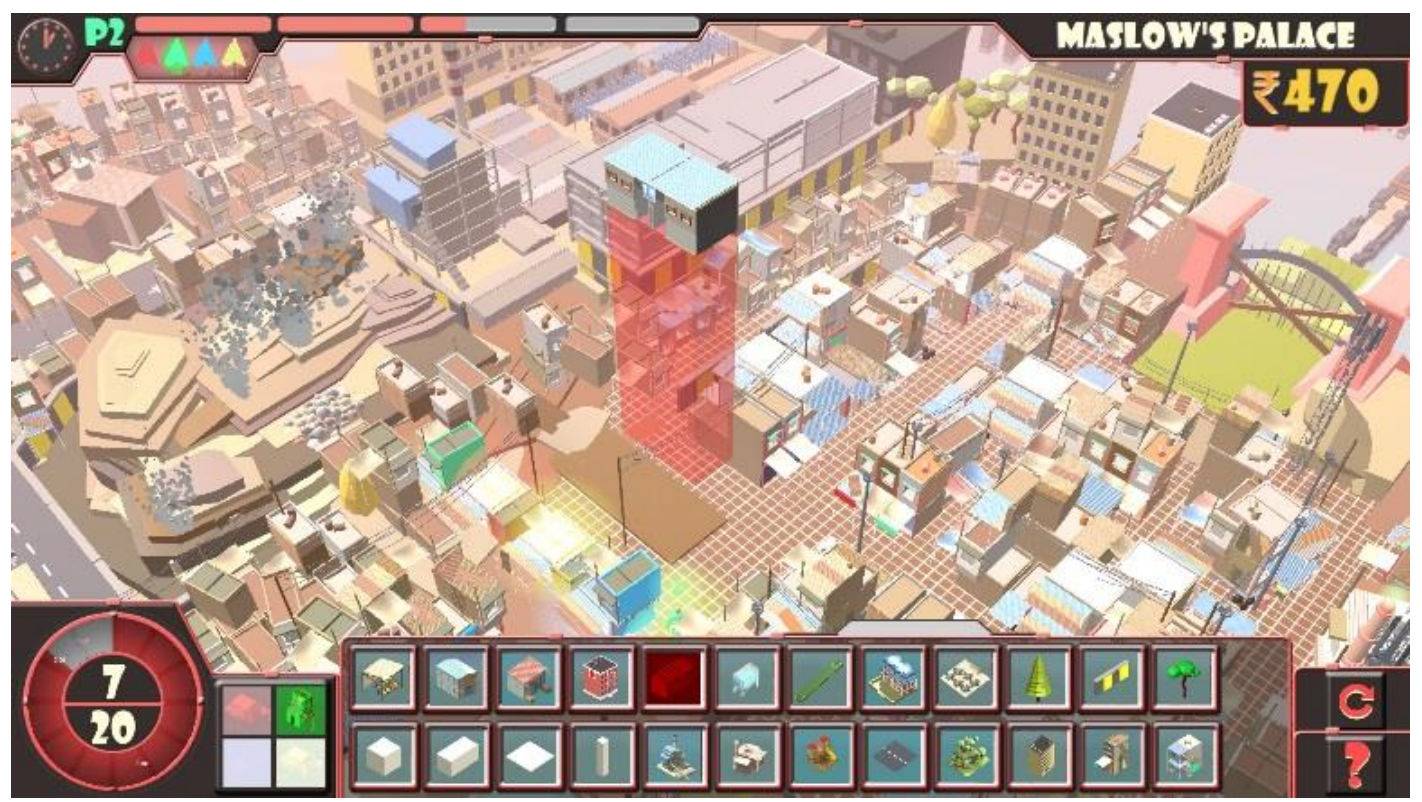

Figure 119. The game environment area that the participants of Group One cleared to explore upgrading ideas.

Although the participants acknowledged that they did not own the land and building houses there would be difficult without consent from the landowner, the participants of Group One revealed during the workshop that exploring the ideas in this space allowed them to understand each other's ideas better. When asked why it was so useful, Participant Two replied: 
"Because we can just build things. No one said we couldn't, so I found out why [Participant Two] wanted to stay" (because of the threat of eviction if they move to someone else's land). (Participant Two, Group One).

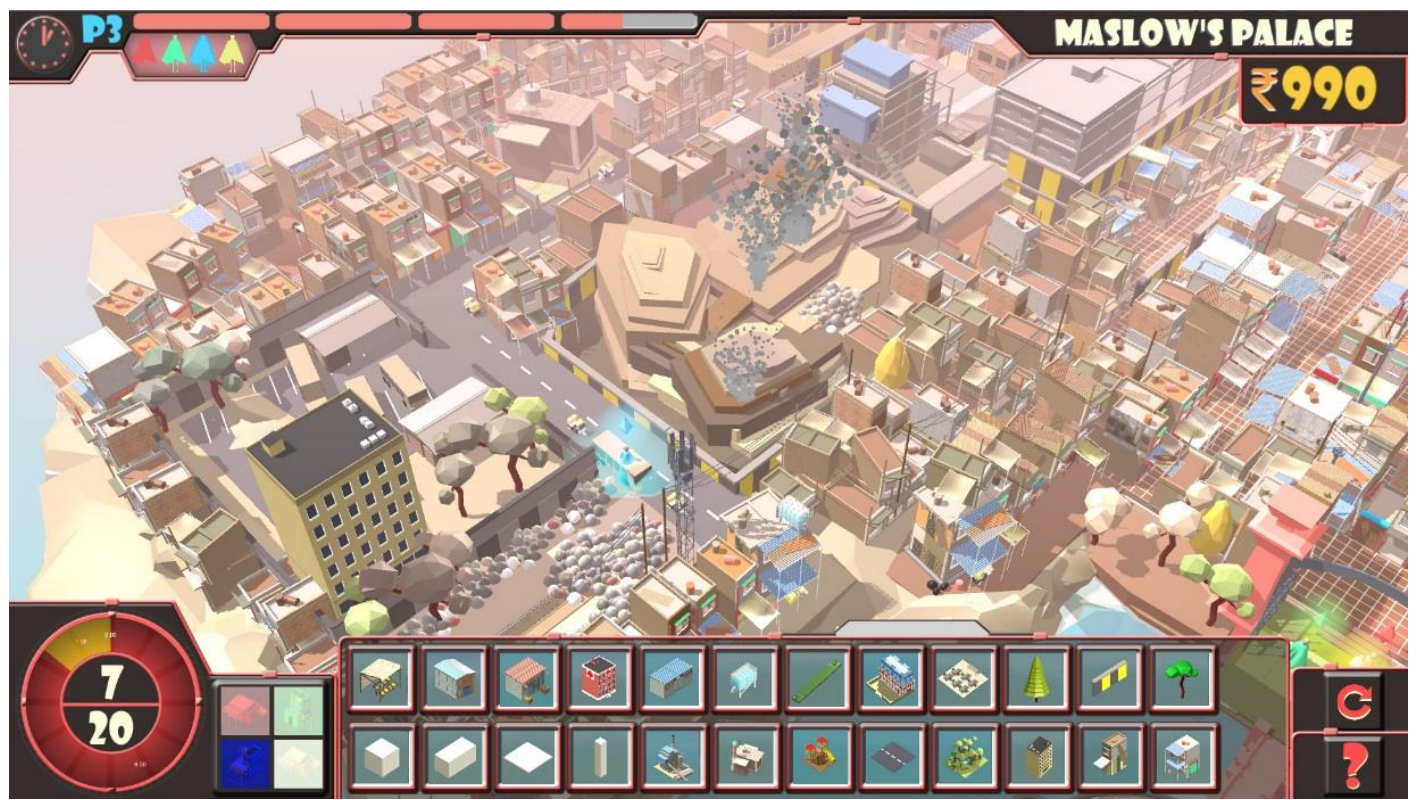

Figure 120. The game map before Group One's gameplay, Bhalswa, 2017.

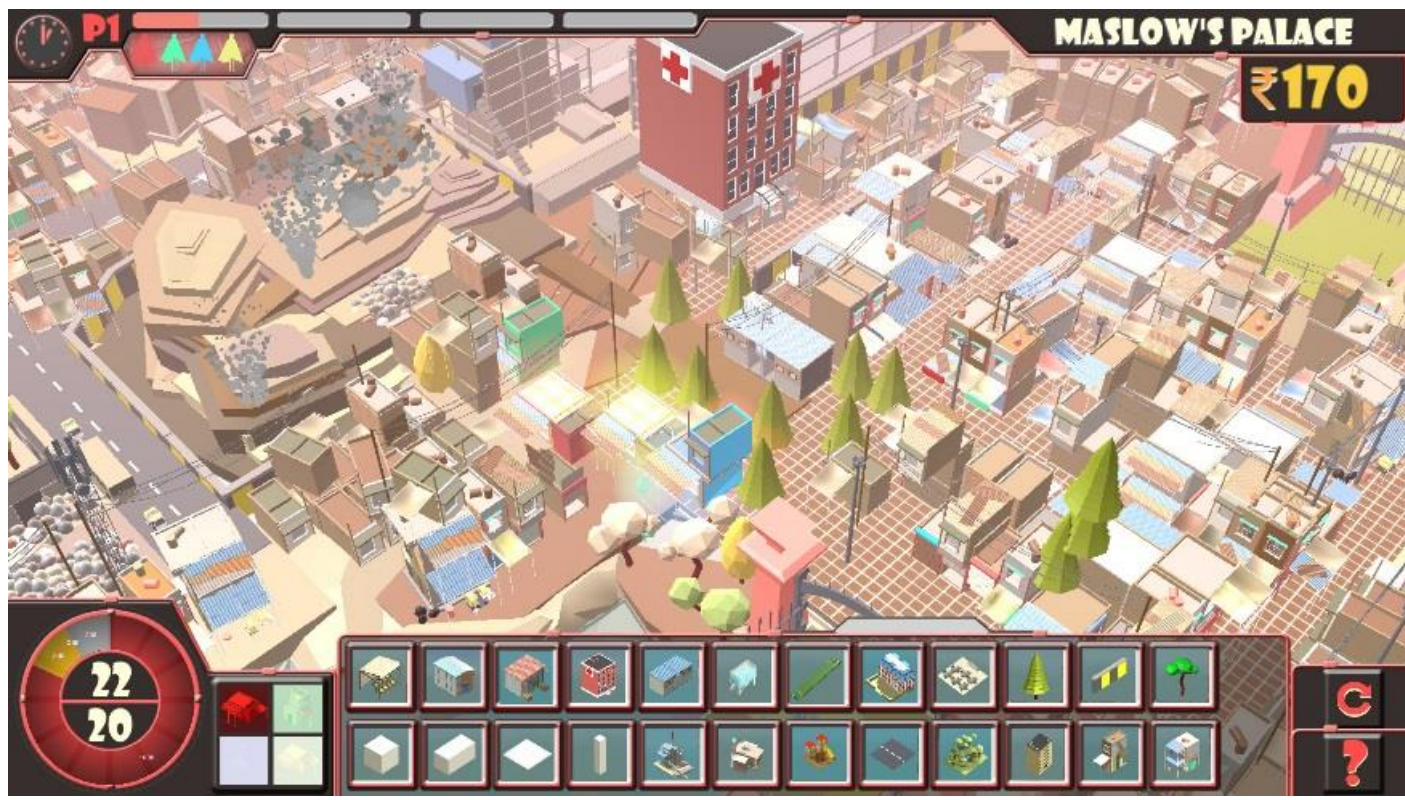

Figure 121. The workshop outcome of Group One, Bhalswa, 2017.

In this way, the participants could sketch ideas within the SPS-UG environment and collectively tinker (J. E. Innes \& Booher, 1999) with ideas that were provoked by the 
game environment, augmented with participants' experiences and stories and refined in the digital environment. This allowed for the participants tacit knowledge- that which cannot readily be expressed in words but can be aided by exploration of ideas-to be revealed.

\subsubsection{Challenges with working with the most marginalised}

Events within the two Bhalswa workshops highlighted three challenges in conducting digital participatory design workshops with marginalised communities.

The first challenge that was faced in conducting the workshops at Bhalswa related to finding an appropriate workshop location. As the Bhalswa community had no publicly accessible meeting space, it was decided that a participant's home was to be used as the workshop location. Holding the workshop in participant's home resulted in a number of concerns - such as an inability to hold the workshops in a neutral space, where no one participant had more power over that space than others due to its location. These concerns was mitigated to some extent by ensuring that all participants were comfortable taking part within the space beforehand. All reported that they felt comfortable in the space, or that it did not affect the way they interacted within other participants within the workshop. The space also created challenges regarding the conducting of digitally-based participatory workshops in locations with unreliable electricity connections and frequent power cuts. While the power cuts ultimately did not affect the workshops, power cuts did happen frequently throughout both workshops and resulted in the computer's battery taking over, while power was restored. The power cuts did serve as a minor distraction for participants, predominantly due to the loss of lighting within the workshop space. Issues such as these have been recently discussed where Racadio, Rose, \& Kolko and Xu \& Maitland stress the importance of contingency planning when conducting participatory design activities with low resource communities (Racadio, Rose, \& Kolko, 2014; Xu \& Maitland, 2019).

A second challenge related to conducting workshops in communities facing a number of acute issues. During the focus group session after workshop Group Two, a community member who was not part of the workshop, entered the workshop room and began talking to one of the participants. It became clear that all of the workshop 
participants were very distracted from this point. When asked, the facilitator stated that it was not important, and that the workshop should continue. Soon after, some of the participants began leaving. When asked again, the workshop facilitator stated that a community member had passed away during childbirth. While this event did not affect the workshop results apart from the final focus group session, as the workshop had concluded, it does highlight one of the challenges of conducting workshops with the most marginalised communities. It was clear the participants and the workshop facilitators valued the workshop process, and that they wanted to continue even in the most adverse of circumstances. It was also challenging, as the facilitators, who were also working as translators, filtered workshop information to the researcher in order for the workshop to continue.

The third challenge related to the actions of the workshop facilitators. During workshop Group Two, the facilitator took control of the game for periods of time due to the low levels of digital literacy exhibited within the group. In this workshop, instead of helping the participants navigate the game interface, the participants instructed the facilitator as to what they wanted to enact within the game. This process had two results. Participants would sometimes object to the action proposed before it had been enacted, and the facilitator sometimes influenced in-game actions as exemplified in the exchange between participants and the facilitator below:

"We should build a toilet as close as possible to the houses, so we don't have to walk so far." (Participant Two, Group Two)

"No! We need to move all of the houses further away. If we do this, they won't be flooded. We should move both away for our children." (Participant Four, Group Two)

"Yes, if you do that, then you won't get sick. We [Chintan] can help and so can Safai Sena [the local waste pickers collective]. We should put them here." (Facilitator, Group Two)

While useful conversation took place between the participants, the facilitator was much more a part of the workshops than in Group One that was led by the participants. This resulted in less discussion amongst participants than in Group One and draws 
parallels with what Cooke and Kothari describe as "facipulation" (Cooke \& Kothari, 2001).

\subsubsection{Experiential stories as a means to explore social and spatial tensions and ideas}

The discussion amongst participants during gameplay in Maslow's Palace was not guided through pre-determined themes; instead, the participants introduced topics and incidents they found meaningful and the developed these into what Leong and Iversen describe as "meaningful alternatives" (Leong \& Iversen, 2015). These were in relationship to the overall focus of the workshop (i.e. slum-upgrading) and in response to the in-game workshop actions by themselves and others to form what Foth and Brynskov describe as meaningful civic engagement (Foth \& Brynskov, 2016).

The interactions between participants evolved through collaborative, participatory storytelling (Baumann, Caldwell, Bar, \& Stokes, 2018; Baumann et al., 2017) about real world experiences within a "hybrid-reality" (Ylipulli et al., 2017) that was an assemblage of virtual (in-game) and real-world components. The participants in both workshop groups proposed events to add to the "story" that evolved through gameplay, which were created collectively to describe specific real-world situations with reference to the speculative digital world of the game (i.e. a hybrid-reality). An example of this is illustrated in section 6.2.4.1.1 where participants projected realworld people into the game and used those as discursive parameters. In doing so this adaptive narrative framing allowed participants to step in and out of the game and provided each participant with new ways to subvert past legitimacies (Pickersgill, 2017, p. 78; Walton, 1993) and socio-cultural structures (Arnab et al., 2015; Kebritchi \& Hirumi, 2008) through actions within "temporary worlds [the game world] within the ordinary world [the real world context of Bhalswa], dedicated to the performance of an act apart [the gameplay]" (Huizinga, 1955, p. 10). In another example, Participant Two of Group Two described the challenges of waste segregation encroaching on living areas, and that it would be better if this was conducted further from homes, in response to landslide debris within Level Three (Figure 123, below).

"We need to move all of the sorting away from homes. Two weeks ago, during the rain, the foil [collected aluminium foil for recycling] was washed through my door. This takes so long [to clean up]. If we 
move all of this and make an area for it where it can stay, then we won't have this problem. See like this. Can you remove all of these?" [the participant instructed the facilitator, who had control of the mouse, to delete in-game debris]. "Then make the houses there with no waste. And that [sorting area] can be over there, maybe with containers" (Participant Two, Group Two).

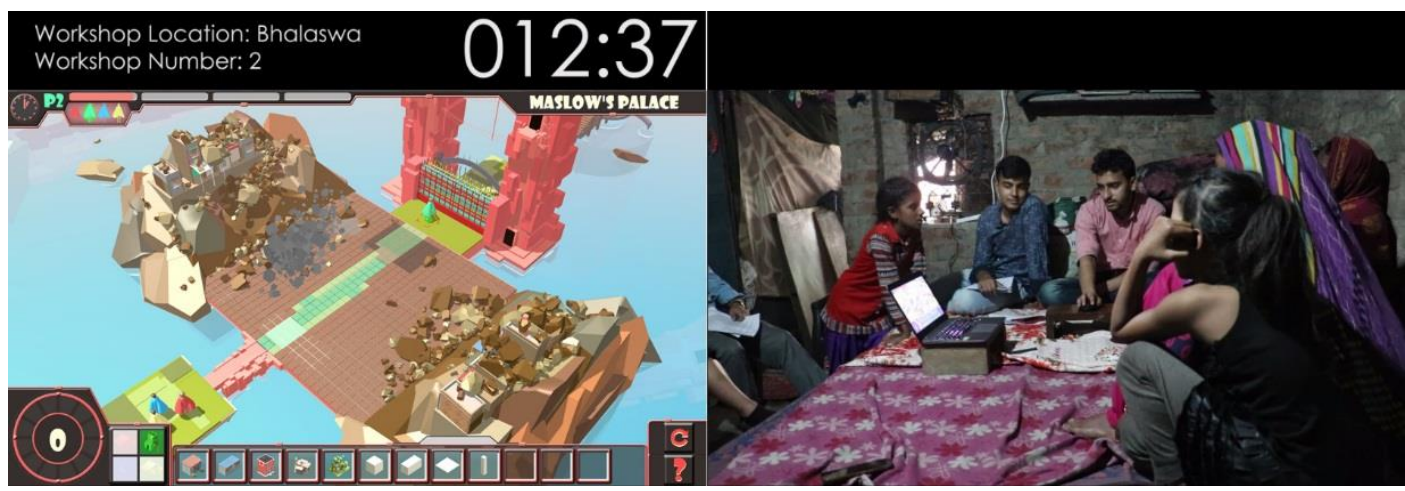

Figure 122. Phase Three research procedure. Bhalswa, Group Two.

In the case study, the effects of telling stories within the Bhalswa groups produced a range of outcomes as described below.

- Participants' personal experiences were embedded within the stories they told or descriptions they gave, such as those that embody the participants' own experiences, and tacit and latent values and needs. Through this process, participants were afforded opportunities to communicate their own insights and supplemental information to the gameplay in an informal manner. This may encourage participants to raise personal or sensitive topics that might otherwise be hard to share in a face-to-face interaction with unfamiliar people, where a power imbalance may be present between participants.

- "Meaningful alternatives" (Leong \& Iversen, 2015) for slum-upgrading action were envisioned through the cooperative evolution of stories.

- By envisioning future scenarios or exploring problems through collaborative, participatory storytelling (Baumann et al., 2018, 2017) a continuous interplay between the imagination and facts is enabled. 


\subsubsection{Summary}

As evidenced by the analysis in this chapter, the slum-upgrading challenges faced by the Bhalswa community are acute, but the SPS-UG workshop process provided a number of both social-oriented outcomes and design-oriented (slum-upgrading) outcomes. In some instances, it helped disparate stakeholders to explore possible futures both within the game and as discourse between participants, and it helped to reconcile conflicting stakeholder perspectives and corresponding goals surrounding social and urban issues.

The social outcomes and the design/slum-upgrading outcomes arising from the Bhalswa workshops were linked by the exploration of conflict (social issues) and which enabled creative solutions to problems. The case study provided new insights into the value of participatory storytelling (Baumann et al., 2018, 2017) about recollections of real-world experiences within a "hybrid-reality" (Ylipulli et al., 2017) which were created collectively to describe specific real-world situations with reference to the speculative digital world of the game. The case study also showed how the SPS-UG process also allowed participants to generate consensus around specific slum-upgrading ideas in some instances and galvanise around broader matters of concern when individual differences were harder to reconcile. The slum-upgrading outcomes were also aided by the participants' abilities to adapt the game environment of Maslow's Palace to represent spaces that were not originally built into the game, and thus explore ideas that were not considered through the development of the game.

However, while the participants arrived at a number of positive outcomes, the case study highlighted some of the challenges faced in conducting ICT-based participatory workshops with marginalised communities, including finding an appropriate workshop location, adapting processes as required, unforeseen challenges - such as sudden bereavements within the community.

The case study also illustrated the importance of understanding how the facilitator's actions can affect the interactions between participants, how the participants utilise digital tools and the workshops outcomes-particularly in low-resource communities with low levels of digital literacy. 


\section{Case Study Three - Shanti Nagar}

In the beginning I just wanted to play [Maslow's Palace]. But then I saw the building and how we can change the community and the area. That is what we should do.

- (Participant Four, Group Five).

\subsection{Introduction}

The previous chapter detailed the research findings of the Ghazipur and Bhalswa case study through a thematic analysis of participatory design workshops utilising the SPS-UG approach with the Ghazipur community. This chapter reports on the findings of the Shanti Nagar case study (CS3), which evaluated Maslow's Palace as a tool and method of participatory design engagement. The chapter details the primary design inquiries and conducts thematic analysis of the pre-test and post-test structured interviews and workshop recordings and observations. This chapter contributes toward:

Aim 4: To develop, implement and reflect on the use of a speculative, participatory, game-based approach to slum-upgrading in order to aid the generation of useful urban slum-upgrading oriented social outcomes and related architectural design slum-upgrading outcomes for disparate stakeholders in marginalised communities, more specifically, dwellers of landfill-oriented slums.

\subsubsection{Summary of Case Study Three - Shanti Nagar}

This chapter summarises the experience and evaluation of the Phase Three participatory design workshops utilising the SPS-UG approach with the Shanti Nagar 
community in accordance with the methods of data collection and analysis detailed in Chapter Three (Figure 123). To respond to the research question, data was gathered through the coordination and recording of a series of four participatory workshops using Maslow's Palace, held with residents of the Shanti Nagar community in collaboration with Apnalaya, a non-profit who work closely with the community, between 16 and 23 November 2017.

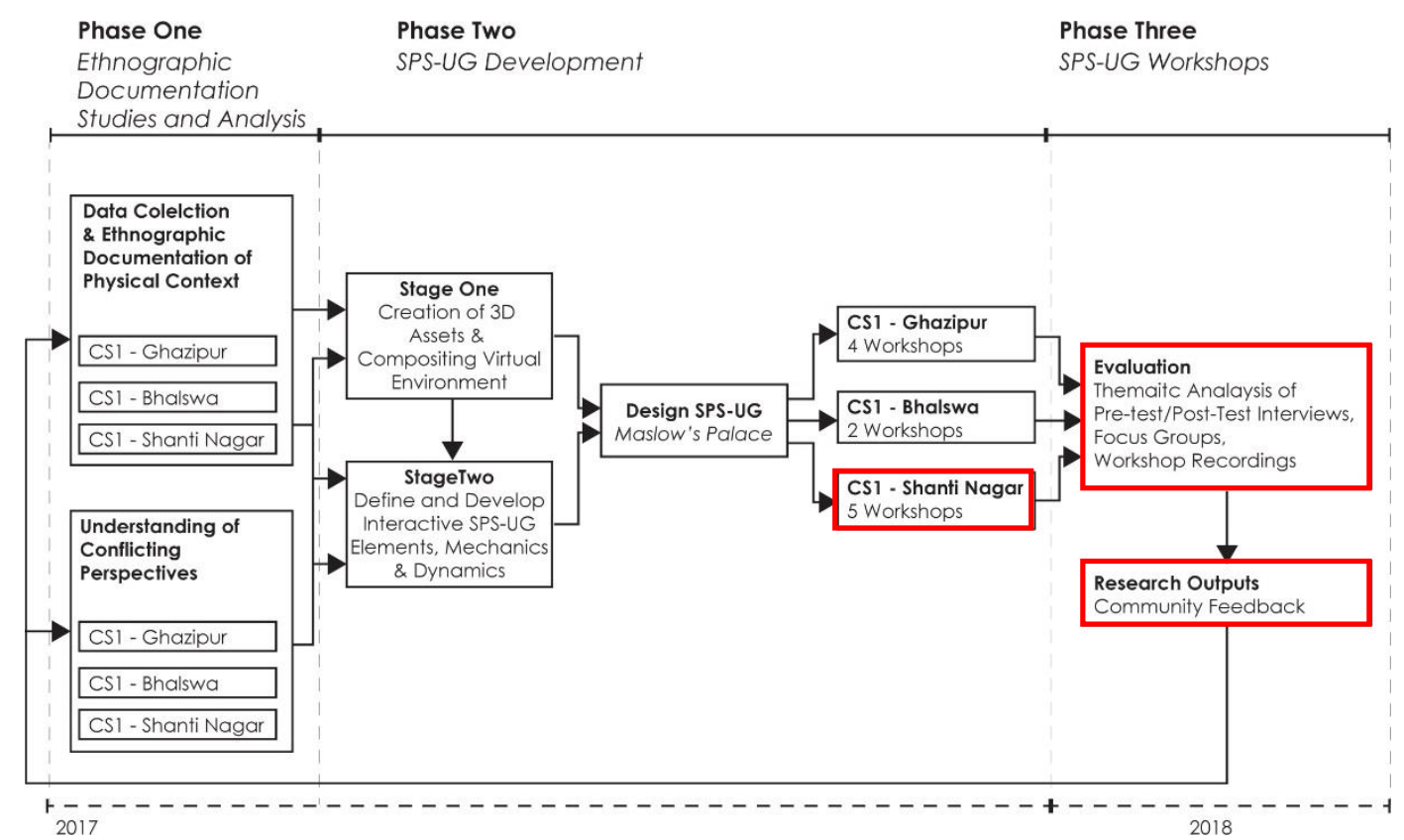

Figure 123. CS3 - Shanti Nagar located within the visual timeline of the research methodology.

The thematic analysis of the workshop data revealed two socially-orientated outcomes:

- aiding the discussion of sensitive topics;

- helping participants reflect on their workshop experiences in relation to their real-world experience through "recursive engagement" (Teli, Bordin, Blanco, Orabona, \& Angeli, 2015).

The analysis also revealed three design-oriented (slum-upgrading) outcomes:

- gaining better access to educational institutions;

- decreasing pollution;

- gaining access to higher quality public and recreational spaces.

Finally, the chapter discusses how playful interaction resulted in cooperation between participants, how the SPS-UG process increased some forms of social capital and how this specifically benefitted the youth involved in the workshops and how the 
SPS-UG aided “participatory visioning” (McCormick, 2013; Quist \& Vergragt, 2006; Ryan, 2013)

\subsection{Case Study: Shanti Nagar}

\subsubsection{Aim of the Workshops}

The participatory design workshops were conducted with the Shanti Nagar community between 16 and 23 November 2017. Each aimed to explore, but was not limited to, a range of key slum-upgrading related issues identified by the community during Phase One, which were embedded into the design of the game Maslow's Palace. As shown in Chapter Four, these included issues relating to access to potable drinking water, reducing pollution, increasing educational opportunities and the development of public and recreational spaces. Specifically, the workshops aimed to aid the Shanti Nagar participants in upgrading ideation and exploring conflicting upgrading perspectives with the Apnalaya community to create solidarity through a recognition of difference via conceiving a plurality of possible futures.

\subsubsection{Shanti Nagar Participants}

A total of five workshops were conducted in Shanti Nagar using Maslow's Palace, involving 20 participants (four per workshop). Most participants were affiliated with Apnalaya in various capacities; however, most had been part of their youth community engagement programme. Some participants were concurrently volunteering with Apnalaya to help them conduct their own research into the hardships faced by the community (such as access to potable water) and so were embedded in development issues faced by the community. Some were involved in youth programmes such as those dealing with domestic violence. Some participants were involved in drama schools in the area, while others had limited or no connection with the organisation. None of the participants were engaged in waste-picking directly, although many of them had family members involved in the practice. Most participants had at least some degree of high school level education. Participants were comprised of a group of youth aged between 16 and 21 years old with a mean age of 17.25 years. All participants were Muslim who had lived in Shanti Nagar since birth. 11 participants were female and 9 were male. Ten of the participants had previously been involved in the Phase 
One study. Most participants largely lived close to or within the grid street resettlement area of Shanti Nagar, while some lived close by in the adjoining colonies of Bainganwadi, with two participants living in the slum area of Rafiq Nagar. All of these areas suffer similar issues (such as access to potable water), as they are the least established within the wider community. A table of participants is shown below.

Table 26. Demographic information about workshop participants - Shanti Nagar, Mumbai

\begin{tabular}{lllllllll}
\hline $\begin{array}{llllll}\text { Grp. } \\
\text { No. }\end{array}$ & $\begin{array}{l}\text { Part. } \\
\text { No. }\end{array}$ & Age & Sex & $\begin{array}{l}\text { Digital } \\
\text { Literacy }\end{array}$ & Religion & $\begin{array}{l}\text { Year } \\
\text { Arrived }\end{array}$ & Arrived from & Occupation \\
\hline 1 & 1 & 21 & $\mathrm{~m}$ & High & Muslim & N/A & N/A & University \\
& & & & & & & Student \\
1 & 2 & 21 & $\mathrm{~m}$ & High & Muslim & N/A & N/A & Mechanic \\
1 & 3 & 18 & $\mathrm{~m}$ & High & Muslim & N/A & N/A & Student \\
1 & 4 & & & High & Muslim & N/A & N/A & Dance \\
& & 20 & $\mathrm{~m}$ & & & & Instructor \\
\hline 2 & 1 & 17 & $\mathrm{~m}$ & High & Hindu & N/A & N/A & Student \\
2 & 2 & 17 & $\mathrm{~m}$ & High & Muslim & N/A & N/A & Student \\
2 & 3 & 16 & $\mathrm{f}$ & Medium & Muslim & N/A & N/A & Student \\
2 & 4 & 17 & $\mathrm{~m}$ & High & Muslim & N/A & N/A & Student \\
\hline 3 & 1 & 16 & f & High & Muslim & N/A & N/A & Student \\
3 & 2 & 16 & $\mathrm{~m}$ & High & Muslim & N/A & N/A & Student \\
3 & 3 & 16 & $\mathrm{~m}$ & High & Muslim & N/A & N/A & Student \\
3 & 4 & 16 & f & Medium & Muslim & N/A & N/A & Student \\
\hline 4 & 1 & 17 & f & Medium & Muslim & N/A & N/A & Student \\
4 & 2 & 16 & f & Medium & Muslim & N/A & N/A & Student \\
4 & 3 & 17 & f & Medium & Muslim & N/A & N/A & Student \\
4 & 4 & 16 & f & Medium & Muslim & N/A & N/A & Student \\
\hline 5 & 1 & 16 & f & Medium & Muslim & N/A & N/A & Student \\
5 & 2 & 19 & f & Medium & Muslim & N/A & N/A & Student \\
5 & 3 & 17 & f & Medium & Muslim & N/A & N/A & Student \\
5 & 4 & 16 & f & Medium & Muslim & N/A & N/A & Student \\
& & & & & & & &
\end{tabular}

\subsubsection{Workshop Preparation Process}

The Shanti Nagar workshops were held within the Apnalaya Community Hall in Shanti Nagar (Figure 124 and Figure 125). 


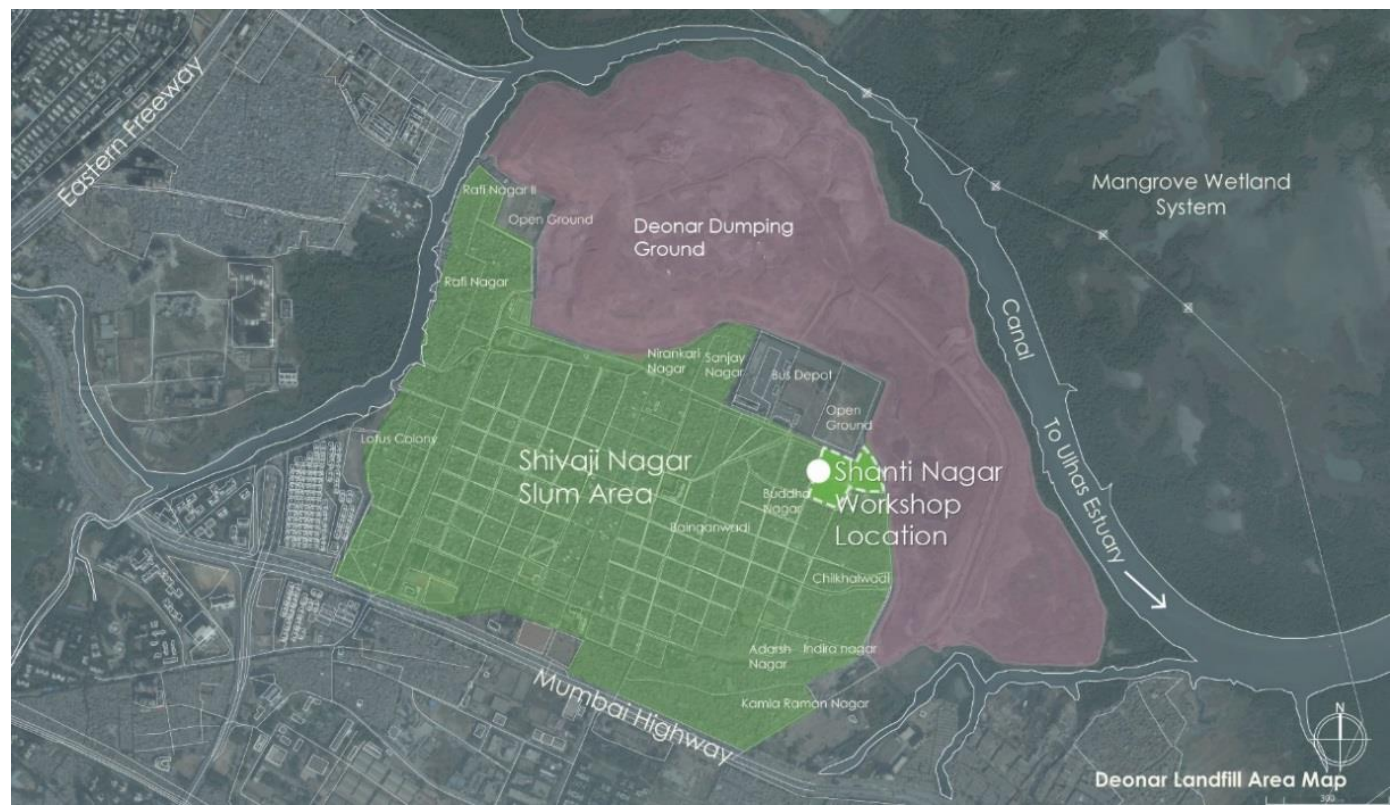

Figure 124. The location of the Shanti Nagar workshops. November 2017.

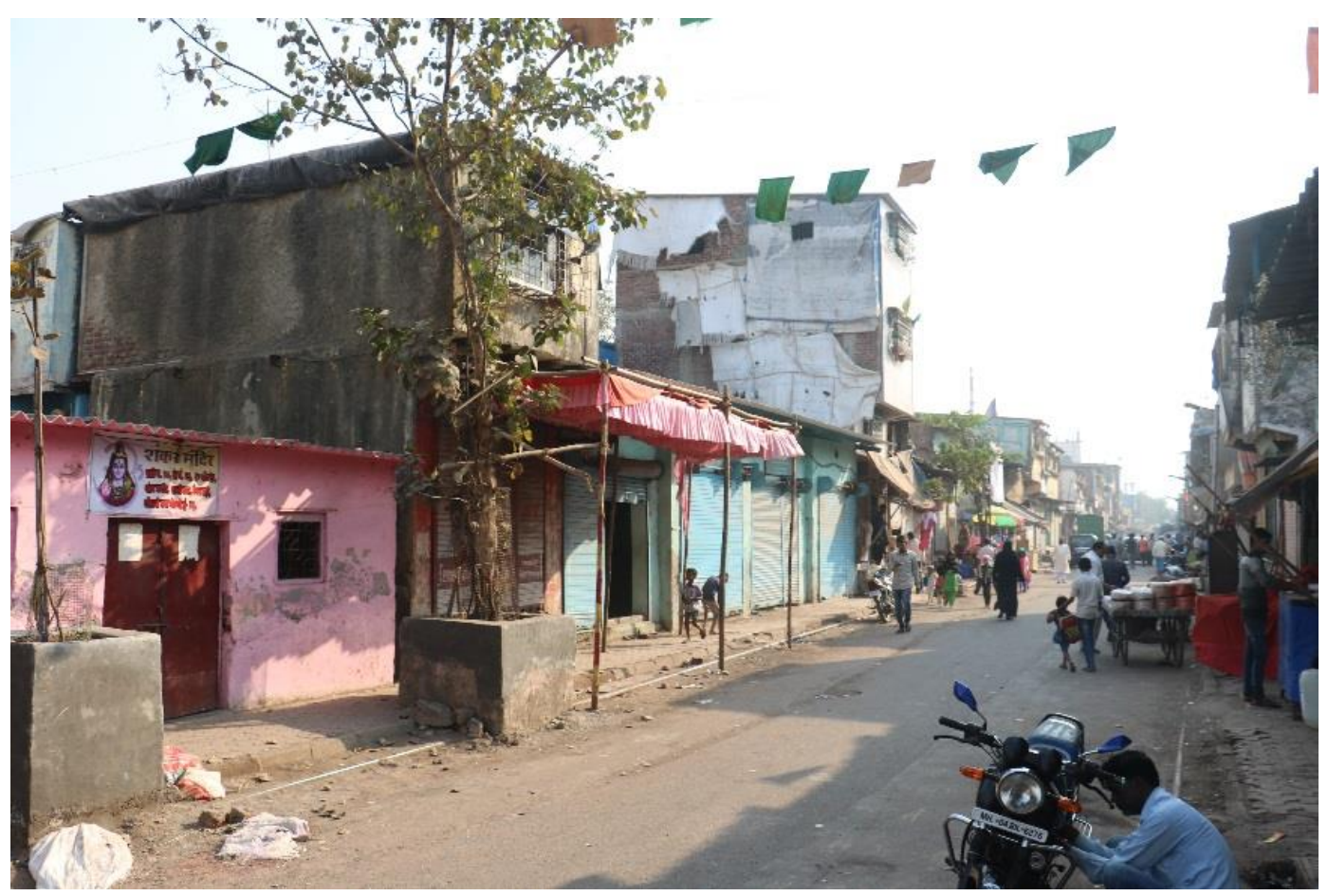

Figure 125. The Apnalaya Community Hall, Shanti Nagar, Mumbai, December 2017.

The Shanti Nagar workshops were organised and facilitated by three staff members from Apnalaya - two male and two female. These staff members worked closely with the community on a range of community development issues and were therefore familiar to all participants. The facilitators were trained in the use of Maslow's Palace and its objectives before the workshops, and they were given a specific set of workshop 
and facilitation instructions to follow (Appendix 3). They were instructed to let the participants play the game by themselves and only provide assistance if a participant specifically asked for help. The twenty participants were divided into five workshop groups of four participants each (see Table 22. ). Within these groups the facilitators conducted the pre-test structured interviews (Appendix 4), after which each group played Maslow's Palace. Each gameplay session took between 45 and 90 minutes. Upon completion, the facilitators conducted the post-test structured interviews.

The participatory workshop space is diagrammed in Figure 126 and shown in Figure 127, below. Maslow's Palace was played by the participants on a laptop, which recorded screen capture footage of the gameplay, with participants sitting on the ground. A digital SLR camera recorded video the workshop procedure, while the researcher recorded photographs and observations.

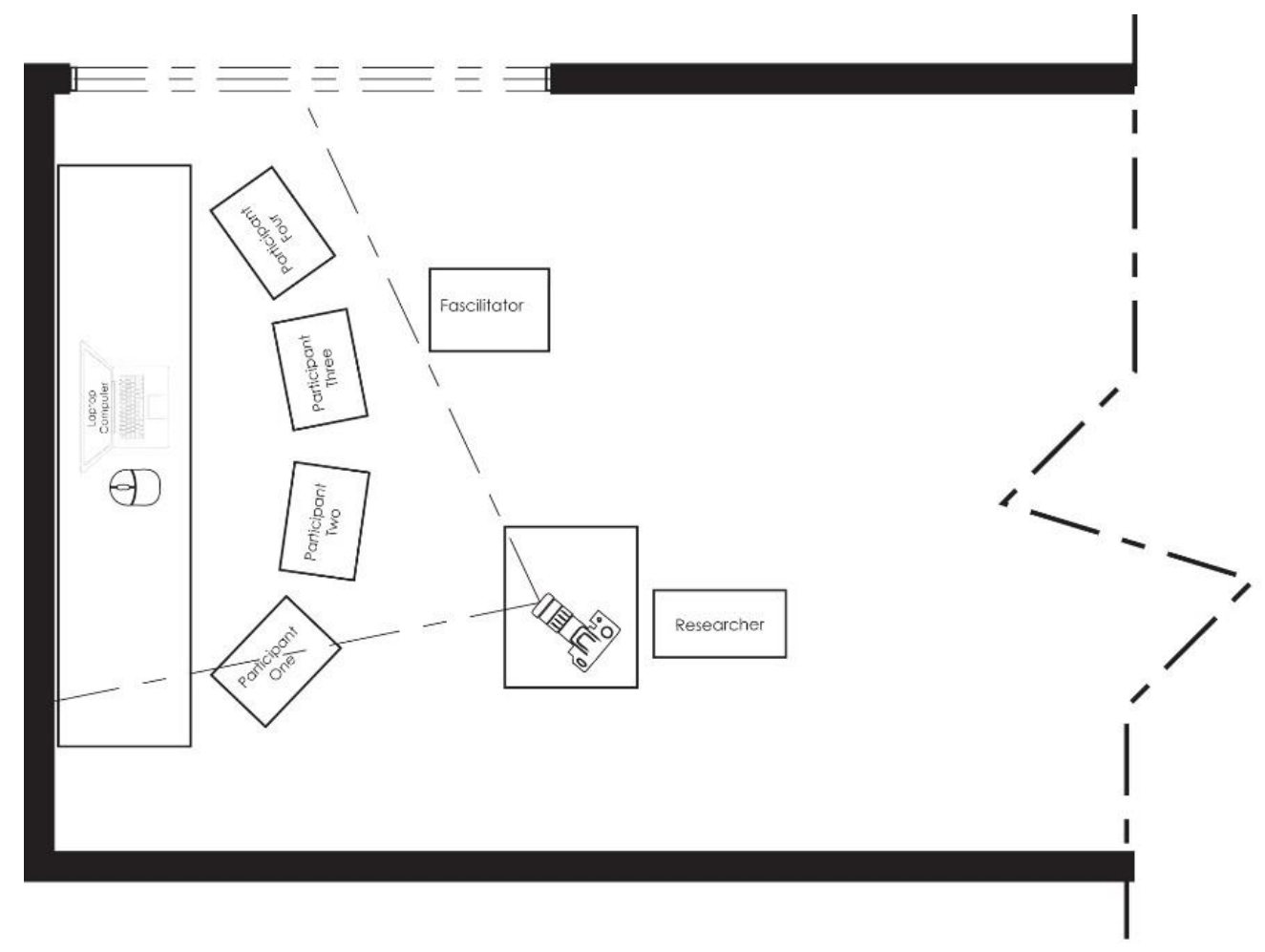

Figure 126. Floorplan of the Shanti Nagar workshop space. 


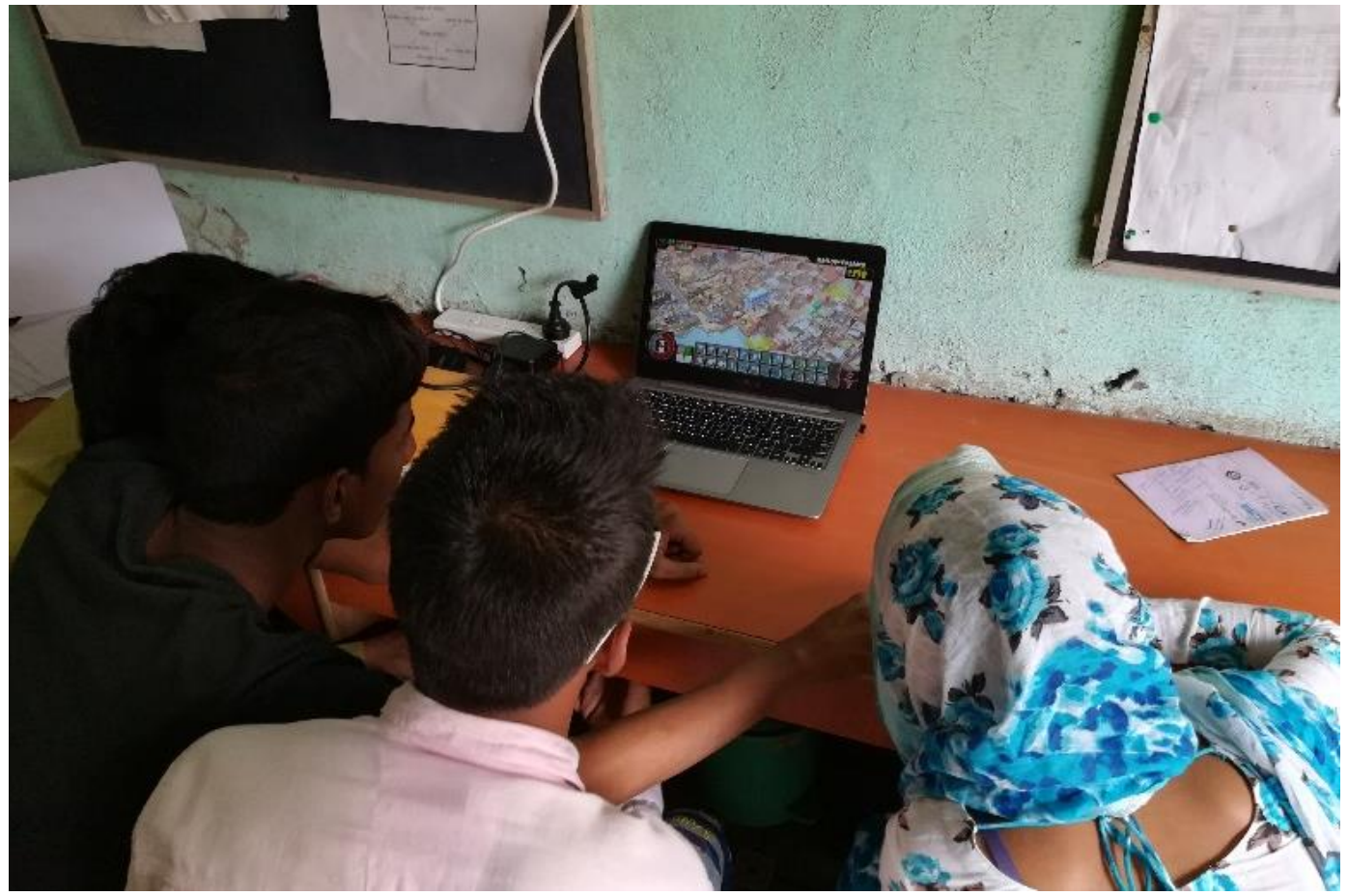

Figure 127. Shanti Nagar Workshop 2 participants playing Maslow's Palace, November 2017.

\subsubsection{Findings}

A level by level summary of workshop outcomes is provided in Table 27 below. This is followed by findings of the thematic analysis of the workshop data are presented in the sections below. Firstly, qualitative assessment of social outcomes, in terms of slum-upgrading ideation resulting during gameplay, is presented (section 7.2.4.1). This is followed by an assessment of design (slum-upgrading) outcomes, in terms of generating consensus around particular slum-upgrading ideas resulting during gameplay (section 7.2.4.2).

Table 27. Maslow's Palace workshop outcomes - Shanti Nagar

\begin{tabular}{|c|c|c|c|c|c|}
\hline & Group 1 & Group 2 & Group 3 & Group 4 & Group 5 \\
\hline Level 1 & $\begin{array}{l}\text { - No slum- } \\
\text { upgrading or } \\
\text { social issues } \\
\text { were discussed. }\end{array}$ & $\begin{array}{l}\text { - No slum- } \\
\text { upgrading or } \\
\text { social issues } \\
\text { were discussed. }\end{array}$ & $\begin{array}{l}\quad \text { Collective } \\
\text { Tinkering (J. E. } \\
\text { Innes \& Booher, } \\
\text { 1999, p. 9) } \\
\text { Evidence: } \\
\text { Participants } \\
\text { helped each other } \\
\text { learn the } \\
\text { navigation } \\
\text { interface. }\end{array}$ & $\begin{array}{l}\text { - No slum- } \\
\text { upgrading or } \\
\text { social issues } \\
\text { were discussed. }\end{array}$ & $\begin{array}{l}\text { - No slum- } \\
\text { upgrading or } \\
\text { social issues } \\
\text { were discussed. }\end{array}$ \\
\hline
\end{tabular}




\begin{tabular}{|c|c|c|c|c|c|}
\hline Level 2 & $\begin{array}{l}\text { - No slum- } \\
\text { upgrading or } \\
\text { social issues } \\
\text { were discussed. }\end{array}$ & $\begin{array}{l}\text { - Collective } \\
\text { Tinkering (J. E. } \\
\text { Innes \& Booher, } \\
\text { 1999, p. 9) } \\
\text { Evidence: } \\
\text { Participants } \\
\text { helped each } \\
\text { other learn the } \\
\text { inventory } \\
\text { interface. }\end{array}$ & $\begin{array}{l}\text { - No slum- } \\
\text { upgrading or } \\
\text { social issues } \\
\text { were discussed }\end{array}$ & $\begin{array}{l}\text { - Collective } \\
\text { Tinkering (J. E. } \\
\text { Innes \& Booher, } \\
\text { 1999, p. 9) } \\
\text { Evidence: } \\
\text { Participants } \\
\text { helped each other } \\
\text { learn the } \\
\text { inventory } \\
\text { interface. }\end{array}$ & $\begin{array}{l}\text { - Collective } \\
\text { Tinkering (J. } \\
\text { E. Innes \& } \\
\text { Booher, 1999, } \\
\text { p. 9) } \\
\text { Evidence: } \\
\text { Participants } \\
\text { helped each } \\
\text { other learn the } \\
\text { inventory } \\
\text { interface. }\end{array}$ \\
\hline Level 3 & $\begin{array}{l}\text { - No slum- } \\
\text { upgrading or } \\
\text { social issues } \\
\text { were discussed. }\end{array}$ & $\begin{array}{l}\text { - Revealing } \\
\text { conflicting } \\
\text { perspectives } \\
\text { (Iversen et al., } \\
\text { 2012) - and } \\
\text { Perceptual } \\
\text { bridging" } \\
\text { (Auger, 2012) } \\
\text { Evidence: The } \\
\text { importance of } \\
\text { better public } \\
\text { toilets. } \\
\text { • The } \\
\text { importance of } \\
\text { mosques }\end{array}$ & $\begin{array}{l}\text { - No slum- } \\
\text { upgrading or } \\
\text { social issues } \\
\text { were discussed. }\end{array}$ & $\begin{array}{l}\text { - No slum- } \\
\text { upgrading or } \\
\text { social issues } \\
\text { were discussed. }\end{array}$ & $\begin{array}{l}\text { - No slum- } \\
\text { upgrading or } \\
\text { social issues } \\
\text { were discussed }\end{array}$ \\
\hline Level 4 & $\begin{array}{l}\quad \text { No slum- } \\
\text { upgrading or } \\
\text { social issues } \\
\text { were discussed. }\end{array}$ & $\begin{array}{l}\text { - No slum- } \\
\text { upgrading or } \\
\text { social issues } \\
\text { were discussed }\end{array}$ & $\begin{array}{l}\quad \text { No slum- } \\
\text { upgrading or } \\
\text { social issues } \\
\text { were discussed. }\end{array}$ & $\begin{array}{l}\text { - No slum- } \\
\text { upgrading or } \\
\text { social issues } \\
\text { were discussed. }\end{array}$ & $\begin{array}{l}\quad \text { No slum- } \\
\text { upgrading or } \\
\text { social issues } \\
\text { were discussed. }\end{array}$ \\
\hline Level 5 & $\begin{array}{l}\text { - Collective } \\
\text { Tinkering (J. E. } \\
\text { Innes \& Booher, } \\
\text { 1999, p. 9) } \\
\text { Evidence: } \\
\text { Participants spent } \\
\text { time demolishing } \\
\text { large portions of } \\
\text { the map "for } \\
\text { fun", but it } \\
\text { restricted in- } \\
\text { game financial } \\
\text { resources. }\end{array}$ & $\begin{array}{l}\text { • Collective } \\
\text { Tinkering (J. E. } \\
\text { Innes \& Booher, } \\
\text { 1999, p. 9) and } \\
\text { perceptual } \\
\text { bridging" } \\
\text { (Auger, 2012) - } \\
\text { Evidence: } \\
\text { Development of a } \\
\text { cricket pitch. }\end{array}$ & $\begin{array}{l}\text { • Collective } \\
\text { Tinkering (J. E. } \\
\text { Innes \& Booher, } \\
\text { 1999, p. 9), } \\
\text { Revealing } \\
\text { conflicting } \\
\text { perspectives } \\
\text { (Iversen et al., } \\
\text { 2012) and } \\
\text { perceptual } \\
\text { bridging" } \\
\text { (Auger, 2012) - } \\
\text { Evidence: } \\
\text { Discussion of } \\
\text { LGTBQIA+ rights } \\
\text { in relationship to } \\
\text { the positioning of } \\
\text { toilets within the } \\
\text { community. } \\
\text { • The } \\
\text { construction of } \\
\text { recycling centre } \\
\text { in Shivaji Nagar } \\
\text { to alleviate } \\
\text { pollution. } \\
\text { • Development } \\
\text { of a playground } \\
\text { and public } \\
\text { spaces. }\end{array}$ & $\begin{array}{l}\text { - Collective } \\
\text { Tinkering (J. E. } \\
\text { Innes \& Booher, } \\
\text { 1999, p. 9) and } \\
\text { perceptual } \\
\text { bridging" } \\
\text { (Auger, 2012) - } \\
\text { Evidence: The } \\
\text { cricket pitch area } \\
\text { could be } \\
\text { developed for } \\
\text { housing and } \\
\text { schools. } \\
\text { - Development } \\
\text { of a playground } \\
\text { and public spaces } \\
\text { - Participants } \\
\text { spent time trying } \\
\text { to walk their } \\
\text { avatars into the } \\
\text { water and } \\
\text { demolishing } \\
\text { large portions of } \\
\text { the map "for } \\
\text { fun". }\end{array}$ & $\begin{array}{l}\text { • Developing } \\
\text { and } \\
\text { Grounding } \\
\text { Knowledge, } \\
\text { Values and } \\
\text { Goals (Brandt, } \\
\text { 2006; Brandt \& } \\
\text { Messeter, 2004; } \\
\text { Brandt et al., } \\
\text { 2008; Dindler } \\
\text { \& Iversen, } \\
\text { 2007) } \\
\text { Evidence: The } \\
\text { workshop group } \\
\text { asked to play the } \\
\text { level again as they } \\
\text { were not satisfied } \\
\text { with their } \\
\text { outcomes } \\
\text { Perceptual } \\
\text { bridging" } \\
\text { (Auger, 2012) - } \\
\text { Evidence: } \\
\text { Housing needs to } \\
\text { be in close } \\
\text { proximity to } \\
\text { schools. }\end{array}$ \\
\hline $\begin{array}{l}\text { Pre- } \\
\text { test/Post- } \\
\text { test } \\
\text { Findings }\end{array}$ & $\begin{array}{l}\text { • Developing } \\
\text { and Grounding } \\
\text { Knowledge, } \\
\text { Values and } \\
\text { Goals (Brandt, } \\
\text { 2006; Brandt \& } \\
\text { Messeter, 2004; } \\
\text { Brandt et al., } \\
\text { 2008; Dindler \& } \\
\text { Iversen, 2007) } \\
\text { Evidence: Reduce } \\
\text { solidarity around } \\
\text { pollution/area } \\
\text { cleanliness. } \\
\text { Solidarity around }\end{array}$ & $\begin{array}{l}\text { • Developing } \\
\text { and Grounding } \\
\text { Knowledge, } \\
\text { Values and } \\
\text { Goals ((Brandt, } \\
\text { 2006; Brandt \& } \\
\text { Messeter, 2004; } \\
\text { Brandt et al., } \\
\text { 2008; Dindler \& } \\
\text { Iversen, 2007) } \\
\text { Evidence: } \\
\text { Reduced solidarity } \\
\text { around drug } \\
\text { problems. } \\
\text { Participants } \\
\text { identified a large }\end{array}$ & $\begin{array}{l}\text { - Developing } \\
\text { and Grounding } \\
\text { Knowledge, } \\
\text { Values and } \\
\text { Goals (Brandt, } \\
\text { 2006; Brandt \& } \\
\text { Messeter, 2004; } \\
\text { Brandt et al., } \\
\text { 2008; Dindler \& } \\
\text { Iversen, 2007) } \\
\text { Evidence: } \\
\text { Participants } \\
\text { highlighted the } \\
\text { need for schools in } \\
\text { their community. }\end{array}$ & $\begin{array}{l}\text { • Developing } \\
\text { and Grounding } \\
\text { Knowledge, } \\
\text { Values and } \\
\text { Goals ((Brandt, } \\
\text { 2006; Brandt \& } \\
\text { Messeter, 2004; } \\
\text { Brandt et al., } \\
\text { 2008; Dindler \& } \\
\text { Iversen, 2007) } \\
\text { Evidence: } \\
\text { Participants } \\
\text { highlighted the } \\
\text { need for schools in } \\
\text { their community. }\end{array}$ & $\begin{array}{l}\bullet \quad \text { Developing } \\
\text { and } \\
\text { Grounding } \\
\text { Knowledge, } \\
\text { Values and } \\
\text { Goals(Brandt, } \\
\text { 2006; Brandt \& } \\
\text { Messeter, 2004; } \\
\text { Brandt et al., } \\
\text { 2008; Dindler } \\
\text { \& Iversen, } \\
\text { 2007) } \\
\text { Evidence: } \\
\text { Participants } \\
\text { highlighted the } \\
\text { need for public }\end{array}$ \\
\hline
\end{tabular}




\begin{tabular}{|c|c|c|c|c|c|}
\hline & $\begin{array}{l}\text { increased access to } \\
\text { drinking water. }\end{array}$ & $\begin{array}{l}\text { range of issues in } \\
\text { the post-test } \\
\text { analysis as being } \\
\text { important to them. }\end{array}$ & & & $\begin{array}{l}\text { spaces in their } \\
\text { community. }\end{array}$ \\
\hline $\begin{array}{l}\text { Focus } \\
\text { Group } \\
\text { Findings }\end{array}$ & $\begin{array}{l}\text { Grounding } \\
\text { Knowledge, } \\
\text { Values and } \\
\text { Goals (Brandt, } \\
\text { 2006; Brandt \& } \\
\text { Messeter, 2004; } \\
\text { Brandt et al., } \\
\text { 2008; Dindler \& } \\
\text { Iversen, } \\
\text { 2007)Playful } \\
\text { public } \\
\text { participation } \\
\text { (Krek, 2008) } \\
\text { Evidence: Gaining } \\
\text { further } \\
\text { understanding of } \\
\text { each other's } \\
\text { perspectives and } \\
\text { that the game made } \\
\text { them feel } \\
\text { comfortable } \\
\text { expressing their } \\
\text { opinions and } \\
\text { development of } \\
\text { social capital. } \\
\text { • Appreciative } \\
\text { of the small } \\
\text { working groups, } \\
\text { as they found it } \\
\text { more comfortable } \\
\text { to express their } \\
\text { opinions. }\end{array}$ & $\begin{array}{l}\text { • Developed } \\
\text { Social Capital } \\
\text { (Brandt, 2006; } \\
\text { Brandt \& } \\
\text { Messeter, 2004; } \\
\text { Brandt et al., } \\
\text { 2008; Dindler \& } \\
\text { Iversen, 2007) } \\
\text { Evidence: } \\
\text { Maslow's Palace } \\
\text { had increased their } \\
\text { interest in } \\
\text { technology and } \\
\text { community } \\
\text { development. }\end{array}$ & $\begin{array}{l}\text { • Grounding } \\
\text { Knowledge, } \\
\text { Values and } \\
\text { Goals (Brandt, } \\
\text { 2006; Brandt \& } \\
\text { Messeter, 2004; } \\
\text { Brandt et al., } \\
\text { 2008; Dindler \& } \\
\text { Iversen, 2007) } \\
\text { Evidence: The } \\
\text { workshop also gave } \\
\text { participants a sense } \\
\text { of purpose in terms } \\
\text { of upgrading goals. }\end{array}$ & $\begin{array}{l}\text { - No slum- } \\
\text { upgrading or } \\
\text { social issues } \\
\text { were discussed. }\end{array}$ & $\begin{array}{l}\text { • Grounding } \\
\text { Knowledge, } \\
\text { Values and } \\
\text { Goals (Brandt, } \\
\text { 2006; Brandt \& } \\
\text { Messeter, 2004; } \\
\text { Brandt et al., } \\
\text { 2008; Dindler } \\
\text { \& Iversen, } \\
\text { 2007) } \\
\text { Evidence: } \\
\text { Participants also } \\
\text { indicated that they } \\
\text { valued the SPS- } \\
\text { UG participatory } \\
\text { process by } \\
\text { suggesting more } \\
\text { community } \\
\text { members should } \\
\text { be involved in the } \\
\text { workshop. } \\
\text { • Developed } \\
\text { Social Capital } \\
\text { (Björgvinsson, } \\
\text { Ehn, \& } \\
\text { Hillgren, 2010; } \\
\text { Hillgren, } \\
\text { Seravalli, \& } \\
\text { Emilson, 2011). } \\
\text { Evidence: } \\
\text { Maslow's Palace } \\
\text { had increased } \\
\text { their interest in } \\
\text { technology and } \\
\text { community } \\
\text { development. } \\
\text { Participants also } \\
\text { called for more } \\
\text { dialogue between } \\
\text { themselves and } \\
\text { older community } \\
\text { members, as well } \\
\text { as officials, to } \\
\text { further improve } \\
\text { learning between } \\
\text { different } \\
\text { stakeholder } \\
\text { groups. }\end{array}$ \\
\hline
\end{tabular}

\subsubsection{Social Outcomes}

\subsection{Aiding the discussion of sensitive topics}

The SPS-UG approach aided participants to discuss sensitive or controversial topics. When conflict arose between participants - often around more complex sociopolitical issues, such as livelihood generation and security of tenure or the placement of toilets within the community in relationship to gender or LGBQTIA+ rightsperipheral issues or other facets of the issue were voiced and explored. 
For example, debate within workshop Group Three centred on the positioning of toilets within game Level Five. After some discussion with the rest of the group, Participant Four, a single man, proposed building a toilet close to the homes of other participants for convenience of access:

"It will be simpler for each person to reach the toilet" (Participant Four, Group Three).

However, this positioning was rejected by the two female participants within the group. Participant Two stated:

"We should put it in the back of the area, because it won't look nice near the houses" (Participant Two, Group Three).

After some probing by the two male participants, it was discussed that the underlying reason for wanting the toilet further away was due to the stigma surrounding menstruation. Participants discussed why the stigma exists.

One of the male participants, who identified as homosexual, raised the issue of the prevalence of violence against the LGBTQIA+ community around public toilets. He offered that:

"Toilets should have good views and cameras to catch violence" (Participant Three, Group Three).

"We decided to place the public toilet in the middle, so it would be simpler for each person to reach the toilet, but [P2] said we should place the public toilet at the back of the area because it would not look nice in the middle and because of women's issues [menstruation]. (Participant Three, Group Three).

All participants of Group Three then agreed to design a park that had good visibility with public toilets as a central component of the composition.

During the focus group discussion after the workshop, participants reported that the workshop made them feel comfortable expressing their positions, as well as enabling 
them to understand the perspectives and positions of others that they had not taken into consideration before.

"I didn't think about it [what I was saying]; I just talked about it. I don't usually talk about it. That is not good to talk about normally" (Participant Three, Group Three).

"I didn't know these things happen. I can see how that sort of fighting and bullying is bad for Shivaji Nagar" (Participant Two, Group Three).

\subsection{Reflecting through Recursive Engagement}

Reflecting on "matters of concern" (Forlano \& Mathew, 2014, p. 20) through "recursive engagement" (Teli et al., 2015) in order to link the design activities to wider societal possibilities (Marttila, Botero, \& Saad-Sulonen, 2014) helped the groups to widen their perspective on what they are concerned about (Kelty, 2008) and to carefully consider their positions and the positions of others.

After Level Five, the Group Five participants stated that they were not completely happy with their workshop outcome, as some of the design moves that they made within the game meant that they did not have enough in-game resources to action some of their desired changes.

“We were playing. I wasn't thinking about using the money. Then we ran out" (Participant Two, Group Five).

"We could try things, but we ran out of money. So we need to try again (Participant Four, Group Five).

In this instance, the workshop group asked to play the level again. During the second round of play, participants were observed collaborating more to enact more clearly defined design strategies than in the first round, as can be seen in Figure 128 and Figure 129 below. 


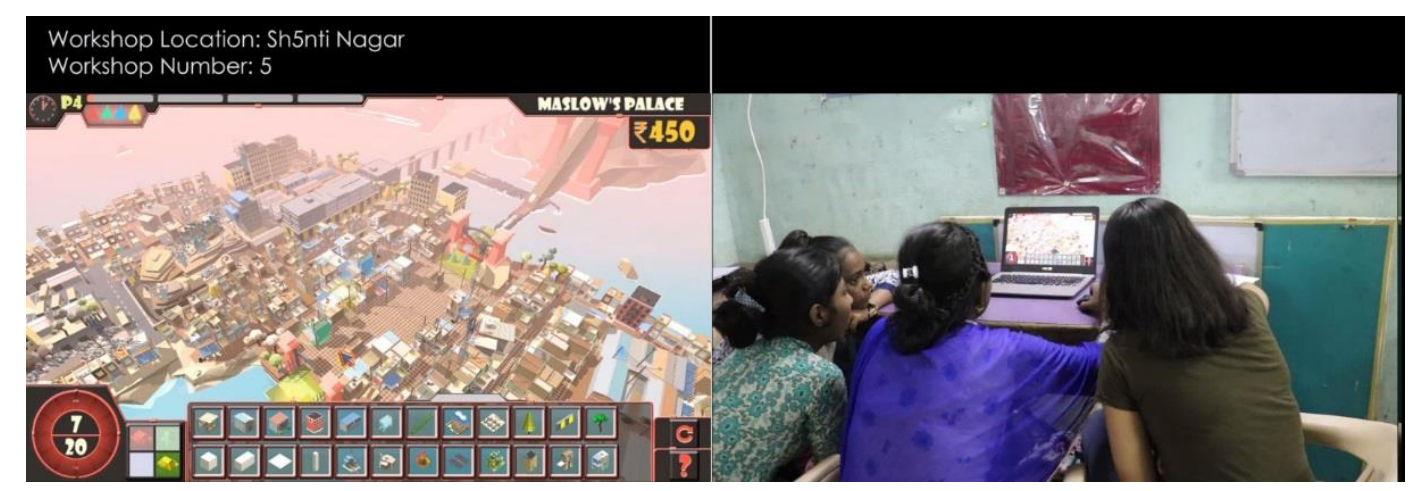

Figure 128. Iteration one. Shanti Nagar, Group Five.

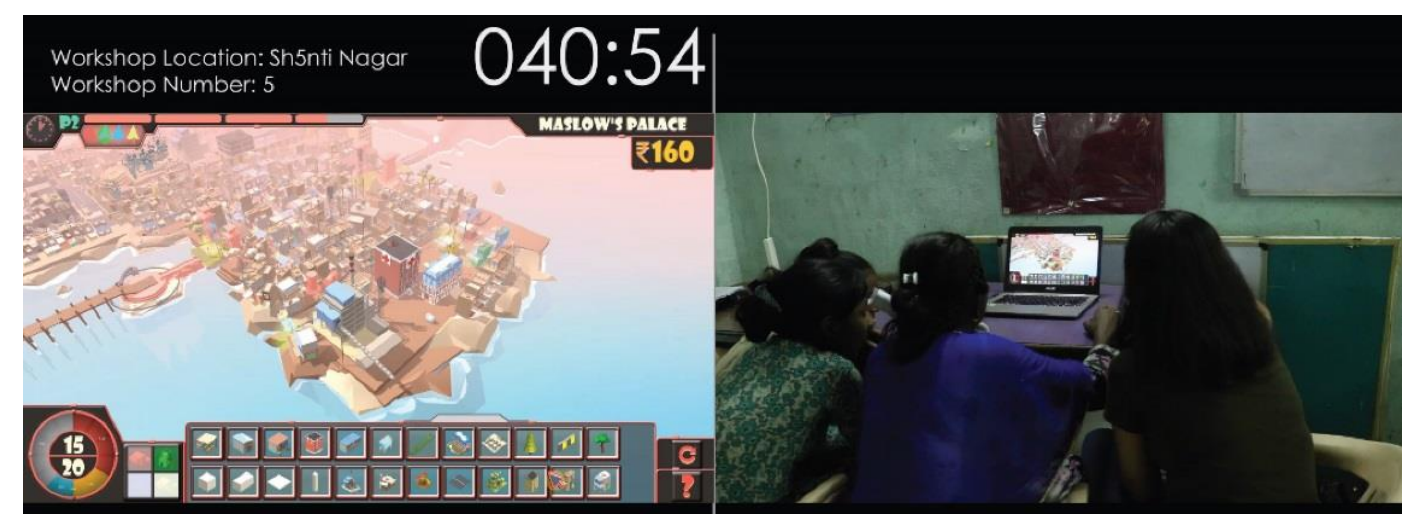

Figure 129. Iteration two. Shanti Nagar, Group Five.

This allowed participants to reflect on their past actions and the actions of others. While no additional issues were raised, the recursive process enabled the participants to refine emergent values and translate them into more concrete design ideas. In this way, the participants acted within cycles of "doing and reflecting" or "joint reflectionin-action” (Argyris \& Schön, 1978; Büscher et al., 2004; J. E. Innes \& Booher, 1999; Polanyi, 1967; Vaajakallio, 2012).

\subsubsection{Slum-upgrading Outcomes}

The workshop process produced a number of ideas, explorations and agreements surrounding urban issues by the Shanti Nagar community. These included access to schools, environmental concerns relating to garbage, position/lack of public toilets, access to public spaces, and social issues such as drug and alcohol abuse and their related effects. While the workshop did not produce feasible urban development ideas for the most part, all groups explored urban issues and created a diverse range of 
responses raised by the game and other workshop participants from the perspectives of built form, political and economic considerations and social implications detailed in the sections below.

These are reflected in the pre-test and post-test analysis of the structured interview data shown in Figure 130, below. The analysis indicates some solidarity surrounding access to drinking water for all workshop groups and lack of access to public toilets for Group Three. Similar to the pre-test responses, all groups expressed a large range of perspectives surrounding the desired changes for their environment. The responses were also categorised more often as self-actualisation and esteem out of of the Maslow's Hierachy deductive codes, than for those gathered from Ghazipur and Bhalswa which tended to be categorised as physiological or safety and security. 


\section{Assessment of Conflicting Perspectives- Shanti Nagar}

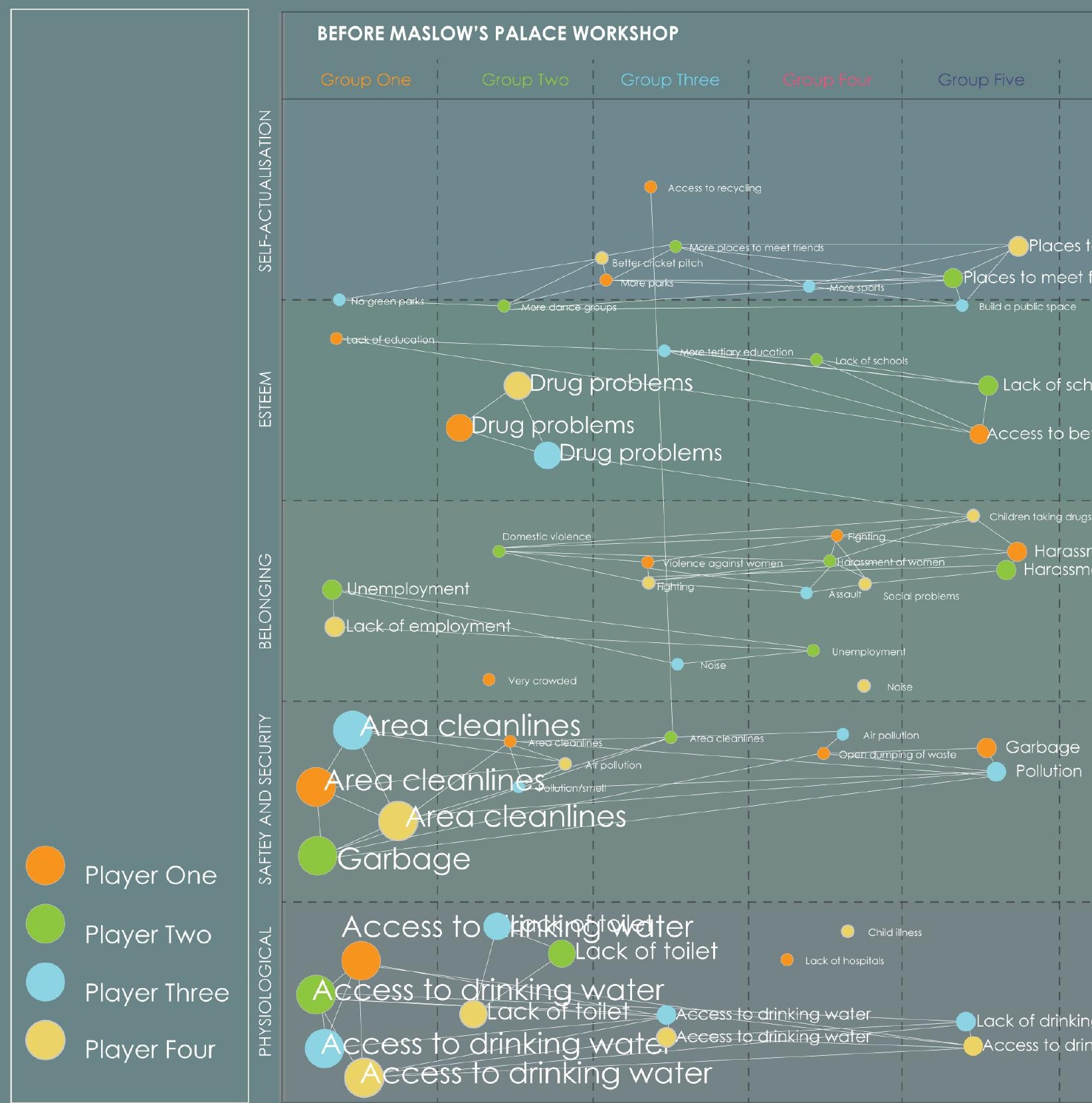

Figure 130. Pre-test / post-test analysis of the Shanti Nagar workshop groups. The diagram indicates some solidarity surrounding access to drinking water for all workshop groups and lack of access to public toilets for Group Three. 


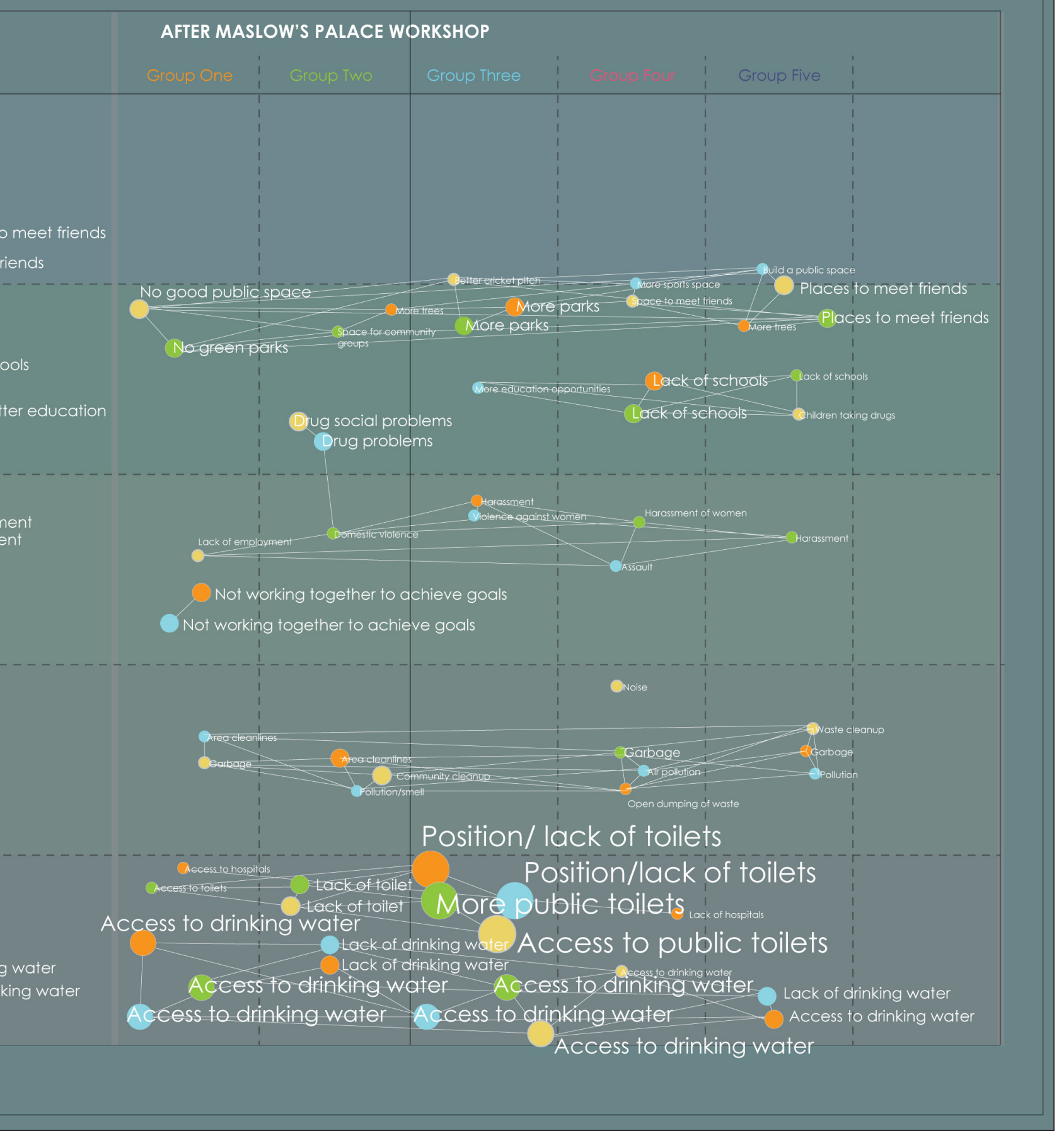




\subsection{Access to schools}

One of the most widely discussed topics amongst all five workshop groups was the provision of schools within the Shivaji Nagar area, specifically high schools and access to tertiary training. Access to education was highlighted by participants in groups one, four and five in the pre-test / post-test analysis, as well as in the game actions of all five workshop groups. During focus group discussions, participants reiterated the importance of education:

"We need schools. If we have education then we can help our family" (Participant Three, Group Three).

Likewise, while better quality housing was acknowledged to be important, it was widely accepted amongst participants that inadequate drainage was one of the most pressing concerns the community faced, which was highlighted in the pre-test and post-test interviews as well as discussed within both workshop groups. Group Four also discussed that houses would need to be in close proximity to educational institutions. This group suggested that the current cricket pitch area northwest of the site could be used as an area for the development of housing and schools.

\subsection{Environmental Concerns Relating to Garbage}

One of the most prominent outcomes of the workshop was in relationship to environmental concerns relating to waste. Workshop groups three, four and five discussed the prominence of waste in and around living areas during various game levels. Participants discussed a number of strategies for dealing with this problem. For example, participants in Group Three explored the reduction of housing density and the construction of a recycling centre in their community to alleviate the disposal of waste around housing areas (Figure 131):

"There are so many houses. Between the houses is where the garbage is. If they were apart, it would be cleaner" (Participant Two, Group Three). 
"But what are we going to do with the waste? Look outside. There is so much. We need to put it somewhere" (Participant Four, Group Three).

"And where will the people from those houses live?" (Participant Two, Group Three).

"What is this? We could build a recycling centre close by" (Participant Four, Group Three).

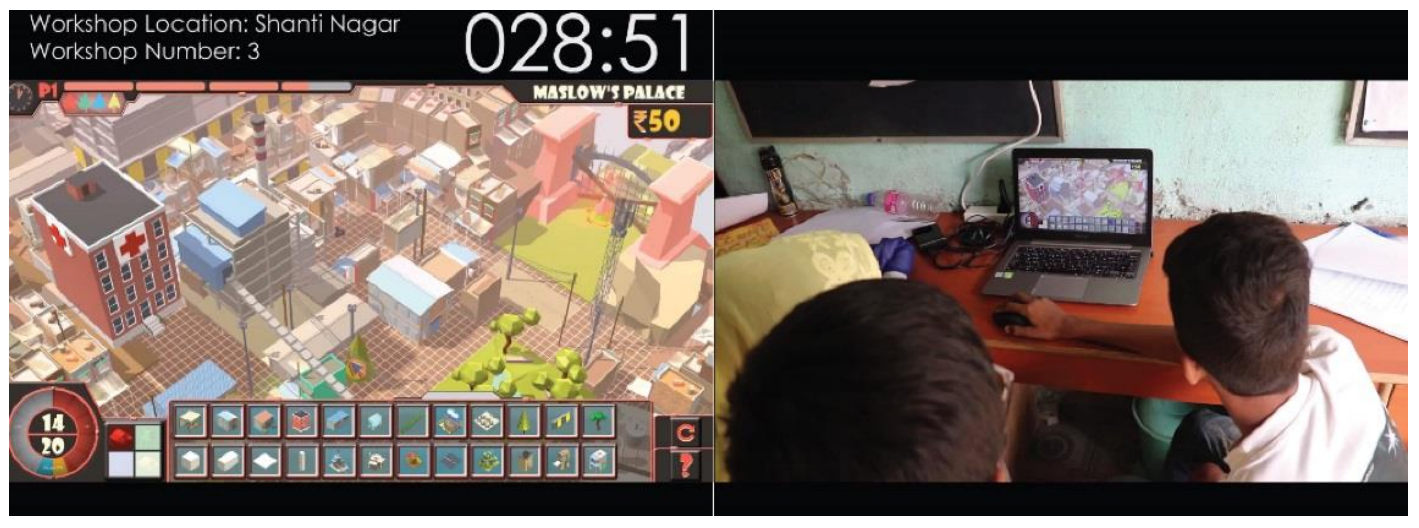

Figure 131. Level Three research procedure. Shanti Nagar, Group Three.

During focus group sessions, participants of Group Three highlighted that more recycling within the community would alleviate some of the issues regarding waste disposal:

"When I was playing the game, there was a recycling centre-which is not at all in Govandi [Shivaji Nagar], so I feel there should be a recycling centre in Govandi. A lot of people waste a lot of thingsplastics, metals, cups, glasses, clothes-so I feel there should be a recycling centre for the wealth of the community. I didn't think about that before" (Participant Three, Group Three).

\subsection{Access to Public Spaces}

One of the most widely discussed topics amongst the workshop groups was gaining access to a range of public spaces. This included the development of a cricket pitch (Group Two) and a playground (Group Three) Group Four combined the development 
of public space as a central component to their in-game scheme, and also included housing, waste recycling facilities, access to water and public toilets (Figure 132).

"We need more trees. They can be for shade. And there we also need access to water. And close to home so we don't have to walk a long way" (Participant One, Group Three).

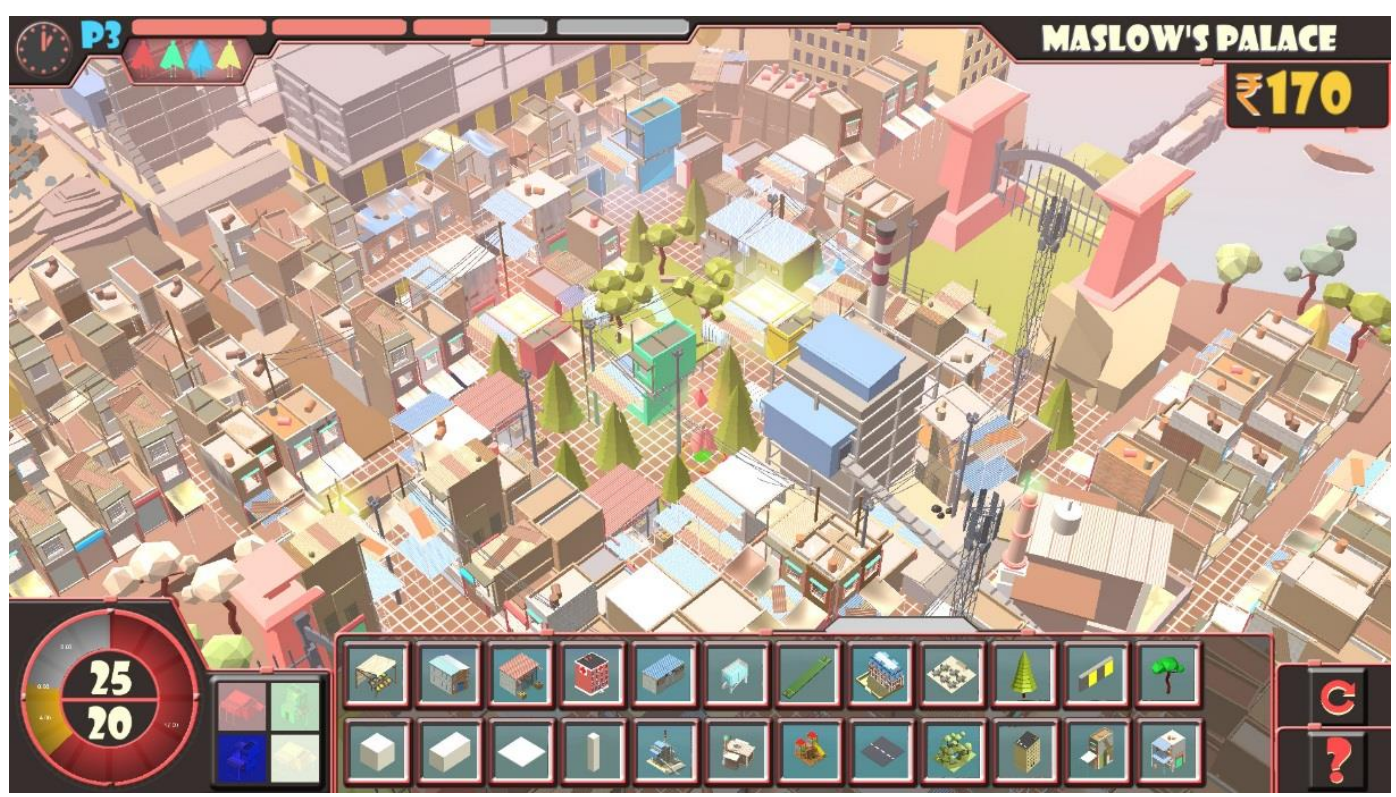

Figure 132. Level five outcome, Workshop Group Four. Shanti Nagar, Group Three.

These reflected a range of opinions identified by the participants in the pre-test / post-test analysis.

\subsubsection{The Role of Playfulness}

The SPS-UG approach is a "playful" activity within a certain structure, i.e. the game rules, and resonates with what Krek (2008) terms "playful public participation" (Krek, 2008); however, as noted by Brandt et al. (2008), these structures or rules are not always fixed or followed by participants. In the Shanti Nagar workshops, the participants moulded the rules, as well as the framing of the game as it progressed. Thus, the participants expanded the game world in a number of ways so that there were not only related to making in-game moves or imagining things within the rules of the 
game. The participants of Group Four spent time trying to walk their avatars into the water surrounding Level Five, as well as demolishing large portions of the game environment. Participant Two suggested all of the avatars should be "drowned in the water" (Participant Two, Group Four). Participant Two told one of the other participants to get her avatar to push hers into the water-something that is impossible to do within the game.

"Use yours to push me into the water" (Participant Two, Group Four).

“Come on, help me blow this all up” (Participant Two, Group Four).

"If we blow it all up, we can put a zoo with animals" (Participant Two, Group Four).

"Okay I'll do this bit" (Participant One, Group Four).

"So, the animals go here?" (Participant One, Group Four).

"Yes" (Participant Two, Group Four).

"I'll build a fence" (Participant Three, Group Four).

"Then we can see them every day" (Participant One, Group Four).

"Yes" (Participant Two, Group Four).

"Lions!” (Participant One, Group Four).

"And fish. Because we'll all be in the water!" (Participant One, Group Four).

"So, the zoo needs to be there. By the water. We can use this [points to park module in inventory]. The lions go in there" (Participant Two, Group Four).

"But they need water too" (Participant One, Group Four).

When asked during the focus group why she wanted to push her avatar into the water, Participant Two stated that it was because "it was fun” (Participant Two, Group Four). This might be due to age being a factor, when compared with the participants of the Ghazipur and Bhalswa workshops who were older.

In another example, Participant One, Group One demolished large portions of the game environment shown in Figure 133. When questioned by the other participants as to why he did this, he said: "I liked blowing them all up! It was fun" (Participant One, 
Group One). This action resulted in tension with other participants, as Participant One used up all of the available financial resources within the game.

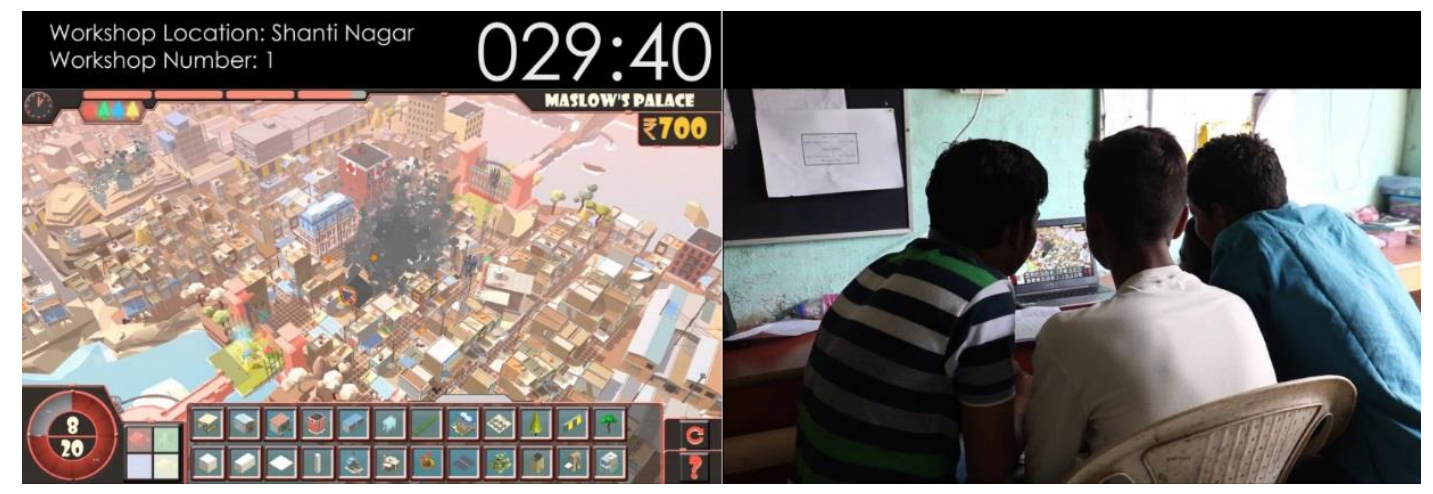

Figure 133. Participant of Group One playing Level Five, Shanti Nagar. Left image via Google Earth, 2019. Right image by author.

The participants were aware that the ideas they developed within Maslow's Palace were not realistic, in the sense that they could not be constructed exactly as they were envisioned - or at all; however, the ideas they generated provided the springboard for discussing the qualities of experience that would be desirable. While a zoo in terms of the way it was described in the workshop was not feasible, it was indicative of a desire for more recreation and public space to meet friends. Through this exchange, participants also expressed agency (Ibrahim \& Alkire, 2007) over the game system by altering the rules of the game to discuss aspects that they found interesting or enjoyable, which resulted in playful interaction and cooperation. This agency is possibly the result of the participants of the Shanti Nagar workshops having a higher level of digital literacy than participants in the other two groups. This was evidenced by Participant Two, Group One asking: "Do you play Clash of Clans?” (Participant One, Group One) — a mobile strategy game — indicating some digital gaming amongst the participants.

Playful actions such as these raise the question of how to interpret the slumupgrading results of the workshop. Can these results be considered the serious opinions of the participants, or just results of the game? For example, a choice to demolish the majority of the buildings and reconstruct a few typologically unfamiliar spaces could be viewed as the playful approach of a participant trying to test a more extreme 
possibility, or it could be classified as their opinion and wish for a solution to the current situation.

\subsubsection{Increasing Social Capital through Participatory Gaming}

It has been shown throughout this case study how, as a result of processes of infrastructuring - or providing conditions needed for social change and aligning inscribed "norms" (Schultz, Nolan, Cialdini, Goldstein, \& Griskevicius, 2007) and values across contexts through socio-material negotiations-participants developed various forms of social capital (Björgvinsson et al., 2010; Hillgren et al., 2011). This included the form of new bonds and ties among participants as a result of playful interactions (Narayan, 1999); the "collaborative learning" of the game (Gordon \& Baldwin-Philippi, 2014a) such as digital gaming and digital collaboration literacy (DiSalvo, Louw, Coupland, \& Steiner, 2009); and capacities such as decision-making, planning and execution (Merkel et al., 2007).

The experience of the SPS-UG workshops showed that a sense of meaningful civic engagement (Foth \& Brynskov, 2016) can foster engagement when the participants feel like their efforts can have a positive impact. The workshop also gave participants a sense of purpose in terms of upgrading goals:

"I wish I could live in the game and make my community like that how I want it that easily" (Participant Three, Group Three).

"According to the game with shops and clean streets I want it [Shanti Nagar] to be like that as well" (Participant Four, Group Three).

Participants also indicated that they valued the SPS-UG participatory process by suggesting more community members should be involved in the workshops:

"Can the community play? We should have this here [in the Apnalaya Community Centre] so everyone can use it" (Participant Four, Group Five). 
Social capital, as described before, refers to the set of relationships that have developed around shared values, norms and trust (J. Coleman, 1988). The interventions studied here enabled social interactions, fostering the development and strengthening of ties and bonds. In the Shanti Nagar workshops, the approach saw the development of a number of shared values (Leong \& Iversen, 2015) amongst disparate participants, e.g., consensus building (Boroushaki \& Malczewski, 2010) around issues such as access to school, environmental concerns relating to garbage and access to public spaces.

\subsubsection{Digital Participatory Workshops with Marginalised Youth}

The Shanti Nagar workshops raised a number of important considerations regarding conducting digital participatory workshops with marginalised youth - as the participant range was between 16 and 21 years of age, which differs from the age groups of the Ghazipur and Bhalswa case studies.

In contrast to the Ghazipur and Bhalswa cases, all participants of the Shanti Nagar workshops exhibited a high level of digital literacy, with most participants owning smartphone devices, as well as many having access to computers through Apnalaya's community centres throughout Shanti Nagar. This aspect undoubtedly resulted in some degree of familiarity with gaming environments. The participants progressed quite quickly through the game levels, but as previously described, they were observed "playing" with the game system, experimenting with its game mechanics and altering its rules during the course of the workshops. This resulted in limited collective learning regarding basic navigation of the game interface, but substantial collaboration and discussion regarding in-game slum-upgrading design.

Two female workshop participants expressed that designing in Maslow's Palace had increased their interest in technology and community development, and that they now would like to explore how to make better use of technology for both leisure and skills development.

"This made me want to make a better community.... I liked the computer to show my group my ideas" (Participant Three, Group Two). 
“In the beginning I just wanted to play [Maslow's Palace]. But then I saw the building and how we can change the community and the area. That is what we should do" (Participant Four, Group Five).

Some of the participants also called for more dialogue between themselves and older community members, as well as officials, to further improve learning between different stakeholder groups. Participant Three, Group Five stated during the focus group session:

"We want to do these things, but we can't build them. We need money and the politicians have the money. We need to talk to them about these things with the community" (Participant Three, Group Five).

\subsubsection{SPS-UG Participatory Visioning}

Within the Shanti Nagar workshops, the participants speculated on a number of participatory visions (McCormick, 2013; Quist \& Vergragt, 2006; Ryan, 2013) of the future. Envisioning these hybrid-realities helped expand the conversation beyond practices of sharing suggestions for in-game actions, to include real-world descriptions of contextual issues, spaces and socio-political factors in which these practices do or could take place - such as those described in sections 7.2.4.1.1.. As cognitive tools, visualisations present working ideas and concepts for personal use, or facilitate a discussion among peers or with external stakeholders.

Overwhelmingly, the visions of the future that the participants described through the workshops were concerned with the way they and others could live in their communities - instead of the buildings or spaces they would want. In order to do this, participants created a range of hybrid-realities that were composed of digital representations of game spaces, as well as verbal recollections of real-world spaces and experiences with people, systems or situations. This type of "participatory visioning" (McCormick, 2013; Quist \& Vergragt, 2006; Ryan, 2013) extends the speculation within the game to a variety of actors and practices, and engages directly with conflicts and divergence in processes of imagining future worlds. 


\subsubsection{Summary}

As evidenced by the analysis in this chapter, the slum-upgrading challenges faced by the Shanti Nagar are varied, but the SPS-UG workshop process provided a number of both social-oriented outcomes and design-oriented (slum-upgrading) outcomes. In some instances, it helped stakeholders explore different perspectives on sensitive topics.

The chapter highlighted that in some instances, due to the level of agency (Ibrahim \& Alkire, 2007) the participants expressed over the game system through the workshop, a number of ideas were created for upgrading action, galvanised around "matters of concern" (Forlano \& Mathew, 2014, p. 20) including gaining better access to educational institutions, reducing pollution related to living near the landfill and gaining recreational and public spaces for their community. Further, by reflecting on "matters of concern" (ibid) through "recursive engagement" (Teli et al., 2015) in order to link the design activities to wider societal possibilities (Marttila et al., 2014), the SPS-UG allowed some participants to reflect on their past actions and the actions of others, and translate them into more concrete design ideas.

The digital participatory workshops enabled youth to exert agency over the game system by altering the rules of the game to discuss aspects that they found interesting or enjoyable and in some cases to reframe the gameplay for fictional means. While this resulted in playful interaction and cooperation (Gordon \& Baldwin-Philippi, 2014a; Krek, 2008) between participants; some of their actions raised questions including the reliability or applicability of the serious opinions of participants, and how such information might be used in terms of design outcomes. This was most likely due younger participants of the Shanti Nagar workshops when compares with the Ghazipur and Bhalswa participants.

The case study also provided new exploratory insights into how the SPS-UG approach can help increase social capital (J. Coleman, 1988) through socio-material negotiations, form bonds and ties among participants as a result of playful interactions (Poplin, 2012), and enhance the development of skills capacities (Devisch et al., 2016), e.g., digital gaming and digital collaboration literacy, such as decision-making and increased participant interest in technology and community development, in some instances. 


\section{Discussion: SPS-UG as an Enabler of Social and Design Outcomes}

"We want to do these things, but we can't build them. We need money and the politicians have the money. We need to talk to them about these things with the community"

- (Participant Three, Group Five, Shanti Nagar).

\subsection{Introduction}

This thesis argued that when marginalised communities can confront and explore conflicting perspectives, values, assumptions and goals through negotiation within participatory design processes, their ability to harness the collective intelligence of people to work towards a range of social and design outcomes can be enhanced. The research posited that speculative architecture, which has been predominantly only internally valuable to architectural discourse and largely unexplored as a participatory design strategy, can be orientated to be purposefully public-facing to engage nonexpert participants in slum communities in crafting and discussing speculations about their futures. When combined with a participatory, serious gaming approach participatory design tools can be designed to generate social and design outcomes with slum communities.

In this thesis, I have explored how speculative architecture, participatory design and serious gaming approaches can be brought together to enhance social outcomes and related design (slum-upgrading) outcomes for urban slum dwellers. I detailed a new approach that synthesises strategies derived from a review of speculative architecture, participatory design and serious games into a framework I call Speculative Participatory Serious Urban Gaming or "SPS-UG", and I explored it in practice through a computer game I designed and tested in three case studies. The three case 
studies in urban India, CS1 (Ghazipur, Delhi), CS2 (Bhalswa, Delhi) and CS3 (Shanti Nagar, Mumbai), focussed on how the SPS-UG operationalised as the computer game Maslow's Palace might be used to help enhance social outcomes and related slumupgrading outcomes for members of these slum communities. Each of these case studies provided insights into how the approach can aid an exploration of possible futures, conflicting stakeholder perspectives, and corresponding goals surrounding social and slum-upgrading issues with community members.

The goal of this chapter is to discuss these experiences and findings in relation to the principal research question stated in Chapter One:

Research Question: How can speculative architecture, participatory design and serious gaming approaches be brought together to enhance both social outcomes and related design (slum-upgrading) outcomes for urban slum dwellers?

A further goal is to discuss these experiences and findings in relation to the literature reviewed in Chapter Two and how they contribute in particular toward Aim 5:

Aim 5: To generate insights, guidelines and recommendations for the future practice of a speculative, participatory, game-based approach in similar contexts.

\subsubsection{Summary of the Discussion}

This chapter discusses the key components of the principal research question through a critical examination and comparison of the findings detailed in Chapters Five, Six and Seven, in relation to the reviewed literature outlined in Chapter Two, in order to make judgments about the commonalities and differences with existing approaches, and the significance and implications of the findings.

Section 8.2 discusses how the SPS-UG approach contributed to the enhancement of social outcomes in each of the research contexts. It compares the findings with current approaches for exploring conflicting participant perspectives and assumptions, and it explores successes and challenges in collectively "revealing" (Bowen, 2010; Iversen et al., 2012, p. 87; Sanders, 2001), "developing” (Brandt, 2006; Brandt \& Messeter, 2004; Brandt et al., 2008; Dindler \& Iversen, 2007) and "grounding" (Brandt, 2006; Brandt \& Messeter, 2004; Brandt et al., 2008; Dindler \& Iversen, 2007) stakeholder knowledge, goals and values. 
Section 8.3 discusses how the SPS-UG approach contributed to enhancing engagement with the design issues surrounding slum-upgrading by utilising a "tool-tothink-with" (Iversen et al., 2012, p. 97), designed to promote upgrading ideation, frame the consideration of alternate views and possible futures, and scaffold discussions about what the future might look like through visual representation of possible design alternatives. It discusses how the SPS-UG approach facilitated pluralistic slumupgrading visions of the future as a key instrument to "defamiliarise" (Bell et al., 2005, p. 150) situations - to open up space for thinking about sensitive upgrading topics through "collective tinkering" (Innes \& Booher, 1999, p. 9) and "perceptual bridging" (Auger, 2012) - and how these speculations are legitimised by the participants in relation to their real-world experience (Auger, 2012, p. 140; Knutz et al., 2016; Pickersgill, 2017). Finally, it discusses opportunities for the SPS-UG approach and interface with slum-upgrading processes outside of the scope of this research.

Section 8.4 gathers and discusses key methodological insights, discusses the challenges faced when working with communities while pursuing social and slumupgrading outcomes using the SPS-UG approach, and it explores the successes and challenges of the methods used.

\subsection{Enhancing Social Outcomes via the SPS-UG approach}

The introduction of this thesis discussed how when marginalised communities have the opportunity to confront and explore conflicting perspectives, values, assumptions and goals through negotiation within participatory design processes, the ability to "harness the collective intelligence" of people to work towards collective action can be enhanced (Davis \& Garb, 2017, p. 77). Creating a broader understanding of these opportunities amongst stakeholders can help to create a more level playing field when working towards upgrading goals. The upgrading of slum communities requires both social outcomes as well as design outcomes; however, Chapter Two identified a lack of research addressing how social outcome and design outcome participatory design processes can be explored simultaneously. This thesis investigated how this dual outcome can be encouraged through a speculative, participatory, serious gaming approach.

This section discusses three key interdependent factors that have not previously been brought together in the context of speculative, participatory, serious games, 
which have been found to contribute to social outcomes through the SPS-UG approach using the computer game Maslow's Palace:

1. The SPS-UG helped to draw out participants' knowledge, values and goals by creating temporary worlds and perceptual bridging and facilitating social interaction and collaborative learning (Bowen, 2010; Iversen et al., 2012, p. 87; Sanders, 2001).

2. The SPS-UG helped participants develop knowledge, values and goals by exploring conflicting perspectives and/or building on and/or developing ideas (Brandt, 2006; Brandt \& Messeter, 2004; Brandt et al., 2008; Dindler \& Iversen, 2007).

3. The SPS-UG encouraged the participants to ground their experiences and reconceive knowledge, values and goals (Brandt, 2006; Brandt \& Messeter, 2004; Brandt et al., 2008; Dindler \& Iversen, 2007) through bricolage and the collaborative testing of prototypes (Sanders \& Stappers, 2014) with reference to the real world within the digital medium of a gaming environment.

\subsubsection{Factor 1: Temporary Worlds and Perceptual Bridging}

The SPS-UG helped to draw out participants' knowledge, values and goals by creating temporary worlds and perceptual bridging and facilitating social interaction and collaborative learning.

The "temporary worlds" created by the SPS-UG within each workshop allowed the processes and artefacts related to the SPS-UG and the workshop to be less likely to appear to be "owned" by one participant at the expense of others, and they functioned as a catalyst and container for imagination (Baumann et al., 2018, 2017). These temporary worlds ranged from the fictional worlds-for example in Shanti Nagar workshop two, where participants playfully debated wanting a zoo within their community - to hybrid-reality worlds (Ylipulli et al., 2017) composed of speculative

digital representations of game spaces as well as verbal recollections of real-world spaces and experiences with people, systems or situations. These types of temporary 
worlds were found to be useful for participants to express ideas and desires for their communities in different ways and were facilitated by the digital medium of the serious game that incorporated speculative and participatory features.

Temporary worlds also allowed for the construction of an "agonistic" participatory environment (DiSalvo, 2010). In some cases, this helped participants discuss different views on "matters of concern" (Forlano \& Mathew, 2014), while also accepting other views as 'legitimate' (Björgvinsson et al., 2012; DiSalvo, 2012)—such as the Ghazipur Group Four participants debating the importance of community meeting spaces, or the Bhalswa Group One debating the lack of available space to develop within the game. These participant understandings are useful for participants to carry into further participatory action either as part of a facilitated project or as a catalyst for bottom up action to enact desired slum-upgrading.

Throughout the SPS-UG process it became clear the speculative and real-world elements within the game were inextricably linked. Similar to the findings of Clarke et al., 2018; Gerber, 2018 and Jones, 2019 in relation to "participatory speculation" using low-fi prototypes, it may be noted that the participants readily conflated elements from everyday experiences with game elements and transformed them into new configurations that incorporated their own perspectives and those of others-such as projecting real issues onto speculative in-game urban elements and arrangements (Clarke et al., 2018; Gerber, 2018; Jones, 2019). To this end the fluid nature of the hybrid-reality created an environment where participants felt comfortable raising, and subsequently debating, urban development issues and to "sketch" (Johansson, 2005, p. 17) future, speculative ideas to illustrate and evaluate current slum-upgrading and social problems their communities face. From this state, participants were able to iteratively scaffold arguments and ideas through subsequent levels of typological familiarity to help visualise, reflect and communicate real-world urban issues to one another. Similar to the findings of Barley, Leonardi, \& Bailey, in some instances, the fictional and nonfictional game elements were discussed in relation to the way in which they had been designed, and in others the participants imbued them with new meanings - particularly the basic building blocks within the earlier levels of Maslow's Palace (Barley et al., 2012). This evidences the value of providing participants with "generic" in-game artefacts that they can appropriate as they see fit, as it is impossible to account for all interpretations within the SPS-UG design process. 
Most other approaches to urban and slum-upgrading approaches to serious games have focussed on realistic representations of urban spaces and systems. For example, the following all focus on realistic representations: the commercial-off-the-shelf (COTS) game Cities Skylines (2016) as applied by Norra Djurgårdstaden, Block by Block's serious application of the sandbox videogame Minecraft to slum-upgrading and public space development, YouPlaceIt! (2018), which utilises a Public Participation Geographic Information System (PPGIS) to enable stakeholders to communicate and resolve specific urban planning issues (Poplin \& Vemuri, 2018), and Markopoulou et al. (2018) who utilise a virtual and augmented reality-based approach to serious games in a slum-upgrading context in Mumbai. Other examples, such as Block'hood (2017) sourced simulation-based serious game oriented towards ecological urbanism, take a more speculative approach to convince players of a particular message or viewpoint (i.e. a social outcome) and are mostly abstract and not situated within an existing urban condition and so are limited in their ability to generate social outcomes (Markopoulou, Ingrassia, Chronis, \& Richard, 2018, p. 226).

Differing from other approaches to urban and slum-upgrading approaches to serious games that focus on realistic representations of urban spaces and systems, my design for Malsow's Palace presented a novel configuration of the three case study contexts that was composited of parts (areas such as neighbourhoods or larger areas of a particular land use), subclasses (generic buildings or spaces), and features (sitespecific real-world buildings, spaces and relationships) that provide participants with typologically familiar elements. The intent of this was to "defamiliarise" the research contexts to open up "discursive space" and aid negotiation and critical ideation discussions through a consideration of a plurality of future possibilities (Bell et al., 2005; Lindley et al., 2014, p. 240), as opposed to either just facilitating decisions on spatially orientated slum-upgrading issues, or just generating slum-upgrading social discourse between participants.

The findings showed that this approach was successful in simultaneously generating a range of social outcomes and design-related slum-upgrading outcomes. While this novel configuration could have possibly introduced tensions regarding participant wishes to respond accurately to realistic site representations, interestingly, no tensions were observed during any workshop group from the three case studies relating to rejection of the speculative configuration of the three communities presented within Maslow's Palace. This, in combination with the results of the workshops, indicates the 
success of the approach of using novel configurations in combination with typologically familiar elements (Auger, 2012, p. 140; Knutz et al., 2016; Pickersgill, 2017) within the SPS-UG environment in order to facilitate social and design-related slum-upgrading outcomes.

The research also showed that the strategy of "perceptual bridging" (Auger, 2013) - i.e. the connections that participants made between entities in the SPS-UG digital environment and the real worl, which increased through the levels of gameplay-helped to connect the game experience to the real-world experiences of the participants. This was highlighted through the participants recognising and discussing particular site features within the SPS-UG while also offering extensional real-world referents (such as verbal recollections of spaces and experiences) to construct consistent possible speculations made of both speculative components and real-world referents (Pickersgill, 2017, p. 78). This corresponded to a number of detailed real-world slum-upgrading and socially-oriented discussion topics amongst workshop groups. In line with Coulton et al. and Morschheuser et al., these constructions were seen to have positive leaning and cooperative effects (Coulton et al., 2014; Morschheuser, Riar, et al., 2017).

Participants also formed "perceptual bridges" when responding to both fictional and nonfictional elements and spatial arrangements within the game. For example, during Level One, participants of Ghazipur workshop Group Three conducted "area cleaning", which they described as the "removal of waste before they could build homes". Here the participants perceived the abstract pink cubes within the level as "waste", and therefore they ascribed a nonfictional, metaphorical identity to a fictional game element. Similarly, participants frequently projected personas, uses and identities onto game objects and then used these to form new or additional discursive parameters. For example, participants suggested that the houses within the game belonged to real people on numerous occasions. This aspect became a design consideration for participants in a number of instances, where the real-world implications of their design decisions were considered within the context of the game. Additionally, in many instances, participants exhibited an ability to push metaphorical meanings or extra criteria onto game objects, such as perceiving people not within the workshop as living within the buildings within the game, and thus not demolishing certain generic buildings within the game. Assertions such as these added further discursive considerations to the organisational problems faced by participants of the 
workshop. This permitted the participants to have more complex social-oriented and upgrading-oriented discussions.

Perceptual bridging was, however, found to be able to be affected by a number of factors within the workshops. Groups with lower levels of digital literacy — such as CS1 (Ghazipur, Delhi) and CS2 (Bhalswa, Delhi) - experimented more with in-game systems in earlier, less complex levels, while those groups with overall higher levels of digital literacy — such as CS3 (Shanti Nagar, Mumbai) — experimented with in-game systems more in later, more complex levels. Higher levels of digital literacy allowed participants to begin experimenting within the game more quickly, which opened up new avenues for discussion in earlier game levels, as well as increased "collective tinkering" (Innes \& Booher, 1999, p. 9) with fictitious and realistic spatial systems. Higher levels of collective tinkering resulted in better conflict resolution, more indepth conversations and more frequent perceptual bridging-with more real-world issues being raised.

In line with Innes and Booher, the case studies also revealed the importance of ensuring adequate facilitation (J. Innes \& Booher, 2010) of the SPS-UG workshop process, as the actions of facilitators can affect the effectiveness of the creation of temporary worlds and perceptual bridging to result in workshop outcomes. The introduction of real-world issues to the workshop by participants was also sometimes affected by the workshop facilitator. In the CS1 (Ghazipur, Delhi) case study, the facilitator explained the game was for community-development purposes to two of the workshop groups, which prompted participants to form perceptual bridges between the most abstract levels and real-world issues at an earlier stage than those groups that had not been prompted as to the purpose of the game. This allowed participants to begin to discuss urban development issues within earlier levels of Maslow's Palace, and in some cases in more depth, and as a result reduce the amount of time that participants spent playing with fictional elements or collaboratively learning the game mechanics.

\subsubsection{Social Interaction and Collaborative Learning}

Social interactions are essential for the development of social norms and social cohesion (Consolvo, McDonald, \& Landay, 2009; Schultz et al., 2007) and are a critical component of community building (Carroll \& Rosson, 2013; Hayes, 2011). 
Through social interactions members of a community form bonds with other members and build social capital (Dalisay et al., 2015; Molyneux et al., 2015; Putnam, 2000).

The findings suggest that participatory design processes within the SPS-UG workshops were driven by social interaction, as most participants learned together to create, develop, express and evaluate their ideas and visions. It has been shown throughout the case studies that as a result of processes of "infrastructuring"providing conditions needed for social change and aligning inscribed norms and values across contexts through socio-material negotiations (Björgvinsson et al., 2010; Hillgren et al., 2011) — most participants developed various forms of social capital (Dalisay et al., 2015). As indicated though participant reflection within the workshops, the workshops also gave some participants a sense of purpose in terms of upgrading goals - as detailed in Section 7.2.6. The social interactions between participants, and the resulting discussions, increased some participants' engagement with the workshop in general, as well as allowing them to establish a "moral proposition" (Iversen et al., 2012, p. 87), as detailed in Section 2.2.2.3, surrounding their ideas, values and goals.

Similar to the findings of Iten \& Petko, enjoyment appeared to be a contributing factor to participating engagement and social interaction (Iten \& Petko, 2016) within the SPS-UG. This in turn helped to open discursive pathways between participants, allowing them to feel more comfortable raising and exploring ideas. Through playfulness, the participants also expressed agency over the game system by altering the rules of the game to discuss aspects that they found interesting or enjoyable. This resulted in playful interaction and cooperation and in some cases novel ideas for upgrading.

For some groups in CS1 (Ghazipur, Delhi) and CS2 (Bhalswa, Delhi), participants learned to play the SPS-UG at a similar rate, without large differences in learning, because participants shared similarly low levels of digital literacy. This was conducive to the sharing of ideas, as each participant developed a similar level of expertise of the gaming task and created a space of collaboration and inclusiveness. However, the "collaborative learning" of the game (Gordon \& Baldwin-Philippi, 2014a) was affected by the participants' reliance on the workshop facilitator in the CS2 Bhalswa workshops where the facilitator took control of the game for periods of time due to the low levels of digital literacy exhibited within the group. This lessened the possibility of increasing digital collaboration literacy (DiSalvo, Louw, Coupland, \& Steiner, 
2009) and building capacities such as collaborative decision-making and planning (Merkel et al., 2007).

Conversely, high levels of digital literacy in the CS3 (Shanti Nagar, Mumbai) participants resulted in participants progressing comparatively quickly through the game, as they did not have to help each other learn the basic game interface mechanics. As previously described, participants in some of the CS3 Shanti Nagar workshops were observed "playing" with the game system, experimenting with its game mechanics and altering its rules during the course of the workshops. This resulted in limited collective learning regarding basic navigation of the game interface, but it resulted in substantial collaboration and discussion regarding design. Some of the CS1 Ghazipur workshop groups exhibited disparities in digital literacy, which resulted in some participants progressing through the game levels at different speeds, and thus less discussion and collaboration.

\subsubsection{Factor 2: Developing Participants' Knowledge, Values and Goals}

The SPS-UG helped participants develop knowledge, values and goals by exploring conflicting perspectives and/or building on and/or developing ideas.

Once knowledge, values and goals were revealed, the SPS-UG process helped the participants develop these by building on and/or developing ideas and/or exploring conflicting perspectives through reflection and discussion surrounding collaborative design activities. This aided participants in honing their collective preferences and ideas through "participatory speculation" (Clarke et al., 2018; Gerber, 2018; Jones, 2019).

Through this process, the SPS-UG allowed participants to find visual "common language" (S. King et al., 1989) in the form of 3-dimensional representations of design ideas that supported collaboration among participants with different skills and backgrounds, which enabled the refinement of emergent values and the ability to begin translating them towards more concrete design ideas.

As has been shown, "matters of concern" were sometimes contested throughout the SPS-UG process. One aspect of participation, which made confrontation between conflicting perspectives and assumptions inevitable within some of the SPS-UG workshops, is that the participants brought to the workshops their personal beliefs. The SPS-UG facilitated the creation of "negotiating space" (Hillier, 2003; Till, 2005, p. 
34), which allowed participants to explore and reframe diverse opinions and aspirations based on their personal beliefs and thus deepen their understanding of the self, others, norms and institutions.

Results suggest that when conflicts arose, peripheral issues or other facets of the issue were voiced and explored, allowing for some participants to gain a better understanding of each other's perspectives through discussion and to develop shared values and norms. This was generally around more complex socio-political issues such as livelihood generation, security or the placement of toilets within the community in relationship to gender or LGBQTIA+ rights as debated within CS3 (Shanti Nagar, Mumbai) workshop Group Three. Integrating speculative processes with the serious game approach to participation was also successful in helping some participants feel comfortable raising and discussing sensitive topics with strangers, as well as engaging in conflict. For example, CS3 (Shanti Nagar, Mumbai) Group Three, Participant Three said during the focus group that it was "important for the participants to talk about and share opinions; otherwise nobody knows why you need something. Participants also noted they were especially appreciative of the small working groups, as they found it more comfortable to express their opinions.

Participants projected personas, uses and identities onto game objects and then used these to form additional discursive parameters. This helped them contextualise the discussions, while the fictional nature of some in-game entities allowed them to distance themselves from the conflict. For example, some participants suggested the idea that the houses within the game belonged to real people, and it would be "bad to destroy someone's house" when deciding when to build a new road (CS3 Participant Two, Group 3). This aspect became a discursive consideration for participants for both social and design discussions, where the real-world implications of their in-game decisions were considered within the context of the game. This added discursive considerations to the organisational problems faced by participants in-game and facilitated more complex discussion.

Through each of these examples, participants explored conflicts in a state of "agonistic pluralism" in "agonistic space" (Section 2.2.4.2), where the different stakeholders do not necessarily reach a consensus surrounding a social or design issue, but rather the SPS-UG revealed some conflicts and agreements, and helped multiple opposing views to co-exist within a common language. 


\subsubsection{Factor 3: Grounding Participants' Knowledge, Values and Goals through Bricolage}

The SPS-UG encouraged the participants to ground their experiences and reconceive knowledge, values and goals through bricolage and the collaborative testing of prototypes with reference to the real world within the digital medium of a gaming environment.

The importance of grounding the workshop experiences in participants' everyday knowledge, values, goals and experience - through bricolage and cycles of reflection and action to create common ground or shared language between participants for future slum-upgrading action-is emphasised in Chapter Two (Brandt, 2006; Brandt \& Messeter, 2004; Brandt et al., 2008; Dindler \& Iversen, 2007). Aiding stakeholders to question their values and goals and even reconceptualise their original values during the SPS-UG process is a good start, but the values and goals are only grounded when stakeholders can negotiate this new-found conceptualisation successfully within their everyday experience (Iversen et al., 2012, p. 97).

Grounding was achieved in the SPS-UG process through a process of "bricolage" the construction of concepts that are combinations of various participant ideas and experiences into a scenario that they collectively believe will work-and the negotiation between "blue-sky conceptualising and pragmatic issues of development and implementation" (Büscher et al., 2004) within cycles of "doing and reflecting" (Argyris \& Schön, 1978) or "joint reflection-in-action" (J. E. Innes \& Booher, 1999). Specifically, the knowledge values and goals of participants were grounded in the users' experiences through creative artefacts produced by the participants during each workshop through "collective tinkering" (Innes \& Booher, 1999, p. 9) with matters of concern".

\subsection{Enhancing Design (Slum-Upgrading) Outcomes via SPS-UGs}

While the SPS-UG approach was successful in generating a range of social outcomes through its speculative, participatory and serious game framing, it was also simultaneously successful in generating a number of design-related slum-upgrading outcomes for the workshop participants. This section discusses two key interdependent 
factors that have been found to contribute to social outcomes through the SPS-UG approach using the computer game Maslow's Palace:

\subsubsection{Factor 1: Hybrid-Realities as a Means to Define Design Parameters}

As well as being useful in helping participants arrive at social outcomes, the construction of hybrid-realities was particularly useful in helping participants to discuss a range of slum-upgrading ideas composed of speculative digital representations of ideas and real-world suggestions for action.

All workshop groups in each case study explored slum-upgrading issues, created a diverse range of in-game slum-upgrading responses and, in some instances, discussed the practical, socio-political, economic considerations and the implications of each. These findings indicate that the game is conducive to provoking discourse and generating consensus around a range of social as well as design-related slumupgrading issues that might be used to interface with future slum-upgrading projects.

Participants in each workshop group debated a range of design-related slumupgrading issues including the importance of housing in close proximity to landfill in relation to income security, strategies for resolving the problems associated with a lack of security of tenure and impending forced eviction, the positive attributes and detrimental effects of infrastructure (such as waste-to-energy plants on livelihood generation) and social tensions and the importance and provision of centrally located public spaces and amenities within communities. These design-related slum-upgrading issues were often deliberated in a "hybrid-reality" by the participants in order to define all of their parameters. For example, CS1 (Ghazipur, Delhi) workshop Group Four debated the role of the waste-to-energy plant within the community when constructing their living areas within Maslow's Palace. It was argued that while this plant provides a means of livelihood, it causes social tensions as only women are employed due to drug and alcohol issues within the community, and it also endangers livelihoodgenerating opportunities for others due to decreased access to solid waste streams for informal recycling.

The hybrid-realities were also composited of verbal recollections within a design context of real-world spaces and experiences with people, systems or situations - such as in Ghazipur Group Four where design considerations are drawn from both the real 
and game world regarding the importance of centrally locating public amenities (Section 5.2.4.2.4). These types of temporary worlds were found to be useful for participants to express ideas and desires for their communities in different ways and were facilitated by the digital medium of the serious game that incorporated speculative and participatory features.

The extensional referents of slum-upgrading discussions in some instances resulted in participants suggesting out-of-game actions to improve their current situations. For example, participants in CS1 (Ghaizpur, Delhi) workshop Group Four suggested that lobbying local politicians might help them gain alternative modes of employment, as well as access to childcare to reduce strain on working mothers. Chintan, the facilitating organisation for the CS1 Ghazipur and CS2 Bhalswa workshops in Delhi, is currently helping them work towards these outcomes. Here the SPS-UG approach helped the participants action collective planning for future actions outside of the workshop.

\subsubsection{Factor 2: Spaces to Think Within}

The findings suggest that Maslow's Palace was effective in creating spaces for participants to collectively think within-allowing participants to simultaneously discuss and debate a large number of design orientated issues, develop understanding around sensitive social topics and resolve conflicts through iterative ideation and discussion.

Similar to the findings of Bell, Blythe, \& Sengers and Leong \& Iversen, if all participants were in agreement about a design situation or idea in the SPS-UG, then they focussed on clarifying and refining values around a "matter or concern" through discussion and trying out different spatial alternatives (Bell et al., 2005; Leong \& Iversen, 2015). For example, CS3 (Shanti Nagar, Mumbai) Group Five designed a new residential area that had access to hospitals, schools, toilets and water supply that was centred on a community mosque, through a recursive process.

Through the negotiation of design alternatives - the personal with the social, and the individual with the collective participants' goals-assumptions and aspirations were revealed through what Till describes as the "political space" of participatory design (Till, 2005, p. 34). Through the "negotiating space" the design processes within 
the SPS-UG produced a foundation for examining and reconstructing social and political conditions through design, as well as for imagining the political and social conditions that might be (DiSalvo, 2012, p. 119).

\subsection{Methodological Insights into the SPS-UG approach \\ 8.4.1 Evaluation of the Approach}

The findings suggest that the approach of integrating speculative, participatory, and serious urban design game approaches for the generation of social and design (slumupgrading) outcomes for slum communities has been successful. The qualitative Action Research approach method (Foth \& Axup, 2006; Frediani et al., 2011; Groat \& Wang, 2002; Pollastri, 2017; Reason \& Bradbury, 2001; Sanders, 2008; Silverman, 2015; Swann, 2002) allowed for a deeper understanding of the processes within the SPS-UG workshops, as well as facilitating the collection of data from a range of sources and opportunities for outcomes to be delivered back to the community. It also allowed diverse stakeholders to collaborate; however, these experiences have also revealed a range of challenges that must be considered when working in this way, as well as a number of key limitations of the SPS-UG as it is presented in this research that must be noted. The following sections will discuss key strengths and opportunities, followed by key challenges and limitations.

\subsubsection{Key Strengths and Opportunities}

First, one of the main strengths of the methods adopted in this research is that by not being overly fixated on producing a "design outcome" as part of the participatory workshop, participants' tacit and latent feelings and values (Bowen, 2010, p. 2; Sanders, 2001) are incorporated into discussion; this is also due to the informal nature of the gameplay. The SPS-UG approach functioned successfully as a tool for capturing and understanding not only explicitly articulated information from participants, but also forms of tacit or experiential knowledge expressed by participants organically throughout the course of the workshop process that align with findings expressed by other researchers (Bjögvinsson, Ehn, \& Hillgren, 2012; Pollastri, 2017, p. 64). In this way the SPS-UG approach has value as a participatory design "icebreaker"-in a way that does not have any immediate implications based on the actions of participants. 
Second, the nature of the data recording - specifically the screen capture software-allows for data to be captured somewhat covertly so participants' actions are not affected by the recording process. The nature of this data collection, combined with its strength of revealing tacit and latent knowledge through gameplay, was instrumental in helping to create an environment conducive to participants raising and discussing sensitive or controversial ideas, developing preliminary planning proposals and more clearly defining urban problems to interface with future design processes. Data generated throughout the gaming process consequently allows for the creation of a "culture" of discussing and identifying urban related avenues for change rather than focussed on tangible outcomes; this emphasis can be invaluable to future pragmatic design and development processes. Because of these factors, the SPS-UG approach also compared favourably with other participatory planning methods in terms of cost, time and benefits such as enjoyment, creativity and engagement. One of the main benefits of the gaming process was the rapidity of the workshops when considering the number of ideas explored by participants in a short time period.

Third, the Action Research approach allowed for the researcher to establish partnerships to conduct action and research simultaneously, aiding in providing means of community improvement, and fostering change by expanding the collective capabilities of the participants through collective learning and creating some ideas for slum-upgrading action. Following this approach-implementing the SPS-UG framework through the game Maslow's Palace that I designed-the case studies became unique opportunities to enact and evaluate factors that contribute to community engagement with digital approaches to slum-upgrading participation, while addressing both social and design (slum-upgrading) issues.

\subsubsection{Key Challenges and Limitations}

While beyond the scope of this investigation, ultimately, the SPS-UG approach aims to introduce the game outcomes directly into the real urban processes they address. The conditions of each context—such as its existing decision-making mechanisms, rules and regulations, or the balance of power between the involved parties - may either support or hinder the link between the play process and the reality that the SPS-UG process aims to influence. In addition, challenges are reflected in internal dynamics such as disparities in digital literacy or imperfect compromises that 
result from negotiations. Acknowledging the limitations of the approach is essential for forecasting the possible impact of an SPS-UG as accurately as possible, as well as reducing hindrances it might face in future applications in different contexts.

\subsubsection{Limitations of Context and Application}

The research is limited in terms of the stakeholders and actors it engaged. As the focus of this research was to explore how the SPS-UG process might enhance both social outcomes and related design (slum-upgrading) outcomes for urban slum dwellers, there is scope for further research to explore how these outcomes can be translated from the SPS-UG workshops to a pragmatic slum-upgrading project. The research approach is also limited in terms of the actors that it involved, as it did not include actors such as local government officials, city planners, architects or development agencies.

The thesis explored one example of an SPS-UG within three different landfill-based informal settlements. The results of this research are largely limited to these contexts. While the game is suitable for these three related contexts, the game is context-specific, and therefore might be difficult to use in sites significantly outside of the contexts of the research case studies. The research does, however, highlight the importance of the ethnographic analysis of context (Section 4.2) to ensure that key contextual factors and challenges are understood by the researcher before the SPS-UG design process and that they are sufficiently integrated into the operationalisation of the SPS-UG framework in order to enable the social and slum-upgrading outcomes seen in this research.

\subsubsection{Limitations of Methodology}

As discussed in Chapter Three, the Action Research approach usually comprises iterative stages of reflection and action (Foth \& Brynskov, 2016). Ideally, the three Phase Three workshops would have been conducted sequentially, with cycles of reflection between each of the case study workshops (the action) so that improvements to the methods and tools used might be made (ibid.). However, because of the location of the case studies and the resourcing limitations related to the international travel component of this research, this was not possible. From a participant perspective, each 
workshop was orientated around cycles of reflection and action, as well as reflection and adaptation of methods to the unique research situations within each case. The adaptation of the method limited my ability to develop the processes between cycles, which would have resulted in an iterative SPS-UG design process, where feedback and experiences of each workshop could have been used to inform further SPS-UG developments before subsequent workshops and mitigate some of the other limitations; however, this did not limit the research method's ability to respond to the research question.

The case studies did also uncover some limitations with regards to myself being an outsider to the communities. As the research was conducted via the use of translators, I was not able to understand all conversations that happened within each workshop in real time, as at times, the translators could not keep up with the speed of the workshop conversations. While every effort was made to understand all workshop details, this limited my ability to respond to certain circumstances as a researcher in real-timesuch as during CS2 Bhalswa, Delhi workshop Group Two relating to the bereavement of a community member.

The research methodology also resulted in limitations regarding the technical development of the SPS-UG. Due to the resources available to me as a $\mathrm{PhD}$ researcher, I needed to undertake the ethnographic documentation and analysis as well as the SPSUG development myself to reduce the cost of the development. However, this resulted in a substantial investment in terms of time. This interoperation may be a limitation for others looking to utilise the SPS-UG approach to develop their own games. As discussed in Chapter Two, this is the reason that many look to utilise an approach to participatory design and slum-upgrading that repurposes commercial-off-the-shelf (COTS) games such as Minecraft or Cities Skylines as a cost- and time-saving strategy. However as Poplin and Ulrich and Henrik-Helms argue, COTS games are hindered by the fact that they are designed for entertainment-not participatory design processes (Poplin, 2011; Ulrich \& Henrik-Helms, 2017). Their use has been shown to confuse players involved in the participatory process and also rely on a combination of verbal or written external workshop instructions provided by a facilitator to structure the gameplay activities, which can lead to negative issues regarding clarity of instruction (Ibid). Further, while incorporating appropriate parts of the SPS-UG framework into the use of COTS game might have some benefits such as resource savings, the results of this research is limited to conducting the three SPS-UG phases in full. 


\subsubsection{Bridging the Gap Between Priming and Generating Slum-Upgrading}

As introduced in Chapter One, this research explores specifically how the SPS-UG approach can prime participants for a slum-upgrading process by enabling an exploration of possible futures, conflicting stakeholder perspectives, and corresponding goals surrounding social, architectural and urban issues. While each case study did result in a number of social and design-related slum-upgrading outcomes, this limitation in scope raises the question of how outcomes achieved through the SPS-UG workshops might be later translated into implementable, slumupgrading outcomes or be used to evaluate design outcomes.

The question of who takes responsibility for the eventual outcome of a slumupgrading project and its implementation can be problematic for collaborative creative processes, especially in relation to some of the risks involved in a slum-upgrading process, such as social inequality, funding, safety and hygiene considerations, and a broad range of other social, material and political uncertainties. Conventionally, the local and national governments, sometimes together with development organisations and communities, take on the responsibility of slum-upgrading. Including these actors in the slum-upgrading process is important, but as discussed in Chapter Two, it raises questions regarding how to navigate the control of "expert" participants, such as design professionals or politicians, in order to include them in the SPS-UG process to facilitate 'genuine' participation by all stakeholders and ensure positive outcomes (K. Bødker et al., 2004).

Including expert actors in order to bridge the gap between priming and slumupgrading projects also raises questions regarding biases in facilitating the SPS-UG process when considering how SPS-UGs might be developed or facilitated by range of external stakeholders with various slum-upgrading agendas. As with the use of any participatory design tool, there is the danger of biases (Holden et al., 2014; Kalir, Fahy, Kupperman, Schiff, \& Stanzler, 2018)—symptomatic of the various ambitions of those involved in the slum-upgrading project - to infiltrate the SPS-UG development process. These might include the SPS-UG designer privileging certain development outcomes though its design, or disproportionally including certain stakeholders' opinions that were gathered through the ethnographic documentation and analysis phase in its design. Care must also be taken to ensure the minimisation of biases from 
the point of view of the workshop facilitators - such as privileging one participant's voice over another - as well as from the point of view of analysis — such as privileging one workshop outcome over another. This is especially important when attempting to bridge the gap between the SPS-UG process and implementing slum-upgrading projects.

The SPS-UG process is a form of design participation intended to be applied at an early stage to slum-upgrading projects. During SPS-UG gameplay, participants construct speculative digital models orientated towards future slum-upgrading projects. As pointed out by Hayes, it is important to manage the expectations of the workshop participants in terms of the pragmatic viability of these in-game models (Hayes, 2011) by enabling transparency from the beginning, making sure participants are aware of the limitations of the outcomes achieved within a workshop. In line with the findings of von Heland et al., ensuring that participants know what the next steps are after the SPS-UG process is important to reduce the possibility of confusion, disappointment and tension amongst participants and project facilitators (von Heland et al., 2015).

As highlighted in Chapter Seven, the playful actions observed during participatory workshops raise the question of how to interpret the implications for slum-upgrading and how these observations and outcome might be used. Can these results be considered the serious opinions of the participants or just results of the game? For example, a choice of the demolition of the majority of the buildings and reconstruction of a few typologically unfamiliar spaces could be viewed as the playful approach of a participant trying to test a more extreme possibility or classified as their opinion and wish for a solution to the current situation. One possible solution would be an option at the end of play that gives the participant the possibility of marking the result as actual intent or playful possibility in order to provide clarity within the data analysis process and ensure more accurate translation of the SPS-UG outcomes to future slumupgrading projects.

\subsection{Summary}

This chapter has presented a discussion of the methodological approach adopted in the thesis within the context of the research results. In summary, the SPS-UG approach explored through Action Research has provided successful methods to investigate 
three case studies where different urban informal settlement communities in India engaged in the SPS-UG workshops.

The strengths of the method have been discussed in terms of having helped participants to gain opportunities to achieve familiarity with other stakeholders' knowledge, values and goals relating to slum-upgrading in each community through a novel speculative framing of real-world issues and to develop ideas for future designrelated slum-upgrading action and ease of data collection, when compared with other participatory planning methods in terms of cost, time and benefits, such as enjoyment, creativity and engagement.

However, there have also been challenges and limitations, such as the limitations of context and application, how the gap between priming activities and real-world project implementation might be bridged, issues of accountability regarding the project implementation, managing participant expectations and potential bias when developing and implementing the SPS-UG approach.

Next, Chapter Nine will answer the research question, outline the implications of the research contributions for architecture and outline areas for future research. 


\section{Conclusion}

The primary motivation driving this research was to explore the potentials of combining speculative architecture, participatory design, and serious gaming as a means to enhance both social outcomes and design-related slum upgrading outcomes for urban informal settlement dwellers.

This thesis has reinforced previous studies that show that when marginalised communities can confront and explore conflicting perspectives, values, assumptions and goals through negotiation within participatory design processes, the ability to harness the collective intelligence of people to work towards collective action can be enhanced. In this thesis, I have explored how speculative architecture, participatory design and serious gaming approaches can be brought together to enhance opportunities for both social outcomes and related design (slum-upgrading) outcomes for urban slum dwellers. I detailed a new approach that synthesises these three fields into a framework I call Speculative Participatory Serious Urban Gaming or "SPS-UG", and I explored it in practice through a computer game "Maslow's Palace" that I designed and tested in three case studies. The three case studies, CS1 (Ghazipur, Delhi), CS2 (Bhalswa, Delhi) and CS3 (Shanti Nagar, Mumbai), focussed on how the SPS-UG operationalised as Maslow's Palace might be used to help enhance social outcomes and related slum-upgrading outcomes for members of the communities.

The discussion of the research findings indicates that participants can be stimulated by the SPS-UG approach to share diverse opinions and aspirations and thus deepen their understanding of self, others, norms and institutions. I posit that the SPS-UG can function as a catalyst for the transformation of physical urban environments and sociocultural contexts.

This chapter concludes the thesis by answering the research question, outlining the implications of the research contributions and outlining areas for future research. 


\subsection{Reflection on the Research Questions}

The research was guided by one primary research question:

Research Question: How can speculative architecture, participatory design and serious gaming approaches be brought together to enhance both social outcomes and related design (slum-upgrading) outcomes for urban slum dwellers?

Because the research question implicates a synthesis of three bodies of literature, it was important to pose five research Aims:

Aim 1: To identify how "speculative architecture" has enabled an exploration of possible futures, conflicting stakeholder perspectives, and corresponding goals surrounding social, architectural and urban issues.

Aim 2: To document how "participatory design" has enabled an exploration of possible futures, conflicting stakeholder perspectives, and corresponding goals surrounding social, architectural and urban issues.

Aim 3: To question how "serious games" have enabled an exploration of possible futures, conflicting stakeholder perspectives, and corresponding goals surrounding social, architectural and urban issues.

Aim 4: To develop, implement and reflect on the use of a speculative, participatory, game-based approach to slum-upgrading in order to aid the generation of useful urban slum-upgrading oriented social outcomes and related architectural design slum-upgrading outcomes for disparate stakeholders in marginalised communities, more specifically, dwellers of landfill-oriented slums.

Aim 5: To generate insights, guidelines and recommendations for the future practice of a speculative, participatory, game-based approach in similar contexts. 
This thesis has answered the Research Question and responded to the Aims by making several original contributions.

1) This thesis contributes an original Speculative, Participatory, Serious, Urban Gaming (SPS-UG) framework for the design and orchestration of "priming" participatory design workshops that help participants arrive at a range of social and slum-upgrading outcomes. This framework is constructed from a review of speculative architecture, participatory design and serious games literature. Each review contributes a number of strategies that have been utilised by other researchers when exploring different approaches-for example at the intersection of participatory design and speculative architecture in a non-serious games context. In particular, the framework shows how speculative architecture, which has been predominantly internally valuable to architectural discourse, can be purposefully public-facing and engage non-expert participants in slum communities in crafting and discussing speculations about their futures. The framework shows how participatory design tools can be used to generate social and design outcomes and extends the serious games literature by showing how in-game visualisations create a "common language" between participants to discuss values, assumptions and goals. The research discussion contributes recommendations and guidance stemming from the analysis of experiences of implementing the framework in three contexts. The framework can be implemented by a range of community groups and organisations to guide and scaffold participatory processes. As shown in Chapters Five, Six and Seven, the three case studies themselves resulted in a number of positive social and design-related slum-upgrading outcomes for the communities of Ghazipur, Bhalswa and Shanti Nagar. The SPS-UG approach's success is evidenced in part by the ongoing use of Maslow's Palace as a participatory communication tool by the Chintan Environmental Research and Action Group with the Ghazipur and Bhalswa communities in Delhi and by Apnalaya with the Shanti Nagar community.

2) The research unpacks and extends a set of definitions and themes that contributes to discourse about "participatory speculation". The research extends and refines the concept of "perceptual bridging" that I adopted from the speculative design literature by showing how the concept can be used to 
describe the connections that participants made between speculative entities in the SPS-UG digital environment and the real world.

3) The research extends the concept of "temporary worlds" through the definition of "hybrid-realities" composed of speculative digital representations of game spaces, as well as verbal recollections of real-world spaces and experiences with people, systems or situations through the process of "perceptual bridging". The research showed how the temporary worlds within the SPS-UG game space can help the participatory processes to be less likely to appear to be "owned" by one participant at the expense of others and function as a catalyst and container for imagination to aid both social and design-related slum-upgrading outcomes amongst participants of the SPS-UG workshops and scaffold discussions about what the future might look like through visual representation of possible design alternatives.

4) The research contributes to discourse by gathering and discussing key methodological insights relating to the implementation of the SPS-UG framework, the challenges faced when working with communities while pursuing social and slum-upgrading outcomes whilst exploring the SPS-UG approach, and the successes and challenges of various methods used in the different contexts detailed within this thesis.

Taken together, these findings serve as a foundation for future studies in participatory slum-upgrading that is concerned with the transformative power of participatory speculation within serious games. The investigations documented through this thesis advance the research and practice of participatory slum-upgrading, speculative architecture, participatory design and serious games beyond the boundary of current knowledge. The results of this research might be applied within a number of fields including architecture and urban design, slum-upgrading and development studies, speculative design and games studies.

\subsection{Recommendations for Future Research}

The findings in this thesis suggest a number of potential future research directions: expanding the SPS-UG framework, developing common platforms, and developing tools for workshop documentation and analysis systems. 


\subsubsection{Expanding the SPS-UG Framework}

This thesis has contributed a methodological and strategic framework for Speculative, Participatory, Serious Urban Gaming. While the framework has been successfully applied in the Ghazipur, Bhalswa and Shanti Nagar communities, there is an opportunity to further validate the framework by testing it in the context of different communities and social contexts. Some further research questions arising from this thesis include:

- How can the SPS-UG approach be used to engage local government or other design professionals with local communities?

- What is the optimal number of participants that could be involved in each phase?

- How best can groups using the approach share learning experiences and evidence between projects?

- How might a common game platform be developed that can be used in most slum-upgrading applications?

- What is the optimal way for the priming exercise to bridge into slumupgrading action?

- How can the SPS-UG framework be used to create template-based game editors to reduce the design time and expertise needed to develop an SPS$\mathrm{UG}$ ?

- How might analysis and documentation tools be embedded into SPS-UG design?

The Shanti Nagar community in coordination with Apnalaya continued to apply the SPS-UG approach within their community centres to facilitate ongoing slumupgrading discussions after the field studies had been completed. This creates an opportunity to investigate how the communities galvanise around the approach and matters of concern over a longer time. Research on these new instantiations of the SPSUG approach may help to further address some of the questions raised. 


\section{Works Cited}

Abebe, G., \& Hesselberg, J. (2015). Community participation and inner-city slum renewal: relocated people's perspectives on slum clearance and resettlement in Addis Ababa. Development in Practice, 25(4), 551-562.

Abt, C. (1970). Serious Games. New York: Viking Press.

Agger Eriksen, M. (2009). Engaging design materials, formats and framings in specific, situated co-designing - a micro-material perspective. Proceedings of the 3rd Nordic Design Research Conference: Engaging Artifacts. Presented at the Nordes '09, Oslo.

Agogué, M., Levillain, K., \& Hooge, S. (2015). Gamification of Creativity: Exploring the Usefulness of Serious Games for Ideation. Gamification of Creativity, 24(3), 415-429.

Aldrich, C. (2009). The complete guide to simulations \& serious games: How the most valuable content will be created in the age beyond Gutenberg to Google. San Francisco: Pfeiffer.

Al-Kodmany, K. (1999). Using visualization techniques for enhancing public participation in planning and design: process, implementation, and evaluation. Landscape and Urban Planning, 45, 37-45.

Ampatzidou, C., Gugerell, K., Constantinescu, T., Devisch, O., Jauschneg, M., \& Berger, M. (2018). All Work and No Play? Facilitating Serious Games and Gamified Applications in Participatory Urban Planning and Governance. Urban Planning, 3(1), 34-46.

Angel, S. (1983). Upgrading Slum Infrastructure: Divergent Objectives in Search of a Consensus. Third World Planning Review, 5(1), 5-33.

Argenton, L., Triberti, S., Serino, S., Muzio, M., \& Riva, G. (2014). Serious Games as Positive Technologies for Individual and Group Flourishing. In Studies in Computational Intelligence: Vol. 536. Technologies of Inclusive Well-Being (pp. 221-244). 
Argyris, C., \& Schön, D. (1978). Organizational Learning: A Theory of Action Perspective. Reading, Mass: Addison-Wesley Pub. Co.

Armstrong, L., Bailey, J., Julier, G., \& Kimbell, L. (2014). Social Design Futures: HEI Research and the AHRC. Brighton UK: University of Brighton.

Arnab, S., de Freitas, S., Bellott, F., Lim, T., Louchart, S., Suttie, N., ... De Gloria, A. (2015). Pedagogy-driven design of Serious Games: An overall view on learning and game mechanics mapping, and cognition-based models. British Journal of Educational Technology, 46(2), 391-411.

Arnstein, S. (1969). A Ladder of Citizen Participation. Journal of the American Planning Association, 35(4), 216-224.

Auger, J. (2012). Why Robot? Speculative design, the domestication of technology and the considered future (PhD). The Royal College of Art, London.

Auger, J. (2013). Speculative design: crafting the speculation. Digital Creativity, 24(1), 11-35.

Awan, N., Schneider, T., \& Till, J. (2013). Spatial Agency: Other Ways of Doing Architecture. London: Taylor \& Francis Ltd.

Babkin, S. (2017, June 1). What is Speculative Architecture? FAQ by Liam Young. Strelka Mag. Retrieved from https://strelkamag.com/en/article/what-is-speculativearchitecture

Bagozzi, R. P., \& Dholakia, U. (2002). Intentional Social Action in Virtual Communities. Journal of Interactive Marketing, 16(2).

Baker, P., Saunders, J., \& Hussain, Z. (1991). Interpreters in Public Services: Policy and Training. London: Venture Press.

Balestrini, M. (2017). A City in Common: Explorations on Sustained Community Engagement with Bottom-up Civic Technologies (PhD). University College London, London.

Bannon, L., \& Ehn, P. (2013). Design Matters in Participatory Design. In Routledge International Handbook of Participatory Design. New York: Routledge.

Barley, W., Leonardi, P. M., \& Bailey, D. E. (2012). Engineering objects for collaboration: strategies of ambiguity and clarity at knowledge boundaries. Human Communication Research, 38(1), 280-308. 
Baumann, K., Caldwell, B., Bar, F., \& Stokes, B. (2018). Participatory Design Fiction: Community Storytelling for Speculative Urban Technologies. Proceedings of the 2018 CHI Conference on Human Factors in Computing Systems. Presented at the CHI EA '18, Montreal.

Baumann, K., Stokes, B., Bar, F., \& Caldwell, B. (2017). Infrastructures of the Imagination: Community Design for Speculative Urban Technologies. Proceedings of the 8th International Conference on Communities and Technologies. Presented at the C\&T '17, Troyes, France.

Baviskar, A. (2003). Between violence and desire: space, power, and identity in the making of metropolitan Delhi. International Social Science Journal, 55(175), 89-98.

Beattie, H. (2013, October 16). Mobile Minecrafting in Central Kenya. Retrieved August 14, 2018, from Block by Block: Un-Habitat and Mojang using Minecraft to involve citizens in public space design website: http://blockby.tumblr.com/post/64203897977/mobileminecrafting-in-central-kenya

Becker, K., \& Parker, J. R. (2011). The Guide to Computer Simulations and Games. Indianapolis: JohnWiley \& Sons.

Bell, G., Blythe, M. A., \& Sengers, P. (2005). Making by Making Strange: Defamiliarization and the Design of Domestic Technologies. ACM Transactions on Computer-Human Interaction, 12(2), 149-173.

Bellotti, F., Kapralos, B., Lee, K., Moreno-Ger, P., \& Berta, R. (2013a). Assessment in and of serious games: An overview. Advances in Human-Computer Interaction, 1-12.

Bellotti, F., Kapralos, B., Lee, K., Moreno-Ger, P., \& Berta, R. (2013b). Assessment in and of Serious Games: An Overview. Advances in Human-Computer Interaction - Special Issue on User Assessment in Serious Games and Technology-Enhanced Learnin, 1, 111.

Ben-Attar, D., \& Campbell, T. (2015). ICT, Urban Governance and Youth. Nairobi: UNHabitat.

Bhalaswa Lok, \& Shakti Manch. (2012). Ground Water Quality and Health Impacts in Bhalaswa, New Delhi (No. 1). Retrieved from Hazards Centre website: 
http://www.indiawaterportal.org/sites/indiawaterportal.org/files/bhalaswagroundwater-and-health-report_hazards-centre-2012.pdf

Billger, M., Thuvander, L., \& Wästberg, B. S. (2017). In search of visualization challenges: The development and implementation of visualization tools for supporting dialogue in urban planning processes. Environment and Planning B: Urban Analytics and City Science, 44(6), 1012-1035.

Bingham, N., Carolin, C., Cook, P., \& Wilson, R. (2004). Fantasy Architecture: 1500-2036. London: Hayward Gallery Publishing.

Bjögvinsson, E., Ehn, P., \& Hillgren, P.-A. (2012). Design Things and Design Thinking: Contemporary Participatory Design Challenges. Design Issues, 28(3), 101-116.

Björgvinsson, E., Ehn, P., \& Hillgren, P.-A. (2010). Participatory Design and 'Democratizing Innovation'. Proceedings of the 11th Participatory Design Conference, 41-50. Sydney, Australia: 41-50.

Björgvinsson, E., Ehn, P., \& Hillgren, P.-A. (2012). Agonistic participatory design: working with marginalised social movements. CoDesign: International Journal of CoCreation in Design and the Arts, 8(2-3), 127144.

Block by Block. (2017). Rebuilding Stability In Mogadishu. Retrieved April 26, 2019, from https://www.blockbyblock.org/projects/mogadishu

Blundell-Jones, P., Petrescu, D., \& Till, J. (Eds.). (2005). Architecture and Participation. New York: Routledge.

Blythe, M. A., \& Wright, P. C. (2006). Pastiche scenarios: Fiction as a resource for user centred design. Interacting with Computers, 18(5), 1139-1164.

Boano, C., \& Kelling, E. (2013). Towards an Architecture of Dissensus: Participatory Urbanism in South-East Asia. Footprint, (13).

Bødker, K., Kensing, F., \& Simonsen, J. (2004). Participatory IT Design: Designing for Business and Workplace Realities. Cambridge, Massachusetts: MIT Press.

Bødker, M. (2009). Performative artefacts: users "speaking through" artefacts in collaborative design. Proceedings of the 21 st Annual Conference of the Australian Computer-Human Interaction Special Interest Group: Design, 23-27. Melbourne: ACM. 
Bogost, I. (2007). Persuasive Games: The Expressive Power of Videogames. Cambridge, Massachusetts: The MIT Press.

Boroushaki, S., \& Malczewski, J. (2010). Measuring consensus for collaborative decisionmaking: A GIS-based approach. Computers, Environment and Urban Systems, 34, 322332.

Borries, F., Walz, S., \& Bottger, M. (Eds.). (2007). Space Time Play - Computer Games, Architecture and Urbanism: The Next Level. Basel, Switzerland: Birkhauser Verlag AG.

Boughzala, I., Bououd, I., \& Michel, H. (2013). Characterization and Evaluation of Serious Games: A perspective of their use in higher education. 46th Hawaii International Conference on System Sciences. Presented at the International Conference on System Sciences, Hawaii.

Bowen, S. (2010). Critical Theory and Participatory Design. Proceedings of CHI.

Bowman, R. F. (1982). "Pac-Man" theory of motivation: Tactile implications for classroom instruction. Educational Technology, 22(9), 14-17.

Boyle, E., Connolly, T., Hainey, T., \& Boyle, J. (2012). Engagement in digital entertainment games: A systematic review. Computers in Human Behavior, 28(3), 771-780.

Brandt, E. (2006). Designing Exploratory Design Games: A Framework for Participation in Participatory Design. Proceedings of Participatory Design Conference. Presented at the PDC2006, Trento, Italy.

Brandt, E. (2007). How Tangible Mock-Ups Support Design Collaboration. Knowledge, Technology \& Policy, 20(3), 179-192.

Brandt, E., \& Binder, T. (2007). Experimental design research: genealogy, intervention, argument. Proceedings of International Associations of Design Research. Presented at the Hong Kong. Hong Kong.

Brandt, E., Binder, T., \& Sanders, E. (2013). Tools and techniques: Ways to engage telling, making and enacting. In Routledge International Handbook of Participatory Design (pp. 145-181). Ney York: Routledge. 
Brandt, E., \& Messeter, J. (2004). Facilitating Collaboration through Design Games. Proceedings of the Eighth Conference on Participatory Design: Artful Integration: Interweaving Media, Materials and Practices, 1, 121-131. Toronto.

Brandt, E., Messeter, J., \& Binder, T. (2008). Formatting design dialogues - games and participation. CoDesign: International Journal of CoCreation in Design and the Arts, $4(1), 51-64$.

Braun, V., \& Clarke, V. (2006). Using thematic analysis in psychology. Qualitative Research in Psychology, 3(2), 77-101.

Brown, E., \& Cairns, P. (2004). A grounded investigation of game immersion. Proceedings of the Conference on Human Factors in Computing Systems. Presented at the Vienna, Austria. Vienna, Austria.

Brown, V., Harris, J., \& Russell, J. (Eds.). (2010). Tackling Wicked Problems Through the Transdisciplinary Imagination. London: Earthscan Publications.

Brydon-Miller, M., Greenwood, D., \& Maguire, P. (2003). Why action research? Action Research, 1(1), 9-28.

Bryson, J., Quick, K. S., Slotterback, C. S., \& Crosby, B. C. (2013). Designing Public Participation Processes. Public Administration Review, 73(1), 23-34.

Buchinger, D., \& Hounsell, M. da S. (2018). Guidelines for designing and using collaborativecompetitive serious games. Computers \& Education, 118(1), 133-149.

Büscher, M., Eriksen, M. A., Kristensen, J. F., \& Mogensen, P. H. (2004). Ways of grounding imagination. Proceedings of the Eighth Conference on Participatory Design: Artful Integration: Interweaving Media, Materials and Practices, 1. Toronto: ACM.

Buzzi, F. (2017, December 28). Gamespace Urbanism: City-Building Games and Radical Simulations for Failed Architecture. Retrieved March 8, 2019, from Failed Architecture website: https://failedarchitecture.com/gamespace-urbanism-city-building-games-andradical-simulations/

Caillois, R. (1961). Man, Play and Games. New York: Free Press of Glencoe.

Canavan, G., \& Suvin, D. (2016). Metamorphoses of Science Fiction. New York: Peter Lang Publishing. 
Carmona, M. (2003). Public Places - Urban Spaces: The Dimensions of Urban Design. Oxford: Elsevier.

Carroll, J., \& Rosson, M. B. (2007). Participatory design in community informatics. Design Studies, 28(3), 243-261.

Carroll, J., \& Rosson, M. B. (2013). Wild at home: the neighborhood as a living laboratory for HCI. ACM Transactions on Computer-Human Interaction, 20(3), 16.

Charnley, F., Lemon, M., \& Evans, S. (2011). Exploring the process of whole system design. Design Studies, 32(2), 156-179.

Charsky, D. (2010). From edutainment to serious games: A change in the use of game characteristics. Games and Culture, 5(2), 177-198.

Cheng, N. Y.-W. (1999). Playing with digital media: enlivening computer graphics teaching. Proceedings of the Association for Computer Aided Design in Architecture, 96-109. Salt lake City: Media and Design Process.

Chintan. (2011). Waste to Energy or Waste of Energy?: Social and Economic Impact Assessment of Waste-to-Energy Projects on Wastepickers near Ghazipur and Okhla Landfills in Delhi. Retrieved from Chintan Environmental Research Action Group website: http://www.chintanindia.org/documents/research_and_reports/chintan_waste_to_energy_or_waste_of_en ergy.pdf

Cities Alliance. (2010). About Slum Upgrading. Retrieved April 10, 2019, from Cities Alliance: Cities Without Slums website: https://www.citiesalliance.org/About-slumupgrading\#Why_is_slum_upgrading_important

Clarke, R., Heitlinger, S., Foth, M., DiSalvo, C., Light, A., \& Forlano, L. (2018). More-thanhuman urban futures: speculative participatory design to avoid ecocidal smart cities. Proceedings of the 15th Participatory Design Conference: Short Papers, Situated Actions, Workshops and Tutoria, 2. Hasselt and Genk, Belgium: ACM.

Clear, N. (2013). Drawing Time. In N. Spiller (Ed.), Drawing Architecture (pp. 70-79). John Wiley \& Sons, Inc. 
Clement, A., \& Besselaar, P. V. den. (1993). A retrospective look at PD projects. Communications of the ACM, 36(6), 29-37.

Coghlan, D., \& Brannick, T. (2005). Doing Action Research in Your Own Organization. London: Sage Publications.

Cohen, L., Manion, L., \& Morrison, K. (2003). Research methods in education. New York: Routledge.

Coleman, J. (1988). Social capital in the creation of human capital. The Americal Journal of Sociology, 94, S95-S120.

Coleman, N. (2005). Utopias and Architecture. New York: Routledge.

Consolvo, S., McDonald, D. W., \& Landay, J. A. (2009). Theory-driven design strategies for technologies that support behavior change in everyday life. Proceedings of the SIGCHI Conference on Human Factors in Computing Systems. Presented at the CHI09, Boston.

Cooke, B., \& Kothari, U. (2001). Participation: The New Tyranny? London: Zed Books.

Corrigan, S., Zon, G. D. R., Maij, A., McDonald, N., \& Mårtensson, L. (2015). An approach to collaborative learning and the serious game development. Cognition, Technology \& Work, 17(2), 269-278. https://doi.org/10.1007/s10111-014-0289-8

Coulton, P., Burnett, D., \& Gradinar, A. (2016). Games as Speculative Design: Allowing Players to Consider Alternate Presents and Plausible Futures. 2016 Design Research Society 50th Anniversary Conference. Presented at the Brighton UK. Brighton UK.

Coulton, P., Jacobs, R., Burnett, D., Gradinar, A., Watkins, M., \& Candice Howarth. (2014). Designing Data Driven Persuasive Games to Address Wicked Problems such as Climate Change. AcademicMindTrek '14, 185-191. New York: ACM.

Crabtree, A., Rouncefield, M., \& Tolmie, P. (2012). Doing Design Ethnography. London: Springer.

Cross, N. (2011). Design Thinking: Understanding How Designers Think and Work. Oxford: Berg.

Crowe, N., \& Laseau, P. (1986). Visual Notes for Architects and Designers. Hoboken, N.J: Wiley. 
Cunningham, C., \& Zichermann, G. (2011). Gamification by design: Implementing game mechanics in web and mobile apps. Sebastopol, CA: O'Reilly Media, Inc.

Dalisay, F., Kushin, M. J., Yamamoto, M., Liu, Y.-I., \& Skalski, P. (2015). Motivations for game play and the social capital and civic potential of video games. New Media \& Society, 17(9), 1399-1417.

Davis, J.-M., \& Garb, Y. (2017). Participatory shaping of community futures in e-waste processing hubs: Complexity, conflict and stewarded convergence in a Palestinian context. Development Policy Review, 37, 67-89.

Denscombe, M. (2010). Good Research Guide : For small-scale social research projects (4th ed.). Open University Press.

DeSmet, A., Thompson, D., Baranowski, T., Palmeira, A., Verloigne, M., \& Bourdeaudhuij, I. D. (2016). Is Participatory Design Associated with the Effectiveness of Serious Digital Games for Healthy Lifestyle Promotion? A eta-Analysis. Journal of Medical Internet Research, 18(4).

Desouza, K., \& Bhagwatwar, A. (2014). Technology-Enabled Participatory Platforms for Civic Engagement: The Case of U.S. Cities. Journal of Urban Technology, 21(4).

Deterding, S., Dixon, D., Khaled, R., \& Nacke, L. (2011). From game design elements to gamefulness: Defining “gamification." Proceedings of the 15th International Academic MindTrek Conference: Envisioning Future Media Environments, 9-15. Tampere: ACM.

Devisch, O., Poplin, A., \& Sofronie, S. (2016). The gamification of civic participation: Two experiments in improving the skills of citizens to reflect collectively on spatial issues. Journal of Urban Technology, 23(2), 81-102.

Di Mascio, D. (2010). Learning from videogames level design: an educational point of view for architecture. Proceedings of the 10th International Conference on Construction Applications of Virtual Reality, 199-208. Sendai, Japan.

Di Mascio, D., \& Dalton, R. (2017). Using Serious Games to Establish a Dialogue Between Designers and Citizens in participatory Design:The Architectural Portal of People's 
Narratives. In Serious Games and Edutainment Applications: Vol. II (pp. 433-454).

Switzerland: Springer.

Dick, B. (2007). What Can Grounded Theorists and Action Researchers Learn from Each Other? In The Sage Handbook of Grounded Theory. London: Sage Publications.

Dindler, C. (2010a). Fictional space in participatory design of engaging interactive environments (PhD). Aarhus University, Department of Information and Media Studies, Faculty of Humanities, Aarhus University.

Dindler, C. (2010b). The construction of fictional space in participatory design practice. CoDesign: International Journal of CoCreation in Design and the Arts, 6(3), 167-182.

Dindler, C., \& Iversen, O. S. (2007). Fictional Inquiry-design collaboration in a shared narrative space. CoDesign: International Journal of CoCreation in Design and the Arts, $3(4), 213-234$.

DiSalvo, C. (2010, July 7). Design, Democracy and Agonistic Pluralism. Presented at the Design Research Society Conference, Montreal.

DiSalvo, C. (2012). Adverserial Design. London: The MIT Press.

DiSalvo, C., Marti Louw, Coupland, J., \& Steiner, M. (2009). Local issues, local uses: tools for robotics and sensing in community contexts. Proceedings of the Seventh ACM Conference on Creativity and Cognition, 245-254. Berkeley: ACM.

Djaouti, D., Alvarez, J., Jessel, J.-P., Méthel, G., \& Molinier, P. (2008). A Gameplay Definition through Videogame Classification. International Journal of Computer Games Technolog, 1-7.

Doležel, L. (1998). Possible Worlds of Fiction and History. New Literary History, 29(4), 785809.

Donnelly, J. (2016). Cities: Skylines used by Swedish city planners to design new city district. Retrieved March 8, 2019, from PC Gamer website: https://www.pcgamer.com/au/cities-skylines-used-by-swedish-city-planners-todesign-new-city-district/

Dörk, M., Collins, C., Feng, P., \& Carpendale, S. (2013). Critical InfoVis: Exploring the Politics of Visualization. In Proceedings of CHI 2013. Presented at the Paris. Paris. 
Dugard, P., \& Todman, J. (1995). Analysis of pre-test-post-test control group designs in educational research. Educational Psychology, 15(2), 181-198.

Duke, R. (1975). Metropolis: The urban systems game. New York: Gamed Simulations, Inc.

Duke, R. (1995). Gaming: an emergent discipline. Gaming and Simulation, 26(4), 426-439.

Dunn, N., Cureton, P., \& Pollastri, S. (2014). A Visual History of the Future. Retrieved from UK Government, Office for Science website: https://www.gov.uk/government/uploads/system/uploads/attachment_data/fil e/360814/14-814-future-cities-visual-history.pdf.

Dunne, A., \& Raby, F. (2001). Design Noir: The Secret Life of Electronic Objects. Basel: Birkhauser.

Dunne, A., \& Raby, F. (2013). Speculative Everything : Design, Fiction, and Social Dreaming. Retrieved from http://helicon.vuw.ac.nz/login?url=http://search.ebscohost.com/login.aspx?direct=true $\& d b=$ lebk\&AN=672907\&site $=$ ehost-live

Echanove, M. (2014, February 26). Shivaji Nagar, M-Ward, Mumbai. Retrieved July 27, 2016, from Urbz: User Generated Cities website: http://urbz.net/shivaji-nagar-m-wardmumbai/

Ehn. (1988). Designing for Democracy at Work. Falköping, Sweden: Arbetslivscentrum.

Eisenhardt, K. (1989). Building Theories from Case Study Research. Academy of Management Review, 14(4), 532-550.

Elden, M., \& Chisholm, R. (1993). Emerging Varieties of Action Research: Introduction to the Special Issue. Human Relations, 46(2), 121-142.

Emilson, A. (2015). Design in the Spcae Between Stories: Design for Social Innovation and Sustainability - from responding to societal challenges to preparing for societal $\begin{array}{llll}\text { collapse } & \text { (Malmö } & \text { University). } & \text { Retrieved }\end{array}$ https://dspace.mah.se/bitstream/handle/2043/19185/2043_19185\%20Emilson\%20mue p.pdf?sequence $=2 \&$ isAllowed $=\mathrm{y}$

Erhel, S., \& Jamet, E. (2013). Digital game-based learning: Impact of instructions and feedback on motivation and learning effectiveness. Computers and Education, 67, 156-167. 
Ermacora, T., \& Bullivant, L. (2016). Recoded City: Co-Creating Urban Futures. Abingdon, Oxon; New York, N: Routledge, Taylor \& Francis Group.

Ertiö, T.-P. (2015). Participatory apps for urban planning — space for improvement. Planning Practice \& Research, 30(3), 202-321.

Fahey, C. (2013). Autonomy and Presupposition in Architecture. 17(2), 131-137.

Falco, E., \& Kleinhans, R. (2018). Digital Participatory Platforms for Co-Production in Urban Development: A Systematic Review. International Journal of E-Planning Research, $7(3), 1-21$.

Fear, D. (2017). Blade Runner 2049': Welcome to the Age of Peak Dystopia Fatigue. Retrieved September 26, 2019, from Rolling Stone website: https://www.rollingstone.com/movies/movie-news/blade-runner-2049-welcome-tothe-age-of-peak-dystopia-fatigue-124865/

Fereday, J., \& Muir-Cochrane, E. (2006). Demonstrating Rigor Using Thematic Analysis: A Hybrid Approach of Inductive and Deductive Coding and Theme Development. International Journal of Qualitative Methods, 5(1), 80-92.

Finke, R., Smith, S., \& Ward, T. (1992). Creative Cognition: Theory, Research, and Applications. Cambridge, Massachusetts: MIT Press.

Forlano, L., \& Mathew, A. (2014). From Design Fiction to Design Friction: Speculative and Participatory Design of Values-Embedded Urban Technology. Journal of Urban Technology, 21(4), 7-24.

Forrester, J. (1969). Urban Dynamics. MA: Pegasus Communications.

Foth, M., \& Axup, J. (2006). Participatory Design and Action Research: Identical Twins or Synergetic Pair? Proceedings of the Participatory Design Conference, 93-96. Trento, Italy.

Foth, M., \& Brynskov, M. (2016). Participatory action research for civic engagement. In Civic Media: Technology, Design, Practive (pp. 563-580). Cambridge, Massachusetts: MIT Press. 
Foth, M., Hearn, G., \& Klaebe, H. (2007). Embedding digital narratives and new media in urban planning. Proceedings Digital Resources for the Humanities and Arts. Presented at the Dartington, UK. Dartington, UK.

Frediani, A. (2016). Re-imagining Participatory Design: Reflecting on the ASF-UK Change by Design Methodology. Design Issues, 32(3), 98-111.

Frediani, A., \& Boano, C. (2012). Processes for Just Products: The Capability Space of Participatory Design. In Philosophy of Engineering and Technology: Vol. 5. The Capability Approach, Technology and Design (pp. 203-222). Dordrecht: Springer.

Frediani, A., French, M., \& Ferrera, I. N. (2011). Change by Design: Building Communities Through Participatory Design.

French, M., Popal, A., Rahimi, H., Popuri, S., \& Turkstra, J. (2018). Institutionalizing participatory slum upgrading: a case study of urban co-production from Afghanistan, 2002-2016. Environment \& Urbanization, 1-22.

Friedman, J. (1987). Planning in the Public Domain: From knowledge to action. Princeton. New Jersey: Princeton University Press.

Fuller, R. B. (1971). The World Game: Integrative Resource Utilization Planning Tool. Carbondale, Illinois: Southern Illinois University.

Fuller, R. B. (2011). Your Private Sky R. Buckminster Fuller: The Art of Design Science (J. Krausse \& C. Lichtenstein, Eds.). Baden, Switzerland: Lars Muller; Zurich : Museum of Design.

Gai, M., \& Wang, G. (2016). Artistic Low Poly rendering for images. The Visual Computer, 32(4), 491-500.

Garris, R., \& Driskell, J. E. (2002). Games, motivation and learning: A research and practice model. Simulation and Gaming, 33(4), 441-467.

Gaver, W. W., Beaver, J., \& Benford, S. (2003). Ambiguity as a Resource for Design. ACM Special Interest Group on Human Computer Interaction, 5, 233-240. Fort Lauderdale, Florida, United States.

Gaver, W. W., Dunne, A., \& Pacenti, E. (1999). Cultural Probes. Interactions, 6(1), 21-29. 
Gbadamosi, N. (2016, July 19). Lagos 2050: Shanty megastructures? Retrieved February 1, 2019, from CNN Style website: https://edition.cnn.com/style/article/lagos-shantymegastructures/index.html

Gee, J. P. (2003). What Video Games Have to Teach Us About Learning and Literacy. New York: Palgrave/Macmillan.

Gerber, A. (2018). Participatory speculation: futures of public safety. Proceedings of the 15th Participatory Design Conference: Short Papers, Situated Actions, Workshops and Tutorial, 2. Hasselt and Genk, Belgium: ACM.

Gissen, D. (2009, February 22). Architecture fiction - a short review of a young concept | HTC Experiments. Retrieved April 11, 2016, from https://htcexperiments.org/2009/02/22/architecture-fiction-\%E2\%80\%94-a-shortreview-of-a-young-concept/

Gooch, D., Barker, M., Hudson, L., Kelly, R., Kortuem, G., Van Der Linden, J., ... Walton, C. (2018). Amplifying Quiet Voices: Challenges and Opportunities for Participatory Design at an Urban Scale. ACM Transactions on Computer-Human Interaction (TOCHI) - Special Issue on Reimagining Participatory Design, 25(1).

Goodman, N. (1978). Ways of Worldmaking. Indianapolis: Hacket \& Company.

Gordon, E., \& Baldwin-Philippi, J. (2014a). Playful Civic Learning: Enabling Lateral Trust and Reflection in Game-based Public Participation. International Journal of Communication, 8, 756-786.

Gordon, E., \& Baldwin-Philippi, J. (2014b). Why We Engage: How Theories of Human Behavior Contribute to Our Understanding of Civic Engagement in a Digital Era. International Journal of Communication, 8, 759-786.

Granic, I., Lobel, A., \& Engels, R. (2014). The benefits of playing video games. American Psychologist, 69(1), 66-78.

Groat, L., \& Wang, D. (2002). Architectural Research Methods. New York: John Wiley \& Sons, Inc. 
Gün, A., Demir, Y., \& Pak, B. (2019). Urban design empowerment through ICT-based platforms in Europe. International Journal of Urban Sciences. https://doi.org/10.1080/12265934.2019.1604250

Habraken, J., \& Gross, M. (1988). Concept design games. Design Studies, 9(3), 150-158.

Halloran, J., Hornecker, E., \& Fitzpatrick, G. (2009). The value of values: resourcing co-design of ubiquitous computing. CoDesign, 4(5), 245-273.

Halskov, K., \& Dalsgaard, P. (2006). Inspiration card workshops. In: Proceedings of the 6th Conference on Designing Interactive Systems, 2-11. New York: ACM.

Hamari, J., Shernoff, D., Rowe, E., Coller, B., Asbell-Clarke, J., \& Edwards, T. (2016). Challenging games help students learn: An empirical study on engagement, flow and immersion in game-based learning. Computers in Human Behavior, 54(1), 170-179.

Hamdi, N. (1991). Housing Without Houses: Participation, flexibility, enablement. London: Van Nostrand Reinhold.

Hamdi, N. (2010). The Placemakers Guide to Building Community. London: Earthscan Publications.

Hamdi, N., \& Goethert, R. (1997). Action Planning for Cities: A Guide to Community Practice. Chichester, UK: John Wiley \& Sons, Inc.

Hancock, T., \& Bezold, C. (1994). Possible futures, preferable futures. The Healthcare Forum Journal, 37(2), 23-29.

Harrington, F., \& Turner, G. (2001). Interpreting Interpreting: Studies and Reflections on Sign Language Interpreting. Coleford, Gloucestershire: Douglas Mclean.

Harvey, D. (2003). The Right to the City. International Journal of Urban and Regional Research, 27(4), 939-941.

Hayes, G. (2011). The relationship of action research to human-computer interaction. ACM Transactions on Computer-Human Interaction, 18(3), 15.

Heller, P., \& Mukhopadhyay, P. (2014). Rehabilitation of Jhuggi Jhopri Clusters in Delhi. Retrieved from Centre for Policy Research website: http://www.cprindia.org/sites/default/files/policy-briefs/Rehabilitation-of-JJCs-inDelhi.pdf 
Henchley, N. (1978). Making sense of futures studies. Alternatives, 7(2), 24-28.

Hillgren, P.-A., Seravalli, A., \& Emilson, A. (2011). Prototyping and infrastructuring in design for social innovation. CoDesign: International Journal of CoCreation in Design and the Arts, 7(3-4), 169-183.

Hillier, J. (2003). Agonizing Over Consensus: Why Habermasian Ideals Connot Be Real. Planning Theory, 2(1).

Holden, J. I., Kupperman, J., Dorfman, A., Saunders, T., Pratt, A., \& MacKay, P. (2014). Gameful learning as a way of being. International Journal of Learning Technology, $9(2), 181$.

Holland, A., \& Roudavski, S. (2016). Mobile gaming for agonistic design. Fifty Years Later: Revisiting the Role of Architectural Science in Design and Practice, 299-308. Adalaide: The Architectural Science Association and The University of Adelaide.

Holtzblatt, K., Wendell, J. B., \& Wood, S. (2004). Rapid Contextual Design. Amsterdam: Morgan Kaufmann Publishers Inc.

Huchzermeyer, M. (2010). Pounding at the Tip of the Iceberg: The Dominant Politics of Informal Settlement Eradication in South Africa. Politikon, 37(1), 129-148.

Huizinga, J. (1955). Homo Ludens - A study of the play element in culture. Boston: Beacon Press.

Hunicke, R., LeBlanc, M., \& Zubek, R. (2004). MDA: A Formal Approach to Game Design and Game Research. Proceedings of the AAAI Challenges in Game AI Workshop. Retrieved from https://www.aaai.org/Papers/Workshops/2004/WS-04-04/WS04-04001.pdf

Huotari, K., \& Hamari, J. (2011). Gamification" from the perspective of service marketing. CHI 2011. Presented at the Vancouver. Vancouver: ACM.

Huxam, C. (2003). Action Research as a Methodology for Theory Development. Policy \& Politics, 31(2), 239-248.

Huybrechts, L., Dreessen, K., Schepers, S., \& Salazar, P. C. (2016). Democratic Dialogues That Make Cities 'work. Strategic Design Research Journal, 9(2), 100-111. 
Ibrahim, S., \& Alkire, S. (2007). Agency and Empowerment: A Proposal for Internationally Comparable Indicators. Oxford Development Studies, 35(4), 379-403.

IDeEA Lab. (2017). Serious Games for Interdisciplinary Design. Retrieved March 7, 2019, from http://ideealab.net/index.php/2017/05/16/lowpoly-beta-2-0/

Indraprastha, A., \& Shinozaki, M. (2009). The Investigation on Using Unity3D Game Engine in Urban Design Study. Journal of Information and Communication Technology, 3(1), $1-18$.

Innes, J., \& Booher, D. E. (2010). Planning with Complexity: An introduction to collaborative rationality for public policy. Oxon: Routledge.

Innes, J. E., \& Booher, D. E. (1999). Consensus Building as Role Playing and Bricolage: Toward a Theory of Collaborative Planning. Journal of the American Planning Association, 65(1), 9-26.

Iser, W. (1993). The Fictive and the Imaginary: Charting Literary Anthropology. Baltimore: Johns Hopkins University Press.

Iten, N., \& Petko, D. (2016). Learning with serious games: Is fun playing the game a predictor of learning success? British Journal of Educational Technology, 47(1), 151-163.

Iversen, O. S., \& Buur, J. (2002). Design is a Game: Developing Design Competence in a Game Setting. Proceedings of Participatory Design Conference, 22-28. Malmö, Sweden: CPSR.

Iversen, O. S., Halskov, K., \& Leong, T. W. (2010). Rekindling Values in Participatory Design. Proceedings of the 11th Biennial Participatory Design Conference Pages, 91-100. Sydney, Australia.

Iversen, O. S., Halskov, K., \& Leong, T. W. (2012). Values-led participatory design. CoDesign: International Journal of CoCreation in Design and the Arts, 8(2-3), 87103.

Jabbar, A. I. A., \& Felicia, P. (2015). Gameplay engagement and learning in game-based learning: A systematic review. Review of Educational Research, 85(4), 740-779.

Jarvis, P., Holford, J., \& Griffin, C. (Eds.). (2003). The Theory and Practice of Learning. London: Kogan Page. 
Joelsson, Y., \& Lord, R. (2016). Urban Solid Waste Management in Mumbai: Current challenges and future solutions for Urban Development. Retrieved from Swedish International Development Cooperation Agency website: http://www.divaportal.org/smash/get/diva2:943376/FULLTEXT01.pdf

Johansson, M. (2005). Participatory Inquiry - Collaborative Design (PhD). Blekinge Institute of Technology, Valhallavägen, Sweden.

Johnson, B. D. (2011). Science Fiction Prototyping: Designing the Future with Science Fiction. Morgan and Claypool.

Jones, H. (2019). Participatory Speculation. Retrieved from http://hefinjones.co.uk/participatory-speculation

Jutraz, A., \& Zupancic, T. (2015). Virtual Worlds as Support Tools for Public Engagement in Urban Design. In Planning Support Systems and Smart Cities (pp. 391-408). New York: Springer.

Kaku, M. (2008). Physics of the Impossible: A Scientific Exploration into the World of Phasers, Force Fields, Teleportation, and Time Travel. New York: Doubleday.

Kalir, J. H., Fahy, M., Kupperman, J., Schiff, F. M., \& Stanzler, J. (2018). Playful Partnerships for Game-Based Learning in International Contexts. In ICT-Supported Innovations in Small Countries and Developing Regions (p. 141). Switzerland: Springer.

Kebritchi, M., \& Hirumi, A. (2008). Examining the pedagogical foundations of modern educational computer games. Computers and Education, 51(4), 1729-1743.

Kelty, C. (2008). The Cultural Significance of Free Software. Durham, NC: Duke University Press.

Kemmis, S. (2014). The action research planner: doing critical participatory action research. Singapore: Springer.

Kensing, F. (2003). Methods and practices in participatory design. Copenhagen: ITU Press.

Kensing, F., \& Greenbaum, J. (2013). Heritage: Having a Say. In Routledge International handbook of Participatory Design (pp. 21-36). New York: Routledge.

Kensing, F., \& Madsen, K. H. (1992). Generating visions: future workshops and metaphors. In Design at work (pp. 155-168). Hillsdale, N.J.: L. Erlbaum Associates Inc. 
Khan, B. (2015). No water in parts of Govandi for the last 7 days. Retrieved from Mumbai North East News website: http://54.254.97.154/locality/mumbai-north-east/no-waterparts-govandi-last-7-days-80348

Khan, Z., Dambruch, J., Peters-Anders, J., Sackl, A., Strasser, A., Fröhlich, P., ... Soomro, K. (2017). Developing Knowledge-Based Citizen Participation Platform to Support Smart City Decision Making: The Smarticipate Case Study. Information, 8(47).

Kickmeier-Rust, M. D., Peirce, N., Conlan, O., Schwarz, D., Verpoorten, D., \& Dietrich Albert. (2007). Immersive digital games: the interfaces for next-generation e-learning. UAHCI’07, 647-656. Berlin: Springer-Verlag.

Kindon, S. (2010). Participation. In The SAGE Handbook of Social Geographies (pp. 517545). London: Sage.

King, N. (2004). Using Templates in the Thematic Analysis of Text. In Essential guide to qualitative methods in organizational research (pp. 257-270). London: Sage.

King, S., Conley, M., Latimer, B., \& Ferrari, D. (1989). Co-Design: A Process of Design Participation. Ney York: Van Nostrand Reinhold.

Kitzinger, J. (1995). Qualitative Research: Introducing focus groups. BJM, 311(7000), 299.

Knutz, E., Markussen, T., \& Lenskjold, T. (2016, June). Fiction as a Resource in Participatory Design. Presented at the 2016 Design Research Society 50th Anniversary Conference, $\begin{array}{llll}\text { Brighton UK. } & \text { Retrieved }\end{array}$ https://static1.squarespace.com/static/55ca3eafe4b05bb65abd54ff/t/5747796f859fd02 7d04f50ff/1464301946235/476+Knutz.pdf

Kolb, D. (1984). Experiential learning: Experience as the source of learning and development. Upper Saddle River, NJ: Prentice-Hall.

Koplin, M., \& Skelton, C. (2012). Betaville - A Massively Participatory Mirror World Game. In Serious Games Development and Applications (pp. 170-174). Berlin: SpringerVerlag.

Korody, N. (2016, September 2). Level up: using video games to unlock the city. Retrieved March 3, 2017, from Archinect website: 
http://archinect.com/features/article/149966152/level-up-using-video-games-tounlock-the-city

Krek, A. (2008). Games in urban planning: The power of playful public participation. In Mobility nodes as innovation hubs. Proceedings of 13th International Conference on Urban Planning, Regional Development and Information Society, 683-691. Vienna, Austria: Schwechat-Rannersdorf.

Kreutz, A., Derr, V., \& Chawla, L. (2018). Fluid or Fixed? Processes that Facilitate or Constrain a Sense of Inclusion in Participatory Schoolyard and Park Design. Landscape Journal: Design, Planning, and Management of the Land, 37(1), 39-54.

Kroll, L. (1986). An architecture of complexity. London: Batsford.

Kumar, A., \& Annabel, M. (Series Ed.). (2017). Life on the Margin: Charting Realities (No. 1). Retrieved from http://apnalaya.org/pdf/situation-analysis-report.pdf

Kurgan, L. (2012). Million Dollar Blocks. Retrieved February 2, 2019, from Spatial Information Design Lab website: http://spatialinformationdesignlab.org/projects.php\%3Fid\%3D16

Lambert, L. (2010). Weaponized architecture : the impossibility of innocence. New York: DprBarcelona.

Lambert, L. (2011, December). Weaponized Architecture: A Discussion with Léopold Lambert (A. Barcklay \& D. Qaddumi, Interviewer). Retrieved from http://arenaofspeculation.org/2011/12/28/weaponized-architecture-discussion/

Lang, J. (1987). Creating Architectural Theory: The Role of the Behavioural Sciences in Environmental Theory. New York: Van Nostrand Reinhold.

Lang, J. (2006). Urban Design: A Typology of Proceedures and Products. Oxford: Architectural Press.

Lanzara, G. F. (1991). Shifting Stories. Learning From a Reflective Experiment in a Design Process. In The Reflective Turn: Case Studies in and on Educational Practice (pp. 285320). New York: Teachers College Press.

Lave, J., \& Wenger, E. (1991). Situated Learning: Legitimate Peripheral Participation. Cambridge: Cambridge University Press. 
Le Guin, U. (2004). The Wave in the Mind: Talks and Essays on the Writer, the Reader, and the Imagination. Colorado: Shambhala.

Leeuwen, B. van. (2015). Absorbing the agony of agonism? The limits of cultural questioning and alternative variations of intercultural civility. Urban Studies, 52(4), 793-808.

Lefebvre, H. (1991). Critique of Everyday Life. London: Verso.

Leong, T. W., \& Iversen, O. S. (2015). Values-led Participatory Design as a Pursuit of Meaningful Alternatives. Roceedings of the Annual Meeting of the Australian Special Interest Group for Computer Human Interaction. Presented at the OzCHI'15, Parkvale, Australia.

Levitas, R. (2013). Utopia as Method: The Imaginary Reconstitution of Society (1st ed.). New York: Palgrave Macmillan.

Lin, Z. (2007). Urban Structure for the Expanding Metropolis" kenzo Tange's 1960 plan for Tokyo. Journal of Architectural and Planning Research, 24(2), 109-124.

Lindley, J., Sharma, D., \& Potts, R. (2014). Anticipatory Ethnography: Design Fiction as an Input to Design Ethnography. 2014 Ethnographic Praxis in Industry Conference Proceedings, 237-253. New York.

Lochner, M., \& Ntema, J. (2013). The upgrading of an informal settlement in South Africa: Two decades onwards. Habitat International, 39, 85-95.

Loh, C. S., Anantachai, A., Byun, J., \& Lenox, J. (2007). Assessing what players learned in serious games: in-situ data collection, information trails, and quantitative analysis. Proceedings of the 10th International Conference on Computer Games: AI, Animation, Mobile, Educational and Serious Games, 10-19.

Loh, C. S., Sheng, Y., \& Ifenthaler, D. (2015). Serious Games Analytics: Theoretical Framework. In Advances in Game-Based Learning. Serious Games Analytics. Cham: Springer.

Lucero, A., Vaajakallio, K., \& Dalsga, P. (2012). The dialogue-labs method: process, space and materials as structuring elements to spark dialogue in co-design events. CoDesign: International Journal of CoCreation in Design and the Arts, 8(1), 1-23. 
Luck, R. (2018). Participatory design in architectural practice: Changing practices in future making in uncertain times. Design Studies, 59(1), 139-157.

Lynch, K. (1984). Site Planning. Cambridge, Massachusetts: MIT Press.

Ma, M., \& Oikonomou, A. (Eds.). (2011). Serious Games and Edutainment Applications. Springer.

Macharia, K. (1992). Slum clearance and the informal economy in Nairobi. Journal of Modern African Studies, 30(2), 221-236.

MacPherson, L. (2013). Participatory Approaches to Slum Upgrading and Poverty Reduction in African Cities. Interdisciplinary Journal of Social Sciences, 1(1), 85-95.

Madsen, K. H. (1994). A guide to metaphorical design. Communications of the ACM 37, 12, $57-62$

Majale, M. (2008). Employment creation through participatory urban planning `and slum upgrading: The case of Kitale, Kenya. Habitat International, 32, 270-282.

Malmgren, C. D. (1985). Fictional Space in the Modernist and Postmodernist American Novel. New Jersey: Associated University Presses.

Malone, T. (1981). Toward a theory of intrinsically motivating instruction. Cognitive Science, 5(4), 333-369.

Malterud, K. (2001). Qualitative research: standards, challenges, and guidelines. The Lancet, 358(9280), 483-488.

Marello, M., \& Helwege, A. (2014). Solid Waste Management and Social Inclusion of Waste Pickers: Opportunities and Challenges. Retrieved from The Global Economic Governance Initiative website: http://www.bu.edu/pardee/files/2014/09/SocialInclusion-Working-Paper.pdf

Markopoulou, A., Ingrassia, M., Chronis, A., \& Richard, A. (2018). City Gaming and Participation: Enhancing User Participation in Design. In Humanizing Digital Realit (pp. 225-236). Singapore: Springer.

Markussen, T. (2017). Disentangling 'the social' in social design's engagement with the public realm. CoDesign: International Journal of CoCreation in Design and the Arts, 13(3), $160-174$. 
Marttila, S., Botero, A., \& Saad-Sulonen, J. (2014). Towards commons design in participatory design. Proceedings of the 13th Participatory Design Conference, 2. New York: ACM. Maslow, A. (1968). Towards a Psychology of Being. New York: Van Nostrand Reinhold.

Mather, L., \& Robinson, P. (2016). Civic Crafting in Urban Planning Public Consultation: Exploring Minecraft's Potential. International Journal of E-Planning Research, 5(3).

Mattelmäki, T. (2006). Design Probes. Helsinki: Gummerus Printing.

Mayer, I. (2009). The Gaming of Policy and the Politics of Gaming: A Review. Simulation and Gaming, 40(6), 825-862.

McAdam, R., \& McClelland, J. (2002). Individual and Team-Based Idea Generation within Innovation Management: Organisational and Research Agendas. European Journal of Innovation Management, 5, 86-97.

McCormick, K. (2013). Advancing Sustainable Urban Transformation. Journal of Cleaner Production, 50(1), 1-11.

McGonigal, J. (2011). Reality is broken: why games make us better and how they can change the world. New York: Penguin Press.

McLaughlin, T. (2005). Taxonomy of digital creatures: interpreting character designs as computer graphics techniques. Presented at the SIGGRAPH '05, New York.

McLaughlin, T., Smith, D., \& Brown, I. A. (2010). A Framework for Evidence Based Visual Style Development for Serious Games. 132-138. Monerey, CA.

Meadows, D., Meadows, D., Randers, J., \& Behrens, W. (1972). The Limits to Growth. New York: Potomac Associates.

Medina, M. (2008). The Informal Recycling Sector in Developing Countries: Organizing Waste Pickers to Enhance their Impact. Retrieved from The World Bank website: https://openknowledge.worldbank.org/bitstream/handle/10986/10586/472210BRI0Bo x31ing1 sectors01PUBLIC1.pdf?sequence $=1$

Merkel, C., Farooq, U., Xiao, L., Ganoe, C. H., Rosson, M. B., \& Carroll, J. M. (2007). Managing technology use and learning in nonprofit community organizations: methodological challenges and opportunities. Proceedings of the 1st ACM Symposium 
on Computer Human Interaction for Management of Information Technology. Presented at the CHIMIT 2007, Cambridge, Massachusetts.

Minnery, J., Argo, T., Winarso, H., Hau, D., Veneracion, C., Forbes, D., \& Childs, I. (2013). Slum upgrading and urban governance: Case studies in three South East Asian cities. Habitat International, 39, 162-169.

Mitchell, T. (2010). Hydrocarbon Utopia. In Michael Gordin, H. Tilley, \& G. Prakish (Eds.), Utopia/Dystopia: Conditions of Historical Possibility. Princeton: Princeton University Press.

Mitgutsch, K., \& Alvarado, N. (2012). Purposeful by design?: a serious game design assessment framework. Proceedings of the International Conference on the Foundations of Digital Games, 121-128. New York: ACM.

Mitrović, I. (2016). Introduction to Speculative Design Practice. Retrieved February 5, 2019, from Speculative website: http://speculative.hr/en/introduction-to-speculative-designpractice/

Mohammed, S., \& Ringseis, E. (2001). Cognitive Diversity and Consensus in Group Decision Making: The Role of Inputs, Processes, and Outcomes. Organizational Behavior and Human Decision Processes, 85(2), 310-355.

Molyneux, L., Vasudevan, K., \& Zúñiga, H. G. de. (2015). Gaming Social Capital: Exploring Civic Value in Multiplayer Video Games. Journal of Computer-Mediated Communication, 20(1), 381-399.

Morrison, A. (2014). Design Prospects: Investigating Design Fiction via a Rogue Urban Drone. Proceedings of DRS 2014 Conference. Presented at the Umeå, Sweden. Umeå, Sweden.

Morschheuser, B., Maedche, A., \& Walter, D. (2017). Designing Cooperative Gamification: Conceptualization and Prototypical Implementation. Proceedings of the 2017 ACM Conference on Computer Supported Cooperative Work and Social Computing. Presented at the Computer Supported Cooperative Work and Social Computing, Portland, OR, USA. 
Morschheuser, B., Riar, M., Hamari, J., \& Maedche, A. (2017). How games induce cooperation? A study on the relationship between game features and we-intentions in an augmented reality game. Computers in Human Behavior, (77), 169-183.

Morse, J. (1998). Validity by Committee. Qualitative Health Research, 1(1), 443-445.

Mortati, M., \& Cruickshank, L. (2012). NETS: A Design Tool for Activating Social Networks. International Journal of Entrepreneurial Behaviour \& Research, 18(4), 509-523.

Mouffe, C. (2000a). Deliberative Democracy or Agonistic Pluralism. Vienna, Austria: Institute for Advanced Studies (IHS).

Mouffe, C. (2000b). The democratic paradox. London: Verso.

Mouffe, C. (2004). Pluralism, Dissensus and Democratic Citizenship. In F. Inglis (Series Ed.), Education and the Good Society. Retrieved from https://link.springer.com/chapter/10.1057/9780230523449_4

Mukhija, V. (2017). Squatters as Developers? Slum Redevelopment in Mumbai. London: Routledge.

Muller, M., \& Druin, A. (2002). Participatory Design: The Third Space in HCI. In The humancomputer interaction handbook. USA: L. Erlbaum Associates Inc.

Municipal Corperation of Greater Mumbai. (2009). Mumbai Human Development Report 2009 (No. 1). Retrieved from http://mhupa.gov.in/writereaddata/Mumbai\%20HDR\%20Complete.pdf

Munthe-Kaas, P. (2015). Agonism and co-design of urban spaces. Urban Research \& Practice, $8(2), 218-237$.

Narayan, D. (1999). Bonds and bridges: Social capital and poverty (Vol. 2167). World Bank Publications.

Nazry, N., \& Romano, D. (2017). Mood and learning in navigation-based serious games. Computers in Human Behavior, 73(1), 596-604.

Neuwirth, R. (2012). Stealth of Nations: The Global Rise of the Informal Economy. New York: Random House. 
Neys, J., Looy, J. V., Grove, F. D., \& Jansz, J. (2012, January). Poverty is Not a Game: behavioral changes and long term effects after playing PING. Presented at the 62nd Annual ICA Conference, Pheonix, AR, USA.

Nielsen, H. S., Phelan, J., \& Walsh, R. (2015). Ten Theses about Fictionality. Narrative, 23(1), $61-73$.

Noymana, A., Holtz, T., Kröger, J., Noennig, J. R., \& Larson, K. (2017). FindingPlaces: HCI Platform for Public Participation in Refugees' Accommodation Process. International Conference on Knowledge Based and Intelligent Information and Engineering Systems, 2464-2472. Marseille, France.

O'Coill, C., \& Doughty, M. (2004). Computer Game Technology as a Tool for Participatory Design. 22nd ECAADe Conference Proceedings. Presented at the Copenhagen. Copenhagen: Architecture in the Network Society.

O’Donoghue, T., \& Punch, K. F. (2003). Qualitative Educational Research in Action: Doing and Reflecting. New York: Routledge.

Okwuosa, A. (2018, May 29). This Is What Lagos Could Look Like in 2115. Retrieved February 1, 2019, from Okay Africa website: https://www.okayafrica.com/this-iswhat-lagos-could-look-like-2115-wale-lawal-olalekan-jeyifous/

Olthuis, K., Benni, J., Eichwede, K., \& Zevenbergen, C. (2015). Slum Upgrading: Assessing the importance of location and a plea for a spatial approach. Habitat International, 50, $270-288$.

Pak, B., \& Verbeke, J. (2014). Geoweb 2.0 and design empowerment: A critical evaluation of eleven cases. Digital Humanities 2014 Conference Proceedings, 290-292.

Patel, S., Siliuzas, R., \& Mathur, N. (2015). The risk of impoverishment in urban developmentinduced displacement and resettlement in Ahmedabad. Environment \& Urbanization, 27(1), 2310256.

Patton, M. (1991). Qualitative Research \& Evaluation Methods. London: Sage.

Perten, J. (2011). The Successes and Shortcomings of Participatory Slum-Upgrading in Villa 31. INDEPENDENT STUDY PROJECT (ISP) COLLECTION. 
Petrescu, D. (2005). Losing control, keeping desire. In Architecture and Participation (pp. 4363). London; New York: Routledge.

Phelan, M., \& Parkman, S. (1995). Work With an Interpreter. British Medical Journal, 311(7004), 555.

Pickersgill, S. (2017). Possibilia: Possible Worlds and the Limitless in Architecture. Footprint, $11(1), 71-84$.

Pinder, D. (2013). Reconstituting the Possible: Lefebvre, Utopia and the Urban Question. International Journal of Urban and Regional Research, 39(1), 28-45.

Pløger, J. (2004). Strife: Urban Planning and Agonism. Planning Theory, 3(1), 71-92.

Polanyi, M. (1967). The Tacit Dimension. London: Routledge.

Pollastri, S. (2017). Visual Conversations on Urban Futures: Understanding participatory processes and artefacts (PhD). Lancaster University, Lancaster, UK.

Pollastri, S., Boyko, C., Cooper, R., Dunn, N., Coulton, C., \& Clune, S. (2017). Envisioning urban futures: from narratives to composites. The Design Journal, 20(1), S4365-S4377.

Poplin, A. (2011). Games and Serious Games in Urban Planning: Study Cases. Computational Science and Its Applications. Presented at the ICCSA.

Poplin, A. (2012). Playful public participation in urban planning: A case study for online serious games. Computers, Environment and Urban Systems, 36, 195-206.

Poplin, A., \& Vemuri, K. (2018). Spatial Game for Negotiations and Consensus Building in Urban Planning: YouPlaceIt! In Geogames and Geoplay Game-based Approaches to the Analysis of Geo-Information (pp. 63-90). Switzerland: Cham: Springer International Publishing : Imprint: Springer.

Postmes, T., Spears, R., \& Lea, M. (2000). The formation of group norms in computermediated communication. Human Communication Research, 26(3), 341-371.

Prado, L., \& Oliveira, P. (2014, February). Questioning the "critical” in Speculative \& Critical Design. Retrieved February 2, 2019, from Medium website: https://medium.com/aparede/questioning-the-critical-in-speculative-critical-design-5a355cac2ca4

Prensky, M. (2001). Digital game-based learning. New York: McGraw-Hill. 
Pugh, C. (1995). Urbanization in developing countries: an overview of the economic and policy issues in the 1990s. Cities, 12(6), 381-398.

Putnam, R. D. (2000). Bowling alone: America's declining social capital. In Culture and Politics (pp. 223-234). U.S.A: Palgrave Macmillan.

Quist, J., \& Vergragt, P. (2006). Past and future of backcasting: The shift to stakeholder participation and a proposal for a methodological framework. Futures, 38(9), 10271045.

Racadio, R., Rose, E. J., \& Kolko, B. E. (2014). Research at the margin: participatory design and community based participatory research. Proceedings of the 13th Participatory Design Conference. Presented at the PDC'14, Windhoek, Namibia.

Rancière, J. (2011). The Thinking of Dissensus: Politics and Aesthetics. In Reading Rancière: Critical Dissensus (pp. 1-17). London; New York: Continuum.

Raphael, C., Bachen, C., Lynn, K.-M., Baldwin-Philippi, J., \& McKee, K. A. (2010). Games for Civic Learning: A Conceptual Framework and Agenda for Research and Design. Games and Culture, 5(2), 199-235.

Raphael, C., Bachen, C. M., \& Pedro F. Hernández-Ramos. (2012). Flow and cooperative learning in civic game play. New Media and Society, 14(8), 1321-1338.

Reason, P., \& Bradbury, H. (2001). Handbook of Action Research: Participative Inquiry and Practice. Sage.

Rigon, A. (2014). Building Local Governance: Participation and Elite Capture in Slumupgrading in Kenya. Development and Change, 45(2), 257-283.

Rittel, H., \& Webber, M. (1973). Dilemmas in a General Theory of Planning. Policy Science, $4(1), 155-169$.

Rokeach, M. (1973). The nature of human values. New York: Free Press.

Rooney, P. (2012). A Theoretical Framework for Serious Game Design: Exploring Pedagogy, Play and Fidelity and their Implications for the Design Process. International Journal of Game-Based Learning, 2(4), 41-60.

Roquet, V., Bornholdt, L., \& Lukic, J. (2015). Urban Land Acquisition and Involuntary Resettlement: Linking Innovation and Local Benefits (p. 90). Retrieved from The World 
https://www.openknowledge.worldbank.org/bitstream/handle/10986/21688/949570W P00PUBL0Urban0Land0FinalWeb2.pdf?sequence $=1$

Rosenbak, S. (2019). Exceptional Futures Vs. Exceptions to the Future: A Pataphysical Approach to Design Ficiton. In NERD - New Experimental Research in Design (pp. 145-169). Basel: Birkhauser.

Ryan, C. (2013). Eco-Acupuncture: designing and facilitating pathways for urban transformation, for a resilient low-carbon future. Journal of Cleaner Production, 50(1), 189-199.

Rynning, M. (2017). Speculative Graphic Design: Visual Identity Branding as a Calalyst for $\begin{array}{llll}\text { Change. } & 7 . & \text { Retrieved }\end{array}$ http://www.nordes.org/nordes2017/assets/short_papers/nordes17b-sub1015-cami26_RYNNING_v2.pdf

Salen, K., \& Zimmerman, E. (2004). Rules of Play - Game Design Fundamentals. Cambridge, Massachusetts: MIT Press.

Salvador, T., \& Howells, K. (1998). Focus troupe: Mini-workshop on using drama to create common context for new product concept end-user evaluations. $C H I$ 98, 1, 18-23.

Sanchez, J. (2015). Block'hood-developing an architectural simulation video game. 16-18. Vienna, Austria.

Sanders, E. (2000). Generative Tools for Co-designing. In Collaborative Design (pp. 3-12). London: Springer.

Sanders, E. (2001). Virtuosos of the experience domain. Proceedings of the 2001 IDSA Education Conference. Presented at the Massachusetts College of Art, Boston. Massachusetts College of Art, Boston.

Sanders, E. (2008). An Evolving Map of Design Practice and Design Research. Interactions Expliences, People, Technology, XV(6), 13-17.

Sanders, E., Brandt, E., \& Binder, T. (2010, November). A Framework for Organizing the Tools and Techniques of Participatory Design. Presented at the PDC 2010, Sydney, Australia. 
Sanders, E., \& Dandavate, U. (1999). Design for experiencing: New tools. Proceedings of the First International Conference on Design and Emotion, 87-92. Delft University of Technology.

Sanders, E., \& Stappers, P. J. (2008). Co-Creation and the New Landscapes of Design. CoDesign, 4(1), 5-18.

Sanders, E., \& Stappers, P. J. (2014). Probes, toolkits and prototypes: three approaches to making in codesigning. CoDesign: International Journal of CoCreation in Design and the Arts, 10(1), 5-14.

Sanders, E., \& William, C. (2002). Harnessing People's Creativity: Ideation and Expression through Visual Communication. In Focus Groups: Supporting Effective Product Development. London: Taylor \& Francis.

Sanoff, H. (1985). The application of participatory methods in design and evaluation. Design Studies, 6(4), 178-234.

Sanoff, H. (2000). Community Participation Methods in Design and Planning. New York: Wiley.

Sanoff, H. (2005). Origins of community design. Progressive Planning, 166, 14-17.

Sanoff, H. (2007). Multiple views on participatory design. International Journal of Architectural Research, 2(1), 57-69.

Sanya, T. (2016). Participatory Design: An Intersubjective Schema for Descision Making. International Journal of Architectural Research, 10(1), 62-74.

Schneider, T., \& Till, J. (2009). Beyond Discourse: Notes on Spatial Agency. Footprint, 4(1), $97-111$.

Schön, D. (1983). The Reflective Practitioner. New York: Basic Books.

Schuler, D., \& Namioka, A. (1993). Participatory design : principles and practices / edited by Douglas Schuler, Aki Namioka. Hillsdale, N.J.: L. Erlbaum Associates.

Schultz, W., Nolan, J. M., Cialdini, R. B., Goldstein, N. J., \& Griskevicius, V. (2007). The constructive, destructive, and reconstructive power of social norms. Psychological Science, $18(5), 429-434$. 
Senbel, M., \& Church, S. P. (2011). Design Empowerment: The Limits of Accessible Visualization Media in eighborhood Densification. Journal of Planning Education and Research, 31(4), 423-437.

Shen, Z., Ma, Y., Sugihara, K., Lei, Z., \& Shi. (2014). Technical Possibilities of Cloud-Based Virtual Reality Implementing Software as a Service for Online Collaboration in Urban Planning. Int. J. Communications, Network and System Science, 7, 463-473.

Shetty, D. (2016, February 12). Deonar: When garbage becomes gold. Retrieved July 27, 2016, from DNA India website: http://www.dnaindia.com/locality/mumbai-northeast/deonar-when-garbage-becomes-gold-85091

Shute, V. J., Ventura, M., Bauer, M. I., \& Zapata-Rivera, D. (2009). Melding the power of serious games and embedded assessment to monitor and foster learning: flow and grow. In Serious Games: Mechanisms and Effects (pp. 295-321). Mahwah, NJ: Routledge, Taylor \& Francis Group.

Sicart, M. (2008). Defining Game Mechanics. The International Journal of Computer Game Research, 8(2). Retrieved from http://gamestudies.org/0802/articles/sicart

Silverman, D. (2015). Designerly Ways for Action Research. In The SAGE Handbook of Action Research. New York: Sage Publications.

Simon, H. (1969). The Sciences of the Artificial. Cambridge, Massachusetts: The MIT Press.

Simonsen, J., \& Robertson, T. (2012). Routledge International Handbook of Participatory Design. Retrieved from http://VUW.eblib.com/patron/FullRecord.aspx?p=1047068

Singh. (2017). Assessment of water quality parameters of Bhalswa Lake in New Delhi. International Journal of Environmental Engineering, 9(1), 52-69.

Singh, A., Rohit, G., Shivangi, G., \& Vipul, V. (2016). Greenhouse Gas Emissions from Landfills: A Case of NCT of Delhi, India. Journal of Climatology \& Weather Forecasting, 4(1).

Singh, V., \& Mittal, A. K. (2011). Groundwater Pollution by Municipal Solid Waste Landfill Leachate: A Case Study of Okhla Landfill Delhi.

Sinha, S. (2012). Architecture for Rapid Change and Scarce Resources. Oxon: Routledge. 
Skinner, R., French, M., Acioly, C., \& Reid, J. (2014). A Practical Guide to Designing, Planning, and Executing Citywide Slum Upgrading Programmes. Nairobi: UN-Habitat. Soja, E. (2010). Seeking spatial justice. London: UMP.

Spiller, N. (2007). Visionary architecture : Blueprints of the Modern Imagination. New York: Thames \& Hudson.

Srivastava, R., \& Echanove, M. (2014, November 28). "Slum" is a loaded term. They are homegrown neighbourhoods. Retrieved April 4, 2019, from The Guardian website: https://www.theguardian.com/cities/2014/nov/28/slum-loaded-term-homegrownneighbourhoods-mumbai-dharavi

Star, S. L. (1989). The structure of ill-structures solutions: heterogeneous problem-solving, boundary objects and distributed artificial intelligence. In Distributed Artificial Intelligence (Vol. 2, pp. 37-54). San Francisco: Morgan Kaufmann Publishers Inc.

Sterling, B. (2012, March). Sci-Fi Writer Bruce Sterling Explains the Intriguing New Concept of Design Fiction. $\quad$ Retrieved from http://www.slate.com/blogs/future_tense/2012/03/02/bruce_sterling_on_design_fictio ns_.html

Suchman, L. (1993). Forword. In Participatory design: principles and practices. Hillsdale, N.J.: Lawrence Erlbaum Associates.

Susi, T., Johannesson, M., \& Backlund, P. (2007). Serious Games - An Overview. Technical Report HS- IKI.

Swain, C. (2007). Designing Games to Effect Social Change. Situated Play, 805-809. Tokyo, Japan.

Swann, C. (2002). Action Research and the Practice of Design. Design Issues, 18(1), 49-61.

Sweetser, P., \& Wyeth, P. (2005). GameFlow: A model for evaluating player enjoyment in games. ACM Computers in Entertainment, 3(3), 1-24.

Tacchi, J., \& Chandola, T. (2016). Complicating connectivity: women's negotiations with smartphones in an Indian Slum. In Routledge Handbook of New Media in Asia. New York: Routledge. 
Tahvilzadeh, N. (2015). Understanding participatory governance arrangements in urban politics: idealist and cynical perspectives on the politics of citizen dialogues in Göteborg, Sweden. Urban Research \& Practice, 8(2).

Tan, E. (2014). Negotiation and Design for the Self-Organizing City: Gaming as a method for Urban Design. Rotterdam: Architecture and the Built Environment.

Tan, E. (2016). The Evolution of City Gaming. In J. Portugali \& E. Stolk (Eds.), Complexity, Cognition, Urban Planning and Design (pp. 271-292). Switzerland: Springer.

Tata Institue of Social Sciences. (2015). Socio-economic conditions and culnerabilities: A report of the baseline survey of M (East) ward, Mumbai. Retrieved from TISS website: http://urk.tiss.edu/images/pdf/M-Ward-Report.pdf

Teli, M., Bordin, S., Blanco, M. M., Orabona, G., \& Angeli, A. D. (2015). Public design of digital commons in urban places: A case study. International Journal of HumanComputer Studies, 81(1), 17-30.

Temple, B., \& Young, A. (2004). Qualitative research and translation dilemmas. Qualitative Research, 4(2), 161-179.

Terzidis, K. (2007). The Etymology of Design: Pre-Socratic Perspective. Design Issues, 23(4), $69-78$.

Tharp, B., \& Tharp, S. (2013). Discursive Design Basics: Mode and Audience. Retrieved from http://www.nordes.org/opj/index.php/n13/article/viewFile/326/306

Tharp, B., \& Tharp, S. (2019). Discursive Design: Critical, Speculative, and Alternative Things. Boston: The MIT Press.

The Cities Alliance. (2014). About slum upgrading. Retrieved November 15, 2018, from http://www.citiesalliance.org/About-slum-upgrading

The World Bank. (2013). Prospects - Organized waste picking improves lives and cities. $\begin{array}{llll}\text { Retrieved } & \text { March } & \text { 12, } & \text { 2016, }\end{array}$ http://econ.worldbank.org/WBSITE/EXTERNAL/EXTDEC/EXTDECPROSPECTS/ 0,,contentMDK:23394671 pagePK:64165401 piPK:64165026 theSitePK:476883,00 .html 
The World Bank Group. (2001). What is urban upgrading? Reference for administrators, policy-makers, and decision-makers. Retrieved from http://web.mit.edu/urbanupgrading/upgrading/whatis/history.html

Till, J. (2005). The Negotiation of Hope. In Architecture and Participation (pp. 23-42). New York: Routledge.

Toffler, A. (1978). Foreword. In M. Maruyama \& Arthur Harkins, Cultures of the Future. The Hague: Mouton.

Tonkinwise, C. (2014). How We Intend to Future: Review of Anthony Dunne and Fiona Raby, Speculative Everything: Design, Fiction, and Social Dreaming. Design Philosophy Papers, 12(2), 169-187.

Tonkinwise, C. (2015, March 2). Design Fictions About Critical Design. Retrieved February 2, 2019, from Modes of Criticism website: http://modesofcriticism.org/design-fictionsabout-critical-design/

Tonkinwise, C. (2016). Cameron Tonkinwise: Speculative Practice Needs Diverse Cultures. Retrieved February 2, 2019, from Speculative website: http://speculative.hr/en/cameron-tonkinwise/

Triantafyllakos, G., Palaigeorgiou, G., \& Tsoukalas, I. A. (2010). Fictional characters in participatory design sessions: Introducing the "design alter egos" technique. Interacting with Computers, 22(3), 165-175.

Turley, R., Saith, R., Bhan, N., Rehfuess, E., \& Carter, B. (2013). Slum upgrading strategies involving physical environment and infrastructure interventions and their effects on health and socio-economic outcomes. Cochrane Database of Systematic Reviews.

Turner, V. (1987). The Anthropology of Performance. New York: PAJ Publications.

Ulrich, F., \& Henrik-Helms, N. (2017). Creating Evaluation Profiles for Games Designed to be Fun: An Interperetive Framework for Serious Game Mechanics. Simulation and Gaming, 48(5), 695-714.

UN-Habitat. (2015a). Informal Settlements. Habitat III. Presented at the United Nations Conference on Housing and Sustainable Urban Development, New York. 
UN-Habitat. (2015b). Practical Guide to Citywide Slum Upgrading. Nairobi: United Nations Human Settlements Programme.

UN-Habitat. (2016a). Urban Planning and Design Labs: Tools for integrated and participatory urban planning. Nairobi: UN-Habitat.

UN-Habitat. (2016b). World Cities Report. Nairobi: United Nations Human Settlements Programme.

United Nations. (2016). New Urban Agenda: Quito Declaration on Sustainable Cities and Human Settlements for All. Quito.

United Nations General Assembly. (2016). The promotion, protection and enjoyment of human rights on the Internet. New York: United Nations General Assembly.

United Nations Human Settlements Programme. (2003). The Challenge of Slums: Global Report on Human Settlements 2003. Retrieved from UN-Habitat website: http://www.unhabitat.org.jo/pdf/GRHS.2003.pdf

United Nations Human Settlements Programme. (2013). State of the World's Cities 2012/2013 - Prosperity of Cities. Routledge.

Vaajakallio, K. (2012). Design games as a tool, a mindset and a structure (PhD). Aalto University, Helsinki.

Vaajakallio, K., \& Mattelmäki, T. (2014). Design games in codesign: as a tool, a mindset and a structure. CoDesign: International Journal of CoCreation in Design and the Arts, 10(1), 63-77.

Veeningen, J. W., Szirbik, N., \& Blokhuis, M. (2017). A Generic Architecture for QuicklyDeployable, Flexible, Scenario-Oriented Serious Games. APMS 2017: Advances in Production Management Systems. The Path to Intelligent, Collaborative and Sustainable Manufacturing. Presented at the IFIP International Conference on Advances in Production Management Systems, Hamburg, Germany.

Vemuri, K., Poplin, A., \& Monachesi, P. (2014). YouPlaceIt!: a Serious Digital Game for Achieving Consensus in Urban Planning. AGILE 2014. Presented at the Castellón, Spain. Castellón, Spain. 
Vines, J., Clarke, R., Wright, P., McCarthy, J., \& Olivier, P. (2013). Configuring participation: on how we involve people in design. Proceedings of the SIGCHI Conference on Human Factors in Computing Systems, 429-438. New York.

Visser, F. S. (2009). Bringing the everyday life of people into design. TU Delft, Delft University of Technology.

Visser, F. S., Stappers, P. J., Van Der Lught, R., \& Sanders, E. (2005). Contextmapping: experiences from practice. CoDesign: International Journal of CoCreation in Design and the Arts, 1(2), 119-149.

Vogel, J., Vogel, D., Cannon-Bowers, J., Bowers, C., Muse, K., \& Wrigh, M. (2006). Computer Gaming and Interactive Simulations for Learning: A Meta-Analysis. Journal of Educational Computing Research, 34(3), 229-243.

von Heland, F., Westerberg, P., \& Nyberg, M. (2015). Using Minecraft as a Citizen Participation Tool in Urban Design and Decision Making. Presented at the Future of Places, Stockholm. Retrieved from http://www.ericsson.com/res/docs/2015/minecraftcitizen-participation-future-of-places.pdf

Voros, J. (2003). A Generic Foresight Process Framework. Foresight, 5(3), 10-21.

Voros, J. (2017, February 24). The Futures Cone, use and history. Retrieved February 1, 2019, from The Voroscope website: https://thevoroscope.com/2017/02/24/the-futures-coneuse-and-history/

Wakefield, J. (2017, March 8). Video game Cities Skylines helps plan Stockholm development. BBC. Retrieved from http://www.bbc.com/news/technology-38404884

Walton, K. (1993). Mimesis as Make-Believe: On the Foundations of the Representational Arts. Cambridge, Massachusetts: Harvard University Press.

Wattanasoontorn, V. (2013). Serious Games for Health and Medicine: A Cardiopulmonary Resusitation (CPR) Case Study (PhD). Universitat de Girona, Girona Spain.

Wenger, E. (1998). Communities of Practice: Learning, Meaning, and Identity. Cambridge: Cambridge University Press. 
Westerberg, P., \& von Heland, F. (2015). Using Minecraft for Youth Participation in Urban Design and Governance. Retrieved from http://unhabitat.org/books/using-minecraftfor-youth-participation-in-urban-design-and-governance/

Westre, A. (2014). Designing Games for Architecture: Creating Digital Design Tools with Unity. New Your: Routledge.

Whitton, N. (2011). Encouraging Engagement in Game-Based Learning. International Journal of Game-Based Learning, 1, 75-84.

Wilkinson, P. (2016). A Brief History of Serious Games. In Entertainment Computing and Serious Games (Vol. 9970, pp. 17-41). Springer Lecture Notes in Computer Science.

Williams, D. (2010). The mapping principle, and a research framework for virtual worlds. Communication Theory, 20(4), 451-470.

Wilson, D., Velis, C., \& Cheeseman, C. (2006). Role of the Informal Sector Recycling in Waste Management in Developing Countries. Habitat International, 30, 797-808.

Wood, J. (2008). Changing the Change:A Fractal Framework for Metadesign. Changing the Change Proceedings. Presented at the Turin, Italy. Turin, Italy.

Woods, L. (2004). Taking On Risk: Nine experimental scenarios. Retrieved from http://www.lebbeuswoods.net/CARNEGIE.pdf

Woods, L. (2007, October 3). Without Walls: An Interview with Lebbeus Woods (G. Manaugh, Interviewer). Retrieved from http://www.bldgblog.com/2007/10/without-walls-aninterview-with-lebbeus-woods/

Woods, L. (2009, January 16). Type Casting. Retrieved from Lebbeus Woods website: https://lebbeuswoods.wordpress.com/2009/01/16/type-casting/

Wouters, P., Nimwegen, C. van, van Oostendorp, H., \& van der Spek, E. D. (2013). A MetaAnalysis of the Cognitive and Motivational Effects of Serious Games. Journal of Educational Psychology, 105(2), 249-265.

Xu, Y., \& Maitland, C. (2019). Participatory data collection and management in low-resource contexts: a field trial with urban refugees. Proceedings of the Tenth International Conference on Information and Communication Technologies and Development. Presented at the ICTS'19, Ahmedabad, india. 
Yamu, C., Poplin, A., Devisch, O., \& De Roo, G. (Eds.). (2017). The Virtual and the Real in Planning and Urban Design: Perspectives, Practices and Applications. London: Routledge.

Yan, W., Culp, C., \& Graf, R. (2011). Integrating BIM and gaming for real-time interactive architectural visualization. Automation in Construction, 20(1), 446-458.

Yin, R. (1981). The Case Study as a Serious Research Strategy. Knowledge, 3(1).

Ylipulli, J., Luusua, A., \& Ojala, T. (2017). On Creative Metaphors in Technology Design: Case "Magic." Proceedings of the 8th International Conference on Communities and Technologies. Presented at the C\&T '17, Troyes, France.

Young, L. (2013). UNDER TOMORROWS SKY. Retrieved February 3, 2016, from http://undertomorrowssky.liamyoung.org/

Zhang, Y., Shen, Z., Wang, K., Kobayashi, F., \& Lin, X. (2017). Cloud-based Virtual Reality Integrated Automatic Presentation Script for Understanding Urban Design Concepts in the Consensus Process. International Review for Spatial Planning and Sustainable Development, 5(1), 29-44.

Zyda, M. (2005). From visual simulation to virtual reality to games. Computer, 38(9), 25-32. 


\title{
APPENDIX 1
}

\section{Phase One: Maslow's Palace Workshops}

\section{Understanding Conflicting Perspective on Slum-Upgrading Issues \\ INTERVIEW QUESTIONS}

\author{
Age: \\ Gender: \\ Religious affiliation: \\ How long have you lived in Ghazipur/Bhalswa/ Shanti Nagar? \\ If you have lived elsewhere please specify where and when: \\ Primary daily activity (please circle): work/school/other \\ If work what type of work:
}

\section{Site Specific/Amenity}

Identify three spaces in Ghazipur/Bhalswa/Shanti Nagar you spend the most time in. (Prompt) Where do you play, meet friends, do other activities etc? (Number 1,2,3 and locate on the map provided).

What do you like about those spaces? (open ended)

What do you dislike about those spaces? (open ended)

What are the main problems associated with living in Ghazipur/Bhalswa/Shanti Nagar?

If you could change three things about Ghazipur/Shanti Nagar what would they be? (Number 1,2,3 and locate on the map provided). 


\section{APPENDIX 2}

\section{Maslow's Palace In- Game Instructions}

Take turns. Click on your character to start your turn.

Explore the world.

Right click to destroy objects.

Make sure everyone is standing next to the gate to open it.

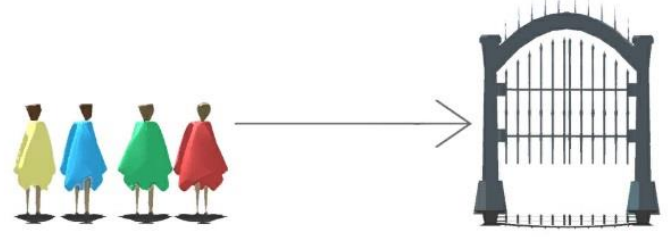

बारी बारी से। अपनी बारी शुर करने के लएि अपने चरत्रि पर क्लकि करें दुनयिा को खोजो।

वस्तुओं को नष्ट करने के लएि राइट कलकि करें

सुनश्चिति करें कसिभी इसे खोलने के लएि फाटक के बगल में खड़े हैं

\section{$\rightarrow$}

Maslow's Palace in-game instructions screen shot-Level One

In this level, you must make sure that every player has a house. Discuss with the other players where you will place your house, and why you placed it there. Make sure everyone is standing next to the gate to open it.

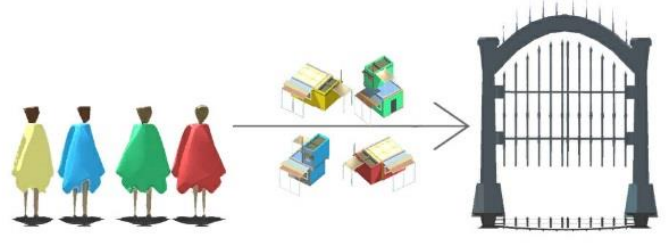

इस स्तर में, आपको यह सुनशिचति करना होगा कपिरतयेक खलिाड़ी के पास एक घर है। अन्य खलिड़ियों के साथ चर्चा करें जहां आप अपना घर रखेंगे, और आपने इसे क्यों रखा है। सुनश्चिति करें कसिभी इसे खोलने के लटि फाटक के बगल में खड़े हैं

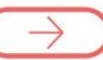

Maslow's Palace in-game instructions screen shot-Level Two 
In this level, you must make sure that every player has a house.

Discuss with the other players where you will place your house, and why you placed it there.

Your group must also place 5 game pieces.

Make sure everyone is standing next to the gate to open it.

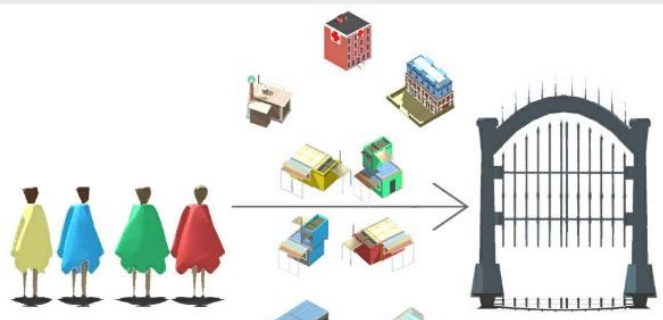

41

इस सतर में, आपको यह सुनशिचति करना होगा कपिरतयेक खलिाड़ी के पास एक घर है।

अन्य खलिाड़यों के साथ चरचा करें जहां आप अपना घर रखेंगे, और आपने इसे क्यों रखा है।

आपके समूह को 5 खेल के टुकड़े रखनी चाहएि।

सुनश्चिति करें कासिी इसे खोलने के लएि फाटक के बगल में खड़े हैं

\section{$>$}

Maslow's Palace in-game instructions screen shot - Level Three

In this level, you must make sure that every player has a house.

Discuss with the other players where you will place your house, and why you placed it there.

Your group must also place 5 game pieces.

Make sure everyone is standing next to the gate to open it.

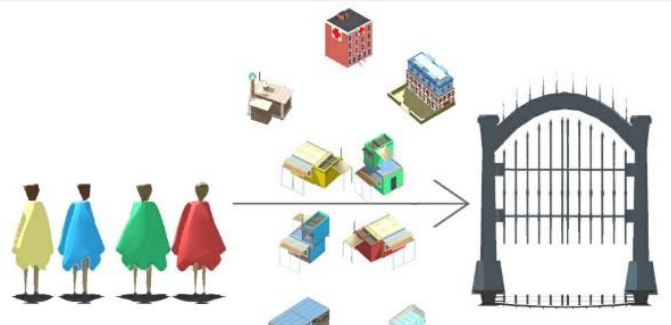

इस स्तर में, आपको यह सुनशिचति करना होगा कप्रित्येक खलिड़ी के पास एक घर है।

अनय खलिाड़यों के साथ चरचा करें जहां आप अपना घर रखेंगे, और आपने इसे क्यों रखा है।

आपके समह को 5 सेल के टकड़े रखनी चाहएि।

सुनशिचति करें कसिभी इसे खोलने के लएि फाटक के बगल में खड़े हैं

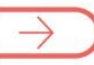

Maslow's Palace in-game instructions screen shot - Level Four 
In this level, you must choose where to build your house.

Design the area around your house to include things you need. Talk to the other group

members about your descisions. Place the most important closest to your house. In this

level, everything costs money.

Make sure everyone is standing next to the gate to open it.

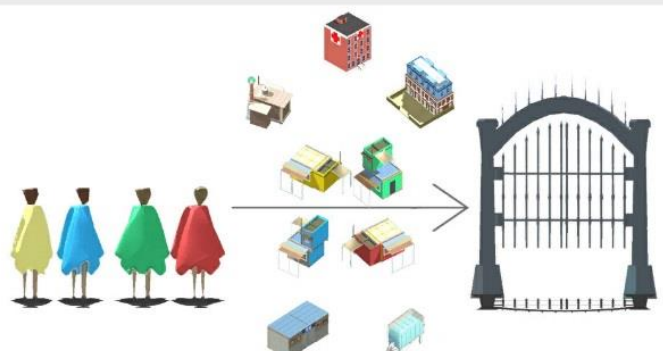

इस स्तर में, आपको यह चुनना होगा कआ आपका घर कहाँ बनाना है।

अपने घर के आस-पास के कषेत्र को डजिाइन करें ताकआिपको चीजों को शामलि कयिा जा सके। अपने समहों के बारे में

अन्य समह के सदसयों से बात करें। आपके घर के नकिटतम सबसे महत्वपूरण जगह रखें।

इस सत्तर में, सब कुछ पैसे खरच करते हैं

सुनश्चिति करें का सिभी इसे खोलने के लएि फाटक के बगल में खड़े है

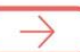

Maslow's Palace in-game instructions screen shot - Level Five 


\title{
APPENDIX 3
}

\section{Phase Three: Maslow's Palace Workshops}

\author{
Understanding Conflicting Perspective on Slum-Upgrading Issues
}

\section{FACILITATION INSTRUCTIONS TO FACILITATORS}

This research involves groups of 4 participants playing the turns based multiplayer game "Maslow's Palace" and completing an interview before and after the gaming process. The questionnaire contains a number of 5-point Likert scale questions as well as a number of open ended questions. After this process, participants will enter focus group stage, which will involve asking them a number of open ended questions about the gaming process.

\section{Introduction}

Inform participants of what they will do within the workshop. Ask participants about their expectations and field any questions they might have about the process. Ensure all participants give verbal consent to the workshops and that they understand how the workshop will be recorded (photos, notes, video, screen capture) and what will happen to the workshop data and how it will be analysed.

\section{Research Procedure}

1. Complete Sections One of the interview with each participant before the game is introduced. This process will take 5 minutes per participant. Record on the sheet provided.

2. Complete Section Two of the interview schedule once the game has been introduced, participants have been put in teams and they have been given the required game background surrounding the problems that will be addressed. This process will take 10 minutes.

3. The participants then asked to play the game. With participants' informed consent, a video camera will capture the game play sessions setting in order to provide a detailed documentation of the whole process. Screen capture software will also be used to record the game screen. This process will take 20 minutes. Ensure to only interject in the gameplay if participants have specific questions about the game content. Encourage them to solve problems regarding learning the game interface themselves. Only help if absolutely necessary. Do not suggest any design ideas or discussion topics within the game.

4. Complete sections Three and Four of the interview schedule with participants. This is to be completed before any further discussions take place after the gaming process. This process will take 10 minutes per participant.

5. After the completion of Sections Three and Four, the facilitator will initiate a brief group discussion about the participants' overall experience with the gaming process, the justification of their game movements, the effect they had on their creativity and their participation/interaction with other players. They will also be asked to evaluate game in general. All informal discussions will be transcribed, and participant's responses to the interview together with the video recordings will be thoroughly examined in order to evaluate the effectiveness of the game as a consensus generating mechanism. This process will take 15 minutes per workshop group/

\section{Workshop Conclusion}

Thank participants for their participation. Ask the participants if they have any questions about the workshop. Reiterate what will happen to the workshop data and how it will be analysed. Provide contact information to Chintan and Apnalaya and inform participants that they can contact the researchers through the partner organisations if they would like their data withdrawn from the study. 


\title{
APPENDIX 4 \\ Phase Three: Maslow's Palace Workshops
}

\author{
RESEARCH PROCEDURE
}

This research involves groups of 4 participants playing the turns based multiplayer game "Maslow's Palace" and completing an interview before and after the gaming process. The questionnaire contains a number of 5-point Likert scale questions as well as a number of open ended questions. After this process, participants will enter focus group stage, which will involve asking them a number of open ended questions about the gaming process.

\section{Research Procedure}

6. Complete Sections One of the interview before the game is introduced. This process will take 5 minutes.

7. Complete Section Two once the game has been introduced, participants have been put in teams and they have been given the required game background surrounding the problems that will be addressed. This process will take 10 minutes.

8. The participants are asked to play the game. With participants' informed consent, a video camera will capture the game play sessions setting in order to provide a detailed documentation of the whole process. Screen capture software will also be used to record the game screen. This process will take 20 minutes.

9. The Sections Three and Four of the interview schedule will be completed before any further discussions take place after the gaming process. This process will take 10 minutes.

10. After the completion of Sections Three and Four, the facilitator will initiate a brief semi-formal group discussion about the participants' overall experience with the gaming process, the justification of their game movements, the effect they had on their creativity and their participation/interaction with other players. They will also be asked to evaluate game in general. All informal discussions will be transcribed, and participant's responses to the interview together with the video recordings will be thoroughly examined in order to evaluate the effectiveness of the game as a consensus generating mechanism. This process will take 15 minutes.

\section{INTERVIEW QUESTIONS}

\section{Section One: Basic Information (5 minutes)}

Age:

Gender:

Religious affiliation:

How long have you lived in Shivaji Nagar/ Ghazipur/ Bhalswa?

If you have lived elsewhere please specify where and when:

\section{Section Two: Before gaming process (10 minutes)}

These questions are answered by participants before the game is played, i.e., after the introduction phase of the game and once players have been assigned to a group.

1) What are the three most important issues/problems in the game?

2) Why are these most important issues/problems?

3) What are the three least important issues/problems in the game?

4) Why are these least important issues/problems?

5) I feel like my ideas and thoughts will be taken into account by the rest of the group.

Strongly Disagree
3
Strongly Agree

4
5

6) I feel like my group members will share similar views as myself. 


\section{1}

2

3

4

5

7) How well do you know the other members of your group?

Not very well

$$
123
$$

34

Very Well

$4 \quad 5$

8) Completing Maslow's Palace successfully can be considered a goal. For this goal, please estimate this goal is to your group:

Strong

$\begin{array}{rrrrr} & & \text { Weak } \\ 1 & 2 & 3 & 4 & 5\end{array}$

9) Completing Maslow's Palace successfully can be considered a goal. For this goal, estimate how important this goal is to you:

Strong

$\begin{array}{rrrr} & & \text { Weak } \\ 2 & 3 & 4 & 5\end{array}$

\section{Section Three: After gaming process (10 minutes)}

These questions are answered by participants after the gameplay is completed.

Sections Three and Four will take approximately 10 minutes.

1) What were the three most important issues/problems in the game?

2) Why were these the most important issues/problems?

3) What were the three least important issues/problems in the game?

4) Why were these the least important issues/problems?

5) I feel like my ideas and thoughts were taken into account by the rest of the group. Strongly Disagree

$\begin{array}{llll}1 & 2 & 3 & 4\end{array}$

Strongly Agree

6) There was good cooperation between group members.

Strongly Disagree

4

5

$\begin{array}{rrrr}1 & 2 & 3 \\ \text { Group members shared similar views as myself. }\end{array}$ Strongly Disagree

2

3

Strongly Agree

5

4

Strongly Agree 5

8) The gameplay allowed our group to reach consensus/talk about issues in our community Strongly Disagree

Strongly Agree

$\begin{array}{lllll}1 & 2 & 3 & 4 & 5\end{array}$

1) Completing Maslow's Palace successfully can be considered a goal. For this goal, please estimate this goal is to your group:

Strong

$$
\begin{array}{rrrrr} 
& \text { Weak } \\
1 & 2 & 3 & 4 & 5
\end{array}
$$

2) Completing Maslow's Palace successfully can be considered a goal. For this goal, estimate how important this goal is to you:

Strong

$$
1
$$

2

3

Weak

1) Playing Maslow's Palace helped me think about our own community:

Strong

$2 \quad 3 \quad 4$

Weak 


\section{Section Four: Reflection on the gaming process}

This section asks question about the process overall (all 5-point Likert scale questions)

1) I understood the objectives of the game.

Strongly Disagree

Strongly Agree

$\begin{array}{lllll}1 & 2 & 3 & 4 & 5\end{array}$

2) I found the game difficult to play.

Strongly Disagree

123

$4 \quad 5$

3) I found the game interface easy to use.

Strongly Disagree

$1 \quad 2 \quad 3 \quad 4 \quad 5$

4) The workshop coordinator gave me adequate instructions on how to play the game.

Strongly Disagree

$\begin{array}{lllll}1 & 2 & 3 & 4\end{array}$

5) We had enough time to play the game.

Strongly Disagree

$\begin{array}{lllll}1 & 2 & 3 & 4 & 5\end{array}$

$\begin{array}{lllll}1 & 2 & 3 & 4 & 5\end{array}$

Strongly Agree

5

Strongly Agree

6) I enjoyed the workshop.

Strongly Disagree

Strongly Agree

1 2 3

5

7) We all know that all members are jointly committed to performing their parts of the common task.

Strongly Disagree

1

2

8) We all know that all members are jointly committed to contributing to the common success.

Strongly Agree

Strongly Disagree

1
2

We all know that all m
Strongly Disagree

3
Strongly Agree

$4 \quad 5$

Strongly Agree

$\begin{array}{lll}1 & 2 & 3\end{array}$

10) We all know that all members are jointly committed to achieving the common goals.

Strongly Disagree

Strongly Agree 1 2 3 4 5

\section{Focus Group Questions (15 minutes)}

1) Was agreement reached within the group?

2) How was agreement reached?

3) How did you use the game visuals/space to help you discuss problems or issues with other players?

4) Do you have any other comments? 


\section{APPENDIX 5}

\section{Digital Link To Maslow's Palace.}

A link to a downloadable version of Maslow's Palace can be found at the following location:

https://app.box.com/s/9a92h7ya5klyczq2kwaurc5hehe60ad2 


\section{APPENDIX 6 \\ Maslow's Palace Workshop Transcripts}

\section{Ghazipur Workshop Group One}

\section{Workshop Transcript}

\section{Pre-Gameplay}

\begin{tabular}{|c|c|}
\hline Facilitator & Okay so we are playing this by Hamish. \\
\hline Facilitator & First we choose the players. Is that right? \\
\hline Hamish & Yes. \\
\hline Facilitator & $\begin{array}{l}\text { It is to teach you how to support each other. What it's teaching you is } \\
\text { that when you help each other everything becomes easier. }\end{array}$ \\
\hline Participant One & Okay. \\
\hline Participant Three & Yes that sounds good. \\
\hline Facilitator & So we choose your colours. \\
\hline Facilitator & How wants to be red? \\
\hline Facilitator & Anyone? \\
\hline Facilitator & How about you? \\
\hline Participant One & Okay. \\
\hline Facilitator & Next is green. \\
\hline Participant Two & Yes me. \\
\hline Facilitator & Blue? \\
\hline Participant Three & Okay, \\
\hline Facilitator & Good. Last is yellow. \\
\hline Participant Four & That is me. \\
\hline Facilitator & So now we play this game. \\
\hline Participant Two & What do we do? \\
\hline Facilitator & $\begin{array}{l}\text { It will tell you. First you all have your colours. Then you take turns and } \\
\text { use this mouse to choose things like this. This one is for busting things. } \\
\text { Then you go through the door like this. Understand? }\end{array}$ \\
\hline Participant Four & So we use this and share? \\
\hline Facilitator & Yes take turns and pass it to her when you are done. \\
\hline Participant Two & Okay and then we go through the door? \\
\hline Facilitator & Yes. \\
\hline Facilitator & Okay now we start. \\
\hline
\end{tabular}

\section{Level One}

Facilitator

Participant Two
There are your colour people. Each of you has one. Red, green, blue, yellow. Remember which is your one. Yes, you told us that already. 


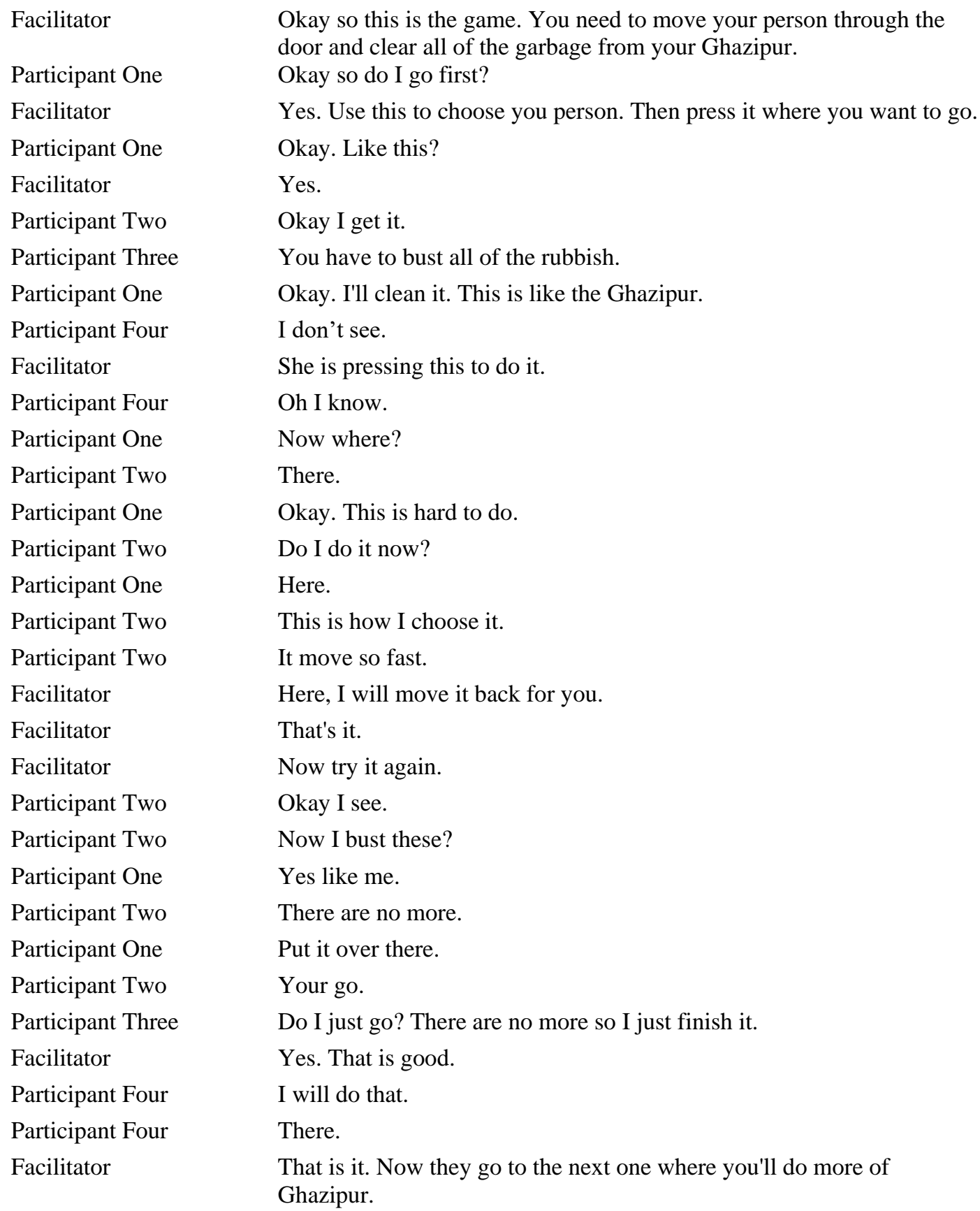

Facilitator

Participant One

Facilitator

Participant One

Facilitator

Participant Two

Participant Three

Participant One

Participant Four

Facilitator

Participant Four

Participant One

Participant Two

Participant One

Participant Two

Participant One

Participant Two

Participant Two

Facilitator

Facilitator

Facilitator

Participant Two

Participant Two

Participant One

Participant Two

Participant One

Participant Two

Participant Three

Facilitator

Participant Four

Participant Four

Facilitator

Okay so this is the game. You need to move your person through the door and clear all of the garbage from your Ghazipur.

Okay so do I go first?

Yes. Use this to choose you person. Then press it where you want to go.

Okay. Like this?

Yes.

Okay I get it.

You have to bust all of the rubbish.

Okay. I'll clean it. This is like the Ghazipur.

I don't see.

She is pressing this to do it.

Oh I know.

Now where?

There.

Okay. This is hard to do.

Do I do it now?

Here.

This is how I choose it.

It move so fast.

Here, I will move it back for you.

That's it.

Now try it again.

Okay I see.

Now I bust these?

Yes like me.

There are no more.

Put it over there.

Your go.

Do I just go? There are no more so I just finish it.

Yes. That is good.

I will do that.

There.

That is it. Now they go to the next one where you'll do more of Ghazipur.

\section{Level Two}

Facilitator

Participant Two

Facilitator

Participant One

Participant Two

Participant One

Participant Two

Facilitator
Now you do some more. There are houses. One, two three, four.

So we place the houses?

Yes. You put them where you want.

First we need to move the rubbish. Those ones are there too.

Okay I will put mine there. It doesn't matter.

Yes that can go there.

How?

You use this like your person. Then chose it. Then put it there with this again. 
Participant Two

Participant One

Participant One

Participant Two

Participant Three

Facilitator

Participant Four

Facilitator

Participant Four

Participant Four

Facilitator

Facilitator

Participant Four

Participant One

Participant Two

Participant Three

Facilitator
Okay. Now here.

Mine will go near to yours.

Here like this. That is what it is already like.

That doesn't make sense.

Over here.

Yes all together if that is what you want.

Okay me too. Is this the one?

Yes. Choose that one.

Now do I do it like this?

Ohh I can't find it.

Here I will find it for you.

There it is.

I did it. Now I put it there? Yes?

Yes like last time you know.

This is like Ghazipur. The houses are there.

It opened.

Yes there are more. It is starting.

\section{Level Three}

Participant Three

Facilitator

Participant Two

Facilitator

Participant One

Participant Four

Participant One

Participant One

Participant Two

Participant One

Participant Three

Participant Two

Participant One

Participant Two

Participant Four

Participant Two

Participant One

Participant Four

Participant Two

Participant Three

Facilitator

Participant One

Facilitator

Participant One
It looks the same. Are you doing it again?

Now there are more. See. Shop, toilet, hospital, Mosque, park. And these are the same. You have to choose where they go., There are houses like the other time.

Yes. That is the same.

We need a hospital. That is the most important.

Yes.

Close in the middle. It is not too far away.

When our children get sick they can't get better. There is none.

Put it there.

Yes in the edge.

Then where are the houses?

Close by. Then we don't have to walk as far.

But bust all of those first.

Like this.

Next the trees. That is what we don't have. It it is that it won't be dirty like it is now. Over there.

Yes that's good too.

But a toilet? There is only one in Ghazipur now.

That can be too. That is good.

We can have more than one. Over there.

Three?

Is that what your want?

Yes there are not many in Ghazipur. It is too far away.

Is it safe?

No there is lots of violence and drunks there. 
Participant Two

Participant One

Participant Two

Participant Four

Participant Two

Participant Three

Participant One

Participant Two

Participant Three

Facilitator

Participant One

Participant Three

Participant Four

Participant Two

Facilitator

Participant Two

Facilitator
Not a safe place.

That is why there is more needed.

More there.

And a Mosque too. That is important.

It is already near Ghazipur.

This house is here.

Yes close by too. That's good. Near the toilet.

Is it done?

Yes. Now to the end?

Yes like the last one.

There.

Mine is there.

That is a good Ghazipur to be.

Yes with the things that we need.

Next is another one where you will do more.

The same?

No it is different.

\section{Level Four}

\begin{tabular}{|c|c|}
\hline Facilitator & $\begin{array}{l}\text { Now there is more. It is like the last one, but there is water, toilets, } \\
\text { school, tree, meeting, market and some other things. }\end{array}$ \\
\hline Participant One & There is also houses like before. \\
\hline Facilitator & Yes you do that one each time new. \\
\hline Participant Three & Where do we do them? There is all those buildings already. \\
\hline Facilitator & You all have to choose. \\
\hline Participant Two & Do we bust them? \\
\hline Facilitator & Yes you choose. \\
\hline Participant Two & Okay. This is where is diary is. \\
\hline Participant Three & Yes bust that. \\
\hline Participant One & The school is most important. We need that. \\
\hline Participant Two & Yes. \\
\hline Participant Four & That should be there in Ghazipur. \\
\hline Participant One & Here? \\
\hline Participant Three & Yes. \\
\hline Participant One & Should we bust this? \\
\hline Participant Three & Yes. \\
\hline Participant One & This is the school. \\
\hline Facilitator & That looks good. What about the Chintan school? \\
\hline Participant Two & $\begin{array}{l}\text { That is not a study school. This is what we need so they don't work in } \\
\text { the plant and get better jobs. }\end{array}$ \\
\hline Participant Three & That is best. \\
\hline Facilitator & What else does it need? \\
\hline Participant One & Water. This is by the house. That is here. \\
\hline Participant Two & More. \\
\hline Participant One & Like this? \\
\hline
\end{tabular}


Participant Two

Participant One

Participant One

Facilitator

Participant One

Participant Two

Participant Three

Participant Four

Participant Four

Participant Three

Participant One

Participant Four

Participant One

Participant Four

Facilitator

Participant One

Participant Two

Participant Two

Participant Three

Participant Two

Participant Three

Participant Two

Participant Three

Participant Two

Participant Three

Participant Two

Participant One

Facilitator

Facilitator

Participant One

Participant Four

Facilitator

Participant Two

Participant Two
They need to be in more places for the people to use most.

Yes.

This is also our Chintan? Than can be there for a school.

Yes that is a good idea.

Okay here.

That is where we are.

There is water now.

Where are we?

Yellow is here. Like that. Close to the Chintan. But we also need a toilet like last time.

Okay yes. Like before we can put it in our Ghazipur.

This house goes there.

Where?

You can do it. Over there.

Yes.

You do it.

Its nice

Mine too.

That is good. Now put green over there.

A market. We never did that one and it is important for Ghazipur.

Where.

It should be close. We have places, but more is better I think so.

But it is not that big.

This can go there.

There should be another one over there.

Yes to there.

Okay.

What are these?

Squares.

Do we need them?

I don't know. We bust them.

We are done I think.

Move your people to the space like the other time.

Just mine.

There.

\section{Level Five}

Facilitator

Participant Two

Facilitator

Facilitator

Participant Three
Now this is the Ghazipur. I will show you the places. This is the landfill, there is the metro.

Plant?

Yes.

Some houses and Mosque and some road. Now you must choose what you want for your Ghazipur. It writes what you need. See here. Yes. 
Facilitator

Participant Four

Participant One

Participant Two

Participant One

Facilitator

Participant One

Participant Two

Participant Three

Participant One

Participant Three

Participant One

Participant Three

Facilitator

Participant One

Participant One

Participant Two

Participant One

Participant Two

Participant Three

Participant Two

Participant One

Participant Two

Participant One

Participant Three

Participant One

Participant Two

Participant One

Participant Three

Participant One

Participant One

Facilitator

Participant One

Participant Two

Participant Two

Participant Two

Participant Three

Participant Two

Participant Three

Participant One

Facilitator

Participant One
There are more. See. Market, hall, shop, hospital, toilet, water, cricket, school, tree, wall, tree, somethings, plant, mosque, playground, road, part, building, house and that.

That is some.

This is the landfill. We should put the houses here. Close to the work.

Yes that would be best.

We need to make sure we can work there.

But what about your health.

If we don't work there we can't have both.

Yes it is important.

Then a hospital like before. That is what we need.

Here?

Yes close to the landfill. That is important. But we need support for it. How do we pay?

We can get the card to help. But it is not that easy.

We have tried to do that before with Chintan. We had a card but not all of us.

But it is better with a hospital than with no hospital.

Yes.

I will put my house there at Ghazipur.

This is the plant. So it should be there.

There is good.

Next a toilet. That is what we need like the other one.

More.

Yes I think it would be three. That would be best.

And a plant.

There it is.

And if there was more we could have more jobs.

But we need more schools. We cant take them with us.

Yes so we have a school too. Then we have more jobs for our Ghazipur.

Lazy drunk men.

That is hard.

They are there?

Yes. They can just go there and then they are all close.

Water too. Like before. Do we do this again?

Yes, it is new so do it again.

Do many there.

Trees. We need more of those in Ghazipur.

Yes there.

Shops.

Yes.

This is good.

All the houses are in.

Yes.

Good. Did this help?

Yes to talk about our Ghazipur. 


\section{Focus Group}

Facilitator

Participant Three

Participant Four

Facilitator

Participant One

Participant Four

Facilitator

Participant Three

Participant Two

Participant One

Facilitator

Participant Two

Participant Three
Was agreement reached within the group?

Yes.

Yes we all agreed. We all did things together and agreed.

How was agreement reached?

We talked about it. If someone wanted to do something they would say and then we would talk..

Yes.

How did you use the game visuals/space to help you discuss problems or issues with other players?

Like that. It was better than just talking.

It was fun. I hadn't done that before.

It was good to talk about problems in Ghazipur.

Do you have any other comments?

No it was good.

Yes fun. 


\title{
Ghazipur Workshop Group Two
}

\section{Workshop Transcript}

\author{
Pre-Gameplay \\ Facilitator \\ Are you ready? \\ Facilitator \\ This is called Maslow's Palace. \\ Participant One \\ What? \\ Facilitator \\ Maslow's Palace. \\ Participant One \\ Okay. \\ Facilitator \\ This is to design a new Ghazipur. What you want in it. \\ Facilitator \\ First we choose colours. \\ Participant One \\ I will be red. \\ Facilitator \\ Green? \\ Participant Two \\ Yes. \\ Facilitator \\ You can be blue and you yellow. \\ Facilitator \\ Next we play the game. You use this things to play. This is the mouse. You \\ have turns like this. Press this to make choices. Then you go through the \\ door. \\ Participant One Fine. \\ Participant One Do I use it first? \\ Facilitator Yes. \\ Facilitator Press this. \\ Facilitator It is starting.
}

\section{Level One}

\begin{tabular}{|c|c|}
\hline Facilitator & Your colours are here. Those are yours. \\
\hline Participant One & Okay. I will move them. \\
\hline Participant One & To here. \\
\hline Participant Two & Now me? \\
\hline Participant Two & Yes okay. \\
\hline Participant Three & Here? \\
\hline Participant One & Yes. \\
\hline Facilitator & Is that it? \\
\hline Participant Three & Yes. \\
\hline Participant Four & Okay. \\
\hline Facilitator & That is the end of this. \\
\hline Facilitator & Now you move. That is done. \\
\hline Participant One & Where do they go? \\
\hline Facilitator & To the next one. \\
\hline
\end{tabular}




\section{Level Two}

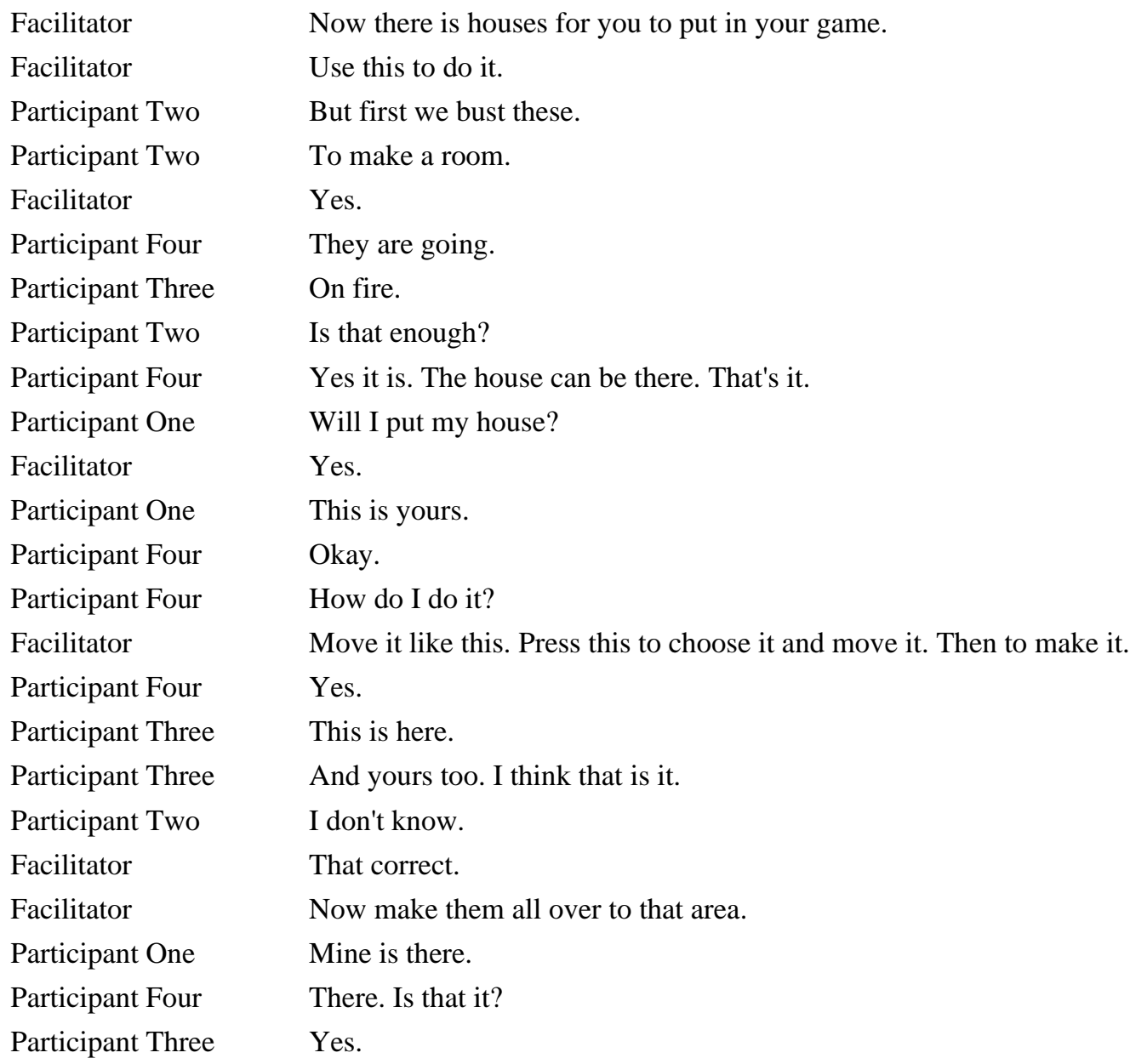

\section{Level Three}

\begin{tabular}{|c|c|}
\hline Facilitator & Next we have more. \\
\hline Facilitator & $\begin{array}{l}\text { The same as that but we have a shop, toilet, hospital, mosque and park and } \\
\text { trees. There is the same houses. }\end{array}$ \\
\hline Participant Two & Do I begin? \\
\hline Facilitator & That is right. \\
\hline Participant Two & I think we need a toilet the most at Ghazipur. There is not many at Ghazipur. \\
\hline Participant One & Yes that is important. \\
\hline Participant Two & Somewhere close. \\
\hline Participant One & But how can it be? \\
\hline Participant Two & Can it be for the women. That helps lots of problems. \\
\hline Participant One & That would be best. \\
\hline Participant Two & Here? \\
\hline Participant One & Yes I think that. \\
\hline Participant Two & And another. \\
\hline Participant Three & Put this house next to it. \\
\hline Participant One & We all go there. \\
\hline
\end{tabular}




$\begin{array}{ll}\text { Participant Two } & \text { Yes. } \\ \text { Participant Three } & \text { And a hospital. } \\ \text { Participant One } & \text { Yes. } \\ \text { Participant Three } & \text { There. } \\ \text { Participant Two } & \text { We already have a mosque. } \\ \text { Facilitator } & \text { But where should it be? } \\ \text { Participant Two } & \text { It doesn't matter. } \\ \text { Participant One } & \text { Just put it there. }\end{array}$

\section{Level Four}

Participant Four

Facilitator

Participant Three

Participant Two

Participant One

Participant Two

Participant One

Participant Two

Participant One

Facilitator

Participant Four

Facilitator

Participant Four

Participant Two

Participant Four

Participant Two

Participant Three

Participant Four

Participant One

Participant Four

Participant Two

Participant Four

Participant Two

Participant Three

Participant One

Participant Three

Participant Two

Participant One

Participant Two

Participant One

Participant Two

Participant Three
This is not the same.

Now there is water tank, toilets, school, some trees, meeting, market and some other things but still houses like before okay?

There is a landfill.

The mountain?

It is small. Is there enough?

Where does it go? I think this is like the metro.

There is no metro.

There.

No.

What will you do?

The school is most important.

Where do you put it?

Now it is too far and there are not that many. We need more close that we can use.

There are some.

But can you use them?

Some can.

But not everyone.

So we need more for our children and older ones.

Yes.

There.

Then water too.

Some more.

Another.

Put it on top. Then you don't bust them. They can be together.

A tree.

On top too.

That can't be there. It doesn't go.

But it can.

Where?

On top.

And a house too?

Yes of course. 
Participant Two

Participant One

Participant Three

Participant One

Participant Three

Participant Two

Participant Four

Participant Two

Participant Three

Participant Two

Participant Four

Participant Two
I think we should have houses there [by the landfill]. Better ones than we have now.

Yes, but we need to have no floods. That's how people get sick. So maybe not so close.

But that is far away from the toilets at Ghazipur. We [the houses] should be closer.

Yes there, I think that is good. This will be better for our Ghazipur.

Yes, and far from the sorting area.

Yes, but not far from the landfill.

All of them together.

Make sure there is distance.

Is that all?

Yes.

My colour is there.

Yes.

\section{Level Five}

Facilitator

Facilitator

Participant One

Facilitator

Participant Two

Participant Three

Participant Two

Participant Four

Participant Three

Participant Two

Participant Four

Participant Three

Participant Four

Participant Three

Participant Two

Participant Three

Facilitator

Participant Three

Participant Two

Participant Two

Participant One

Participant Two

Participant Three

Participant Three

Participant Four

Participant Two
These are the things in Ghazipur.

This is the landfill and the metro station and plant, here close to the landfill and some Ghazipur houses here next to it.

So what do you do?

First is market, then meeting, shop, see this things, hospital, toilet, tank, cricket, school, restaurant, tree, wall, tree, some things, building, apartment, park, road, playground, mosque, plant.

Yes, a mosque. This is close. And then a school is next.

Yes.

We put a school close to it.

That is in Ghazipur.

Where is the water?

A meeting. This is where we are.

Okay.

Yes too?

No more plants.

Yes, then that is more work for us.

It is there.

It went away.

Does Ghazipur have a park?

Yes, but not now.

A park can be there too.

Next to our Ghazipur.

The house is needs to be near the landfill. I

Yes mine too.

Not there. That was a mistake.

That's better.

There.

Then we need to stop those. 
Participant Three

Participant Two

Participant Three

Participant Two

Facilitator

Participant Two

Participant Three

Facilitator
A wall.

Where?

Yes there. I think here too.

This makes your Ghazipur.

Then you move your colours.

Okay I will.

It is there.

Good.

\section{Focus Group}

Facilitator

Participant One

Participant Two

Facilitator

Participant Three

Participant One

Facilitator

Participant Two

Participant Three

Facilitator

Participant One
Was agreement reached within the group?

Yes.

Yes we agree that there are problems.

How was agreement reached?

By playing the game.

Yes and we talking about the problems and what can be done about them in Ghazipur.

How did you use the game visuals/space to help you discuss problems or issues with other players?

To show them how it should be.

Yes, to show where the things are. Buildings and what the problems are.

Do you have any other comments?

I think it was good for us. But also we need to talk to everyone about it not just four. That way will help us. 


\section{Ghazipur Workshop Group Three}

\section{Workshop Transcript}

\section{Pre-Gameplay}

$\begin{array}{ll}\text { Facilitator } & \text { This is the game } \\ \text { Facilitator } & \text { First we choose the players. } \\ \text { Facilitator } & \text { Who wants to be red? } \\ \text { Participant One } & \text { Me. } \\ \text { Facilitator } & \text { Green? } \\ \text { Participant Two } & \text { Yes. } \\ \text { Facilitator } & \text { Blue? } \\ \text { Participant Three } & \text { Yes. } \\ \text { Participant Four } & \text { You are yellow. } \\ \text { Facilitator } & \text { Okay choose this one. } \\ \text { Facilitator } & \text { Okay so you take turns. Use this to choose things with this button. Use } \\ & \text { this button to bust things and then you all go through the door together } \\ & \text { Yes? } \\ \text { Participant Two } & \text { Yes. } \\ \text { Facilitator } & \text { Okay now you start. Push that button. } \\ \text { Facilitator } & \text { See through the door all together. Yellow, blue, green, red. One, two, }\end{array}$

\section{Level One}

Facilitator

Facilitator

Facilitator

Facilitator

Facilitator

Participant Two

Facilitator

Participant One

Facilitator

Facilitator

Facilitator

Facilitator

Facilitator

Participant One

Facilitator

Participant Two

Facilitator

Participant Two

Facilitator

Participant Two
Four player's 1-2-3-4 each of them have a different colour level 1. Imagine that they're going to Delhi.

Before they reach Ghazipur that's what it looks like.

This used to be a house.

What needs to be done first - obviously cleaning.

It's like a jungle - it's all rubbish.

What should they do first?

Clean up the area first. There is lots of rubbish.

So let's clean - we're cleaning.

Look it's done. You removed the rubbish (pink boxes)

Look it's clean now in this Ghazipur.

Each of these houses have a different colour - which colour do you want to pick for your house (Participant One).

I was asking you P1.

I'll choose the red one.

The red needs to go onto the empty space to make a house. You can put it there with this button.

I will have yellow.

Whose one is yellow? Where are you going to put it?

I'll put it over here next to your house. Yes that is good.

But you could put it alone?

I will clean some more here so it is not by my house. 
Participant Three

Participant Four

Participant Three
I will put blue here.

I think that is good (placing blue house near others).

It opened by itself (the door)

Nobody helped - it opened by itself (the door)

\section{Level Two}

Facilitator

Facilitator

Facilitator

Facilitator

Facilitator

Facilitator

Facilitator

Facilitator

Facilitator

Facilitator

Facilitator

Facilitator

Facilitator

Facilitator

Facilitator

Participant Two

Facilitator

Facilitator

Facilitator

Participant Four

Facilitator

Facilitator

Facilitator

Facilitator

Facilitator
What it's teaching you is how to support each other.

What its teaching is that when you help each other everything becomes easier.

So let's look at the next one.

In the next stage you have to do the same thing.

Whatever we cleaned is there again so we have to clean it first.

And now we need to make a house here.

Now they need to go from here to there (player.

Do you want some cold drink?

Now look the red ones reached.

So we'll make a house for the red player.

Look there's a house already made.

We'll sit it in this corner and well make a house here.

The house is built.

We'll take the yellow one.

Did you understand?

Yes.

So what we did - this is what our life is like.

Whatever we've (done/experienced) so far is what shown.

We'll put that one there.

These are all matching houses.

Now we'll make one on this side.

First we'll just make houses.

And the house is made.

Now look my Ghazipur is ready.

Now over here ... somethings.

\section{Level Three}

Participant One

Participant Three

Facilitator

Participant Two

Participant One

All

Participant Three

Participant Four

Participant One

Participant Three

Participant Four

Participant Three

Participant Two
Look different buildings. What are these?

A toilet. Yes we need that.

Yes there are different buildings now. You can choose them and put them how you want it to be like.

Okay yes I like the park. We do not have anything like this in Ghazipur. It is all dirty. Some place to be outside.

I want the hospital first. We need that it is the most important.

Agreement.

Yes that can go in the middle and we put our houses there.

Yes close to it. I will put mine here.

Okay. Yes and a toilet. Where should we put that? Our toilet it far away.

Let me try.

Okay. Yes and a toilet. Where should we put that? Our toilet it far away.

I will put the toilet over here. Not so close.

Yes that is good. 
Participant Four Participant One

Participant Three

Participant Three

Participant Two

Participant Two

Participant Three

Participant Two

Participant One

Participant Two

Participant Four

Participant One

Participant Three

Facilitator

Participant Three

Participant Two
And the Mosque. That can go there. But not so close to the hospital.

Yes there.

I will put my house here near to your house too.

I think a shop is good. But not an alcohol shop. That will make a big problem for us.

Yes the alcohol shop is too close.

I still need to put my house.

Okay here.

Okay but first I make one more grass.

No that is on my house.

Okay over here. Yes that is where it should go.

That is better.

Maybe we need more shops. Over there. The shops let us buy things and maybe there will be some more jobs for us.

Can we have a school?

There is not a school in this game.

Okay hopefully soon.

I think that hospital is good. But there isn't that much area here. Where are the roads?

\section{Level Four}

Facilitator

Participant Three

Participant One

Participant Two

Participant Four

Participant One

Participant Two

Participant One

Participant Three

Participant Three

Participant Two

Participant Three

Participant One

Participant Two

Participant One

Participant One

Participant Two

Facilitator

Participant Two

Participant One

Participant Four

Participant One

Participant Four

Participant Two

Participant Three

Participant One

Participant Two

Participant Three

Participant One

Participant Three
There is a school now.

Yes good. We should have a school

But there is no space. There are all of the buildings there.

Yes where do we put them.

Maybe we bust them.

Oh yes. If we move them or break them then we can build what we want.

But we bust those houses to build our houses.

Yes let us bust them.

Okay lets move these.

More. That one too.

Okay that is good. We can fit a market there.

But the school first. That is what we need.

Yes the school can go there. Then they can go there when we work.

We need support for more schools. We have Chintan, but not more.

How will we have high school?

Make another school. That can the high school there. Then that will work.

Water.

Yes we need water. A few places.

You have taps already. Do you need to put more here?

Yes. Most do not work for us but some do.

There are close by our houses.

Maybe we put them by the school.

Yes and by the houses.

I will put mine there.

Okay

Okay I will put mine too.

Some trees.

Yes. Around the houses.

Like before the metro.

Here?

Yes and there. 
Participant Two

Participant One

Facilitator

Participant One

Participant Two

Participant Four

Participant Two
Yes.

Now to the door?

Yes if your are complete it is open.

Okay.

I think it is good.

I'll move mine next.

Okay here it is.

\section{Level Five}

Facilitator

Facilitator

Facilitator

Facilitator

Facilitator

Facilitator

Facilitator

Facilitator

Facilitator

Facilitator

Participant Four

Participant Four

Facilitator

Facilitator

Participant Two

Facilitator

Participant One

Participant Two

Facilitator

Participant Three

Participant Three

Participant One

Participant Two

Participant Four

Facilitator

Facilitator

Participant Two

Participant Three

Participant Two

Participant One

Participant Two

Participant Three

ALL

Facilitator

Participant Two
But what he asked he made something else for else for that.

Now look that's Ghazipur.

It's made like this

Now I'll show you what's in Ghazipur and we've reached Ghazipur.

That's your university.

That's the landfill.

That's the plant.

And over here he's written what you need.

So where do you want the house do you want it with the landfill?

With the school or with the plant or somewhere else?

The (waste-to energy plant) labourers should live by the plant.

Those who don't work can be put somewhere else

Can I ask you one question?

Before plants were placed in Ghazipur how many people used to work here (in the landfill)? Did all of them work here?

Yeah all of them were working there.

In the plant not even half of Ghazipur's people are able to work there.

No, more people work there.

No more than half do.

If the plant didn't come it would stay a shithole.

Imagine if there was not plant and it was just the landfill.

If the landfill closes tomorrow then the plant also closes and visa versa.

The waste from the plant goes into the landfill.

We want to keep the plant and the landfill

If we are evicted, we have no way to earn money... We need to make sure we live close to the landfill and have access to waste... But we need our children to go to school so they do not have to do this dirty work for their children.

Both are important to think about in terms of your health

What I would say is to get rid of both. Wouldn't that be better?

Living close to landfill ensures the ability to take care of income and children. That's why I built the buildings there. We need to make this place better.

In each house what will we do with work? What is the benefit of that? We would have no way to earn money.

There will be election soon and we can ask for more work and for them to clean the area.

Who should we vote for?

Someone who will help us. But you have to give him money.

Okay so we'll have both? We want both the plant and the landfill.

Yes.

Okay what else do you want in Ghazipur?

We need what's most important which is a toilet. 
Participant Three

Participant Three

Facilitator

Facilitator

Participant Two

Facilitator

Participant Two

Participant Two

Participant Three

Participant Two

Facilitator

Participant One

Participant Three

Facilitator

Participant Two

Facilitator

Participant Three

Participant Two

Participant Two

Facilitator

Facilitator

Participant Four

Facilitator

Participant Two

Participant Three

Facilitator

Participant Two

Participant Three

Participant Three

Facilitator

Participant Three

Facilitator

Facilitator

Participant Two

Participant Two

Participant One

Facilitator

Facilitator

Facilitator

Facilitator

Participant Three

Participant Two

Facilitator
Someone that takes a lot of salary.

No they're government people.

This sir wants to know what other stuff you want in Ghazipur.

So this is the toilet.

I think it should be over there. Near the houses.

What about the hospital.

It should be placed right in the middle.

We want a school for the kids. I think it needs to be there.

There's one nearby.

But still I want a school so they don't have to walk far.

It's not a tuition school it's a primary school.

At least they'll study.

At least they'll be nearby.

Do you want a water tank?

Yes!

Where should it be?

On the left side. Over there.

It should be in between he hospital and the school.

One plant is enough.

We're having a look at what you have and what you don't have.

Mosque.

Everyone says we already have one.

Do you want a hall?

I want a park.

Put it behind the toilet.

Shall we have another tree?

We need a market to have fun.

Groceries where are we going to go?

We got everything but where are we going to eat? To have fun?

Where shall we put the market. In the middle?

If it's in the middle it will be good for everyone.

We'll put it with the park

Now we're going to the next level. Why do you want a market though?

Where are we going to go shopping though.

Well we can go anywhere to get groceries though.

Oh look its going now. And the third one?

The third ones coming too.

This is one type of training for you guys.

As in if somebody comes to you and asks you what you have.

Sometime you feel like whoever comes fills their bag and runs away.

That's everyone's thought.

That's not everyone's thought though

This game helps you put your situation in front of somebody else.

\section{Focus Group}

Facilitator

Participant Four

Participant One

Participant Two

Facilitator

Participant Three

Participant Two
Was agreement reached within the group?

I think yes.

Yes we did. But sometimes no about everything.

Yes we disagree sometimes. But we agree on the problems in Ghazipur.

How was agreement reached?

By playing this games.

Yes we showed them like a drawing. 
Facilitator

Participant Two

Participant Three

Facilitator

Participant One

Participant Two
How did you use the game visuals/space to help you discuss problems or issues with other players?

It helped us show them not just talk about things.

Yes.

Do you have any other comments?

It was good. I liked the busting of the blocks and the making houses and things. It was good.

Yes we thought about the problems which is not that much in Ghazipur. 


\section{Ghazipur Workshop Group Four}

\section{Workshop Transcript}

\section{Pre-Gameplay.}

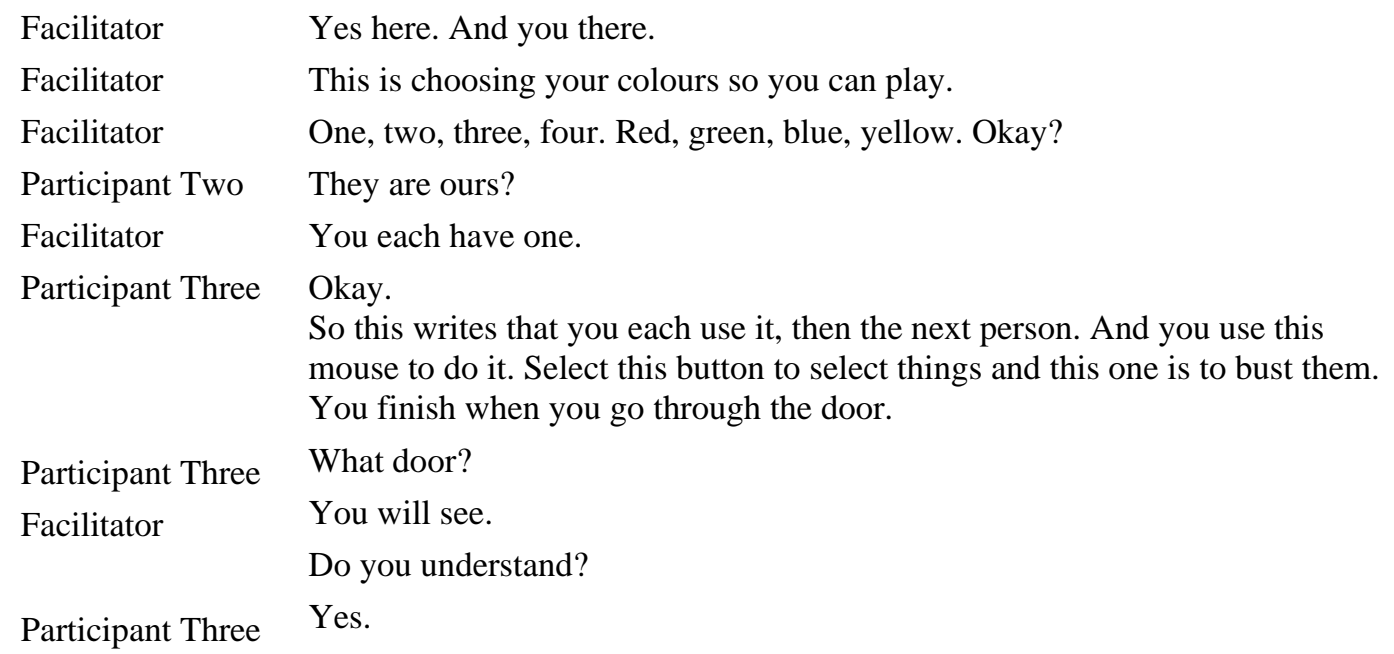

\section{Level One}

\begin{tabular}{|c|c|}
\hline Facilitator & You can hold this. \\
\hline Participant One & Okay. How? \\
\hline Facilitator & Here like this. And use this button. \\
\hline Facilitator & Select your colour. \\
\hline Participant One & Where? \\
\hline Participant Three & That one. Like before. \\
\hline Facilitator & Yes. Then press where you want to put it. \\
\hline Participant One & Where is that? \\
\hline Participant Two & By the door. \\
\hline Participant Three & There. \\
\hline Participant One & It's going. \\
\hline Participant Two & Good. \\
\hline Participant Two & Can I? \\
\hline Participant Two & Together. \\
\hline Participant Three & Okay there. \\
\hline Participant Four & It's moving. Ah it's opened. \\
\hline Participant One & Is that all? \\
\hline Facilitator & Now we do more. \\
\hline
\end{tabular}

\section{Level Two}




\begin{tabular}{|c|c|}
\hline Facilitator & Next we do this but with houses. \\
\hline Participant One & The same? \\
\hline Facilitator & Yes, but you choose where your house goes. \\
\hline Participant One & Do I use it now? \\
\hline Facilitator & Yes. \\
\hline Facilitator & You put your house. \\
\hline Participant One & But I move here? \\
\hline Participant Three & Yes. \\
\hline Participant One & It is difficult. \\
\hline Participant Four & Now me. \\
\hline Participant Three & These should all be together. \\
\hline Participant Two & Yes. Put them there. \\
\hline Participant Three & Then we don't walk as far. \\
\hline Participant Two & Close. \\
\hline Participant One & Where is our Ghazipur? \\
\hline Participant Four & Is it done? \\
\hline
\end{tabular}

\section{Level Three}

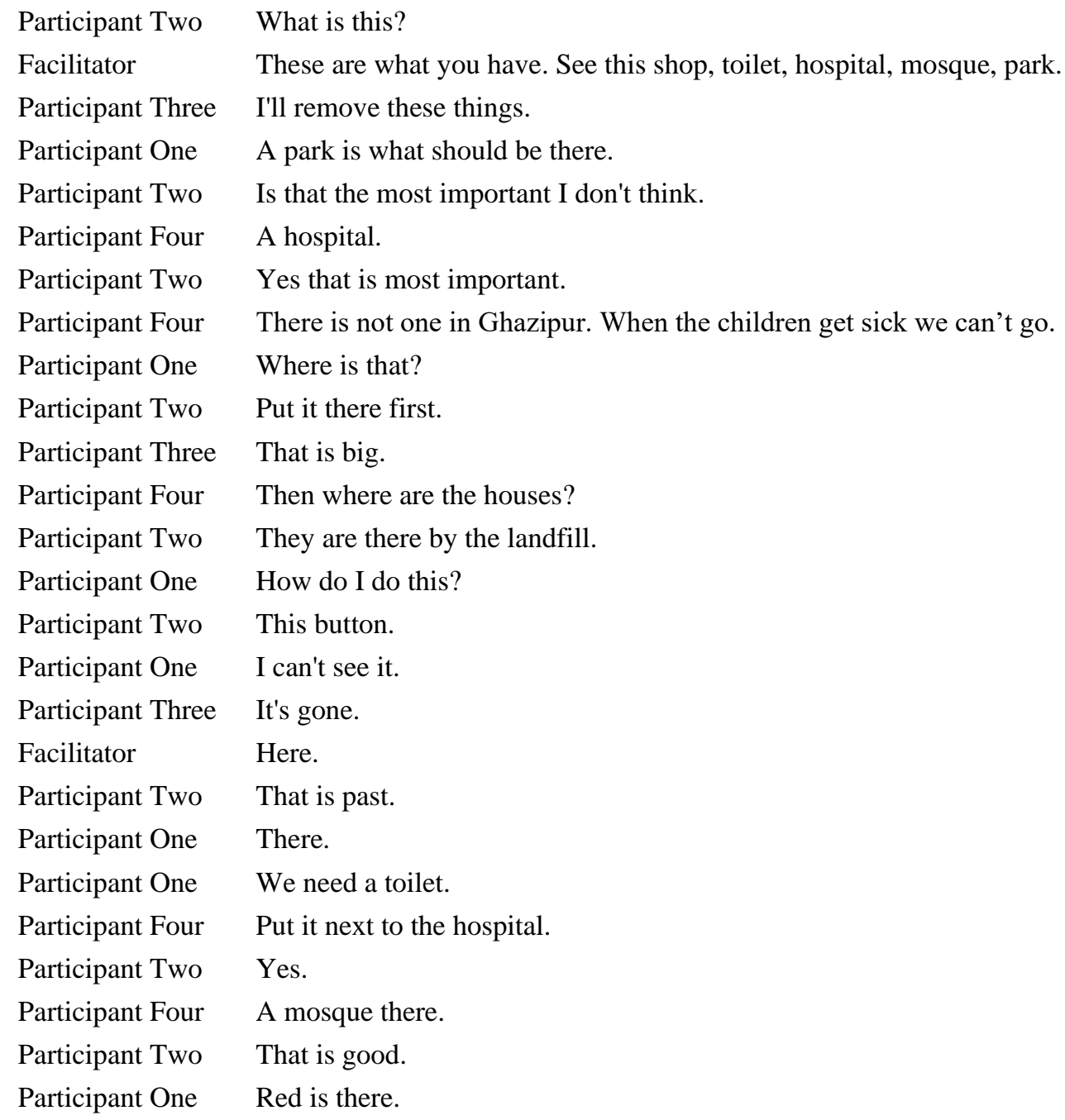




$\begin{array}{ll}\text { Participant Two } & \text { Hurry up. } \\ \text { Participant Three } & \text { What? } \\ \text { Participant Two } & \text { Yours needs to be there to finish. } \\ \text { Participant Three } & \text { Oh. }\end{array}$

\section{Level Four}

\section{Participant Three Read it again.}

Facilitator

Participant One

Participant Two

Participant One

Participant Three

Participant Four

Participant Three

Participant Two

Facilitator

Participant One

Facilitator

Participant One

Participant Three

Facilitator

Participant Two

Participant Three

Participant One

Participant Three

Participant Two

Participant One

Participant Two

Participant Three

Participant Four

Participant Two

Participant Four

Participant One

Participant Two

Participant Three

Participant One

Participant Two

Houses.

Is it my turn?

Yes.

Yes.

No. in. well. let us.

Yes.
There are these things. There is water, toilets, school, tree, meeting, market and some other things.

My one is red.

They are together.

I'll break them.

No you have to choose.

What are they?

All the things from Ghazipur are here.

Ohh so you understand.

That made space.

Is that the landfill?

We should build the meeting room close to the houses and to work. Over there.

No. There is no room for it there. There are all of the houses.

But if we build that there, we will have to demolish a house that someone lives

But we need one.

But there is already a school there. We should use that. We are in the school now. We could meet here.

A meeting hall would be better. Then we can use it when school is underway as

We could move our houses, and group them together. Then we can make space there for a hall.

What if they (the government) tells us to leave? Then we have no houses. That might happen soon.

But if we can have meetings then we can plan.

If I move my house, I cannot afford to build it again. We should use the school.

Yes that is a good idea.

Okay, but we need to make sure that the school is in Ghazipur. By those houses. Then we can build the toilets, and all use them.

Okay but we should talk to them, to make sure it is okay. The school might not

Okay we will do that. 
Participant Three But also water. That is by the houses.

Participant Four And the meeting.

Participant Two We need to move this.

Participant Three Put it here.

Participant Four There or here?

Participant One Over there.

Participant Four Put your colour here.

\section{Level Five}

Facilitator

So it works the same as before.

Facilitator

Participant One

Facilitator

Participant Three

Facilitator

Participant Two

Participant Three

Participant Two

Participant Four

Participant Three

Participant Two

Participant Three

Participant Two

Participant Two

Participant Three

Participant One

Participant Two

Participant Four

Participant Three

Participant Two

Participant One

Participant Three

Participant One

Participant Four

Participant One

Participant Three

Participant Two

Participant Three

Participant Four

Facilitator

Participant Four

Facilitator

So some of the things.

Water.

Landfill.

Some here.

Yes, they need to be close.

The metro is bad for us.

Yes.

Yes, but it is far and no work.

We don't know.

Yes on there.

I should do my one.

Where?

It goes over there.

No, no, no.

Why?

Why is there a dairy?

Is it my turn?

The Chintan school helps?

Yes up not always.

All the children can come.
There are some of the things in Ghazipur.

Yes. Plant, metro, houses and some things.

The houses should be here. All of the things to make a Ghazipur.

Yes that is why they left. Tell him to bust it.

We could go back to the village. Some people have already gone after the construction of the metro station.

They are in drought. There is no rain and there is no food.

But is it better? Will they move us? This is a problem.

That's why we need to be close so they can move us.

Okay put the house there first. We make our Ghazipur here so it is harder.

This hospital. That is what is needed in our Ghazipur.

There is room for the dairy and to walk.

We need to help with our children. Who will look after them? 


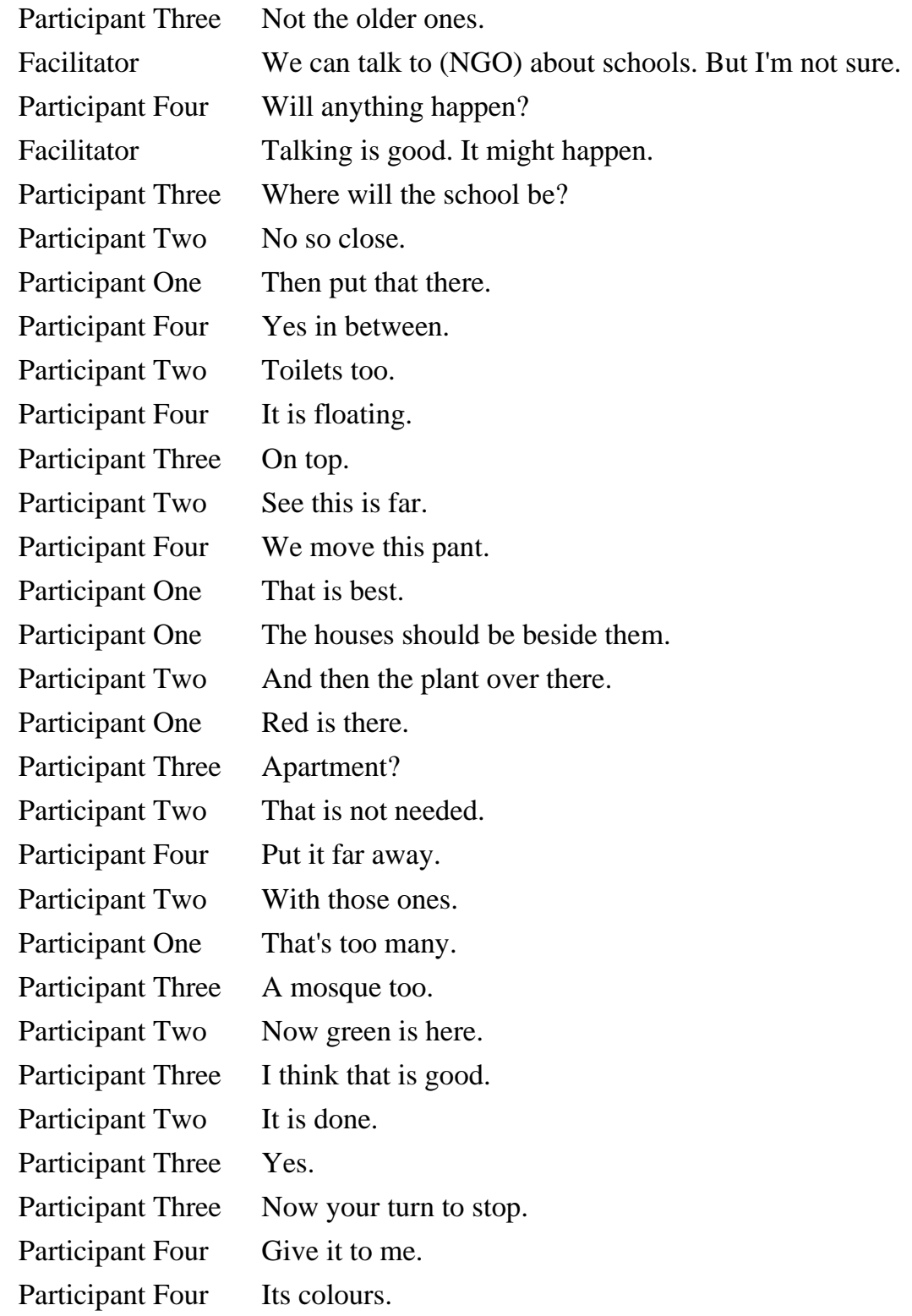

\section{Focus Group}

Facilitator Was agreement reached within the group?

Participant Two Yes mostly.

Participant One Yes. We agree.

Facilitator How was agreement reached?

Participant One First we played the game and then we talked about it.

Participant Two But not always.

Participant Three Sometimes they just did things. But then we could change things like the school.

Participant Four Yes that was how.

Facilitator How did you use the game visuals/space to help you discuss problems or issues with other players?

Participant One I showed them.

Participant Two Yes we showed them what we wanted to do. 
Facilitator

Participant Four

Participant Two
Do you have any other comments?

No.

It would be good to have more of the Ghazipur community play this game.

There is not may people here. That will helps. Some other people have other problems that we don't have . 


\section{Bhalswa Workshop Group One}

\section{Workshop Transcript}

\section{Pre-Gameplay}

Facilitator

Participant Three

Facilitator

Facilitator

Facilitator

Facilitator

Facilitator

Facilitator

Participant Two
Are we okay?

Yes.

Okay, this game is called Maslow's Palace, yes?

I will help you understand.

First we will choose the colours. This one is red. Then green, blue yellow, yes?

Each of you has one. We will go you to you. Red, green, blue, yellow.

This is the game. Each has 5 levels. We will start with level one.

So you take turned. Click on your character to start your turn. Explore. Right click with this mouse to bust objects. Then do to this gate, see, to open it. All of you do that when you are finished.

Yes.

\section{Level One}

\begin{tabular}{|c|c|}
\hline Facilitator & This is first going to help you learn. \\
\hline Facilitator & So your turn now. Who starts? \\
\hline Participant One & Okay. \\
\hline Participant One & Ohh I choose this. \\
\hline Participant One & It's not working. \\
\hline Participant One & It's not. \\
\hline Facilitator & You have to remove it. \\
\hline Participant One & How? \\
\hline Facilitator & Use this one. \\
\hline Participant One & Do I do it for each? \\
\hline Facilitator & Yes to remove them. \\
\hline Participant One & I understand. \\
\hline Participant One & Then what? \\
\hline Facilitator & Move it to that area. \\
\hline Participant Three & Okay now what. \\
\hline Participant Three & It's there. \\
\hline Participant Three & It's closed. \\
\hline Facilitator & You all need to do it. \\
\hline Participant Three & I haven't. \\
\hline Participant Three & There. \\
\hline
\end{tabular}

\section{Level Two}


Facilitator

Participant One

Facilitator

Participant One

Participant Two

Participant One

Participant One

Participant Three

Participant Two

Facilitator

Participant Two

Participant Three

Participant Two

Participant Three

Participant One

Participant Two

Participant Four
See each of the four players. This time we have the houses.

Okay. But there is no space.

First you need to make space.

I will move these like before.

Leave some.

There.

I think it is in the corner.

No. That doesn't make sense.

Over in that one.

Now you move to the end.

That is the same.

Let her do it.

Why are you doing it?

Do you want to put it there too?

But not on top.

The house will be there.

That's all of them.

\section{Level Three}

Participant Two

Facilitator

Participant Three

Facilitator

Facilitator

Participant Two

Participant Two

Participant Three

Participant Two

Participant Four

Participant Two

Participant Three

Participant One

Participant Four

Participant Two

Participant Three

Participant Four

Participant Two

Participant Four

Participant Four

Participant Three

Facilitator

Participant Three
There is more now.

Yes, this is a shop, toilet, hospital, mosque, park and trees and some blocks.

What was this?

Toilet.

There is houses here too. Each of you need this okay?

Yes we need houses.

Do I begin?

Okay.

Where is the road? That's what is needed.

All of this is a road.

This is a hospital first.

Yes. That is needed most.

We'll clear this.

Put the yellow house there.

But also the toilet.

Yes a toilet.

Where will it be?

By the hospital.

Take it further back.

Yes yes there.

What was this one?

Mosque remember.

No. 
Participant Three

Participant Four

Participant Two

Participant One

Participant Two

Participant Four

Participant Three

Participant One

Participant One

Participant Two

Participant Four

Participant Three

Participant Four

Participant Three
That should be there.

Yes very important.

And the toilet over there. Close to the houses, by the edge.

Not too close.

Enough.

Some trees.

That is in that park bit is what it can be.

Yes.

This is the house. I'm there now.

Don't bust it for some reason.

Yes.

Move it.

No it is fine.

No to the end.

\section{Level Four}

Participant Two

Participant Three

Facilitator

Facilitator

Participant Three

Facilitator

Participant Two

Participant One

Participant Four

Participant Three

Participant Four

Participant Three

Participant Two

Participant Three

Participant One

Participant Three

Participant Four

Participant Two

Participant Two

Participant Three

Participant One

Participant Two

Participant Four

Participant Two
What are the new things.

Tree

Yes there are these things

Water tanks.

Yes!

Toilets, school, tree, meeting hall, market, and some blacks. There is the houses.

Good.

There is nowhere to build.

We can't destroy those houses. People live there.

Well we have to build them somewhere. Maybe we destroy them.

If we build them up there, there will be less water.

We can't get though there. There's no path. We should build our houses in the valley and make a road.

We can walk up the hill. It's better than having water in our houses, and the garbage can fall on us.

We should put water there. Then we don't have that problem.

I'll do it.

There.

Toilets next.

Not only one.

Put it there.

It's on top of that house. Next to it.

Then they can't walk over.

They should all be in a line.

Put yours there.

Okay. 


\section{Level Five}

Facilitator

Participant Two

Participant Three

Participant Four

Facilitator

Participant Two

Participant Three

Participant Four

Participant Three

Participant One

Participant Two

Participant Three

Participant Four

Participant Three

Participant Four

Participant Three

Participant Two

Participant One

Participant Three

Participant Two

Participant Three

Participant Four

Participant Two

Participant Three

Facilitator

Participant Three

Participant Two

Participant Three

Facilitator

Participant Three

Participant Two

Participant Three

Participant Four

Participant Three

Participant Four

Participant Three

Participant Two

Participant One

Participant Two

Participant One
These are the new things. There is a market, meeting hall like before, shop, toilet, water, cricket, school, restaurant, tree, wall, buildings, park, road, playground for children, mosque, plant, blocks.

That is a lot of things.

Where do we put them?

We can change it.

Yes change it like you want Bhalswa.

This is important.

We need to use that ground.

Yes there is nothing there.

Just waste.

But that is not open.

It can be used. We should try.

Where is it?

There. Bust all of that there.

Yes. More?

What do you think?

First the houses.

We just need a better road.

Yes. That is here. That way.

Then the houses are there.

You do them all.

That way.

A toilet is next. That is what is not in Bhalswa.

There.

What is these things?

Trees.

Yes. But under there. That is nice.

A hospital. Not here but close.

Where is the landfill?

There.

Then over there. Not so close.

Yes.

We need to keep the water out of the houses.

There, a wall.

Now to the end.

What are you doing?

That's not it.

Yes.

It's not there.

It is now.

It's done. 


\section{Focus Group}

Facilitator Was agreement reached within the group?

Participant Two We showed the things that were needed in Bhalswa. Like water. That is what is needed most we all agree.

Participant Three Yes that is important.

Facilitator How was agreement reached?

Participant Two Talking.

Participant Three Yes we talked about it.

Facilitator

How did you use the game visuals/space to help you discuss problems or issues with other players?

Participant Two

It helped me show them what I wanted.

Participant One

I liked it. But it was quite hard moving fast.

Facilitator

Do you have any other comments?

Participant One

Yes, more time would have been better. It was quite fast.

Participant Two

Yes, I enjoyed it buy that would help. 


\section{Bhalswa Workshop Group Two}

\section{Workshop Transcript}

\section{Pre-Gameplay}

\begin{tabular}{|c|c|}
\hline Facilitator & Okay sit down. \\
\hline Facilitator & Are you ready? \\
\hline Facilitator & We will do a game called Maslow's Palace. \\
\hline Facilitator & We'll think about a new Bhalswa. What it will be like. \\
\hline Facilitator & First this is where we choose the colours. Yes? Each of you will have one. \\
\hline Facilitator & Who is red? \\
\hline Facilitator & You can be. \\
\hline Facilitator & Green? \\
\hline Participant Two & Okay. \\
\hline Facilitator & Blue? \\
\hline Participant Three & Yes. \\
\hline Facilitator & You are yellow. \\
\hline Facilitator & Remember those are yours. \\
\hline Facilitator & $\begin{array}{l}\text { Next we play the game Maslow's Palace. You use this things to play. This } \\
\text { mouse and you have turns like this and pass to her. Press this button to } \\
\text { make choices. Then you go through the door. }\end{array}$ \\
\hline Facilitator & Understand? \\
\hline Participant Two & Yes. \\
\hline Participant Four & Okay. \\
\hline Facilitator & Now it is time to start. \\
\hline Facilitator & Press that button. \\
\hline
\end{tabular}

\section{Level One}

Participant One

Facilitator

Participant One

Participant One

Facilitator

Facilitator

Facilitator

Participant Three

Facilitator

Participant Three

Facilitator

Participant Three

Facilitator
How do I do it?

First you have to bust those rocks.

How?

It's too fast. It's gone.

Here let me see.

There it is.

Press this button on them. See it's gone.

How?

This one.

Oh.

So you need to make a path?

Why?

So that you can go to the door. 


\begin{tabular}{|c|c|}
\hline Facilitator & You move your colours. \\
\hline Participant Three & Is that how it ends? \\
\hline Facilitator & Yes you all go together to the next one. \\
\hline Participant One & There. Is that good? \\
\hline Facilitator & Yes. \\
\hline Participant Two & Is that correct? \\
\hline Participant One & Yes, it is moving. \\
\hline Participant Three & Good. \\
\hline Participant Three & Where did it go? \\
\hline Participant Two & Over there. \\
\hline Participant Three & I can't find it. \\
\hline Facilitator & Here I can help. \\
\hline Participant Three & This is hard. \\
\hline Participant Four & No. \\
\hline
\end{tabular}

\section{Level Two}

Facilitator

Participant Two

Facilitator

Participant One

Participant Two

Participant One

Participant Four

Participant Three

Participant Two

Participant Three

Participant Three

Participant Two

Participant One

Participant Three

Participant One
Good so you all did it together. Understand?

Yes it opened together.

Next there is houses So you can choose where to put it. Use this button. But still make a space.

I will remove them.

There in each corner.

That makes a room.

That is many.

I want to do some.

Put it in the corner near there.

Here?

Here?

Okay fine there is okay.

It is on the gate. No.

Put that house there.

Hurry up.

\section{Level Three}

$\begin{array}{ll}\text { Facilitator } & \text { There is these now. } \\ \text { Participant One } & \text { What? } \\ \text { Facilitator } & \text { There are more buildings now. } \\ \text { Facilitator } & \text { See. } \\ \text { Participant One } & \text { Yes. } \\ \text { Facilitator } & \text { Now a shop, a toilet, a hospital, a mosque, a park and some boxes. } \\ \text { Facilitator } & \text { You have to choose what you want. } \\ \text { Participant Two } & \text { Do we put them there? }\end{array}$


Facilitator

Facilitator

Participant Three

Participant Two

Participant One

Participant Two

Participant Two

Participant One

Participant Two

Participant Two

Participant Four

Participant One

Participant Two

Participant One

Participant Three

Participant Four

Participant Two

Participant Four

Participant Four

Participant Three

Participant Four

Participant Three

Participant Two

Participant One

Participant Two
Yes.

You have to decide together where they go and what is important to Bhalswa.

We need a hospital the most.

No a road.

Yes.

There is too much water.

If we has a proper road it would be better. And no sorting.

Yes.

We need to move all of the sorting away from homes. Two weeks ago, during the rain, the foil was washed through my door. This takes so long. If we move all of this and make an area for it where it can stay, then we won't have this problem. See like this. Can you remove all of these?

Then make the houses there with no waste. And that can be over there, maybe with containers.

Yes that is good. Behind.

What about that button. Does that work?

That is better than before.

The hospital is there too.

No there.

Let me do it.

No that's better.

Yes there.

A toilet too.

We have that.

No a better one. With water.

Move your colour.

Who?

Her.

It's there.

\section{Level Four}

$\begin{array}{ll}\begin{array}{l}\text { Participant Two } \\ \text { Facilitator }\end{array} & \text { What is now? } \\ \begin{array}{l}\text { Participant Two is more now. } \\ \text { Participant Three }\end{array} & \text { The same? } \\ \text { Facilitator } & \text { That's funny. } \\ & \text { box. } \\ \text { Participant One } & \text { Where to we put them? } \\ \text { Facilitator } & \text { There. You have to decide. } \\ \text { Participant Two } & \text { In there? } \\ \text { Facilitator } & \text { Yes. So you might have to bust things. } \\ \text { Participant Three } & \text { What are they? } \\ \text { Participant Four } & \text { It doesn't matter. } \\ \text { Participant One } & \text { Okay they can go there. }\end{array}$


Participant Three

Participant Two

Participant One

Participant Two

Participant One

Participant Two

Participant One

Participant Four

Participant One

Participant Three

Participant Two

Participant One

Participant Three

Participant Two

Participant Four

Participant Two

Participant Three
The houses are the same.

Can they go there?

On top?

They are in a pile.

There's no room. Your house is there. We need a toilet as there is none in Bhalswa. Move it.

Why don't we build on the hill? It will be quiet there.

No. Just move your house. You always think about yourself only.

I'll build one then you build one.

Okay, only if we can also have water there.

See like this, these are steps, we can walk up.

That is too many. How to you go there?

Just go up. It doesn't matter.

It will work.

There is the water.

That can be down there by the houses.

Yes.

Hurry up.

\section{Level Five}

Facilitator

Participant Two

Participant One

Participant Three

Participant One

Participant Two

Participant Three

Participant Two

Participant Three

Participant Three

Participant Two

Participant Four

Participant Three

Participant Two

Participant Three

Participant Two

Participant One

Participant Three

Participant Three

Participant Two
In this one there is more. Let me show you. There are your colours. Then see the landfill yes? And a road, and a plant, the houses. Then you decide what you want your Bhalswa to be like.

The houses should be by the landfill.

That is best.

Where is the road?

There.

That doesn't make sense.

How can we have a road with the houses?

But there is the water. How do we stop it?

It is there.

But if there is houses there is water.

We need that most.

Okay go straight there.

They have to be busted.

Where to though?

The can't be there. How do you make a good road?

If we build them there then they don't need fixing.

Yes.

They should be there. So then they can have a hospital.

We need to have hospitals. My child gets sick. He is left at home when I work in the landfill when he is sick, and I cannot look after him. If the hospital was close to home, he could get better and I could earn money for my family doing this work.

Yes that is important. 


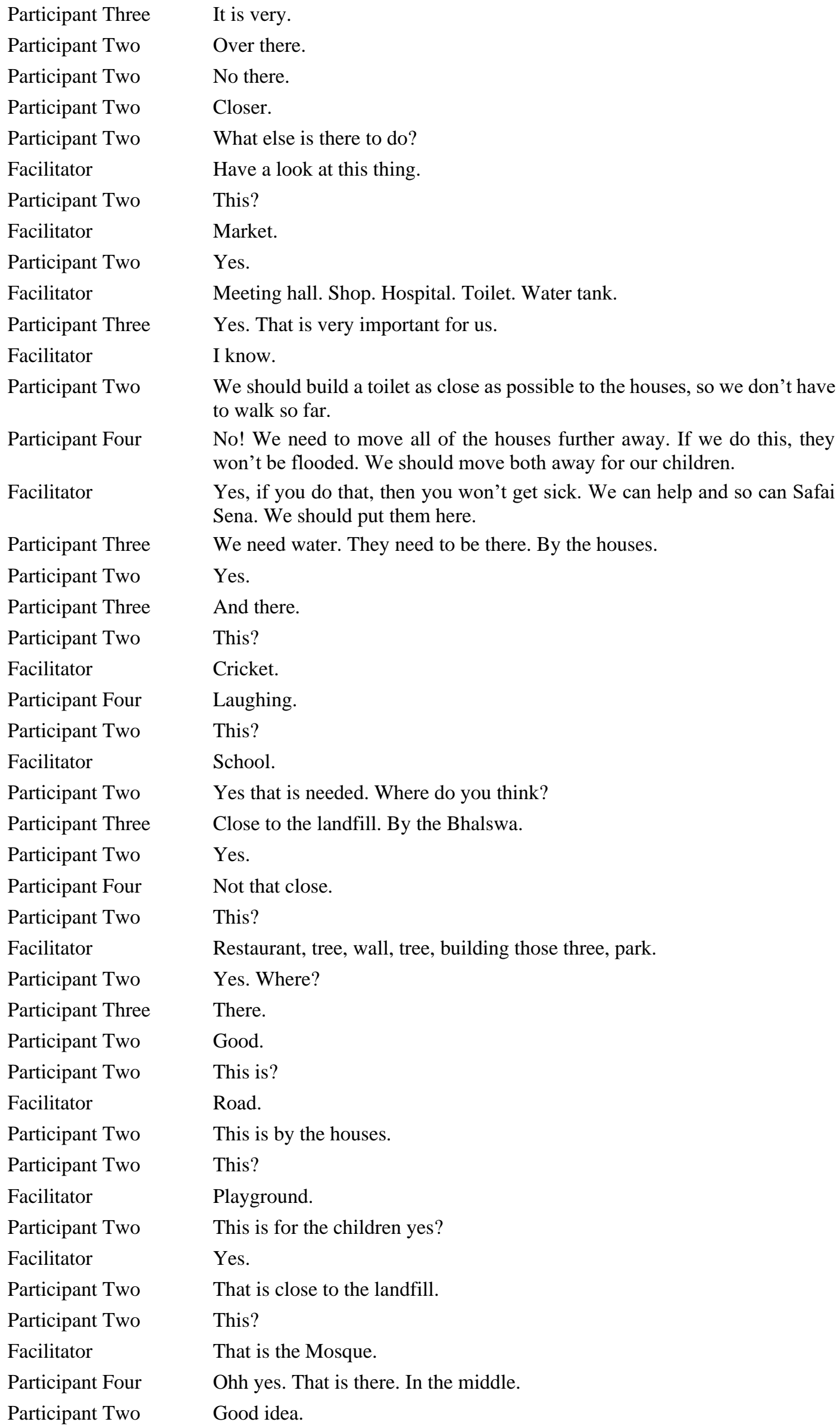

Good.

This is?

Road.

This is by the houses.

This?

Playground.

This is for the children yes?

Yes.

That is close to the landfill.

This?

That is the Mosque.

Ohh yes. That is there. In the middle.

Good idea. 


\begin{tabular}{|c|c|}
\hline Participant Four & Yeah I know. \\
\hline Participant Two & And this? \\
\hline Facilitator & Recycling plant. \\
\hline Participant Four & No. \\
\hline Participant Two & I know what these are. \\
\hline Participant Three & You have to be there too. \\
\hline Participant Two & I'm coming. \\
\hline Participant Three & There. \\
\hline
\end{tabular}

Focus Group

Focus Group of Bhalswa Group Two was not conducted. 


\section{Shanti Nagar Workshop Group One}

\section{Workshop Transcript}

\section{Pre-Gameplay}

Participant One

Participant Three

Participant One

Participant Three

Participant One

Participant One

Participant Two

Participant Two

Participant One

Participant Three
Okay to is it this one?

Yes.

This one?

Yes.

What colours will we be?

I'll just do it.

Fine.

There.

Now we go forward and reach the gate.

Stop doing that.

\section{Level One}

Participant One

Participant Three

Participant Two

Participant Four

Participant Two

Participant Two

Participant One

Participant Three

Participant One

Participant Two

Participant Three

Participant Two

Participant One

Participant Two

Participant Two

Participant Three

Participant Four
So they look like this. I think we click this to break it.

We must. There is no way around.

Try this.

I'll play too.

Go.

You need to get rid of those things. Bring them here.

How will it break?

There.

Click this button.

We need to put them all by the gate.

How are your going to break it?

It's walking funny.

No look here.

That's no it.

There.

By the gate.

Oh.

\section{Level Two}

Participant Two

Participant Three

Participant Four

Participant Two
Now what?

Is it the same.

No, didn't you read the instructions?

There's buildings. 


$\begin{array}{ll}\text { Participant Four } & \text { Houses. } \\ \text { Participant Three } & \text { Oh. } \\ \text { Participant Two } & \text { Bust them all. } \\ \text { Participant One } & \text { I will. } \\ \text { Participant One } & \text { This is yours. } \\ \text { Participant Three } & \text { Yes it is. The house can be there. That's it. } \\ \text { Participant Two } & \text { How do I do it? } \\ \text { Participant Four } & \text { Just press that. } \\ \text { Participant One } & \text { Is that enough? } \\ \text { Participant Four } & \text { Yes. } \\ \text { Participant One } & \text { Yes. } \\ \text { Participant Four } & \text { Okay. } \\ \text { Participant Two } & \text { How do I do it? } \\ \text { Participant Four } & \text { Over there. Press that like before. } \\ \text { Participant Four } & \text { Mine is there. } \\ \text { Participant Two } & \text { There. Is that it? } \\ \text { Participant Four } & \text { Yes. }\end{array}$

\section{Level Three}

Participant Two

Participant Three

Participant Two

Participant Four

Participant Two

Participant Three

Participant One

Participant Two

Participant One

Participant One

Participant Two

Participant One

Participant Three

Participant Four

Participant Two

Participant Three

Participant One

Participant Two

Participant Four

Participant One

Participant Two

Participant Three

Participant Two

Participant Four

Participant Four
This is different. There are more now.

Yes a toilet.

And a hill. Both sides.

Where will it be?

Ohh what is this?

We will have to bust it all.

There is so much.

Hurry up.

There take it further back.

Yes yes there.

Toilets.

Yes. That is needed most.

We'll clear this.

Put the yellow house there.

But also the toilet.

There is a road there.

This is a hospital first.

We all need to do a house. Otherwise we can't finish.

Yes we need houses.

Do I begin?

Okay.

Where is the water? That is what we need.

There. Your turn.

Thank you.

Mosque remember. 


\section{Level Four}

Participant One

Participant Two

Participant One

Participant Two

Participant Three

Participant One

Participant Three

Participant Three

Participant Two

Participant One

Participant Two

Participant Three

Participant Two

Participant One

Participant Three

Participant Two

Participant One

Participant Three

Participant Two

Participant Four

Participant Two

Participant Four

Participant Three

Participant One

Participant Two

Participant Three

Participant Four

Participant Two

Participant One

Participant Two
My one is red.

They are together.

They should go.

No you have to choose.

What are they?

Houses.

Ohh so you understand.

Is it my turn?

Yes.

That made space.

But not for everyone.

So we need more for our children and older ones.

Yes.

There.

Then water too.

Some more.

Another.

Put it on top. Then you don't bust them. They can be together.

A tree.

Where to we put them?

There. You have to decide.

In there?

Yes. So you might have to bust things.

What are they?

It doesn't matter.

Okay they can go there.

The houses are the same.

Can they go there?

On top?

Finally.

\section{Level Five}

Participant Two

Participant Two

Participant One

Participant Two

Participant Two

Participant Two

Participant Three

Participant Four
What are you doing?

That is too much.

Oh. Sorry.

There is meant to be a school.

They should all be in a line.

A market can go there.

There. No that's too much.

Put yours there. 


$\begin{array}{ll}\text { Participant Two } & \text { Okay. } \\ \text { Participant Four } & \text { Okay. } \\ \text { Participant One } & \text { I'll do it. } \\ \text { Participant Three } & \text { There. } \\ \text { Participant Four } & \text { Toilets next. } \\ \text { Participant Two } & \text { Not only one. } \\ \text { Participant Two } & \text { Put it there. } \\ \text { Participant Three } & \text { It's on top of that house. Next to it. } \\ \text { Participant One } & \text { Then they can't walk over. } \\ \text { Participant Three } & \text { Yes too? } \\ \text { Participant Four } & \text { No more plants. } \\ \text { Participant Three } & \text { Yes, then that is more work for us. } \\ \text { Participant Two } & \text { It is there. } \\ \text { Participant Three } & \text { It went away. } \\ \text { Participant Three } & \text { Where is the landfill? } \\ \text { Participant Two } & \text { There. } \\ \text { Participant Three } & \text { But there should also be a park. } \\ \text { Participant Two } & \text { Yes for the cricket! } \\ \text { Participant Three } & \text { A meeting hall is here at Apnalaya. } \\ \text { Participant Two } & \text { Yes that looks like it. } \\ \text { Participant One } & \text { Hurry up. } \\ \text { Participant Two } & \text { It walks so slowly. }\end{array}$

\section{Focus Group}

Facilitator

Participant Four

Participant Two

Participant One

Participant Two

Participant One

Participant Three

Participant One

Facilitator

Participant Three

Participant Two

Participant One

Participant Two

Facilitator

Participant Two

Participant One

Participant Three

Facilitator

Participant Two
Was agreement reached within the group?

Yes I think it was good.

You busted a lot and then we ran out. I didn't agree with that.

I liked blowing them all up! It was fun.

Yes, but it didn't help.

I didn't know.

So we didn't always.

If we tried again maybe.

How was agreement reached?

For some things we talked about them. But some we just showed.

Yes, showing was the easiest.

I should have talked more.

Maybe we work as a team more.

How did you use the game visuals/space to help you discuss problems or issues with other players?

I liked seeing everything.

I don't understand the first levels, but I can see the last one.

Good for showing.

Do you have any other comments?

It was fun playing with them. 
Yes I would play again. 


\section{Shanti Nagar Workshop Group Two}

\section{Workshop Transcript}

\section{Pre-Gameplay}

Participant One

Participant Two

Participant One

Participant Two

Participant Three

Participant One

Participant Two

Participant One

Participant One

Participant Two
Which one do you want?

That one.

You?

Yes.

What colours will we be?

There it is.

Fine.

I think we have to read this.

Done?

Yes.

\section{Level One}

Participant Two

Participant One

Participant Two

Participant Three

Participant Two

Participant Three

Participant Four

Participant Two

Participant Three

Participant One

Participant Two
Which one is yours?

Red

So we all go to that thing?

Yes.

$\mathrm{Oh}$

That's is.

Bust them.

Why?

Because you can.

That doesn't make sense.

Break them.

\section{Level Two}

Participant Three

Participant One

Participant Three

Participant One

Participant Two

Participant Three

Participant Two

Participant Four

Participant One

Participant Two

Participant Four
Just go over there to the next level yes?

You should break that first.

Go over there now.

There is only one way/

Its by the edge.

That wasn't smart.

Just don't do that. That's not the way.

It's the blue one that is yours.

No blue. That one.

That's not your house.

Where should I put it. 
Participant Two

Participant One

Participant Two

Participant One

Participant Three

Participant Two

Participant One
Here

I don't want to break it.

There put it over it.

Don't break the house.

I didn't drop it. It wasn't meant to be like that.

Okay I'm coming. It is done.

It will only open when we are all there.

\section{Level Three}

Participant Two

Participant One

Participant Three

Participant Two

Participant Three

Participant Four

Participant Two

Participant One

Participant Three

Participant One

Participant Four

Participant Two

P5

Participant One

Participant Three

Participant Two

Participant Three

Participant Four

Participant One

Participant Two

Participant Four

Participant Two

Participant Four

Participant One

Participant Two

Participant Four

Participant Two
Oh those are different.

Stop that.

But not everyone.

There is a hospital. That should be first.

There.

Then water too.

But there is none.

But it can.

Where?

No there silly.

Okay they can go there.

The houses are the same.

It over at the end.

On the bottom.

That can't be there. It doesn't go. Put the mosque there and it will be good.

It should only be there though.

Behind.

We have to get rid of this though.

Put it by the water.

There is more needed.

Where is the water.

It's okay but could be better.

Like that.

Have a look at this thing.

Yes.

This is yours.

It's not there yet.

\section{Level Four}

Participant One

Participant Two

Participant Two

Participant One
There is more now look. Water and a school.

But some it the same.

It's small though.

But there's no room. I think we have to choose. 
Participant Three

Participant Three

Participant One

Participant Four

Participant One

Participant Two

Participant One

Participant Four

Participant Two

Participant Three

Participant Two

Participant Three

Participant One

Participant Four

Participant Two

Participant One

Participant Two

Participant Three

Participant Four

Participant Four

Participant Three

Participant One

Participant Four

Participant One

Participant Two

Participant Three

Facilitator

Participant One

Participant Two

Participant One

Participant Two

Participant One

Participant Two

Participant Two

Participant Three

Participant Two

Participant Three

Participant Two

Participant Three

Participant Two

Participant Three

Participant One

Participant Four

Facilitator

Participant Two

Participant Two
You all have to choose.

Do we break them down?

Yes I think so.

There, is that the landfill?

Yes bust that.

The toilet is the most important for the community.

Yes.

There should be many of them.

Here?

Yes.

Should we bust this?

Yes.

This is the water tank.

That looks good. What about the school?

Yes that is a good idea.

Okay over there.

What is that there?

There is water now.

Where were those guys?

I think that hall should be there.

Okay, yes like before.

I think your house will fit there.

Where?

You can do it. Over there.

This is no what is was meant for. The tank can be on the road I think.

No.

What else does it need?

More water.

More? We already have lots.

Like this?

Yes.

Its nice

Mine too.

That is okay. But it's not as good as before. You removed too many.

We don't have a, what it that?

Market.

Yes one of these.

But it is not that big.

This can go there.

No there.

Are you sure?

Yes. Put your house then we are done I think.

We are done I think.

Move it over there you know.

No you.

There. 


\section{Level Five}

Participant Two

Participant One

Participant One

Participant One

Participant Two

Participant Four

Participant One

Participant Four

Participant Three

Participant Two

Participant Four

Participant Three

Participant Four

Participant Three

Participant Two

Participant Three

Facilitator

Participant Three

Participant Two

Participant Two

Participant One

Participant Two

Participant Three

Participant Three

Participant Four

Participant Two

Participant Three

Participant Two

Participant Three

Participant Two

Facilitator

Participant Two

Participant Three
There are lots of these things in Govandi.

Just move the mouse to them so we can see.

So what do you do?

Market, then meeting, shop, see this things, hospital, toilet, tank, cricket, school, restaurant, tree, wall, tree, some things, building, apartment, park, road, playground, mosque, plant.

Yes a Mosque first like that other one.

Yes.

But it should be a toilet near to there.

That is by Govandi.

Where is the cricket?

It should be there. That is the most fun.

But is it important?

First we need to bust.

Watch out for the money.

Your using it.

Put the cricket there.

Not yet.

Does this Govandi have a park?

Yes, but not now.

A park can be over there.

Next to those factories.

A playground goes with it too.

Yes, bu my house.

Not there. I didn't mean that.

That's better.

But the road too.

Then the shops.

More toilets.

Where?

Yes there. I think here too.

This makes it good I think. It has most of the things that we need. Move that box.

That's my house.

That was funny. He didn't get there though.

\section{Focus Group}

Facilitator

Participant Three

Participant Two
Was agreement reached within the group?

Yes we made a good Govandi. Particularly the last one. That is how it should be.

Yes, I think it was good too. 
Participant One

Participant Two

Facilitator

Participant Three

Participant Two

Participant One

Facilitator

Participant Two

Participant Three

Participant One

Participant Four

Participant Three

Facilitator

Participant One

Participant Two
Sometimes we didn't agree though. But we talked about it.

Yes talking was important.

How was agreement reached?

Talking about it. And showing also.

Sometimes we didn't. But that's okay. We can do different things sometimes.

But we would just talk about them.

How did you use the game visuals/space to help you discuss problems or issues with other players?

It was good to see the things. We could show you what we wanted.

I liked the explosions. They were my favourite part.

Me too.

Yes, but I think there needed to be more roads. That is what it is like here.

That would help.

Do you have any other comments?

I think it was good. I would like to do it again.

Yes. 


\section{Shanti Nagar Workshop Group Three}

\section{Workshop Transcript}

\section{Pre-Gameplay}

Participant Two

Participant Three

Participant Two

Participant One
All four players' names in over here.

Put Yasmin here, there's two e's in my name.

What is this?

If anything comes in the way.

\section{Level One}

\section{Facilitator}

Participant Three

Participant One

Participant One

Participant Two

Participant Three

Participant Two

Participant Two

Participant Three

Participant One

Participant Two

Participant Three

Participant Two

Participant One

Participant Two

Participant One

Participant Three

Participant One

Participant Two

Participant Four

Participant One

Participant Three

Participant Two

Participant Two

Participant Three

Participant One

Participant One

Participant One

Participant Two
Red green and yellow look like this, if anything in the way click right and break it.

And we need to go forward to reach the gate

Go there's nothing there.

I'll play too, I know how to play.

You do it.

You need to bring it here.

Okay do it.

How will we break it?

Well click this button.

Well ask that.

Do you want to drown him in water?

We need to take them all by the gate.

So how are going to break it (the gate).

With the middle button.

Should I click the middle one?.

What about the side button (telling him to do it).

If you want to break it then you break it like this.

So you break it from here right.

I don't want to play anymore.

Oi don't swear it me.

It's running.

Help me.

Show me there (that part of the map).

Drown my son (character) too.

No look here (to stop side-track).

Okay fine go straight.

No but first drown him.

It opened.

One by one kill them in the water. 


\section{Level Two}

Participant Two

Participant Three

Participant Two

Participant Three

Participant Two

Participant One

Participant Three

Participant One

Participant One

Participant Three

Participant Three

Participant Three

Participant Three

Participant Four

Participant One

Participant Three

Participant Two

Participant One

Participant Three

Participant Four

Participant Three

Participant One

Participant Three

Participant Three

Participant Two

Participant One

Participant Three

Participant One

Participant Three

Participant One

Participant Three

Participant Four

Participant One

Participant Three

Participant Three

Participant Four

Participant Three

Participant Three

Participant Two

Participant One

Participant Two

Participant Three

Participant Two

Participant Two
My one's going to be red.

Shut up (continues explaining the rules).

They're all going together.

Now its player ones turn.

The red one.

Okay understand you break (explode/slang) this.

Ohh so you understand.

Take mine forward, straight..

My ones green.

My ones blue.

Okay lets continue (insulting tone)

You just need to break everything.

You broke them all?

What are these guys going to break man?

You're and idiot.

Just go away, why are you breaking all of these.

He's telling us the colour.

Yellow.

There's no house.

Kill him.

So you just need to break all of these?

Now it's my turn.

Now this one you need to stand it next to the gate.

Now this green one we want to put it next to the gate.

Where is my house going to be?

Hey go get him.

Who's going to go first?

The blue one.

Where should I put it.

It should only go there.

It's in the corner.

Put hers in the middle.

Ahead.

Wait wait wait wait.

Now this one is your house (pointing to screen).

Quickly quickly set his house on fire.

Your house is this one.

Tell me where do you want it.

I want it there in the corner.

Over here?

Yeah there.

Take it there.

Yip do it

Chuck it in the water. 
Participant One

Participant Two

Participant One

Participant One

Participant Three

Participant Two

Participant One

Participant Three

Participant Three

Participant Three

Participant Three

Participant Three

Participant Two

Participant Three

Participant One

Participant Three

Participant Three

Participant One

Participant Three

Participant Four

Participant Three

Participant Three
Take it there in the corner.

Put it in the water.

Put it in the corner near there.

Here?

Here?

Okay fine take it over there.

Haha it's at the gate.

Where's your house.

She's going to drown it.

She walks in style (the character).

Your house is half drowned.

We have to remove this.

Come let's take them into the water.

Put it there.

Here or there?

Here?

You go there.

Now Juliette's going to come running.

Oh shit what if she drowns.

Suicide.

Do we start from here?

Read it.

\section{Level Three}

Participant Two

Facilitator

Facilitator

Participant Two

Participant Three

Participant One

Participant Four

Participant Two

Participant Three

Participant Two

Participant Three

Participant One

Participant Three

Participant Four

Participant Two

Participant One

Participant Three

Participant Two

Participant Three

Participant One
It is very easy.

There are more now.

Make sure you read the things. There are lots.

Closer.

What else is there to do?

Have a look at this thing.

It should only go there.

Ahead.

We have to remove this.

Come let's take them into the water.

Put it there.

Put hers in the middle.

It's in the corner.

On top too.

That can't be there. It doesn't go.

But it can.

Where?

Okay they can go there.

The houses are the same.

Can they go there? 


$\begin{array}{ll}\text { Participant Two } & \text { On top? } \\ \text { Participant Four } & \text { They are in a pile. } \\ \text { Participant Three } & \text { Yes it is. The house can be there. That's it. } \\ \text { Participant One } & \text { Will I put my house? } \\ \text { Participant Two } & \text { Yes. } \\ \text { Participant Four } & \text { This is yours. } \\ \text { Participant One } & \text { Okay. }\end{array}$

\section{Level Four}

Participant Two

Participant Two

Participant One

Participant Four

Participant Three

Participant Two

Participant One

Participant Four

Participant Three

Participant Two

Participant One

Participant Three

Participant One

Participant Two

Participant Three

Participant Two

Participant One

Participant Three

Participant Two

Participant Four

Participant Three

Participant Four

Participant One
Yes there are these things

Water tanks.

Yes!

There are some.

But can you use them?

Then water too.

Some more.

Another.

Yes.

There.

Some can.

But not everyone.

There needs to be another school.

But not there.

Why not?

It doesn't fit.

Yes.

No but the houses.

Oh.

There needs to be more water too. That is the biggest problem in Govandi.

Yes.

We are finished though.

That was fast.

\section{Level Five}

Participant One

Participant Three

Participant Three

Participant Three

Participant Three

Participant One

Participant Two
All the things from Mumbai have come.

Read it again.

We need to decide where our house goes.

If I put my house there I have to decide what is around my house (do I want a grocery store).

And for all these things we have to pay money.

It looks like a film.

Come lets go inside. 
Participant Three

Participant Three

Participant Three

Participant Three

Participant Four

Participant One

Participant Three

Participant Two

Participant Three

Participant Two

Participant Four

Participant Four

Participant One

Participant Three

Participant Three

Participant Two

Participant Two

Participant Four

Participant Four

Participant One

Participant Two

Participant Four

Participant Three

Participant Three

Participant Two

Participant Two

Participant Three

Participant One

Participant Two

Participant Two

Participant Four

Participant Two

Participant Four

Participant Three

Participant Three

Participant Three

Participant Three

Participant One

Participant Two

Participant Three

Participant Three

Participant Three

Participant Four
Ohh I've got 1000 rupees.

What the guy said is that we need our house somewhere and we need to decide what things we would like around it - park etc.

And what is this?

Between us we've only got 980 rupees only.

If we break something it costs 10 rupees and if we make something it also costs 10 rupees.

What is that.

Its all edible food.

It's a market.

This is the market so we'll break this area.

Please done break the market.

Break something.

Get rid of the tree instead.

Whatever you do don't break the market.

Now I need to place my one.

Where?

Put it in the corner.

No no forward.

We need space to still walk through.

Just chick it there.

Is it my turn?.

No that should be the playground.

Oi don't break them all it will create too much waste.

Now we have this much area.

My house have come here (hovering over house).

There is so much garbage.

How do we move it?

Put it in the landfill

But they always bring it out.

They have to.

There are so many houses. Between the houses is where the garbage is. If they were apart, it would be cleaner.

But what are we going to do with the waste? Look outside. There is so much. We need to put it somewhere.

And where will the people from those houses live?

What is this? We could build a recycling centre close by.

Still breaking things) Participant One says that's enough.

One will go here and one will go here.

We'll clear this path.

Well put the yellow house.

Whose house?

The yellow ones house.

This is my house right?.

This is number 4 .

Pick up all your things and settle over here.

And so you put your house here. 
Participant One

Participant Two

Participant Two

Participant Three

Participant Four

Participant Four

Participant Three

Participant Two

Participant Four

Participant Two
Oh but there's a market there.

Worried that building a house will destroy the market.

Where my house.

Over there.

Move the market.

Ill put the rest of my money towards that.

Mosque.

Do it for the mosque (destroy).

But there's a mosque already there right?.

Yeah toilet.

\section{Focus Group}

Facilitator

Participant One

Participant Two

Facilitator

Participant One

Participant Three

Participant Three

Participant Four

Participant Two

Facilitator

Participant Three

Participant One

Facilitator

Participant Three

Participant Two

Participant Three

Participant Three

Participant Four
Was agreement reached within the group?

Yes, we made a Govandi that we like.

It made a big difference seeing what the community could be like

How was agreement reached?

We talked about things as a group.

But sometimes we just did things.

So somethings were not at all as a group.

But the most important things were.

Yes.

How did you use the game visuals/space to help you discuss problems or issues with other players?

Yes it helped me see where the buildings go and how they go together.

Yes it was very helpful.

Do you have any other comments?

We need schools. If we have education then we can help our family.

Yes that is what is needed most.

When I was playing the game, there was a recycling centre-which is not at all in Govandi [Shivaji Nagar], so I feel there should be a recycling centre in Govandi. A lot of people waste a lot of things - plastics, metals, cups, glasses, clothes-so I feel there should be a recycling centre for the wealth of the community. I didn't think about that before.

I wish I could live in the game and make my community like that how I want it that easily.

According to the game with shops and clean streets I want it to be like that as well. 


\title{
Shanti Nagar Workshop Group Four
}

\section{Workshop Transcript}

\author{
Level One \\ Participant One \\ Participant Three \\ Participant Two \\ Participant Four \\ Participant Two \\ Participant Three \\ Participant Two \\ Participant Three \\ Participant Two \\ Participant One \\ Participant Three \\ Participant One \\ This is what they are. What don't they look different? \\ We must. There is no way around. \\ Try this. \\ I'll do it. \\ So we all have to go there? \\ Yes. \\ $\mathrm{Oh}$ \\ There. \\ Which is yours? I can't tell them apart. \\ That one. \\ Oh. \\ That was fast.
}

\section{Level Two}

Participant One

Participant Two

Participant One

Participant Three

Participant Two

Participant Two

Participant Three

Participant One

Participant Two

Participant One

Participant Two

Participant Three

Participant Two

Participant Three

Participant Four
You have to read it.

I did.

No to her. She cant understand.

Yes.

It says there are houses now and we all need one see.

Then it's the same as before.

Thank you.

Do we bust these?

It didn't tell us.

I think we can.

Put yours there.

Then we can line them all up like a road.

That's nice.

Yes, and then come to the end with us.

So that we are all there and it will open.

\section{Level Three}

Participant Two

Participant Three

Participant One
This one says there are more buildings a things. And we need five of them and then go to that door again.

Okay.

We should do the houses first. 
Participant Two

Participant Three

Participant One

Participant Three

Participant Two

Participant One

Facilitator

Participant Two

Participant One

Participant Three

Participant One

Participant Three

Participant Two

Participant Two

Participant Three

Participant One

Participant Two

Participant One

Participant Two

Participant One

Participant Two

Participant Four
Yes that is important.

Then we can put the others around it I think.

I'll put this house there.

Good idea.

Here?

Yes I think that.

But where should it be?

It doesn't matter.

There should be a mosque in the middle not a house.

And a hospital.

Yes.

There.

We already have a mosque.

Then change it for a shop.

Put this house next to it.

We still all have to go there.

What do these do. We didn't use them.

Yes that is important.

Somewhere close.

Put this there.

Can that be for all of us?

That's the point.

\section{Level Four}

Participant Two

Participant Three

Participant Two

Participant One

Participant Two

Participant Three

Participant One

Facilitator

Participant Three

Participant Two

Participant One

Participant Two

Participant Two

Participant One

Participant Four

Participant Three

Participant One

Participant Two

Participant One

Participant Three
This one has different stuff, but it's the same as before.

Okay.

What are those hills?

That's hard. Do we do it different?

Yes I think.

Where do we start?

Over here?

We should start with the water. That's what he wants.

Yes!

Good.

I don't think there is enough room.

We will make some.

Can't they be there?

No first do the meeting room.

Tell me where do you want it

What is yours?

My one is red.

They are together.

I'll bust them up though.

No you have to choose. 


$\begin{array}{ll}\begin{array}{l}\text { Participant Four } \\ \text { Participant Three }\end{array} & \text { What are they? } \\ \text { Participant Two } & \text { More of the water tanks can be there. } \\ \text { Participant One } & \text { Ohh so you understand. } \\ \text { Participant One } & \text { It's your turn now. } \\ \text { Facilitator } & \text { There you are. } \\ \text { Participant One } & \text { That made a lot of room. Now trees can be there. } \\ \text { Participant Three } & \text { Is that the landfill? } \\ \text { Facilitator } & \text { I think so. } \\ \text { Participant Three } & \text { Those are rocks. Like a cliff. } \\ \text { Participant One } & \text { Then the market underneath. } \\ \text { Participant Four } & \text { Yes move it up the stairs. } \\ \text { Participant Two } & \text { On to the green bit. } \\ \text { Participant Three } & \text { Okay there it's done. } \\ \text { Participant One } & \text { Nearly there. }\end{array}$

\section{Level Five}

Participant One

Participant Two

Participant Two

Participant Two

Participant Three

Participant Two

Participant One

Participant Two

Participant One

Participant Two

Participant One

Participant Three

Participant One

Participant Two

Participant Four

Participant Two

Participant One

Participant Two

Participant Three

Participant Two

Participant Two

Participant Two

Participant One

Participant One

Participant Two
Have you read it yet?

No.

So now we need 20 and there is Rupees I think.

I think we need to make a park. Like a middle bit for the people.

Yes, with trees.

So should we bust these bits first?

Yes. It can go there. From there.

Yes. It can go there. From there.

We need more trees. They can be for shade. And there we also need access to water. And close to home so we don't have to walk a long way.

That's like the cricket ground.

Yes!

Then we could use it too.

No just for cricket.

But when we put the houses, the school needs to be close so they can walk to it.

The houses should be there, all around.

No in the middle.

If they are all together it won't be as dirty.

That doesn't make sense.

Yes. Then everyone can clean.

Use yours to push me into the water.

Come on, help me blow this all up.

If we blow it all up, we can put a zoo with animals.

Okay I'll do this bit.

So, the animals go here?

Yes. 
Participant Three

Participant One

Participant Two

Participant One

Participant One

Participant Two

Participant Four

Participant Four

Participant One

Participant Three

Participant Four

Participant Two

Participant Two

Participant Two

Participant Four

Participant Two
I'll build a fence.

Then we can see them every day.

Yes.

Lions!

And fish. Because we'll all be in the water!

So, the zoo needs to be there. By the water. We can use this. The lions go in there.

But they need water too.

You can't put it on top of anything though.

I think that's good.

We should go to the end now.

Yes.

Yes I'm bored.

You'll find it there.

Finally.

Yes he's there that sir.

Let's do something else.

\section{Focus Group}

$\begin{array}{ll}\text { Facilitator } & \text { Was agreement reached within the group? } \\ \text { Participant Two } & \text { Sometimes we agreed. But sometimes we didn't. } \\ \text { Participant Three } & \text { Yes not always. } \\ \text { Participant One } & \text { We don't need a zoo. But it was fun to do. } \\ \text { Facilitator } & \text { How was agreement reached? } \\ \text { Participant Two } & \text { I don't know. I didn't think about it. } \\ \text { Participant Three } & \text { We talked. } \\ \text { Participant Four } & \text { Yes. We talked to each other about the game things. } \\ \text { Facilitator } & \text { How did you use the game visuals/space to help you discuss problems } \\ \text { Participant Four } & \text { or issues with other players? } \\ \text { Participant Three } & \text { It was good to show them what it could be like. } \\ \text { Participant Four } & \text { Yes sometimes it is hard to see what you mean. But we could show it. } \\ \text { Facilitator } & \text { I liked the colours, how it looked. } \\ \text { Participant One } & \text { Do you have any other comments? } \\ \text { Participant Two } & \text { Yes it was helpful to see the community. I liked breaking the boxes and } \\ \text { Participant Three } & \text { making the people walk. } \\ \text { Participant Two } & \text { It was fun to try to push it in the water. That was the best part. }\end{array}$




\section{Shanti Nagar Workshop Group Five}

\section{Workshop Transcript}

\section{Level One}

Participant Three

Facilitator

Facilitator

Facilitator

Facilitator

Participant Four

Participant Three

Facilitator

Participant Two

Facilitator

Facilitator

Facilitator

Participant Four

Facilitator

Participant Three

Participant Two

Facilitator

Participant Two

Facilitator

Participant Three

Participant One

Participant Two

Participant Three

Facilitator

Participant Three

Facilitator

Facilitator

Participant Two

Participant Four

Participant Two

\section{Lets start.}

Don't go there go here wait wait.

The red ones yours right?

Your ones red.

So your red one you need to bring it here and the break that.

Break that.

Is there danger in this?

No.

How do we go forward?

Wait wait how to go forward wait wait wait.

If you want to go forward then you need to click this and then it will go there.

Now you wall need to stand in one line.

Okay give it to me I'll do it.

Its player number twos turn.

To player number 2 - its your turn.

That's mine, green ones yours.

Whose is the green one?

It's hers.

You can break those rocks in front of you as well it's your choise ladies.

I'm going to break these.

It's gone ahead.

That's it.

I'll get the rock.

Right click.

It's done.

Is it done? Then go ahead.

Don't touch that.

Click it again.

I'm not going to click it.

Click it.

\section{Level Two}

Participant Four

Facilitator

Facilitator

Participant One
Yip we need to make our own houses and we need to discuss whose house will stay and where it will go.

Wait wait wait first player one.

Facilitator, red colours house is this one, where do we want to take it?

All here here here here. 
Facilitator

Facilitator

Participant One

Facilitator

Facilitator

Participant Three

Facilitator

Facilitator

Facilitator

Facilitator

Participant Four

Facilitator

Facilitator

Facilitator

Facilitator

Facilitator

Facilitator

Participant One

Participant Three

Participant Three

Facilitator

Facilitator

Facilitator

Facilitator

Facilitator

Facilitator

Facilitator

Facilitator

Participant Two

Facilitator

Participant One

Facilitator

Participant Three

Participant Four

Participant Two

Participant Four

Participant Three

Participant Four
Facilitator, there's surface there. Do you want to put it on the surface or the water?

Okay we'll put it on the side.

So its made.

Do you understand?

And well do that for all four.

Go it's your turn.

Now look at yours.

Make sure that the middle space is empty.

Don't drop it into the water.

Now you want to take your red one and put it that way by the gate.

So by the gate.

Yep by the gate.

Now look it stopped you will have to break it.

Be careful you don't want to break your own.

Go back a bit.

Now the first ones on so now player two.

You need to choses where your spot will be.

First break the rocks then put it there.

Don't do that the house will break.

You silly girl.

Leave it leave it.

You guys need to think carefully and locate your houses.

You can stroll around and go as well.

If you click it once it should go to the main gate.

Please break the stone over there.

Player number three blue.

First where are you going? Wait.

Where do you want your? Here.

Here

There you don't want to break the stone there.

Here lift your house up.

Don't break the house.

We didn't drop a house we dropped a stone here.

Just go from here we want to go to the next level right?

Why don't you break the rock.

Go forward now.

Open the gate I'm coming.

The gate will only open when four people are there.

\section{Level Three}

Facilitator

Participant One

Participant Two
This now has some more things for you. Make sure you have a look and read it.

We know.

Yes. 
Participant Three

Participant One

Participant Two

Participant Three

Participant Four

Participant Two

Participant One

Participant Three

Participant Two

Participant One

Participant Two

Participant Three

Participant Two

Participant Two

Participant Three

Participant One

Participant Two

Participant Four

Facilitator

Participant One

Participant Two
We need more close that we can use. But there should be schools there.

There are some.

But can you use them?

Some can.

But not everyone.

There.

Then water too.

Some more.

Where is the water.

Its nice

Mine too.

You can do it. Over there.

Yes.

You do it.

This house goes there.

Where?

Make your house.

That will do.

Are you finished?

Yes.

Go over there then.

\section{Level Four}

Participant Two

Facilitator

Participant Two

Participant Three

Participant One

Participant Two

Participant Two

Participant One

Participant Four

Participant Three

Participant Two

Participant Three

Participant One

Participant Three

Participant Two

Participant Three

Participant Two

Participant One

Participant Two

Participant Two
There's no space.

That's the challenge.

That's hard.

I want it there in the corner

Over here?

Yeah there

Can they go there?

On top?

Tell me where do you want it

What are they?

It doesn't matter.

Okay they can go there.

The houses are the same.

Yes.

Now to the door?

Yes if your are complete it is open.

Okay.

I think it is good.

I'll move mine next.

Okay here it is. 
Participant Three

Participant One

Participant Four

Participant Two

Participant Three

Participant One
Here?

Yes and there.

Take it there

Yip do it

Okay there it's done.

Look at him walk.

\section{Level Five}

Facilitator

Facilitator

Facilitator

Participant Three

Facilitator

Facilitator

Facilitator

Facilitator

Facilitator

Facilitator

Participant Four

Facilitator

Facilitator

Facilitator

Facilitator

Facilitator

Facilitator

Facilitator

Participant Two

Participant Two

Participant Three

Participant Four

Participant Three

Participant Three

Facilitator

Facilitator

Participant Three

Participant Two

Participant Two
This level is interesting - read it.

Did you understand, this whole town is already made for you. All four of you have 1000 you have 1000 it's not like that.

That 1000 everybody has to collectively use it. It depends on you how you want to use it.

So there will be an expense when the house it broken.

All four of you are in a line.

Suppose if you want to break anything, if you want to break it you will have to pay for labourers, you will need cars and to clean it you will need money. So if you want to break it will cost you 10 rupees.

If you want to get anything.

Suppose if you want a hospital or a water tank or a shop or a market there a road park school all of them are for 10 rupees, if you want to buy it is will cost you 10 rupees.

04:39, Facilitator, so first each of you make your own house

And whatever you want around your house. What do you want around your house a toilet water tank?

Hospital.

So you want a hospital you want a school you want a park for the kids.

You place them as you wish.

Look the park will take this much space.

Clear the surface a bit.

So in that space you can put whatever you want and settle your house there.

First destroy a whole area.

For 500 rupees destroy the whole area.

We'll destroy the bigger places first.

Because it will cost 10 rupees.

Look at the place first and then decide.

Break all of this.

Where am I going to get big ones from? These are all small.

Can we move the wires?

No.

If the wires go away then how is there going to be electricity, there's nothing for electricity there then.

But it will get empty right?

Remove this.

Remove that again. 
Participant Four

Participant Three

Participant Four

Participant Four

Participant Three

Participant Three

Participant Four

Participant Two

Participant Three

Participant Two

Participant Three

Participant Two

Participant Two

Participant Two

Participant Three

Participant One

Participant Three

Participant Three

Facilitator

Participant Four

Facilitator

Participant Two

Facilitator

Participant Four

Participant Three

Participant Four

Participant Two

Participant Two

Participant Two

Participant Four

Participant Two

Participant Four

Participant Four

Participant Four

Participant Three

Participant Four

Participant Two

Participant Four

Participant Four

Participant Three

Participant One

Participant Four

Participant Three

Participant Four

Facilitator

Participant Three
Attack what's below.

You have brains.

Yeah I do.

Don't break anything for no reason.

I'm not breaking anything for no reason.

Will it be done?

We want to go to the gate.

It's over there.

What your colour - your ones red.

It's her turn let her play.

Yeah it's her turn.

Zoom in so we can see more.

It will go there.

Stop stop stop.

First move the house.

Go here go there.

Allah she broke it.

Show me I'll do it.

Allah, you made a house and broke it.

No she didn't make one yet she just made some space.

take it up.

What are you doing?

Go further up.

Okay now you want to make a house right?

Tell me where you want it.

Let her make it.

Why are you doing it?

You'll find it there.

Do you want to put it here.

You can't put it on top of anything.

Put it on the side.

Not behind.

The house will come here.

We'll have to break this right.

You're out.

Who's next?

You should have broken that.

Take the mouse further back and go there.

Give me the mouse.

Do we want to go by the house are by the gate.

By the gate.

Should I break this.

Yes.

Do we want to go by the gate?

You want to go by the gate.

I'll do it. 
Facilitator

Facilitator

Facilitator

Participant Three

Participant One

Participant Two

Participant Three

Participant Three

Participant Three

Participant Four

Participant One

Participant Three

Participant Three

Facilitator

Participant Four

Participant Three

Facilitator

Participant Four

Participant Four

Participant Three

Participant Three

Participant One

Participant Two

Participant Four

Facilitator

Participant Four

Participant Four

Participant One

Participant Four

Participant Three

Participant Two

Participant Three

Participant Three
We want to go the end gate.

That's the starting gate.

That's the starting gate and that the last.

How are you going to take it there?

Put it next to it put it in the corner.

Where are you taking it?

It's my turn give it to me.

Here take it.

Oh no wait a second.

Oi don't take it in your hand.

Put it further there.

Stop stops stop.

That's enough for now I'm telling you.

You need space to go forward as well don't you.

That's the thing but look at this.

We'll have to jump on top of everyone's houses.

We'll have to shove through to get anywhere.

It will go there by itself.

It will go to its destination by itself.

Give it to me.

Do I not have a house?

Go here.

14:17, Participant Two, what did you break?

Is it online?

Yeah it will be on the PC.

Okay.

So is it not online though?

It will be on the PC so you four can come and play on it.

What level are you on.

Allah it's finished.

Well done.

It's finished.

Nobody told us that we shouldn't go outside of the gate.

\section{Level Five}

Participant Three

Participant Two

Participant One

Participant Four

Participant Three

Participant Four

Participant Three

Participant Four

Participant Four
Whatever space we had in the last one it's the same.

Oh it's more than last time.

Break them both.

Listen.

Tell me where I should put it.

Don't keep it that far away.

It's in the middle.

And what.

Don't break it. 
Participant Four

Participant Two

Facilitator

Participant Three

Participant Four

Participant Four

Participant Three

Participant Three

Participant Three

Participant Three

Participant Three

Participant Three

Participant Three

Participant Four

Participant Four

Participant Three

Participant Three

Participant Three

Participant Two

Participant Three

Participant Four

Participant Two

Participant Two

Participant Two

Participant Two

Participant One

Participant Four

Participant Two

Participant One

Participant Two

Facilitator

Participant Four

Participant Four

Participant Three

Participant Three

Facilitator

Participant Four

Participant Three

Participant Three

Participant Three

Participant Three

Participant Three

Participant Two

Participant One

Participant Four

Participant Four
We need to make it again and then go.

Lower.

First all four of you make your house ad then go to the gate.

No if we go to the gate then the gate will open.

First we need to make your house.

Select that.

I don't understand any of this.

Take it.

Go a bit more forward.

More.

There more space go.

A little bit that way.

Move.

Put the blue to the side.

That's it that's good.

It's done.

A bit more a bit more.

Stop.

It's to big.

Take it to the corner. Stop.

Let's take a school.

Put the toilet there.

Close to the school.

That's enough put it there.

Go further.

Further from the hospital.

Its water are they going to drink salty water?

Put them closer to the water.

Are you going to drink salty water? Does she think its lemonade?

You should have taken it further that way.

You guys have spent the least.

You need to go further that way, the toilet or nothing will fit there.

Do them all.

I want to finish them all.

You broke my house.

Even your 10 rupees is gone.

We'll take the toilet.

Look how much it's come to this side.

What else do we want to take?

Market.

Market what are you going to eat?

We'll put the market in the middle.

There's heaps of space we'll put it in the middle.

Where did it go?

Put it in the middle.

Why did you take the market take the shop. 


$\begin{array}{ll}\begin{array}{l}\text { Participant Four } \\ \text { Participant Three }\end{array} & \begin{array}{l}\text { Do you want it? } \\ \text { Participant One }\end{array} \\ \text { Facilitator } & \text { We'll we're going to have to break that . } \\ \text { Participant Four } & \text { What is it? } \\ \text { Participant Three } & \text { It's the mosque. } \\ \text { Participant Three } & \text { We were going to make it. } \\ \text { Participant Two } & \text { It will fit. } \\ \text { Facilitator } & \text { No it won't fit. } \\ \text { Facilitator } & \text { Wait because your arrows there it will fall there. } \\ \text { Participant Three } & \text { Go away. } \\ \text { Participant One } & \text { Just spending all the money. } \\ \text { Facilitator } & \text { Break it. } \\ \text { Participant Two } & \text { If we break the middle one it will fit. } \\ \text { Participant One } & \text { We still need money to get to the gate. } \\ \text { Participant Four } & \text { We don't need money to get to the gate. } \\ \text { Participant Four } & \text { Take a water tank. } \\ \text { Participant Four } & \text { No over there. } \\ \text { Participant Four } & \text { In front of the school. } \\ \text { Participant Three } & \text { I think this is an area to eat. } \\ \text { Participant Four } & \text { Oi don't take it over there. } \\ \text { Participant Two } & \text { Take it. } \\ \text { Participant Two } & \text { The park is too big. } \\ \text { Participant Four } & \text { Whatever is big should go there. } \\ \text { Participant Two } & \text { It hasn't gone look there. } \\ & \text { Doneys }\end{array}$

\section{Focus Group}

Facilitator

Participant Three

Participant Two

Facilitator

Participant Three

Participant One

Facilitator

Participant Two

Participant Four

Participant Two

Facilitator

Participant Four

Facilitator

Participant Four
Was agreement reached within the group?

Mostly.

Yes on most things but not on everything.

How was agreement reached?

Someone would do something, then we would say whether it was a good thing for Govandi or not. Then we sometimes tried again.

Yes, we did it as a group.

How did you use the game visuals/space to help you discuss problems or issues with other players?

The game helped me see what the community is like.

Yes, at so I could show them what I wanted. Then we could all talk about it.

Yes that was what was the most help.

Do you have any other comments?

Can the community play? We should have this here so everyone can use it.

Yes it is going to be here.

That is good. 
Participant Four

Participant Three

Facilitator

Participant Three

Facilitator
In the beginning I just wanted to play]. But then I saw the building and how we can change the community and the area. That is what we should do.

We want to do these things, but we can't build them. We need money and the politicians have the money. We need to talk to them about these things with the community.

Yes, that it $w$ good idea. This is the start. The community will help.

Yes that is the most important, with Apnalaya.

Yes. 